Pós-Graduação em Desenvolvimento Sustentável

Entre a Fome e a burocracia: Políticas Públicas e a Segurança Alimentar na Índia

James Augusto Pires Tiburcio

Tese de Doutorado

Brasília - DF, fevereiro/2015 
Universidade de Brasília

Centro de Desenvolvimento Sustentável

UNIVERSIDADE DE BRASÍLIA

CENTRO DE DESENVOLVIMENTO SUSTENTÁVEL

\title{
Entre a Fome e a burocracia: Políticas Públicas e a Segurança Alimentar na Índia
}

\author{
James Augusto Pires Tiburcio
}

Orientador: Marcel Bursztyn

Tese de Doutorado

Brasília - DF, fevereiro 2015 
Tiburcio, James Augusto Pires

Entre a Fome e a burocracia: Políticas Públicas e a

Segurança Alimentar na Índia./ James Augusto Pires Tiburcio.

Brasília, 2015.

310 p. : il.

Tese de Doutorado. Centro de Desenvolvimento Sustentável. Universidade de Brasília, Brasília.

1. Segurança Alimentar. 2. Políticas Públicas. 3. Índia.

I. Universidade de Brasília. CDS.

II. Título.

É concedida à Universidade de Brasília permissão para reproduzir cópias desta tese e emprestar ou vender tais cópias, somente para propósitos acadêmicos e científicos. O (a) autor (a) reserva outros direitos de publicação e nenhuma parte desta tese de doutorado pode ser reproduzida sem a autorização por escrito do(a) autor(a). 


\title{
Entre a Fome e a burocracia: Políticas Públicas e a Segurança Alimentar na Índia
}

\author{
James Augusto Pires Tiburcio.
}

Tese de Doutorado submetida ao Centro de Desenvolvimento Sustentável da Universidade de Brasília, como parte dos requisitos necessários para a obtenção do Grau de Doutor em Desenvolvimento Sustentável, área de concentração em Políticas Públicas, Cultura e Sustentabilidade.

Aprovado por:

Marcel Bursztyn, Doutor, (Centro de Desenvolvimento Sustentável - Universidade de Brasília, CDS-UnB)

Orientador

Carlos Hiroo Saito, Doutor, (Centro de Desenvolvimento Sustentável - Universidade de Brasília, CDS-UnB)

Examinador Interno

Laura Maria Goulart Duarte, Doutora, (Faculdade de Planaltina, Universidade de Brasília, FUP-UnB)

Examinador Interno

José Aroudo Mota, Doutor, (Instituto de Pesquisa Econômica Aplicada - Ipea)

Examinador Externo

Suely Salgueiro Chacon, Doutora, (Programa de Pós-Graduação em Desenvolvimento Regional Sustentável, Universidade Federal do Cariri, Proder-UFCA)

Examinador Externo

Brasília - DF, 27 de fevereiro de 2015. 
À minha esposa, Sílvia; aos meus pais, João e Sônia; e aos meus sogros, Cleuza e Edison.

A eles dedico essa vitória. Caelitus mihi vires. Dei gratia. 


\section{AGRADECIMENTOS}

Agradeço à minha esposa, Sílvia, que me apoia sempre e nunca me deixa esmorecer. Que sacrificou, ao longo de quatro anos, nosso tempo, nossos recursos, nossos sonhos em nome deste trabalho de tese. Parece que nos conhecemos desde a infância; sempre te amei. Aos meus pais, João e Sônia, que me convencem de que o impossível é algo que nunca foi tentado e que a verdadeira sabedoria vem do alto. Aos meus sogros que sempre me mantêm em suas orações e ações.

Ao meu orientador e professor Marcel Bursztyn, pela orientação, acompanhamento e incentivo.

Aos meus colegas e amigos da turma de doutorado.

Aos funcionários e professores do CDS.

Aos meus amigos na Índia que acolheram o estrangeiro.

Aos fundadores da TTN em Bangalore, Eddie e Maslova.

A Adenilton Peixoto e Rosilene, Alessandro e Silvana; de fato, a fé move montanhas.

Ao apoio da CAPES pela concessão de bolsa de doutorado, sem o qual este trabalho de tese dificilmente teria sido realizado. 
"Denunciei a fome como flagelo fabricado pelos homens, contra outros homens."

(Josué de Castro) 


\section{APRESENTAÇÃO}

Em 2010, quando me preparava para concorrer a uma vaga no programa de pósgradução no Centro de Desenvolvimento Sustentável da Universidade de Brasília, o projeto que preparei e com o qual fui aprovado não mencionava a Índia, embora já tratasse de políticas públicas para a segurança alimentar. Tanto no mestrado quanto no período entre o mestrado e o doutorado em que trabalhei como assistente de pesquisa no Ipea, meus focos de interesse eram a África subsaariana e o Brasil. Ao estudar a África subssariana, especificamente Angola e as redes de sustentação da guerra regional (1973-2002) no mestrado, a questão da segurança alimentar sobressaiu.

Porém, foi apenas após um encontro fortuito em dezembro de 2010 em uma conferência em Brasília que a Índia passou a figurar em meu projeto de vida e pesquisa. Ao decidir estudar políticas de segurança alimentar na Índia abri um caminho anteriormente não trilhado em minha vida e da minha esposa. É a velha história do "Out of sight, out of mind". O problema foi que fiz exatamente o oposto, aquilo que desconhecia, deixei entrar na mente e coração. Sinceramente, hoje se pudesse voltar atrás, voltaria. A corrupção, miséria, desencanto, desalento, cobiça, egoísmo e a lista de coisas terríveis vai longe, que entrei em contato para preparar este trabalho de tese, mesmo que apenas no plano intelectual, bibliográfico e ocasionalmente, como observador ocular, participante ou meramente contemplativo, quase me envenenaram. Por alguns longos momentos, perdi a fé na redenção da humanidade por qualquer veículo que seja, do desenvolvimento sustentável ao divino, e pensei que havia apenas futilidade e vaidade em estudar e receber um título de doutor por algo que naquele momento percebia que não poderia levar ou resultar em alguma mudança real para as centenas de milhões que vão dormir com fome na Índia. Ao constatar e investigar o "fracasso" de políticas públicas para a segurança alimentar na Índia, deparei-me com a letra morta de políticas e políticos que matam: cerceam o direito ao alimento de centenas de milhões, esvaziam suas bocas e corpos, em nome de alguns milhões em suas contas.

Em novembro de 2012, minha esposa e eu embarcamos para a Índia, eu pela segunda vez, ela pela primeira, não sabíamos muito bem o que esperar. Ao longo desses 24 meses passamos por bons e maus momentos, surpresas desagradáveis e outras muito agradáveis. Embora o âmago de minha pesquisa tenha se revelado algo pouco esperançoso, fomos surpreendidos pela boa vontade, fragilidade, simpatia e cordialidade de tantos indianos e expatriados com os quais convivemos nesses dois anos em Bangalore. Depois que "passamos a conhecer" a Índia nunca mais seremos os mesmos pois por mais que fechemos os olhos, ouvidos e boca, a memória daquilo que experimentamos e vivemos nos impede de ignorar o clamor dos que nos chamam. 


\section{RESUMO}

Esta pesquisa aborda políticas públicas de segurança alimentar e nutricional da República da Índia, especificamente o Sistema Público de Distribuição de Alimentos. A proposta deste trabalho de tese é apresentar e realizar uma análise crítica da segurança alimentar como campo de estudo e aplica-la ao caso da Índia, caracterizado pela complexidade e gigantismo de uma política de segurança alimentar e nutricional direcionada a 10 por cento da população mundial em um único Estado-Nação. A tese é direcionada e estruturada à volta de duas questões de fundo teórico e metodológico e uma de análise. A primeira questão teórica-metodológica é: a segurança alimentar e nutricional pode ser definida e medida objetivamente? A segunda questão teórica-metodológica: políticas públicas em geral e de segurança alimentar e nutricional especificamente podem ser analisadas quanto aos seus fundamentos? E a questão de propósito (fim) e análise: no contexto conceitual e empírico das questões teórico-metodológicas, o Sistema de Distribuição de Alimentos da Índia é socioeconomicamente e ambientalmente sustentável? Para responder a estes questionamentos, adotou-se uma metodologia dupla - exploratória e explicativa -, organizada em duas partes, em um total de 7 capítulos. Os quatro capítulos iniciais se atêm ao marco de referência teórico-conceitual da evolução empírica e histórica do conceito de segurança alimentar, a partir do crescente entendimento da subnutrição, da fome, da pobreza, de meios de subsistência em um contexto macroeconômico. O principal resultado dos capítulos de 1 a 4, é a constatação de que a segurança alimentar e nutricional, embora definida e entendida com ampla aceitação tanto de acadêmicos quanto de practitioners, não possui um conjunto de indicadores inequívocos e de operacionalização simples e direta. O quinto capítulo apresenta as principais teorias e modelos de análise de políticas públicas. Neste, foi constatado que as teorias e modelos não são exclusivos e concorrentes e possibilitam a análise qualitativa de políticas públicas. A teoria (e modelo) de análise mais empiricamente fundamentada é a da opção pública, que tem sido mais amplamente testada e ampliada. Seu uso, no entanto, para os propósitos deste trabalho se provaram limitados devido à falta de dados sobre a formulação e execução das políticas públicas indianas de segurança alimentar. Na segunda parte da tese, os capítulos 6 e 7 tratam do caso da Índia como unidade política. Inicialmente, exploram os Códigos de Fome, fundamento histórico e metodológico das políticas públicas de segurança alimentar indianas do século 20 e ainda presentes nas formulações contemporâneas, além das principais políticas governamentais para a eliminação da subnutrição crônica e eliminação da pobreza extrema. Constatou-se que o principal conjunto de políticas de segurança alimentar e nutricional do Governo da Índia não cumpre sua missão e tem níveis baixos de eficácia e eficiência socioeconômica e ambiental e sofre de desvios incentivados por sua própria estrutura. Ao final do capítulo sete, um estudo de caso do mesmo conjunto de políticas nacionais aplicadas ao âmbito do estado indiano de Karnataka, constatou que os resultados estaduais espelham a realidade nacional. Por fim, a partir dos resultados gerais se remete à uma proposta com recomendações de mudanças estruturais, especialmente na subpolítica de logística armazenagem e transporte e distribuição - do sistema nacional de segurança alimentar da Índia e, especificamente, do estado de Karnataka.

Palavras-chave: Segurança alimentar; Políticas públicas; Índia; Karnataka; Sistema Público de Distribuição 


\section{ABSTRACT}

This dissertation deals with food and nutrition security in the republic of India. The proposal of this doctoral dissertation is to present and critically analyze food security as a field of study and apply it to the case of India, which is characterized by the complexity and gigantism of a food and nutrition security policy aimed at 10 percent of the world population in a single Nation State. This thesis is directed and structured around two methodological and theoretical research questions and a third analytical one. The first methodological and theoretical question: can food and nutrition security be defined and measured objectively? The second methodological and theoretical question: can public policy in general and food and nutrition security policy specifically be analyzed as to its fundamentals qualitatively? And the analytical question: is the Indian food security system environmentally and socioeconomically sustainable? In order to answer these questions a double methodological approach was adopted - exploratory and explicative -, organized in 2 parts, totaling 7 chapters. The first 4 chapters examine the conceptual and theoretical reference of the historical and empirical evolution of the concept of food security, having its starting point in the growing understanding of malnutrition, hunger, poverty and livelihoods in a macroeconomic context. The main result found in the research of chapters 1 to 4 is the realization that food and nutrition security, though defined and understood with broad acceptance by academia and practitioners, does not possess a set of unequivocal indicators that are also simple and direct to operate. The fifth chapter presents the main theories and models for analyzing public policy. In that chapter, the results show that theories and models are not exclusive of others and also do not compete against each other, and do, in fact, allow for qualitative analysis of public policy. Of all the theories (and models) of analysis, the most empirically well based is Public option, as it has been widely tested and enlarged. Its usage for the purposes of this dissertation thesis, nonetheless, was much curtailed by the lack of data on formulation and execution of Indian policy on food security. In the second part, chapters 6 and 7 deal with the case study of India as a political unity. Initially, the Famine Codes are explored as the methodological and historical foundations of public policy for food security in India in the 20th century and still present in contemporary formulations of policy. Also, other important governmental policies aimed at the elimination of chronic malnutrition and extreme poverty. The main results are that the set of public policies for food and nutrition security of the Government of India do not accomplish their mission and enjoy low levels of environmental and socioeconomic efficacy and efficiency, apart from diversions that are driven by the structure of the programs themselves. The second part of chapter 7 is a case study of the same set of national policies applied to the state of Karnataka. The results showed that state level results mirror the national level. In conclusion, having the results as a basis, a proposal with a set of recommendations are also included, aimed mostly at structural changes to the logistics sub policy - storage and transportation and distribution - of the national food security system of India.

Key words: Food security; Public policy; India; Karnataka; Public Distribution System. 


\section{RESUMÉ}

La présente thèse de doctorat examine les politiques publiques de sécurité alimentaire et la nutrition de la République de l'Inde. Le but de cette thèse est de présenter et d'analyser de manière critique la sécurité alimentaire comme un domaine d'étude et de l'appliquer au cas de l'Inde, caractérisé par la complexité et le gigantisme d'une politique de sécurité alimentaire et nutritionnelle pour les 10 pour cent des la population mondiale d'un état-nation unique. La thèse est dirigée et structurée sur deux questions de fond et d'analyse théorique et méthodologique. La première question théorique-méthodologique est: la sécurité alimentaire et la nutrition peut être définie et mesurée objectivement? La deuxième question - théorique-méthodologique: la politique publique en général et spécifiquement de la sécurité alimentaire et la nutrition peut être analysée par rapport à ses fondations, qualitativement? Et la question principal de l'analyse: dans le cadre conceptuel et empirique des questions théoriques et méthodologiques, est-ce que le système de distribution alimentaire en Inde est socio-économiquement et écologiquement durable? Pour répondre à ces questions, nous avons adopté une double approche , exploratoire et explicatif, organisée en deux parties, pour un total de sept chapitres. Les quatre premiers chapitres s'accrocher à le cadre du cadre théorique et conceptuel de l'évolution empirique et historique de la notion de sécurité alimentaire, de la compréhension croissante de la malnutrition, la faim, la pauvreté, les moyens de subsistance dans un contexte macroéconomique. Le principal résultat de chapitres 1-4, est la réalisation que la sécurité alimentaire et la nutrition, bien définis et compris largement acceptée par les chercheurs e les décideurs, n'a pas un ensemble d'indicateurs clairs, simples et directes. Le cinquième chapitre présente les principales théories et des modèles d'analyse des politiques. En cela, il a été constaté que les théories et les modèles ne sont pas exclusifs et concurrents et permettent d'analyse qualitative des politiques publiques. La théorie (et le modèle d'analyse) de l'analyse comparative plus empirique est cela de l'option publique qui a été largement testé et élargi. Son utilisation, cependant, pour les fins de cette étude se est avérée limitée en raison du manque de données sur la formulation et la mise en œuvre des politiques publiques de sécurité alimentaires indiennes. Dans la deuxième partie de la thèse, les chapitres 6 et 7 portent sur le cas de l'Inde comme une unité politique. Initialement, les codes de la famine, le fondement historique et la méthodologie des politiques de sécurité alimentaire publique indiennes du 20e siècle sont explorent; encore ils sont présents dans les formulations contemporaines, les politiques clés du gouvernement pour l'élimination de la malnutrition chronique et l'élimination de l'extrême pauvreté. II a été constaté que le principal ensemble de politiques de sécurité alimentaire et nutritionnelle du gouvernement de l'Inde ne remplit pas sa mission et a de faibles niveaux d'efficacité et d'efficacité socio-économique et environnementale et souffre de faiblesses encouragés par sa propre structure. La dernière part de le chapitre sept est une étude de cas du même ensemble de politiques nationales pour la portée de l'État indien de Karnataka. II a été constaté que les résultats de l'etat reflètent la réalité nationale. Enfin, à partir des résultats une proposition est faite avec des recommandations pour des changements structurels, en particulier de la politique logistique - stockage, transport et distribution - du système national de la sécurité alimentaire en Inde.

Mots-clés: sécurité alimentaire; politique publique; Inde; Karnataka; système de distribution publique. 


\section{RESUMEN}

Esta investigación estudia las políticas públicas de seguridad alimentaria y nutricional de la República de la India. La propuesta de este trabajo de tesis es presentar y realizar un análisis crítico de la seguridad alimentaria como campo de estudio y aplicarlo al caso de la India, caracterizado por la complejidad y gigantismo de una política de seguridad alimenticia y nutricional dirigida al 10 por ciento de la población mundial de un único Estado-Nación. La tesis esta dirigida y estructurada sobre dos cuestiones de fondo teórico y metodológico y una de análisis. La primera cuestión teórica-metodológica es: la seguridad alimentaria y nutricional puede ser definida y medida objetivamente? La segunda cuestión es teóricametodológica: las políticas públicas en general y la de seguridad alimenticia y nutricional específicamente pueden ser analizadas desde sus fundamentos cualitativamente? Es este el objetivo final de análisis: en el contexto conceptual y empírico de las cuestiones teóricometodológicas, el Sistema de Distribución de Alimentos de la India es socio-económica e ambientalmente sostenible? Para responder a estos cuestionamientos, se optó por una metodología doble, explorativa y explicativa, organizada en dos partes, para un total de 7 capítulos. Los cuatro capítulos iniciales se limitan al marco de referencia teórico-conceptual de la evolución empírica e histórica del concepto de seguridad alimenticia, a partir de la creciente conciencia de la subnutrición, el hambre, la pobreza, de medios de subsistencia en un contexto macroeconómico. El principal resultado de los capítulos de 1 a 4 , es la constatación de que la seguridad alimenticia y nutricional, aunque definida y entendida con amplia aceptación tanto de académicos como de practitioners, no posee un conjunto de indicadores inequívocos y de operabilidad simple y directa. El quinto capítulo presenta las principales teorías y modelos de análisis de políticas públicas. En este, fue constatado que las teorías y modelos no son exclusivos ni concurrentes aunque posibiliten un análisis cualitativo de políticas públicas. La teoría (y modelo) de análisis más empíricamente fundamentada es la de opción pública, que ha sido más ampliamente testada y extendida. Su uso, específicamente, para los propósitos de este trabajo se demostraron limitados debido a la falta de datos sobre la formulación y ejecución de las políticas públicas índicas de seguridad alimenticia. En la segunda parte de la tesis, los capítulos 6 y 7 tratan del caso de la India como unidad política. Inicialmente, explora los Códigos del Hambre, fundamento histórico y metodológico de las políticas públicas de seguridad alimenticia índicas del siglo 20 e aún presentes en las teorías contemporáneas, además de las principales políticas gubernamentales para la eliminación de la subnutrición crónica y de la pobreza extrema. Se constató que el principal conjunto de políticas de seguridad alimenticia e nutricional del Gobierno de la India no cumple con su misión pues presenta discretos niveles de eficacia y eficiencia socio-económica y ambiental pues sufre los desvíos derivados de su propia estructura. La segunda parte del capítulo 7 es un estudio del caso del mismo conjunto de políticas nacionales aplicadas al ámbito del estado índico de Karnataka. Se constató que los resultados de tal estado reflejan la realidad nacional. Finalmente, a partir de los resultados generales se procede a una propuesta de recomendaciones sobre los cambios estructurales, especialmente en la subpolítica de logística - almacenamiento, transporte y distribución - del sistema nacional de seguridad alimenticia de la Índia

Palabras Ilave: Seguridad alimentaria; Política pública; India; Karnataka; Sistema de Distribución Pública 


\section{LISTA DE ILUSTRAÇÕES}

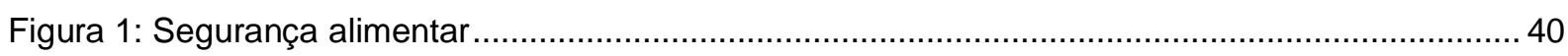

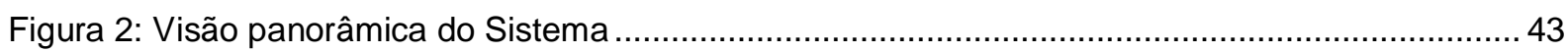

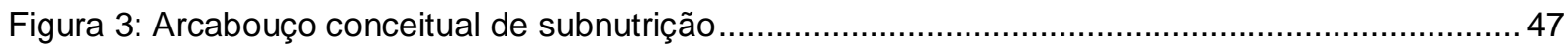

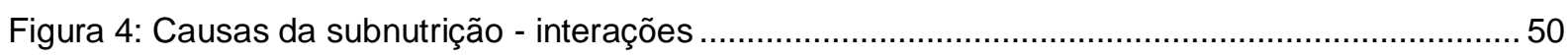

Figura 5: Causas subjacentes e recursos associados ................................................................ 52

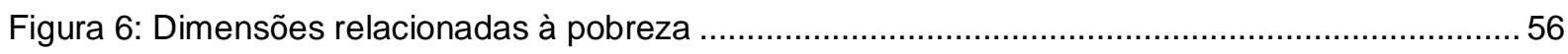

Figura 7: Os 5 componentes da vulnerabilidade e seus principais determinantes ............................. 70

Figura 8: Fundamentos da Segurança Alimentar e fluxos de manutenção da produção de alimentos 79

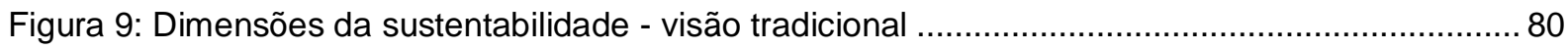

Figura 10: Representação concêntrica das dimensões da sustentabilidade ....................................... 89

Figura 11: Conexões e escalas das dimensões do desenvolvimento ..............................................90

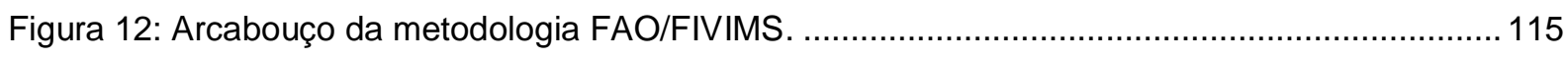

Figura 13: Modelo institucional - freios e contrapesos constitucionais ........................................... 140

Figura 14: Teoria de preferências das elites ......................................................................... 145

Figura 15: Modelo racional de sistema de decisão ..................................................................... 149

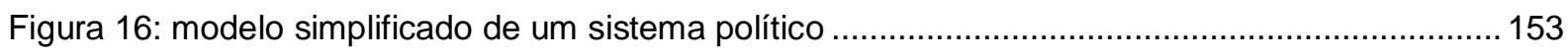

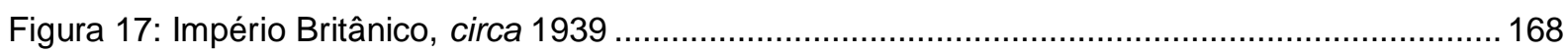

Figura 18: Estrutura Geral do Sistema Público de Distribuição de Alimentos .................................. 182

Figura 19: Estrutura e componentes do custo econômico do TPDS - situação atualizada até 2014.198

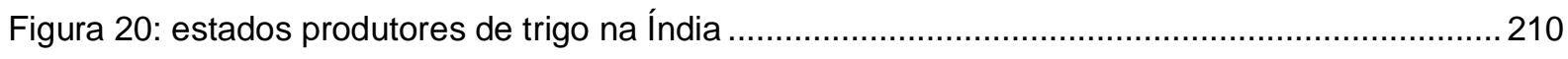

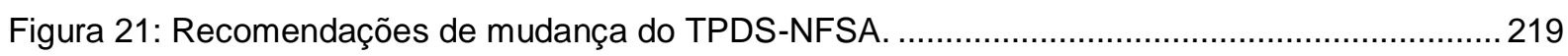

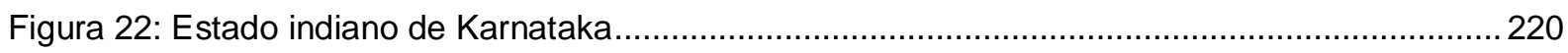

Figura 23: Caminhão de entrega de produtos do PDS em Karnataka, Índia .....................................224 


\section{LISTA DE TABELAS}

Tabela 1 - Indicadores objetivos de sustentabilidade social.

Tabela 2: Correlação entre diferentes indicadores de segurança alimentar em 60 países.

Tabela 3: Utilidade de indicadores de alimento e nutrição na avaliação de choques.

Tabela 4 - Alocação do orçamento do Governo da Índia para programas sociais, 2011-2012

Tabela 5 - Linhas de Pobreza estaduais para 2011-12, em dólares (USD), câmbio de agosto de 2014. Metodologia Tendulkar.

Tabela 6 - Percentual de domicílios em cada quintil de gasto mensal per capita na compra de arroz e trigo do PDS

Tabela 7: Compra de arroz pela FCl ( x 100 mil toneladas) 209

Tabela 8: Compra de trigo pela $\mathrm{FCl}$ ( x 100 mil toneladas)

Tabela 9 - Distribuição (\%) de indivíduos que ingerem menos de 50\% abaixo das recomendações nutricionais de micronutrientes

Tabela 10 - Índice de Fome Estadual da Índia e componentes subjacentes - estados selecionados.

Tabela 11 - Situação de cartões temporários do TPDS em Karnataka em outubro de 2012. 


\section{LISTA DE QUADROS}

Quadro 1: Exemplos de instrumentos para a avaliação da Situação de Segurança Alimentar e Nutricional nos 3 níveis sócio organizacionais.

Quadro 2: Resumo das interações entre subnutrição e doenças

Quadro 3: Fontes de risco para a Segurança Alimentar doméstica.

Quadro 4: Estrutura de Meios de Subsistência Sustentável

Quadro 5: : Objetivo de meios de subsistência sustentáveis da DFID - melhor acesso à educação de qualidade, tecnologia da informação, treinamento e melhor nutrição e saúde. Alcançável por meio de, por exemplo.

Quadro 6: Exemplo da DFID de um objetivo de meios de subsistência sustentável - busca por um ambiente social coeso.

Quadro 7: Escala de Severidade da insegurança alimentar e nutricional e de meios de subsistência.

Quadro 8: Vertentes econômicas e a sustentabilidade .....

Quadro 9: O modelo processual de análise de políticas públicas

Quadro 10: Processos políticos e atividades funcionais

Quadro 11: Seleção de problemas enfrentados pelas lojas de preço justo em Karnataka e propostas correspondentes. 


\section{LISTA DE GRÁFICOS}

Gráfico 1 - Índice de preços de alimentos da FAO (2002-2004=100) ….........................................93

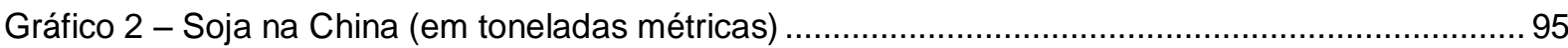

Gráfico 3 - China e Índia no mercado internacional de arroz (Milhões de toneladas métricas) ............98

Gráfico 4 - Mercado Mundial de Cereais (grãos) na Índia ............................................................... 99

Gráfico 5 - Preço médio do barril de petróleo cru em dólares americanos (USD) ............................ 103

Gráfico 6 - Baltic Dry Index - Frete transoceânico 1985-2013....................................................... 104

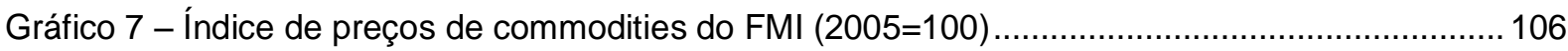

Gráfico 8 - Prevalência de desnutrição - metodologia FAO, 1990-2012.........................................118

Gráfico 9 - Cronologia e número aproximado de mortes em crises de segurança alimentar durante o

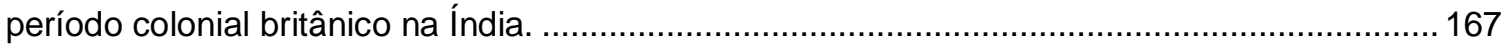

Gráfico 10 - Número de pobres baseado na metodologia do Comitê Lakdawala .............................. 186

Gráfico 11 - Subsídio aos preços mínimos agrícolas na Índia, 1990 a 2013, em bilhões de rúpias indianas............... 197

Gráfico 12 - Compra de arroz pela FCI para o PDS por estado como percentual do excedente comercializado e da produção total de arroz, 2012-2013

Gráfico 13 - Estoques totais de grãos e capacidade de armazenagem da FCl em nível nacional, 2003-2012 (valores aproximados - em milhões de toneladas)

Gráfico 14 - Perdas do TPDS no estado de Karnataka, razões. 222

Gráfico 15 - Tipos de cartões do PDS em Karnataka.

Gráfico 16 - Situação de cartões AAY, BPL e APL do TPDS em Karnataka em outubro de 2012....229

Gráfico 17 - Índice de Fome Global [Global Hunger Index (GHI)] 241 


\section{LISTA DE ABREVIATURAS E SIGLAS}

AADHAAR - Aam Aadmi Ka Adhikaar (Direitos do Homem [pessoa] comum] (sigla em hindi) AAY - Antyodaya Anna Yojana (sigla em hindi)

AsA - Acordo sobre Agricultura

BACP - Bureau of Agricultural Costs and Prices

BJP - Bharatiya Janata Party [Partido do Povo Indiano - sigla em hindi]

CACP - Commission for Agricultural Costs and Prices (sigla em inglês)

CAG - Comptroller and Auditor General of Índia (sigla em inglês)

CCT - Conditional Cash Transfers (sigla em inglês)

CJWSPD - Comitê do Juiz Wadhwa para o Sistema Público de Distribuição.

CMMAD - Comissão Mundial [das Nações Unidas] sobre o Meio Ambiente e o Desenvolvimento

CFS - Comitê de Segurança Alimentar Mundial [Commitee on World Food Security] (sigla em inglês)

CFSVA - Comprehensive Food Security and Vulnerability Analysis (sigla em inglês)

DFID - Department for International Development (sigla em inglês)

DFPD - Department of Food and Public Distribution [Departamento de Alimentação e

Distribuição Pública] (sigla em inglês)

EPE - Entreprises pour L'environnement (sigla em inglês)

EOECK - Escritório do Oficial Eleitoral Chefe, Karnataka

FANTA - Food and Nutrition Technical Assistance Project (sigla em inglês)

FISPL - Feedback Infrastructure Services Private Limited (sigla em inglês)

FIVIMS - Food Insecurity and Vulnerability Information and Mapping System (sigla em inglês)

GRAAM - Grassroots Research and Advocacy Movement (sigla em inglês)

HCESs - Pesquisas de Gasto e Consumo Doméstico [Household Consumption and

Expenditure Surveys] (sigla em inglês)

IATP - Institute for Agriculture and Trade Policy (sigla em inglês)

ICDS - Serviços Integrados para o Desenvolvimento da Criança [Integrated Child

Development Services] (sigla em inglês)

ICESCR - International Covenant on Economic, Social and Cultural Rights [Pacto Internacional dos Direitos Econômicos, Sociais e Culturais] (sigla em inglês)

ICN - International Conference on Nutrition (sigla em inglês)

ICSU - International Council for Science (sigla em inglês)

ICTSD - International Centre for Trade and Sustainable Development (sigla em inglês)

IFAD - International Fund for Agricultural Development (sigla em inglês) 
IFPRI - International Food Policy Research Institute (sigla em inglês)

IIPS - International Institute of Populations Sciences (sigla em inglês)

IISD - Institut Internacional du dévelopment Durable (sigla em inglês)

IPCC - Intergovernmental Panel on Climate Change (sigla em inglês)

FAO - Organização das Nações Unidas para Alimentação e Agricultur (sigla em inglês)a

$\mathbf{F C I}$ - Food Corporation of Índia (sigla em inglês)

HFIAS - Household Food Insecurity and Access Scale (sigla em inglês)

KFCSC - Karnataka Food and Civil Supplies Corporation (sigla em inglês)

MGNREGA - Mahatma Gandhi National Rural Employment Guarantee Act

NAAS - National Academy of Agricultural Sciences [Acadêmia Nacional de Ciências

Agrícolas] (sigla em inglês)

NABARD - National Bank for Agriculture and Rural Development (sigla em inglês)

NAFED - National Agricultural Cooperative Marketing Federation of India Ltd (sigla em inglês)

NCEUS - Comissão Nacional para o Emprego no Setor Informal (sigla em ingles)

NFSA - National Food Security Act [of Índia] (sigla em inglês)

NRAA - Autoridade Nacional de Áreas de Agricultura de Sequeira da Índia (sigla em inglês)

NSSO - National Sample Survey Organisation (sigla em inglês)

ONU - Organização das Nações Unidas

OECD - Organisation for Economic Co-operation and Development (sigla em inglês)

OMC - Organização Mundial do Comércio (sigla em inglês)

OPEC - Organization of Petroleum Exporting Countries (sigla em inglês)

PAM - Programa Mundial de Alimentos da Organização das Nações Unidas (sigla em inglês)

PIB - Produto Interno Bruto

PPC - Paridade do poder de compra

RPDS - Revamped Public Distribution System (sigla em inglês)

SAN - Segurança Alimentar e Nutricional

SDP - Sistema de Distribuição Pública

SECC - Censo Socioeconômico e de Castas (Socio Economic and Caste Census)

SJSRY - Programa de Emprego Urbano Jubileu de Ouro (sigla em hindi)

TPDS - Sistema Público de Distribuição Direcionado (sigla em inglês)

UIDAI - Unique Identification Authority of Índia (sigla em inglês)

UNESCO - Organização das Nações Unidas para a Educação, a Ciência e a Cultura [United Nations Educational, Scientific and Cultural Organization] (sigla em inglês)

UNICEF - Fundo das Nações Unidas para a Infância (sigla em inglês) 
UNU - United Nations University (sigla em inglês)

USAID - United States Agency for International Development (sigla em inglês)

WMO - World Meteorological Organization (sigla em inglês) 


\section{SUMÁRIO}

LISTA DE ILUSTRAÇÕES

LISTA DE TABELAS

LISTA DE ABREVIATURAS E SIGLAS

INTRODUÇÃO ................................................................................................................ 24

PRIMEIRA PARTE: MARCO DE REFERÊNCIA TEÓRICO-CONCEITUAL ...................................32

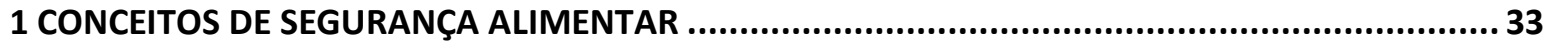

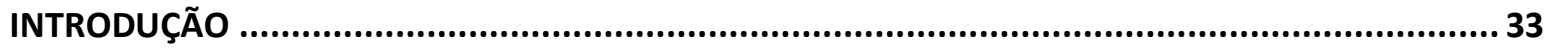

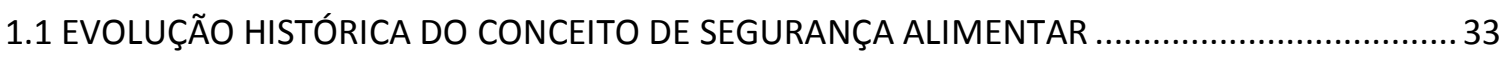

1.1.1 A Declaração Universal sobre a Erradicação da Fome e Desnutrição ..............................................36

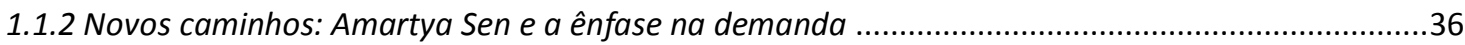

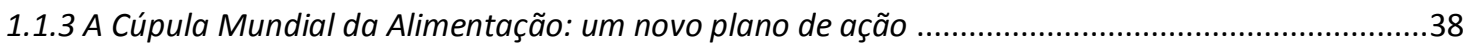

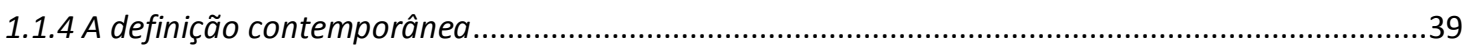

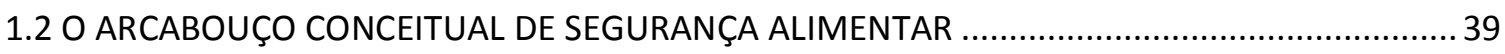

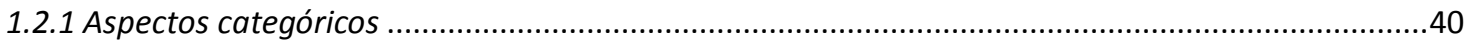

1.2.2 Aspectos sócio organizacionais da Segurança alimentar e nutricional ...........................................44

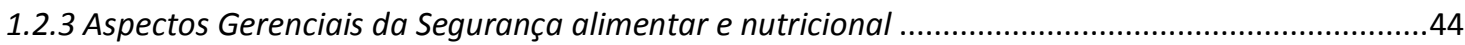

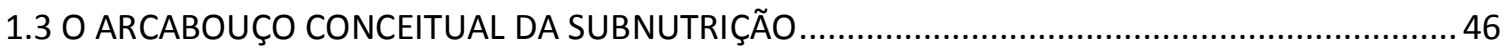

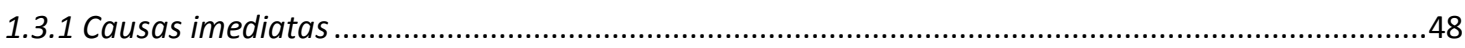

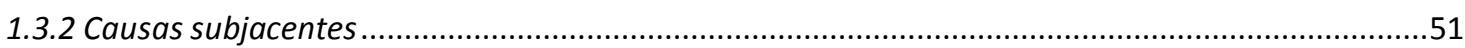

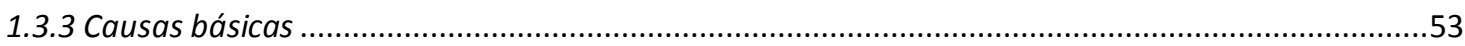

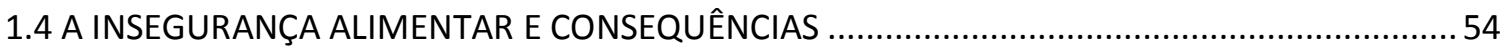

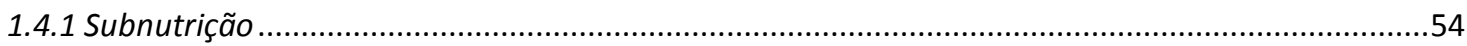

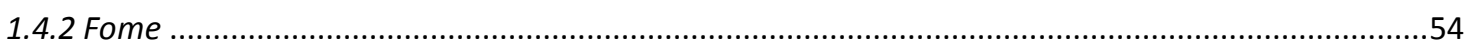

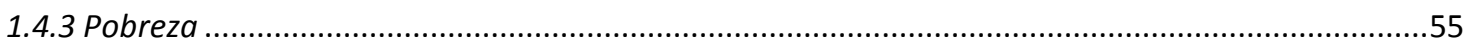

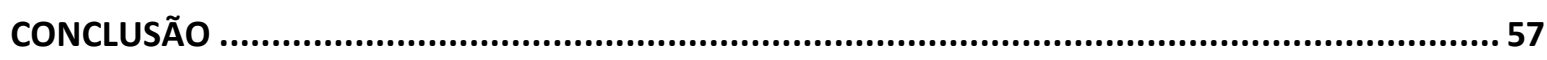

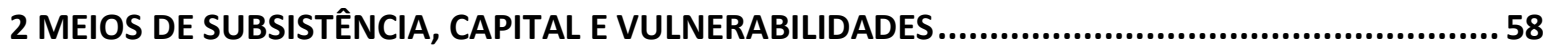

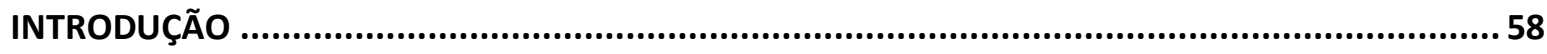

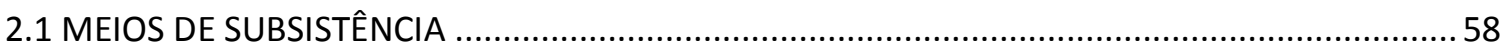

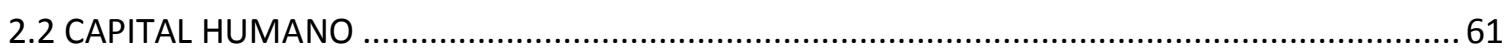

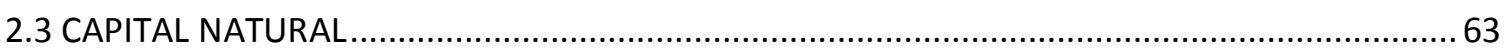

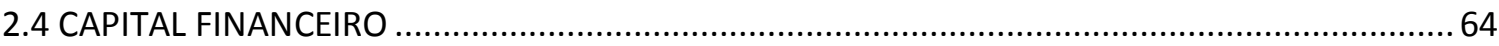

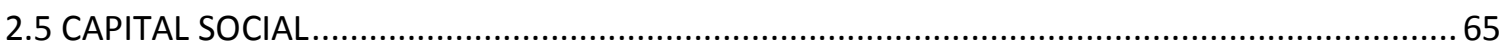

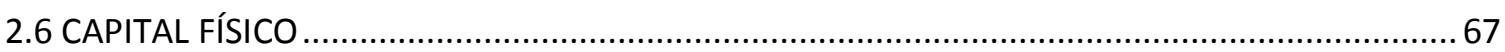

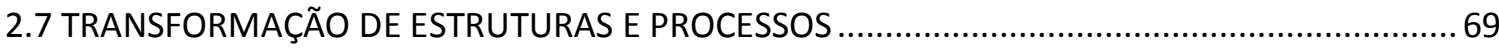

2.8 OS 5 COMPONENTES DA VULNERABILIDADE E SEUS PRINCIPAIS DETERMINANTES ................. 70

2.8.1 Componente 1 - A força e resiliência dos meios de subsistência.....................................................70

2.8.2 Componente 2 - $O$ status de linha de base e o bem-estar ..............................................................71

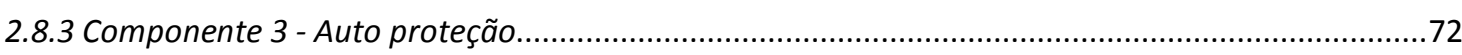

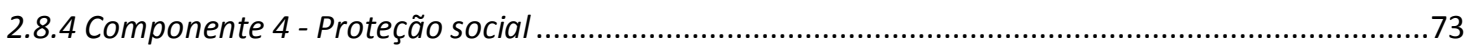

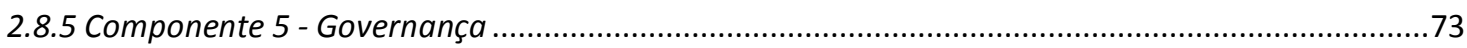




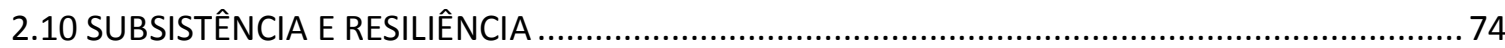

2.11 RELAÇÃO ENTRE MEIOS DE SUBSISTÊNCIA, VULNERABILIDADE E RESILIÊNCIA ..................... 75

2.12 AS DIMENSÕES DA SUSTENTABILIDADE E A PLURALIDADE DE AGENDAS SUSTENTÁVEIS ... 79

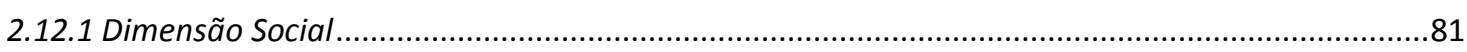

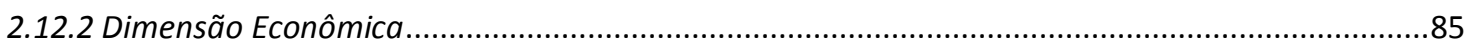

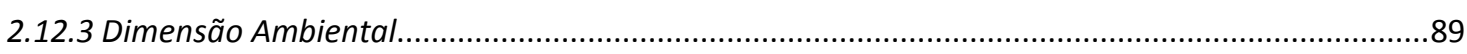

2.12.4 Sistemas de alimentação sustentáveis no âmbito da economia verde ..........................................90

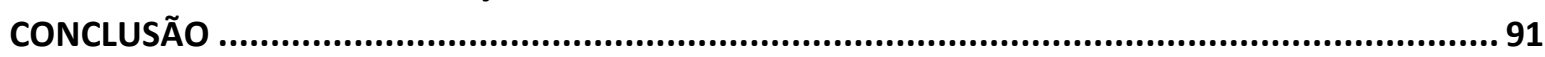

3 O CONTEXTO MACROECONÔMICO DE SEGURANÇA ALIMENTAR .........................................92

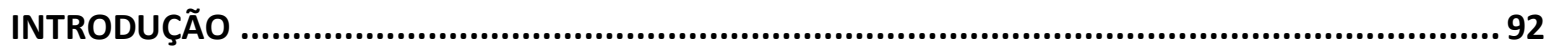

3.1 QUESTÕES MACROECONÔMICAS

3.1.2 Catalizadores da crise de preços de alimentos de 2008 e 2011 ................................................94

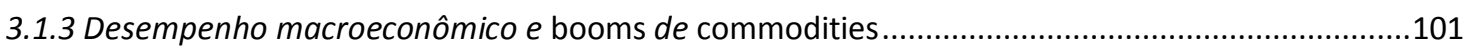

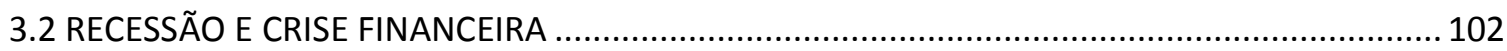

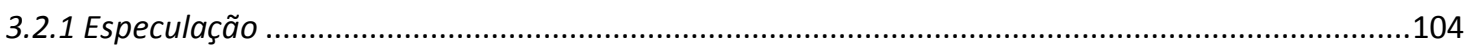

3.2.2 0 mercado de futuros agrícolas e os grandes fundos de investimento.........................................105

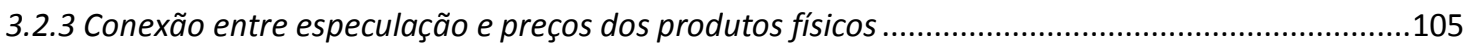

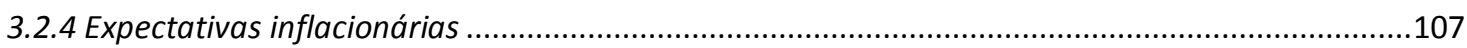

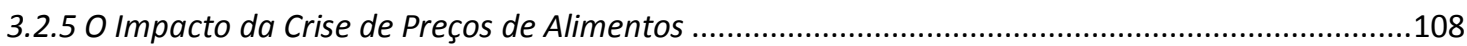

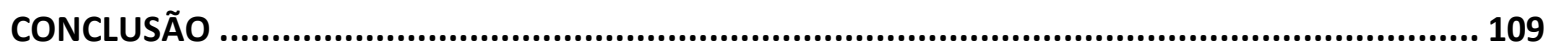

4 MENSURANDO UM CONCEITO: INDICADORES DE SEGURANÇA ALIMENTAR ........................ 110

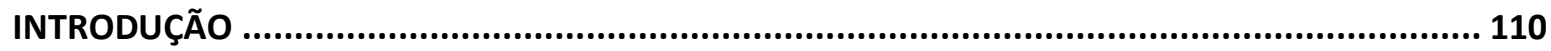

4.1 INDICADORES DE SEGURANÇA ALIMENTAR PASSIVEIS DE MENSURAÇÃO E COMPARAÇÃO110

4.2 DIRECIONAMENTO DE POLÍTICAS DE SEGURANÇA ALIMENTAR (TARGETING) .......................112

4.3 A FOME, A NUTRIÇÃO E A SEGURANÇA ALIMENTAR NO CONTEXTO DOS INDICADORES .... 113

4.4 INDICADORES: CARACTERÍSTICAS E PRINCIPAIS TIPOS ...................................................... 116

4.4.1 Indicadores de restrição calórica: Indicador de subalimentação ou disponibilidade de calorias da

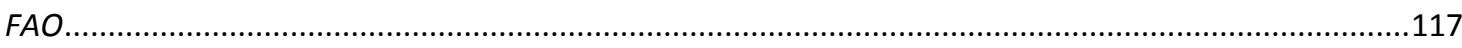

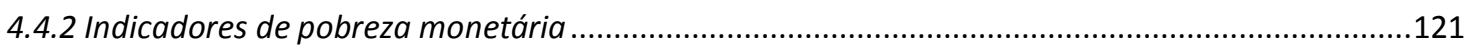

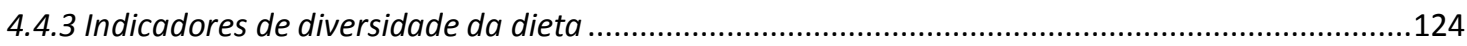

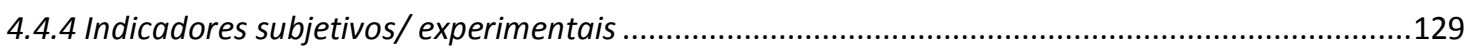

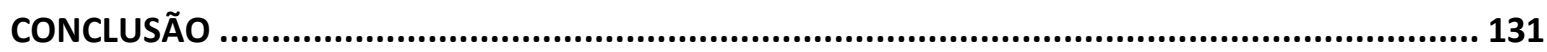

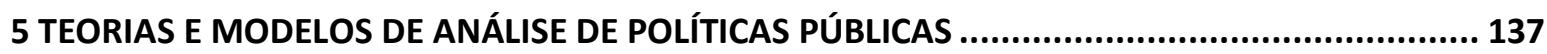

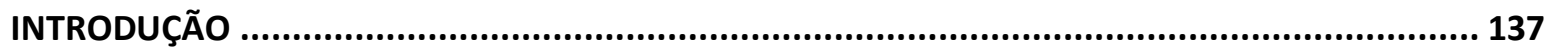

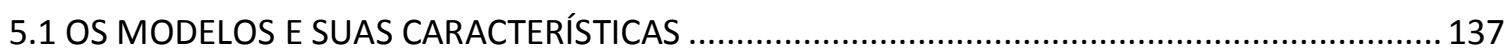

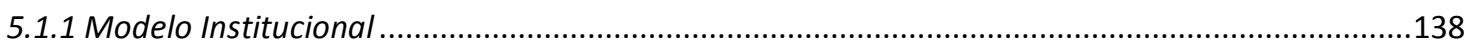

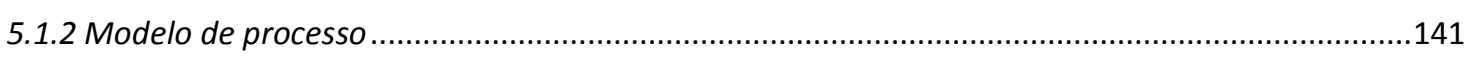

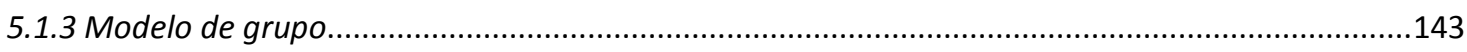

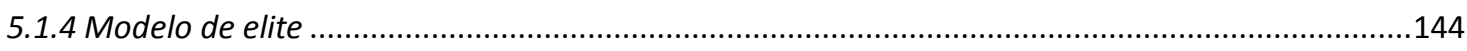

5.1.5 Modelo racional ou a política como ganho social máximo ……………………................................146

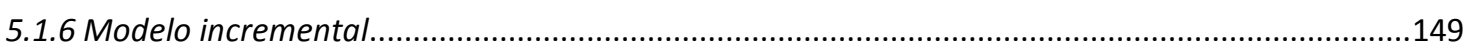

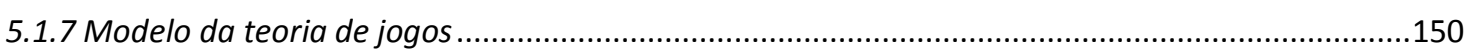

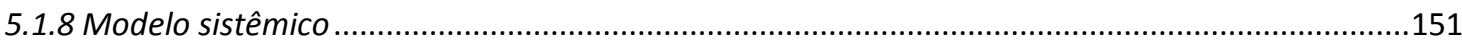

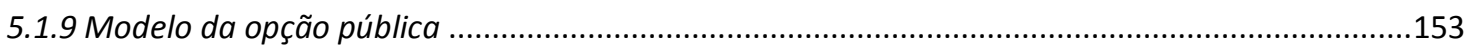

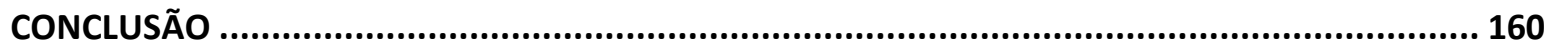

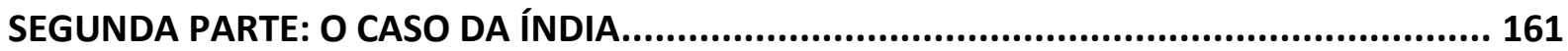




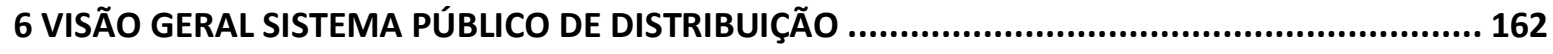

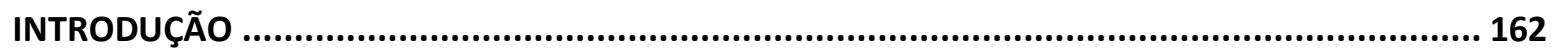

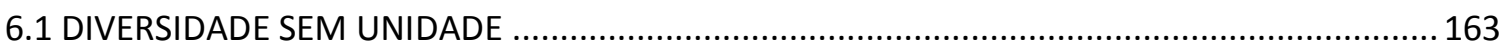

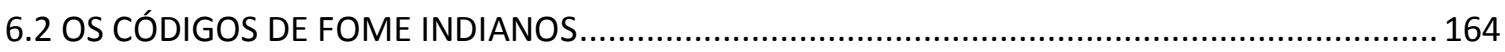

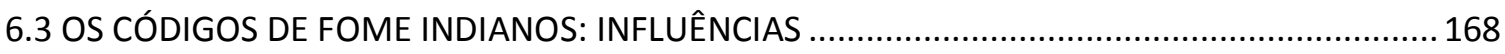

6.4 POLÍTICAS DE SEGURANÇA ALIMENTAR PÓS-COLONIAL: A COMISSÃO DE PLANEJAMENTO

6.5 A GÊNESE DO SISTEMA PÚBLICO DE DISTRIBUIÇÃO - PDS................................................... 171

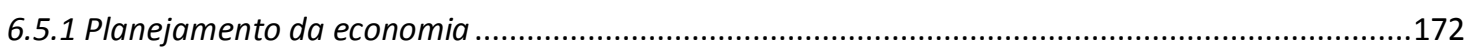

6.5.2 A Sexta Conferência de Controle de Preços ...............................................................................

6.5.3 A Lei Alimento pela Paz de 1966 e a Lei Pública 480 [The Food for Peace Act of 1966, Public Law

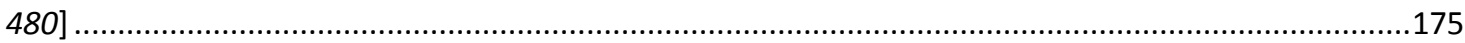

6.6 SISTEMA DE DISTRIBUIÇÃO PÚBLICO RENOVADO - REVAMPED PUBLIC DISTRIBUTION

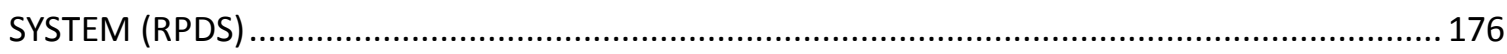

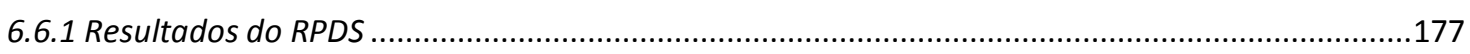

6.7 SISTEMA DE DISTRIBUIÇÃO PÚBLICA DIRECIONADO - TARGETED PUBLIC DISTRIBUTION

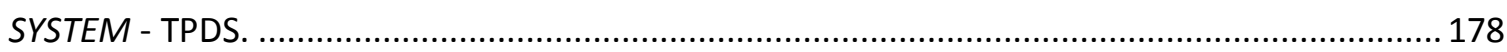

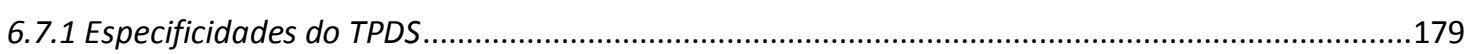

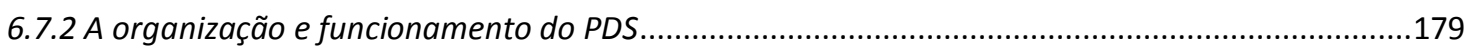

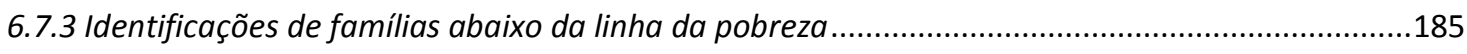

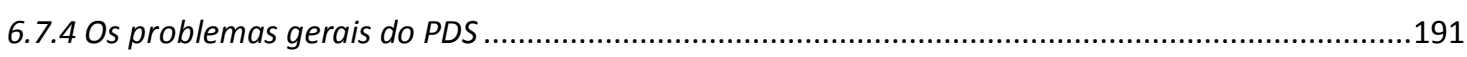

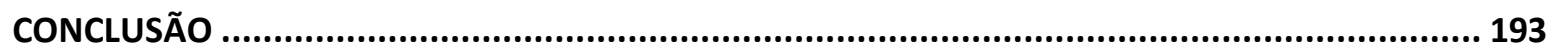

70 PDS NACIONAL E O PDS EM KARNATAKA - PROPOSTAS PARA MUDANÇAS ...................... 195

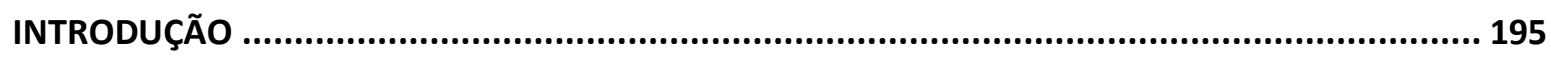

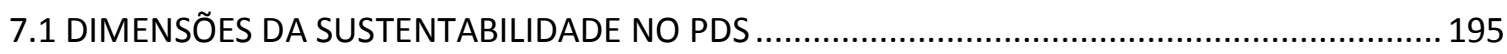

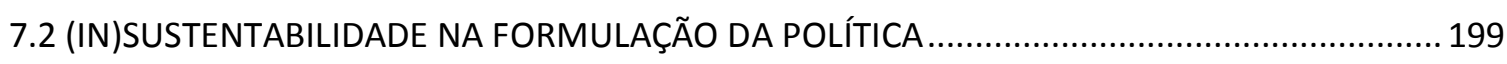

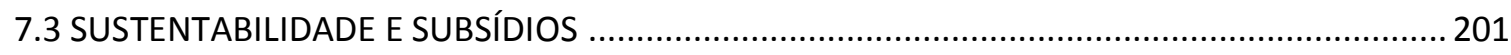

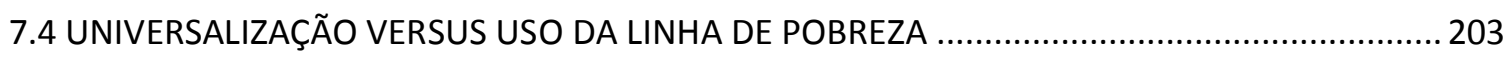

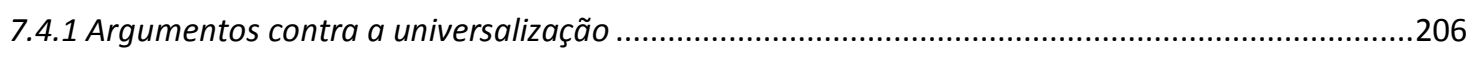

7.4.2 Estudo de caso do PDS universal no estado de Tamil Nadu: contra o universalismo .....................206

7.4.3 Mais argumentos contra a universalidade: Comitê do Juiz Wadhwa ............................................207

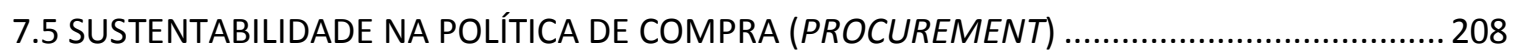

7.6 INCLUSÃO DE MILHETO E OUTROS GRÃOS E LEGUMINOSAS TRADICIONAIS ........................ 211

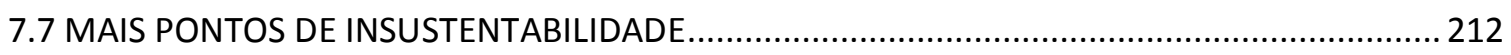

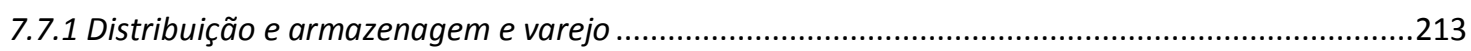

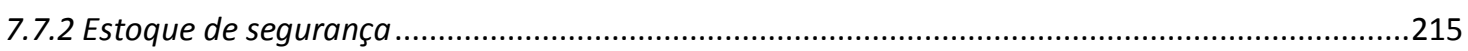

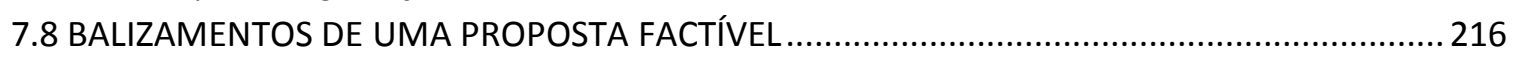

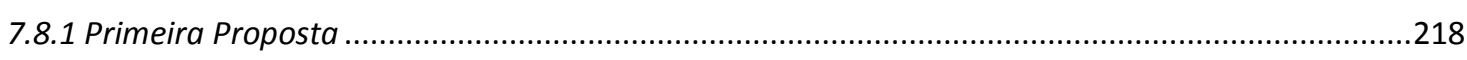

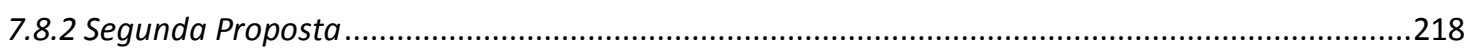

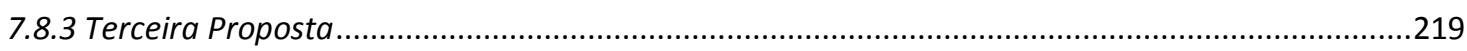

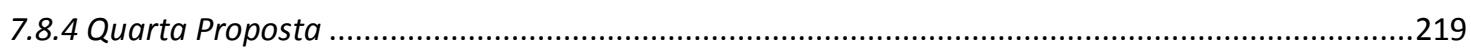

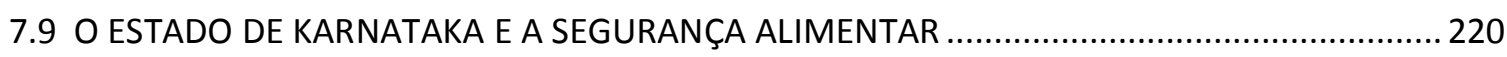

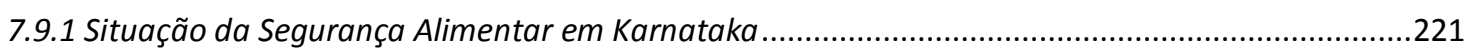

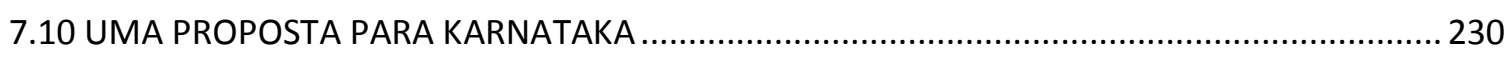

7.10.1 Primeira Proposta para Karnataka: Fortalecimento de meios de subsistência ............................231

7.10.2 Segunda Proposta para Karnataka: Menos intervenção e manipulação estatal direta ................231

7.10.3 Terceira Proposta para Karnataka: um sistema competitivo regulamentado ..............................231 


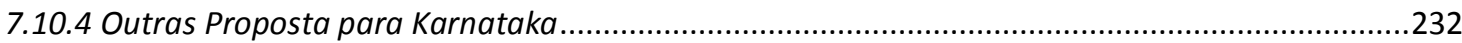

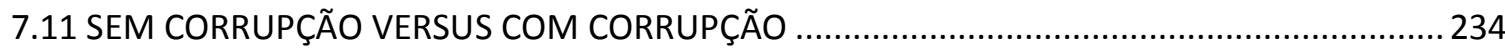

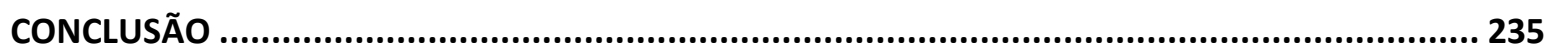

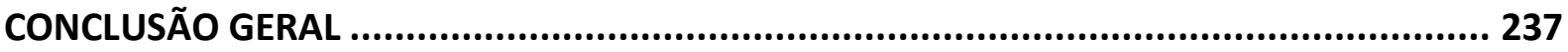

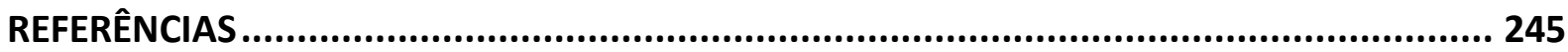

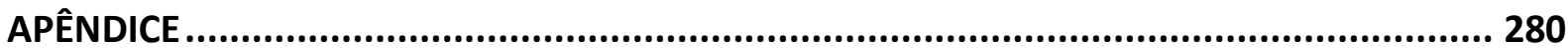

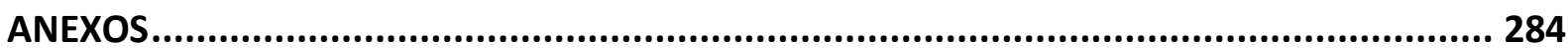

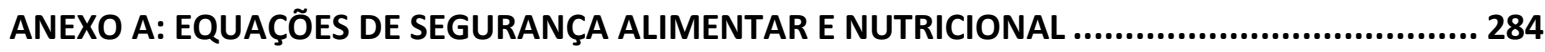

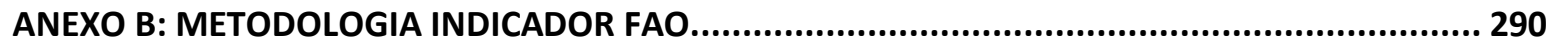

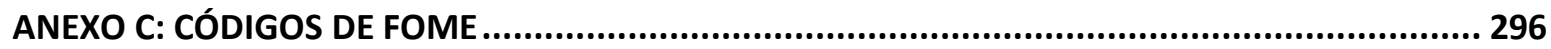

ANEXO D: FACSÍMILES ORIGINAIS - CÓDIGOS DE FOME, DOCUMENTOS E FOTOGRAFIAS ........ 299

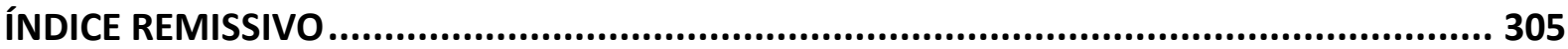





\section{INTRODUÇÃO}

Uma política de segurança alimentar e nutricional é um guia legalmente restritivo balizado por princípios ideológicos, econômicos, sociais, políticos e culturais. Este guia se presta à ação dos órgãos executivos administrativos de um Estado, consistente com a lei, regulamentos e costumes institucionais do país. ${ }^{1} \mathrm{O}$ objetivo da política é assegurar o direito ao acesso a alimentos de qualidade, em quantidade suficiente e permanentemente. Além de suprir, a política deve respeitar as idiossincracias socioculturais inerentes ao ato de se alimentar, baseado em saberes e práticas saudáveis e sustentáveis. Este trabalho de tese apresenta e realiza uma análise crítica da segurança alimentar como campo de estudo e a aplica ao caso da Índia para a segurança alimentar e nutricional da Índia. Confronta, também, elementos teóricos, regulamentares e institucionais de segurança alimentar e nutricional e de análise de políticas públicas com a política e economia política da prática das políticas na Índia.

A relevância do tema desta tese (dificilmente pode ser exagerada pois) afeta e trata da existência de cerca de 10 por cento da população humana do planeta naquilo que está entre uma de suas mais altas prioridades: a alimentação e o direito à alimentação. $O$ modo como esses 10 por cento da humanidade são providos ou deixam de ser providos de alimento, tem consequências incontornáveis e atuais aos outros 90 por cento, especialmente no contexto de mudanças climáticas e da crescente consciência da unidade sistêmica que se vive. Dezessete e meio por cento da população do planeta Terra estão sob a soberania do Estado indiano, governados por representantes da maior democracia eleitoral do planeta. A necessidade de estudos sobre este gigante, especialmente a partir do sul econômico e político, não poderia ser mais premente.

O objeto de pesquisa desta tese está na junção de duas agendas de pesquisa no contexto maior do desenvolvimento (necessariamente sustentável): segurança alimentar e nutricional e análise de políticas públicas. Esse objeto de pesquisa é constituído principalmente por documentos oficiais, relatórios, papers e artigos acadêmicos e observações em âmbito nacional e estadual, que tratam de segurança alimentar e nutricional. Nesta tese se propõe descrição e análise das políticas de segurança alimentar e nutricional do Governo da Índia, da prática de programas e projetos iniciados a partir dessas políticas, da situação resultante e também uma proposta para possíveis e necessários avanços. O objetivo geral é apresentar a segurança alimentar e nutricional, as políticas de segurança alimentar e nutricional, mensuração e a realidade dessas mesmas e mostrar em que medida essas alcançam aquilo a que se propõem e quais seriam os caminhos adiante

\footnotetext{
${ }_{1}^{1}$ Adotou-se a grafia "Estado", com letra inicial maiúscula para o Estado nacional soberano e "estado", com letra inicial minúscula para o estado subnacional ao longo de todo o trabalho de tese.
} 
na Índia. O acesso à alimentação se tornou a principal intervenção do Estado - tanto colonial, quanto independente - na vida da população mais pobre da Índia já a partir do século XIX.

Esta tese é norteada por meio de duas questões de contextualização teórica e metodológica da pesquisa que são respondidas pela bibliografia levantada e uma de fim [Intenção, propósito, escopo, alvo, objeto, fito] e análise da tese.

- Primeira questão: a segurança alimentar e nutricional pode ser definida e medida objetivamente?

- Segunda: políticas públicas em geral e de segurança alimentar e nutricional especificamente podem ser analisadas qualitativamente e quais são os fundamentos?

- Terceira: no contexto do arcabouço das primeiras duas questões, o sistema público direcionado de distribuição de alimentos da Índia é sustentável sob o prisma socioeconômico e ambiental?

A partir do objetivo geral, sete objetivos específicos foram demarcados:

Teóricos:

I. Definir e discutir o conceito de segurança alimentar no contexto de meios de subsistência e na estrutura maior macroeconômica para entender a que se referem as políticas que procuram garantir o direito gerado a partir do conceito;

II. Entender a mensuração do conceito por meio de indicadores - a validade transversal, relevância nutricional e validade intertemporal para permitir a apreciação da complexidade que cerca a questão;

III. Apresentar as teorias e modelos de análise de políticas públicas. A ideia é refletir e preparar a base da análise e discussão sobre a construção da política indiana de segurança alimentar;

Empíricos:

IV. Analisar as características das políticas públicas de segurança alimentar indianas à luz da definição de segurança alimentar, de sua mensuração e da teoria de análise de segurança alimentar;

V. Identificar possíveis fatores de sustentabilidade das políticas públicas de segurança alimentar indiana, especificamente do Sistema Público de Distribuição e suas variantes;

VI. Contextualizar a gama de assuntos discutidos ao longo do trabalho de tese a partir de um breve estudo de caso do estado indiano de Karnataka; 
VII. Avaliar propostas de mudanças pragmáticas ao Sistema Público de Distribuição, observando o posicionamento do Estado indiano e da sociedade civil organizada indiana na conformação aos caminhos possíveis de evolução do sistema.

As hipóteses (ou respostas provisórias) foram geradas pela pesquisa:

1. Em relação à primeira questão de pesquisa, segurança alimentar e nutricional pode ser definida e medida objetivamente de forma satisfatória embora não sem dificuldades relevantes;

2. Em relação à segunda questão, políticas públicas em geral e de segurança alimentar e nutricional especificamente são passivas de análise qualitativa e há pesquisa consolidada sobre o campo, embora sua aplicação além da descrição e narração seja limitada;

3. Em relação ao terceiro problema - no contexto do arcabouço das primeiras duas questões, o sistema público direcionado de distribuição de alimentos da Índia é sustentável sob o prisma socioeconômico e ambiental -, cinco desdobramentos:

a. O sistema público direcionado de distribuição de alimentos da Índia (TPDS) não é sustentável e gera custos socioeconômicos e ambientais consideráveis;

b. A falta de sustentabilidade é patente sob todos os níveis e pilares da sustentabilidade abordados por este trabalho de pesquisa;

c. Há forte resistência institucional e organizacional a mudanças significativas;

d. Os serviços providos pelo TPDS não garantem o mínimo necessário para a segurança alimentar e nutricional, mesmo havendo exceções localizadas e altíssimo custo ao contribuinte indiano;

e. A ênfase na venda subsidiada de cereais sem fortalecimento de meios de subsistência ou geração de renda inviabiliza uma política de segurança alimentar e nutricional sustentável.

Adotou-se uma metodologia híbrida: exploratória e explicativa. Exploratória pois se buscou oferecer informações sobre o objeto e explicativa porque se procurou o registro de fatos de políticas de segurança alimentar indianas, analisando-os, interpretando-os e identificando possíveis causas, além de um esforço de síntese, teorização e reflexão a partir do objeto de estudo. Procurou-se identificar fatores que possam afetar a letra e a prática de segurança alimentar e nutricional na Índia.

A pesquisa se desdobrou em duas fases sobrepostas, com estratégias de pesquisa distintas. A primeira foi a realização de um levantamento bibliográfico sobre segurança 
alimentar e nutricional: conceito que permeia todo o objeto de pesquisa e que é a base da existência das políticas públicas analisadas. Prioritariamente, trabalhos teóricos e da prática de segurança alimentar e nutricional e de análise de políticas públicas, tanto qualitativos quanto quantitativos foram expostos e discutidos. O autor decidiu dar relevante espaço no trabalho de tese às duas questões gerais e embasadoras do tema, por entender que há uma lacuna não necessariamente de pesquisa e bibliográfica mas de real entendimento sobre o que seria segurança alimentar e nutricional. Isto é, definição, mensuração, fatores e conceitos correlatos e possíveis tratamentos que visam atender a questão definida além de modelos teóricos de análise da empiria de políticas públicas. Essa investigação, que ocupa dois terços do trabalho de tese sobre a própria natureza da segurança alimentar, evidencia a existência de uma disjunção cognitiva por parte de múltiplos agentes políticos, econômicos e sociais. Parece não existir um diálogo contrutivo entre aqueles que buscam a compreensão correta do problema de segurança alimentar e nutricional e aqueles que buscam sanar esse problema de segurança alimentar e nutricional na Índia por meio de políticas públicas. Assim, pela análise do que constitui segurança alimentar e nutricional e seus diferentes pilares se percebe a inadequação das políticas existentes em relação às necessidades existentes, dentro daquilo que deveria ser atendido pelas políticas na Índia.

A segunda fase de pesquisa foi feita in loco, em Bangalore, capital do estado de Karnataka, Índia, de dezembro de 2012 a agosto de 2014. A prática e a realidade do Sistema Público de Distribuição, principal política de segurança alimentar e nutricional do Governo da Índia foi testemunhada pelo pesquisador. Neste período relativamente longo de contato direto com a realidade indiana se propiciou um processo de dar forma, um Gestalt ${ }^{2}$ de pesquisa que colocou em confronto direto aquilo previsto em estudos internacionais e nacionais, projetos de lei e leis, regulamentos e normas, programas e projetos e a prática real das ruas de Bangalore e outras cidades e vilas visitadas pelo pesquisador. Este período deixou claro a impossibilidade de uma comparação relevante em nível de tese de doutorado dos sistemas de segurança alimentar do Brasil e da Índia, e a necessidade de se concentrar na compreensão da segurança alimentar e do sistema indiano. Essa segunda fase também se valeu de um levantamento bibliográfico de trabalhos científicos mas também de jornais, relatórios oficiais e de organizações não governamentais, e de consultas verbais. Para este trabalho o pesquisador optou por não realizar entrevistas formais. Amparado por um período mais longo de inserção na vida local, o pesquisador, obviamente enviesado por sua carga sociocultural mas, mesmo assim, isenta de preconcepções em relação ao seu objeto de

2 O termo em língua alemã significa 'forma'. Gestalt ou Psicologia da Forma tem como um de seus temas principais a busca pelo entendimento das leis da habilidade humana para adquirir e manter percepções dotadas de significado em um meio percebido como sendo caótico. Isto é, deixar mais explícito o que está implícito. Veja, Kohler, 1969. 
pesquisa, em tempo se certificou de que havia um consenso entre os que o cercavam de que o Sistema Público de Distribuição, política central do estudo da tese, era visto como insubstituível a despeito de seus vícios e shortcomings estruturais. Em conversas informais, ficou evidente que não havia o contraditório em relação ao sistema adotado pelo governo por todos aqueles que aceitaram o contato para fornecimento de informações. Optou-se, portanto, por pesquisa bibliográfica de trabalhos de pesquisa acadêmicos e não acadêmicos, preferencialmente publicados entre 2005 e 2014, artigos da imprensa local e relatórios de órgãos respeitados e documentos oficiais para embasamento de percepções e direções da tese na terceira parte que trata da descrição, crítica e proposta dos sistemas de segurança alimentar e nutricional da Índia e no estudo de caso do estado de Karnataka.

$O$ relatório da pesquisa levado a cabo para alcançar esses objetivos e procurar possíveis respostas, está estruturado em duas partes, totalizando sete capítulos, além de introdução, conclusão e elementos pós textuais. A primeira parte corresponde à necessidade de compreender conceitos e teorias de segurança alimentar e nutricional, além de modelos de análise a serem utilizados nas partes seguintes e se encontra dividida em cinco capítulos.

Esta primeira parte se inicia com o estado da arte do conceito "segurança alimentar" e do contexto histórico e conceitual da sua origem. Apresenta-se uma breve revisão da formação dos organismos internacionais, Organização das Nações Unidas (ONU) e Organização das Nações Unidas para Alimentação e Agricultura (FAO), no meio e por meio das quais o conceito foi primeiramente pensado, proposto, discutido e formalmente organizado. Trata-se também das questões econômicas que afetam a segurança alimentar e encerra-se com um capítulo dedicado aos modelos qualitativos de análise de políticas. Após as primeiras definições, segue uma apresentação das definições contemporâneas que incorporam os avanços conceituais e empíricos das décadas finais do século XX, por exemplo, Amartya Sen e a ênfase na demanda, e as mais recentes pesquisas sobre o tema. Dada a complexidade e diversidade de níveis de análise do tema, ao longo do capítulo, os quatro pilares da definição contemporânea - disponibilidade, acesso, utilização e estabilidade - são discutidos detalhadamente e os desdobramentos expostos por meio da literatura especializada. Na sequência, as causas da subnutrição, conceito integrante da segurança alimentar e nutricional da $\mathrm{FAO}$, são analisadas em um grau razoável de profundidade e preenchem espaço relevante no capítulo 1 da primeira parte.

Segue o capítulo 2 sobre meios de subsistência - que se encontra baseado quase que exclusivamente no trabalho desenvolvido pelo Departamento de Desenvolvimento Internacional do Governo do Reino Unido (DFID - sigla em inglês), embora haja contribuições importantes de outros organismos internacionais e autores. A seção sobre os 
cinco (5) componentes da vulnerabilidade e seus principais determinantes está baseada no trabalho de Terry Cannon pesquisador do Instituto de Estudos do Desenvolvimento (IDS sigla em inglês) da Universidade de Sussex, que tem publicado extensivamente sobre o assunto. Na seção seguinte, busca-se a interligação da extensa gama de conceitos e definições apresentadas ao longo do capítulo naquilo que concerne a segurança alimentar e nutricional. A prática e as práticas da política (no sentido amplo, geral de ação governamental) de segurança alimentar é avaliada ante os pilares da sustentabilidade ambiental, sócio-institucional e econômica. A discussão se adensa na dimensão social da sustentabilidade e sobre os conceitos centrais dessa dimensão: equidade, conscientização para a sustentabilidade, participação e coesão social. Dentre eles, o conceito de 'equidade' é destacado dado à sua proeminência na agenda política de garantia de direitos, no caso, o direito à alimentação.

No capítulo 3, uma análise do contexto macroeconômico da segurança alimentar, com especial atenção às crises de preços de alimentos de 2008 e 2011 cujos efeitos ainda se contabilizam. Por tratar-se da parte introdutória e panorâmica, correu-se o risco de fragmentação da narrativa tão característica de textos acadêmico-científicos que almejam cobrir de forma panorâmica determinado assunto. Espera-se que esta deficiência seja satisfatoriamente sanada nas partes subsequentes. $O$ trabalho de tese segue e trata da mensuração do conceito de segurança alimentar. No capítulo 4 são apresentados inicialmente os indicadores de segurança alimentar passíveis de mensuração e comparação. A complexidade da conversão de definições em grandezas físicas mensuráveis e comparáveis é apreciada a partir da dificuldade de direcionamento de políticas (targeting), uma das maiores dificuldades do Governo da Índia, e em plano segundo, a ausência de consenso sobre o que deve ser mensurado para operacionalizar e reificar a realidade abstrata e permeada de dor chamada 'fome'. As características básicas de indicadores e os testes que indicadores de segurança alimentar devem passar são brevemente expostos e os quatro tipos principais de indicadores de segurança alimentar de restrição calórica, de pobreza monetária, de diversidade da dieta e experimentais e/ ou subjetivos - são discutidos em algum detalhe. Na conclusão do capítulo, recorreu-se a um quadro para resumir os indicadores em relação a alguns critérios que demonstram a utilidade e facilidade de uso de cada um.

O capítulo 5 apresenta de forma mais objetiva e direta as teorias e modelos de análise de políticas públicas que serão implicitamente utilizados nos capítulos de análise e crítica da segunda parte do trabalho de tese. As teorias e modelos não exclusivos e também, não necessariamente concorrentes, quais sejam, institucional, de processo, de grupo, de elite, racional, incremental, da teoria de jogos, sistêmico e da opção pública são analisados pelo 
que são: representações simplificadas da realidade que auxiliam mas não substituem a pesquisa dedutiva. Especial atenção é dedicada ao mais econômico dos modelos e teorias de análise de políticas públicas: o modelo da opção pública. Os conceitos de logrolling e rent-seeking explicam parte dos arranjos políticos e institucionais à volta do sistema de segurança alimentar da Índia.

A segunda parte do trabalho de tese corresponde à apresentação, análise e crítica do caso da política pública de segurança alimentar e nutricional da Índia e está configurado em 2 capítulos. O capítulo 6 , dividido em duas partes, trata, na primeira parte, da conformação histórica, gênese, expansão e consolidação do sistema público de distribuição de alimentos do Governo da Índia em nível nacional. Trata-se de uma parte do capítulo de características narrativas e descritivas, fundamentalmente histórica que apresenta o background da formação e idealização das políticas formuladas e adotadas por sucessivos governos. Os Códigos de Fome Indianos da década de 1870 formaram a base das políticas de segurança alimentar da Índia até meados da década de 1980, demonstrando a profundidade e real significância dos mesmos e razão da dedicação de um espaço relativamente grande para estes neste trabalho de tese. Na segunda parte do mesmo capítulo, o caminho jurídico, político e organizacional do Governo da Índia para a segurança alimentar é apresentado, evidenciando os arranjos político-institucionais que resultaram na forma do sistema até 2014. Os mecanismos de direcionamento da políticas de segurança alimentar são expostos e analisados e algumas falhas do sistema pontuadas e criticadas.

O capítulo 7 afunila um pouco mais o foco da terceira parte do trabalho de tese ao apresentar uma análise e discussão das dimensões da sustentabilidade econômica, ambiental e social do Sistema Público de Distribuição (PDS - sigla em inglês), principal política e programa do Governo da Índia para a segurança alimentar e nutricional no país. Uma análise qualitativa é apresentada ao final do capítulo 7 sobre a integração da política ambiental sustentável na formulação e execução da Lei de Segurança Alimentar Nacional de 2013, conhecida como NFSA (sigla em inglês) especialmente no que concerne a política de compra (procurement) do PDS e na distribuição, armazenagem e operação no varejo. A segunda parte do capítulo 7 possui dois trilhos distintos porém paralelos: o primeiro, uma abordagem de estudo de caso ao PDS no estado de Karnataka. A discussão iniciada no início do capítulo em âmbito nacional é confinada ao plano estadual. Como esperado pelas hipóteses levantadas, os mesmos fatores que oneram o sistema no plano nacional se repetem no estadual. Caminhos possíveis são discutidos e avaliados tendo em vista o melhoramento do sistema. É nesse ensejo que o segundo trilho se compõe de propostas gerais, no entanto, factíveis para um grau positivo de sustentabilidade da política de segurança alimentar e nutricional no estado de Karnataka. 
Nas conclusões gerais, as respostas provisórias (ou hipóteses) construtivas geradas pela pesquisa da primeira parte do trabalho de tese são acareadas com a situação do sistema público direcionado de distribuição de alimentos da Índia (TPDS) que não é sustentável e gera custos socioeconômicos e ambientais consideráveis. Além de insustentáveis, os serviços providos pelo TPDS não garantem o mínimo de segurança alimentar e nutricional (embora hajam exceções). A não aceitação por parte dos establishments político, ativista e acadêmico indiano de mudanças estruturais no sistema de segurança alimentar e nutricional (por exemplo, 'vales alimentação' ou, então, dinheiro, como é o caso do Bolsa família no Brasil) e a ênfase na venda subsidiada de cereais sem fortalecimento de meios de subsistência ou geração de renda inviabiliza uma política de segurança alimentar e nutricional sustentável. 
PRIMEIRA PARTE: MARCO DE REFERÊNCIA TEÓRICO-CONCEITUAL 


\title{
CAPÍTULO 1: CONCEITOS DE SEGURANÇA ALIMENTAR
}

\author{
1 CONCEITOS DE SEGURANÇA ALIMENTAR
}

\section{INTRODUÇÃO}

O capítulo um trata de termos, conceitos e definições de segurança alimentar. A evolução histórica do conceito de segurança alimentar é revista a partir da Segunda Guerra Mundial (1939-1945) até a segunda década do século 21. Marcos na evolução conceitural e histórica são desatacados, como a Declaração Universal sobre a Erradicação da Fome e Desnutrição, e o pioneiro 'conceito de acessos' de Amartya Sen - apontado como um dos marcos nos estudos de segurança alimentar ao dar ênfase à demanda e não à produção. Os aspectos categóricos, sócio organizacionais e gerenciais do arcabouço conceitual de segurança alimentar são discutidos e criticados a partir da literatura especializada. $\mathrm{Na}$ sequência, o arcabouço conceitual da subnutrição é apresentado a partir das causas imediatas, básicas e subjacentes, além da manifestação da subnutrição em si. A segunda parte do capítulo se debruça sobre as consequências da insegurança alimentar (que também podem ser consideradas causas), nomeadamente, a subnutrição, a fome e a pobreza. O capítulo é encerrado com uma breve discussão dos aspectos culturais da alimentação, do perfil da alimentação e das fontes de nutrientes advindas da alimentação tradicional.

\subsection{EVOLUÇÃO HISTÓRICA DO CONCEITO DE SEGURANÇA ALIMENTAR}

O conceito operacional de segurança alimentar passa por constante revisão desde sua primeira concepção contemporânea e se confunde com a fundação da Organização das Nações Unidas para Alimentação e Agricultura (FAO). Durante a Segunda Guerra Mundial (1939-1945), as vitórias das forças aliadas no inverno do hemisfério norte de 1942-43 fortaleceu a perspectiva crescente de uma vitória aliada contra os países do Eixo que por sua vez encorajou o governo dos Estados Unidos a levar adiante os preparativos para a fundação da Organização das Nações Unidas. ${ }^{3} 4$

Entre 18 de maio e 3 de junho de 1943, quarenta e quatro países se fizeram representar em Hot Springs, estado da Virgínia, Estados Unidos da América, para a

\footnotetext{
${ }^{3}$ As forças aliadas tinham a frente o Reino Unido, a União Soviética e os Estados Unidos. Formavam ainda o grupo dos Aliados: Austrália, Nova Zelândia, Nepal, África do Sul, Canadá, Noruega, Bélgica, Luxemburgo, Países Baixos, Grécia, lugoslávia, Panamá, Costa Rica, República Dominicana, El Salvador, Haiti, Honduras, Nicarágua, Guatemala, Cuba, Coréia, Checoslováquia, México, Etiópia, Iraque, Bolívia, Irã, Colômbia, Libéria, Romênia, Bulgária, San Marino, Albânia, Brasil, Equador, Paraguai, Peru, Uruguai, Venezuela, Turquia, Líbano, Arábia Saudita, Argentina, Chile e Dinamarca, China, Polônia e a França livre.

${ }^{4}$ Os países do Eixo: Alemanha, Itália e Japão, além de Bulgária, Hungria e Romênia.
} 
Conferência das Nações Unidas para a Alimentação e Agricultura (Phillips, 1981). Convocada pelo então presidente estadunidense Franklin Delano Roosevelt (FDR), a conferência se baseava na proclamação de princípios preconizada pelo próprio Roosevelt: a Carta do Atlântico (1941) e as Quatro Liberdades (1942). ${ }^{5}$

Os termos e conceitos usados nas definições atuais de segurança alimentar e nutricional têm suas raízes nesta primeira conferência do sistema da Organização das Nações Unidas. Em 1943, os confrontos da Segunda Guerra Mundial já haviam destruído parte da produção agrícola na Europa e consequentemente, havia escassez e fome em muitas regiões (Brassley et al., 2012). Os delegados dos governos representados na conferência concluíram que na ausência de necessidade, freedom from want, se incluía um suprimento adequado (adequate), conveniente (suitable) e seguro (secure) de alimentos para todo ser humano, sendo que "seguro" se referia ao acesso ao alimento, "adequado" à quantidade suficiente do suprimento e "conveniente" se referia ao conteúdo nutricional do suprimento alimentar (CFS, 2012, p. 4). Concomitantemente, os delegados presentes definiram como prioridade zero a busca pela liberdade em relação à fome (freedom from hunger).

Diante deste contexto, acreditava-se que a maior urgência se encontrava no reestabelecimento da produção de cereais e outros alimentos de base para que a demanda pela manutenção dos requerimentos mínimos dietéticos fosse satisfeita, especialmente na Europa. Após a satisfação da demanda reprimida, a Conferência propunha o aumento da produção de alimentos com alto teor proteico e de outros nutrientes essenciais. Reconheceu-se também a centralidade da pobreza como causa da insegurança alimentar e nutricional e a necessidade de ter o crescimento econômico global e geração de empregos como objetivos de longo prazo necessários para a redução da pobreza e a obtenção de níveis de nutrição satisfatórios para todos (CFS, 2012, p. 4).

Com a criação oficial da FAO em 1945, o marco seguinte foi o Pacto Internacional dos Direitos Econômicos, Sociais e Culturais (ICESCR - sigla em inglês) de 16 de dezembro de 1966 e em vigor na ordem internacional a partir de 3 de janeiro de 1976, que consagrou o direito à alimentação adequada e o direito de ser livre da fome no Artigo 11 .

1. Os Estados Partes no presente Pacto reconhecem o direito de todas as pessoas a um nível de vida suficiente para si e para as suas famílias, incluindo alimentação, vestuário e alojamento suficientes, bem como a um melhoramento constante das suas condições de existência. Os Estados Partes tomarão medidas apropriadas destinadas a assegurar a realização deste direito reconhecendo para este efeito a importância essencial de uma cooperação internacional livremente consentida.

\footnotetext{
${ }^{5}$ Para maiores detalhes, Borgwardt, 2009.
} 
2. Os Estados Partes do presente Pacto, reconhecendo o direito fundamental de todas as pessoas de estarem ao abrigo da fome, adotarão individualmente e por meio da cooperação internacional as medidas necessárias, incluindo programas concretos:

a) Para melhorar os métodos de produção, de conservação e de distribuição dos produtos alimentares pela plena utilização dos conhecimentos técnicos e científicos, pela difusão de princípios de educação nutricional e pelo desenvolvimento ou a reforma dos regimes agrários, de maneira a assegurar da melhor forma a valorização e a utilização dos recursos naturais;

b) Para assegurar uma repartição equitativa dos recursos alimentares mundiais em relação às necessidades, tendo em conta os problemas que se põem tanto aos países importadores como aos países exportadores de produtos alimentares. ${ }^{6}$ (ONU, 1966).

O ICESCR de 1966 - classificado como tratado multilateral adotado pela Assembleia Geral das Nações Unidas - lançou os fundamentos gerais para o conceito atual de segurança alimentar, inclusive reconhecendo a importância da nutrição no nível do indivíduo. Como parte do conjunto de documentos conhecidos como Declaração Universal dos Direitos Humanos, o ICESCR compartilha a mesma gênese institucional na Conferência de San Francisco de 1945. O texto inicial foi apresentado à Assembleia Geral em 1954, adotado e aberto à assinatura, ratificação e adesão apenas em 1966, passando a vigorar 10 anos mais tarde (Dowell-Jones, 2004; ONU, 1966).

No entanto, foi apenas na década de 1970 que a definição de segurança alimentar e nutricional tomou sua forma atual. Entre 1963-1966 e 1970-1974, uma série de secas na então União Soviética, além de Índia e África Saheliana causaram sucessivas crises de insegurança alimentar, que ocasionaram um declínio na disponibilidade de alimento principalmente entre 1970-75, especialmente de grãos (Smith \& Haddad, 2000; Shaw, 2012; Manassah, 1981). ${ }^{7}$ A escassez provocou um aumento no nível geral de preços das commodities agrícolas nos mercados internacionais, acirrada pela crise do petróleo de outubro de 1973 a março de 1974 (Kemp, 2004). ${ }^{8}$

Em vista da situação, a Assembleia Geral da ONU convocou uma Conferência Mundial para a Alimentação por meio da resolução 3180 (XXVII) de 17 de dezembro de 1973, que

\footnotetext{
6 ORGANIZAÇÃO DAS NAÇÕES UNIDAS. Pacto Internacional sobre os Direitos Econômicos, Sociais e Culturais, adotado em 16 de dezembro de 1966, Resolução da Assembleia Geral 2200 (XXI), 21 UN GAOR Supp. (No. 16) at 49, UN Doc. A/6316 (1966), 993 UNTS 3, em vigor no sistema internacional a partir de 3 Jan. 1976. Versão em português disponível em: <http://www.unfpa.org.br/Arquivos/pacto_internacional.pdf>. Acesso em: 28/05/2013.

7 A África Saheliana, termo é originário do árabe para "costa" ou "fronteira"- sahil, é a faixa que varia de 500 a 700 quilómetros de largura ao sul do deserto do Saara e se estende das costas oeste de Senegal, Mauritânia e Gâmbia até os litorais de Sudão e Eritréia, cerca de 5.400 quilómetros de extensão (Documentation Française, 2013).

8 A Crise do Petróleo de 1973 foi provocada quando países membros árabes da OPEC, mais Egito, Síria e Tunísia decidiram punir os Estados Unidos por rearmar Israel após o ataque de Egito e Síria contra o Estado judeu no dia mais sagrado para o judaísmo, Yom Kippur, em 6 de outubro de 1973. A guerra se encerrou com a vitória israelense em 25 de outubro de 1973. Veja Kemp, 2004.
} 
ocorreu entre os dias 5 e 16 de novembro de 1974 em Roma, Itália (ONU, 1975; CFS, 2012; Shaw, 2012).

\title{
1.1.1 A Declaração Universal sobre a Erradicação da Fome e Desnutrição
}

A Conferência Mundial para a Alimentação de 1974 contou com a participação de 135 representantes de Estados-membros da ONU, além de representantes de movimentos de libertação reconhecidos pela Organização, o próprio secretário geral (1972-1981), Kurt Waldheim, diversos órgãos e agências da ONU, e organizações internacionais dedicadas à questão. A Declaração Universal sobre a Erradicação da Fome e Desnutrição, documento final da conferência preconiza como responsabilidade comum de toda a "comunidade" internacional a busca por uma solução para a subnutrição e a erradicação da fome (ONU, 1975).

$\mathrm{Da}$ declaração depreende-se que os representantes entendiam que governos, organismos internacionais e empresas possuíam recursos suficientes para alimentar a população mundial. O nó górdio se apresentava no não compartilhamento e no uso limitado dos recursos disponíveis ${ }^{9}$. Governos eram encorajados a aumentar e melhorar a produção de alimentos. Além disso, a crença no comércio livre é evidente no texto, que afirma que o comércio internacional de alimentos auxiliaria na erradicação da subnutrição (Hospes \& Ladiprayitno, 2010, p. 57).

\begin{abstract}
All States should strive to the utmost to readjust, where appropriate, their agricultural policies to give priority to food production, recognizing in this connection the interrelationship between the world food problem and international trade. In the determination of attitudes towards farm support programmes for domestic food production, developed countries should take into account, as far as possible, the interest of the food-exporting developing countries, in order to avoid detrimental effect on their exports. (ONU, 1974:5). ${ }^{10}$
\end{abstract}

\subsubsection{Novos caminhos: Amartya Sen e a ênfase na demanda}

A Declaração Universal sobre a Erradicação da Fome e Desnutrição de 1974 ainda é considerada um marco no desenvolvimento do conceito e da prática de segurança alimentar. No entanto, a primeira declaração multilateral a enfrentar a questão da fome como mazela a ser eliminada no âmbito internacional enfatizava fortemente apenas o lado

\footnotetext{
9 O "nó górdio" provem de uma lenda que envolve o rei da Frígia e Alexandre, o Grande; uma metáfora de como um problema sem solução aparente pode ser resolvido de forma fraudulenta ou extremamente inovadora, no caso, cortando o nó. Fox, 2006.

10 "Todos os Estados deveriam buscar ao máximo reajustar, onde apropriado, suas políticas agrícolas para dar prioridade à produção de alimentos, reconhecendo nesta conexão o inter-relacionamento entre o problema alimentar mundial e o comercio internacional. Na determinação de atitudes para o apoio de programas de apoio à produção doméstica de alimentos, países desenvolvidos deveriam levar em consideração, tanto quanto possível, o interesse dos países em desenvolvimento exportadores de alimento, para que se eveite efeito prejudicial em suas exportações.". Tradução livre do autor.
} 
da oferta de alimentos. Foi apenas com o trabalho pioneiro do economista indiano Amartya Sen (1981) que o enfoque gradualmente foi redirecionado para o consumo e para o direito (entitlement) de indivíduos e domicílios, também conhecido como o 'conceito de acessos'. E, embora do ponto de vista conceitual e empírico, a abordagem de Sen tenha sido enfraquecida ao longo dos anos, a contribuição do autor permanece como um ponto de virada nos estudos e prática da segurança alimentar.

De acordo com Devereux (2001), a contribuição mais importante da abordagem de $s$ $(1981,1984)$ é a mudança no foco analítico. Sen foi capaz de desviar as ciências econômica e sociais da fixação com a oferta de alimentos - ainda carregada da lógica da teoria da população de Thomas Robert Malthus (1999 [1826]) - e redirecionar as lentes analíticas para as condições dos demandantes do alimento.

No enfoque de Sen (1981), a insegurança alimentar impacta a parcela da população de determinada área que não dispõe de acesso a alimento adequado devido à pobreza a despeito da disponibilidade de alimento. O limitador de acesso é a não disponibilidade de recursos legais que garantam o direito ao alimento. Desta observação seminal, conclui-se que uma situação de fome generalizada pode vir a ocorrer mesmo com disponibilidade de alimentos, linhas de suprimentos apropriadas e mercados em pleno funcionamento.

O conjunto de direitos de um indivíduo, afirma Sen (1981) se resume ao conjunto de bens e serviços que ele adquire ao converter direitos, tais como, ativos financeiros e recursos próprios (por exemplo, força de trabalho). O conceito descritivo de Sen (1981; 1984) se baseia no direito legal e econômico, despido de qualquer recurso à moral ou aos direitos humanos. Daí a conclusão que se tornou célere entre estudiosos do tema, "The law stands between food availability and food entitlement. Starvation deaths can reflect legality with a vengeance" (SEN, 1981, p. 166). A conclusão permanece atual em vista da situação de insegurança alimentar em um país como a Índia, no qual há abundância de alimento estocados que não chegam ao estomago dos famintos por causa da e pelo descumprimento da lei.

No modelo de Sen (1981), há quatro categorias de direitos:

a) Direitos baseados na produção, isto é, cultivo de alimentos: o direito de um indivíduo possuir aquilo que ele produz com seus próprios (ou contratados) recursos;

b) Direitos baseados no comércio (compra de alimentos): o direito de se possuir aquilo que se adquire por meio da troca de commodities com partes anuentes;

c) Direitos da própria mão-de-obra, portanto, trabalho pela comida: o direito de se auto empregar ou ser autônomo, vender a própria mão-de-obra; e, 
d) Direitos de transferência e herança, isto é, o receber alimentos providenciados por outros: o direito de possuir aquilo que é voluntariamente doado por outros (Sen, 1981, p. 2; Devereux, 2001, p. 15).

A teoria descritiva de Sen $(1981 ; 1984)$, levou ao reconhecimento de que o suprimento de alimento não garante a segurança alimentar por si mesmo. Os mais pobres e vulneráveis necessitam também de garantia física e econômica de acesso ao alimento.

\subsubsection{A Cúpula Mundial da Alimentação: um novo plano de ação}

O contexto histórico e econômico de insegurança alimentar do início dos anos 1980, no ápice da segunda crise alimentar mundial acelerou a revisão do conceito de segurança alimentar proposto pela FAO e apoiado pelo Comitê de Segurança Alimentar da mesma organização em 1983. A nova definição unia três objetivos: a adequação da oferta de alimento, a estabilidade da oferta e mercados de alimentos, e a segurança do acesso à oferta (CFS, 2012, p. 4).

Em fevereiro de 1986, o Banco Mundial publicou um estudo denominado, "Poverty and Hunger: Issues and Options for Food Security in Developing Countries". Os analistas do Banco Mundial sublinharam a importância do acesso do indivíduo ao alimento. Também relevante no estudo era a distinção explícita entre os aspectos de curto e longo prazo da segurança alimentar. O curto prazo é definido como insegurança alimentar transitória, dando conta da incapacidade temporal de acessar alimento suficiente, enquanto o longo prazo descreve a insegurança alimentar crônica e está associada a uma dieta continuamente deficiente (Banco Mundial, 1986; Clay, 2002; Pieters et al., 2012, p. 6).

Mais de uma década mais tarde, em novembro de 1996 representantes de 185 países e a então Comunidade Europeia se reuniram na Cúpula Mundial da Alimentação em Roma. Os chefes de Estado e governo aprovaram uma declaração e um plano de ação contra a insegurança alimentar e nutricional. Das tratativas que levaram à cúpula, a seguinte definição foi adotada, com o acréscimo subsequente indicado:

Existe segurança alimentar quando as pessoas têm, a todo momento, acesso físico [, social] e econômico a alimentos seguros, nutritivos e suficientes para satisfazer as suas necessidades dietéticas e preferências alimentares, a fim de levarem uma vida ativa e sã. A este respeito é necessário uma ação concertada, a todos os níveis. (FAO, 1996).

A definição foi confirmada e aprovada em 1998 e oficialmente reafirmada em 2009 na Declaração da Cúpula Mundial sobre Segurança Alimentar (CFS, 2012). Na mesma ocasião, o Comitê de Segurança Alimentar Mundial (CFS) abraçou definitivamente a inclusão da esfera nutricional na interpretação oficial da definição de segurança alimentar ao afirmar que 
a dimensão nutricional é integral ao conceito de segurança alimentar e ao trabalho do CFS (CFS, 2009/2 Ver. 2 apud CFS, 2012:6).

\subsubsection{A definição contemporânea}

Maxwell e Frankenberger (1992), Maxwell (1995), Clay (1997, 2002), Gross et al. (1998) e o IFPRI (1999), juntos levantaram mais de 200 definições e 450 indicadores de segurança alimentar que foram utilizadas ao longo dos anos pela comunidade científica acadêmica e pelos practitioners.

A definição da FAO oficial e atualizada afirma que,

Segurança Alimentar e Nutricional existe quando todas as pessoas, em todos os momentos, têm acesso físico, social e econômico à alimentação em quantidade e qualidade suficientes em termos de variedade, diversidade, conteúdo nutricional e segurança para atender suas necessidades de dieta e preferências alimentares para uma vida ativa e saudável, associada a um ambiente sanitário, saúde adequada, educação e cuidado. (FAO/AGN, 2011). ${ }^{11}$

De acordo com a FAO (2006), a definição vigente se baseia em quatro pilares:

1. Disponibilidade: Uma situação de disponibilidade em segurança alimentar é alcançada quando quantidades suficientes de alimento são fornecidas por meio da produção, comércio e ajuda humanitária em gêneros alimentícios;

2. Acesso: quando indivíduos têm acesso a recursos adequados, direitos (entitlements) para adquirir alimentos apropriados para uma dieta nutritiva;

3. Utilização: a utilização de alimentos por meio de uma dieta adequada, água potável, saneamento e saúde para se atingir um estado de bem-estar no qual todas as necessidades fisiológicas são atendidas;

4. Estabilidade: para que uma população tenha segurança alimentar e nutricional, a unidade familiar ou o indivíduo devem ter acesso à alimentação adequada a todo tempo. Os indivíduos não deveriam sofrer o risco de perder o acesso ao alimento em decorrência de choques inesperados, tais como, crises econômicas ou climáticas, ou mesmo, eventos cíclicos como fomes sazonais (FAO, 2006).

\subsection{O ARCABOUÇO CONCEITUAL DE SEGURANÇA ALIMENTAR}

Os quatro pilares - disponibilidade, acesso, utilização e estabilidade - são a base para uma compreensão real da segurança alimentar e nutricional, base esta que é didaticamente dividida em três aspectos: 1) Categóricos; 2) Sócio organizacionais; e, 3) Gerenciais.

\footnotetext{
11 Tradução do autor.
} 


\subsubsection{Aspectos categóricos}

O primeiro pilar - disponibilidade - tem dois determinantes, um físico e outro temporal que têm impacto direto no arcabouço conceitual de segurança alimentar. O fluxo de alimento é o determinante físico, isto é, a disponibilidade condiciona a acessibilidade, que por sua vez, condiciona a acessibilidade, o uso e a utilização conforme a Figura 1 (Weingartner, 2004). O determinante temporal da segurança alimentar e nutricional está ligado à estabilidade que impacta os três elementos físicos. A disponibilidade no conceito de segurança alimentar e nutricional se refere à existência dos alimentos e, em geral, o termo disponibilidade se refere à oferta de alimentos em níveis regionais e nacionais e não no nível do domicílio (Riely et al., 1999; Weingartner, 2004, p. 6).

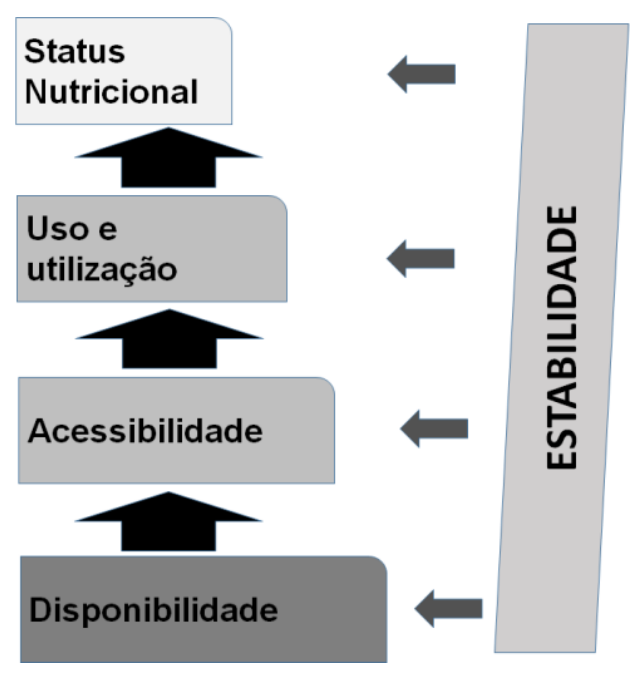

Figura 1: Segurança alimentar Fonte: Weingartner, 2004, p. 6.

\section{Acesso}

O acesso, conceito definido anteriormente neste capítulo, depende dos preços praticados no mercado e da disponibilidade de recursos - capital, trabalho, conhecimento. Exceto em relativamente poucos locais, o acesso é crescentemente uma função da disponibilidade e habilidade de geração de renda e não da habilidade de autossuficiência do grupo familiar (Riely et al., 1999; Weingartner, 2004, p. 6).

O acesso ao alimento é uma função do meio ou ambiente físico, do meio social e das políticas públicas. Esses três ambientes determinam quão efetivamente as famílias utilizam seus recursos para atender suas necessidades de segurança alimentar. Choques nas condições em vigor interrompem estratégias de produção e ameaçam o acesso da família. Essas mudanças repentinas podem resultar na perda de parte ou de toda a habilidade de 
produção e de bens que possibilitam a produção, compromete o potencial produtivo de longo prazo do grupo familiar e resulta em insegurança alimentar (Riely et al., 1999, p. 22).

Um exemplo de choque ao acesso ao alimento da primeira década do século 21 , foi a crise financeira e econômica de 2008-2011. Durante o período destacado e além, o custo da cesta básica aumentou em vários países e resultou na redução da qualidade e da quantidade de alimento consumido no nível domiciliar. O risco de subnutrição aumentou, e o número de famílias vulneráveis também. O grupos populacionais mais afetados foram os que têm necessidades mais específicas como crianças, mulheres grávidas e lactantes, além daqueles sofrendo de doenças crônicas como HIV/AIDS e tuberculoses. Como a subnutrição nos primeiros 2 anos de idade tem consequências de longo prazo, mesmo uma crise de acesso de curto prazo produz efeitos de longo prazos (Brinkman et al., 2010). Este exemplo será mais será mais amplamente discutida na seção que trata das questões macroeconômicas.

Uso

O uso do alimento é a base do aspecto sócio econômico da segurança alimentar no nível do domicílio ou do grupo familiar e é determinado pelos hábitos e conhecimentos dos indivíduos e da comunidade maior em que estes vivem. Cabe à família tomar decisões relacionadas à compra, preparo e consumo quando as condições disponibilidade e acesso a alimento suficiente e nutritivo estão satisfeitas. Em muitos contextos culturais, a distribuição de alimentos é estratificada e certos indivíduos podem sofrer de subnutrição mesmo quando no agregado há segurança alimentar (Appadurai,1981; Haddad et al., 1996; Berti, 2012). mesmo ocorre quando os alimentos consumidos em si não se conformam aos padrões do que a ciência nutricional julga ser uma dieta balanceada (Weingartner, 2004).

\section{Utilização}

A utilização do alimento se refere à segurança alimentar no nível do indivíduo e foca na utilização biológica do alimento. A utilização se encontra no escopo dos nutricionistas e atenta para a habilidade biológica do indivíduo ingerir e metabolizar o alimento, convertendo-o em energia para sustentar a sobrevivência do organismo. Um meio ambiente físico saudável no qual a disponibilidade de água potável e saneamento são requisitos essenciais e o conhecimento, a compreensão e prática de cuidados com a saúde pessoal, preparação de alimentos e processos de preservação são precondições para uma dieta adequada (Weingartner, 2004). 
Estabilidade ou Sustentabilidade

A sustentabilidade ou estabilidade se refere à dimensão temporal da segurança nutricional. A literatura de segurança alimentar em geral distingue entre a) insegurança alimentar crônica: a inabilidade de atender às necessidades de alimento continuamente; e, b) insegurança alimentar transitória: a inabilidade de satisfazer a necessidade de alimento temporariamente (Maxwell; Frankenberger, 1992).

A insegurança alimentar transitória é frequentemente dividida em duas subcategorias: ii) cíclica: ocorre dentro de um padrão aparentemente regular, em geral, em áreas rurais, na entre safra; e, ii) temporária: em geral, de curta duração e de natureza exógena e não necessariamente regular, tais como secas, inundações e por vezes, conflitos armados (alguns autores preferem colocar em outra categoria, já que os efeitos podem ser muito mais duradouros), a visão geral dada na Figura 2 (Maxwell; Smith, 1992; Tiburcio, 2009). 
MICRO: familias

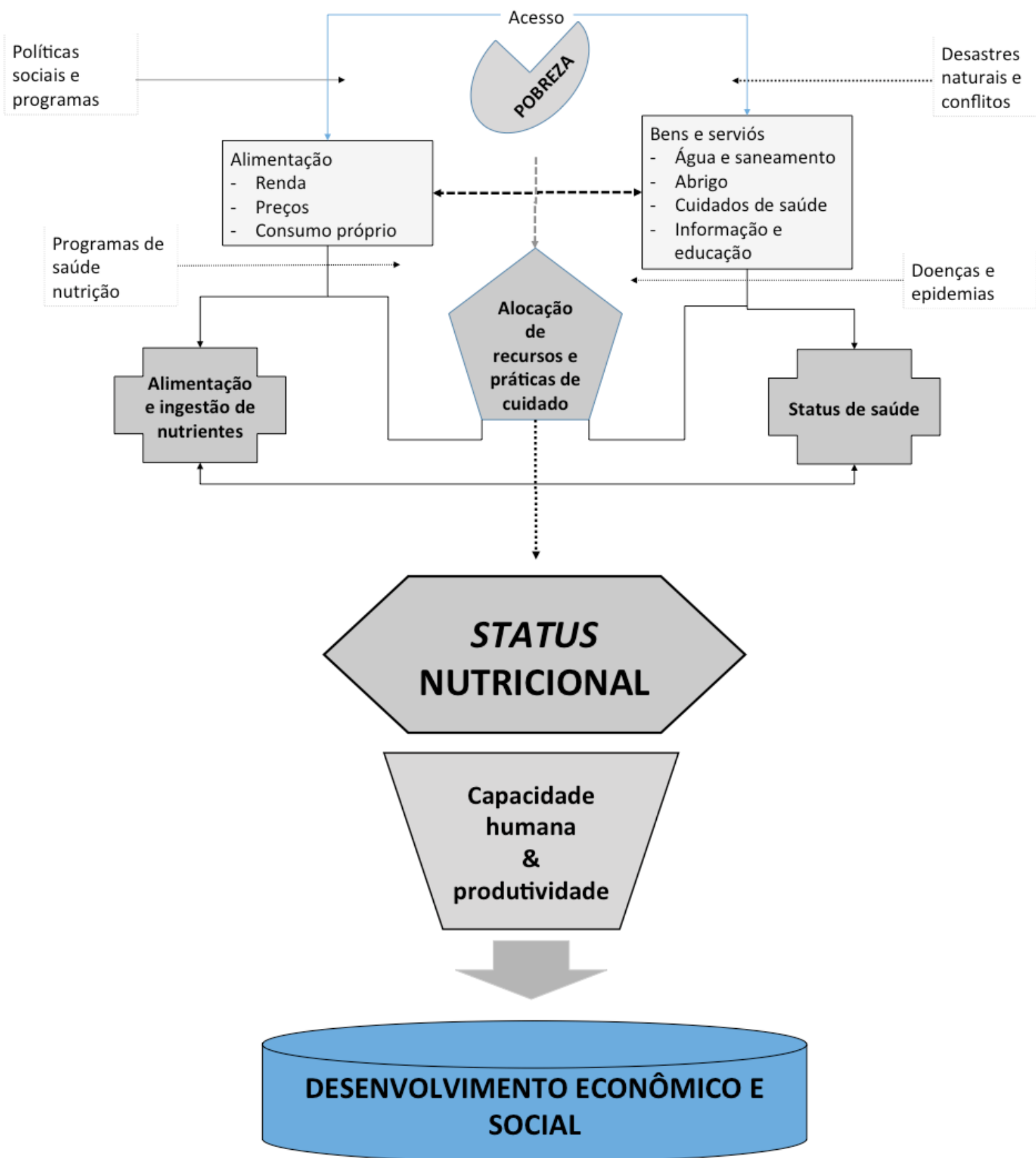

Figura 2: Visão panorâmica do Sistema

Fonte: Ecker e Breisinger, 2012:11. Adaptação do autor. 


\subsubsection{Aspectos sócio organizacionais da Segurança alimentar e nutricional}

Níveis

Os elementos categóricos da segurança alimentar e nutricional - disponibilidade, acesso, uso e utilização e estabilidade - são relevantes a todos os níveis de organização administrativa e social:

a) indivíduo - domicílio: nível micro;

b) comunidade, distrito, província, estado: nível meso; e,

c) Estado-nação, região, sistema internacional: nível macro (Weingärtner, 2004, p. 11).

A importância relativa de cada um dos determinantes da subnutrição varia com o nível de organização social. Em níveis mais altos de organização social, as condições políticas, econômicas e ecológicas assumem um grau de relevância maior. Dada a natureza diversidade dos fatores determinantes do status de segurança nutricional e os diferentes níveis em que eles interagem, a segurança alimentar e nutricional (SAN) necessariamente envolve tanto aspectos das ciências naturais quanto das ciências sociais. A interdisciplinaridade é imposta ao estudo da SAN que deve dar conta da interação entre todos os níveis sócio organizacionais. A natureza, causas e efeitos dos aspectos categóricos - disponibilidade, acesso, uso e utilização diferem nos níveis macro, meso e micro. No caso do arcabouço da subnutrição, os aspectos categóricos - segurança alimentar, cuidado, saúde e ambiente - também têm efeitos, causas e natureza diversas em cada um dos níveis de organização sócio organizacional. (Weingärtner, 2004).

\subsubsection{Aspectos Gerenciais da Segurança alimentar e nutricional}

Após uma breve revisão dos aspectos categóricos - disponibilidade, acesso, uso e utilização -, e dos aspectos sócio organizacionais, segue uma visão dos aspectos gerenciais.

As políticas governamentais de segurança alimentar (ou de organismos domésticos e internacionais) são postas em prática por meio de programas e projetos. Para que estes sejam eficientes e sustentáveis todas as fases de qualquer programa e projeto de segurança alimentar e nutricional (ou de qualquer política governamental) precisa passar por avaliação, análise, ação e intervenção, monitoramento e novamente avaliação (FAO, 2012; BishopSambrook, 2001).

As três dimensões da segurança alimentar e nutricional - categórica, organizacional e gerencial possuem instrumentos e processos de avaliação distintos, no entanto, estão intrinsecamente interligados. A avaliação incorreta, por exemplo, da disponibilidade de 
alimento pode resultar na formulação de intervenções disfuncionais que podem ter o efeito oposto ao esperado. Isso se deve devido ao fato de que todos os elementos estão interrelacionados verticalmente e horizontalmente por natureza, causa e efeito (Weingartner, 2004).

Para avaliar políticas, programas e projetos, governos e organizações internacionais usam um variado leque de ferramentas gerenciais, tais como: o Triplo A da UNICEF e o Gerenciamento de Ciclo de Projeto (PCM - sigla em inglês). Todos se baseiam em um processo de aprendizado que depende de reavaliações contínuas e ajustes de curso, sendo que os instrumentos variam em cada nível de organização social, tal como ilustrado na Quadro 1. 


\begin{tabular}{l|l|l|l|l}
\hline $\begin{array}{l}\text { Nível } \\
\text { social }\end{array}$ & Disponibilidade & Acesso & $\begin{array}{l}\text { Uso e } \\
\text { Utilização }\end{array}$ & Estabilidade \\
\hline \multirow{4}{*}{ Macro } & $\begin{array}{l}\text { Registro de } \\
\text { precipitação }\end{array}$ & $\begin{array}{l}\text { Mapeamento e } \\
\text { Análise de } \\
\text { Vulnerabilidade } \\
\text { (VAM) }\end{array}$ & $\begin{array}{l}\text { Pesquisas de } \\
\text { Saúde e } \\
\text { Demográficas }\end{array}$ & $\begin{array}{l}\text { Sistema de } \\
\text { Informação } \\
\text { Prévia Global } \\
\text { (GIEWS) }\end{array}$ \\
\cline { 2 - 5 } & $\begin{array}{l}\text { Pesquisa de } \\
\text { Alimentação }\end{array}$ & $\begin{array}{l}\text { Sistema de } \\
\text { Monitoramento } \\
\text { de Saúde } \\
\text { (WHO) }\end{array}$ \\
\hline \multirow{2}{*}{ Meso } & $\begin{array}{l}\text { Pesquisa de } \\
\text { Mercado de } \\
\text { Alimentos }\end{array}$ & $\begin{array}{l}\text { Grupos de } \\
\text { discussão } \\
\text { (Food Focus } \\
\text { Group } \\
\text { Discussion) }\end{array}$ & $\begin{array}{l}\text { Pesquisa de } \\
\text { Saúde }\end{array}$ & $\begin{array}{l}\text { Pesquisa } \\
\text { Antropométrica } \\
\text { de Saúde } \\
\text { Infantil }\end{array}$ \\
\hline \multirow{2}{*}{ Micro } & $\begin{array}{l}\text { Plano de } \\
\text { Produção } \\
\text { Agrícola }\end{array}$ & $\begin{array}{l}\text { Questionário de } \\
\text { Frequência } \\
\text { alimentar } \\
\text { Intradomiciliar }\end{array}$ & $\begin{array}{l}\text { Tabela de } \\
\text { Imunização }\end{array}$ & $\begin{array}{l}\text { Tabela de } \\
\text { Peso da } \\
\text { Gestante }\end{array}$ \\
\hline
\end{tabular}

Quadro 1: Exemplos de instrumentos para a avaliação da Situação de Segurança Alimentar e Nutricional nos 3 níveis sócio organizacionais.

Fonte: Weingartner, 2004, p. 13

\subsection{O ARCABOUÇO CONCEITUAL DA SUBNUTRIÇÃO}

A UNICEF $(1991 ; 2004)$ é responsável pelo arcabouço conceitual mais aceito na literatura especializada para segurança nutricional, Figura 3. O arcabouço se assenta nas causas imediatas, causas básicas, causas subjacentes, e manifestação da subnutrição (Black et al., 2008, p. 244). Em relação ao nível de análise, as causas imediatas afetam os indivíduos, as subjacentes as famílias e as básicas as comunidades e as famílias: quanto mais indireta a causa, maior a parcela da população afetada (em seu status nutricional) (Gross et al., 2000, p. 6; Pelletier, 2002). 


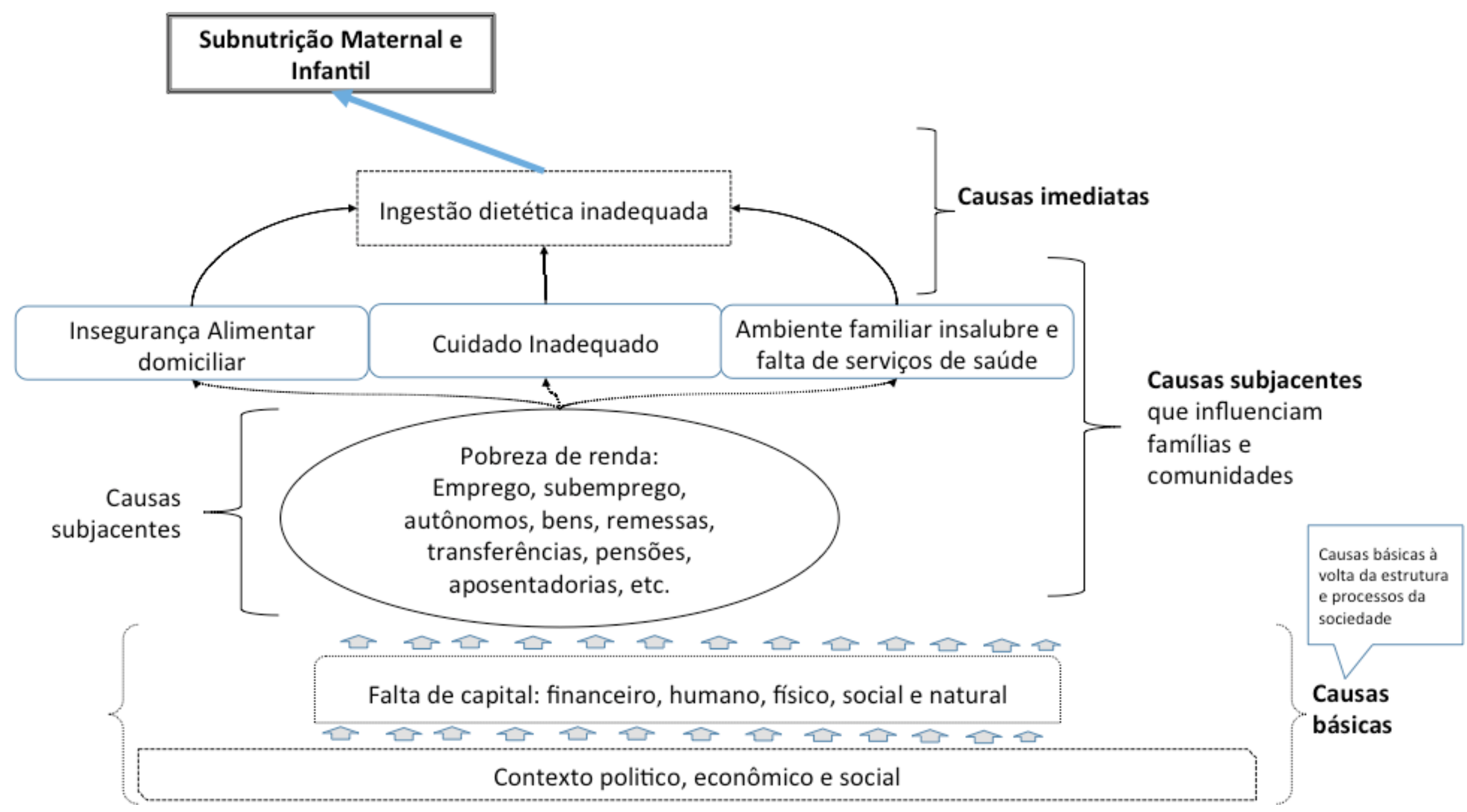

Figura 3: Arcabouço conceitual de subnutrição

Fonte: UNICEF 1991, 2004; Black et al., 2008. Adaptação do autor. 


\subsubsection{Causas imediatas}

As causas imediatas devem ser analisadas no nível do indivíduo (Figura 4). Os determinantes imediatos - necessariamente interdependentes - são: 1) o consumo de alimentos, isto é dieta, ingestão e absorção de alimentos energéticos, proteínas, gordura e micronutrientes; e, 2) a situação ou status de saúde (Smith; Haddad, 1999, p. 4).

O consumo de alimentos inadequados em quantidade e qualidade e em combinações não apropriadas para o corpo humano dificulta a absorção de nutrientes pelo sistema digestivo humano. A ingestão insuficiente de nutrientes acarreta no enfraquecimento do sistema imunológico, abrindo o organismo a doenças infecciosas. O sistema imunológico é continuamente enfraquecido pela falta de nutrientes e atrela o indivíduo a um ciclo vicioso potencialmente letal (Gragnolati et al., 2006).

Nutrição e infecção

Há extensa literatura sobre a correlação entre nutrição e infecção, especialmente em crianças. A perda de peso associada a um episódio isolado de infecção pode ser combatida pelo próprio organismo quando a dieta do indivíduo é adequada (Quadro 2). No entanto, quando a dieta é inadequada, a recorrência de infecções sem a dieta adequada e tempo suficiente para o corpo se recuperar são as causas interdependentes decorrentes do crescimento inadequado (raquitismo; baixa estatura) de crianças em países em desenvolvimento (Rice et al., 2000).

\begin{tabular}{l|l|l}
\hline Doença & Impacto da subnutrição & $\begin{array}{l}\text { Impacto de doenças infecciosas } \\
\text { na situação nutricional }\end{array}$ \\
\hline $\begin{array}{l}\text { Diarreia ou } \\
\text { disenteria } \\
\text { (exemplos: }\end{array}$ & 1. Duração aumentada & 1. Dificuldade de absorção \\
$\begin{array}{l}\text { Shigelose, } \\
\text { Síndrome de } \\
\text { Marlow, disenteria } \\
\text { bacilar) }\end{array}$ & 2. Severidade aumentada & 2. Perda de apetite \\
\cline { 2 - 3 } $\begin{array}{l}\text { Infecções } \\
\text { respiratórias } \\
\text { agudas }\end{array}$ & 1. Severidade aumentada morte aumentado & \\
\cline { 2 - 3 } & 2. Risco de morte aumentado & $\begin{array}{l}\text { 2. Aumento da taxa metabólica } \\
\text { resultando em colapso muscular }\end{array}$ \\
\hline Sarampo & 1. Duração aumentada & 1. Perda de apetite \\
\hline
\end{tabular}




\begin{tabular}{|c|c|c|}
\hline & $\begin{array}{l}\text { 2. Severidade aumentada, } \\
\text { especialmente se há deficiência } \\
\text { de vitamina } A\end{array}$ & $\begin{array}{l}\text { 2. Baixos níveis plasmáticos de } \\
\text { vitamina A }\end{array}$ \\
\hline & 3. Risco de morte aumentado & $\begin{array}{l}\text { 3.Imunossupressão } \\
\text { resultando em risco aumentado de } \\
\text { diarreia e Infecções respiratória } \\
\text { agudas }\end{array}$ \\
\hline & & $\begin{array}{l}\text { 4.Aumento da taxa metabólica } \\
\text { resultando em colapso muscular }\end{array}$ \\
\hline & & 5.Perda de proteínas no intestino \\
\hline Malária & $\begin{array}{l}\text { Há alguma evidência de que a } \\
\text { severidade aumenta quando há } \\
\text { deficiência de vitamina A e }\end{array}$ & 1.Perda de apetite \\
\hline & & 2.Aumento de taxa metabólica \\
\hline & & $\begin{array}{l}\text { 3.Destruição de corpúsculos de } \\
\text { células vermelhas que resultam em } \\
\text { anemia }\end{array}$ \\
\hline & & $\begin{array}{l}\text { 4.Desenvolvimento } \\
\text { prejudicado }\end{array}$ \\
\hline
\end{tabular}

Quadro 2: Resumo das interações entre subnutrição e doenças

Fonte: Tomkins \& Watson, 1993. Tradução e adaptação do autor.

Se as infecções são frequentes, altas taxas de peso abaixo da média da idade para a dada população serão maiores mesmo quando a ingestão de alimento é adequada. Por outro lado, se as infecções são menos comuns ou menos severas, taxas mais baixas de subnutrição infantil serão prevalentes mesmo quando a ingestão de alimento for mais baixa. Portanto, a ingestão suficiente de alimento é apenas mais um determinante da situação nutricional e está relacionado ao conceito de biodisponibilidade (Gragnolati et al., 2006; Barreto et al., 1994).

Em adultos, o prognóstico é semelhante. Uma pessoa doente tende a se alimentar menos, a digerir com menor eficiência e eficácia e é forçada a utilizar mais nutrientes para combater uma eventual infecção. A queda de nutrientes disponíveis ao organismo enfraquece o sistema imunológico e deixa o indivíduo mais suscetível a infecções. A infecção, por sua vez, aumenta o potencial e a severidade de subnutrição. Esse cenário é comum em muitos países em que parcelas relevantes da população sofrem de subnutrição, sendo que doenças infecciosas como a diarreia e infecções agudas do trato respiratório são os problemas de saúde mais comuns relacionados à subnutrição (Weingärtner, 2009). 

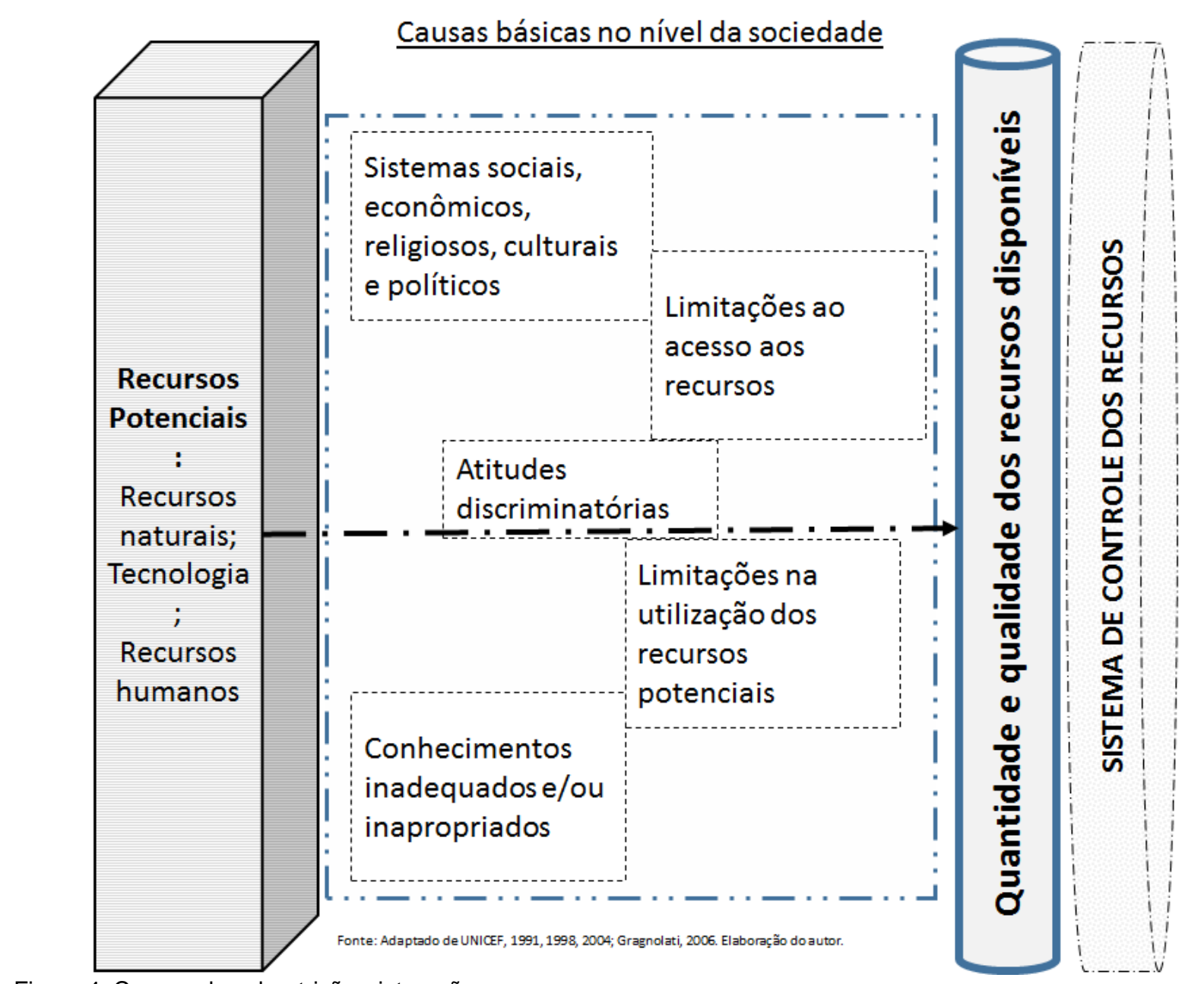

Causas

subjacentes no

nível familiar

Causas

$\underline{\text { imediatas }}$

Acesso

insuficiente a

alimentos

Práticas de

cuidado

maternal e

infantil

inadequadas

Serviços de

saúde, água e

sanamento

inadequados
Doença

Nutrição, sobrevivênciae desenvolvimento infantil

Ingestão

dietética

inadequada

Figura 4: Causas da subnutrição - interações

Fonte: Adaptado de UNICEF, 1991, 1998, 2004; Gragnolati, 2006. Adaptação do autor. 


\section{Biodisponibilidade}

O conceito de biodisponibilidade é essencial para a análise da segurança alimentar e nutricional pois a simples ingestão de nutrientes não assegura sua assimilação pelo organismo. Cozzolino (2005), define biodisponibilidade de um nutriente como a acessibilidade deste para os processos metabólicos e fisiológicos normais, podendo ser eficiente - sua utilização sistemática pelo organismo em questão por meio dos órgãos de metabolismo normal, e bioeficaz - quando os nutrientes são absorvidos e convertidos para o nível em que são utilizados pelo organismo. O funcionamento, os mecanismos e as implicações da biodisponibilidade estão fora do escopo deste trabalho de tese de doutorado, no entanto, são reconhecidos e levados em consideração, principalmente para fundamentar que o acesso e a disponibilidade não são suficientes para assegurar a segurança alimentar e nutricional.

\subsubsection{Causas subjacentes}

Para se alcançar a disponibilidade, acesso, utilização e estabilidade caracterizadas como segurança alimentar há a necessidade de (1) Produção de alimentos; (2) Renda para a compra de alimentos; e/ ou, (3) Troca (escambo) de alimento em espécie. No nível do domicílio, a decisão do que vai à mesa, isto é, a demanda, e quem come, (a distribuição intrafamiliar), determina a composição das refeições para o indivíduo. Simultaneamente, os hábitos e tabus, o conhecimento comunitário - modos de preparo, processamento, práticas de amamentação e alimentação de crianças - também determinam a composição e a utilização biológica do alimento (Weingärtner, 2009).

As categorias de causas subjacentes são intimamente inter-relacionadas e devem ser vistas como continuidades. Aquilo que afeta uma área pode ter consequências relevantes em outra. As decisões tomadas no nível domiciliar são influenciadas por diferentes fatores, entre os quais: (a) a cultura; (b) bens e meios disponíveis, inclusive o tempo; (c) renda, educação formal, terra cultivável disponível; e, (d) gado, em meios rurais e até urbanos (a exemplo da Índia e Nepal) (UNICEF, 2011). Para que cada uma das causas ou dos determinantes (há o uso de ambos os termos na literatura especializada) seja alcançado há um conjunto de recursos associados a cada um, conforme a Figura 5. 


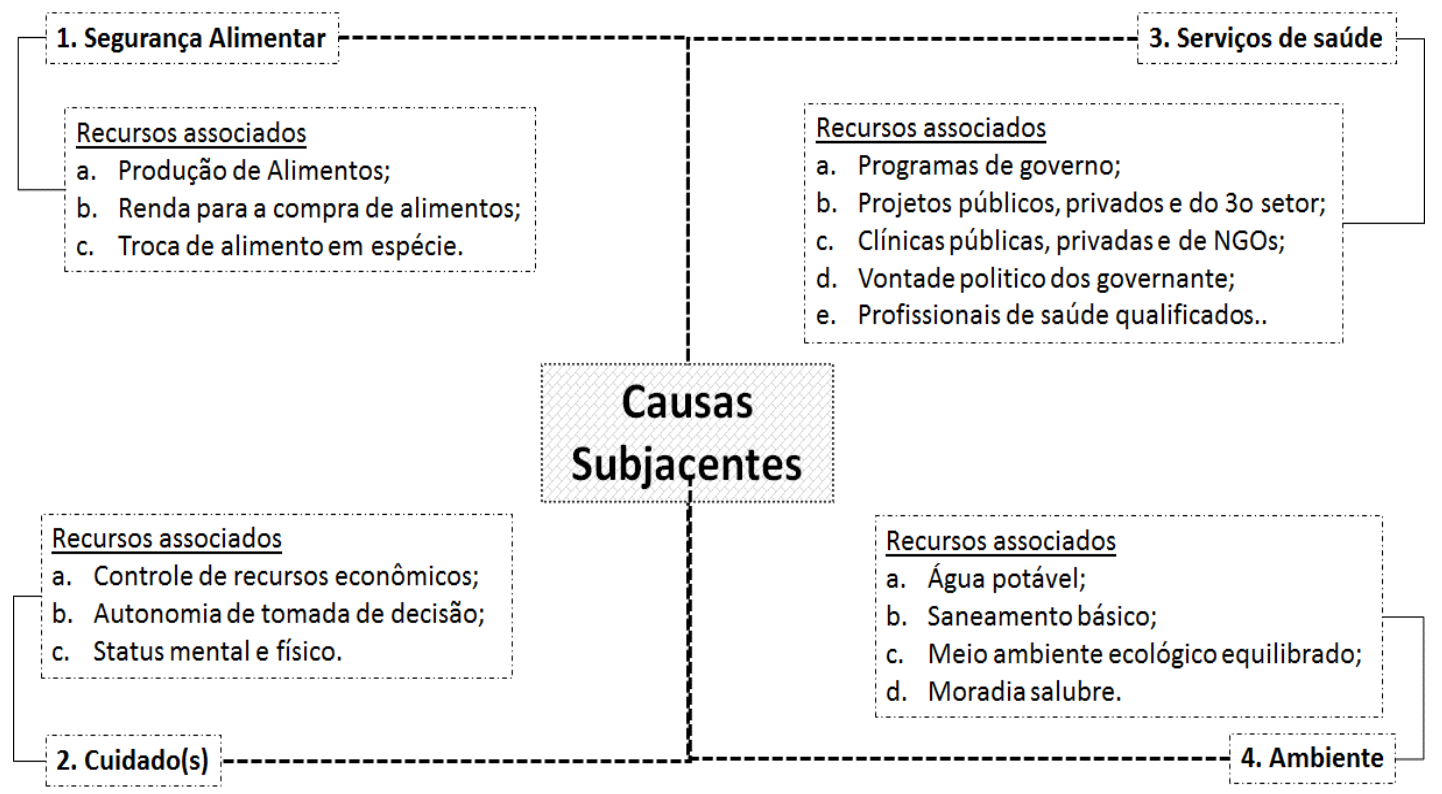

Figura 5: Causas subjacentes e recursos associados Fonte: Smith \& Haddad, 2000. Adaptado pelo autor.

Causa subjacente 1: Segurança alimentar familiar adequada

Os componentes da segurança alimentar, disponibilidade, acesso, utilização e estabilidade já foram discutidos extensivamente ao longo deste capítulo. Como causa subjacente, cabe apenas destacar: (1) a questão da sazonalidade dos suprimentos de alimento e renda; e (2) a distribuição populacional da segurança alimentar (já que há diferenças em uma mesma comunidade). Diferentes famílias têm acesso diferenciado ao alimento e às oportunidades de geração de renda e também ao sistema público e privado de saúde e saneamento básico (UNICEF, 2011, p. 8).

\section{Causa subjacente 2: Cuidados adequados para mães e crianças}

A espécie humana carece de cuidados pós-parto e na primeira infância que são indispensáveis à sobrevivência do indivíduo. Essa faceta da nutrição infantil é encapsulada no conceito de cuidados adequados para mães e crianças. O cuidado é definido pela Conferência Internacional sobre a Nutrição (1992), como o suprimento por parte das famílias e comunidades de "tempo, atenção e apoio para atender as necessidades físicas, mentais e sociais da criança em crescimento e de outros membros do grupo familiar" (ICN, 1992, p. 41). ${ }^{12}$ No caso, o tempo, a atenção e o apoio permitem o uso ótimo de recursos organizacionais, econômicos e humanos.

12 Tradução do autor. 
Além dos cuidados fisiológicos, o cuidado abrange aspectos psicológicos e emocionais que são determinantes significantes especialmente na nutrição de crianças nos primeiros estágios de vida (ICN, 1992:41). O controle de recursos econômicos, a situação mental e física e o grau de autonomia daquela que cuida e o status em relação a outros membros do grupo familiar determinam a adequação dos cuidados (Smith; Haddad, 1999).

Causa subjacente 3: Ambiente de saúde apropriado

A disponibilidade de água potável, saneamento básico, meio ambiente ecológico equilibrado e moradia estão incluídos nesta causa subjacente. Além destes, o acesso a um sistema de saúde (ambiente de saúde e serviços de saúde/médicos), inclusive diversos serviços de saúde específicos a cada região têm papel determinante na segurança nutricional. Exemplos:

i. A imunização é uma das ferramentas contra o ciclo de subnutrição e infecção;

ii. A hidratação oral e alimentação adequada contra a diarreia;

iii. Cuidados antes, durante e após o parto;

iv. Suplementação de ferro, vitamina A e iodo.

Os quatro (4) exemplos são intervenções de saúde necessárias e eficientes que configuram a causa subjacente "Ambiente de saúde apropriado" (ICN, 1992, p. 38; Hotchkiss et al., 2002; Gragnolati et al, 2006; Gross, 2005, p. 6; Gragnolati, 2006, p. 36; Black, 2008, p. 246; Klennert, 2010, p. 27).

\subsubsection{Causas básicas}

As causas básicas da subnutrição, conforme pode ser visto na Figura 5, são a existência, a disponibilidade e a utilização de recursos organizacionais, econômicos e humanos. O uso desses recursos é definido pela maneira como uma dada sociedade está organizada - organizações econômica e política, além das expectativas ideológicas. O veículo dessa organização são as instituições que regulam e administram os recursos. A conversão de recursos potenciais em recursos utilizáveis e em utilização e os valores sociais atrelados a estes dependem desses fatores (Gragnolati et al, 2006). Os recursos naturais do Estado-nação e a maneira como estes recursos são distribuídos e utilizados, o acesso à tecnologia e a formação e utilização dos recursos humanos na sociedade definem também como os recursos organizacionais, econômicos e humanos são usados para a segurança alimentar geral, tal como esquematizado na Figura 6 (Smith; Haddad, 1999). 


\subsection{A INSEGURANÇA ALIMENTAR E CONSEQUÊNCIAS}

Três consequências da insegurança alimentar, praticamente inseparáveis, são frequentemente mencionadas na literatura especializada e incorretamente confundidas em vários graus com a mesma: (1) a subnutrição, (2) a fome e (3) a pobreza.

\subsubsection{Subnutrição}

A subnutrição é a tradução biológica de uma doença social com raízes históricas, pois a despeito da produção agrícola haver triplicado nos últimos 50 anos, principalmente por meio de maiores rendimentos por unidade de terra, fertilizantes artificiais e pesticidas, $12,5 \%$ da população do planeta, ou cerca de 870 milhões de seres humanos, continuam subnutridos (FAO, 2013). Isso se deve, em parte, devido aos determinantes sociais e econômicos que levam à subnutrição de uma parcela da população mundial serem macro determinados enquanto as causas mais imediatas são micro determinantes (Schuftan, 1988).

A subnutrição ocorre quando um indivíduo não consome micro e/ou macro nutrientes em quantidades suficientes. Essa situação resulta de uma dieta pobre, problemas de digestão ou absorção ou de diversos problemas de saúde isolados ou combinados. O indivíduo pode sofrer de subnutrição simplesmente por não digerir uma única vitamina essencial. A FAO (2008) tipifica 3 tipos de subnutrição: subnutrição de energia proteica, isto é, deficiência de proteínas; subnutrição de micronutrientes, vitaminas e minerais; e, a obesidade, que é o excesso de calorias.

Em alguns casos, a subnutrição é leve e não deixa sequelas. Muitas vezes, no entanto, a subnutrição é tão grave que o dano causado ao corpo do indivíduo é irreversível, embora o mesmo continue vivo. (Enciclopédia Médica Medline Plus, 2013). Não há, no entanto, concordância entre estudiosos de nutrição e áreas correlatas sobre os elementos que definem objetivamente a subnutrição (Meijers et al., 2010).

\subsubsection{Fome}

Tal como a subnutrição, a definição de fome não é unânime, porém, suas consequências são mais prontamente reconhecíveis. "Food fascinates us. Yet the opposite is also true. Hunger fascinates us" (RUSSEL, 2005, p. 3). E, "[n]ão é verdade dizer que comemos para viver, comemos porque temos fome". Isto é, a necessidade pelo alimento não tem a existência como seu objetivo, mas o alimento (Levinas, 1993).

Borghini (2013) ao comentar Levinas, argumenta que o aspecto mais "interessante" da fome é que ela abrange cada e toda faceta do ser humano. O ser humano tem fome antes de nascer e mesmo assim não se trata de uma realidade automática do corpo, já que o 
mesmo é treinado para "segurar" a fome, "ficar" com fome e "resistir" à fome. O lidar com a fome é algo inerente à educação humana, é uma ação cultural. A fome se posiciona na fronteira do fisiológico e o psicológico, entremeado pela cultura. A fome é também acima de tudo uma tradução de necessidade, porém, treinada e domesticada, tendo fortes laços com lado humano racional (Borghini, 2013).

A fome como categoria cultural e também condição material foi estudada a fundo diversos pesquisadores, inclusive o brasileiro e pioneiro, Josué de Castro (Castro, 2003; 1982; 1953) e mais recentemente por Vernon (2007). A fome gerou sua própria história e tornou-se uma categoria que tem sido utilizada para gerar reflexão sobre o mundo. Por meio dela, a humanidade teria transformado o modo como pensa de si mesma, as responsabilidades mútuas e as relações para com o Estado e o mercado. A luta para definir e regular a fome teria produzido suas próprias redes de poder, suas próprias representações políticas, seu próprio entendimento das responsabilidades de governo, e suas próprias formas de estadismo (Vernon, 2007, p. 8). Neste entendimento, se insere está tese já que no caso da Índia observa-se a ocorrência destes fenômenos políticos, econômicos e sociais.

\subsubsection{Pobreza}

A pobreza engloba diferentes dimensões diretamente ligadas às capacidades (capabilities) humanas, tais como o consumo e a segurança alimentar, saúde, educação, direitos, voz, segurança, dignidade e trabalho decente, conforme a Figura 6 ilustra (Kamanou; Morduch, 2002). 


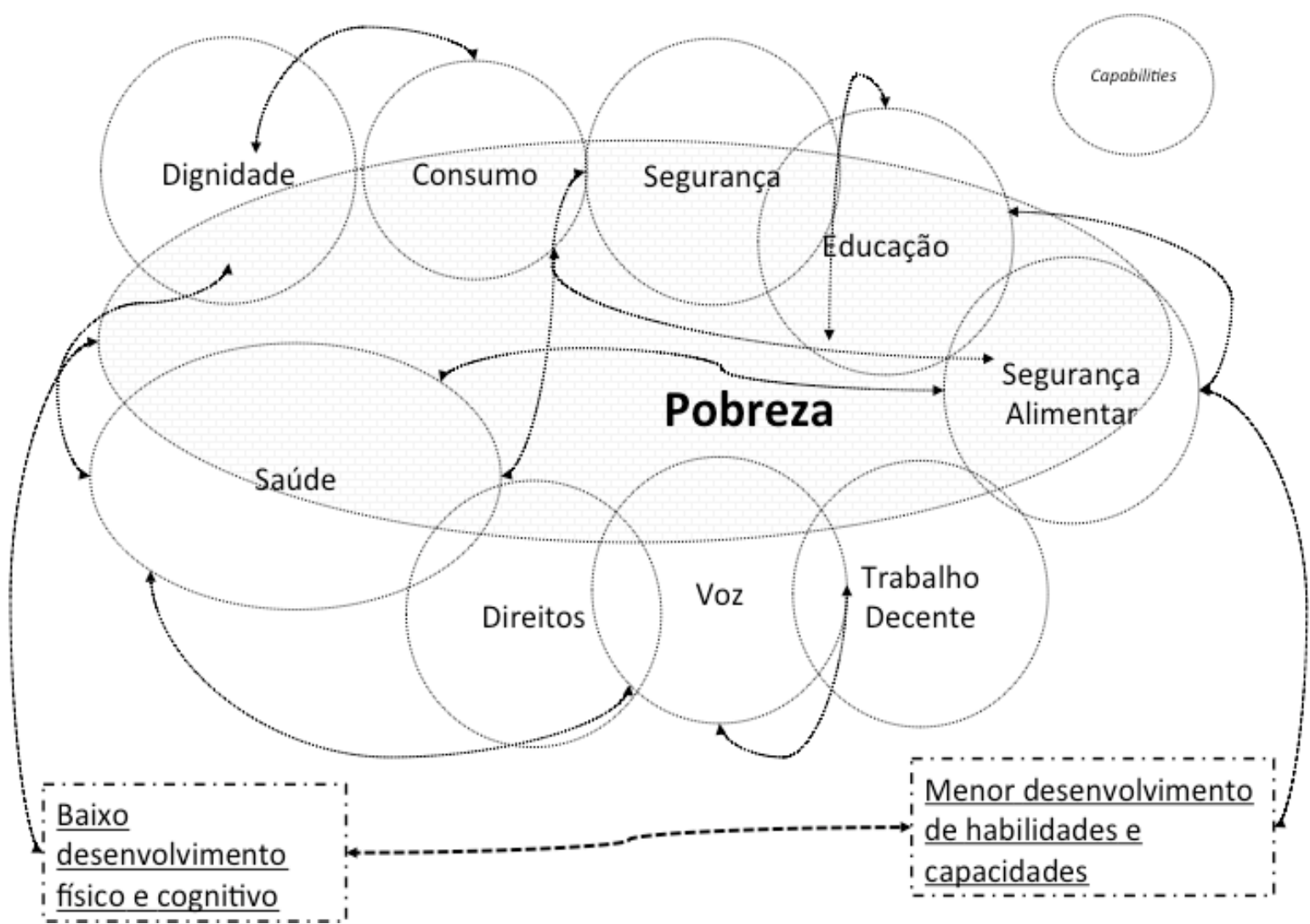

Figura 6: Dimensões relacionadas à pobreza

Fonte: Kamanou; Morduch, 2002. Elaboração e adaptação do autor.

A pobreza provoca a insegurança alimentar e, simultaneamente, é consequência da insegurança alimentar. ${ }^{13} \mathrm{~A}$ probabilidade de permanecer no ciclo de pobreza aumenta à medida que há menor desenvolvimento de habilidades e capacidades (Grantham-McGregor et al., 2007). Essa situação é mais comum quando o desenvolvimento físico e cognitivo é baixo devido à ausência de alimento nutritivo, seguro e suficiente (FAO 2008; Pieters et al., 2012).

Aspectos culturais da alimentação, perfil da alimentação (culinária tradicional) e fontes de nutrientes advindos da alimentação tradicional

A insegurança alimentar também está correlacionada aos aspectos culturais da alimentação, principalmente em países em desenvolvimento como Brasil e Índia. Há extensa bibliografia sobre cultura e alimentação e sustentabilidade que não se encontra no cerne do escopo deste trabalho de tese. Entre os principais aspectos culturais da alimentação se encontra a condição das mulheres ou de gênero na cultura em questão e como esta afeta o acesso ao alimento (Neogy, 2010). A desigualdade de gênero praticada, por exemplo, na

${ }^{13}$ Veja o Anexo A sobre a representação algébrica da insegurança alimentar. 
Índia, é amplamente documentada em relação também à insegurança alimentar e nutricional que acarreta (Agarwal, 2011). Em geral, mulheres e meninas, tanto na zona urbana quanto na zona rural (especialmente nas classes C, D e E), só comem depois que os membros masculinos da unidade familiar tenham comido o quanto desejarem ou aquilo que estiver disponível (Chinnakali et al., 2014). A situação da mulher acaba por se sobrepor a outros aspectos culturais da alimentação como o perfil da alimentação e as fontes de nutrientes da alimentação tradicional pela sua relevância e impacto (Neogy, 2010).

\section{CONCLUSÃO}

O conceito de segurança alimentar e nutricional evoluiu consideravelmente desde seus primórdios com a organização da FAO e da Declaração Universal sobre a Erradicação da Fome e Desnutrição de 1974 até a definição contemporânea inclusiva e holística calcada na sustentabilidade, resiliência e controle de vulnerabilidade. A mudança de enfoque ocasionada por Sen (1981) gerou uma real transformação conceitual: da oferta para a demanda; e do consumo do alimento ao direito a alimentação. $O$ trabalho de pesquisa à volta da FAO e das organizações governamentais e não governamentais gerou massa crítica de pesquisa empírica e teórica que alçou a temática da alimentação a um nível de adensamento raramente visto nas ciências sociais aplicadas em conjunção com as ciências da saúde e biológicas. A interdisciplinaridade necessária ao estudo da segurança alimentar e nutricional é evidente dada as imbricações e ramificações de seus efeitos em diferentes áreas da existência humana, sobretudo no meio ambiente.

Nessas condições, as diversas questões abordadas neste capítulo introdutório estão mais intimamente relacionadas do que aparentam. Insegurança alimentar, fome, pobreza, meios de subsistência e vulnerabilidade são alternadamente, causas e efeitos de um mesmo ciclo e dificilmente podem ser isolados pois são fenômenos sociais justapostos e sobrepostos. Estes fenômenos ocorrem em um contexto de meios de subsistência, sustentabilidade e insustentabilidade, além de um ambiente macroeconômico transnacional em que políticas comerciais, especulação e baixos níveis de governança permeiam as condições que possibilitam a segurança de alguns e a insegurança alimentar de muitos. 


\title{
CAPÍTULO 2: MEIOS DE SUBSISTÊNCIA, CAPITAL, VULNERABILIDADES E SUSTENTABILIDADE
}

\author{
2 MEIOS DE SUBSISTÊNCIA, CAPITAL E VULNERABILIDADES
}

\section{INTRODUÇÃO}

O capítulo 2 trata, inicialmente, dos meios de subsistência como parte do complexo maior da segurança alimentar e nutricional. Uma abordagem mais economicista, com viés neoliberal é utilizada na análise e toma forma no uso das categorias chave de capital. Neste sentido, o termo 'capital' é usado como sinônimo de 'recurso' por meio do qual os seres humanos viabilizam a subsistência. Essa subsistência é reificada em fenômenos sociais e objetivos sociais como uma renda maior, bem estar e segurança alimentar.

Este capítulo também examina as dimensões da sustentabilidade - ambiental, socialinstitucional e econômica. Apresenta-se a pluralidade de agendas sustentáveis no contexto dos processos sociais no qual a comoditização da alimentação e a comercialização da agricultura ocorreram. ${ }^{14}$ A discussão segue na dimensão social da sustentabilidade e sobre os conceitos centrais dessa dimensão: equidade, conscientização para a sustentabilidade, participação e coesão social. Dentre estes, elegeu-se o conceito de 'equidade' para uma apresentação mais detalhada dada a sua importância para a agenda política de garantia de direitos, no caso, o direito à alimentação (Vian, 2009).

Segue uma introdução ao princípio de integração horizontal e vertical da política ambiental nas políticas públicas em geral. A dimensão econômica é vista sob a ótica de duas principais divisões ideológicas: a visão tecnocêntrica e a visão ecocêntrica, que defendem tipos de desenvolvimento e crescimento ou não crescimento muito díspares. $A$ predominância de uma ou de outra tem consequências consideráveis para o sistema econômico como um todo e para o modelo de desenvolvimento a ser buscado por Estados nacionais e pelas forças econômicas globais. A dimensão ambiental encerra esta parte do capítulo, com a discussão da relação entre qualidade ambiental e pobreza. A última parte do capítulo trata de sistemas de alimentação sustentáveis no âmbito da economia verde.

\subsection{MEIOS DE SUBSISTÊNCIA}

A mera disponibilidade de alimentos no nível nacional e regional não bastam para a segurança alimentar no nível do indivíduo. A segurança alimentar precisa ser estudada no contexto maior da segurança dos meios de subsistência (livelihoods). A utilização do

\footnotetext{
14 "Comoditização", tradução e adaptação do inglês commoditization. Não se trata de um termo consagrado em português mas traduz e transmite claramente a ideia implícita de mercantilização da alimentação (Vian, 2009).
} 
conceito de meios de subsistência aplicado à segurança alimentar se justifica pelo modo como o conceito em si abre caminhos e simultaneamente fecha os objetivos, o escopo e as prioridades do desenvolvimento. Chambers e Conway (1991), afirmam que meios de subsistência (livelihoods) abrangem os meios (capabilities), os recursos - materiais e sociais -, e as atividades necessárias para um meio de vida ou subsistência. Este meio de subsistência se torna sustentável quando é capaz de suportar e se recuperar de pressões e choques e manter ou até mesmo melhorar os meios e recursos na atualidade e no futuro, ao mesmo tempo em que não enfraquece ou mina a base de recursos naturais. A sustentabilidade dos sistemas dos meios de subsistência, levando em consideração a sensibilidade e resiliência, é essencial e deve estar na base de qualquer intervenção. As intervenções devem apoiar a adaptabilidade e a flexibilidade dos sistemas de meios de subsistência. As percepções de vulnerabilidade e risco predominam nas estratégias individuais de segurança alimentar com o intuito de retirar o medo de que não haverá o suficiente para comer. Os valores culturais também são importantes na determinação da qualidade do direito (entitlement), ao invés de apenas a quantidade. Não obstante a percepção dos indivíduos envolvidos, eficiência e custo-benefício e custo eficácia são objetivos genuínos e devem ser metas do domicílio e do Estado. Ao Estado é imposto e este mesmo se auto impõe o direito dos cidadãos ao alimento, e este deve promover e proteger a segurança alimentar (Maxwell; Smith, 1992, p. 4). 


\begin{tabular}{|c|c|c|c|c|c|}
\hline \multirow{3}{*}{$\begin{array}{c}\text { Fonte do } \\
\text { direito } \\
\text { (Entitlement) }\end{array}$} & \multicolumn{5}{|c|}{ Fontes de risco à Segurança Alimentar familiar } \\
\hline & \multicolumn{5}{|c|}{ Tipo de risco } \\
\hline & Natural & Estado & Mercado & Comunidade & Outros \\
\hline $\begin{array}{l}\text { Capital } \\
\text { produtivo } \\
\text { (terra, } \\
\text { maquinário, } \\
\text { ferramentas, } \\
\text { animais, } \\
\text { prédios da } \\
\text { fazenda, } \\
\text { árvores, } \\
\text { poços de } \\
\text { águas, etc. }\end{array}$ & $\begin{array}{l}\text { Seca, } \\
\text { contaminação } \\
\text { de } \\
\text { suprimento } \\
\text { de água, } \\
\text { degradação } \\
\text { do solo, fogo, } \\
\text { enchentes }\end{array}$ & $\begin{array}{l}\text { Redistribuiçõ } \\
\text { es/ confisco } \\
\text { de terra } \\
\text { e/outros } \\
\text { bens }\end{array}$ & $\begin{array}{l}\text { Mudanças no } \\
\text { custo de } \\
\text { manutenção }\end{array}$ & $\begin{array}{l}\text { Desapropriação } \\
\text { e perda de } \\
\text { acesso a } \\
\text { recursos de } \\
\text { propriedade } \\
\text { comunitária }\end{array}$ & $\begin{array}{l}\text { Perda de terra } \\
\text { em resultado de } \\
\text { conflitos }\end{array}$ \\
\hline $\begin{array}{l}\text { Capital não } \\
\text { produtivo } \\
\text { (jóias, } \\
\text { habitação, } \\
\text { celeiros, } \\
\text { alguns } \\
\text { animais, } \\
\text { poupança } \\
\text { em dinheiro) }\end{array}$ & $\begin{array}{l}\text { Pragas, } \\
\text { doenças do } \\
\text { gado }\end{array}$ & $\begin{array}{l}\text { Aquisição } \\
\text { compulsória; } \\
\text { aldeiamento; } \\
\text { imposto } \\
\text { sobre o } \\
\text { patrimônio }\end{array}$ & $\begin{array}{l}\text { Choques de } \\
\text { preço (por } \\
\text { exemplo, } \\
\text { queda no } \\
\text { valor de jóais } \\
\text { e gado) }\end{array}$ & $\begin{array}{l}\text { Colapso de } \\
\text { mecanismos de } \\
\text { compartilhament } \\
\text { o }\end{array}$ & $\begin{array}{l}\text { Perda de bens } \\
\text { em resultado de } \\
\text { guerra; roubo }\end{array}$ \\
\hline $\begin{array}{l}\text { Capital } \\
\text { humano } \\
\text { (força de } \\
\text { trabalho, } \\
\text { educação, } \\
\text { saúde) }\end{array}$ & $\begin{array}{l}\text { Doenças } \\
\text { epidêmicas; } \\
\text { morbidade; } \\
\text { mortalidade, } \\
\text { incapacidade } \\
\text { s }\end{array}$ & $\begin{array}{l}\text { Investimento } \\
\text { s públicos } \\
\text { decrescentes } \\
\text { na saúde } \\
\text { pública; } \\
\text { introdução } \\
\text { de taxas de } \\
\text { uso; } \\
\text { restrições } \\
\text { contra o } \\
\text { trabalho de } \\
\text { migrantes }\end{array}$ & $\begin{array}{l}\text { Desemprego; } \\
\text { Queda nos } \\
\text { salários reais }\end{array}$ & $\begin{array}{l}\text { Colapso de } \\
\text { práticas de } \\
\text { trabalho } \\
\text { recíproco }\end{array}$ & $\begin{array}{l}\text { Trabalho forçado; } \\
\text { recrutamento/alist } \\
\text { amento; } \\
\text { restriçòes à } \\
\text { mobilidade; } \\
\text { destruição de } \\
\text { escolas e clínicas } \\
\text { durante períodos } \\
\text { de guerra }\end{array}$ \\
\hline $\begin{array}{l}\text { Renda } \\
\text { (produto da } \\
\text { atividade } \\
\text { agrícola; } \\
\text { gado; } \\
\text { atividades } \\
\text { não } \\
\text { relacionadas } \\
\text { à agricultura) } \\
\end{array}$ & $\begin{array}{l}\text { Pragas, } \\
\text { secas; outros } \\
\text { fenômenos } \\
\text { climáticos }\end{array}$ & $\begin{array}{l}\text { Término de } \\
\text { serviços de } \\
\text { extensão } \\
\text { rural }\end{array}$ & $\begin{array}{l}\text { Queda nos } \\
\text { preços das } \\
\text { commodities; } \\
\text { Choques de } \\
\text { preços dos } \\
\text { alimentos }\end{array}$ & & $\begin{array}{l}\text { Canais de } \\
\text { comércio } \\
\text { interrompidos por } \\
\text { guerra; embargos }\end{array}$ \\
\hline $\begin{array}{l}\text { Requeriment } \\
\text { os } \\
\text { (empréstimo } \\
\text { s, doações, } \\
\text { previdência) }\end{array}$ & & $\begin{array}{l}\text { Reduções } \\
\text { em } \\
\text { programas } \\
\text { de nutrição }\end{array}$ & $\begin{array}{l}\text { Aumento nas } \\
\text { taxas de } \\
\text { juros; } \\
\text { Mudanças na } \\
\text { capacidade } \\
\text { de } \\
\text { empréstimo }\end{array}$ & $\begin{array}{l}\text { Recuperação de } \\
\text { empréstimos } \\
\text { por parte de } \\
\text { credores (loan } \\
\text { recall); Colapso } \\
\text { de práticas de } \\
\text { reciprocidade }\end{array}$ & $\begin{array}{l}\text { Comunidades } \\
\text { deslocadas/desfe } \\
\text { itas pela guerra }\end{array}$ \\
\hline
\end{tabular}

Quadro 3: Fontes de risco para a Segurança Alimentar doméstica.

Fonte: Maxwell e Smith, 1992, p. 16. 
Os meios de subsistência daqueles que mais sofrem com questões de segurança alimentar, isto é, os mais pobres, também precisam ser compreendidos por meio da interdisciplinaridade. Há aspectos econômicos, sociais, técnicos, culturais e políticos que demandam a atenção de vários campos do conhecimento. O sistema de meios de subsistência é mais do que um conjunto de fatores econômicos, trata-se de um todo que engloba aspectos físicos, econômicos, sociais e culturais conforme a Tabela 4 (Baumgartner; Hogger, 2006).

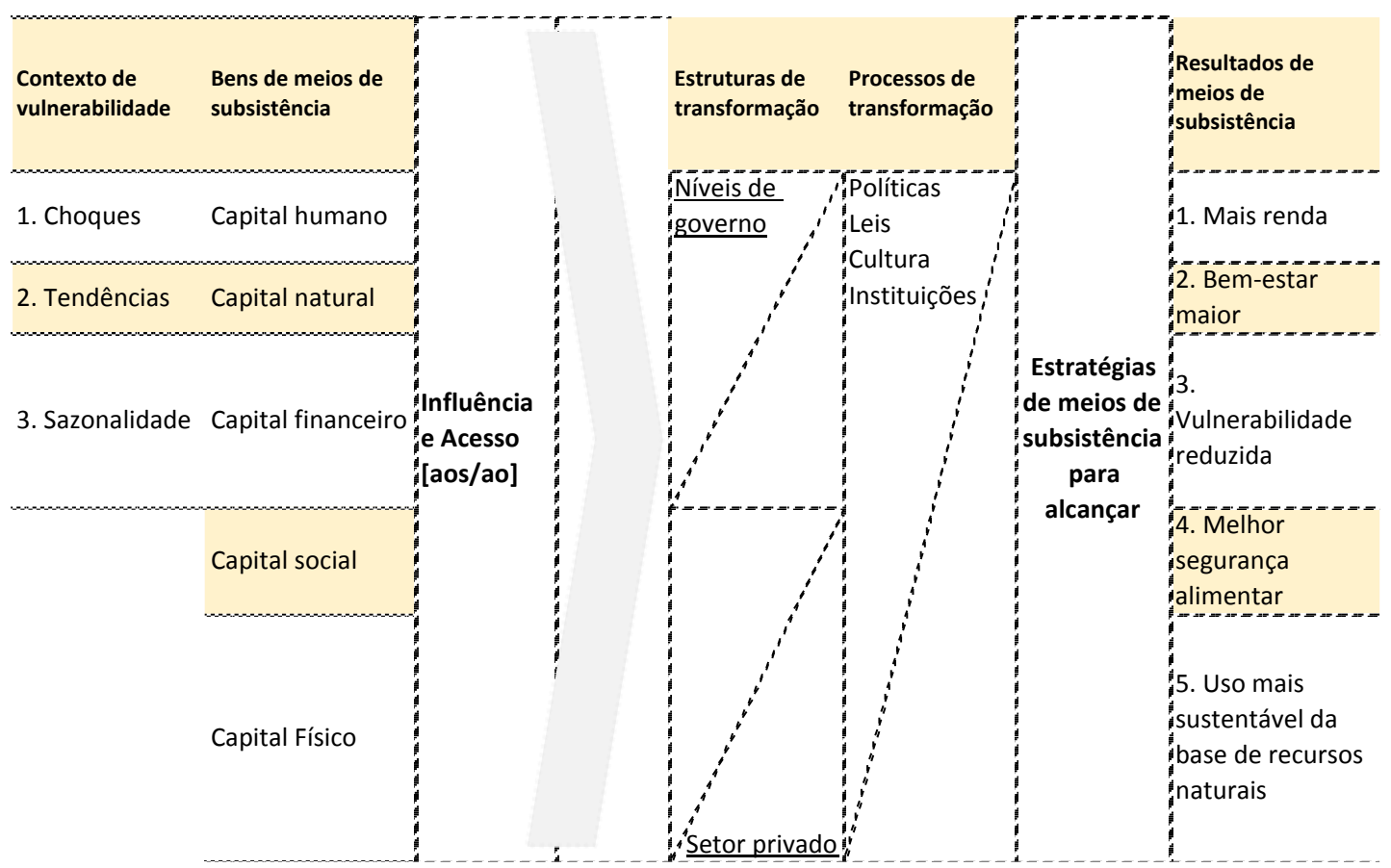

Quadro 4: Estrutura de Meios de Subsistência Sustentável

Fonte: DFID, 1999. Adaptado pelo autor.

O arcabouço conceitual de meios de subsistência sustentável (Quadro 3) ressalta os pontos fortes e os ativos que os indivíduos e famílias possuem para assegurar a própria segurança alimentar e os meios de subsistência. Há cinco categorias chave de capital das quais as pessoas extraem recursos para alcançar resultados de subsistência positiva, tais como renda maior, bem-estar maior e segurança alimentar: 1) Capital humano; 2) Capital Natural; 3) Capital Financeiro; 4) Capital social; e, 5) Capital físico (ACF, 2010:22).

\subsection{CAPITAL HUMANO}

'Capital humano' é o termo genérico que reúne o conjunto ‘saúde, habilidades laborais e conhecimento', essenciais para as atividades de acesso aos meios de subsistência. Especialmente no nível da família, o capital humano é um fator da quantidade e qualidade da mão de obra disponível. A falta ou escassez de educação formal e um estado de saúde precário do indivíduo são fatores diretamente correlacionados à pobreza e estratégias para 
enfrenta-los e superá-los são frequentemente inseridos nos objetivos de programas de fortalecimento de meios de subsistência (DFID, 1999, p. 7).

Quando a saúde dos ganhadores do pão e das mães vai mal, o peso para a família é ainda maior e um dos resultados imediatos é uma conta médica mais alta. Na maioria dos países em desenvolvimento esta conta é desembolsada pela própria família sem auxílio do governo. Essa despesa maior retira recursos normalmente utilizados para a compra de alimentos. Adicionando ao espiral descendente, o estresse psicológico agrava a situação da família e afeta negativamente a renda familiar, pois limita o horizonte motivacional. $O$ estresse aliado à renda menor e consequente perda de poder aquisitivo tende a resultar em mais depressão e insegurança alimentar. Enquanto as inter-relações entre condições de saúde específicas e sintomas depressivos é bem documentada na literatura especializada, há dificuldades em determinar a direção causal da relação entre segurança alimentar e as variáveis indicadoras relacionadas ao capital humano (Olson, 2006, p. 2).

A importância do capital humano é primeiramente intrínseca. Segundo, ela é basilar para o uso dos outros capitais. O seu desenvolvimento e acúmulo são, portanto, fenômenos sociais sine qua non para os meios de subsistência. É também 'o mais voluntário' dos bens de subsistência, uma vez que mesmo quando as estruturas e condições para o apoio ao acúmulo de capital humano direto e indireto estão prontamente disponíveis, os indivíduos precisam estar dispostos a investir em si mesmos, por exemplo, ao participar de treinamentos. O apoio indireto ao capital humano permite que estruturas e processos contrários - políticas, normas sociais, situação econômica - sejam superadas. Em geral, o apoio ao acúmulo de capital humano se dá por meio de um conjunto de políticas de governo integradas e holísticas que mitigam as diferenças de oportunidade conforme ilustrado no Quadro 5 (DFID, 1999, p. 7). 


\begin{tabular}{|c|c|c|}
\hline $\begin{array}{l}\text { Apoio direto à formação de capital } \\
\text { humano }\end{array}$ & $\begin{array}{l}\text { Apoio Indireto - por meio da } \\
\text { transformação de processos } \\
\text { e estruturas }\end{array}$ & $\begin{array}{l}\text { Retroalimentação da realização } \\
\text { de resultados de meios de } \\
\text { subsistência - ciclo virtuoso }\end{array}$ \\
\hline $\begin{array}{l}\text { 1. Para infraestrura de saúde, } \\
\text { educação, treinamento }\end{array}$ & $\begin{array}{l}\text { 1. Reforma das políticas de } \\
\text { treinamento, educação e } \\
\text { saúde }\end{array}$ & $\begin{array}{l}\text { 1. Situação de saúde está } \\
\text { diretamente correlacionada à } \\
\text { renda e segurança alimentar, } \\
\text { associada ao conhecimento } \\
\text { relevante }\end{array}$ \\
\hline $\begin{array}{l}\text { 2. Para o treinamento, educação e } \\
\text { saúde do pessoal da área de saúde }\end{array}$ & $\begin{array}{l}\text { 2. Reforma das organizações } \\
\text { de treinamento, educação e } \\
\text { saúde }\end{array}$ & $\begin{array}{l}\text { 2. Renda crescente é } \\
\text { frequentemente reinvestida } \\
\text { em educação }\end{array}$ \\
\hline $\begin{array}{l}\text { 3. Para o desenvolvimento de } \\
\text { habilidades e conhecimentos } \\
\text { relevantes }\end{array}$ & $\begin{array}{l}\text { 3. Mudanças nas instituições } \\
\text { locais: cultura, normas - } \\
\text { limitadores do acesso à } \\
\text { saúde, educação, } \\
\text { treinamento, por exemplo, } \\
\text { de meninas. }\end{array}$ & $\begin{array}{l}\text { 3. Vulnerabilidade reduzida } \\
\text { pode reduzir a taxa de } \\
\text { natalidade e ter efeitos } \\
\text { positivos sobre a nutrição e a } \\
\text { formação da mão de obra }\end{array}$ \\
\hline
\end{tabular}

Quadro 5: : Objetivo de meios de subsistência sustentáveis da DFID - melhor acesso à educação de qualidade, tecnologia da informação, treinamento e melhor nutrição e saúde. Alcançável por meio de, por exemplo. Fonte: DFID, 1999:7. Adaptação do autor.

\subsection{CAPITAL NATURAL}

Termo usado para os estoques de recursos naturais dos quais se retiram os fluxos e serviços essenciais para os meios de subsistência. Há, também, inúmeros recursos naturais que são classificados como bens públicos intangíveis como a atmosfera e a biodiversidade e bens divisíveis diretamente relacionados à produção de alimentos como as árvores e a terra. Entre os estoques de recursos naturais, encontram-se: (1) terra; (2) florestas; (3) recursos marinhos; (4) água; (5) qualidade do ar; (6) proteção contra erosão; (7) Assimilação de dejetos; (8) proteção contra tempestades; (9) grau de biodiversidade e ritmo de mudança; e, (10) ciclo de nutrientes (DFID, 1999, p. 11).

O capital natural define a existência física. A compreensão das imbricações entre os recursos permanece limitada, embora muitos avanços nas pesquisas têm dado pistas quanto ao funcionamento de ecossistemas complexos que em geral não figuram da contabilidade social nacional. Há iniciativas promissoras que buscam inserir e contabilizar os serviços naturais, contudo estas ainda carecem de aceitação e utilização por parte da maioria dos governos (Tiburcio, 2011; Bartelmus, 2008).

A maior contribuição da abordagem de meios de subsistência é o foco nas pessoas. Há uma busca por uma visão holística tanto em relação à conservação do capital natural quanto ao seu uso juntamente com outros capitais para possibilitar a sustentabilidade dos 
meios de subsistência. A importância das estruturas e processos - por exemplo, sistemas de alocação de terra, legislação referente à indústria extrativista - é levada em consideração pela abordagem de meios de subsistência para melhor contabilizar a maneira como o capital natural é utilizado e sugerir modos mais justos de distribuir o valor por ele criado (DFID, 1999, p. 11).

\subsection{CAPITAL FINANCEIRO}

Capital financeiro na literatura de meios de subsistência inclui fluxos e estoques que financiam produção e também consumo, e incluem qualquer meio de pagamento que permita a realização de diferentes estratégias de subsistência. Há duas fontes principais de capital financeiro: (1) Estoques disponíveis: a poupança é o capital financeiro por excelência já que em geral não tem outras obrigações atreladas e também outorga algum grau de autonomia em relação a outros. Normalmente, pode-se acumular poupança em dinheiro vivo, depósitos bancários e/ ou bens de alta liquidez como joias e gado. Também classificado como estoque disponível, recursos financeiros podem ser requeridos a empresas que provêm crédito, tais como financeiras, bancos e outras casas de crédito; (2) Fluxos regulares de dinheiro: remessas (domésticas e internacionais), dinheiro recebido de programas de transferência de renda estatais, e outros fluxos, como pensões e aposentadorias, também são fontes importantes de capital financeiro principalmente em países de média e baixa renda (DFID, 1999, p. 15).

Mesmo sendo o capital, mormente menos disponível aos mais afetados pela insegurança alimentar, trata-se do mais versátil e convertível e frequentemente, o mais desejado. Para o bem ou para o mal, o capital financeiro é convertível em influência política e tem o potencial para "liberar" indivíduos e comunidades para terem uma participação mais ativa em organizações detentoras do processo político de formulação de legislação e políticas específicas e que acabam sendo barreira e acesso aos recursos disponíveis para o meio de subsistência (DFID, 1999, p. 15).

$\mathrm{Na}$ área de micro finanças, a sustentabilidade institucional é provavelmente o fator mais relevante. Isto é, a não ser que as pessoas acreditem ter evidências de que as organizações de serviço financeiro são duradouras e confiáveis e continuarão a cobrar e pagar taxas de juros competitivas, elas não se arriscam a participar, tanto como pagadoras como poupadoras (Qayyum \& Ahmad, 2006; Guntz, 2011).

Além de programas governamentais que fazem uso de transferência de dinheiro, como o 'bolsa família' no Brasil, em geral, o capital financeiro pode ser incrementado por meios indiretos, por exemplo: 
1) Meios organizacionais: serviços financeiros para a camada da população mais sujeita à insegurança alimentar podem ser veículos de estabilidade dos meios de subsistência. Quando estes serviços são confiáveis e duradouros e também são percebidos como tal pelo público alvo, encorajam as pessoas a economizar parte do pouco que têm. A produtividade dos fluxos financeiros e poupanças existentes podem ser melhoradas e os serviços de remessa podem ser mais eficientes;

2) Meios institucionais: para o mercado financeiro uma das deficiências financeiras mais relevantes dos mais pobres não é a simples falta de recursos financeiros líquidos; é a falta de garantias em bens para empréstimos, tema amplamente explorado por De Soto (1989). A provisão de garantias comunitárias e de mecanismos criativos de garantia é um meio para aumentar o acesso a serviços financeiros pela via institucional.

3) Meios legislativos e regulatórios: o contexto de leis e regulamentos no qual os serviços financeiros atuam são também barreiras e pontos de acesso aos mais pobres. Os governos e a sociedade civil organizada detêm boa parte da capacidade para reformar este contexto e possibilitar a existência de redes de acesso e proteção (Carney et al., 1999; DFID, 1999).

\subsection{CAPITAL SOCIAL}

Fugindo do debate acadêmico sobre o real significado da expressão, para os propósitos desta discussão, trata-se dos recursos sociais que os indivíduos utilizam para buscar seus objetivos de subsistência. O capital social é acrescido por meio dos seguintes três agrupamentos didáticos:

i. Redes de apoio e conexões sociais, verticais do tipo patrão-cliente, ou horizontais, indivíduos com interesses em comum, que incrementam e possibilitam o trabalho com fins comuns e ampliam o acesso a instituições políticas e outras formas sociais de organização de atributos mais abrangentes;

ii. Filiação a grupos mais formalizados cuja adesão acarreta a aceitação de regras, normas e sanções mutuamente impostas;

iii. Relações de troca, reciprocidade e confiança que promovem a cooperação e reduzem custos de transação. Estas relações são as linhas que compõem as redes de segurança informal, principalmente entre os mais pobres (DFID, 1999, p. 9).

Os meios de desenvolvimento do capital social estão fortemente interligados entre si e também aos processos e estruturas de uma dada sociedade, sendo o próprio capital social um produto e ao mesmo tempo um gerador destas mesmas estruturas e processos. Como 
parte inseparável, resultado e resultante de uma dada sociedade, o capital social pode ser uma espada de dois gumes, uma vez que exclui e inclui de várias maneiras, por exemplo:

i. Aqueles que são excluídos de grupos fortes que garantem ou potencializam a obtenção de benefícios diversos, frequentemente também são excluídos de outros benefícios não diretamente correlacionados;

ii. As redes de apoio e as conexões sociais tendem a ser baseadas em relações sociais rigidamente hierárquicas e/ ou coercitivas que dificultam a mobilidade social e seguram as pessoas na situação em que se encontram, comumente, na pobreza.

iii. Ser membro de um grupo ou rede frequentemente acarreta em obrigações e direitos. Tanto quanto o membro pode pedir ajuda em momentos inoportunos para outros membros, o inverso pode ocorrer (Mitra, 2008; Torres Vitola, 2011; Carney et al., 2009).

A construção e fortalecimento de capital social benéfico, não obstante seus pontos cinzentos são possíveis e desejáveis. Pode, por outro lado, ser destruído e enfraquecido, especialmente o capital social benéfico, quando novas relações sociais são forçadas sobre um grupo, sem consideração para com as forças das relações precedentes. Diferente do capital financeiro que tende a crescer quando, por exemplo, depositado em uma conta poupança, o capital social requer atenção e uso corretos continuados para alcançar o crescimento desejado (DFID, 1999).

Em geral, a construção de capital social se dá de modo direto - pelo treinamento de competências e capacitação, treinamento de lideranças, injeção de recursos -, e/ ou de modo indireto - pela facilitação para a criação de um ambiente propício para a construção de capital social benéfico, portanto, um ambiente aberto e democrático. Frequentemente, a multiplicação de capital social é um subproduto de outras atividades de um ambiente democrático que encoraja confiança transversal em uma dada comunidade, tal qual o exemplo da Quadro 6 (DFID, 1999; Mitra, 2008; Torres Vitola, 2011; Carney et al., 2009). 


\begin{tabular}{l|l|l}
\hline $\begin{array}{l}\text { Apoio direto para } \\
\text { acumulação de bens } \\
\text { sociais }\end{array}$ & $\begin{array}{l}\text { Apoio indireto por meio de } \\
\text { transformação de estruturas e } \\
\text { processos }\end{array}$ & $\begin{array}{l}\text { Retroalimentação por meio } \\
\text { de resultados alcançados } \\
\text { de objetivos de } \\
\text { subsistência sustentáveis }\end{array}$ \\
\hline $\begin{array}{l}\text { Melhorar o } \\
\text { funcionamento interno } \\
\text { de grupos em termos de } \\
\text { liderança e } \\
\text { administração }\end{array}$ & $\begin{array}{l}\text { Dar apoio a formação e } \\
\text { estruturação de grupos e redes }\end{array}$ & $\begin{array}{l}\text { Relações auto fortalecedoras } \\
\text { ["Self-reinforcing"] (por } \\
\text { exemplo, sucesso em } \\
\text { aumentar a sustentabilidade } \\
\text { de recursos naturais pode } \\
\text { fortalecer a administração do } \\
\text { grupo). }\end{array}$ \\
\hline $\begin{array}{l}\text { Estender as ligações } \\
\text { externas de grupos } \\
\text { locais }\end{array}$ & $\begin{array}{l}\text { Apoiar o desenvolvimento de } \\
\text { um ambiente de formulação e } \\
\text { elaboração de políticas mais } \\
\text { aberto e previsível - boa } \\
\text { governança. }\end{array}$ & $\begin{array}{l}\text { Renda maior pode estender } \\
\text { o escopo para participação }\end{array}$ \\
& $\begin{array}{l}\text { Apoio a organizações para que } \\
\text { estas desenvolvam sistemas de } \\
\text { consulta externa a sociedade } \\
\text { civil }\end{array}$ & \\
\hline
\end{tabular}

Quadro 6: Exemplo da DFID de um objetivo de meios de subsistência sustentável - busca por um ambiente social coeso.

Fonte: DFID, 1999, p. 11. Elaboração do autor.

\subsection{CAPITAL FÍSICO}

Trata-se da infraestrutura básica de apoio e bens necessários para a execução de estratégias de subsistência. Para que as pessoas sejam mais produtivas no trabalho envolvido na realização de seus objetivos de subsistência há a necessidade de realizar mudanças no meio físico, uma adequação da infraestrutura, produção de bens para o trabalho (aquilo que os economistas chamam de bens de capital). Para os estudiosos de meios de subsistência, em geral, a infraestrutura é um bem público que pode ser usado sem pagamento direto. No entanto, há exceções dependendo do país, por exemplo, abrigos (privados), vias com pedágio e linhas de alta tensão de eletricidade. Bens de capital alto valor agregado frequentemente são de propriedade de empresas especializadas, cooperativas de produtores e municipalidades que alugam o serviço do equipamento (DFID, 1999).

Em sociedades primariamente agrárias como boa parte da Índia, o acesso à terra e atividades correlatas são primordiais para a sobrevivência (Morse et al., 2009). Além da terra, no âmbito da sustentabilidade dos meios de subsistência há itens imprescindíveis, entre os quais:

a) Transporte economicamente acessível;

b) Abrigos e construções seguras;

c) Oferta (suprimento) de água adequada e saneamento;

d) Energia economicamente acessível e limpa; 
e) Acesso à informação (comunicação) (Carney et al., 2009; DFID, 1999).

A importância do capital físico não pode ser demasiadamente enfatizada. A ausência de acesso a serviços básicos como água e energia acarreta na necessidade de busca por, por exemplo, água potável e lenha, atividades não produtivas que consomem muitas calorias e sobrecarregam o indivíduo. Os efeitos negativos sobre a saúde, principalmente de crianças e mulheres, as principais responsáveis por essas atividades, são notáveis e questões de segurança à medida que se afastam de casa são fartamente documentadas na imprensa e literatura especializada (Danish Refugee Council, 2012).

A falta de infraestrutura ou infraestrutura deficiente gera custos de oportunidade que têm o potencial para severamente dificultar a educação formal, o acesso a serviços de saúde e a geração de renda. O custo maior de todos os tipos de capital reflete diretamente na competitividade daquilo que é produzido afetando negativamente a habilidade de indivíduos e comunidades de alcançar seus objetivos de meios de subsistência (DFID, 1999).

Há divergências sobre como melhor construir o capital físico dos mais pobres já que questões ideológicas permeiam o debate político e econômico em relação, por exemplo, a (o/s):

i. A atuação do Estado como fornecedor direto de bens. Muitos argumentam que este papel pode gerar dependência e interferir nos mercados privados de forma negativa;

ii. O fornecimento direto, especialmente quando por parte do segundo e terceiro setores, pode retirar a pressão sobre o Estado como provedor e defensor da parcela mais vulnerável da população, e também protelar reformas e mudanças nas estruturas e processos que garantiriam ganhos sustentáveis para a sociedade como um todo;

iii. Muitos produtores de bens de capital em economias de mercado são empresas privadas. Quando há fornecimento direto por meio de um agente externo, necessariamente há favorecimento de um grupo ou conjunto de beneficiados sobre outro. Esta situação é potencialmente geradora de profundas divisões e tem o efeito oposto ao inicialmente proposto.

iv. O racionamento de bens e a criação de reservas de mercado também tendem a ser contraproducentes. Em geral, a camada mais afluente da sociedade encontra maneiras de acessar os bens racionados em detrimento dos mais pobres, invertendo o princípio gerador da política.

Por essas e outras razões, a abordagem de meios de subsistência enfoca programas que encorajam a participação dos envolvidos que então definem necessidades e prioridades 
bottom-up ao invés de top-down (FAO, 2007). Essa abordagem sofre limitações já que investimento em infraestrutura é ordinariamente dispendioso e mesmo em países em que há, por exemplo, orçamento participativo em diferentes níveis de governo, os órgãos de governo responsáveis por infraestrutura acabam por influenciar fortemente em todas as fases. Isso se dá, principalmente, pela necessidade de comprometimento continuado de recursos humanos especializados e financeiros ao longo de projetos comumente prolongados (DFID, 1999, p. 14).

\subsection{TRANSFORMAÇÃO DE ESTRUTURAS E PROCESSOS}

A transformação de estruturas e processos no contexto de meios de subsistência diz respeito às instituições, organizações e legislação que moldam os meios de subsistência. Elas têm influência direta sobre a habilidade de indivíduos se inserirem (ou sentirem-se parte) em uma comunidade e alcançarem o bem-estar desejado. Esses objetivos são extremamente culturais - mesmo com a globalização crescente - e, portanto, a cultura dá conta do ruído (na linguagem econométrica) em meios de subsistência, isto é, tudo aquilo que não tem nenhuma explicação clara e frequentemente é diferente a cada sociedade (DFID, 1999; FAO, 2007).

Instituições, organizações e legislação atuam em todos os níveis, micro e macro, e em todas as esferas, público e privado. São elas que determinam o acesso aos diferentes tipos de capital, às estratégias de subsistência, aos órgãos tomadores de decisão e às fontes de influência. Além de acesso, instituições, organizações e legislação determinam os termos de troca entre os tipos diferentes de capital. Por fim, as três determinam os rendimentos (econômicos e de outras naturezas) de todas as estratégias possíveis de subsistência.

Existe um mecanismo de retroalimentação direto entre as estruturas e processos e o contexto de vulnerabilidade. Por exemplo, os processos, cujos instrumentos são as políticas, estabelecidos e levados a cabo por meio de estruturas, têm impacto direto - e indireto (por exemplo, política fiscal e tendências econômicas; política de saúde e tendências populacionais). As estruturas e processos também podem suavizar o impacto de choques externos, tais como, políticas de combate à seca. Por outro lado, instituições têm o potencial de limitar o leque de escolhas de parte dos indivíduos, por exemplo, como ocorre através do sistema de castas, ainda profundamente impregnado, principalmente, no mundo rural de Índia e Nepal (DFID, 1999, p. 18). 


\subsection{OS 5 COMPONENTES DA VULNERABILIDADE E SEUS PRINCIPAIS DETERMINANTES}

Conforme a discussão anterior, permeando a estrutura conceitual de meios de subsistência há o contexto de vulnerabilidade. A vulnerabilidade é em si mesmo um conceito complexo e para defini-lo a literatura analisa os cinco componentes que encapsulam as diferentes facetas que são relacionadas entre si. As ligações entre elas são de especial importância para o entendimento das causas da vulnerabilidade e de políticas públicas para reduzi-la. Os componentes são: a) força dos meios de subsistência e resiliência; b) bemestar e status de linha de base; c) autoproteção; d) proteção social; e, e) Governança (Cannon, 2008, p. 4-5).

\section{GOVERNANÇA: determina a qualidade da PROTEÇÃO SOCIAL e a ALOCAÇÃO DE BENS \\ Desconexão chave 3 \\ Renda distribuição de bens desiguais \\ Desconexão chave 2 \\ Má governança acarreta em proteção social deficitária \\ 4. PROTEÇÃO SOCIAL - é a substituta da auto-proteção contra perigos conhecidos \\ 3. AUTO-PROTEÇẤO - renda e recursos utilizados para prover proteção contra perigos conhecidos \\ : \\ Desconexão chave 1-a avaliação de risco familiar depende de \\ questões culturais e prioridades que não põe a família em perigo. \\ Desconexão chave 2 -disponibilidade de recursos e gastos \\ 2. BEM-ESTAR - status de linha de base, status nutricional, saúde física e mental \\ Conexão chave/ desconexão chave 1 - renda e provisão de subsistência \\ 1. MEIO DE SUBSISTÊNCIA - FORÇA E RESILIÊNCIA}

Figura 7: Os 5 componentes da vulnerabilidade e seus principais determinantes Fonte: Cannon, 2008, p. 5.

\subsubsection{Componente 1 - $A$ força e resiliência dos meios de subsistência}

O meio de subsistência permite a sobrevivência do indivíduo, da família, da comunidade, da região, da nação. Cada atividade de meio de subsistência demanda do indivíduo, da família, a posse ou acesso a um bem ou bens, tais como terra, habilidade intelectual e/ ou física, ferramentas, gado, que permitam o exercício de um dado meio de subsistência - frequentemente chamados de capital. Aqueles que não dispõem de um meio de subsistência dependem de outros que disponham para subsistir (Cannon, 2008, p. 6).

Um meio de subsistência pode ser qualquer tipo de atividade que gere renda. Nas áreas urbanas, em geral, as pessoas precisam ser empregadas formalmente ou 
informalmente, receber pensão, aposentadoria, ou receber renda ou produtos em espécie de algum programa governamental ou de alguma organização não governamental. O acesso a bens tangíveis, que são os mais comuns, depende do dinheiro nas áreas urbanas. Mais em países de baixa e média renda e menos em países de renda alta, no campo mais pessoas dependem de suas habilidades manuais na agricultura e pecuária e acesso à terra própria ou alugada (Cannon, 2008, p. 6).

Por ser a primeira linha de defesa, o meio de subsistência é a base para a segurança alimentar (a linha base), a possibilidade de saúde e bem-estar. O meio de subsistência em si possui suas forças (e fraquezas), já que enquanto uns geram retornos altos, outros mal geram algum retorno. Neste ponto reside a importância da resiliência dos meios de subsistência para a segurança alimentar e nutricional. A perda ou a possibilidade de perda de um meio de subsistência está diretamente relacionada à segurança alimentar. Segundo Cannon (2007), os principais determinantes de um meio de subsistência são (1) quantidade e qualidade dos bens (capitais) de posse ou de acesso ao indivíduo - bens que permitam atividades produtivas e de geração de renda e/ ou de subsistência; (2) Acesso ao emprego formal ou informal e/ ou outras atividades e oportunidades geradoras de renda.

Há correlação significativa entre meios de subsistência e a governança. O tipo e a qualidade dos bens disponíveis para cada pessoa estão diretamente ligados à maneira como uma dada sociedade distribui riqueza e renda entre seus membros - dentro do contexto maior de relações de poder. Distribuição fundiária, o sistema de impostos, sistema previdenciário e outros mecanismos socioeconômicos estão diretamente ligados aos vieses ideológicos dos governos. Estes influenciam as leis de Estados-nações e que por sua vez estão baseadas nos valores da sociedade em questão (Bursztyn, 2008).

\subsubsection{Componente 2 - O status de linha de base e o bem-estar}

O status de linha de base capta a auto avaliação do indivíduo em relação à sua identidade no meio familiar, à localidade, identidade, sensação de segurança, estado de espírito (ânimo), saúde mental, saúde física, nível de estresse, além do status nutricional. Como a componente vulnerabilidade - em segurança alimentar e nutricional - é também uma derivada da força do meio de subsistência (isto é, a renda ou recurso de subsistência disponibilizada pela atividade do meio de subsistência do indivíduo), este afeta a qualidade e a quantidade da dieta do indivíduo e de seus dependentes.

O ânimo e a senso de resiliência pessoal, o nível de estresse percebido e real, e a saúde mental são todos fatores que têm correlação com a parcela que depende 'apenas' da pessoa em sobreviver, resistir, reabilitar, recuperar seu meio de subsistência de choques negativos. Origina-se daí o conceito de vulnerabilidade do meio de subsistência e sua 
relação com a segurança alimentar e nutricional. Há, portanto, quatro fatores que contribuem para o bem-estar:

(1) Situação nutricional;

(2) Saúde física;

(3) Saúde mental; e,

(4) Segurança e identidade.

$E$, estes são determinados principalmente por 2 elementos: (1) A força do meio de subsistência; e, (2) A segurança e a liberdade em relação ao estresse. Tanto os quatro fatores quanto os dois elementos (denominações meramente distintivas) estão interligados e de certa forma, têm maior ou menor grau de relevância isolada, pelo alcance da governança exercida pelo governo e delimitada pelas leis do Estado-nação (Cannon, 2006).

\subsubsection{Componente 3 - Auto proteção}

Este componente capta a capacidade e disposição dos indivíduos em proteger a si mesmos o máximo possível dos elementos da natureza como chuvas, enchentes, secas, ventos, furacões, deslizamentos de terra e outros. Boa parcela desta capacidade e disposição depende da renda. No entanto, além da renda (que está também correlacionada fortemente à auto proteção), o conhecimento e a habilidade para fazer (know-how) afetam a auto proteção. Frequentemente, os mais pobres não têm para onde ir ou realocar suas moradias, não possuem os incentivos e os meios para se auto protegerem.

Por exemplo, as vítimas de deslizamentos de terra na região serrana do Rio de Janeiro em sua grande maioria era e continuada sendo de baixa renda (Licco, 2013).

Os principais determinantes da auto proteção são, portanto:

(1) Renda suficiente;

(2) Disponibilidade de materiais (por exemplo, de construção), conhecimento técnico e habilidades (por exemplo, de construção); e,

(3) Disposição para tomar as medidas necessárias.

Os determinantes, por sua vez, dependem principalmente de meios de subsistência adequados para fornecer os recursos financeiros e a motivação. Em todos os fatores descritos nesta seção, o papel da comunidade é fraco. Embora a comunidade possa prover as redes sociais que facilitam as habilidades e o conhecimento para gerar, por exemplo, os determinantes para a auto proteção, em geral, a viabilidade dos meios de subsistência é um processo bastante individual (Adams et al., 2010; Lutz et al., 2010). Neste ponto, destaca-se a importância da proteção social para os meios de subsistência. 


\subsubsection{Componente 4 - Proteção social}

A proteção social diz respeito aos modos e formas de prevenção a ameaças aos meios de subsistência que careçam do envolvimento direto e indireto de diferentes níveis de uma dada sociedade por sua complexidade, tamanho e custo. As consequências da ausência ou insuficiência deste fator podem ser devastadoras para a própria sociedade. Por vezes, a proteção social é a única disponível para as parcelas mais pobres da sociedade e atua como substituta da auto proteção. Em geral, a proteção social é realizada pelo governo e envolve a execução de políticas públicas de características precaucionarias (Cannon, 2008, p. 9).

Os principais fatores facilitadores da proteção social são:

(1) disponibilidade de recursos públicos para as diferentes esferas de governo para a realização daquilo que for necessário;

(2) Vontade política nos níveis local e nacional. Este fator possibilita a concepção e execução de programas, projetos e obras;

(3) Disponibilidade de conhecimento técnico e competências relevantes para que o fator "vontade política" passe à prática.

Estes fatores, uma vez mais, são factíveis e dependem do contexto de governança praticado no Estado-nação balizados pelos seguintes parâmetros:

A. Eficiência das leis e regulamentos de planejamento de infraestrutura e construção civil;

B. O nível de corrupção;

C. A participação da sociedade civil local e internacional na prevenção de desastres e na redução da vulnerabilidade.

\subsubsection{Componente 5 - Governança}

A governança tem sido promovida como o fator em falta e sempre em demanda pela academia e agências especializadas internacionais desde os anos 1990 nas questões em torno das políticas públicas nas mais diversas áreas. A governança é definida como o foro no qual todos negociam por uma parcela própria do espaço, recursos e direitos (entitlements) disponível em uma dada sociedade, no intuito de suprir suas necessidades reais e percebidas e desenvolver seus interesses. Está relacionada à decisão de quem consegue fazer ou influenciar decisões, como essas decisões são tomadas e em benefício de quem (Fukuyama, 2013).

A governança afeta a distribuição de riscos na sociedade pois aloca diferentes níveis de vulnerabilidade entre os diferentes grupos populacionais. Uma definição alternativa descreve a governança como a maneira pela qual o poder é exercido na administração dos 
recursos econômicos e sociais de um país para o desenvolvimento (Cannon, 2008). Envolve, portanto, não apenas o governo, mas também todos os outros sistemas de obtenção e exercício de poder. Destarte, no cerne da governança se encontra o poder (Carney, 2003; 1999).

O status quo da qualidade da governança beneficia alguns e prejudica outros. Portanto, a mudança raramente é algo unânime pois o equilíbrio de forças de agentes políticos, stakeholders, governo, setor privado, sociedade civil e agentes diversos internacionais são forçados a encontrar um novo ponto de equilíbrio sendo que a força de barganha de cada um é necessariamente desigual.

Altos níveis de vulnerabilidade estão correlacionados a baixos graus de governança pois a ausência de influência no sistema maior de governo afeta os meios de subsistência e a proteção social. A governança ultrapassa o conceito tradicional de governo e envolve o uso e a distribuição de poder em todos os níveis. Um grau melhor de governança pode ser exemplificado com a mudança de comportamento prejudicial dos que possuem muito poder para um comportamento que beneficie os que têm menos poder por meio de negociações coletivas. A população em geral passa a influenciar ativamente as prioridades de governo. A influência no sistema maior de poder permite que as pessoas com menos poder possam se precaver melhor contra situações de vulnerabilidade (Cannon, 2003; 2008; Sen \& Drèze, 1989).

\subsection{SUBSISTÊNCIA E RESILIÊNCIA}

Os cinco componentes da vulnerabilidade - força dos meios de subsistência e resiliência, bem-estar e status de linha de base, autoproteção, proteção social e governança - estão ligados ao conceito geral de resiliência. Resiliência é a habilidade que a maioria dos sistemas de meios de subsistência possuem de voltar a operar após desastres naturais (influenciados por seres humanos ou não), conflitos armados e qualquer outro fenômeno natural ou não e adaptar os recursos e habilidades sobreviventes aos novos sistemas e condições de operação. No nível do indivíduo, é a habilidade do agente de superar, aguentar, suplantar e/ ou adaptar-se à situações que ameaçam destruir e/ ou acabam por destruir seus meios de subsistência. Essa ação é o produto do grau de preparação planejada à vista de perigos potenciais previstos e também de ajustes deliberados ou espontâneos realizados em resposta ao evento sofrido, inclusive ações de socorro e ajuda humanitária. (Pelling, 2003, p. 48).

A resiliência e a vulnerabilidade estão em extremos opostos, ou seja, são inversamente correlacionados: altos níveis de vulnerabilidade necessariamente implicam em baixos níveis de resiliência. Ao relacionar os cinco componentes da vulnerabilidade à 
resiliência, identificam-se maneiras de reduzir a vulnerabilidade por meio do aumento da resiliência. Cannon (2008), conclui que:

1. Meios de subsistência fortes e dotados de resiliência implicam que as atividades de geração de renda do indivíduo estão suficientemente robustas e dotadas de poder de adaptação quando ameaçadas;

2. Bem-estar e status de linha de base: maior resiliência é possível quando as pessoas gozam de boa saúde e boa nutrição. A probabilidade de resistir a doenças é maior e o nível de motivação para superar o choque também é maior;

3. Auto proteção: altos níveis de auto proteção permitem que as pessoas protejam suas propriedades, reduzam ferimentos e mortalidade e percam menos tempo repondo suas posses;

4. Proteção social: a presença de proteção social supre aquilo que a auto proteção não alcança e aumenta a probabilidade e a velocidade com que as pessoas recuperam seus meios de subsistência;

5. Governança: quando funcional melhora os meios de subsistência e a eficiência da proteção social. (Cannon, 2008, p. 12).

\subsection{RELAÇÃO ENTRE MEIOS DE SUBSISTÊNCIA, VULNERABILIDADE E RESILIÊNCIA}

A insegurança alimentar e nutricional resulta de crises e eventos que assolam uma população e que combinadas à ausência de adaptação e mecanismos de sobrevivência levam à escassez. No contexto da discussão anterior de vulnerabilidade e resiliência, as famílias mais vulneráveis entram em um processo de degradação social, frequentemente acompanhado de degradação do meio em que vivem. A partir de um dado momento do processo, as famílias não são mais capazes de equilibrar suas necessidades alimentares de curto prazo relacionadas à própria sobrevivência e gerenciamento/administração/manejo de seus meios de subsistência no longo prazo (ACF, 2010, p. 25).

Nos estágios iniciais, as famílias mais vulneráveis sacrificam a qualidade e diversidade da dieta. A origem do alimento e os níveis de predileção mudam: opta-se por fornecedores e produtos mais baratos e de qualidade inferior; alimentos preferidos mas também mais caros deixam de ser adquiridos. A quantidade de alimento muda na sequência ou mesmo simultaneamente: membros da família reduzem o número e tamanho das refeições. A ordem dos membros da família que primeiramente se submetem a essas mudanças depende do contexto cultural. Além disso, o nível de insegurança se aprofunda quando estratégias de sobrevivência irreversíveis são adotadas, tais como venda de bens de capital e migração. Em geral, as famílias sofrem por longos períodos antes de vender bens de capital e migrar 
devido, principalmente, ao desejo socialmente construído de preservar um meio de subsistência (ACF, 2010).

O Quadro 7 ilustra exemplos de caminhos das estratégias adotadas pelas famílias, baseada nas experiências da organização não governamental "Action contre la faim" (ACF). Resultados de referência são baseados na convergência de evidência direta e indireta e não em limites absolutos. Cada estágio não apresenta todas as características, necessariamente; ilustra, no entanto, em que estágio uma dada situação atingiu e em que direção, provavelmente progredirá.

\begin{tabular}{|c|c|c|c|}
\hline $\begin{array}{l}\text { Severidade da } \\
\text { insegurança alimentar e } \\
\text { risco de morte }\end{array}$ & $\begin{array}{l}\text { Insegurança } \\
\text { alimentar }\end{array}$ & $\begin{array}{l}\text { Crise de Meios de } \\
\text { Subsistência e } \\
\text { Alimentar }\end{array}$ & Fome \\
\hline Taxa de mortalidade & Normal & Maior ou alta & $\begin{array}{l}\text { Extremamente } \\
\text { alta }\end{array}$ \\
\hline $\begin{array}{l}\text { Taxa global de } \\
\text { subnutrição }\end{array}$ & $\begin{array}{l}\text { Pode } \\
\text { aumentar }\end{array}$ & Maior & $\begin{array}{l}\text { Extremamente } \\
\text { alta }\end{array}$ \\
\hline $\begin{array}{l}\text { Taxa de subnutrição } \\
\text { severa }\end{array}$ & Baixa & Moderada ou alta & Alta \\
\hline $\begin{array}{l}\text { Movimentos } \\
\text { populacionais }\end{array}$ & $\begin{array}{l}\text { Migração } \\
\text { temporária }\end{array}$ & $\begin{array}{l}\text { Deslocamento } \\
\text { populacional maior ou } \\
\text { menor }\end{array}$ & $\begin{array}{l}\text { Concentrado, } \\
\text { larga escala }\end{array}$ \\
\hline $\begin{array}{l}\text { Fontes de renda e } \\
\text { meios de subsistência }\end{array}$ & $\begin{array}{l}\text { Normal ou } \\
\text { levemente } \\
\text { perturbado }\end{array}$ & Reduzido & Exaurido \\
\hline $\begin{array}{l}\text { Bens de capital - meios } \\
\text { de subsistência }\end{array}$ & $\begin{array}{l}\text { Sob pressão } \\
\text { e utilização } \\
\text { não } \\
\text { sustentável }\end{array}$ & $\begin{array}{l}\text { Perda de acesso ou } \\
\text { redução acelerada ou } \\
\text { crítica }\end{array}$ & $\begin{array}{l}\text { Perda efetiva } \\
\text { completa; } \\
\text { colapso }\end{array}$ \\
\hline $\begin{array}{l}\text { Estratégias de } \\
\text { adaptação }\end{array}$ & $\begin{array}{l}\text { Adaptativa, } \\
\text { temporária, } \\
\text { reversível }\end{array}$ & $\begin{array}{l}\text { Agonizante, } \\
\text { reversível/irreversível, } \\
\text { em crescimento }\end{array}$ & $\begin{array}{l}\text { Sobrevivência, } \\
\text { irreversível }\end{array}$ \\
\hline $\begin{array}{l}\text { Disponibilidade de } \\
\text { alimentos }\end{array}$ & $\begin{array}{l}\text { Normal ou } \\
\text { levemente } \\
\text { maior }\end{array}$ & Reduzida & $\begin{array}{l}\text { Rara ou } \\
\text { nenhuma }\end{array}$ \\
\hline Acesso ao alimento & $\begin{array}{l}\text { Levemente } \\
\text { reduzida }\end{array}$ & Reduzida & $\begin{array}{l}\text { Severamente } \\
\text { reduzida ou } \\
\text { nenhuma }\end{array}$ \\
\hline Diversidade da dieta & $\begin{array}{l}\text { Déficit } \\
\text { crônico }\end{array}$ & Déficit agudo & $\begin{array}{l}3 \text { ou menos } \\
\text { grupos } \\
\text { alimentares } \\
\text { consumidos } \\
\text { regularmente }\end{array}$ \\
\hline $\begin{array}{l}\text { Dependência de } \\
\text { assistência alimentar } \\
\text { (doações) }\end{array}$ & Baixa & Alta ou moderada & Completa \\
\hline
\end{tabular}




\begin{tabular}{l|l|l|l}
\hline $\begin{array}{l}\text { Redução em práticas } \\
\text { de cuidado }\end{array}$ & Baixa & Moderada ou alta & Alta \\
\hline $\begin{array}{l}\text { Acesso à água e } \\
\text { disponibilidade }\end{array}$ & $\begin{array}{l}\text { Adequação } \\
\text { limítrofe; } \\
\text { instável }\end{array}$ & $\begin{array}{l}\text { Acesso por meio da } \\
\text { perda de bens }\end{array}$ & $\begin{array}{l}\text { Extremante } \\
\text { baixa, apenas } \\
\text { para uso humano }\end{array}$ \\
\hline Saúde pública & Estável & $\begin{array}{l}\text { Situação de epidemia; } \\
\text { em crescimento }\end{array}$ & $\begin{array}{l}\text { Situação de } \\
\text { pandemia }\end{array}$ \\
\hline
\end{tabular}

Quadro 7: Escala de Severidade da insegurança alimentar e nutricional e de meios de subsistência. Fonte: ACF, 2010, p. 25.

Existem tantas possibilidades de sustentabilidade quanto advogados da mesma. Indivíduos, grupos privados, organizações intergovernamentais, internacionais, órgãos governamentais dedicados ao tema podem divergir tanto no entendimento quanto na aplicação da sustentabilidade e suas dimensões. Discordâncias são esperadas em relação à ênfase dada a diferentes dimensões e interpretações e também distorções interpretativas e de objetivos, além de tensões quanto à definição de políticas e medidas. No caso da Índia, as expectativas e direitos adquiridos das partes interessadas - stakeholders - são, como em praticamente todo mundo, frequentemente conflitantes e competitivas, havendo disparidades fundamentais nas preocupações e prioridades e também a improbabilidade de encontrar uma definição aceita pela maioria. Diferentes grupos de interesse ativos também acabam por açambarcar a agenda pública e por vezes requerem negociações específicas. Ao mesmo tempo, interesses e agendas também podem coincidir ou se sobrepor em situações mutuamente benéficas e interesses convergentes se formarem. Esses interesses convergentes podem servir de pontes de comunicação e plataformas de ação em eventuais iniciativas de cooperação. A cooperação entre dois agentes pode se tornar motor para iniciativas políticas mais amplas e que possivelmente possam influenciar um setor do sistema produtivo, ou de transporte, estocagem e distribuição. Destarte, a identificação de pontos de divergência e convergência é considerado ponto de partida para estratégias de aumento de níveis de sustentabilidade em políticas públicas (Leat et al., 2011; Redclift, 1991).

Goodman e Redclift (1991), no contexto da sustentabilidade proposta pelo Relatório Brundtland ou Comissão Mundial [da Organização das Nações Unidas] sobre Meio Ambiente e Desenvolvimento (CMMAD, 1987) e o conceito de meios de subsistência sustentáveis de Chambers e Conway (1991), teorizam como o sistema alimentar mundial se tornou fortemente comercial. A partir do reconhecimento da complexidade da questão, Goodman e Redclift (1991), procuram levar em consideração todos os tipos de mudança, inclusive aquelas relacionadas à alimentação a partir do conhecimento acumulado nas áreas de desenvolvimento agrícola, desenvolvimento técnico e tecnológico, política alimentar e 
hábitos alimentares e nutrição. Os autores afirmam que o desenvolvimento do sistema alimentar contemporâneo e seu modus operandi pode ser interpretado como o resultado de uma evolução intencionalmente provocada pelas sociedades ocidentais - Europa e suas ramificações - na busca pela "remodelagem da natureza" (Beardsworth \& Keil, 2002; Goodman \& Redclift, 1991).

Os processos sociais que resultaram na comoditização da alimentação foram acompanhados nos países desenvolvidos e nas classes sociais mais altas de alguns países em desenvolvimento pela diversificação do consumo doméstico, pela entrada das mulheres no mercado de trabalho formal e pela produção de bens de consumo duráveis para uso domiciliar, inclusive para o preparo de alimentos (Goodman \& Redclift, 1991; Beardsworth \& Keil, 2002, p. 43). Tão relevante quanto foi a mudança na produção de alimentos baseada naquilo que Goodman e Redclift (1991) rotularam "um novo contrato social" entre produtores rurais e governos, com a integração maior do complexo agrícola-industrial. Com a industrialização da produção agrícola pari pasu à busca pelo controle da natureza mecanização, defensivos agrícolas e mais para o final do século 20 , organismos geneticamente modificados -, a natureza foi, de certo modo, forçada a seguir a lógica de mercado (Vian, 2009; Goodman \& Redclift, 1991; Beardsworth \& Keil, 2002).

E nesse ponto salienta-se a contradição: os países em desenvolvimento se beneficiaram dessa mutação sistêmica e muitos, como Brasil e Índia, implantaram a Revolução Verde (que nada tinha de verde) nos seus complexos agropecuários. O benefício do alimento mais barato e comoditizado estabilizou o suprimento de alimentos e simultaneamente enfraqueceu a agricultura familiar e de subsistência (Goodman \& Redclift, 1991; Beardsworth \& Keil, 2002). O equilíbrio com o meio, ou pelo menos a agressão de mais baixa intensidade ao meio ambiente foi substituída por exploração insustentável, e países mais desenvolvidos e os menos desenvolvidos passaram a sentir os efeitos negativos da contradição à medida que a degradação ambiental e social se intensificou.

A noção de sistema alimentar com processos (i.) biológicos - a produção de alimentos, (ii.) econômicos e políticos - controle dos diferentes inputs e outputs do sistema, (iii.) sociais e culturais, isto é, dos fatores que moldam o modo como as pessoas selecionam e usam os alimentos, são a superestrutura na qual as políticas de segurança alimentar são desenvolvidas (Tansey \& Worsley, 1995). A ciência, tecnologia, a informação e o controle dessa informação, a administração e o arcabouço legal são usados para dominar e controlar a produção e a distribuição de alimento. E, embora a suficiência global e também nacional alimentar sejam uma realidade, a sustentabilidade em nível global e nacional ainda se encontra longe de ser alcançada. 


\subsection{AS DIMENSÕES DA SUSTENTABILIDADE E A PLURALIDADE DE AGENDAS SUSTENTÁVEIS}

A sustentabilidade é um conceito multidimensional que inclui a sociedade, o meio ambiente e a economia, conforme as Figuras 8 e 9 . O desenvolvimento sustentável, que segundo a definição do Relatório Brundtland atenderia as necessidades vigentes sem comprometer a capacidade das gerações vindouras de suprir suas necessidades, permanece um ideal atingível e desejável, contido em seus dois conceitos centrais, necessidades e limitações (CMMAD, 1987).

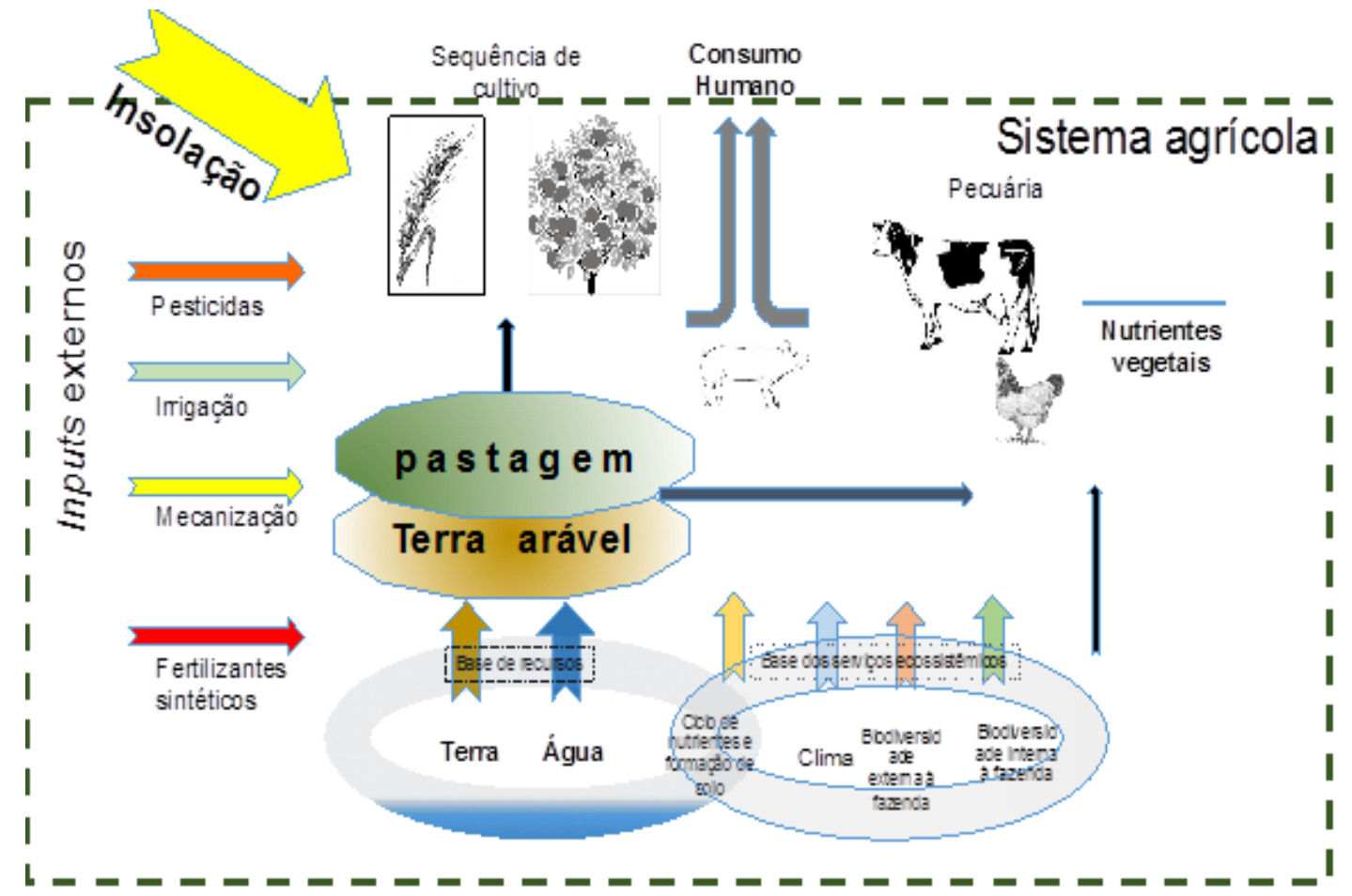

Figura 8: Fundamentos da Segurança Alimentar e fluxos de manutenção da produção de alimentos Fonte: Alcamo, 2012. Adaptações do autor.

Há um grande número de definições, sendo que a maioria demanda a aceitação e entendimento dos conceitos de entropia, sistema e resiliência na área de Desenvolvimento Sustentável. ${ }^{15} \mathrm{O}$ planeta Terra é um sistema que conecta espaço e tempo e as atividades

15 Gallopín (2003), ensina que um sistema pode ser definido como um conjunto de elementos interligados, também chamados de subsistemas. Os elementos podem ser tudo aquilo que compõe o mundo percebido e conhecido, por exemplo, moléculas, organismos, dispositivos como máquinas e suas partes, instituições, entidades sociais e até mesmo conceitos abstratos. Os elementos e a relação entre os elementos definem o sistema, sendo que o termo "relação" é usado no seu sentido amplo e inclui termos relacionados como "restrição" "estrutura", "organização", "coesão", "interação", "interconexão", "correlação", e "padrão". As relações, interligações, que também podem ser rotuladas "acoplamentos", entre os elementos podem também ter manifestações, isto é, podem se materializar, de maneiras diferentes, como por exemplo, transações e operações econômicas, fluxos de matéria ou de energia, ligações causais em cadeia e assim por diante. Todos os sistemas físicos existentes são abertos, afirma Gallopín (2003), trocam energia, matéria e informação com o ambiente, trocas essas que são relevantes para o funcionamento para o funcionamento deles. Assim, o funcionamento do sistema, aquilo que o sistema faz, seu comportamento, não depende apenas do sistema em si, mas também dos fatores, elementos ou variáveis advindos do ambiente do sistema e que o influenciam de variadas maneiras (não necessariamente para mais ou menos, melhor ou pior, positivamente ou negativamente). 
humanas e naturais, por exemplo, práticas agrícolas e políticas econômicas passadas e presentes que afetam a vida futura adulta das crianças de hoje (IISD, [s.d.]; Bursztyn \& Bursztyn, 2012). ${ }^{16}$

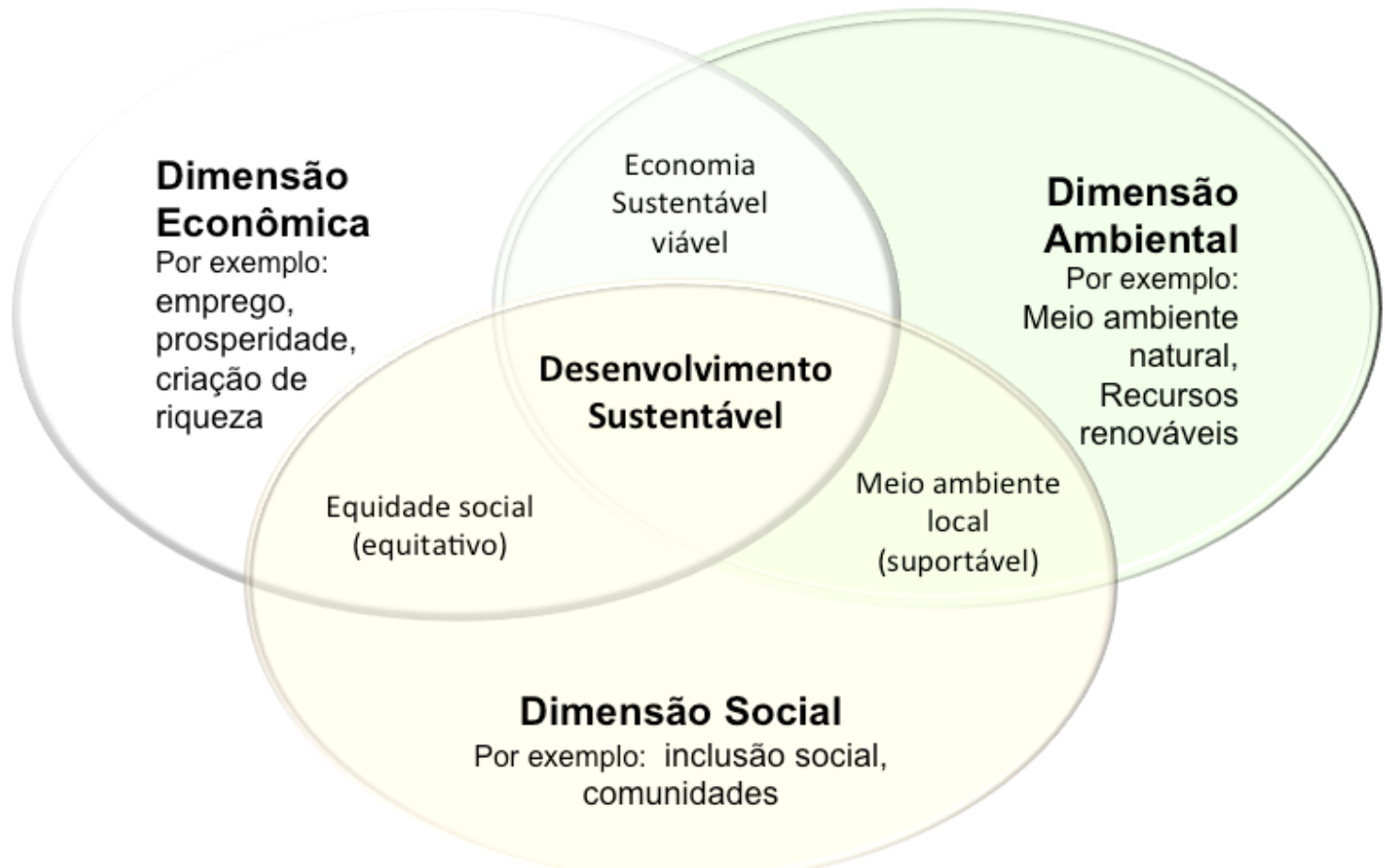

Figura 9: Dimensões da sustentabilidade - visão tradicional Fonte: Leat et al., 2011; ONU, 2013. Elaboração do autor.

Além das tradicionais dimensões ou pilares, ainda se pode adicionar a dimensão institucional, sendo que alguns autores a inserem na dimensão social. Portanto, toda

De sua parte, o sistema também provoca e gera variáveis que exercem influência sobre o ambiente. Portanto, o estado ou situação de um sistema - o conjunto de valores assumidos por todas as variáveis internas de um sistema - em um momento qualquer, é determinado pelo estado anterior do sistema e pelos inputs recebidos pelo sistema no período anterior (GALLOPÍN, 2003:9-10).

Entropia (S), também conhecido como a Segunda Lei da Termodinâmica, é uma medida do número de maneiras específicas pelas quais um sistema termodinâmico pode se organizar, entendida como uma medida de desordem. É a medida de energia não disponível em um sistema fechado que é usualmente considerada também como uma medida de desordem, uma propriedade do estado do sistema e que varia diretamente com qualquer mudança em calor reversível no sistema e inversamente com a temperatura do sistema; portanto, em termos gerais, o grau de desordem ou incerteza no sistema. Em Desenvolvimento Sustetável é usado para se referir à degradação de matéria e energia no universo resultando em um estado último de uniformidade inerte. Veja, Poirier, 2014, p. 77-80.

Uma definição descritiva comumente usada para o conceito de "resiliência" nos estudos da sustentabilidade: a magnitude de perturbação que pode ser absorvida por um sistema até que este mude sua estrutura pela mudança de variáveis e processos que controlam seu comportamento devido à perturbação sofrida (Holling \& Gunderson, 2002:4). Neste ponto em que a magnitude de perturbação atinge o ponto de mudança, o sistema em questão pode ser levado a mudar de uma base de atração para outra como resultado da perturbação exógena. Se o sistema não mudar ("flip") por causa da perturbação exógena em um dado período de tempo, diz-se que o sistema em seu estado inicial é "resiliente". Neste contexto, a resiliência não é quantitativamente mensurável, mas pode ser classificada qualitativamente, isto é, um sistema em um dado estado ou é resiliente ou não é (Derissen et al., 2009).

16 Para maiores detalhes sobre sistemas em Desenvolvimento Sustentável e outros temas relacionados, veja também Bursztyn \& Bursztyn, 2012; Pappas, 2012 e Pisano, 2012. 
sociedade e a sociedade humana universal, compreende as quatro dimensões - econômica, social, ambiental e institucional. Cada uma das dimensões é uma entidade complexa, dinâmica, dotada de auto-organização, evolutiva em si mesma, tornando o sistema das quatro dimensões como um todo, uma entidade de complexidade considerável. Para que este sistema seja sustentável, cada um dos subsistemas precisa também manter sua capacidade de sobreviver e evoluir, ao mesmo tempo que as imbricações dos subsistemas conservam e possibilitam uma coevolução permanente ${ }^{17}$ (Spangenberg, 2005).

\subsubsection{Dimensão Social}

A literatura de Desenvolvimento Sustentável sugere quatro conceitos primordiais da dimensão social: (i.) Equidade; (ii.) Conscientização para a sustentabilidade; (iii.) Participação; e, (iv.) Coesão social. (Murphy, 2012). Existe sobreposição e também interdependência entre os três pilares do desenvolvimento sustentável, especialmente entre os pilares social e econômico, como pode ser visto na Figura 9. Há bastante espaço para a exploração de indicadores objetivos da dimensão social e dada a importância relativa maior da questão da equidade para a segurança alimentar, elegeu-se discutir apenas esta neste trabalho de tese.

\section{Equidade}

Uma sociedade equitativa, saudável e robusta, resultante de oportunidades de emprego a partir da cadeia alimentar, que preserva as funções social e ambiental com o uso adequado da terra é um exemplo do conjunto de objetivos da dimensão social para o caso indiano na segurança alimentar (Leat, 2011). A distribuição de bens relacionados ao bemestar e oportunidades de vida de forma justa em nível nacional, internacional e intergeracional estão na base do conceito de equidade em Desenvolvimento Sustentável. Redistribuição equitativa significa dar aos cidadãos oportunidades semelhantes de sobrevivência e realizar o potencial de desenvolvimento a despeito de gênero, religião, orientação sexual, casta ou qualquer outra divisão social, e que é executada por meio de políticas públicas que dão acesso a, por exemplo, água potável, nutrição adequada, emprego, educação, abrigo, medicamentos essenciais, um meio ambiente livre de poluentes, liberdade de discriminação de gênero, religião, ou raça (Murphy, 2012).

A relação entre equidade e sustentabilidade ainda é pouco compreendida e não há uma correlação simples entre maior equidade e mais sustentabilidade. Há, todavia,

17 Coevolução é a evolução simultânea de duas ou mais espécies que compartilham de um relacionamento ecológico próximo, ou também um tipo de resposta evolutiva correspondente entre populações. Veja, Ricklefs (2008); Spangenberg, 2005, p. 47). 
evidências crescentes da existência de uma relação positiva entre os dois. As discussões em torno da questão têm se concentrado em torno:

- Dos efeitos das mudanças climáticas que são sentidos desproporcionalmente pelas camadas mais pobres da população independente da localização geográfica e divisões políticas. Populações mais pobres tendem a morar em áreas de risco e terras marginais, além de disporem de relativamente menos recursos e dispositivos econômicos e legais para lidarem com fenômenos naturais, por exemplo, cobertura de seguros (Gough et al., 2008 apud Murphy, 2012:22).

- Das mudanças climáticas relacionadas ao crescimento econômico: gerações futuras sofrerão sérios riscos ambientais devido a efeitos colaterais do crescimento econômico (Stern, 2006; OECD, 2009). As concentrações de dióxido de carbono na atmosfera entre 2012 e 2013 cresceram no ritmo mais rápido desde 1984 (WMO, 2014). Com o aumento e aceleração das emissões de dióxido de carbono e outros gases responsáveis pelo efeito estufa por países desenvolvidos e em desenvolvimento, as abordagens alternativas para a questão da equidade intergeracional estão se desenvolvendo à volta da necessidade de redução do consumo pelas gerações atuais. Assim, neste contexto, a busca por equidade intergeracional pode ser entendida em termos da força do compromisso em reduzir o consumo e não apenas em termos de soluções e inovações de mercado e tecnológicas.

- Da maneira desproporcional que países em desenvolvimento são mais afetados pelos efeitos das mudanças climáticas devido a questões geográficas (principalmente, localização) e também por limitações de recursos aplicados à mitigação e estratégias de adaptação do que países desenvolvidos (Keane et al., 2009). Murphy (2012), salienta que embora países menos desenvolvidos tenham contribuído e contribuam menos, já são eles que sofrem mais e continuarão sofrendo mais os efeitos das mudanças climáticas. Uma vez mais, a questão da equidade se levanta e uma vez mais, o compromisso em reduzir as emissões necessita ir além de inovações de mercado, como o mercado de créditos de carbono e incluir além da redução em si, por exemplo, a transferência de tecnologia (Murphy, 2012).

- Da necessidade de compatibilizar a equidade intra-geracional e intergeracional (Hunter, 2011; Fitzpatrick \& Cahill, 2002; Beder, 2000). Para Murphy (2012), isto significa que a atenção e os fundos utilizados na proteção de gerações futuras não devem ser desviados de políticas que vão de encontro às necessidades dos pobres na atualidade. E, de igual forma, as necessidades das gerações futuras não podem deixar de serem provisionadas devido à atenção dada aos pobres atuais. Para que 
tal ocorra, a integração da política de meio ambiente, tanto na horizontal quanto na vertical é fundamental. 
Tabela 1 - Indicadores objetivos de sustentabilidade social

\begin{tabular}{|c|c|c|}
\hline Critério & Indicador & Alvo \\
\hline $\begin{array}{l}\text { Necessidades } \\
\text { Básicas }\end{array}$ & $\begin{array}{l}\text { HPI 1: PNUD Índice de Pobreza Humana para países } \\
\text { em desenvolvimento. } \\
\text { Privação de longevidade: \% da população com } \\
\text { expectativa de vida abaixo de } 40 \text { anos (P1). } \\
\text { Privação de conhecimento: \% de adultos analfabetos } \\
\text { (P2). } \\
\text { Privação de padrões razoáveis de vida (P3): [\% da } \\
\text { população sem acesso à água potável (P31); \% da } \\
\text { população sem acesso a serviços de saúde (P32); \% } \\
\text { de criaças subnutridas abaixo de } 5 \text { anos de idade } \\
\text { (P33)] \{P31+P32+P33/3\}. }\end{array}$ & Alto \\
\hline Recursos Sociais & $\begin{array}{l}\text { Tempo médio gasto com atividades volutárias - } \\
\text { inclusive trabalho comunitário e político. }\end{array}$ & Baixo \\
\hline Oportunidades & $\begin{array}{l}\text { Coeficiente de Gini de distribuição de renda } \\
\text { GEM PNUD - medida de empoderamento de gênero } \\
\% \text { de mulheres no legislativo, em posições de } \\
\text { liderança, nas áreas de ciência e engenharia. } \\
\% \text { feminino no total da renda gerada por salários }\end{array}$ & Alto \\
\hline Participação & $\begin{array}{l}\text { Comparecimento ponderado do eleitor e engajamento } \\
\text { em outras formas de participação não } \\
\text { institucionalizadas. }\end{array}$ & Baixo \\
\hline Sustento próprio & Taxa de desemprego de longo prazo & Alto \\
\hline $\begin{array}{l}\text { Diversidade } \\
\text { Cultural }\end{array}$ & $\begin{array}{l}\text { Apoio ao desenvolvimento, continuidade e } \\
\text { documentação de vida cultural amplamente acessível } \\
\text { e compreensível em pluralidade de diversidade por } \\
\text { meio de pesquisa política, educacional e cultural. }\end{array}$ & Baixo \\
\hline
\end{tabular}

Fonte: Empacher \& Wehling 1999. Elaborado e adaptado pelo autor. 
Integração da política ambiental

A integração da política ambiental requer que as demandas ambientais sejam continuamente envolvidas em todo processo do ciclo politico. Para isto ocorrer, praticamente todo o processo politico, desde sua condução, organização e procedimentos até a execução precisam incorporar as questões ambientais desde o primeiro momento. A integração pode ser vertical: o grau de adoção de objetivos ambientais por um órgão, setor, área ambiental de um governo no âmbito de suas atividades; e, horizontal: a dimensão da abrangência estratégica transversal de integração da política ambiental de ministérios, secretarias, autarquias e outros que tenham autoridade central em um governo ou Estado (Lafferty \& Hovden, 2003). Tanto a integração vertical quanto a horizontal não são atingíveis ordinariamente pois vão contra aquilo que é normalmente praticado e cristalizado nas organizações governamentais contemporâneas: hierarquização e especialização. Além disso, o número de diferentes setores que têm relevância para o meio ambiente e para o desenvolvimento sustentável - política, social, econômica e estrutural é alto e fragmentado. E, para tornar a integração da política ambiental mais difícil ainda, os ministérios e secretarias de meio ambiente e economia e desenvolvimento sustentável, em geral, têm atuação relativamente menos forte na estrutura estatal, frequentemente por conflito de interesse e interesses no interior do próprio governo, entre por exemplo, um ministério da agricultura e um ministério do meio ambiente (Ross \& Dover, 2008).

\subsubsection{Dimensão Econômica}

A sustentabilidade econômica é a habilidade de uma economia sustentar um nível definido de produção econômica por tempo indeterminado, considerando a mesma possibilidade para as gerações futuras, além de também criar valor "sustentável" por meio da identificação de valor que contribui para o desenvolvimento sustentável. Por sua vez, a sustentabilidade desse valor criado é necessária, e por extensão, da unidade econômica (e fornecedores) que é sua originadora (EPE, 2004).

Existe divergência nas ciências econômicas sobre como alcançar a situação descrita no parágrafo anterior e no cerne se encontra a aceitação e a subsequente interpretação da realidade entrópica, conforme resumido e esquematizado na Quadro 8. De forma resumida, o crescimento continuado sem reconhecimento da entropia é especialmente advogado por economistas da tradição Neoclássica que teoricamente aceita a possibilidade de perfeita substituibilidade entre recursos naturais e tecnológicos, a visão tecnocêntrica (D'Alisa, 2007). Estes podem ser divididos em tecnocêntricos da abundância e tecnocêntricos da acomodação: os primeiros por advogarem que as estruturas de mercado são suficientes para garantir o desenvolvimento sustentável, e os segundos por aceitarem alguns limites e 
mecanismos para garantir a sustentabilidade. No outro extremo do espectro de alinhamentos de escolas, tradições e linhas de pesquisa econômica, encontra-se a visão ecocêntrica, que dá prioridade às demandas ecológicas sobre as humanas. Esta também pode ser dividida em duas principais linhas, a primeira, a ecocêntrica comunitária que se permite mais espaço para a sociedade humana nas considerações do ecossistema; e, a ecocêntrica radical que advoga uma nova fundamentação geral para a economia baseada no reconhecimento da inelutabilidade da lei da entropia: isto é, não é passível de contestação e precisa ser necessariamente levada em consideração (D’Alisa, 2007; Rifkin, 1989; 2000). 


\begin{tabular}{|c|c|c|c|c|}
\hline & \multicolumn{2}{|c|}{ Tecnocêntricos } & \multicolumn{2}{|c|}{ Ecocêntrica } \\
\hline & $\begin{array}{l}\text { De } \\
\text { abundância }\end{array}$ & $\begin{array}{l}\text { De } \\
\text { acomodação }\end{array}$ & Comunitária & Radical \\
\hline Característica & $\begin{array}{l}\text { Exploração } \\
\text { de recursos } \\
\text { naturais }\end{array}$ & $\begin{array}{l}\text { Manejo e } \\
\text { preservação de } \\
\text { recursos } \\
\text { naturais }\end{array}$ & $\begin{array}{l}\text { Proteção dos } \\
\text { recursos naturais }\end{array}$ & $\begin{array}{l}\text { Preservação } \\
\text { extrema de } \\
\text { recursos } \\
\text { naturais }\end{array}$ \\
\hline \multirow[t]{3}{*}{$\begin{array}{l}\text { Tipo de } \\
\text { economia }\end{array}$} & Anti-verde & Verde & $\begin{array}{l}\text { Profundamente } \\
\text { verde }\end{array}$ & $\begin{array}{l}\text { Rigorosament } \\
\text { e verde }\end{array}$ \\
\hline & $\begin{array}{l}\text { Sem } \\
\text { restrições }\end{array}$ & $\begin{array}{l}\text { Adesão a } \\
\text { restrições por } \\
\text { meio de } \\
\text { políticas } \\
\text { microeconômica } \\
\text { s }\end{array}$ & $\begin{array}{l}\text { Adesão a } \\
\text { restrições por } \\
\text { meio de políticas } \\
\text { macro e } \\
\text { microeconômicas }\end{array}$ & $\begin{array}{l}\text { Restrições } \\
\text { rígidas para } \\
\text { minimizar os } \\
\text { impactos de } \\
\text { recursos }\end{array}$ \\
\hline & $\begin{array}{l}\text { Orientada } \\
\text { para o } \\
\text { crescimento }\end{array}$ & $\begin{array}{l}\text { Orientada para } \\
\text { o crescimento } \\
\text { sustentável }\end{array}$ & $\begin{array}{l}\text { Orientada para o } \\
\text { desenvolvimento } \\
\text { sustentável }\end{array}$ & $\begin{array}{l}\text { Orientado ao } \\
\text { decrescimento }\end{array}$ \\
\hline \multirow[t]{3}{*}{$\begin{array}{l}\text { Estratégias de } \\
\text { gerenciamento }\end{array}$} & \multirow[t]{3}{*}{$\begin{array}{l}\text { Os preços, } \\
\text { como } \\
\text { indicadores } \\
\text { de escassez, } \\
\text { asseguram o } \\
\text { sinal correto } \\
\text { para o } \\
\text { agente que } \\
\text { negocia } \\
\text { livremente }\end{array}$} & $\begin{array}{l}\text { Necessidade de } \\
\text { ajustamento } \\
\text { levando-se em } \\
\text { consideração as } \\
\text { consequências } \\
\text { da produção e } \\
\text { do consumo } \\
\text { sobre o meio } \\
\text { ambiente. }\end{array}$ & $\begin{array}{l}\text { Estado } \\
\text { estacionário: sem } \\
\text { crescimento de } \\
\text { capital físico. }\end{array}$ & $\begin{array}{l}\text { Decrescimento } \\
\text { de capital } \\
\text { físico. }\end{array}$ \\
\hline & & $\begin{array}{l}\text { Imposto } \\
\text { Pigouviano; } \\
\text { ocasionalmente, } \\
\text { cotas de } \\
\text { produção. }\end{array}$ & $\begin{array}{l}\text { Escala ótima; } \\
\text { distribuição justa; } \\
\text { alocação ótima }\end{array}$ & $\begin{array}{l}\text { Nível } \\
\text { populacional } \\
\text { sustentado } \\
\text { apenas pela } \\
\text { agricultura } \\
\text { orgânica. }\end{array}$ \\
\hline & & $\begin{array}{l}\text { Regra } \\
\text { operacional: } \\
\text { capital total } \\
\text { constante no } \\
\text { período. }\end{array}$ & $\begin{array}{l}\text { Planejamento de } \\
\text { permissão } \\
\text { transferível }\end{array}$ & $\begin{array}{l}\text { Distribuição } \\
\text { justa }\end{array}$ \\
\hline
\end{tabular}

(Continua) 


\begin{tabular}{|c|c|c|c|c|}
\hline & \multicolumn{2}{|c|}{ Tecnocêntricos } & \multicolumn{2}{|c|}{ Ecocêntrica } \\
\hline & $\begin{array}{l}\text { De } \\
\text { abundância }\end{array}$ & De acomodação & Comunitária & Radical \\
\hline \multirow[t]{2}{*}{ Etica } & $\begin{array}{l}\text { Maximização } \\
\text { do bem- } \\
\text { estar } \\
\text { individual }\end{array}$ & $\begin{array}{l}\text { A maximização } \\
\text { individual é } \\
\text { corrigida para } \\
\text { enfrentar alguns } \\
\text { dos problemas } \\
\text { de justiça } \\
\text { intergeracionais } \\
\text { e } \\
\text { infrageracionais. }\end{array}$ & $\begin{array}{l}\text { Interesses } \\
\text { coletivos } \\
\text { presentes e } \\
\text { futuros são } \\
\text { predominantes } \\
\text { em relação } \\
\text { aos interesses } \\
\text { privados e } \\
\text { individuais. }\end{array}$ & $\begin{array}{l}\text { Busca de } \\
\text { interesses } \\
\text { humanos } \\
\text { como espécie } \\
\text { biológica. }\end{array}$ \\
\hline & & $\begin{array}{l}\text { A natureza tem } \\
\text { valor } \\
\text { instrumental. }\end{array}$ & $\begin{array}{l}\text { Os } \\
\text { ecosistemas } \\
\text { têm valor } \\
\text { primário. }\end{array}$ & $\begin{array}{l}\text { Ecossistemas } \\
\text { são o } \\
\text { aspecto } \\
\text { fundamental } \\
\text { da vida. }\end{array}$ \\
\hline \multirow[t]{2}{*}{$\begin{array}{l}\text { Critério da } \\
\text { sustentabilidade }\end{array}$} & Muito fraco & Fraco & Forte & Muito forte \\
\hline & & & $\begin{array}{l}\text { Regra } \\
\text { operacional: } \\
\text { capital natural } \\
\text { constante no } \\
\text { período }\end{array}$ & \\
\hline
\end{tabular}

Não obstante as divisões internas e a própria complexidade das ciências econômicas, a dimensão econômica do desenvolvimento sustentável é por definição inseparável das outras, como pode ser visto na Figura 10, e de acordo com a visão mais holística, se encontra contida na dimensão social e na dimensão ambiental. 


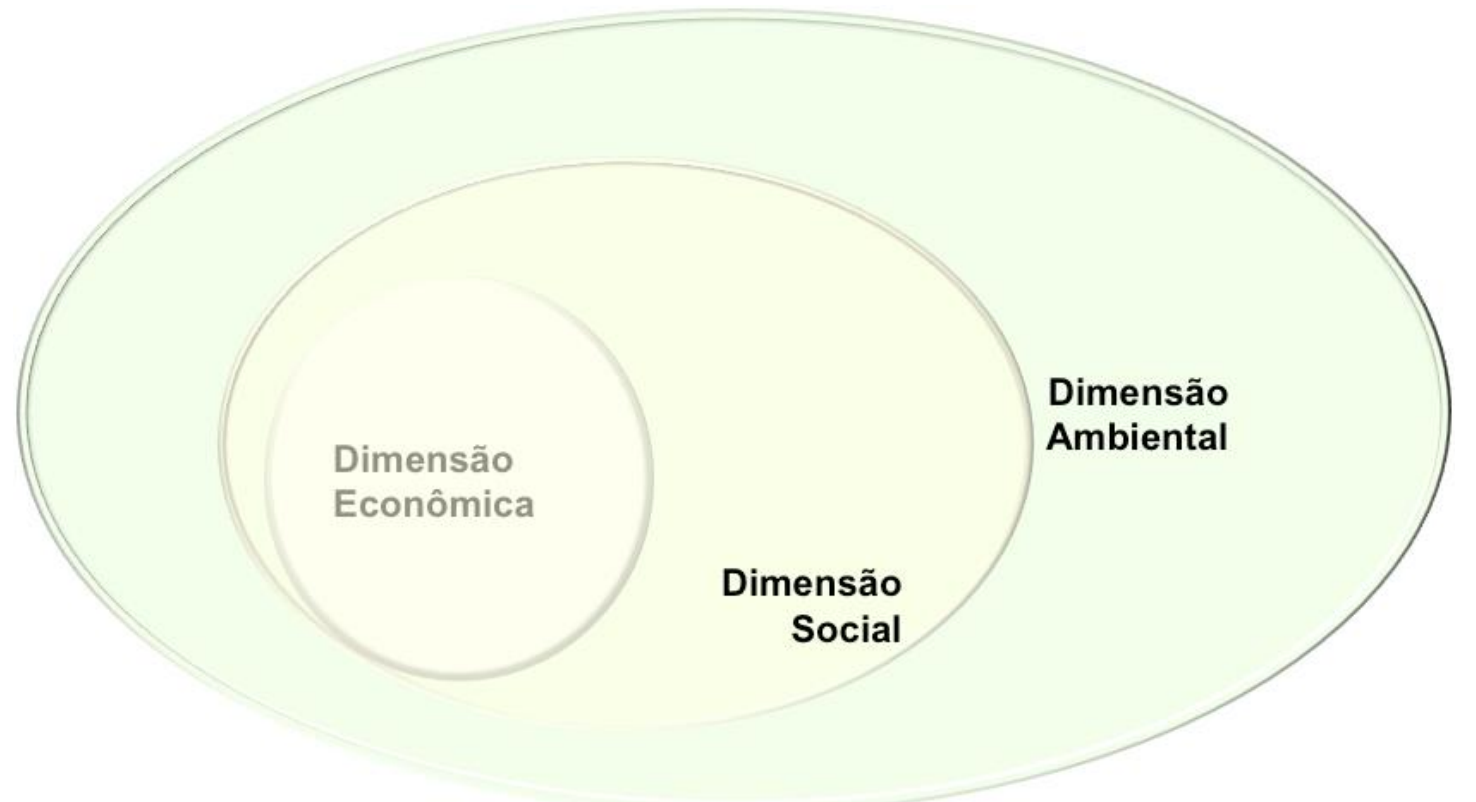

Figura 10: Representação concêntrica das dimensões da sustentabilidade Fonte: D'Alisa, 2007. Elaboração e adaptação do autor.

\subsubsection{Dimensão Ambiental}

O meio ambiente é obviamente muito mais do que uma dimensão ou pilar do desenvolvimento sustentável: é o próprio meio em que toda a atividade orgânica e inorgânica ocorre. Todavia, a divisão didática é necessária dada a complexidade da realidade estudada e limitações das ciências atuais. Para os fins do estudo desta tese sobre o PDS do Governo da Índia, a dimensão ambiental pode ser simplificada para se referir ao manejo de recursos naturais com o intuito de garantir a disponibilidade dos mesmos no futuro para garantir a segurança alimentar. Inclui também, por exemplo, a proteção de paisagens naturais, habitats, manutenção da biodiversidade e boa qualidade de ar e água (CMMAD, 1987; UNEP, 2012; UNEP, 2013).

A relação entre o desenvolvimento ambientalmente sustentável e a pobreza e por conseguinte, a segurança alimentar depende de como a pobreza é definida, da situação ambiental em questão e dos grupos entre os classificados como pobres que são ou estão sendo afetados pela mudança ou degradação ambiental em contextos, por exemplo, de níveis de desenvolvimento socioeconômico assimétrico. As origens da pobreza extrema e da degradação ambiental são organizadas ou estruturadas por esses processos assimétricos de desenvolvimento que atuam por meio de tecnologias, incentivos e instituições e regulamentos que favorecem intencionalmente e/ ou aleatoriamente a alguns e outros não (Masika \& Joekes, 1997).

Há fortes evidências que sugerem que a distribuição social da qualidade ambiental é desigual e usualmente enviesada contra os mais pobres e marginalizados. Quase sempre também são os mesmos que ocupam áreas de qualidade ambiental mais baixa do que 
outros grupos mais privilegiados. As desigualdades são reforçadas pelas vulnerabilidades já existentes - baixa renda, vulnerabilidades relacionadas à infância, velhice, gravidez - e intensificadas cumulativamente pelos impactos ambientais (Pye, et al., 2008). Relacionar teoricamente, quantificar e mensurar essa relação é um desafio presente da pesquisa em desenvolvimento sustentável (Bartelmus, 2013; Bartelmus, 2008; Tiburcio, 2011).

Logo, a formulação de políticas públicas de qualquer natureza, inclusive de segurança alimentar, que sejam ambientalmente neutras e eficazes e eficientes é um esforço em andamento com conexões e escalas de dimensões de desenvolvimento múltiplas, como esquematizado na Figura 11. Reforça-se, uma vez mais, a necessidade de integração vertical e horizontal de políticas públicas, especialmente se as camadas da população mais pobres e vulneráveis à degradação ambiental forem de fato levadas em consideração (Pye, 2008).

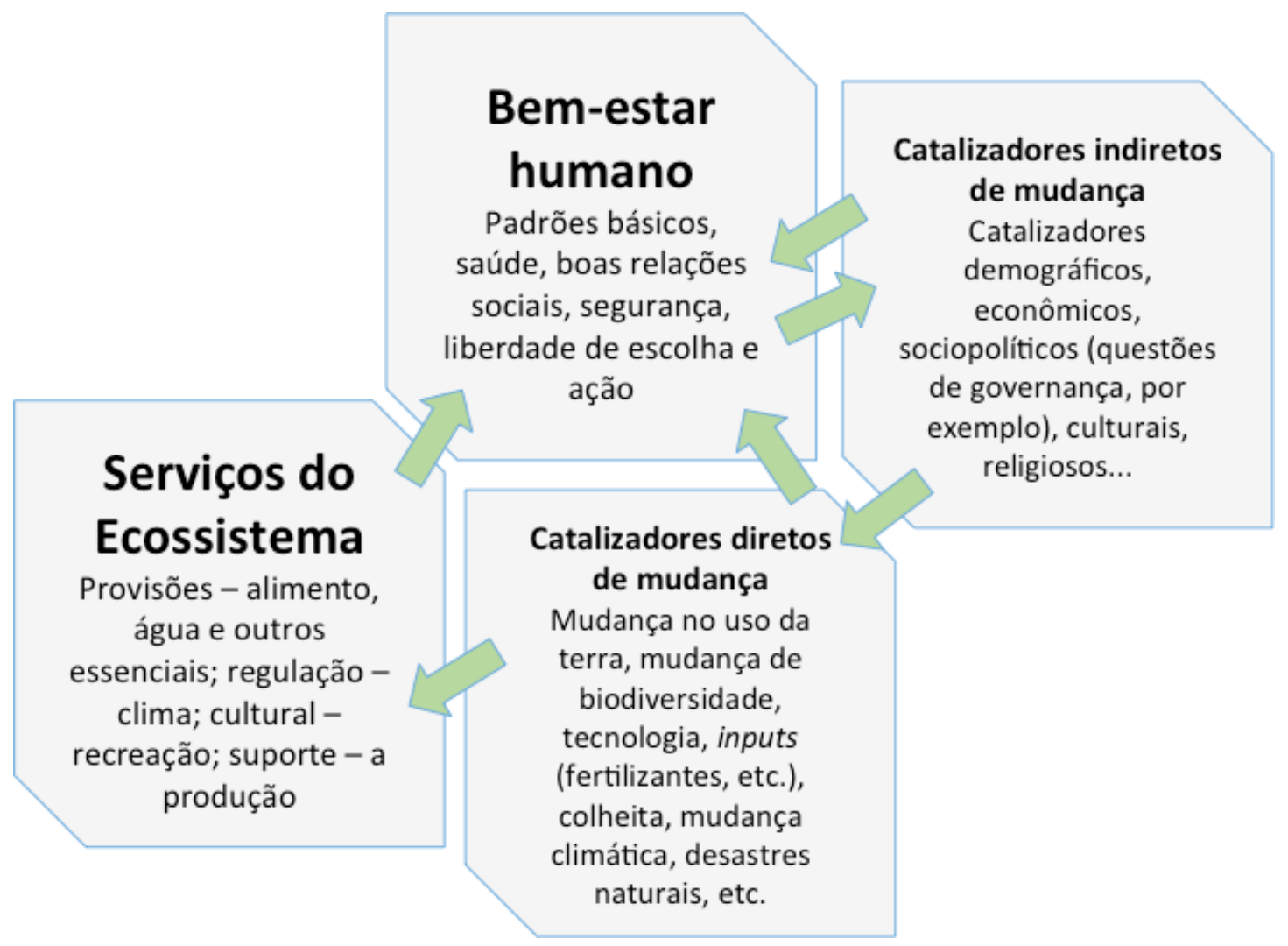

Figura 11: Conexões e escalas das dimensões do desenvolvimento

Fonte: Millennium Ecosystem Assessment, 2005. ICSU; UNESCO; UNU, 2008. Adaptação do autor.

\subsubsection{Sistemas de alimentação sustentáveis no âmbito da economia verde}

As políticas de segurança alimentar devem considerar os fundamentos ecológicos que garantem a disponibilidade, o acesso, a utilização e a estabilidade do sistema de segurança alimentar (UNEP, 2012). A continuidade de uma política de segurança alimentar do ponto de 
vista do abastecimento depende da oferta. A oferta está condicionada às condições naturais básicas necessárias para a produção agrícola: por exemplo, água, formação do solo e biodiversidade. As condições básicas são direta e indiretamente afetadas pelos produtos e efeitos secundários resultantes da produção que minam a sustentabilidade da mesma: por exemplo, contaminação do solo e água (Figura 11). Embora a ciência ainda não disponha de medidas claras do dano já causado, sabe-se que há redução de produtividade devido à degradação (Matson et al., 1997; Eswaran et al., 2001; Bartelmus, 2008). A competição pela água e terra, as práticas da agricultura convencional moderna (monocultura, aragem excessiva, uso constante e excessivo de fertilizantes resultando em eutrofização e contaminação de reservatórios de água), as práticas da agricultura tradicional (que também podem danificar o ambiente por meio de, por exemplo, cultivo de encostas íngremes, excesso de uso de pastagens, etc.), o desflorestamento, a contaminação com pesticidas, combinadas com mudanças no clima são ameaças aos fundamentos da agricultura que por sua vez ameaçam a sustentabilidade das políticas de segurança alimentar (UNEP, 2012).

\section{CONCLUSÃO}

O fortalecimento dos meios de subsistência é essencial para a segurança alimentar, com especial ênfase à sensibilidade e à resiliência dos instrumentos que levam a este fortalecimento. Neste capítulo, as fontes de risco à segurança alimentar familiar foram levantadas a partir das fontes de direito (entitlements à segurança alimentar), convencionadas 'capitais' produtivo, não produtivo, humano e renda e requerimentos. Embora o uso do termo capital e um tratamento mais econômico da questão dos meios de subsistência seja facilmente alvo de críticas, este tipo de análise permite uma compreensão mais completa da interface econômica que permeia a conceituação e a realidade empírica do fenômeno. O estudo sobre os cinco componentes da vulnerabilidade e seus principais determinantes dão o ensejo para uma apresentação das dimensões da sustentabilidade ambiental, social-institucional e econômica, utilizada no estudo de caso sobre a Índia e o estado de Karnataka na segunda parte deste trabalho de tese. O princípio da integração horizontal e vertical da política ambiental nas políticas públicas, em geral, indica já, de forma hipotética, a insustentabilidade das políticas de segurança alimentar quando não dispõem de integração. 


\title{
CAPÍTULO 3: O CONTEXTO MACROECONÔMICO DE SEGURANÇA ALIMENTAR
}

\author{
3 O CONTEXTO MACROECONÔMICO DE SEGURANÇA ALIMENTAR
}

\section{INTRODUÇÃO}

A compreensão do que seria a segurança alimentar e nutricional demanda uma análise do contexto macroeconômico no qual a discussão anterior se encontra. Boa parte dos elementos e fatores já apresentados possuem raízes causais macroeconômicas, embora seja extremamente complexo mapear os caminhos exatos e o peso das variáveis que influenciam a macroeconomia e impactam a subnutrição. Com base nas crises de preços de alimentos de 2008 e 2011, a discussão presente neste capítulo 3 busca mapear possíveis catalizadores inflacionários, entre os quais, os choques de demanda persistentes, a maior inelasticidade de mercado, as questões climáticas e estoques físicos, a política de comércio e estoques de alimentos da China e fatores macroeconômicos. Após esta discussão inicial, passa-se à uma análise do desempenho macroeconômico e booms de commodities e o papel destes em situações de recessão e crise financeira. A influência dos mercados futuros agrícolas sobre a especulação e os preços dos produtos físicos e expectativas inflacionárias ocupam a parte final deste capítulo 3.

\subsection{QUESTÕES MACROECONÔMICAS}

Entre as razões para a insegurança alimentar e nutricional, figura o sistema da economia política agrícola internacional que interfere no principal sinalizador de oferta e demanda de alimentos: os preços. Restrições comerciais por parte dos principais exportadores de alimentos, políticas relacionadas aos biocombustíveis, especulação com commodities agrícolas e baixos níveis de governança igualmente conspiram contra a segurança alimentar e nutricional (Ecker \& Breisinger, 2012; Thomson \& Metz, 1999). 


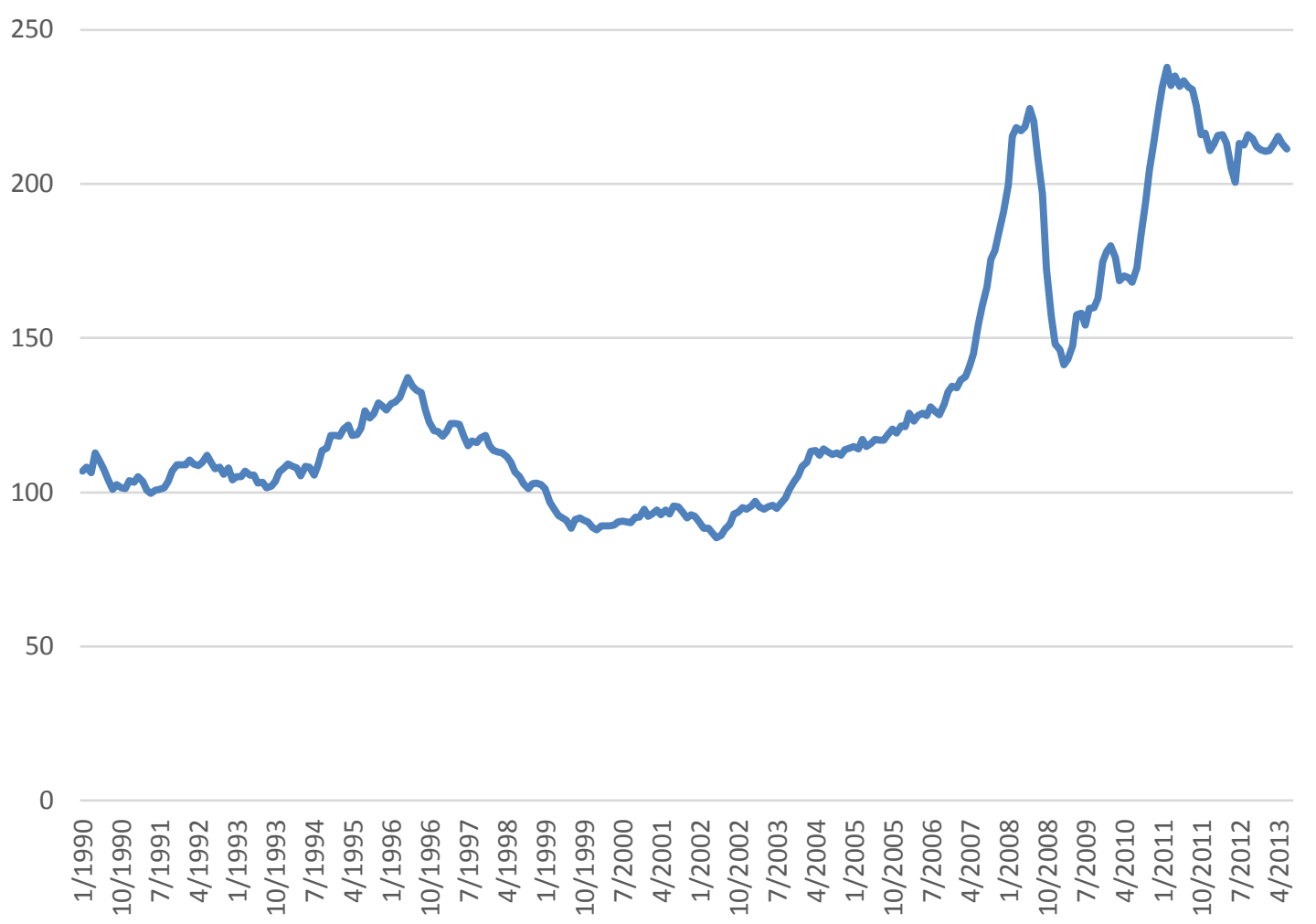

Gráfico 1 - Índice de preços de alimentos da FAO (2002-2004=100)

Fonte: FAO, 2013

Em 2008 e 2011, os preços internacionais dos alimentos, conforme a Gráfico 1, dispararam e se estabilizaram em um patamar em nível quase que o dobro dos preços praticados em 2005. O Índice de Preços de Alimentos da FAO é preparado e divulgado no início de cada mês. O índice é uma medida da mudança de preços mensal nos mercados internacionais de uma cesta de commodities alimentares. O número consiste da média dos índices de preços de um grupo de cinco commodities - carnes, laticínios, cereais, óleos e gorduras e açúcar - que representam 55 cotações, ponderado pela média das participações de cada grupo nas exportações para 2002-2004. (Banco Mundial, 2012; Carter et al., 2008; FAO, 2013).

As consequências da disparada de preços das commodities agrícolas de 2008 e 2011 para os mais pobres mundo afora ainda estão sendo analisadas, no entanto, pode-se afirmar que uma vez mais a vulnerabilidade destes aos preços internacionais está longe de ser reduzida, embora muito tenha sido proposto e pouco feito. Entre as propostas que foram feitas e muito provavelmente jamais serão colocadas em prática se encontram emendas às regras de comércio global que restrinjam a possibilidade de exportadores de alimentos suspenderem exportações, regras mais restritivas para a produção de biocombustíveis e especulação com commodities agrícolas, a institucionalização de reservas de grãos com o intuito de estabilizar os preços em tempos de crise, a criação e expansão de mecanismos de salvaguarda social nacional. Há, no entanto, propostas com maiores probabilidades de 
serem concretizadas em âmbito global, tais como maiores investimentos para o aumento da produtividade agrícola e medidas sustentáveis de adaptação às mudanças climáticas (Ecker \& Breisinger, 2012, p. 7; Banco Mundial, 2012; Oxfam, 2008).

O fator comum entre 2008 e 2011 e provavelmente será também na próxima crise de preços de alimentos é a pressão de demanda crescente sobre a base de recursos globais que o crescimento econômico e as mudanças dele advindas, especialmente nos países em desenvolvimento, exercem sobre os preços. Por isso, os formuladores de políticas precisam tomar decisões que afetam as políticas agrícolas, de segurança alimentar e do setor de energia que são intimamente correlacionados (Abbott et al., 2011).

\subsubsection{Catalizadores da crise de preços de alimentos de 2008 e 2011}

Abbott, Hurt e Tyner (2011), identificaram cinco catalizadores da crise de preços de alimentos de 2008 e 2011: i) os choques de demanda persistentes; ii) a maior inelasticidade de mercado; iii) as questões climáticas e estoques físicos; iv) a política de comércio e estoques de alimentos da China; e, v) os fatores macroeconômicos.

Catalizador 1: Choques de demanda persistentes

O primeiro choque de demanda se refere à demanda por biocombustíveis que é problemática e insustentável principalmente em relação ao uso do milho como matériaprima. Exclusivamente nos Estados Unidos, o uso do milho para a produção de etanol aumentou quase 50\% entre 2007-2011 e influenciou o preço do milho nos mercados internacionais. Além do milho, sementes oleaginosas também têm demanda crescente e contínua. Estas são usadas principalmente cultivadas como matéria-prima na produção de óleos vegetais, insumos para a produção de biodiesel, ração animal e por último, para o consumo humano (Abbott et al., 2011).

O segundo choque de demanda é a procura e compra crescente de soja por parte da China, que é usada, em ordem de importância, para ração animal, consumo de óleo vegetal humano e formação de estoque de reserva (Masters, 2008). De 2006 a 2011 a demanda chinesa mais que dobrou, representando mais de $90 \%$ do crescimento de demanda internacional. Como desde 1997-98, a China deixou de buscar a autossuficiência na produção de soja - como pode ser visto na Gráfico 2 - a perspectiva desde 2011 tem sido de um choque de demanda crescente e constante ano após ano por um prazo ainda indeterminado. Esse choque duplo tem demandado, principalmente no Brasil, Paraguai, Argentina e Estados Unidos, um aumento em terras cultivadas (milho nos EUA e soja no Brasil, Paraguai e Argentina) e a mudança em culturas cultivadas por parte dos agricultores (Abbott et al., 2011; Contini et al., 2012; Hirakuri e Lazzarotto, 2011). 


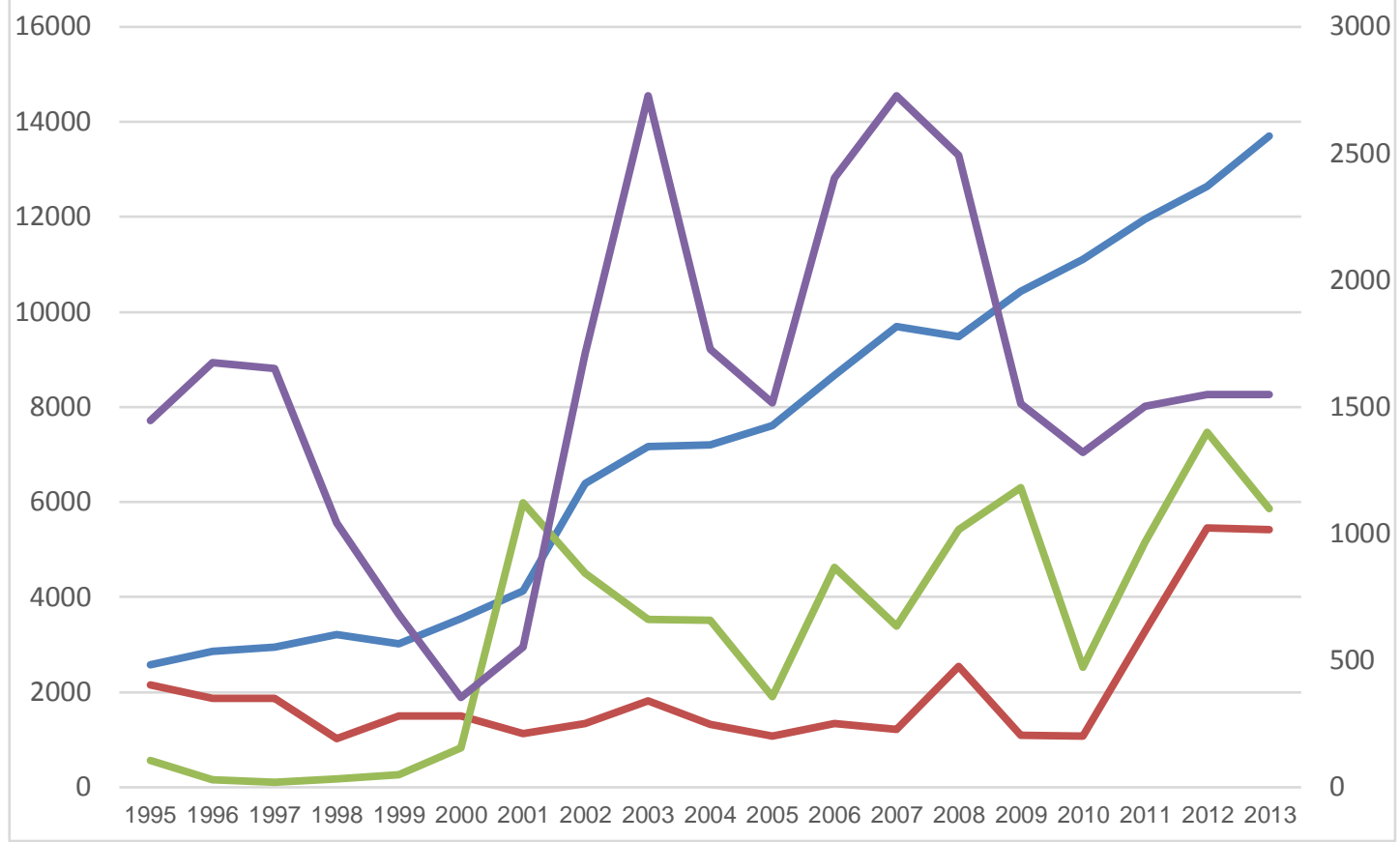

Gráfico 2 - Soja na China (em toneladas métricas)

Fonte: United States Department of Agriculture. Foreign Agricultural Service.

Legenda

Azul: Consumo doméstico de Óleo de soja;

Verde: Exportação de soja esmagada;

Vermelho: Estoques finais de óleo de soja;

Púrpura: Importação de soja esmagada

\section{Catalizador 2: Maior inelasticidade de mercado}

A partir de 2006/7 se iniciou um período de menor resposta em termos de preço em relação à demanda e oferta, isto é, inelasticidade, nos mercados de commodities agrícolas, tanto internacionais quanto nacionais. À medida que a demanda se torna mais inelástica, a reação a choques de oferta percebidos ou reais se torna mais volátil já que os ajustes e expectativas de preço futuros são afetados pela ausência de elasticidade. De acordo com Abbott et al. (2011), as principais fontes de inelasticidade nos mercados agrícolas internacionais são:

a) A rigidez na oferta de terra e as limitações em relação à mudança de uso;

b) As restrições nas políticas de biocombustíveis;

c) Preços em alta do gado e a demanda crescente persistente por ração animal;

d) Preços futuros e estoques de grãos; e,

e) Políticas comerciais que isolam mercados nacionais. (Abbott et al., 2011, p. 6) 
Rigidez na oferta de terra e as limitações em relação à mudança de uso

A disponibilidade de terras cultiváveis teve papel maior na crise de preços de 2011 do que de 2008. Mais terra menos produtiva foi e tem sido convertida em terra agrícola enquanto terra utilizada para culturas menos lucrativas têm sido convertidas para o cultivo, principalmente, de milho, soja e colza. ${ }^{18} \mathrm{~A}$ produtividade das novas terras tende a ser menor, requer maiores investimentos e, consequentemente reduziu ainda mais a elasticidade da reação da oferta. Concomitantemente, como a terra se torna um fator de produção cada vez mais escasso, este processo de equalizar os retornos marginais da terra por todos os cultivos, resulta em preços mais altos mesmo naquelas culturas que não sofrem choque de demanda mas que competem pela mesma terra disponível (Scolari, 2006; Abbott et al., 2011).

Restrições nas políticas de biocombustíveis

Os maiores produtores e consumidores de biocombustíveis, Estados Unidos e Brasil, possuem políticas que regulam o uso e a mistura de biocombustíveis em combustíveis fósseis, gerando uma fração alta de demanda quase fixa, sem qualquer relação ao preço do milho ou da cana-de-açúcar no curto prazo. Dependendo das taxas de câmbio do Real e do Dólar americano e do preço do açúcar no mercado internacional, o Brasil perde ou ganha espaço e os Estados Unidos também, um deslocando o mercado do outro ao sabor do pêndulo cambial e climático, e do preço do açúcar (Abbott et al., 2011, p. 8-9; Ribeiro et al., 2013).

Preço em alta do gado e a demanda crescente e persistente por ração animal

Entre 2008 e 2009, o ambiente econômico para a indústria agropecuária mundial foi de prejuízos financeiros consideráveis, em parte devido aos altos preços das rações que não tinham como ser repassados ao consumidor. Os prejuízos econômicos resultaram na diminuição da produção por meio de liquidação do gado. A produção menor, por sua vez, resultou em preços mais altos para os produtos de origem animal, já que a oferta havia diminuído. Em 2011, preços mais altos ainda do milho e de rações tiveram resultados semelhantes partindo de uma base mais alta de preços (Abbot et al., 2011, p. 9). Em países desenvolvidos, margens de lucro mais apertadas de produtores, processadores e distribuidores pecuários amorteceram os efeitos de preço para os consumidores no biênio 2007-2008. Já em 2011, a margem de lucro menor não permitia à indústria espaço de

18 No Brasil apenas a espécie 'colza de primavera' (Brassica napus) é cultivada, popularmente conhecida como 'canola' - Canadian Oil Low Acid). 
manobra. Esta situação se traduziu em inflação de produtos pecuários para quase todos os países, tendo sido maior nos países em desenvolvimento, tanto em 2008 quanto em 2011 (Garrett, 2008; Conceição et al., 2011).

Consequentemente, a insegurança alimentar e a pobreza aumentaram nos países nos quais houve maior aumento de preços, segundo estimativas do Banco Mundial (2009, 2011), levando milhões de volta à pobreza entre 2008 e 2011. De acordo com Headey (2011) apud Abbot et al. (2011) nos países onde políticas públicas anticíclicas foram adotadas no intuito de minimizar os efeitos dos preços internacionais, os efeitos sobre os indicadores de insegurança alimentar e pobreza foram efetivamente diminuídos.

\section{Preços Futuros}

Preços altos no futuro próximo são um sinal de que existe a necessidade de economizar estoques atuais disponíveis. Preços altos futuros de prazos mais longos indicam as expectativas de mercado em anos vindouros. São essas diferenças entre preços esperados próximos e distantes que encorajam mercados e governos a aumentar ou diminuir estoques. Quando estoques estão altos, os estoquistas se ajustam a choques de oferta e demanda por meio do controle de quanto do estoque atual é reservado para o ano seguinte (carry-out stocks). Prefere-se estocar a vender-se a preços mais baixos. Está manobra é válida até o momento em que os estoques não são mais repostos em maior quantidade ou igual à utilização e se aproximam do esgotamento. A partir deste ponto, há crescente inelasticidade de demanda de estoques carregados (carry-out stocks). Como a taxa de uso - estoque é usada pelo mercado para mensurar a situação do mercado de grãos, estas fazem parte do conjunto de indicadores sobre o mercado alimentar e auxiliam a explicar os picos de preço. (Abbott et al., 2011, p. 9)

\section{Política Comercial Internacional}

O quinto mecanismo do item inelasticidade são as políticas de comércio internacional. Em geral, quando preços internacionais aumentam, como visto entre 2007 e 2008, os governos tendem a exercer políticas comerciais mais isolacionistas na tentativa de estabilizar os mercados domésticos. Em 2008, as políticas comerciais foram mais relevantes do que em 2011. Mesmo assim, entre as medidas de comércio internacional que mais causaram danos à segurança alimentar e nutricional e provavelmente a mais relevante como fator dos picos de preço, foi a restrição às exportações, principalmente as de arroz (Timmer, 2008; Sharma, 2011; Abbott et al., 2011).

Os países importadores de arroz decidiram quase que conjuntamente cortar tarifas de importação e tarifas domésticas, impostos diretos e indiretos, liberar estoques de grãos e 
subsidiar a importação e o consumo doméstico (Sharma, 2011). O movimento de mercado em uma direção - busca da estabilidade do mercado doméstico - causou desequilíbrio pois ao invés de absorverm o custo do ajuste de estoque pelo menos parcialmente, todos escolheram empurrar o problema para o vizinho, Gráfico 3 (Abbott et al., 2011).

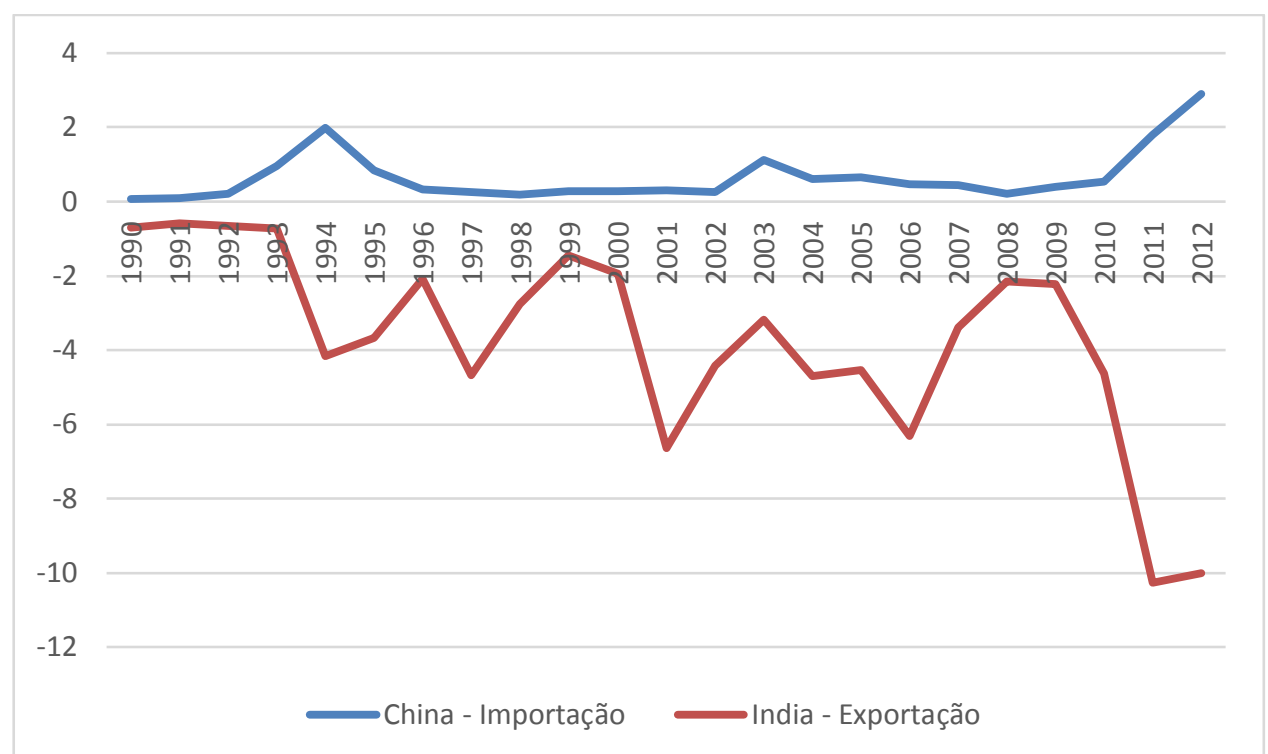

Gráfico 3 - China e Índia no mercado internacional de arroz (Milhões de toneladas métricas) Fonte: United States Department of Agriculture. Foreign Agricultural Service.

Para proteger a segurança alimentar doméstica, vários governos com relevância no mercado de grãos internacional decidiram manter as importações e/ ou reduzir as exportações. Além de manter ou aumentar as quantidades importadas, alguns decidiram também adiantar o cronograma de compras como medida preventiva a aumentos subsequentes de preço. Ao agir deste modo, os governos interferiram nos mecanismos de mercado de transmissão de preços, agregando a imperfeições de integração de mercado já existentes. Além das diferenças internacionais em relação às domésticas, adicionaram-se as diferenças entre os diferentes mercados internos, entre os quais, os mercados urbanos e rurais (Jacquet, 2012; FAO, 2011; Listorti e Esposti, 2012).

Fato relevante, é que o comércio internacional de grãos não desacelerou por causa dos preços mais altos. Pelo contrário, houve inelasticidade de demanda crescente em relação a preço. ${ }^{19} \mathrm{E}$, embora em 2013 os preços agrícolas tenham experimentado ligeira queda e se estabilizaram em um patamar abaixo do de 2011, estes permanecem altos em relação ao período anterior a 2008, como pode ser visto na Gráfico 4.

${ }^{19}$ Para um interessante estudo sobre a inelasticidade da demanda por alimentos em nível micro, veja Andreyeva et al., 2010. 
Catalizador 3: Questões climáticas e estoques físicos

A redução do inventário global de grãos em 2010-11 causado por questões climáticas teve impacto relevante nos picos de preços já que a produção global total de grãos havia caído comparação ao ano anterior, conforme Gráfico 4. Devido a anomalias climáticas em regiões tão díspares como o Mar Negro, Canadá e Austrália, a produção mundial de trigo em 2010/11 encolheu 37 milhões de toneladas métricas. A produção de cevada caiu 27 milhões de toneladas métricas devido a mudança dos fazendeiros para cereais mais rentáveis e também pela seca na Europa e em alguns países do leste Europeu. A produção de milho foi afetada pela pior seca nos Estados Unidos desde a década de 1930. Soja e arroz também foram afetados pelo clima mais incerto tanto em 2008 quanto em 2011 (Abbott et al., 2011; Banco Mundial, 2013).

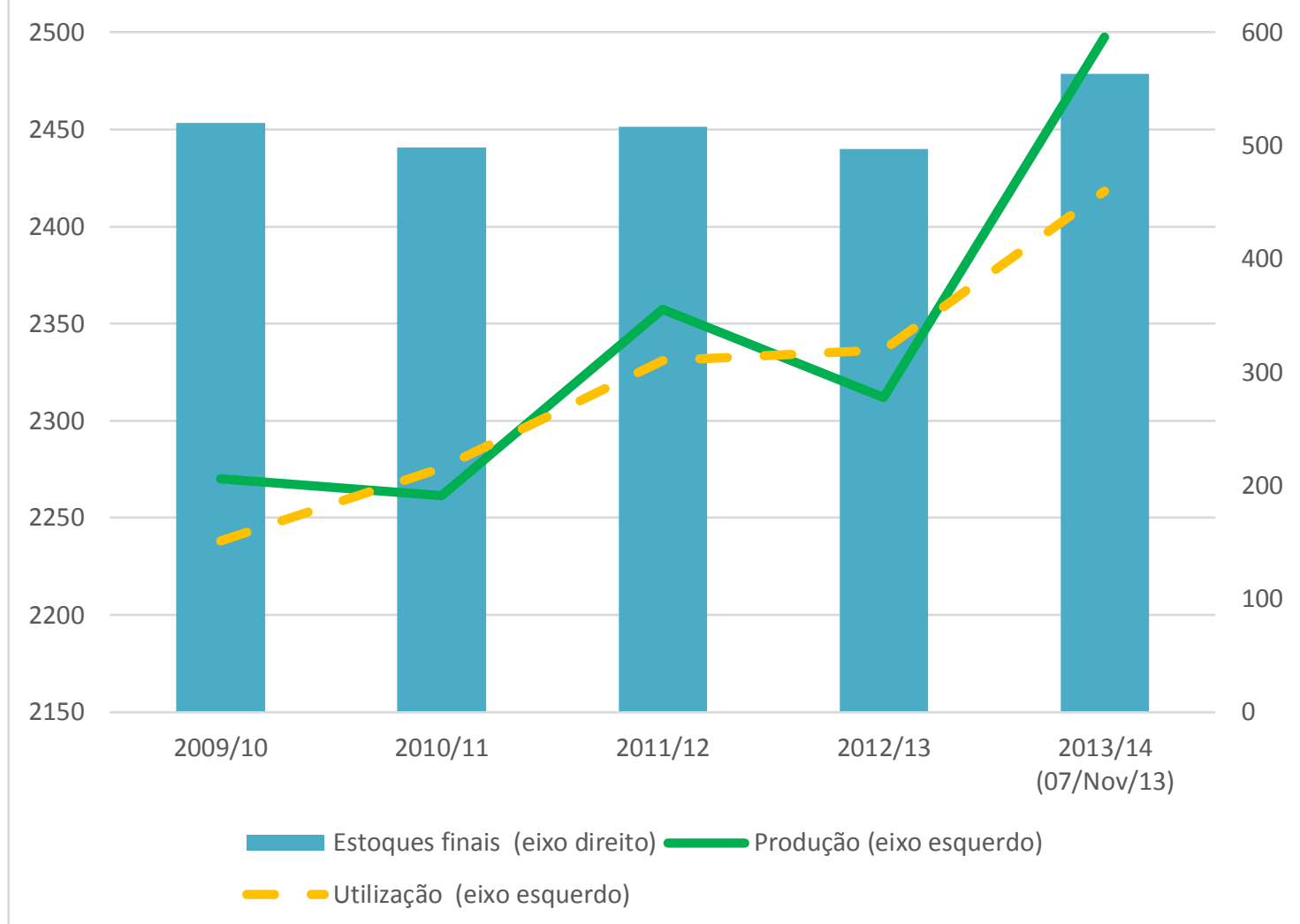

Gráfico 4 - Mercado Mundial de Cereais (grãos) na Índia

Fonte: FAO Cereal Supply and Demand Brief. Disponível em: <http://www.fao.org/worldfoodsituation/csdb/en/>. Acesso: 09/11/2013. Elaborado pelo autor a partir de Fao Cereal Supply and Demand Brief.

Como o consumo da classe média de países emergentes aumenta e se diversifica de modo acelerado, a capacidade de repor os estoques é constantemente desafiada e mais e mais também é demandado do meio ambiente. Essas mudanças tornam o clima menos previsível e mais sujeito a padrões de clima irregulares que afetam a produção agrícola e que têm sido mais frequentes e de maior amplitude. O "bottom line" é que a segurança 
alimentar mundial é crescentemente vulnerável aos efeitos das mudanças climáticas e o reflexo é visto em termos de picos de preço e o impacto causado aos mais pobres (Abbott et al., 2011; Banco Mundial, 2013).

Catalizador 4: Política de comércio e estoques de alimentos da China

A China é o país chave no comércio internacional agrícola e qualquer explicação sobre a oferta e o uso, e principalmente seus estoques precisam inclui-la. De acordo com Abbott et al., (2011, p. 13), baseado nas médias entre 2008-2011, a China é responsável pela produção de $19 \%$ dos cereais e $32 \%$ do estoque de uso final. No entanto, detém apenas $1,6 \%$ das importações e 0,6\% das exportações. De especial relevância para o Brasil, a China produz apenas $6 \%$ da produção mundial de soja, porém, importa $57 \%$ de tudo que é produzido. Em contrapartida, retém $23 \%$ do estoque final mundial. Portanto, os mercados chineses de grãos fora a soja não são conectados aos mercados mundiais. Nos grãos em geral, a China permanece um dos países mais isolados e autossuficientes. O comércio líquido representa menos que $1 \%$ da produção e uso, e por isso os preços domésticos possuem baixa correlação com os preços dos mercados internacionais (Abbott et al., 2011; Banco Mundial, 2013).

Desde a segunda metade da década de 1990, a China abandonou por completo a política de autossuficiência em soja e agressivamente passou a importar mais e mais até os $82 \%$ das necessidades do mercado doméstico em 2013. Já em milho, trigo e arroz, a China alcançou e mantém a autossuficiência desde o ano 2000. A produção e o uso têm sido razoavelmente os mesmos com variações em alguns anos (Gráfico 3 ) que demandaram maior uso dos estoques gigantescos, principalmente até 2006. A produção doméstica de soja estacionou, porém o uso aumentou ao longo de toda década de 2000. Com a crise de 2008, a China voltou a investir no aumento de seu estoque, tanto que desde aquele ano, o aumento na importação de mais de $40 \%$ em soja, se deu quase que exclusivamente para reposição e aumento de estoque. Estoques em outros grãos também aumentaram devido ao aumento da produção doméstica e não por meio de importação (Abbott et al., 2011, p. 15; FAS - UDSA PS\&D, 2013).

Por outro lado, o papel do crescimento econômico da China e da Índia nos mercados de grãos tende a ser exagerado. Abbott et al. (2008) e Headey e Fan (2010) apud Abbott et al. (2011, p. 15) argumentam que políticas comerciais motivadas pela busca da autossuficiência de Índia e China têm efeitos limitados (limited spillover) nos mercados internacionais. Políticas de autossuficiência desconectam preços domésticos de grãos dos preços internacionais de uma correlação direta embora influenciem as perspectivas produtivas de longo prazo (Timmer, 2008; Abbott, 2011). 
Conforme apontado, a exceção é o mercado de soja que tem sido orientado por uma política completamente diferente. Tantos as políticas de petróleo quanto de soja têm sido marcadas por crescente abertura. Para os autores, o aumento nas importações refletem um mercado mais aberto, enquanto o aumento nos estoques refletem um governo ativo, preocupado com a oferta de alimento (Abbott et al., 2011:15; Macedo et al., 2011).

Catalizador 5: Fatores macroeconômicos

Primeiramente, o óbvio: o ambiente internacional macroeconômico influência os preços das commodities agrícolas. Uma série de eventos macroeconômicos, entre os quais, as crises de dívida de países europeus, têm influenciado a taxa de câmbio do dólar e resultado em movimentos pendulares desde a crise de 2008. O dólar mais fraco do período imediatamente anterior à crise da dívida europeia (2009- ) faz parte do conjunto de variáveis macroeconômicas que explicam os altos preços agrícolas internacionais em dólares em 2008 (Lane, 2012). A questão que se apresenta é que variações cambiais que afetam os agentes mais importantes do mercado, necessariamente afetam os preços de mercado (Abbott et al., 2011).

Além das variações cambiais, o crescimento econômico e as expectativas de crescimento econômico podem influenciar o câmbio e os preços das commodities. Assim sendo, o dólar fraco pode ser uma das causas de preços agrícolas altos, e também pode ser um sintoma de forças macroeconômicas globais mais amplas que influenciam estes preços (Abbott et al., 2011, p. 17; Herrmann, 2009).

\subsubsection{Desempenho macroeconômico e booms de commodities}

As variáveis macroeconômicas são o contexto no qual os fatores de oferta/utilização que determinam a segurança alimentar e nutricional ocorrem. Taxas de câmbio, ciclos de negócio (crescimento econômico), taxas de juros e expectativas inflacionárias estão entre os fenômenos macroeconômicos mais importantes que influenciam os preços internacionais de commodities. Abbott, Hurt e Tyner (2011), listam três questões relacionadas ao contexto macroeconômico de segurança alimentar:

1. O papel da recessão e da crise financeira como catalizadores do fim do boom de commodities anterior (2003-2008);

2. O papel e a explicação por trás dos preços agrícolas terem ultrapassado as flutuações cambiais, isto é, terem excedido o preço esperado mesmo levando em consideração a taxa de câmbio; e 
3. O papel da especulação como um fator por trás de aumentos de preço de commodities passados e atuais. (Abbott et al., 2011, p. 17).

Tanto o crescimento econômico quanto as expectativas inflacionárias contribuem para o aumento dos preços de commodities nos mercados internacionais. O crescimento econômico gera pressão de demanda. Esta pressão seria menor para commodities que têm baixa elasticidade de renda de demanda como os alimentos. O que se observa nos mercados internacionais a partir de 2011 pode ser uma mudança de preços relativos reais e não inflação, caso estejam sendo causados por pressão de demanda. A hipótese é plausível já que a população continua a crescer e a classe média do mundo em desenvolvimento também. A recessão de 2008-2009 em países de renda média e baixa não foi profunda nem prolongada, especialmente nos dois países - China e Índia - que respondem por parte relevante da demanda naqueles cereais em que não são autossuficientes. A renda crescente e maior capacidade de resposta ao crescimento econômico com aumento de consumo e importação de alimentos e ração animal continuarão a contribuir para maior demanda agrícola global e a exercer pressão sobre os preços de commodities alimentícias (Trostle et al., 2011, p. 10).

\subsection{RECESSÃO E CRISE FINANCEIRA}

Preços mais altos, conforme discutido anteriormente, não é um fator que limita a importação de commodities agrícolas. Por outro lado, recessões e crises financeiras resultam em fortes quedas conforme foi verificado em 2008 e 2010 (Gobbée, 2008; Abbott, 2009; Trostle et al., 2011).

O crescimento econômico global que se estendeu de 2001 a 2008 foi interrompido no segundo semestre do mesmo ano. Em sete anos a economia mundial havia crescido em média 2,9 por cento e repentinamente em 2009 cresceu abaixo de um por cento, tendo se recuperado parcialmente em 2010. No mesmo ano houve crescimento econômico razoavelmente forte nas economias de renda média e baixa, especialmente nas economias com participação maior de indústrias intensivas em energia. Este crescimento acarretou em demanda maior por energia e o resultado foi o aumento nos preços do petróleo cru, que tem peso substancial nos preços das commodities agrícolas (Trostle et al., 2011, p. 10-11).

Em abril de 2011, os preços do petróleo se encontravam cerca de 3 vezes acima do ponto mais baixo de 2008 (dezembro 2008), conforme Gráfico 5 e ainda abaixo do pico do mesmo ano. Estes preços começaram a afetar o preço do frete oceânico global que por sua vez passou a afetar o preço dos alimentos importados. Segundo Trostle et al. (2011), à medida que os preços das commodities agrícolas aumentavam até o pico de 2008, os preços de carga seca não fracionada aumentaram ainda mais rapidamente, chegando a 
mais de 350 por cento entre janeiro de 2006 e novembro de 2007, como pode ser visto na Gráfico 6.

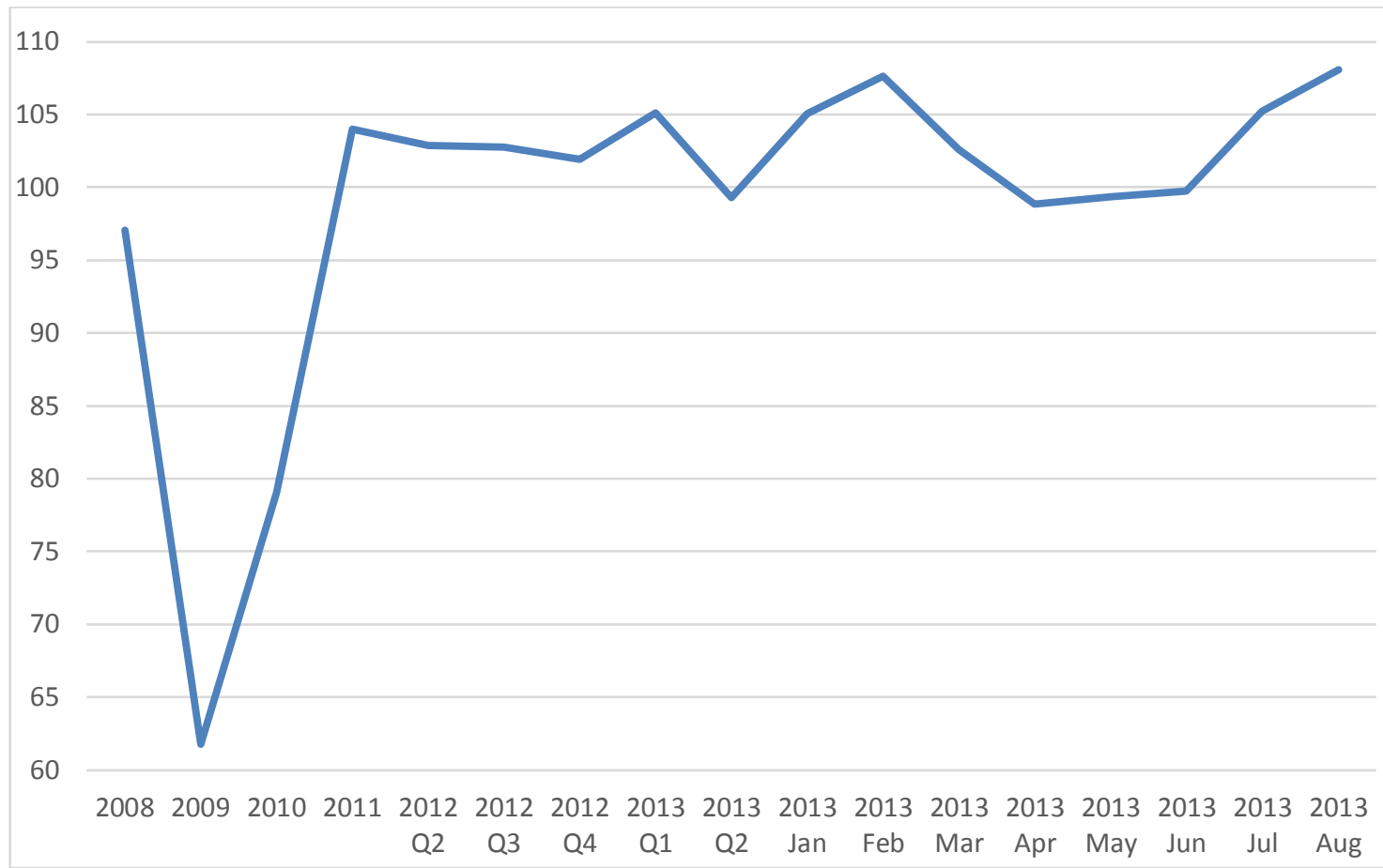

Gráfico 5 - Preço médio do barril de petróleo cru em dólares americanos (USD)

Fonte: Fundo Monetário Internacional, 2013. Disponível em: <http://imfstatext.imf.org/>. Acesso: 12/10/2013. Elaborado pelo autor a partir dos dados indicados.

Os preços altos do petróleo, o aumento da demanda por serviços de transporte transoceânico e o aumento lento na disponibilidade de novos navios de carga seca foram os fatores mais relevantes para o aumento do custo do frete oceânico. O verso da moeda ocorreu nos meses seguintes, quando ao final do ano de 2008, a queda no preço do petróleo, da demanda reduzida associada à recessão e com o aumento no número de embarcações disponíveis se combinaram para levar o preço do frete a valores 90 por cento mais baixos, conforme Gráfico 6 (Trostle et al., 2011). 


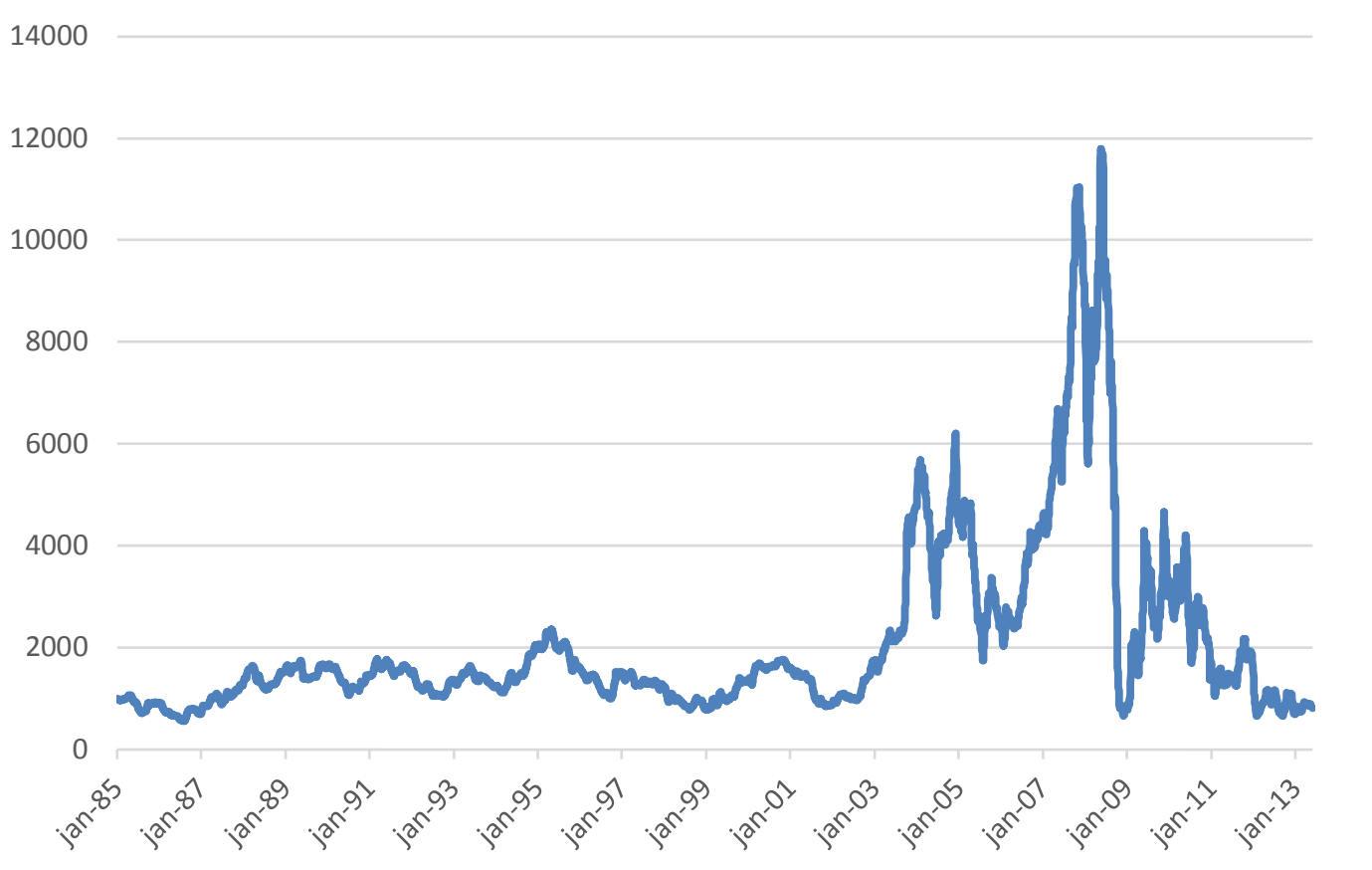

Gráfico 6 - Baltic Dry Index - Frete transoceânico 1985-2013

Fonte: Capital Link Marine Transportation. Disponível em: <http://marine-

transportation.capitallink.com/indices/baltic_exchange_history.html?ticker=BDI\&date_r=1yr\&c=1\&s=BDI>.

Acesso: 12/10/2013. Elaborado pelo autor a partir dos dados indicados.

\subsubsection{Especulação}

No sentido lato, toda forma de investimento é especulativa. A especulação comercial, entre compradores e vendedores de commodities tem origem nos primórdios da humanidade. Na era contemporânea, passou a ser organizada em um mercado de commodities desde o século 19 e cresceu exponencialmente com a abertura da Chicago Board of Trade em 1848. A especulação consiste em um conjunto de operações comerciais (ou financeiras) cujo propósito é obter um ganho financeiro baseado nas flutuações de preço. O objetivo inicial de comerciantes de commodities e processadores era se proteger contra a volatilidade de preços de curto prazo, isto é, uma forma de seguro. Os compradores se protegem contra aumentos repentinos de preço, enquanto vendedores se protegem contra quedas repentinas de preço (Suppan, 2008, p. 2).

Quando o investidor se compromete apenas com o movimento de capital e não tem qualquer envolvimento com o artigo físico, trata-se de especulação financeira. A especulação não comercial procura se beneficiar por antecipar-se ao aumento de preços (betting long) ou à baixa de preços (short). Os especuladores não comerciais fornecem o capital que permite o funcionar do mercado quando os especuladores comerciais liquidam suas posições contratuais pagando pelo commodity no contrato ou vendendo o contrato para compensar o risco de outras posições contratuais que o investidor detém (Suppan, 2008, p. 4; Vargas \& Chantry, 2011). 
Vargas e Chantry (2011) identificam três tipos de especulação no setor de commodities agrícolas:

1) Armazenamento direto (direct hoarding): a forma mais antiga consiste em armazenar e manter o produto fora do mercado na expectativa do aumento do preço. Corretores e grandes empresas ocasionalmente se valem do armazenamento direto;

2) Especulação em mercados futuros: trata-se da compra e venda de contratos futuros na expectativa de lucrar em ambas as transações, independente da efetuação dos contratos;

3) Produtos financeiros complexos e multi nivelados: a forma mais complexa que mescla diferentes produtos financeiros baseados em um ativo subjacente, taxas de referência ou índices de commodities que reúnem cestas de produtos e em geral são operados por fundos de pensão e fundos de derivativos ativos (Hedge Funds).

\subsubsection{0 mercado de futuros agrícolas e os grandes fundos de investimento}

Nos três anos anteriores à crise de 2008, o mercado de futuros agrícolas passou a interessar crescentemente grandes fundos de investimento. Durante esse período, a parcela de contratos futuros de posse de fundos de investimento dobrou. Os investidores estavam interessados em diversificar suas posições e portfólios - diversidade de classes de aplicações - e não nas commodities agrícolas específicas. Os investidores estavam "comprados" nos mercados financeiros e não estavam hedging commodities físicas, como fariam hedgers agrícolas comerciais. Novamente, em 2010-11, o mesmo cenário se repetiu crescente envolvimento não comercial no mercado de futuros agrícolas em posições longas, isto é, contratos de compra, nas mãos de investidores não comerciais (Trostle et al., 2011, p. 23).

\subsubsection{Conexão entre especulação e preços dos produtos físicos}

Na contramão do mainstream, Vargas e Chantry (2011), afirmam que os preços dos mercados físicos seguem os preços dos contratos futuros. De acordo com os autores, quando o preço de um contrato futuro de um produto básico sobe, o preço que o produto supostamente terá no futuro sobe na sequência. Esta situação resultaria em um aumento real de preços correntes do produto. Deste modo, as variações de preço nos mercados futuros influenciariam as variações de preço dos produtos referenciados nos contratos (Vargas \& Chantry, 2011, p. 12). 
Não há, no entanto, na literatura especializada ampla aceitação da posição dos autores pela escassez de evidências claras sobre os efeitos da especulação nos preços dos produtos agrícolas, reunidos no Índice de preços de commodities do FMI, Gráfico 7. No verso do argumento, uma compilação de estudos sobre a questão, concluiu que há esparsas evidências de que os especuladores não comerciais teriam contribuído de forma significativa para o aumento de preços, especialmente da crise de 2007-08 (Irwin \& Sanders, 2011 apud Trostle et al., 2011).

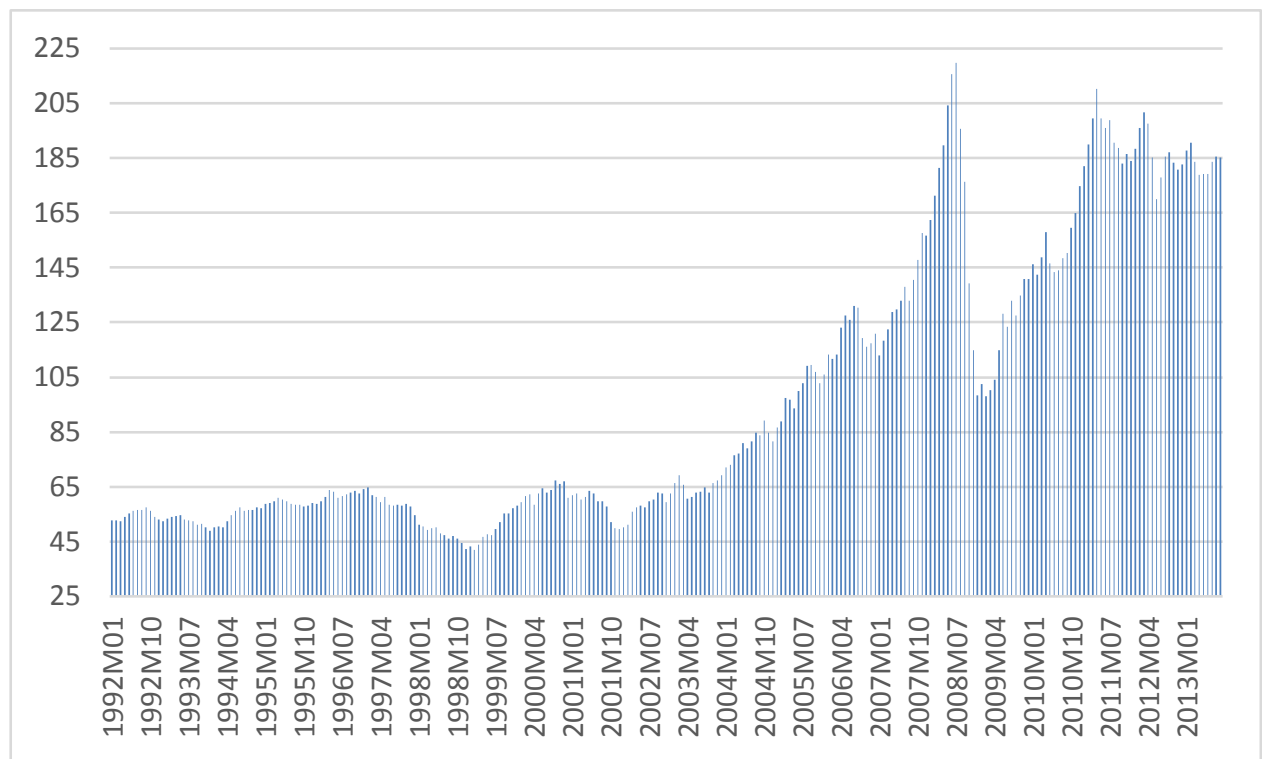

Gráfico 7 - Índice de preços de commodities do FMI (2005=100)

Fonte: FMI. Disponível em: <http://www.imf.org/external/np/res/commod/index.aspx>. Acesso: 15/10/2013. Elaborado pelo autor a partir dos dados indicados.

Há diversos argumentos sobre a questão do envolvimento de especuladores não comerciais. A demanda por contratos futuros como hedges em veículos de aplicação financeira baseados em commodities teria contribuído para o aumento de preços dos cereais. Além disso, as expectativas de preço sobre as quais estas aplicações financeiras estavam baseadas estariam fora da realidade quando vistos à luz dos fundamentos de mercado. Uma bolha nos mercados agrícolas, desconectada dos preços de saldos de usooferta reais teria sido o resultado (Abbott et al., 2011).

Não há uma resposta definitiva e a controvérsia continua sobre a importância da especulação e financialização dos mercados de commodity agrícolas como fatores que influenciam os preços crescentes dos alimentos, ao menos entre 2007-08 e 2010-12 (Abbott et al., 2011). As quantias estratosféricas envolvidas incomodam governos e ativistas e convencem alguns de que deve haver sim alguma conexão entre especulação financeira e preços reais. Porém, diversos estudos apontam que tal mecanismo não existe (Irwin \& Sanders, 2010; Wright, 2011 apud Abbott et al., 2011). 
Em todo caso, outros apontam que fundos de investimento que baseiam operações de mercado em tendências e modelos computacionais e matemáticos parecem ter expandido a amplitude das flutuações de curto prazo dos preços agrícolas, além de que fatores macroeconômicos que talvez incluam a especulação possam ter atuado de forma significativa em 2008 (Gilbert, 2010 apud Abbott et al., 2011; Petzel, 2009; Master, 2008 apud Trostle et al., 2011).

Há alguma correlação entre preços mais altos e a presença maior de investidores não comerciais no mercado de commodities mas estas não indicam nenhum efeito causal inequívoco. Quando vistos em séries temporais longas, as mudanças de preço parecem refletir mudanças nos fundamentos de mercado de oferta e demanda. Portanto, os efeitos de investidores não comerciais seria passageiro (Trostle et al., 2011:23).

Irwin (2013) demostra que a literatura especializada não tem encontrado evidências que indiquem que a pressão de compra de investimento de índices de commodities a partir de 2005, principalmente, tenha causado a bolha nos preços futuros agrícolas de 2008 e 2011-2012. Por último, os resultados empíricos de Rezitis e Sassi (2012), indicam que os preços de commodities da cadeia alimentar direta apresentam sazonalidade e ciclicidade, sendo a periocidade mais longa de 2 anos e, portanto, as bolhas seriam em grande apenas reflexos destes fenômenos econômicos.

\subsubsection{Expectativas inflacionárias}

Alguns autores defendem que expectativas inflacionárias por parte de um número relevante de analistas influentes e bancos centrais do G20 econômico parecem contribuir ativamente para o aumento no preço das commodities. ${ }^{20}$ As expectativas são um dos possíveis fatores relacionados tanto ao câmbio quanto ao preço das commodities. Alguns pesquisadores argumentam que as taxas de câmbio capturam os efeitos de forças macroeconômicas mais amplas, inclusive as expectativas inflacionárias (Abbott et al., 2009).

O valor nominal da taxa de câmbio pode refletir investidores com expectativas inflacionárias ou uma política monetária expansiva. O câmbio está correlacionado com outros fatores macroeconômicos como o crescimento econômico mundial, a inflação, as taxas de juros, déficits da conta corrente, dívida pública e o rating da dívida, os termos de comércio exterior e estabilidade política e desempenho econômico (Raddatz, 2011).

Conforme afirmado anteriormente, o crescimento econômico, principalmente de Índia e China, e expectativas inflacionárias parecem ter contribuído para o aumento contínuo dos

20 Trata-se da principal contribuição de Robert Lucas (entre muitos outros) às ciências econômicas, contida em diversos artigos e capítulos de livros, entre os quais, Lucas (1976). 
preços das commodities nos anos 2000. A crença de alguns agentes econômicos mundialmente relevantes de que haveria inflação mais alta no futuro próximo, pode ter representado, nas palavras de Abbott (2011), o bordo de ataque do fenômeno no período seguinte. ${ }^{21}$ Os preços das commodities aumentaram antes dos preços de produtos industrializados, serviços e salários nos estágios iniciais. Isso se deu pela própria natureza dos preços de commodities que tendem a ser mais flexíveis e sensíveis à pressão de demanda advinda do crescimento econômico e inflação (Abbott et al., 2011, p. 17).

Como as taxas de câmbio nominais também refletem expectativas inflacionárias, uma explicação para o dólar mais fraco no primeiro semestre de 2008 quanto em 2011 poderia ter sido a política monetária mais expansionista dos Estados Unidos em relação ao resto do mundo. No entanto, Celasun et al. (2012), afirmam que as variações dos preços das commodities não estavam associadas a uma política monetária expansionista por parte dos Estados Unidos e, sim às expectativas de que autoridades econômicas de diferentes países realizassem um arrocho monetário mais rápido após a crise, especialmente no caso do petróleo - altamente correlacionado ao preço dos alimentos.

\subsubsection{O Impacto da Crise de Preços de Alimentos}

Efeitos negativos

Os efeitos negativos do aumento de preços das commodities agrícolas são sentidos mais intensamente pela parcela de menor poder aquisitivo da população já que:

(1) consumidores de baixa renda gastam uma parcela maior da renda em alimentos;

(2) commodities básicas - milho, trigo e soja - são responsáveis por uma parcela maior das despesas com alimentação em famílias de baixa renda;

(3) consumidores em países de baixa renda e com déficit alimentar são altamente vulneráveis pois dependem da importação de uma fatia considerável dos suprimentos de grãos, comumente adquiridos a preços mais altos; e

(4) países recipientes de doações de alimentos atreladas a orçamentos fixos acabam recebendo uma quantidade menor de alimentos (Trostle et al., 2011, p. 24).

Fatores mitigadores

Há, no entanto, fatores mitigadores destes efeitos negativos no curto prazo:

(1) mesmo países de baixa renda e deficitários na produção de alimentos experimentam anos de produção doméstica alta, safras excepcionalmente boas, tal como

${ }^{21}$ Bordo de ataque se refere à extremidade dianteira da asa de uma aeronave, geralmente arredondada. Dale, C: Dictionary of Aeronautical Terms, 3. ed. Newcastle, Washington: Aviation Supplies \& Academics, 2012. 
ocorrido em 2010, que limitam os efeitos dos preços altos internacionais e seguram os preços domésticos em patamares mais baixos;

(2) o clima é o fator mais importante em países de baixa renda e, portanto, em anos com condições favoráveis para os cultivares preferidos, preços permanecem estáveis ou mesmo sofrem deflação;

(3) Outro fator crucial é a estrutura de transmissão de preços do mercado internacional para o mercado local. Em muitos países de baixa renda a integração com o mercado internacional é mínima. As razões podem ser a combinação de prevalência de agricultura de subsistência e um percentual alto de população rural. Infraestruturas de transporte e armazenagem inadequadas também impedem maior integração, aliadas ao baixo poder aquisitivo;

(4) Subsídios governamentais de segurança alimentar como o "Fome Zero" e o "Bolsa Família" no Brasil são extremamente eficazes em limitar os efeitos de variações positivas de preços internacionais (Hespanhol \& Hespanhol, 2010); e,

(5) Políticas públicas de comércio, preços de alimentos, subsídios agrícolas, barreiras fitossanitárias, políticas de preços máximos e mínimos ao consumidor final e políticas direcionadas ao mercado de alimentos também influenciam em que grau oscilações internacionais são repassadas aos consumidores (Rosen et al., 2011; Trostle et al., 2011; Gouel, 2013; Mittal, 2008).

\section{CONCLUSÃO}

Conforme afirmado no capítulo presente, existe uma complexidade inerente ao contexto macroeconômico de segurança alimentar. Há poucas evidências sobre os efeitos da especulação nos preços agrícolas, e da importância da especulação e da financialização nos mercados agrícolas. Outra questão levantada em que não há evidências inequívocas, é a de que expectativas inflacionárias possam contribuir decisivamente para aumentos generalizados de preços agrícolas.

Mesmo com tantas incertezas, há indicações claras de que entre os fatores da insegurança alimentar, se encontra o sistema discutido neste capítulo. O sistema econômico agrícola internacional interfere sim nos preços, os principais sinalizadores de aumento e diminuição da oferta de alimentos. Os mecanismos desta interferência, no entanto, não são facilmente mapeados e muito menos, entendidos. O que é bastante óbvio é que há uma correlação entre o aumento generalizado dos preços agrícolas e o aumento de insegurança alimentar e pobreza em países em desenvolvimento e desenvolvidos no período discutido. 


\section{CAPÍTULO 4: MENSURANDO UM CONCEITO: INDICADORES DE SEGURANÇA}

\section{ALIMENTAR}

4 MENSURANDO UM CONCEITO: INDICADORES DE SEGURANÇA ALIMENTAR

\section{INTRODUÇÃO}

Políticas públicas, programas e projetos para a segurança alimentar e nutricional requerem dados. Muito embora a mensuração de segurança alimentar tenha caminhado uma longa distância, especialmente nas últimas décadas do século 20 e primeira do século 21, existe ainda lacuna considerável na literatura especializada. Mesmo com o progresso alcançado, as metodologias e métodos mais comumente utilizados, os atuais índices, tabelas e critérios deixam muito a desejar quando comparados com indicadores de outras ciências, inclusive sociais (Clay, 2002).

O capítulo 4 é um levantamento panorâmico do estado da arte em mensuração da segurança alimentar. $\mathrm{O}$ direcionamento de políticas públicas para a segurança alimentar depende de pesquisas censitárias e amostrais que permitam tomadas de decisão. Os dados dessas pesquisas são usados na elaboração de indicadores de situação de segurança alimentar. Os principais tipos de indicadores são avaliados em relação a três características básicas: seletividade, passado (memória) e nível de análise. Além dessas características, a discussão também inclui aquilo que a literatura especializada dispõe sobre as dimensões intertemporais e transversais (cross-sectional), além da relevância nutricional de cada um dos indicadores elencados.

\subsection{INDICADORES DE SEGURANÇA ALIMENTAR PASSIVEIS DE MENSURAÇÃO E COMPARAÇÃO}

A tese de Amartya Sen $(1981,1984)$ - de que a falta de acesso é responsável por grande parte da insegurança alimentar - exemplifica como aquilo que se escolhe mensurar é antes de mais nada uma opção baseada na teoria que se julga mais adequada para a análise. Sen foi grandemente responsável pelo redirecionamento das políticas de segurança alimentar para a demanda e não mais para questões relacionadas à oferta. A partir da proposta do autor, o foco passou para as informações de peso e fome do indivíduo, tendo como consequência o fortalecimento de estratégias de segurança alimentar voltadas para a redução da pobreza, preços de alimentos e políticas de proteção social (Barret, 2010).

De um lado, na maioria dos países em desenvolvimento permanece um desafio reunir vontade política e recursos financeiros e humanos especializados para coletar, processar e analisar informações sobre segurança alimentar e nutricional. Em países como Índia e Brasil, em que recursos estão disponíveis, políticas de segurança alimentar estão 
intimamente ligadas às flutuações na agenda eleitoral da democracia, tendem a afetar resultados e por isso são alvo de cobiça e manipulação política. De outro, aqueles que idealizam, constroem, articulam e normatizam políticas de segurança alimentar demandam informações confiáveis sobre a situação de segurança alimentar, desde global até distrital e mesmo domiciliar. Do ponto de vista do Estado, das organizações governamentais e intergovernamentais e não governamentais qualquer política, programa e projeto deve ser a melhor dentro de um conjunto de opções que precisa ser simultaneamente politicamente factível e economicamente viável. O modelo de proposta, implantação, monitoramento e avaliação depende de informação confiável. No entanto, a notória dificuldade de obtenção de dados na grande maioria de países em desenvolvimento é uma barreira para políticas eficazes e afetam desde a concepção até a avaliação de todas as políticas de governo, resultando em ações baseadas em estimativas sem base estatística e empírica (Babu \& Sanyal, 2009).

Em políticas públicas, mensuração precede diagnóstico e reação (Barrett, 2010). E, a mensuração correta é essencial mas não suficiente para um diagnóstico correto e resposta adequada (Headey e Ecker, 2012). O policymaker necessita entender o contexto e as dimensões demográficas, temporais e espaciais de insegurança alimentar no país e os caminhos pelo qual a mesma alimenta a subnutrição. No contexto nacional, o operador de políticas precisa também compreender e saber quais regiões são mais fortemente afetadas pela insegurança alimentar. A sazonalidade e os choques que resultam em insegurança alimentar e de meios de subsistência (livelihoods), tais como secas, enchentes, choques de preço, quedas bruscas de renda, e como estes afetam os meios de vida e a segurança alimentar da população também fazem parte dos conhecimentos imprescindíveis. Outrossim, o policymaker precisa estudar as dimensões demográficas da insegurança alimentar, tais como as variações que advêm de fatores idiossincráticos relacionados à vulnerabilidade infantil, às diferenças etárias da infância, às diferenças entre adultos homens e mulheres, às mulheres grávidas e que estejam amamentando, entre outras variações demográficas. Atrelado as dimensões demográficas, estão as dimensões epidemiológicas que fazem a ligação entre a ingestão de alimentos e os resultados nutricionais (Headey \& Ecker, 2012). ${ }^{22}$

\footnotetext{
22 "A epidemiologia é o campo da ciência médica preocupado com o inter-relacionamento de vários fatores e condições que determinam a frequência e a distribuição de um processo infeccioso, uma doença ou um estado fisiológico em uma comunidade humana" (MAXCY, \& ROSENAU, 1951, p. 9). "A epidemiologia é o estudo da distribuição e dos determinantes da saúde das populações humanas". (MORRIS,1975, p. 17). A epidemiologia estuda a ocorrência, a distribuição e também os fatores na população que são determinantes de eventos relacionados com a saúde. (Rouquayrol \& Almeida Filho, 2003).
} 


\subsection{DIRECIONAMENTO DE POLÍTICAS DE SEGURANÇA ALIMENTAR (TARGETING)}

Uma parte relevante de políticas públicas depende da identificação correta dos beneficiários de programas e projetos que delas resultam, como será visto no caso da Índia na terceira parte deste trabalho de tese. Barrett (2010) chega a afirmar que o fator mais importante na determinação da eficácia de intervenções de segurança alimentar é a qualidade da identificação dos alvos da política. Existem grandes dificuldades para a identificação de beneficiários pois frequentemente, os mais necessitados são vítimas de discriminação e segregação social e raramente tomam a iniciativa de demandar inclusão, que é o caso indiano.

Situações de insegurança alimentar temporárias, comumente associadas a desastres naturais, ou conflitos armados de curta duração, pela própria dimensão temporal, raramente demandam esforços de identificação de necessitados e necessidades mais apurados. Por outro lado, situações de insegurança alimentar estrutural e/ ou crônica exigem identificação e monitoração continuado de necessitados e necessidades, caso contrário políticas são idealizadas a partir de uma compreensão falsa da realidade de segurança alimentar a ser atendida e os mais necessitados não entram no rol de beneficiados (Barrett, 2010). Esta é a situação vivida pelo Sistema Público Direcionado de Distribuição de Alimentos (TPDS - sigla em inglês) na Índia. A insegurança é crônica, de fundo estrutural. No entanto, pouco é investido em identificação e monitoramento, ocasionando uma cultura de fraude institucionalizada.

A correta identificação de beneficiados em potencial de políticas públicas de segurança alimentar e a identificação da forma ótima de assistência se baseiam em, por exemplo:

i. Um conjunto de indicadores geográficos, características observáveis individuais e de família, restrições e regras de cada programa que demandam a auto seleção, por exemplo, a necessidade de declarar ter filhos em idade escolar ou não;

ii. Trade-offs, isto é, compensações e trocas entre período de tempo de aplicação da política, eficácia versus eficiência, custo e triangulação de indicadores, tendo o tempo e recursos disponíveis e níveis de agregação (de beneficiados, de idade, entre outros) como pontos de partida. (Barrett, 2010, p. 827)

Programas de alimentação e distribuição de alimento são essenciais em emergências e em determinados grupos etários isolados (crianças e idosos), porém, conclui Barrett (2010), os maiores avanços em segurança alimentar e nutricional se dão por meio de programas indiretos como programas de redução de pobreza por meio da criação de emprego, programas de aumento da produtividade de pequenos fazendeiros, além de redes 
de proteção socioeconômica de grupos que se encontram pouco acima da linha de pobreza. De acordo com o autor, melhor e maior controle dos bens de produção e acesso a tecnologias e mercados para o uso sustentável desses para a geração de meios de subsistência (livelihoods) estáveis são especialmente cruciais para a redução da vulnerabilidade à insegurança alimentar e para catalisar a quebra de ciclos de pobreza. Essa conclusão é a base de diversos programas de segurança alimentar embasados no fortalecimento de meios de subsistência sustentáveis que parecem ser os mais recomendados para situações de insegurança alimentar estrutural.

\subsection{A FOME, A NUTRIÇÃO E A SEGURANÇA ALIMENTAR NO CONTEXTO DOS INDICADORES}

Conforme visto anteriormente, não há consenso sobre o que deve ser medido para a determinação da segurança alimentar. No âmago da questão, estão as definições operacionais de "fome", a sensação humana à volta da qual o conceito de segurança alimentar revolve. ${ }^{23} \mathrm{~A}$ tensão entre cientistas sociais e biomédicos quanto à abordagem correta em relação à segurança alimentar e nutricional gera atritos. Em geral, cientistas sociais tratam a nutrição como variável dependente e que deve ser analisada como tal. Esta variável deve ser estudada e analisada em sua relação com outras variáveis e no contexto de condições políticas, socioculturais e econômicas, sendo a nutrição uma resultante destes. No caso dos cientistas biomédicos, em geral, a nutrição é estudada como um conjunto de variáveis independentes e dependentes (veja Figura 12). Tão importante quanto, é o fato que estes cientistas, mormente, analisam a nutrição a partir do laboratório, do ponto de vista micro, chegando ao nível celular e sub-celular. Isso os difere dos cientistas sociais que por definição, estudam o nível da sociedade, o nível macro e até o nível do indivíduo (Field, 2002; Drèze \& Sen, 1989).

A incorporação do termo "nutricional" à definição de segurança alimentar gerou novas possibilidades de cooperação entre as diferentes áreas, especialmente com o crescimento de programas de pós-graduação e pesquisa inter e multidisciplinares. ${ }^{24}$ Programas de pesquisa em segurança alimentar e nutricional começaram a ser encorajados a serem "nutrition sensitive". Especialmente a partir dos anos 2000, a FAO, especificamente a Divisão de Proteção ao Consumidor e Nutrição passou a ativamente encorajar o uso do

\footnotetext{
${ }^{23}$ A definição operacional define algo - variáveis, termos ou objetos - em termos do processo específico ou conjunto de testes de validação usados pra determinar sua presença e quantidade, isto é, a definição em termos das operações que contam como medida daquilo que é definido (Boyd, 2002).

${ }_{24}$ Neste trabalho de tese, a não ser que indicado, os termos 'segurança alimentar e nutricional' e 'segurança alimentar' são usados indiscriminadamente.
} 
termo "food and nutrition security" (Thompson et al., 2009). ${ }^{25}$ No entanto, há poucos avanços na pesquisa sobre como a mensuração de segurança alimentar pode captar a questão da nutrição (Nubé, 2003; Heady \& Ecker, 2012; Hoddinott \& Yohannes, 2002). ${ }^{26}$

${ }^{25} \mathrm{Na}$ língua portuguesa, as traduções do termo "food security and nutrition" anteriormente utilizado e o termo atual "food and nutrition security" não fazem jus à mudança implícita nos termos em inglês.

${ }^{26}$ Field (2002), por exemplo, defende o uso da desnutrição energético-proteica - DEP (sigla em inglês) por sua base empírica e definição operacional amplamente aceita nas ciências da saúde. 


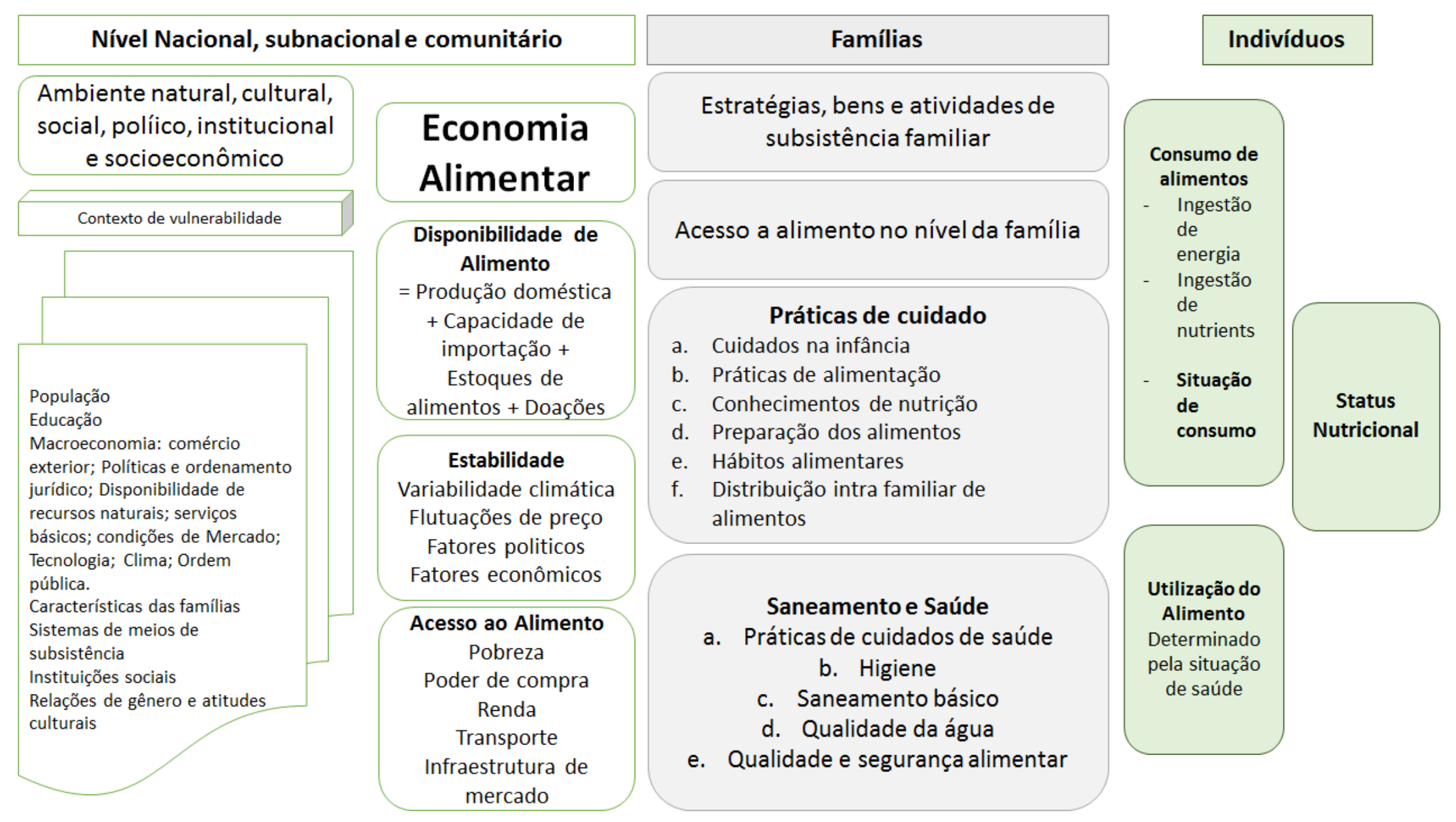

Figura 12: Arcabouço da metodologia FAO/FIVIMS.

Fonte: Thompson et al., 2009. Adaptação e elaboração do autor. 


\subsection{INDICADORES: CARACTERÍSTICAS E PRINCIPAIS TIPOS}

As considerações da subseção 4.3 levam ao reconhecimento das múltiplas dimensões da segurança alimentar e nutricional e a complexidade requerida de indicadores do fenômeno. Há três características básicas de indicadores que devem ser levadas em consideração:

i. Seletividade: todo indicador capta e necessariamente negligencia diferentes fenômenos inerentes ao conceito de segurança alimentar. Essa seletividade acaba por influenciar, às vezes sutilmente, outras fortemente, os diferentes pilares de segurança alimentar - disponibilidade, acesso, utilização e estabilidade - que são enfocados e priorizados nas políticas, programas e projetos de segurança alimentar;

ii. Passado (memória): um indicador ideal deveria fazer jus ao nome, isto é, indicar a série de tempo de probabilidades que satisfaça o critério de acesso. No entanto, a informação de observação coletada é sempre relacionada ao passado. Até o final de 2014 há pouca pesquisa estatística sobre o grau de confiabilidade de previsão dos indicadores de segurança alimentar existentes. No caso de agências governamentais e não governamentais Ihes interessa o efeito futuro provável de políticas, programas e projetos, daí a importância do indicador mais próximo do ideal; ${ }^{27}$

iii. Nível de análise: indicadores em nível nacional, em geral, são válidos apenas para questões de segurança alimentar e nutricional em nível nacional. Não se prestam, por exemplo, a questões regionais. Além disso, na medida que a demanda por indicadores se dá pela necessidade de guiar ações, os indicadores em si apenas são úteis se puderem ser relacionados a fatores de vulnerabilidade domiciliar e/ou individual que possam ser mitigados a partir de políticas públicas (Barrett, 2010; Bertalanffy, 1976).

Além das características acima citadas, indicadores de segurança alimentar devem ser submetidos a testes de validade no que diz respeito às dimensões intertemporal e transversal (cross-sectional) e de relevância nutricional. Em outras palavras, os indicadores devem fornecer informações válidas e confiáveis sobre diferenças verdadeiras entre diferentes estados: indivíduos, grupos, países e intervalos temporais, além de informar corretamente e conclusivamente sobre a participação ou responsabilidade da insegurança alimentar para a subnutrição.

A validade em si, refere-se a quanto um conceito, conclusão ou medida se encontra bem fundamentado na teoria e o quão precisamente corresponde ao mundo real. A confiabilidade é o atributo consistência do indicador, o grau ao qual uma ferramenta de avaliação gera resultados consistentes e estáveis. Por exemplo, quando submetido ao teste

\footnotetext{
${ }^{27}$ Indicadores para o futuro são simulações com base em cenários.
} 
de confiabilidade teste-resteste (test-retest reliability) ${ }^{28}$, as diferenças entre o primeiro teste e o segundo teste são correlacionadas e avalia-se a estabilidade dos resultados (Headey \& Ecker, 2012).

Quantificar a insegurança alimentar e a subnutrição é tarefa intricada pois os dois fenômenos envolvem fatores complexos e inter-relacionados conforme visto na parte I e não existe um padrão universalmente aceito. Os principais tipos de indicadores de segurança alimentar são:

i. Indicadores de restrição calórica;

ii. Indicadores de pobreza monetária;

iii. Indicadores de diversidade da dieta;

iv. Indicadores experimentais e/ ou subjetivos.

A subseção que segue elenca exemplos dos tipos de indicadores listados acima não é exaustiva, mas dá uma visão geral do estado da arte.

\subsubsection{Indicadores de restrição calórica: Indicador de subalimentação ou disponibilidade de calorias da FAO}

Um dos mais antigos indicadores de insegurança alimentar busca mensurar a disponibilidade ou insuficiência de calorias, também conhecido em português como "Indicador de subalimentação" ou simplesmente, "método da FAO". Em relação ao debate sobre indicadores de segurança alimentar e subnutrição, a metodologia da FAO assume a nutrição como um fenômeno social e demográfico de ingestão de alimentos. Este fenômeno é medido por meio da quantidade de energia da dieta, já que a correlação entre a energia consumida na dieta e a qualidade da dieta é relevante, conforme discutido anteriormente no capítulo primeiro (Cafiero \& Gennari, 2011).

O indicador - de periodicidade anual - é definido pela Organização das Nações Unidas para Alimentação e Agricultura (FAO) como a medida da oferta de alimento para consumo humano disponível por pessoa durante o período de referência em termos de quantidade, valor calórico e conteúdo de proteína e gordura (FAO, 2002). ${ }^{29}$ O suprimento ou oferta em termos de peso do produto são derivados da oferta total disponível para consumo humano, isto é, o alimento disponível, dividido pela população total do período que é beneficiada pela oferta dentro das fronteiras geográficas de um dado país - exclusive de cidadãos no exterior e inclusive de estrangeiros residentes. Os valores per capita

\footnotetext{
${ }^{28}$ Confiabilidade teste-resteste é obtida através da mensuração repetida com o mesmo respondente ou grupo de respondentes usando o mesmo instrumento de mensuração e sob condições semelhantes. Os resultados são comparados para determinar o nível de semelhança. Se forem semelhantes, tradicionalmente medidos por um coeficiente de correlação, dizemos que têm alta confiabilidade teste-reteste (Yu, 2005).

${ }^{29} \mathrm{~A}$ unidade de calorias continua sendo usada, segundo a FAO (2002), até que o quilojoule (kJ) tenha maior aceitação e compreensão, sendo que 1 caloria corresponde a 4,19 quilojoule.
} 
representam a média de oferta de alimentos disponível para a população como um todo e, obviamente, não aquilo que é de fato consumido. Os dados do indicador são derivados de tabelas que estimam a disponibilidade nacional de alimentos, por meio de pesquisas amostrais. A disponibilidade é calculada da produção, mais as importações líquidas, menos armazenamento e desperdício registrados em planilhas. Os dados são distribuídos com base em pesquisas domiciliares e estimativas das necessidades demograficamente ajustadas (Headey \& Ecker, 2012).

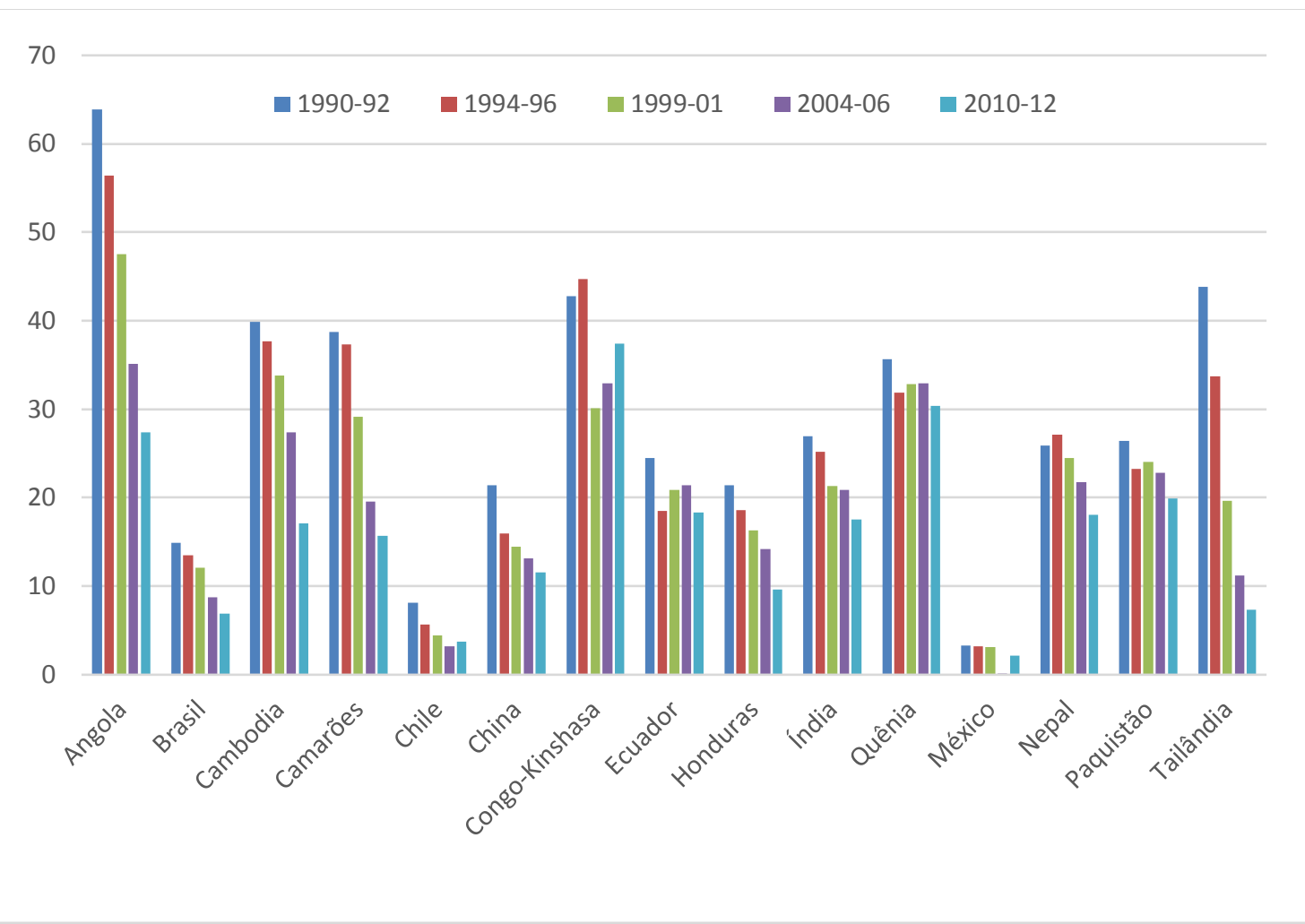

Gráfico 8 - Prevalência de desnutrição - metodologia FAO, 1990-2012.

Fonte: FAO, 2013. Elaboração do autor. Baseado em Roser, 2014.

Resumindo, o indicador da FAO estima a prevalência de desnutrição, como pode ser visto na Gráfico 8, para o período 1990-2012. Para o indicador da FAO, a desnutrição é definida como a proporção da população de um determinado país que usufrui de um nível de consumo de energia dietética (Dietary Energy Consumption - DEC em inglês) abaixo da Necessidade de Energia Dietética (Dietary Energy Requirements - DER) estipulada pela FAO (Mernies, 2004; FAO, 2008). O Indicador de subalimentação ou disponibilidade de calorias da FAO é um indicador de fome crônica, isto é, captura a evolução de fatores fundamentais que direcionam a situação nutricional de longo prazo e por isso não se presta a medição de fatores contingentes. 
O indicador é, portanto, uma medida da fome crônica pelo fato de se basear em medidas antropométricas (peso e altura) e está direcionado para a captura de elementos fundamentais da evolução de longo prazo das condições de nutrição de um país. E, por basear-se na média per capita anual de consumo de alimento, fenômenos como crises sazonais, crises de preços de curta duração estão fora do escopo do indicador (Cafiero \& Gennari, 2011). Outro ponto a ser considerado, é que esses dados não revelam, por exemplo, a má alimentação ou maus hábitos alimentares e suas consequências como a obesidade, que pode ser o caso do México no Gráfico 8, que aparenta se encontrar em situação excelente.

Da validade transversal (cross-sectional validity)

Headey e Ecker (2012) afirmam que as inúmeras suposições embutidas no indicador debilitam sua validade transversal. Dados de pesquisas domiciliares de consumo de alimentos estão no cerne do indicador e em princípio podem ser usados para medir a proporção da população que dispõe de quantidades inadequadas de calorias. No entanto, há dúvidas quanto ao uso das pesquisas de forma agregada já que há erros de medição consideráveis advindos de fontes não confiáveis, dados de desperdício e armazenagem incompletos, vieses, erros de registro e de escolha do instrumento de coleta (OECD, 2013; Beegle et al., 2012 apud Headey \& Ecker, 2012; Smith \& Subandoro, 2007).

Outro problema que constantemente compromete pesquisas domiciliares de consumo de alimentos é a própria maneira de consumo de alimentos no domicílio contemporâneo em transição: o consumo de alimentos fora de casa, o desperdício e o armazenamento, visitas, consumidores domésticos que por definição não fazem parte do domicílio, por exemplo, empregados temporários e a repartição com animais de alimentos para consumo humano que podem fortemente influenciar e até mesmo invalidar os dados obtidos (Fuwa, 2005). Do ponto de vista da validade transversal, o maior comprometimento da validade transversal do indicador da FAO é a distribuição de calorias na população simulada a partir de dados de renda ou de gastos e não observada diretamente. Outro fator limitador da validade transversal é a impossibilidade de se extrair estimativas para grupos subnacionais (Headey e Ecker, 2012).

Relevância nutricional

A relevância nutricional do indicador da FAO é limitada por não medir consumo de calorias no nível do indivíduo. O consumo de calorias no nível do domicílio não é indicador de segurança alimentar individual confiável pelo fato de que a distribuição de calorias no domicílio ser influenciada por fatores subjetivos, como o complexo de valores socioculturais 
(Fuwa et al., 2006). Há pesquisas que até mesmo defendem que a correlação entre deficiência calórica e indicadores antropométricos de desnutrição é estatisticamente irrelevante ou inexistente (Deaton \& Drèze, 2009; Pelletier et al., 1995).

Validade intertemporal

Não há evidências estatísticas suficientes de que a deficiência de calorias seja um indicador confiável e válido de tendências, impacto de choques e sazonalidade de segurança alimentar. Pesquisas indicam que há um crescente descolamento, por exemplo, dos números de deficiência de calorias com os de crescimento econômico (Ecker et al., 2011). Embora haja crescente disponibilidade de calorias em países como Índia e China, pesquisas baseadas em amostras indicam queda no consumo de calorias mesmo com a redução da pobreza monetária e crescimento econômico, especialmente na Índia (Deaton \& Drèze, 2009).

Disponibilidade de calorias não é um bom indicador de tendências em segurança alimentar devido à baixa elasticidade de alimentos básicos em relação à renda e demanda mesmo na Índia e China. Em geral, pessoas que passam de um nível de renda mais baixo para um superior tendem a mudar o conjunto de alimentos mais caros, mantendo os alimentos básicos (embora diminuindo a quantidade consumida), ao invés de maximizar o consumo total de calorias (Jensen \& Miller, 2010).

No caso da Índia, o aumento dos percentuais de desnutrição desde a segunda metade dos anos 1980 ocorreu na contramão do crescimento econômico significativo principalmente a partir de 1990. Aparentemente, a principal causa da discrepância se deu pela coleta incompleta de informações sobre o consumo de alimentos, especialmente fora do domicílio pela Pesquisa de Consumo e Despesas das famílias (Household Consumption and Expenditure Surveys - HCESs). Um outro fator que pode ter influenciado, é a migração do campo para a cidade, a urbanização e subsequente demanda por alimentos daqueles que deixaram de produzir e passaram a demandar alimentos no mercado. O resultado foi o baixo nível de confiança que os dados sobre desnutrição e pobreza desfrutam no país (Smith, 2013). Outras possibilidades para a causa da discrepância é o gasto energético fisiológico reduzido devido a melhoras de infraestrutura e mecanização, além de menores perdas de energia devido a avanços na saúde pública (Headey \& Ecker, 2012; Deaton \& Drèze, 2009).

Jensen e Miller (2010) argumentam que quando os mais pobres sofrem perda de renda, a reação é a mudança de fontes ricas em proteína como carne para fontes de baixo valor calórico, por exemplo, arroz. No entanto, em um país como a Índia onde perto de 50\% do população é vegetariana e consome principalmente arroz e trigo, essa mudança não é possível. Mesmo assim, admite-se que o total de gasto domiciliar com alimentação caia 
quando há perda de renda, embora o consumo de calorias não se reduza na mesma proporção. Além disso, no caso da população rural, os alimentos produzidos para subsistência tendem a substituir parcialmente alimentos comprados. Dado este quadro, a disponibilidade de calorias parece não ser um bom indicador de segurança alimentar (Haen et al., 2011).

\section{Críticas e a defesa da FAO}

As críticas ao indicador da FAO estão concentradas em três grupos: a) em torno da definição operacional de fome; b) da solidez da abordagem metodológica sobre a qual a estimativa é obtida; e, c) da fiabilidade dos dados elementares que são utilizados para a construção da estimativa. Para os especialistas da FAO responsáveis pelo indicador, o criticismo ao indicador é muito mais direcionado às inadequações do indicador em relação a objetivos analíticos não intencionados pelos idealizadores do indicador do que por questões fundamentais como confiança das estimativas e viabilidade prática (Cafiero \& Gennari, 2011). A discussão sobre a validade dos procedimentos estatísticos do indicador estão fora do escopo deste trabalho de tese, no entanto, um resumo pode ser encontrado no Anexo B deste trabalho de tese.

\subsubsection{Indicadores de pobreza monetária}

Indicadores de pobreza monetária são indicadores indiretos do direito ao acesso a alimento. O padrão de pobreza do Banco Mundial é de USD1,25/dia por pessoa (Chen \& Ravallion, 2008). ${ }^{30} \mathrm{O}$ uso de indicadores de pobreza monetária em segurança alimentar parte da lógica de substituição potencial entre a demanda por bens alimentícios versus a demanda por bens não alimentícios. Alguns pesquisadores, especialmente economistas, preferem indicadores de pobreza monetária ao invés de indicadores de calorias, já que preços mais altos de alimentos, conforme visto na discussão anterior, não necessariamente reduzem o consumo de calorias, no entanto, reduzem significativamente despesas com produtos não alimentícios. ${ }^{31}$ Há também o vínculo empírico que o próprio cálculo das linhas

\footnotetext{
30 Para uma discussão sobre os valores e índices de medidas monetárias de pobreza, veja Chen \& Ravallion, 2008, além de Deaton, 2010.

31 Harvey [1973] (2009), desenvolve um conceito que remete aos indicadores de pobreza monetária. Renda monetária seria o que o indivíduo ganha em dinheiro. Existe também a renda real, que é o que este de fato dispõe, independente de ser monetizado. Por exemplo, um morador urbano que dispõe de assistência médica e seus filhos na escola, tende a ter renda real acima da monetária. Em contrapartida, se este mesmo indivíduo gastar, em relação à sua renda, muito tempo e dinheiro com deslocamento para e do seu trabalho, sua renda real será menor do que a monetária. No caso da segurança alimentar e nutricional, por exemplo, agricultores que dispõe de terra e recursos e que cultivam para o auto-consumo detêm o potencial para ter uma renda real maior. Porém, quando migram para a cidade, essa renda não monetária se perde. Se a família é incluída em um programa de segurança alimentar de alimentos em espécie, a renda real da família aumenta, enquanto a monetária não muda. Se, no entanto, for um programa de transferência de renda em dinheiro condicionada
} 
de pobreza absoluta com as necessidades de consumo mínimo de calorias potencialmente produz (Headey \& Ecker, 2012).

Linhas separam, assim sendo, linhas de pobreza são pontos de corte que, teoricamente, separam "pobres" de "não pobres". Em geral, a medida da pobreza está baseada na comparação entre recursos e necessidades. Uma pessoa ou família é identificada como pobre quando seus recursos ficam abaixo do limiar de pobreza. As linhas podem ser monetárias, tais como níveis de consumo, ou não monetárias, tais como níveis de educação formal. Em geral, usam-se linhas de pobreza relativa e linhas de pobreza absoluta (Foster, 1998).

Linhas de pobreza relativa são definidas em relação à distribuição geral de renda ou consumo em um país. Por exemplo, a linha de pobreza pode ser estabelecida em $40 \%$ da renda média ou consumo médio do país. Já linhas de pobreza absoluta são definidas a partir de padrões dados como absolutos daquilo que as unidades familiares ou unidades de compartilhamento de recursos, necessitam para satisfazer suas necessidades básicas. No caso de linhas de pobreza monetária, as estimativas estão baseadas no custo de necessidades alimentares básicas, tido como mínimo em um dado país e por sua vez baseado em uma cesta de alimentos, isto é, uma cesta básica. Além das necessidades básicas de alimentação, uma alocação para o consumo de bens não alimentícios é adicionada. Linhas de pobreza absoluta são mais utilizadas para países em desenvolvimento com PIBs baixos ou médio-baixos, pelo fato de que um percentual maior da população vive próximo da linha de pobreza. Dois métodos são mais utilizados para a definição da linha de pobreza absoluta:

I. O método de consumo de energia de alimentos (calorias): a linha de pobreza é definida pelo nível de renda ou de despesas de consumo pelo qual uma pessoa típica padronizada teria o mínimo necessário para sobreviver em relação à um padrão de necessidade de energia de alimentos predeterminado. Reconhecidamente, dentro de um mesmo país, o padrão de consumo de alimentos do grupo populacional que consome apenas o necessário de quantidade de nutrientes varia. Por essa razão, este método pode gerar diferenciais em linha de pobreza em excesso do diferencial de custo de vida enfrentado pelos mais pobres;

II. O método de custo de necessidades básicas: parte da valoração de uma cesta de alimentos tipicamente consumidos pelos pobres primeiramente em preços locais. Após essa valoração inicial, uma quantia específica consistente com os gastos dos pobres é adicionada para gastos não relacionados à alimentação.

(conditional cash transfer - CCT), o oposto ocorre. Essa conclusão pode ter bastante relevância na opção de política pública. 
Conforme pode ser entendido, toda linha de pobreza, independentemente do método de definição sempre tem um alto grau de arbitrariedade, já que, por exemplo, deve-se assumir como o limiar de consumo de calorias varia para o grupo populacional em questão. Por vezes, as linhas de pobreza relativa e de pobreza absoluta são utilizadas em conjunto para que a situação de desigualdade e a posição relativa da família possam ser levados em consideração e simultaneamente se reconhece a necessidade de um mínimo absoluto abaixo do qual a família não tem como sobreviver.

Há também considerações de natureza mais qualitativa que precisam ser levadas em consideração. Por exemplo, normas sociais de diferentes sociedades têm o mesmo número de entendimentos sobre o que representa uma linha de pobreza e o que o mínimo representa quanto o número de normas sociais mais um. Em alguns países, o salário mínimo (naqueles em que tal conceito econômico é levado em consideração) ou algum benefício de algum programa de auxílio social do governo que sejam amplamente reconhecidos podem representar o mínimo (Banco Mundial, 2011; Ravallion, 1998; Ravallion, 2003).

Da validade transversal (cross-sectional validity)

O tendão de Aquiles dos indicadores de pobreza monetária é exatamente a validade transversal. Converter gastos de família em algo comparável internacionalmente em uma moeda internacional por meio do uso de Paridade do Poder de Compra (purchasing power parity - PPP) é temerário devido a dois problemas:

I. Em geral, as paridades de poder de compra não são derivadas dos padrões de consumo dos pobres;

II. Há erros de mensuração devido a escolha equivocada de instrumentos de pesquisa além de limitações das instituições que realizam pesquisas, especialmente em países em desenvolvimento.

Além das dificuldades de conversão internacional, há limitações mesmo dentro de um mesmo país, especialmente no que tange a comparação entre pobreza urbana e pobreza rural (Deaton \& Paxson, 1995; Deaton \& Dupriez, 2011). ${ }^{32}$ Explicações possíveis são, por exemplo,

i. A dificuldade de se precificar o consumo de subsistência característicos de populações rurais;

ii. Déficits sazonais são relevantes na zona rural mais do que na urbana;

\footnotetext{
$32 \mathrm{Na}$ Índia, por exemplo, as diferenças entre o consumo de calorias e proteínas per capita entre campo e cidade são consideráveis, particularmente quando calculadas em termos monetários (Deaton \& Paxson, 1995).
} 
iii. Serviços e utilidades públicos como educação, saúde e planejamento familiar não são capturados por indicadores monetários e acabam por distorcer desigualdades (Deaton \& Tarozzi, 2008; Deaton \& Drèze, 2009; Headey \& Ecker, 2012).

\section{Validade intertemporal}

Tal como no caso de indicadores de consumo de calorias, no cerne de indicadores de pobreza monetária se encontram as pesquisas de consumo/ orçamento doméstico ou familiar. Conforme visto, pesquisas de consumo e orçamento doméstico frequentemente contêm imprecisões consideráveis. Em pesquisas em áreas rurais, precificação de gêneros alimentícios que não são normalmente vendidos em feiras ou mercados geram espaço para estimativas errôneas. Os preços também variam de família em família, às vezes em escalas consideráveis devido a diferenças na qualidade, quantidade, período, negociação, relações pessoais, erros de cálculo, variedade de pesos e medidas e aferição (Smith \& Subandoro, 2007).

Além dessas questões, pesquisas de consumo são onerosas e por isso, são realizadas apenas de tempos em tempo. Essa infrequência dificulta a análise de sazonalidade e praticamente impossibilita a medição do impacto de choques, mesmo grandes, como o choque de preços de 2008. Há estudos que usam simulações para estimar esses impactos na ausência de pesquisas de consumo. Contudo, essas simulações esbarram em uma série de dificuldades técnicas que limitam o poder de previsão. A solução seria pesquisas de consumo e orçamento doméstico mais frequentes. Evidentemente, o problema é o custo destas pesquisas, especialmente onde são mais necessárias: países menos desenvolvidos (Headey \& Ecker, 2012).

\section{Relevância nutricional}

Indicadores de pobreza monetária não possuem relevância nutricional direta, pois não incluem nenhuma variável que meça ingestão de nutrientes ou que a represente, embora sejam utilizados como indicadores substitutos (proxy indicators).

\subsubsection{Indicadores de diversidade da dieta}

Indicadores de diversidade da dieta possuem duas fortes características que os posicionam acima de indicadores de restrição calórica e de indicadores de pobreza monetária: 
I. As definições padrão de segurança alimentar e nutricional ressaltam a importância da nutrição macro e micro e, portanto, em princípio, o consumo de uma grande variedade de alimentos abarca o consumo de macro e micro nutrientes; e,

II. As teorias de demanda da ciência econômica e da psicologia social parecem corroborar as definições de segurança alimentar e nutricional ao defender que indivíduos tendem a diversificar a alimentação para incluir alimentos mais ricos em micronutrientes apenas após terem saciado suas necessidades calóricas básicas. Isto é, à medida que os mais pobres melhoram economicamente, passam, paulatinamente, do consumo de alimentos menos diferenciados e de características de sabor menos marcantes para alimentos mais ricos em micronutrientes que proporcionam utilidade maior e também mais variedade gustativa (Headey \& Ecker, 2012; Jensen \& Miller, 2010).

A literatura de indicadores de diversidade da dieta identifica três abordagens (Bernardo et al., 2011):

1) Biológica e ecológica: trata da diversidade de espécies animais e da cadeia alimentar e é estudada pelas ciências biológicas e agrárias;

2) Cultural: diversidade de práticas alimentares advinda da própria evolução da espécie e que resultou em diferentes combinações de arranjos alimentares cada um com seus próprios simbolismos estruturais de acordo com sistemas alimentares e culinários distintos;

3) Nutricional: refere-se a diversidade alimentar provinda de uma dieta balanceada com a presença de todos os grupos de alimentos e é a abordagem relevante e adotada em indicadores de diversidade da dieta (Bernardo et al., 2011). Nesta abordagem, três aspectos importantes são considerados na diversidade de alimentos saudável: número, distribuição e valor para a saúde dos alimentos consumidos (Drescher et al., 2007).

Indicadores de diversidade da dieta são operacionalizados por meio de questionários sobre o consumo de alimentos e/ ou grupos alimentares ao longo de um período curto próximo ao da aplicação do questionário, geralmente de um dia e até duas semanas. $\mathrm{O}$ Programa de Alimentação Mundial (PAM) e outras organizações adotam principalmente os seguintes indicadores, que de fato são variações bastante similares:

A. Sistema de pontuação de variedade de alimentos (food variety score - FVS): o FVS gera uma contagem do número de diferentes itens alimentares consumidos;

B. Sistema de pontuação de diversidade da dieta (dietary diversity score - DDS): fornece uma listagem de 7 a 15 grupos alimentares diferentes consumidos no período pesquisado; 
C. Sistema de pontuação de frequência alimentar (food frequency score - FFS): trata-se de um questionário que procura mapear a frequência com que um grupo alimentar específico foi consumido dentro do período escolhido para a pesquisa (Headey \& Ecker, 2012).

O Projeto de Assistência Técnica de Nutrição a Alimentação da Agência de Desenvolvimento Internacional dos Estados Unidos (FANTA - USAID, siglas em inglês) é responsável por um dos sistemas de pontuação de diversidade da dieta (DDS) mais utilizados. O uso de um indicador completo seria relevante para o sistema de segurança alimentar indiano, por exemplo, mas esbarra em questões diversas, principalmente de custo. Este sistema consiste de 12 gradações de diversidade da dieta no nível do domicílio (Swindale \& Bilinsky, 2006). A FAO possui sua própria versão do sistema com 9 gradações, direcionado à avaliação da segurança alimentar de mulheres (Kennedy et al., 2011).

O Programa de Alimentação Mundial - PAM (ou WFP, sigla em inglês) também tem seu próprio sistema, o sistema de pontuação de consumo alimentar que se baseia na pontuação de diversidade alimentar de frequência ponderada, calculada a partir do consumo domiciliar de um período de sete dias disponibilizados pelas pesquisas de análise de vulnerabilidade e segurança alimentar abrangentes. Diferente dos outros sistemas, o sistema da WFP dá mais peso aos alimentos considerados mais relevantes do ponto de vista nutricional. Os maiores pesos são dados à carne, peixe e leite, 4 pontos, seguidos de leguminosas, 3 pontos, cereais, 2 pontos, produtos hortícolas e frutos, 1 ponto, e açúcar e óleo, meio ponto. O sistema do PAM desconsidera condimentos que, em geral, são consumidos em quantidades desprezíveis e outros que não influenciam a dieta de forma benéfica. Entre os condimentos e alimentos desconsiderados pelo sistema do PAM, encontram-se o café, o chá, e o sal (PAM, 2008).

Da validade transversal (cross-sectional validity)

A literatura de indicadores de segurança alimentar dispõe de vários estudos que exploram a validade transversal de indicadores de diversidade da dieta. Há estudos que validaram dados de indicadores de diversidade da dieta com a adequação da dieta em países em desenvolvimento e que confirmam a associação positiva já bastante documentada observada em países desenvolvidos. Além da correlação positiva entre diversidade da dieta e adequação da dieta, há também associação positiva entre a diversidade da dieta e o crescimento infantil. Há evidências também da associação entre diversidade da dieta com a renda per capita familiar e a disponibilidade de energia. Um ponto a salientar, entretanto, é a contribuição de alimentos de origem animal para a 
adequação do consumo de nutrientes. Como se dá o papel independente destes alimentos ainda é pouco entendido (Ruel, 2003).

Tabela 2: Correlação entre diferentes indicadores de segurança alimentar em 60 países.

\begin{tabular}{|c|c|c|c|c|c|c|c|}
\hline & $\begin{array}{l}\text { Calorias per } \\
\text { capita }\end{array}$ & $\begin{array}{l}\text { Diversidade da } \\
\text { dieta }\end{array}$ & $\begin{array}{l}\text { Pobreza } \\
\text { U\$1,25/ dia }\end{array}$ & $\begin{array}{l}\text { Privação } \\
\text { calórica }\end{array}$ & $\begin{array}{l}\text { Desnutrição } \\
\text { infantil }\end{array}$ & $\begin{array}{l}\text { Raquitismo } \\
\text { infantil }\end{array}$ & $\begin{array}{l}\text { Baixo índice } \\
\text { de massa } \\
\text { corporal } \\
\text { maternal }\end{array}$ \\
\hline Calorias per capita & 1.00 & & & & & & \\
\hline $\begin{array}{l}\text { Diversidade da } \\
\text { dieta }\end{array}$ & 0.26 & 1.00 & & & & & \\
\hline Pobreza U\$1/ dia & -0.63 & -0.55 & 1.00 & & & & \\
\hline Privação calórica & -0.46 & -0.30 & 0.71 & 1.00 & & & \\
\hline $\begin{array}{l}\text { Desnutrição } \\
\text { infantil }\end{array}$ & -0.53 & -0.63 & 0.68 & 0.51 & 1.00 & & \\
\hline Raquitismo infantil & -0.07 & -0.58 & 0.38 & 0.28 & 0.45 & 1.00 & \\
\hline $\begin{array}{l}\text { Baixo índice de } \\
\text { massa corporal } \\
\text { maternal }\end{array}$ & -0.21 & -0.47 & 0.31 & 0.08 & 0.47 & 0.77 & 1.00 \\
\hline
\end{tabular}

Fonte: Headey \& Ecker, 2012. Elaboração do autor.

Dados: planilhas de balanço alimentar da FAO; banco de dados do Indicador de Desenvolvimento do Banco Mundial (2012), Pesquisas de Saúde Demográfica. A amostra é de cerca de 60 países, variando com os pares de variáveis.

Notas: células em vermelho - coeficiente é estatisticamente significativo a 5\%; células em amarelo - coeficiente é significativo a $10 \%$.

Headey e Ecker (2012), fortalecem a hipótese de que indicadores de diversidade da dieta nacionais são comparáveis ao propor uma medida de diversidade da dieta que considera o percentual de calorias provindas de alimentos não básicos, em dietas em que os alimentos básicos são oriundos principalmente de cereais e tubérculos. Os autores comparam o indicador a outros indicadores de segurança alimentar e nutricional em vários países. Os resultados publicados (Tabela 1) pelos autores demonstram que o indicador de diversidade da dieta se correlaciona mais fortemente com indicadores antropométricos de subnutrição do que o indicador da FAO (Headey \& Ecker, 2012).

Validade intertemporal

Duas regras empiricamente sustentadas na área de desenvolvimento agrícola são frequentemente citadas em relação à diversidade da dieta: a lei de Engel e a lei de Bennett, ambas disseminadas principalmente pelo pesquisador C. P. Timmer (1983). Essas leis são baseadas no fato de que o crescimento na demanda alimentar é uma função do aumento populacional, do crescimento da renda per capita, da urbanização e das preferências culturais. Desses fatores, o crescimento da renda per capita e a urbanização estão especialmente ligados à diversificação da dieta (Naylor, 2008). 
A lei de Engel afirma que à medida que a renda cresce, o percentual de renda gasto em alimentação, no agregado, decresce (Pindyck \& Rubinfeld, 2006; Timmer et al., 1983). Mesmo que a qualidade da alimentação melhore com o crescimento da renda, há limites físicos de ingestão de alimentos que levam as famílias a gastar uma parcela crescente da renda incremental em itens não alimentos como educação, moradia, saúde, serviços e bens materiais em geral. A lei tem validade intertemporal, já que a parcela da renda familiar gasta em alimentação diminui à medida que os países se desenvolvem e, também tem validade espacial, já que famílias em áreas mais pobres gastam uma parcela maior da renda familiar em alimentação do que famílias em áreas mais ricas diversidade (Naylor, 2008; Timmer et al, 1983).

A lei de Bennet também afirma que a ingestão de calorias das famílias é constituída principalmente de alimentos básicos ricos em amido em níveis mais baixos de renda. Com o crescimento da renda, a dieta passa a ser dominada por uma combinação de frutos, vegetais e produtos de origem animal. A lei de Bennett reflete que há um desejo inerente à diversidade influenciada pela renda. A taxa de consumo de alimentos ricos em amido é definida como a parcela de disponibilidade de caloria derivada de alimentos ricos em amido e de acordo com a lei de Bennett, esta taxa é inversamente relacionada à importância de alimentos ricos em amido mais baratos proporcionalmente aos alimentos ricos em micro nutrientes, mais caros (Naylor, 2008; Timmer et al, 1983; Chaudhri \& Timmer, 1983; Skoufias et al., 2011).

É no contexto desta literatura que indicadores de diversidade da dieta parecem ser adequados para o acompanhamento de tendências mais lentas em segurança alimentar e nutricional. No entanto, inexistente uma massa crítica mínima de estudos sobre a capacidade de resposta ou grau de sensibilidade de indicadores de diversidade da dieta a choques e sazonalidade (Headey \& Ecker, 2012).

\section{Relevância nutricional}

A maior vantagem dos indicadores de diversidade da dieta em relação aos outros é a possibilidade de aplica-los tanto para indivíduos quanto para famílias. Infelizmente, pesquisas de demografia e saúde em países em desenvolvimento são pouco frequentes pois requerem altos investimentos. Há estudos que indicam uma associação positiva consistente entre indicadores de diversidade da dieta e o crescimento infantil e o status nutricional em vários países. Por exemplo, indicadores de dieta também são variável explicativa com significância estatística em análises sobre raquitismo infantil (Ruel, 2003; Arimond \& Ruel, 2006).

A conclusão em relação a indicadores de diversidade da dieta é que: 
I. A diversidade dietária, número de alimentos diferentes consumidos, é um bom indicador de mudanças no consumo per capita e na aquisição calórica per capita;

II. Assim sendo, a diversidade dietária pode ser efetivamente usada para identificar e monitorar mudanças em situações de segurança alimentar (Hoddinott \& Yohannes, 2002).

Limitações

É complexo comprovar causalidade entre, por exemplo, baixo crescimento e deficiências nutricionais específicas em estudos epidemiológicos. Uma grande variedade de nutrientes são necessários para o crescimento do organismo humano e, em geral, as deficiências são múltiplas. Além do grande número de variáveis, a mensuração exata do consumo de nutrientes é, também, complexa. Daí, a justificativa para estudos qualitativos e estudos quantitativos simplificados, focados em características da dieta que são amplamente aceitas na literatura especializada como associadas a dietas adequadas (Onyango, 2003).

\subsubsection{Indicadores subjetivos/ experimentais}

Indicadores subjetivos, também conhecidos como "indicadores experimentais" são assim classificados porque os entrevistados respondem a questões que avaliam subjetivamente a frequência e/ ou o grau de insegurança alimentar do entrevistado. Os indicadores subjetivos captam as dimensões psicológicas da insegurança alimentar e diversas áreas que estudam segurança alimentar admitem que as famílias têm segurança alimentar plena apenas quando se sentem seguras do ponto de vista da alimentação não obstante dados objetivos indicarem o contrário ou demonstrarem variações substantivas ou mínimas (Timmer, 2010). E, ao captarem a dimensão psicológica da insegurança alimentar e nutricional, indicadores subjetivos também captam expectativas, especialmente inflacionárias (Headey \& Ecker, 2012).

A relevância desses indicadores fica mais evidente quando se considera que o fenômeno da fome é universal mas as experiências que levam a fome e a insegurança alimentar não são (Castro, 2003; 1982; 1953). As diferentes iniciativas de indicadores qualitativos são interessantes e relevantes porque procuram gerar medidas simples e diretas de insegurança alimentar e nutricional mas que são, comumente, específicas ao país e ao contexto no qual são geradas. As escalas de segurança alimentar dependem de metáforas para expressar conceitos de fome e falta de alimento. Até que ponto esses símbolos 
linguísticos são comparáveis transversalmente em contextos culturais distintos, é algo bastante aberto ao debate (Kennedy, 2003).

O custo baixo relativo da obtenção de dados para indicadores subjetivos quando comparados às estimativas de consumo de calorias e pobreza, também é um atrativo importante. Há questionários de uma única pergunta e outros que procuram detalhar o grau de acessibilidade financeira ao alimento nos 12 meses anteriores à pesquisa (Headey \& Ecker, 2012). São exemplos de indicadores subjetivos/ experimentais:

a. Gallup World Poll;

b. Afrobarometer Survey;

c. A Análise de Vulnerabilidade e Segurança Alimentar do Programa de Alimentação Mundial da Organização das Nações Unidas (Comprehensive Food Security and Vulnerability Analysis - CFSVA);

d. Pesquisa - Questionário Indicador de Bem-estar de Núcleo (Core Welfare Indicator Questionnaire survey) do Banco Mundial; e o

e. Medida de Acesso e Insegurança Alimentar (Household Food Insecurity and Access Scale - HFIAS) da USAID, projeto FANTA (Food and Nutrition Technical Assistance Project);

Da validade transversal (cross-sectional validity)

A validade transversal de indicadores subjetivos/ experimentais qualitativos é prejudicada pela ausência de uma referência comum em questões subjetivas e pelo viés do respondente: críticas comuns a indicadores qualitativos na literatura das ciências econômicas. Um ponto geralmente aceito é que a ordem das questões afeta as respostas do respondente da pesquisa. Há também dificuldade recorrente de comparação transversal entre indivíduos, famílias e grupos devido a padrões e referenciais de dieta diversos presentes em cada um dos contextos (Deaton, 2011).

A inconsistência de uma cultura para outra é algo esperado simplesmente porque são culturas diversas. O questionário usado no HFIAS, por exemplo, contém nove questões, das quais apenas três são comparáveis com seis países de acordo com um estudo realizado em 2010 (Deitchler et al., 2010). Outras possíveis fontes de viés de resposta, estão a vergonha associada à admissão de fome, especialmente presente no sul e sudeste asiático, medo de represália em países sob regimes autoritários e repressivos, e, não menos importante, o incentivo à inclusão do entrevistado em políticas públicas de segurança alimentar, alívio à pobreza e transferência de renda que geram a superestimava de insegurança alimentar (Headey \& Ecker, 2012, p. 20). 
Validade intertemporal

A validade intertemporal de indicadores experimentais ainda é pouco estudada e há poucos parâmetros em relação à validade dos mesmos para avaliar impactos de choques e escassez sazonal. O crescimento econômico, por exemplo, tem um efeito significativo e negativo nas respostas nas pesquisas e fazem os valores dos indicadores variarem bruscamente sem a devida correspondência nos indicadores monetários, de diversidade e antropomórficos. Existe, também, muito a ser pesquisado na interpretação de variações nos indicadores subjetivos especialmente antes e depois de crises (Headey \& Ecker, 2012).

Relevância nutricional

Indicadores subjetivos podem ser aplicados a famílias e/ ou indivíduos. Na prática, as pesquisas são realizadas no nível do domicílio, da família. Mesmo quando realizadas no nível do indivíduo, existe o viés de gênero na distribuição de alimento no seio da família e nas respostas às questões (Smith \& Subandoro, 2007). Além disso, crianças "delegam" suas respostas aos adultos, que, podem, por razões econômicas e socioculturais, enviesar suas respostas, afetando a acurácia e relevância nutricional dos indicadores (Connell et al., 2005; Cook, 2006).

As evidências não são claras quanto ao poder explicativo e prognóstico dos indicadores subjetivos para o status da segurança alimentar e nutricional. Não existe um número de estudos suficientes para definitivamente fortalecer o caso destes indicadores. Por exemplo, Headey e Ecker (2012) citam alguns casos de evidências conflitantes:

a. Insegurança alimentar severa conforme medido pela HFIAS é um forte preditor de obesidade entre meninas adolescentes no Brasil (Kac et al., 2012);

b. No Nepal, um estudo não encontrou associação entre indicadores de subnutrição infantil e indicadores baseados na HFIAS (Osei et al., 2010);

c. Na Tanzânia, foi encontrado associação significante entre a HFIAS e indicadores objetivos de contagem de caloria (Cordeiro et al., 2012);

d. Por meio de questionário simples, um estudo transversal incluindo Bangladesh, Etiópia e Vietnã concluiu haver forte correlação entre indicadores de contagem de caloria e indicadores subjetivos (Ali et al., 2012).

\section{CONCLUSÃO}

A fronteira do conhecimento em indicadores de segurança alimentar e nutricional se encontra no desenvolvimento de indicadores que possam ser usados e comparados independente de fronteiras internacionais. Busca-se também indicadores que monitorem de forma longitudinal e tenham capacidade analítica nos níveis da família e do indivíduo, além 
de captar o consumo adequado ou não de micro e macro nutrientes (Barrett, 2010, p. 826; Headey \& Ecker, 2012).

As evidências levantadas parecem indicar que indicadores de diversidade da dieta parecem ser os mais próximos de um indicador ideal. Pelo menos parecem relevantes para os requisitos básicos de um indicador de segurança alimentar e nutricional: possuem validade transversal, intertemporal e nutricional (Tabela 2):

1) Têm relevância nutricional já que podem captar a adequação da dieta em relação a nutrientes macro e micro;

2) Podem ser aplicados no nível do indivíduo; e,

3) Diversos estudos demonstraram correlação com dados nutricionais.

Em um mesmo país, a diversidade da dieta aumenta com a renda de forma mais linear do que o consumo de calorias em si. Assim sendo, estes indicadores podem ser explorados para avaliar impactos de choques e sazonalidade porque a diversidade da dieta doméstica é sensível a choques e pelo baixo custo das pesquisas possibilitarem aplicações mais frequentes. Por outro lado, a robustez da validade transversal (cross-country) não é tão auto evidente. No entanto, mesmo um indicador simples de diversidade da dieta tem o potencial de correlação com outros indicadores de segurança alimentar tão razoável quanto indicadores antropométricos e de pobreza (Headey \& Ecker, 2012).

As evidências também sugerem que indicadores de subalimentação ou disponibilidade de calorias da FAO e de pobreza possuem desempenho aquém do desejado para indicadores de segurança alimentar e nutricional (Tabela 2). Ambos dependem de pesquisas pouco frequentes e onerosas e compartilham dos mesmos problemas de falta de dados no nível do indivíduo e capacidade limitada para captar efeitos sazonais e de choques. Há também controvérsias quanto às definições internacionais de pobreza e dúvidas quanto à capacidade de indicadores de pobreza para avaliar o status nutricional (Headey \& Ecker, 2012).

Indicadores subjetivos - experimentais compartilham algumas características comendatórias com indicadores de diversidade da dieta como a possibilidade de aplica-los ao indivíduo, sensibilidade potencial a diferenciação entre macro e micro nutrientes e baixo custo. Os pontos fracos que desqualificam estes indicadores são:

- Falta de validade transversal;

- Hipersensibilidade ao ordenamento das questões;

- Efeitos do contexto sociocultural;

- Vieses diversos dos respondentes, além da

- Dificuldade de comprovar a validade e consistência estatística de indicadores subjetivos. 
No que diz respeito aos vieses enfrentados pelos respondentes de pesquisas de questionário, de surveys, há conflito de interesses especialmente em países nos quais redes de seguridade social e de políticas abrangentes de segurança alimentar se encontram em expansão. É de interesse do respondente ser incluído entre os elegíveis e, portanto, existe um incentivo inerente a exagerar a situação de insegurança alimentar familiar e individual, além da tendência do poder público de superestimar necessidades por razões políticas (Segall-Corrêa et al., 2008; Hoffmann \& Kageyama, 2007). 
Tabela 3: Utilidade de indicadores de alimento e nutrição na avaliação de choques

\begin{tabular}{l|l|l|l|l}
\hline Critério / Tipo & $\begin{array}{l}\text { Disponibilidade } \\
\text { de calorias }\end{array}$ & Pobreza & $\begin{array}{l}\text { Diversidade } \\
\text { de dieta }\end{array}$ & $\begin{array}{l}\text { Subjetivo/ } \\
\text { experimental }\end{array}$ \\
\hline \multicolumn{1}{l|}{ Transversal } & \multicolumn{3}{l}{} \\
\hline & $\begin{array}{l}\text { Potencialmente } \\
\text { útil. Utilidade } \\
\text { limitada por } \\
\text { questões à volta } \\
\text { dos métodos da } \\
\text { FAO. }\end{array}$ & Útil & $\begin{array}{l}\text { Potencialmente } \\
\text { útil. Mais } \\
\text { pesquisa } \\
\text { necessária } \\
\text { sobre } \\
\text { comparações } \\
\text { transversais }\end{array}$ & $\begin{array}{l}\text { Limitado. Restrita } \\
\text { devido ao viés do } \\
\text { entrevistado e } \\
\text { ausência de } \\
\text { referencial } \\
\text { comum. }\end{array}$ \\
\hline Doméstica & Útil & Útil & $\begin{array}{l}\text { Limitado. Restrita } \\
\text { pelo viés do } \\
\text { entrevistado e } \\
\text { ausência de } \\
\text { referencial } \\
\text { comum. }\end{array}$ \\
\hline
\end{tabular}

\begin{tabular}{|c|c|c|c|c|}
\hline \multicolumn{5}{|l|}{ Intertemporal } \\
\hline $\begin{array}{l}\text { Avalia } \\
\text { tendências de } \\
\text { bem-estar? }\end{array}$ & $\begin{array}{l}\text { Potencialmente } \\
\text { útil. Limitado } \\
\text { pela demanda } \\
\text { instável de } \\
\text { calorias e } \\
\text { elasticidades de } \\
\text { demanda baixa } \\
\text { de calorias }\end{array}$ & Útil & $\begin{array}{l}\text { Útil. É } \\
\text { necessário } \\
\text { mais pesquisa } \\
\text { em } \\
\text { comparações } \\
\text { transversais } \\
\text { (cross- } \\
\text { country). }\end{array}$ & $\begin{array}{l}\text { Limitado. Restrito } \\
\text { pelo viés do } \\
\text { entrevistado e } \\
\text { ausência de } \\
\text { referencial } \\
\text { comum. }\end{array}$ \\
\hline $\begin{array}{l}\text { Avalia } \\
\text { impactos de } \\
\text { choques? }\end{array}$ & $\begin{array}{l}\text { Limitado. Baixa } \\
\text { frequência de } \\
\text { coleta; limitado } \\
\text { a análise de } \\
\text { simulações }\end{array}$ & $\begin{array}{l}\text { Limitado. } \\
\text { Baixa } \\
\text { frequência de } \\
\text { coleta; limitado } \\
\text { a análise de } \\
\text { simulações }\end{array}$ & $\begin{array}{l}\text { Potencialmente } \\
\text { útil. Devido ao } \\
\text { baixo custo de } \\
\text { coleta pode ser } \\
\text { realizado com } \\
\text { mais } \\
\text { frequência }\end{array}$ & $\begin{array}{l}\text { Potencialmente } \\
\text { útil. Devido ao } \\
\text { baixo custo de } \\
\text { coleta pode ser } \\
\text { realizado com } \\
\text { mais frequência; } \\
\text { é possível } \\
\text { questionar em } \\
\text { retrospecto. }\end{array}$ \\
\hline $\begin{array}{l}\text { Avalia } \\
\text { sazonalidade? }\end{array}$ & Limitado. & Limitado. & $\begin{array}{l}\text { Potencialmente } \\
\text { útil. Baixo } \\
\text { custo de } \\
\text { coleta, } \\
\text { portanto, pode } \\
\text { ser realizado } \\
\text { com mais } \\
\text { frequência }\end{array}$ & $\begin{array}{l}\text { Potencialmente } \\
\text { útil. Baixo custo } \\
\text { de coleta, } \\
\text { portanto, mais } \\
\text { frequência; } \\
\text { possibilidade de } \\
\text { fazer questões } \\
\text { em retrospecto. }\end{array}$ \\
\hline
\end{tabular}

(Continua) 


\begin{tabular}{|c|c|c|c|c|}
\hline $\begin{array}{l}\text { Critério / } \\
\text { Tipo }\end{array}$ & \multirow[t]{2}{*}{$\begin{array}{l}\text { Disponibilidade } \\
\text { de calorias }\end{array}$} & \multirow[t]{2}{*}{ Pobreza } & \multirow[t]{2}{*}{$\begin{array}{l}\text { Diversidade } \\
\text { de dieta }\end{array}$} & \multirow[t]{2}{*}{$\begin{array}{l}\text { Subjetivo/ } \\
\text { experimental }\end{array}$} \\
\hline Nutrição & & & & \\
\hline $\begin{array}{l}\text { Mensurável } \\
\text { no nível do } \\
\text { indivíduo? }\end{array}$ & $\begin{array}{l}\text { Limitado. Falta } \\
\text { de dados no } \\
\text { nível do } \\
\text { indivíduo. }\end{array}$ & $\begin{array}{l}\text { Limitado. Falta } \\
\text { de dados no } \\
\text { nível do } \\
\text { indivíduo. }\end{array}$ & $\begin{array}{l}\text { Útil. Pode ser } \\
\text { realizado no } \\
\text { nível da } \\
\text { família e do } \\
\text { indivíduo. }\end{array}$ & $\begin{array}{l}\text { Útil. Pode ser } \\
\text { realizado no } \\
\text { nível do } \\
\text { indivíduo assim } \\
\text { como da família. }\end{array}$ \\
\hline $\begin{array}{l}\text { Micro e macro } \\
\text { nutrientes? }\end{array}$ & $\begin{array}{l}\text { Potencialmente } \\
\text { útil. Apenas } \\
\text { macro } \\
\text { nutrientes. }\end{array}$ & $\begin{array}{l}\text { Potencialmente } \\
\text { útil. } \\
\text { Necessidade de } \\
\text { micronutrientes } \\
\text { ainda não } \\
\text { incorporada } \\
\text { especificamente. }\end{array}$ & $\begin{array}{l}\text { Útil. Pode ser } \\
\text { realizado no } \\
\text { nível da } \\
\text { família e do } \\
\text { indivíduo. }\end{array}$ & $\begin{array}{l}\text { Potencialmente } \\
\text { útil. Pode ser } \\
\text { realizada sobre a } \\
\text { qualidade da } \\
\text { dieta mas falta } \\
\text { um arcabouço de } \\
\text { referências em } \\
\text { comum. }\end{array}$ \\
\hline \multirow[t]{2}{*}{$\begin{array}{l}\text { Pontuação } \\
\text { total = } 14\end{array}$} & $5 / 14$ & $7 / 14$ & $11 / 14$ & $5 / 14$ \\
\hline & $36 \%$ & $50 \%$ & $80 \%$ & $36 \%$ \\
\hline
\end{tabular}

Pontuação

Utilidade do indicador: Limitado $=0$ ponto; Potencialmente útil $=1$ ponto; Útil $=2$ pontos

Fonte: Headey \& Ecker, 2012. Elaboração do autor.

O desafio de um indicador de diversidade da dieta multinacional que meça uma dada diversidade comum e que permita a real comparação entre países permanece ilusivo. A própria definição de diversidade da dieta parece ser intransponível dada a própria variedade de dietas. No entanto, os micro e macro nutrientes necessários são compartilhados por todos. E, portanto, é o conteúdo dessa dieta que se encontra em questão e não os alimentos que constituem o veículo nutricional. Um indicador de qualidade da diversidade da dieta comparável internacionalmente pode ser desenvolvido pelas agências e organismos da ONU especializados e maior coordenação e frequência das pesquisas (surveys) de segurança alimentar e nutricional também são realizáveis e já há alguns esforços nesta direção coordenadas pelo Banco Mundial, USAID, FAO e PAM. Se aplicado a um país como a Índia onde a principal política agrícola e de segurança alimentar e nutricional encoraja o consumo de arroz e trigo, provavelmente a situação de segurança alimentar revelada seria ainda mais sombria do que a atual.

A maior barreira ao desenvolvimento de um indicador e à realização das pesquisas que gerem os dados para o indicador é o custo de manutenção, isto é, de realizar pesquisas com frequência. É apenas por meio de pesquisas frequentes que os impactos de choques e variações sazonais podem ser de fato medidos e a dinâmica da insegurança alimentar e nutricional compreendida, além de modelos matemáticos, estatísticos e teóricos serem 
fortalecidos ou enfraquecidos. Como a necessidade dessas pesquisas se dá principalmente em países e regiões mais pobres, a vontade política internacional e nacional é a chave para que recursos sejam alocados não apenas durante crises que ganham destaque na mídia internacional mas, sobretudo preventivamente e continuamente. Os benefícios de longo prazo em muito excedem os custos, considerando que as novas tecnologias de coleta de dados já auxiliam a reduzir os custos de coleta e de divulgação. O custo de não fazer nada, ou apenas manter o sistema atual, pode ser muitas vezes maior tendo em vista as evidências crescentes de que regiões vulneráveis têm sido alvo de fenômenos climáticos destruidores de meios de subsistência mais devastadores e frequentes (Headey \& Ecker, 2012; Barrett, 2010; Deaton \& Dupriez, 2011; IPCC, 2014). Essa questão merece ser explorada em pesquisa futura. 


\section{CAPÍTULO 5: TEORIAS E MODELOS DE ANÁLISE DE POLÍTICAS PÚBLICAS}

5 TEORIAS E MODELOS DE ANÁLISE DE POLÍTICAS PÚBLICAS

\section{INTRODUÇÃO}

A análise de políticas públicas de segurança alimentar se dá no contexto mais amplo de análise de políticas públicas. A análise de políticas é uma área do conhecimento que se consolidou ao longo do século 20, entre a ciência política e as ciências econômicas e se vale de modelos, isto é, representações simplificadas de aspectos do mundo real, para analisar políticas públicas. O quinto capítulo se vale, principalmente, do trabalho de Thomas R. Dye sobre análise e modelos de políticas públicas. Dye $(2009,2012)$, trabalha à volta das instituições governamentais e como essas executam políticas púlbicas e cumprem as preferências do Estado. Ao todo, nove modelos são apresentados e brevemente analisados: institucional, de processo, de grupo, de elite, racional, incremental, da teoria de jogos, sistêmico e, por fim, da opção pública. O último modelo, o da opção pública, é descrito e analisado com um pouco mais de detalhe por se prestar melhor ao estudo econômico de políticas públicas. Três conceitos basais são apresentados e comentados: (i) falhas de governo; (ii) Logrolling; e, Rent-seeking. O conceito de Rent-seeking é revisto em duas categorias: (i) PERTs e PESTs.

\subsection{OS MODELOS E SUAS CARACTERÍSTICAS}

Há uma série de modelos amplamente utilizados por pesquisadores de várias áreas, entre os mais conhecidos: Os modelos não são exclusivos e/ ou concorrentes. Pelo contrário, como o enfoque de cada um é diferente, políticas são, em geral, melhor explicadas por uma composição de, por exemplo, planejamento, racionalismo, incrementalismo, atividade de grupos de interesse, preferências de elites, forças sistêmicas, teoria dos jogos, opção pública, processos políticos e influências institucionais (Dye, 2009).

Outra característica que deve ser considerada é que políticas públicas e instituições governamentais se confundem na adoção, implementação e cumprimento de uma política. Além disso, essas instituições governamentais conferem três características às políticas públicas que estimulam indivíduos e grupos organizados a se comprometerem a cumprir as preferências estatais:

1) Legitimidade: o fato das políticas governamentais serem obrigações legais fazem com que o governo (e, mais especificamente, as instituições governamentais que estabelecem, implementam e fazem cumprir as políticas) seja o fiador das mesmas, 
sendo que a própria legitimidade do governo é, frequentemente, sinônimo da legitimidade da política também.

2) Universalidade: embora indivíduos possam ter consideração e julgar políticas de organizações não governamentais, instituições religiosas e até mesmo empresas como relevantes, apenas políticas governamentais podem possuir caráter universal.

3) Coercibilidade: o governo pode legitimamente cobrar e fazer cumprir, isto é, obrigar a obedecer. Esta característica está associada ao monopólio do uso legítimo da força: poder legitimamente coagir e privar de liberdade aqueles que violam suas políticas, qualidade que a maioria dos Estados contemporâneo detém à vista de seus pares (Dye, 2012; 2009).

As subseções que seguem, resumem diferentes modelos de análise de políticas públicas, sem nenhuma tentativa de serem exaustivas ou completas. No contexto deste trabalho de tese, servem para ilustrar algumas das possibilidades de modelos de análise de políticas públicas que são implicitamente utilizados nos capítulos 6,7 , 8. Optou-se por não nomear expoentes dos modelos e suas obras a cada um dos modelos. Pareceu mais sensato no contexto da tese, apenas resumi-los a partir de uma obra de síntese Dye, 2009 -, e apenas onde a claridade pedia, evocar alguns autores cujas obras definem o modelo e a teoria de suporte.

\subsubsection{Modelo Institucional}

Boa parte da literatura de análise de políticas públicas institucional se atem à descrição de instituições públicas. Questões relacionadas a estrutura, organização, atribuições e funções ocupam parte considerável das pesquisas. A forma como se dão as disposições constitucionais e jurídicas e a estrutura dos poderes e seus níveis acabam dominando esse tipo de análise. O modelo, em geral, não busca entender as conexões entre a estrutura das instituições governamentais e o conteúdo das políticas públicas. Questões como, "que impacto as características institucionais têm nos resultados das políticas? ", ou "qual relação entre os arranjos institucionais e políticas? ", não são alvo das pesquisas. Mesmo assim, Dye (2012) argumenta que os estudos, ao analisarem os padrões estruturados de comportamento de indivíduos e grupos, por aproximação, são capazes de gerar indicações de como os mesmos obstruem ou facilitam políticas públicas, exemplificado na Figura $13 .{ }^{33}$ As configurações institucionais permitem o favorecimento de uns em prejuízo

33 No caso brasileiro e também em outros, por exemplo, Estados Unidos, há outras instâncias além das representadas na Figura 13, tais como, tribunais de contas vinculados ao legislativo, Ministério Público, Controladoria Geral da União, Procuradoria da República, entre outros. 
de outros, ao, por exemplo, permitirem acesso direto de alguns indivíduos e grupos aos centros de decisão e deste modo influenciarem políticas de governo (May, 1991).

Com tudo isso, os modos como a estrutura das instituições governamentais impactam políticas permanece uma caixa preta. Não há estudos empíricos suficientes para fortalecer a hipótese de que mudanças institucionais provocam mudanças nas políticas. Se os diferentes arranjos institucionais têm muita ou pouca consequência política independente em um contexto de forças subjacentes constantes, é questão ainda sem evidências contundentes. 


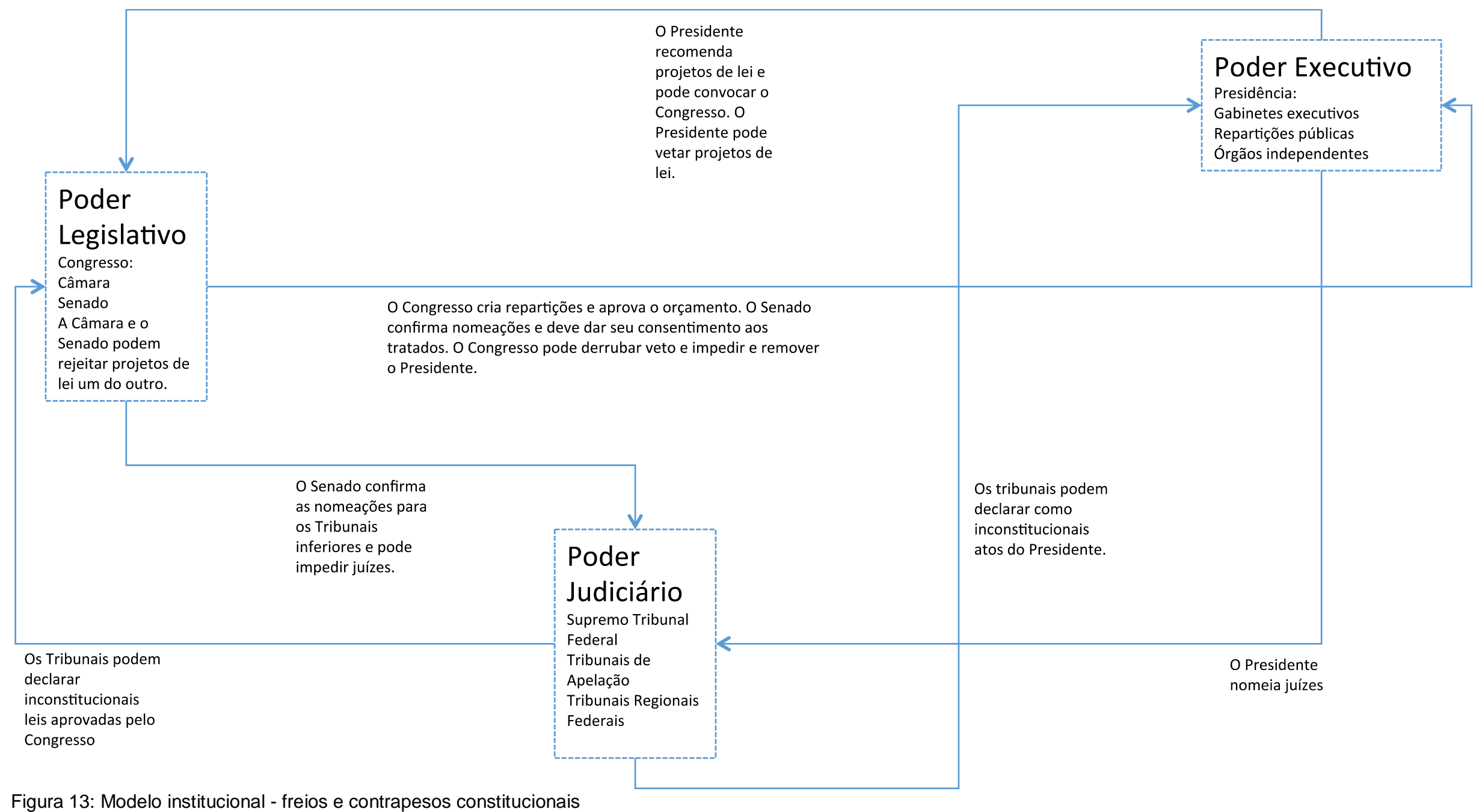

Figura 13: Modelo institucional - freios e contrapesos constitucionais Fonte: DYE, 2012, p. 102. 


\subsubsection{Modelo de processo}

O termo "processo" se refere aos padrões identificáveis de atividades de agentes políticos que segue a seguinte disposição geral dada pelo Quadro 8.

\begin{tabular}{l|l} 
Identificar problemas & $\begin{array}{l}\text { Tornar manifestas as demandas, para } \\
\text { a ação governamental }\end{array}$ \\
\hline $\begin{array}{l}\text { Montar Agenda para } \\
\text { deliberação }\end{array}$ & $\begin{array}{l}\text { Escolher as questões a serem } \\
\text { decididas e os problemas a serem } \\
\text { tratados. }\end{array}$ \\
\hline $\begin{array}{l}\text { Formular propostas de } \\
\text { políticas }\end{array}$ & $\begin{array}{l}\text { Desenvolver propostas de políticas, } \\
\text { para resolver as questões e os } \\
\text { problemas. }\end{array}$ \\
\hline Legitimar políticas & $\begin{array}{l}\text { Selecionar uma proposta. Articular } \\
\text { apoio político para a proposta. } \\
\text { Transformá-la em lei. }\end{array}$ \\
\hline Implementar políticas & $\begin{array}{l}\text { Organizar burocracias. Prestar } \\
\text { serviços ou prover pagamentos. Criar } \\
\text { impostos. }\end{array}$ \\
\hline Avaliar políticas & $\begin{array}{l}\text { Estudar programas. Relatar os outputs } \\
\text { dos programas governamentais. } \\
\text { Avaliar os impactos dos programas } \\
\text { sobre os grupos-alvo e sobre os } \\
\text { outros grupos. Propor mudanças e } \\
\text { ajustes. }\end{array}$ \\
Quadro 9: O modelo processual de análise de políticas públicas \\
Fonte: Dye, 2009. Elaboração do autor
\end{tabular}

Os defensores deste modelo preconizam o estudo do processo político e seu funcionamento e não do problema alvo da política, como pode ser visto na Quadro 9. O problema só interessa em relação à sua interação com o processo e qualquer proposta advinda deste modelo deveria se relacionar ao processo em si, por exemplo, mais acesso, garantia de debate público, publicidade de decisões e caminhos das decisões tomadas. 


\begin{tabular}{|c|c|c|c|}
\hline $\begin{array}{l}\text { Atividades } \\
\text { funcionais }\end{array}$ & $\begin{array}{l}\text { Como } \\
\text { categorias } \\
\text { no } \\
\text { governo }\end{array}$ & $\begin{array}{l}\text { E como } \\
\text { sistemas }\end{array}$ & Como produto \\
\hline Percepção & \multirow{5}{*}{$\begin{array}{l}\text { Problemas } \\
\text { para o } \\
\text { governo }\end{array}$} & \multirow{5}{*}{$\begin{array}{l}\text { Identificação de } \\
\text { problemas }\end{array}$} & \multirow{5}{*}{$\begin{array}{l}\text { Problema a } \\
\text { exigir solução }\end{array}$} \\
\hline Definição & & & \\
\hline Agregação & & & \\
\hline Organização & & & \\
\hline Representação & & & \\
\hline Formulação & \multirow{3}{*}{$\begin{array}{l}\text { Ação } \\
\text { dentro do } \\
\text { governo }\end{array}$} & \multirow[b]{3}{*}{$\begin{array}{l}\text { Desenvolvimento } \\
\text { do programa }\end{array}$} & \multirow{3}{*}{$\begin{array}{l}\text { Proposta a ser } \\
\text { incluída no } \\
\text { orçamento- } \\
\text { programa }\end{array}$} \\
\hline Legitimação & & & \\
\hline Apropriação & & & \\
\hline Organização & \multirow{3}{*}{$\begin{array}{l}\text { Governo } \\
\text { diante do } \\
\text { problema }\end{array}$} & \multirow{3}{*}{$\begin{array}{l}\text { Implantação do } \\
\text { programa }\end{array}$} & \multirow{3}{*}{$\begin{array}{l}\text { Varia (serviço, } \\
\text { pagamentos, } \\
\text { instalações, } \\
\text { controles, etc.) }\end{array}$} \\
\hline Interpretação & & & \\
\hline Aplicação & & & \\
\hline Especificação & \multirow[t]{3}{*}{$\begin{array}{l}\text { Programa } \\
\text { para o } \\
\text { governo }\end{array}$} & \multirow[t]{3}{*}{$\begin{array}{l}\text { Avaliação do } \\
\text { programa }\end{array}$} & \multirow{3}{*}{$\begin{array}{l}\text { Varia } \\
\text { (justificação, } \\
\text { recomendação, } \\
\text { etc.) }\end{array}$} \\
\hline Mensuração & & & \\
\hline Análise & & & \\
\hline Solução/Conclusão & $\begin{array}{l}\text { Solução do } \\
\text { problema } \\
\text { ou } \\
\text { mudança }\end{array}$ & $\begin{array}{l}\text { Encerramento do } \\
\text { programa }\end{array}$ & $\begin{array}{l}\text { Solução ou } \\
\text { mudança }\end{array}$ \\
\hline
\end{tabular}

Quadro 10: Processos políticos e atividades funcionais

Fonte: Jones, 1984. Elaboração do autor

No modelo de processo, o mais importante é a maneira como se chega a uma decisão e qual seria a maneira ideal de se chegar a uma decisão. No entanto, o conteúdo das políticas públicas - "quem ganha o que e por que" - não é alvo das pesquisas.

Em paralelo ao modelo institucional, o modo como se chega às políticas pode ter influência no conteúdo das políticas públicas tal como o conteúdo pode ter influência na maneira como as políticas são formuladas. Uma vez mais, Dye (2012) alerta sobre o equívoco de se assumir que mudanças no processo de formulação necessariamente acarretam em alterações significativas ou mesmo mínimas no conteúdo das políticas. Os processos de tomada de decisão, sejam eles formais ou informais, têm potencial para 
influenciar o conteúdo das políticas públicas. No entanto, o contexto das tomadas de decisão e dos tomadores de decisão restringe o conteúdo das políticas. Restrições sociais e econômicas podem ser mais relevantes ao conteúdo das políticas públicas do que a escolha entre um processo aberto ou fechado de formulação, se há competição ou não, se há representatividade e pluralidade ou elitismo. (Dye, 2012). Novamente, a variação nos processos não garante variação de conteúdo.

\subsubsection{Modelo de grupo}

A teoria dos grupos, também conhecida como "Pluralista", trabalha com a hipótese de que a influência mútua, ou interação entre grupos é o fator mais relevante do mundo político. De acordo com a teoria aprofundada por Wildavsky (1979) e Lindbblom e Woodhouse (1993), agrupamentos de interesse, formais ou informais, se aglutinam para fazer demandas junto aos governos e a outros grupos na sociedade. Também, a política gira em torno da luta entre grupos e a influência que buscam ter sobre políticas públicas. O indivíduo só tem importância quando integrante ou em nome de um ou outro grupo, pois o grupo é a ligação entre o indivíduo e o governo. O sistema político serve para administrar o conflito entre os grupos, por meio:

a. Do estabelecimento das regras do jogo para a luta entre os grupos;

b. Da negociação de acordos e o equilíbrio dos interesses;

C. Da oficialização dos acordos na forma de políticas públicas;

d. Do cumprimento efetivo desses acordos (Dye, 2012).

A influência relativa de cada grupo de interesse determina o equilíbrio que resulta da luta entre grupos representada nas políticas públicas. Cada mudança na importância respectiva deveria refletir nas políticas públicas, que se aproximariam dos interesses dos mais influentes e se distanciariam dos menos influentes. Grandeza, riqueza, capacidade de mobilização e organizacional, liderança, acesso aos centros e líderes de poder e formadores de opinião, além de harmonia interna definem a influência de cada grupo. Os políticos eleitos ou não, canalizam as pressões de grupos por meio de negociações constantes e buscam fechar acordos entre interesses divergentes. A margem de discrição de cada um dos grupos depende da diversidade dos interesses que cada um representa, sendo que presidentes, senadores e deputados gozam de graus de flexibilidade de acordo com suas posições e do mesmo modo, os órgãos do executivo também representam interesses dos clientes dos grupos (Tollison, 1998). 
Generalizando a análise de Dye (2012) ${ }^{34}$ sobre o sistema de grupos de interesse nos Estados Unidos, o sistema político em países democráticos se sustenta pelo equilíbrio dinâmico de várias forças:

- Sendo a primeira das forças a do grupo latente que defende o sistema, por exemplo, constitucional e as regras do jogo inerentes a este sistema. Trata-se do grupo que deve congregar a quase totalidade dos cidadãos do país e defende o sistema em si quando censura outros grupos que ponham o sistema em perigo ao ameaçar o equilíbrio geral;

- A segunda força de equilíbrio é a "filiação simultânea a vários grupos". A filiação simultânea e através de subdivisões sociais, étnicas e econômicas reforça o sistema já que impede extremismos por parte de grupos que se desviem demasiadamente dos valores mais amplamente aceitos por uma dada sociedade. Há moderação na variedade;

- A ausência de maiorias absolutas, isto é, um grupo isolado dominante no sistema, gera "freios e contrapesos" derivado da concorrência entre grupos que resulta em maior equilíbrio no sistema (Figura 13). À medida que cada grupo almeja expandir os limites de sua influência, essas tentativas são rechaçadas pelos outros grupos concorrentes e desse modo põem em cheque a influência exagerada de um grupo em detrimento de outros.

A teoria do grupo de interesse contemporânea evoluiu em dois ramos principais, principalmente na academia dos Estados Unidos. A Economia Política de Chicago se preocupa principalmente com regulação e o papel do Estado, do governo (e até mesmo da Academia) na alocação de recursos, preço e quantidade. A Economia Política da Virgínia foca nos impactos de instituições no processo de transferência de riqueza, o papel do judiciário como garantidor de contratos de longo prazo entre legisladores e grupos de interesse, o impacto das instituições legislativas nos custos e "benefícios" de atividades de lobbying (Tollison, 1998).

\subsubsection{Modelo de elite}

Também conhecida como teoria de preferências das elites, a visão elitista da política advoga que a elite se apodera da opinião das massas e a molda de acordo com suas prioridades. Isso se dá, principalmente porque o povo seria indiferente e desinformado e de certo modo incumbe a condução da política e das políticas públicas à elite. A elite por sua vez, delega o dia a dia da administração pública ao governo - administradores e

\footnotetext{
${ }^{34}$ A primeira edição de "Understanding Public Policy" de Thomas R. Dye é de 1969.
} 
funcionários - que simplesmente cumprem as ordens da elite traduzidas em políticas públicas, sempre originadas "top-down" e nunca "bottom-up" (Dye, 2012; Domhoff, 2005).

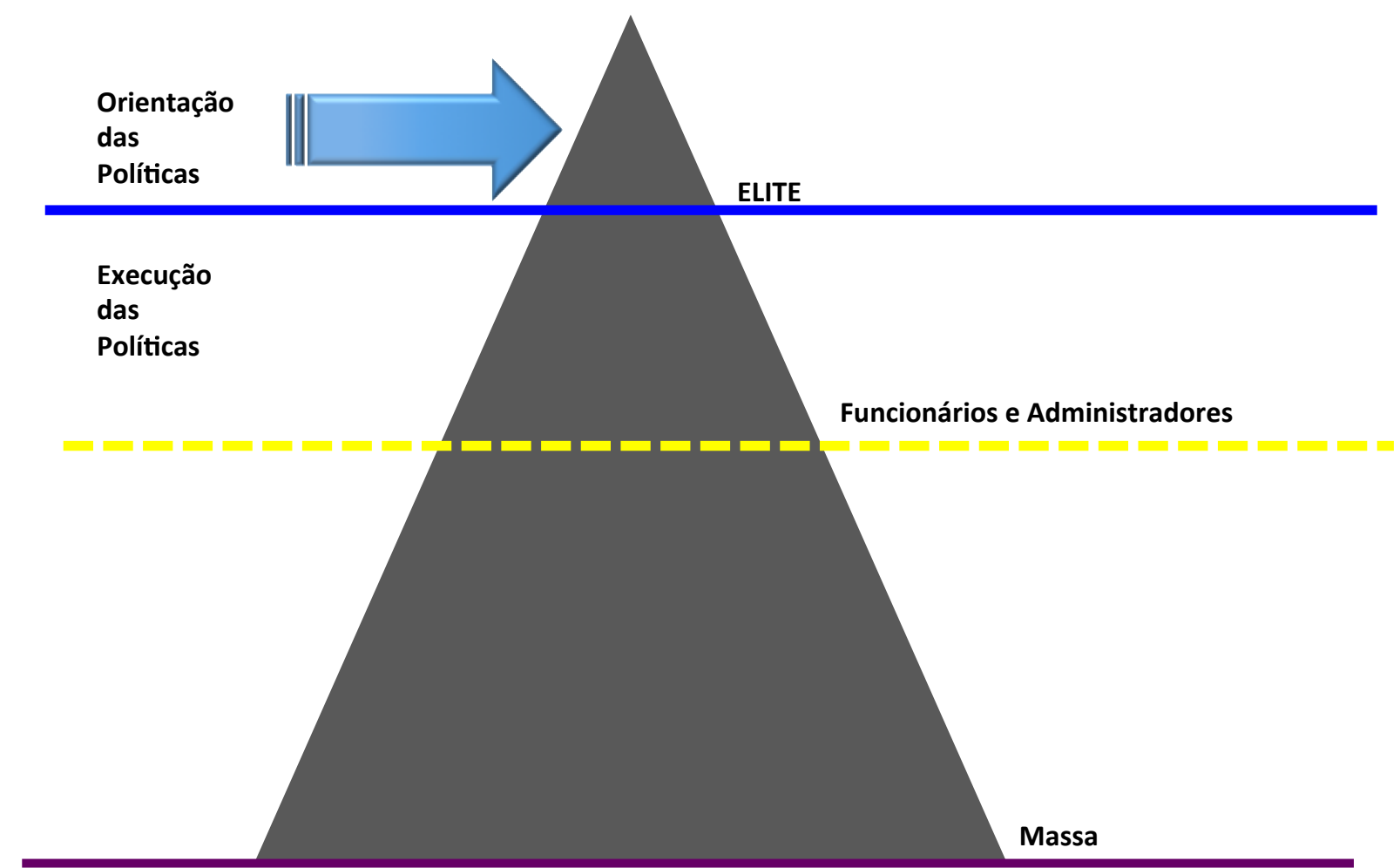

Figura 14: Teoria de preferências das elites

Fonte: Dye, 2012.

Para os elitistas, há apenas "haves" e "have-nots". Os que têm são poucos, os que não têm são muitos. Por definição, a elite é restrita e não representativa; o acesso é difícil e paulatino e sempre com o intuito de conservar a ordem estabelecida e impedir mudanças violentas nas instituições políticas, isto é, revoluções. Mesmo para aqueles que possuem todos os pré-requisitos para se considerarem parte da elite, a aceitação de conceitos consensuais, por exemplo, respeito à propriedade privada, delimitação do tamanho do governo e liberdade individual, são condições sine qua non. Os elitistas insistem que pouco advém das massas apáticas para a elite. Deste modo, a elite de forma marginal define mudanças que lhe convém e influencia como e quando a massa se move (Dye, 2012).

Sob o prisma da teoria da elite, as políticas públicas são o veículo dos valores e interesses das elites e não o reflexo das demandas dos eleitores. Mudanças e inovações são meros realinhamentos e ajustes; visam sempre a preservação do status quo. A elite é reacionária em seu comportamento e assim, evita substituir políticas, ao invés disso, tenta modifica-las de acordo com suas necessidades. Mudanças profundas somente ocorrem quando as próprias elites se sentem ameaçadas e decidem - tendo em vista a autopreservação e como base o próprio interesse esclarecido - agir para preservar o sistema e sua posição. Seja por esse interesse próprio ou por qualquer outra razão, as ações da elite podem levar em consideração o bem-estar das massas. Todavia, o encargo 
pelo bem-estar geral é de responsabilidade única da elite: a massa apática aceita de bom grado as benesses dos iluminados (Kornhauser, 2010; Dye, 2012).

Nesta visão de mundo, a democracia eleitoral e partidária não passa de uma formalidade que dá às massas um senso de responsabilidade e participação em momentos das campanhas eleitorais e nos dias de votação. Partidos políticos congregam e apaziguam ânimos e dão um senso de identidade mas não conduzem as deliberações das elites, podendo apenas influenciar de forma indireta a condução política das elites.

O modelo assume que há mais concordância que discordância no seio da elite, embora haja espaço para disputas por supremacia e haja dissenso dentro das regras do jogo. Os valores fundamentais nunca são postos em disputa nem a prova, já que deles emanam as bases para a perpetuação do status quo e da própria elite (Dye, 2012).

Após décadas de debates e críticas, a teoria da elite atualizada, foi relançada sobre três premissas:

a. As elites são inevitáveis em sociedades burocratizadas e grandes;

b. A natureza geral de uma determinada sociedade depende das variações na estrutura, funcionamento e formação da elite naquilo que tange, por exemplo, o uso e incentivo de acordos e o uso de eleições para a contenção e administração de conflitos;

c. O relacionamento entre as elites e as não elites é de interdependência, situação que cria contenção naquilo que um pode fazer em relação ao outro. Desta premissa, deriva-se que elites não detém poder ilimitado e que não há animosidade e oposição desenfreada e inevitável entre elites e não elites. (Domhoff, 2005).

Por fim, diferente do criticismo às primeiras formulações da teoria da elite, os pesquisadores e defensores contemporâneos do modelo negam qualquer agenda ou objetivo ideológico e político, exceto em relação à possibilidade de sociedades não hierárquicas, conforme afirmam Burton e Higley (1987):

No sentido de que não aceita qualquer utopia social e política, a teoria da elite pode ser rotulada 'conservadora', embora prefiramos o termo 'realista'. Fora isso, entretanto, os argumentos são provavelmente compatíveis com praticamente qualquer posição ideológica geralmente aceita, inclusive social democrata. Assim, a crítica e o confronto do modo de agir de uma elite específica é completamente consistente com as premissas da teoria da elite. (BURTON \& HIGLEY, 1987, p. 237).

\subsubsection{Modelo racional ou a política como ganho social máximo}

O modelo se rege por duas premissas:

- Os custos de uma política não podem superar os benefícios; e,

- Políticas adotadas sempre serão aquelas que gerem o maior benefício descontados os custos. 
Racional seria a política sempre que a diferença entre os ganhos que ela gera e os valores que ela sacrifica for positiva e maior que o saldo de qualquer outra proposta (Dye, 2012). Esse racionalismo inclui tudo aquilo que um Estado-nação sacrifica em nome de uma política pública, inclusive: valores sociais, políticos e econômicos, mensuráveis monetariamente ou não. Pressupondo que as preferências valorativas do conjunto da sociedade sejam conhecidas e ponderadas, o processo racional de seleção de políticas públicas demanda que formuladores de políticas tenham conhecimento:

i. Das preferências de valor e os pesos relativos de cada um de suas sociedades;

ii. Do universo de propostas de políticas públicas disponíveis;

iii. Das consequências de cada uma das propostas disponíveis; e,

iv. Dos cálculos dos quocientes custo/benefício de cada uma das propostas alternativas disponíveis;

As exigências não param por aí. Para escolher o projeto de política pública mais eficiente, os formuladores também precisam:

i. Ter entendimento completo dos valores da sociedade;

ii. Informações exaustivas sobre as propostas de políticas públicas alternativas;

iii. "Capacidade preditiva" para aferir acuradamente as relações custo e benefícios futuros;

iv. De um sistema de tomada de decisão que possibilite o uso da abordagem racional no processo de desenvolvimento de políticas.

Embora o modelo possa parecer atraente para se alcançar o "máximo ganho social", há empecilhos à racionalidade prescrita no modelo que dificilmente podem ser contornados, que Dye (2012) resume em 10 pontos:

i. A inexistência de benefícios societários harmônicos: muitos benefícios são específicos a grupos e indivíduos, excluindo outros;

ii. Há benefícios e custos que não são comparáveis ou ponderáveis;

iii. A busca pela maximização de benefícios e recompensas motiva a maioria dos formuladores de políticas. Os objetivos maiores para o bem geral da sociedade não tomam precedência;

iv. No mundo real, assim que uma solução que funcione é encontrada, os agentes políticos se dão por satisfeitos e se ocupam da próxima política em debate. Não há uma busca incessante pela maximização do ganho social líquido;

v. O investimento de longo prazo e a própria inércia da burocracia estatal não permitem a reconsideração de políticas rejeitadas anteriormente. O custo simplesmente inviabiliza mudanças bruscas nas políticas públicas que sejam politicamente sustentáveis; 
vi. Existe o custo de coleta de informações. Pesquisas, estudos, censos, e outros instrumentos de aquisição de informação têm custo elevado, além de limites e prazos que impossibilitam a exaustão da busca pelo conhecimento de todas as propostas políticas possíveis;

vii. Não há ferramentas e métodos estatísticos ou de observação que permitam a apreensão e a compreensão de todos os custos e benefícios de todas as propostas;

viii. As equipes que formulam políticas, por mais especializadas e generalistas que sejam, e mesmo com todos os consultores disponíveis não têm como avaliar os "valores políticos, sociais, econômicos e culturais" da totalidade dos envolvidos. Além disso, limitações de custo e tempo em orçamentos também limitados encurtam as pesquisas;

ix. O histórico de políticas públicas passadas afasta ou atraí a atenção de formuladores de políticas públicas sempre em busca de minimizar o risco político em todas as suas atividades. Esse comportamento faz com que grande parte de "novas" políticas sejam variações marginais de políticas anteriores com o intuito de amortizar incertezas e efeitos inesperados.

x. As rivalidades inter e intra partidárias impedem a cooperação na formulação de políticas e a real decisão mais racional disponível. Consultores especializados são contratados por visões de mundo diferentes e no momento decisório, mesmo opiniões reconhecidamente relevantes são descartadas por questões não diretamente relacionadas ao debate à volta de políticas públicas específicas. 


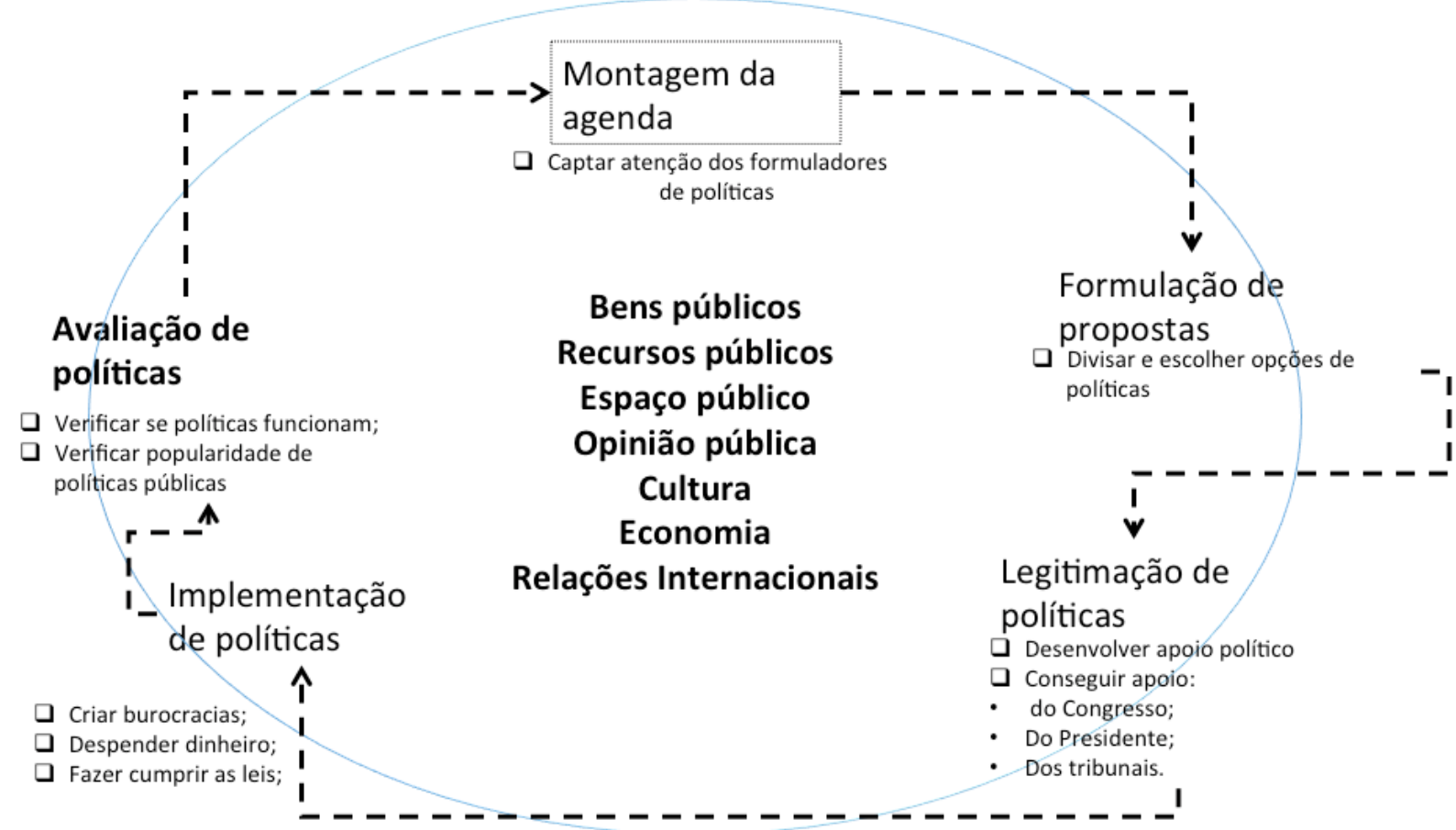

Figura 15: Modelo racional de sistema de decisão Fonte: Dye, 2012, p. 114.

\subsubsection{Modelo incremental}

O incrementalismo, como o próprio termo explicita, concebe a formulação de políticas públicas como uma atividade de continuação e melhoras paulatinas e marginais. Para os incrementalistas, por pragmatismo, políticos não despendem muito tempo na análise de opções racionais de política. Pelo contrário, por conservadorismo e praticidade e contenção de gastos, tomam como base e modelo de quaisquer ações, políticas, projetos e programas, aquilo que já é vigente. Mesmo políticas iniciadas em mandatos de partidos rivais são geralmente continuadas caso tenham legitimidade e aceitação; comumente nomes são mudados e pequenas mudanças realizadas. Dye (2012), resume o incrementalismo nos seguintes pontos:

I. Escassez. O modelo incremental é o modelo da falta: faltam tempo, informação e financiamento para pesquisas exaustivas de alternativas. A coleta de dados é onerosa, a capacidade de processamento do risco de cada opção também. Por isso, para o incrementalismo, o processo racional é considerado ineficiente pelos custos financeiros e temporais nele envolvidos;

II. Seguro. Políticas anteriores são mais seguras e assegurar continuidade é menos arriscado do que apoiar políticas novas. E, essa continuidade não está diretamente relacionada com eficácia. A política pode até ser ineficaz, no entanto, se há a percepção de apoio popular, a probabilidade de sua manutenção é alta; 
III. Custos imobilizados. O investimento realizado ao longo dos anos à volta de determinadas políticas inviabiliza o abandono das mesmas pelos altos custos envolvidos. Estruturas físicas, organizacionais e burocráticas se tornam parte do próprio tecido do qual a sociedade é construída e muda-las pode se tornar politicamente inviável.

IV. Conveniente e não beligerante. Mudanças incrementais geram menos conflito ou potencial de conflito. Quando as alterações sugeridas não mudam a base da política e não envolve ganhos ou perdas que mudem o status quo, a probabilidade de aprovação é maior. Menos conflito pode ser igual a mais estabilidade e preservação de avanços conquistados ao longo dos anos pela população ou parte dela.

V. Pragmatismo e satisfação. A busca por "algo que funcione" é o padrão de comportamento humano da maioria, inclusive de políticos. O "mais racional", ou "o melhor" são quase sempre abstrações que são postergadas assim que qualquer coisa que funcione mais parecido com algo conhecido e familiar é encontrado. Pequenos ajustes a políticas existentes geralmente são direcionadas a atender demandas específicas e mudanças mais radicais são adiadas ad nauseam.

VI. O modelo do possível. A continuidade geralmente é mais palatável e atingível em meio à dissensão sobre questões ideológicas, valores ou mesmo metas no contexto de um Estado-nação democrático.

Depreende-se dos pontos acima que o modelo incrementalista analisa apenas os impactos mais relevantes de uma política pública. Conclui-se também que não há a busca por políticas eficientes e eficazes, nem a busca por soluções ótimas. O que existe é a busca constante por acordos pois a política correta é aquela que atende ao mínimo denominador comum de todos participantes envolvidos e remedia a necessidade premente. Essa característica faz com que o processo de formulação e implantação de políticas públicas seja sempre de acerto e erro. À medida que erros passados se tornam aparentes, novas medidas são tomadas para corrigi-los e acertos, em geral, marginais, são acordados entre agentes políticos, sempre permeados pelo pragmatismo da política possível (Dunn, 2012; Lindblom \& Woodhouse, 1993; Dye, 2012).

\subsubsection{Modelo da teoria de jogos}

Trata-se de um modelo abstrato e dedutivo do processo de tomada de decisão (Dye, 2012). A política na teoria dos jogos se assemelha a um jogo em que todos os envolvidos têm suas escolhas balizadas pela escolha de todos os outros participantes. O modelo é comumente aplicado a situações do processo de formulação de políticas públicas em que a melhor opção é sempre resultante do conjunto de escolhas de todos os agentes envolvidos. 
Há interdependência complexa em que cada agente precisa concertar suas ações de acordo com aquilo que espera dos outros agentes, desde que tomem decisões racionais.

O conceito central do modelo é a estratégia: o conjunto de decisões e subsequentes ações que levam o "jogador" à melhor posição relativa possível, considerando todas as possíveis de seus concorrentes. A melhor estratégia possível é chamada de "minimax", aquela que simultaneamente minimiza o maior prejuízo e maximiza o lucro de um dos participantes, independentemente daquilo que o concorrente faça e desse modo, proteja o participante contra o melhor conjunto de decisões que o concorrente possa concatenar. $O$ minimax é a melhor estratégia racional possível, por definição conservadora, já que busca minimizar prejuízos e assegurar lucros mínimos e não tentar ganhos máximos arriscando maiores prejuízos (Dye, 2012; McCain, 2009).

A teoria dos jogos é uma ferramenta analítica válida e instigante que apresenta uma forma lúdica de abstração sobre o conflito em formulação de políticas públicas. No entanto, falta-lhe o grau de detalhamento que permita uma aproximação maior com situações mais comumente enfrentadas por formuladores de políticas. Além da dificuldade de formular políticas puramente racionais, conforme visto anteriormente, as condições apresentadas nas matrizes utilizadas no modelo dificilmente se apresentam de forma tão evidente na política real. Também, não há tempo e "conhecimento de prateleira" suficientes para que os formuladores saibam dos valores corretos das recompensas dos concorrentes ou dos seus nos diferentes posicionamentos e cenários políticos possíveis. A utilidade prática, portanto, da teoria dos jogos é posta em jogo mesmo por ilustres estudiosos do modelo, além de existir forte discordância entre os teoristas de jogos sobre a relevância e uso potencial da mesma (Rubinstein, 2004; Dye, 2012).

Na opinião de Rubinstein (2004), o objeto de estudo da teoria dos jogos é tão somente estudar aquilo que é levado em conta no processo decisório em situações interativas, identificar padrões de raciocínio e investigar implicações das mesmas em situações estratégicas de processos decisórios. Esta opinião também refuta qualquer papel normativo ao modelo e restringe sua relevância empírica, sendo sua utilidade e praticidade apenas indireta, pois "[...] we need to keep in mind that the challenges facing the world today are far too complex to be captured by any matrix game." (RUBINSTEIN, 2004, p. 636).

\subsubsection{Modelo sistêmico}

A teoria sistêmica analisa causalidade e resultados de políticas públicas. No contexto do sistema político - o complexo estrutural e processual que legitimamente dispõe dos valores da sociedade - há inputs e outputs. Os inputs são as influências advindas do contexto geral (ambiente) que impactam o sistema político, enquanto os outputs são as 
alocações legítimas de valores do sistema, ou políticas públicas. Em outras palavras, as políticas públicas são o produto do sistema político. O sistema é o conjunto de instituições e ações que canalizam as demandas da sociedade e as convertem em leis de acordo com o desejo da mesma, no contexto de uma democracia. Sendo que, em um sistema, os componentes são interligados e reagem aos estímulos do ambiente, constantemente buscando o equilíbrio que preserva o próprio sistema (Dye, 2012).

A sociedade gera os inputs para o sistema político por meio de demandas e apoios. As demandas são as ações dos indivíduos para influenciar os resultados da política enquanto o apoio é tudo aquilo que pode ser interpretado como conformidade e aceitação dos resultados do sistema por parte de indivíduos e grupos - por exemplo, aceitação do resultado de eleições, subordinação às leis e pagamento de impostos. Tanto as demandas quanto os apoios se dão como reação às circunstâncias verdadeiras e/ ou imaginárias de grupos e indivíduos. Obviamente, demandas e apoios são muitas vezes colidentes e é o sistema que catalisa acordos, compromissos e comprometimentos entre as partes interessadas. Também é o sistema que deve fazer cumprir essas obrigações recíprocas ou outputs que tomam a forma de políticas públicas (Dye, 2012; Hoos, 1983).

Os outputs têm o potencial de modificar o ambiente e as demandas que partem dele, além de influenciar o próprio sistema político, isto é, modificar o ambiente a partir de um mecanismo de feedback ou retroalimentação. A autopreservação do sistema é garantida pelo encorajamento de políticas públicas, ou outputs, suficientemente eficazes e eficientes, no contexto de subordinação e aceitação dos compromissos inalienáveis que sustentam o próprio sistema, e por fim, o exercício do monopólio legítimo da ameaça e do uso da força (Dye, 2012).

As seguintes questões são significativas na análise realizada por meio do modelo sistêmico:

a. Quais são as dimensões ambientais significativas que geram demandas sobre o sistema político?

b. Quais são as características relevantes do sistema político que o habilitam a transformar demandas em políticas públicas e a preservar-se ao longo do tempo?

c. Como os inputs ambientais afetam o caráter do sistema político?

d. De que maneira as características do sistema político influenciam o conteúdo das políticas públicas?

e. De que modo os inputs ambientais influenciam o conteúdo das políticas públicas?

f. Como as políticas públicas afetam, via feedback, o ambiente e o caráter do sistema político? (Dye, 2012). 


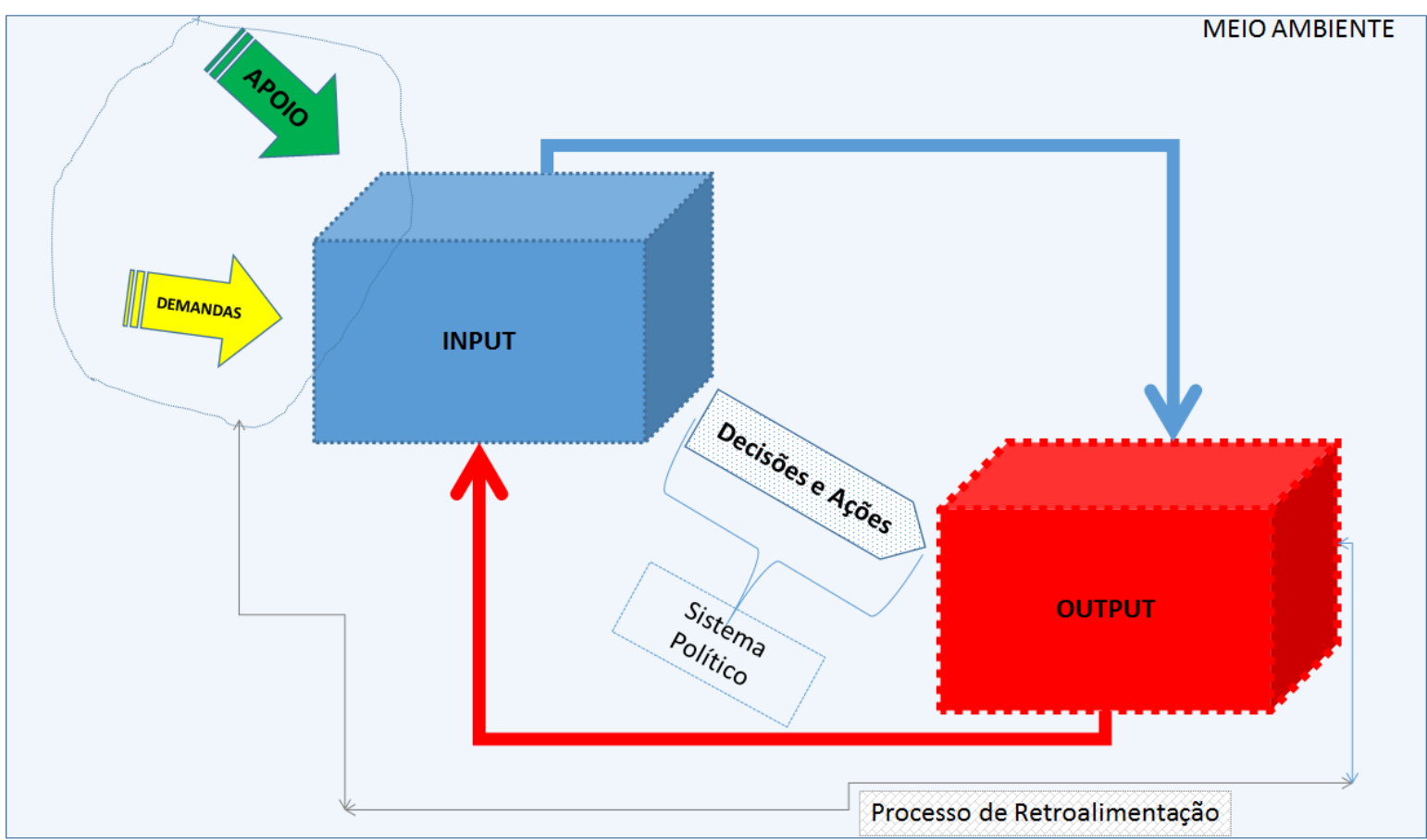

Figura 16: modelo simplificado de um sistema político

Easton, 1965, p. 112. Adaptado e elaborado pelo autor a partir da fonte.

O modelo sistêmico parece ser razoavelmente útil para o campo de estudo de políticas públicas quando reconhecidas as limitações inerentes à abordagem. Também existe a necessidade de reconhecer que em dadas circunstâncias e/ ou períodos, a natureza errática e discricionária do processo político supera os limites computacionais de identificação de uma teoria causal geral no atual estágio de desenvolvimento das ciências sociais aplicadas. Apesar disso, as estruturas institucionais, os processos legislativos e consuetudinários, em mutação ou aparentemente permanentes são padrões de comportamento e regras que balizam decisões que podem ser analisadas pelas ferramentas do modelo de sistemas (Rissmiller, 2000).

\subsubsection{Modelo da opção pública}

A política na teoria da opção pública é a deliberação - debate oral, discussão, reflexão, decisão - coletiva de indivíduos no contexto de um sistema econômico e político, estimulados pelo interesse próprio. O homo economicus e o homo politicus não existem em isolamento, tanto um quanto outro atuam simultaneamente nas arenas econômica e política. $\mathrm{E}$ nas duas agem movidos pelo interesse próprio. Os agentes políticos agem como os agentes econômicos da teoria econômica neoclássica e buscam maximizar seus ganhos. Tanto na política quanto na economia, os participantes negociam com o objetivo de gerar benefícios mútuos ocasionados pelo modo coletivo de tomada de decisão (Munger, 2013; Dye, 2012). 
O governo é em si resultado de um contrato social entre "iguais" que voluntariamente aceitam leis e pagam impostos que sustentam o Estado a troca da defesa de seus valores, vidas e propriedades. O Estado assume aquilo que empreendedores particulares não têm interesse em assumir devido aos custos envolvidos e outras desvantagens e os provê como bens públicos Os custos de bens públicos são proibitivos já que ultrapassam o valor econômico e não há como excluir seu uso para alguns e permiti-lo para outros ${ }^{35}$. Diferente da interpretação neoliberal da opção pública, a análise das "falhas de governo" e do processo de formulação de políticas públicas não remete à necessidade de Estado e governo menores, e sim, Estado e governo melhores (Pereira, 1997).

Concomitantemente a questão dos bens públicos, há as externalidades, custos ou benefícios que não são transmitidos pelos preços e que são incorridos por um agente que não concorda explicitamente com a ação que gera o custo ou o benefício. O custo de uma externalidade é uma externalidade negativa, ou custo externo enquanto o benefício de uma externalidade é uma externalidade positiva, ou benefício externo. Como explica Krugman et al (2012), tanto no caso de externalidade positiva quanto na negativa, preços em um mercado concorrencial não refletem os custos totais ou benefícios de produção ou consumo do produto ou serviço. Dye (2012), cita os exemplos da poluição da água e do ar e os custos generalizados que estes causam a todos.

Segundo a teoria da opção pública, partidos e candidatos políticos em regimes políticos democráticos sempre procuram a melhor estratégia de maximização de votos. Não são os princípios que mais interessam mas o sair-se bem nas eleições seguintes. Isso não quer dizer que os princípios não são importantes: eles apenas tomam um papel secundário em períodos eleitorais. Por essa premissa, partidos não extremistas tendem para o centro, pois é no centro, seja de esquerda ou de direita, que se concentra a maioria dos votos (Dye, 2012; Sobel \& Pellillo, 2013).

Há dissonância entre os interesses de políticos, burocratas e eleitores médios, às vezes por desinformação mútua e mais frequentemente pela preeminência dos interesses dos próprios políticos - reeleição, contribuições de campanha, orçamentos direcionados e redirecionados, controle de órgãos governamentais, prestígio pessoal e partidário, "mais poder". A teoria da opção pública reconhece essa distinção e a dificuldade de aferição dos anseios do eleitorado: consumidores políticos se envolvem pouco no dia a dia da política, diferente de consumidores econômicos que continuamente atuam no "mercado" (Dye, 2012; Sobel \& Pellillo, 2013; Tullock et al., 2002).

\footnotetext{
${ }^{35} \mathrm{O}$ bem público é aquilo (bem, serviço, etc.) que é fornecido sem lucro a todos os membros de uma sociedade, ou pelo Estado ou por um indivíduo ou por uma organização, ou por uma combinação dos três. O bem é nãoexclusivo, não-rival e é caracterizado pela indivisibilidade. Por exemplo, as forças armadas, transmissão de rádio e televisão abertas, iluminação pública. Vide Krugman et al., 2012.
} 
Aproveitando-se desse fato, políticos e burocratas acabam por alocar mais recursos para seus projetos, interesses pessoais e partidários e subestimam custos e superestimam dividendos. O resultado são bens públicos que não são totalmente públicos pois favorecem mais a alguns, em indústrias e setores específicos e prejudicam a todos pois socializam os custos. Grupos mais homogêneos, organizados, informados e militantes tendem a sequestrar a agenda política nacional e são capazes de alocar recursos na forma de subsídios, benefícios, regulamentações, proteções e tratamentos especiais e privilégios. No mercado político, grupos de interesse, quando atuam sem forte regulamentação, levam ao descontrole organizacional do Estado e minam os incentivos à produtividade, investimento $\mathrm{e}$ trabalho (Dye, 2012; Ostrom \& Ostrom, 1977). Essa conclusão ressoa na análise do sistema de segurança alimentar indiano dos Capítulos 6 e 7.

Entender o gap entre aquilo que o legislador pretende e os outputs das políticas públicas não entra no escopo de quase nenhum modelo. Entre os dois pontos há, por exemplo, (i.) regulamentações que alteram a implementação, (ii.) o financiamento fora do escopo necessário ou do prazo demandado, (iii.) a gestão inadequada de programas previstos nas políticas e (iv.) a alocação equivocada dos custos e benefícios ao longo da vigência da política. Winkler (2009), defende que apenas a teoria da opção pública investiga o que incentiva diferentes grupos a promoverem ou dificultarem a implementação de políticas baseado no conhecimento dos objetivos das partes interessadas por meio da investigação do acesso à informação e prestação de contas (accountability). A teoria da opção pública seria a mais compreensiva, enquanto as outras teorias poderiam ser vistas como teorias auxiliares. A teoria da opção pública seria a mais consistentemente testada, adaptada e ampliada para explicar melhor e mais fenômenos de, por exemplo, "[d]o papel da assimetria informacional na elucidação das divergências entre a intenção do legislador e o impacto final da decisão política. " (WINKLER, 2009, p.132).

A teoria da opção pública aplica uma versão adaptada do modelo de escolha racional das ciências econômicas a questões de tomada de decisão fora do mercado econômico, isto é, economia mainstream aplicada às políticas públicas: o indivíduo maximizando o interesse próprio no mercado político restrito por limites institucionais e orçamentários. O governo é apenas um conjunto de instrumentos para a provisão de certos serviços e bens que o mercado tem dificuldade de prover.

Os teóricos da opção pública foram influenciados por Maquiavel (1469-1527) e Hobbes (1588-1679), mas foi apenas após a Segunda Guerra Mundial (1939-1945) que a teoria começou a tomar sua forma contemporânea. Motivados pelo trabalho teórico sobre as funções de bem-estar social, o desenvolvimento das teorias de falhas de mercado e o aumento do tamanho do governo, economistas foram levados a teorizar sobre o papel do 
governo e como indivíduos se comportam para alcançar seus objetivos coletivamente (Hill, 1999:1). Embora muitos outros tenham contribuído, James Buchanan e Tullock (1962), e novamente Buchanan (1969), foram os principais e mais influentes exponentes da teoria.

Falhas de governo

A teoria da opção pública interessa a este trabalho de tese principalmente devido à análise das chamadas "falhas de governo", espelhada no conceito de "falhas de mercado" no estudo da economia. Falhas de governo são situações nas quais a eficiência de alocação pode ser reduzida após intervenção do governo nos mercados com o intuito de corrigir falhas de mercado. Em geral, o governo intervém para: (1) corrigir escassez ou excessos; (2) fornecer produtos e/ ou serviços que o mercado não deseja e/ ou não tem como prover; (3) regular e corrigir mercados nos quais acredita-se que há desigualdade ou ineficiência não justificada; (4) proteger indivíduos e grupos considerados vulneráveis e incapazes de se protegerem; (5) reduzir a pobreza; e, (6) influenciar direitos de propriedade. Para intervir, em geral, o governo usa: (I) tributação, para redistribuir e gerar incentivos ou efeitos de desincentivo; (II) subsídios: para estimular a produção e o consumo; (III) Regulamentação: para dar direção, regulamentar; (IV) Direitos de propriedade: processo de patenteamento, identificação de direitos de propriedade; e, (V) Direcionamento, alocação de recursos e bens. As intervenções do governo, no entanto, têm vieses e limitações devido a uma série de fatores, entre os quais o modelo da opção pública se concentra em dois: logrolling e rentseeking.

A opção pública e o logrolling

Logrolling traduzido literalmente para o português, "rolar toras", é a troca de votos. O termo originado nos Estados Unidos, provavelmente deriva do ato de mover os troncos de árvores cortadas que quase sempre demandava o esforço conjunto de vizinhos, um dia na terra de um, outro dia na terra de outrem. O logrolling explícito é o acordo para a troca de votos em negociações e votações diversas. A prática é comum em assembleias legislativas, comitês e outros órgãos deliberativos democráticos nos quais os membros individuais e agrupamentos divulgam suas posições e intenções de voto abertamente e há razoável disciplina partidária. O logrolling implícito ocorre quando os grupos de interesse agrupam diferentes propostas antes de uma votação. Os votantes que fortemente apoiam um determinado item da pauta acabam por votar em outras propostas também. Os benefícios para os legisladores são muitos, principalmente no que diz respeito ao compartilhamento de responsabilidades na aprovação de matérias pouco ou não consensuais (Butler, 2012). 
A prevalência de logrolling é comum em regimes democráticos. O logrolling implícito é o mais comum e pode ser mais facilmente observado na política partidária, especialmente antes de eleições e na elaboração de programas partidários. Como partidos são ajuntamentos de interesses vagamente coesos, as políticas apoiadas e adotadas pelo grupo precisam ser uma combinação de políticas populares com a maioria dos adeptos e algumas que talvez não sejam de importância para a maioria. Em assembleias legislativas, o logrolling implícito também domina e praticamente toda proposta que chega a ser votada é resultado de logrolling, com concessões e compromissos que 'compram' o apoio de minorias e possibilitam a passagem da proposta (Evans, 1994; Carrubba \& Volden, 2000).

Há benefícios e malefícios ao logrolling. Pode ser benéfico e eficiente quando exibe as posições de indivíduos e grupos e facilita a aferição de preferências. Também em situações em que os benefícios de uma política pública extrapolam os custos, mesmo que a maioria da população, se oponha a ela por qualquer razão que seja. O logrolling permite a troca de votos para a realização de tais iniciativas (Dye, 2012; Evans, 1994; Carrubba \& Volden, 2000).

A prática, no entanto, pode ser facilmente viciada. Em democracias grandes como nos Estados Unidos, Brasil e Índia, o logrolling resulta em custos maiores para os contribuintes, já que a compra de apoio político nos volume e escala praticados, em geral não justificam o custo econômico envolvido, embora existam estudos que contradigam esta posição (Ricci, 2003). Em inglês, o termo é pork barrel politics ("política do barril de carne suína"). O pork é o financiamento de políticas, programas e projetos governamentais e/ ou serviços que beneficiam uma área, indústria ou parcela da população específica, mas que em contrapartida, compartilha custos com 0 universo de contribuintes. Minorias bem organizadas, decididas e persistentes são especialmente propensas a se utilizarem desse instrumento pois não têm como fazer valer sua vontade por meio da urna de votação. Do outro lado da equação, se encontram políticos que desejam 'comprar' o voto minoritário mesmo a altos custos. Embora parte da vida política democrática, o logrolling tende, quando abusado, a obscurecer e ocultar os reais interesses e aumentar custos (Lancaster, 1986; Ricci, 2003).

Onde termina o logrolling e onde inicia a corrupção desvelada de compra e venda de votos é algo sem clara definição. Os meios para conter abusos propostos pela literatura são:

1) Referendos e plebiscitos sobre questões isoladas ou raras;

2) Poder legislativo bicameral, com bases de eleição diferenciadas; e,

3) A previsão constitucional de veto presidencial (Engstrom \& Vanberg, 2010; Butler, 2012). 
Mesmo assim, aponta Butler (2012), não há como garantir a eficiência dos pesos e contrapesos. Nos Estados Unidos, por exemplo, mesmo com a existência dos três instrumentos, o logrolling e o pork barrel são endêmicos à política do país. Mais efetivos parecem ser restrições orçamentárias e fiscais sobre o tamanho do governo em si e seus gastos.

A opção pública e o Rent-seeking

Rent-seeking, conceito desenvolvido por Gordon Tullock (1967) e termo cunhado por Anne Krueger (1974), é o processo concorrencial de expropriação de rendas artificiais geradas da intervenção do Estado na economia. Esta intervenção é motivada por meio de lobbying político, financiado por interessados nos resultados das políticas. Rent-seeking, em português, 'busca de rendas', implica na busca de renda econômica ${ }^{36}$ por meio de influência ativa nos meios político e social no contexto dos quais as atividades econômicas acontecem. Há extração de ganhos não compensados de outros agentes políticoeconômicos sem qualquer contribuição à produtividade. Grupos com interesses especiais em determinadas indústrias e/ ou setores se organizam para captar transferências instituídas por intervenção do governo nas transações privadas, além de procurarem influenciar formuladores de políticas a criarem transferências por meio de legislação direcionada a interesses especiais. Os custos do rent-seeking para a economia de um país incluem os recursos gastos com os esforços para "encorajar" os legisladores a aprovarem leis que criam escassezes artificiais e também os gastos com a captura desses benefícios após a promulgação das leis (Buchanan, 1980; Butler, 2012; Mbaku, 1998).

Oportunidades de ganhos acima de mercado podem ser criadas pelo Estado por meio da criação de monopólios e reservas de mercado. Tullock (1967) observou que os grupos interessados despendem recursos consideráveis para deslocar o "sistema" em seu favor, distorcendo o processo de decisão e formulação para restringir a concorrência em benefício próprio e onerar o universo de contribuintes indiscriminadamente. Em economias de mercado, com ou sem prejuízos à economia como um todo, a concorrência e competição pela renda econômica é legalmente aceita, praticada e encorajada. Por outro lado, práticas como o contrabando, suborno, corrupção ativa e passiva e alguns tipos de atividades econômicas nocivas à concorrência, previstas em lei, são coibidas.

As categorias de políticas rent-seeking de Rausser: PERTs e PESTs

Rausser (1982), sugere as seguintes categorias de rent-seeking:

\footnotetext{
${ }^{36}$ Renda econômica é a parte da renda paga a um fator de produção além daquilo que é necessário para mantêlo empregado em seu uso atual. Veja Pindyck \& Rubinfeld, 1995; Djolov, 2013.
} 
I. PERTs - (Political Economic Resource Transactions) Transações Políticas de Recursos Econômicos: são políticas governamentais de intervenção para correção de falhas de mercado. Objetivam reduzir custos de transação do sistema econômico privado. Os efeitos líquidos de políticas do tipo PERT são acrescer as dimensões do mercado e/ ou indústria alvo da política; e,

II. PESTs - (Political Economic-seeking Transfers) Transferências Políticas de Interesse Econômico: são políticas inequivocamente de natureza rent-seeking. À volta desta categoria de rent-seeking se encontra o posicionamento político e ideológico de que o governo é apenas um grande mecanismo de transferência de renda e riqueza. O governo intervém não devido às falhas de mercado, e sim, devido às falhas de governo. Nesta visão, o governo não tem qualquer autonomia, pelo contrário, é constantemente manipulado por grupos de interesse que o direcionam para o bem-estar do grupo e seus interesses, em detrimento da sociedade como um todo. Assim, o governo não interfere para aumentar a eficiência, reduzir custos de transação, mas apenas para redistribuir riqueza de um grupo para outro.

Rausser (1992), argumenta que o estudo da história da política pública agrícola nos Estados Unidos por exemplo, demonstra tanto conflito entre Transações Políticas de Recursos Econômicos (PERTs) e Transferências Políticas de Interesse Econômico (PESTs), como também coordenação entre os dois tipos de políticas públicas agrícolas. Esta combinação de conflito e coordenação resultou em combinações de programas governamentais aparentemente contraditórias. A aprovação ou não desses programas, por sua vez, é consequência dos arranjos institucionais que favorecem um conjunto de políticas produtivas e também predatórias (Rausser, 1982; 1992).

Em geral, economistas estudam as PESTs como se fossem algo diferente de outros tipos de política. A maioria tenta explicar a existência de 'Transferências Políticas de Interesse Econômico' (PESTs) por meio da influência relativa de grupos de interesse ou pela falta de transparência dos estudos de impacto das políticas. Rausser (1992), no entanto, afirma - em relação a políticas públicas nos Estados Unidos - que as políticas tendem a ser combinadas para que interesses divergentes possam aquiescer a uma determinada política em troca de outra. O autor argumenta que o mesmo vale para todas as categorias de atividades do setor público, por exemplo:

i. Privatizações com salvaguardas para alguns grupos sociais em áreas da economia previamente planejadas e controladas pelo governo;

ii. Planejamento urbano e a permissão de exceções de zoneamento em troca do fornecimento de bens públicos locais; e, 
iii. Ajustes de compensação especial a trabalhadores de indústrias enfrentando concorrência internacional crescente. (Rausser, 1992, p.152).

\section{CONCLUSÃO}

Este capítulo descreveu e examinou modelos e teorias de análise de políticas públicas. Não existe um único modelo ou teoria que baste para a análise de políticas públicas em geral ou de políticas públicas para a segurança alimentar. O modelo serve como representação estilizada e simplificada da realidade multidimensional, complexa e sempre atrelada à variável tempo. Ao facilitar a exposição de ideias sobre as políticas, o contexto e caminho das mesmas e propor explicações e previsões de resultados diretos e indiretos, os modelos, teorias e as visões de mundo por trás de ambos permitem ao pesquisador organizar sua tese. Reconhecendo as vantagens e deficiências de cada um, para os objetivos desta tese, a aplicação de conceitos e ferramentas de modelos das ciências econômicas, da economia política e da ciência política à análise de políticas públicas de segurança alimentar e nutricional, sem necessariamente priorizar um modelo, é o mais indicado. 
SEGUNDA PARTE: O CASO DA ÍNDIA 


\title{
CAPÍTULO 6: VISÃO GERAL SISTEMA PÚBLICO DE DISTRIBUIÇÃO
}

\author{
6 VISÃO GERAL SISTEMA PÚBLICO DE DISTRIBUIÇÃO
}

\section{INTRODUÇÃO}

O capítulo 6 trata das políticas públicas de segurança alimentar da Índia, especialmente do Sistema Público de Distribuição (PDS - sigla em inglês), a principal intervenção estatal no provimento de alimentos subsidiados aos mais pobres no país. Primeiramente, apresenta-se parte do universo dos programas de segurança alimentar e correlatos do Governo da Índia. Em seguida, segue um breve histórico das políticas de segurança alimentar a partir da década de 1880, quando a Comissão [contra a] da Fome do governo colonial foi formada e codificou as respostas do governo a situações de crise alimentar. As influências ideológicas e conjunturais são apresentadas na subseção imediata no intuito de situar a iniciativa colonial no contexto econômico do período. Na sequência, as políticas de segurança alimentar pós-colonial no âmbito da Comissão de Planejamento são apresentadas como parte da gênese do PDS durante o ocaso do sistema colonial inglês quando as politicas agrícola e de assistência alimentar tinham como caraterística principal o controle de preços e o racionamento. Os primórdios do PDS e sua mutação de instrumento de controle de preços e racionamento para um sistema de segurança social, alimentar e econômica é discutida à luz da Lei de Assistência de Desenvolvimento de Comércio Agrícola dos Estados Unidos de 1954 que proveu parte relevante das condições que possibilitaram a Índia a consolidação de programas de segurança alimentar, especialmente entre as décadas de 1950 e 1960.

A segunda parte do capítulo, trata das tentativas do Governo da Índia de remodelar o sistema e também da própria organização física do mesmo. A primeira das tentativas ocorreu em 1992 com o Sistema Público de Distribuição Renovado - Revamped Public Distribution System (RPDS - sigla em inglês), que teve duração efêmera, sendo que elementos cruciais da reforma não saíram do papel. A segunda tentativa, de 1997, ocorreu com o Sistema Público de Distribuição Direcionado - Targeted Public Distribution System TPDS. Como indica o nome, o governo converteu o programa em um sistema não universal, direcionado à parcela da população abaixo da linha de pobreza, linha esta traçada por grupos de especialistas comissionados pelo governo de tempos em tempos. Em seguida, as especificidades da estrutura, organização e funcionamento do SDP são apresentadas até sua configuração em 2013, quando um novo projeto de lei - que se propôs a reformular o PDS - foi passado pelo poder legislativo indiano. No contexto da discussão sobre estrutura, o instrumento econômico no cerne do sistema, o subsídio para alimentação e suas implicações para as politicas econômicas domésticas e internacionais e as posições da Índia 
na Organização Mundial do Comercio (OMC) em defesa de sua política de segurança alimentar e agrícola é exposto sucintamente. A metodologia de cálculo da linha da pobreza é discutida com alguma profundidade na seção seguinte dada sua importância para a identificação das famílias abaixo da linha de pobreza e para a viabilidade do próprio sistema de distribuição de alimentos direcionado. Na sequência, as principais críticas técnicas e gerais ao processo de cálculo seguem à apresentação da metodologia de cálculo. Por fim, algumas das principais falhas do PDS são compiladas e na seção de conclusões o autor encerra o capítulo com uma exposição opinada dos achados contidos no mesmo.

\subsection{DIVERSIDADE SEM UNIDADE}

A Índia - o maior país democrático do mundo com um bilhão e duzentos milhões de habitantes - é uma união de 29 estados e 7 territórios da união regidos por uma sistema federativo de estado, com um sistema de governo parlamentarista bicameral, cujo presidente é o chefe de Estado e um primeiro ministro, chefe de governo. Do ponto de vista formal, a estrutura legal do estado indiano é muito semelhante àquela adotada por muitos estados democráticos europeus e americanos. O presidente da república é eleito indiretamente pelos representantes de ambas as Casas do parlamento a cada 5 anos, enquanto o primeiro ministro é eleito também indiretamente, mas apenas pela Casa mais baixa. A Casa que corresponde ao senado em diversos países, é chamada de Rajya Sabha na Índia, contando com 245 membros que são eleitos pelos membros eleitos das Casas legislativas estaduais de seus respectivos estados (exceto 12 membros que são nomeados pelo presidente). A cada 2 anos, um terço do Rajya Sabha é renovado. O Lok Sabha é a Casa mais baixa e congrega 545 membros que representam o povo e são escolhidos por eleições diretas (exceto 2 membros que são apontados pelo presidente da república para representar a comunidade anglo-indiana) a cada 5 anos. O Governo da Índia é oficialmente conhecido como o Union Government, o Governo da União, e geralmente chamado de Governo Central, cuja capital é Nova Délhi. O sistema jurídico é baseado na lei comum inglesa e dispõe de um sistema semelhante ao inglês, tendo, no entanto, a Suprema Corte da Índia como autoridade judiciária máxima (Sharma, B. K., 2007).

O Serviço Civil da Índia é a burocracia permanente do estado e tem suas raízes e pode ser considerado uma continuidade do governo colonial inglês, o British Raj. O Serviço Administrativo Indiano (IAS - sigla em inglês), comandado pelo secretário de gabinete é a burocracia mais prestigiosa e concorrida no país, sendo o braço do primeiro ministro (Parashar, 2003). Em nível estadual, há os ministros chefes (chief ministers). Em seis estados (Uttar Pradesh, Maharashtra, Bihar, Karnataka, Jammu e Kashmir, Andhra Pradesh e Telangana) existe um sistema bicameral, enquanto todos os outros são unicamerais. No 
nível subestadual, há os panchayats na zona rural e as municípios na zona urbana. Em relação à prática política partidária, embora a política nacional seja dominada por dois partidos, o Congresso Nacional da Índia (INC - sigla em inglês) e o Bharatiya Janata Party (BJP - Partido do Povo Indiano - sigla em hindí), há centenas de partidos estaduais e regionais baseados em religião, língua, casta e outras divisões características do país (Mitra, S. K., 2011).

Da independência em 1947 até o início da década de 1990, o pais foi governado por uma sucessão de governos socialistas (principalmente do INC), com planejamento central da economia, protecionismo exacerbado e consequente criação de monopólios e conglomerados que dominam a economia continuamente. Combinada à distorção econômica, houve um recrudescimento de diferenças regionais baseadas principalmente em grupos linguísticos, etnias, castas, religião (embora o separatismo não tenha prosperado no país) que sobrevivem (especialmente na zona rural) e até mesmo se fortalecem com o crescimento econômico e aumento paulatino do nível educacional geral. A relativa autonomia de cada estado e discricionariedade se expressam nos sistemas administrativos do poder público. E, a diversidade regional se reflete, por exemplo, na interpretação e aplicação de políticas públicas nacionais, inclusive de segurança alimentar (Mitra, S. K., 2011).

\subsection{OS CÓDIGOS DE FOME INDIANOS}

A Índia dispõe de diversas políticas de segurança alimentar que não se encontram sob um único guarda-chuva político e programático, como ocorre, por exemplo, no Brasil. Outros programas do Governo da Índia para segurança alimentar além do principal - o Sistema de Distribuição Pública Direcionado ou Sistema Público de Distribuição Direcionado, em inglês, Targeted Public Distribution System, TPDS -, são: (1) Projeto de Almoço ("Mid-Day-Meal-Scheme" - MDM); (2) Programa de Nutrição Baseado no Trigo ("Wheat Based Nutrition Programme" - WBNP); (3) Dormitórios e Pensionatos para Castas Reconhecidas, Tribos Reconhecidas e Outras Classes Atrasadas ("SC/ST/OBC" Hostels); 37 (4) Programa Annapurna ${ }^{38}$; (5) Programa de Fornecimento de Grãos Alimentares para Indigentes custodiado por Instituições de bem-estar; (6) Programa de Emprego Rural

${ }^{37}$ Em inglês, Scheduled Castes (SC), Scheduled Tribes (ST) and Other Backward Classes (OBC). A constituição Indiana reconhece a existência de grupos populacionais indianos que se encontram em graus e níveis de desenvolvimento educacional, econômico e social abaixo e atrás da maioria da população e para nivelar o acesso politico, econômico e social criou um sistema complexo de cotas e reservas baseado em castas e tribos reconhecidas. Por isso, o uso do termo "atrasadas", que obviamente denota algo que permeia a sociedade indiana: o preconceito e a segragação social em diversas bases. Veja, Rana (2008)

38 O Programa Annapurna ou Annapoorna, lançado no ano 2000 , tem por objetivo garantir a segurança alimentar de da população com idade acima de 60 anos que embora elegível ao Programa Nacional de Pensões para a Terceira Idade, não se encontram sob a cobertura do mesmo e que estão abaixo da linha de pobreza do Governo da Índia (Governo da Índia, 2011). 
Universal ("Sampoorna Gramin Rozgar Yojana” - SGRY), encerrado como programa independente em 2006, quando passou a fazer parte do (7) Programa Nacional de Garantia de Emprego Rural ("National Rural Employment Guarantee Programme"- NREGP); Programa de Alimentação para Mulheres Lactantes, Grávidas e Adolescentes ("Food grains to Adolescent Girls, Pregnant and Lactating Mothers - AGPLM"); e o (9) Programa de Intervenção de Mercado. ${ }^{39}$ Há também muitos outros programas não governamentais, de organismos internacionais do sistema da Organização das Nações Unidas, como, por exemplo, o Programa Mundial de Alimentação e também de organizações não governamentais internacionais, organizações religiosas e cívicas nacionais e internacionais (Murthy \& Ramanayya, 2007, Governo da Índia, 2001).

A primeira política pública, no entanto, que pode ser considerada de segurança alimentar na Índia "moderna" foram as recomendações e leis cujo conjunto ficou conhecido como "Os Códigos de Fome Indianos" de 1883. De 1860 a 1877, ocorreram várias crises alimentares severas na então Índia britânica que custaram milhões de vidas, oneraram a economia e geraram danos políticos ao poder colonial e à elite local. Do período de $1870 \mathrm{a}$ 1910, calcula-se que 30 milhões de indianos morreram de causas relacionadas a inanição (Gráfico 9), mais tarde chamado de "Holocausto Vitoriano tardio" (Davis, 2001).

Como a agricultura indiana era e contínua extremamente dependente de monções de verão originárias do sudoeste, secas foram as principais causas de crises de insegurança alimentar. Aliadas às secas, falhas generalizadas de ação governamental por meio de políticas públicas agravaram situações já gravíssimas (Roy, 2007).

Para estabelecer políticas públicas para a segurança alimentar, o governo colonial formou a Comissão de Fome Indiana em 1878. A composição da comissão refletiu os interesses envolvidos, com representantes do Serviço Indiano (governo central colonial) e outros órgãos dos governos central e provinciais. Houve bastante conflito interno na comissão e embora bastante tenha sido acordado, apenas um relatório representando a posição minoritária foi apresentado. Em 1880, um relatório (a publicação disponível é de 1898) que refletia a opinião da maioria foi apresentado a partir do qual o secretário da comissão redigiu o projeto de lei do código de fome. O projeto passou pela burocracia e processos internos do Raj, e tempestivamente foi adotado como os Códigos de Fome Provinciais pelo governo colonial (Brennan, 1984).

O Código estipulava medidas de intensidade e magnitude de crises de insegurança alimentar e possuía descrições e instruções extremamente detalhadas. A Comissão

\footnotetext{
${ }^{39}$ Programa pontual para a horticultura e outros produtos agrícolas de validade curta que não são incluídos no programa do governo indiano de apoio a preços mínimos. O programa protege agricultores de preços extremamente baixos no pico da safra e é acionado por meio de pedido dos governos estaduais (Governo da Índia, 2001).
} 
estabeleceu três níveis de crise alimentar: "quase escassez", "escassez", e "fome". A "escassez" ficou caraterizada como um período de três anos consecutivos de quebra de safra, produtividade entre metade e um terço do considerado normal e uma fatia considerável da população em perigo de fome. "Fome" era classificada como além dos itens de "escassez", um aumento de $140 \%$ nos preços de alimentos acima dos preços considerados normais (Índia, 1898).

A política contra a fome era em parte resultado de experiências anteriores de intervenções bem sucedidas do governo colonial inglês por meio da política de combate a fome adotadas eficazmente, por exemplo, na grande fome de Bihar, na então Presidência de Bengal de 1873-4. Após um período de seca, parte da população de 20 milhões foi considerada em perigo de fome (não sendo usada à época o termo "insegurança alimentar"). A vontade política de intervir com todos os meios disponíveis partiu do recém chegado vice-governador Sir Richard Temple (Davis, 2001). ${ }^{40}$ Uma das primeiras medidas tomadas foi a importação de arroz da vizinha Birmânia (Figura 17, quadrante superior, direito) assim que foi constatada a alta probabilidade de escassez. Também de forma inédita na Índia britânica, o governo provincial ordenou que oficiais da administração da província visitassem e avaliassem a situação das vilas mais afetadas para que fosse feita a identificação e triagem daqueles que precisavam de auxílio para alimentação imediata ou de trabalho (Hall-Matthews, 1996). O início da construção da estrada de ferro do Vale de Irrawaddy na Birmânia (hoje Myanmar) em 1874, e o Ato de Cess Road, de 1875, para a construção de vias públicas, geraram a demanda por trabalho que empregou a oferta de mão de obra rural inativa devido à seca (Yang, 1998).

\footnotetext{
40 Temple foi inicialmente punido pelo governo colonial por interferir no 'mercado' e desrespeitar a política de laissez-faire rígida defendida pela metrópole. Na Grande Fome do Sul (também conhecida por Fome de Madras de 1876-78), Temple, como delegado plenipotenciário do viceroy, procurou recuperar seu prestígio e conduziu uma política de omissão que levou à morte de milhões por inanição (Gráfico 9). Pelos seus serviços, a Coroa Ihe conferiu o título de baronete e em 1877 foi apontado governador da presidência de Bombaim (Davis, 2001).
} 


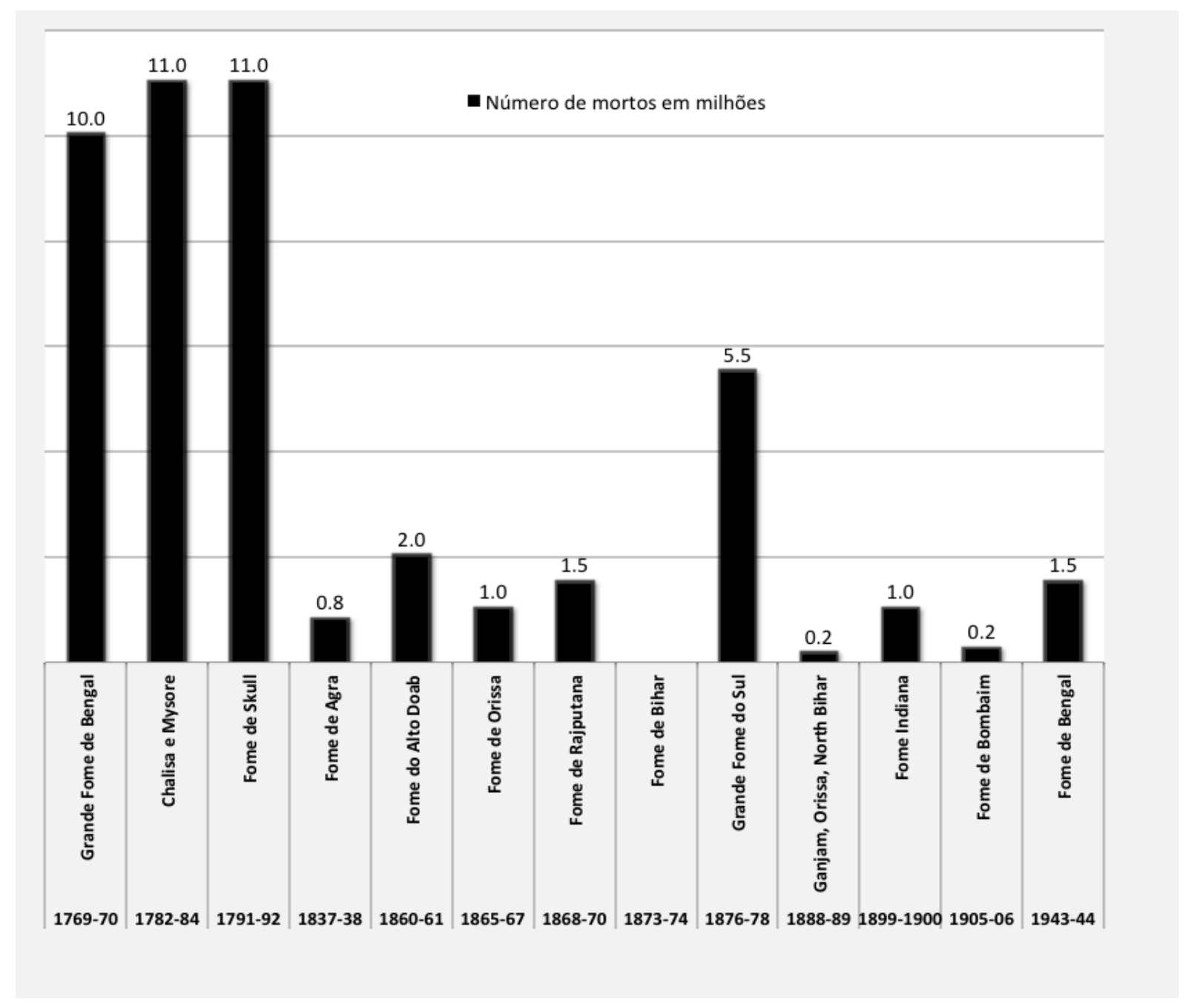

Gráfico 9 - Cronologia e número aproximado de mortes em crises de segurança alimentar durante o período colonial britânico na Índia.

Fontes: Tabela - Wikimedia Foundation, Inc, 2014. 1. Grande Fome de Bengal; Fome de Bombaim; Fome de Bengal: Kumar \& Desai , 1983. 2. Chalisa e Mysore: Fome de Skull: Grove, 2007. 3. Fome de Agra; Fome de Alto Doab; Grande Fome do Sul; Fome Indiana; Fome Indiana: Fieldhouse, 1996. 4. Fome de Rajputana: Meyer et al., 1907. 5. Fome de Bihar: Hall-Matthews, 2008.

Observação: alguns comentaristas consideram certas estimativas exageradas, principalmente devido à inclusão de mortes por outras causas como por epidemias de cólera, malária, varíola e peste bubônica (Wakimura, 2011; Hall-Matthews, 2008).

Elaboração e adaptação do autor.

A ação expediente do governo colonial, principalmente ao importar arroz da Birmânia, segurou o aumento generalizado de preços. A política de assistência de Bihar (que também ficou conhecida como a Fome de Bengal) em 1874-75 também se diferenciou das anteriores, especialmente:

a. Ao remunerar melhor aqueles que foram empregados nas obras públicas;

b. Ao prover assistência indireta em dinheiro e grãos aos donos de terra (Zamindars) para que esses auxiliassem seus arrendatários; e, 
c. Ao permitir que qualquer um que trabalhasse nas obras públicas fosse remunerado ao nível salarial considerado normal à época em contrapartida de um desempenho de trabalho também considerado normal. (BHATIA, 1991, p. 84-86).

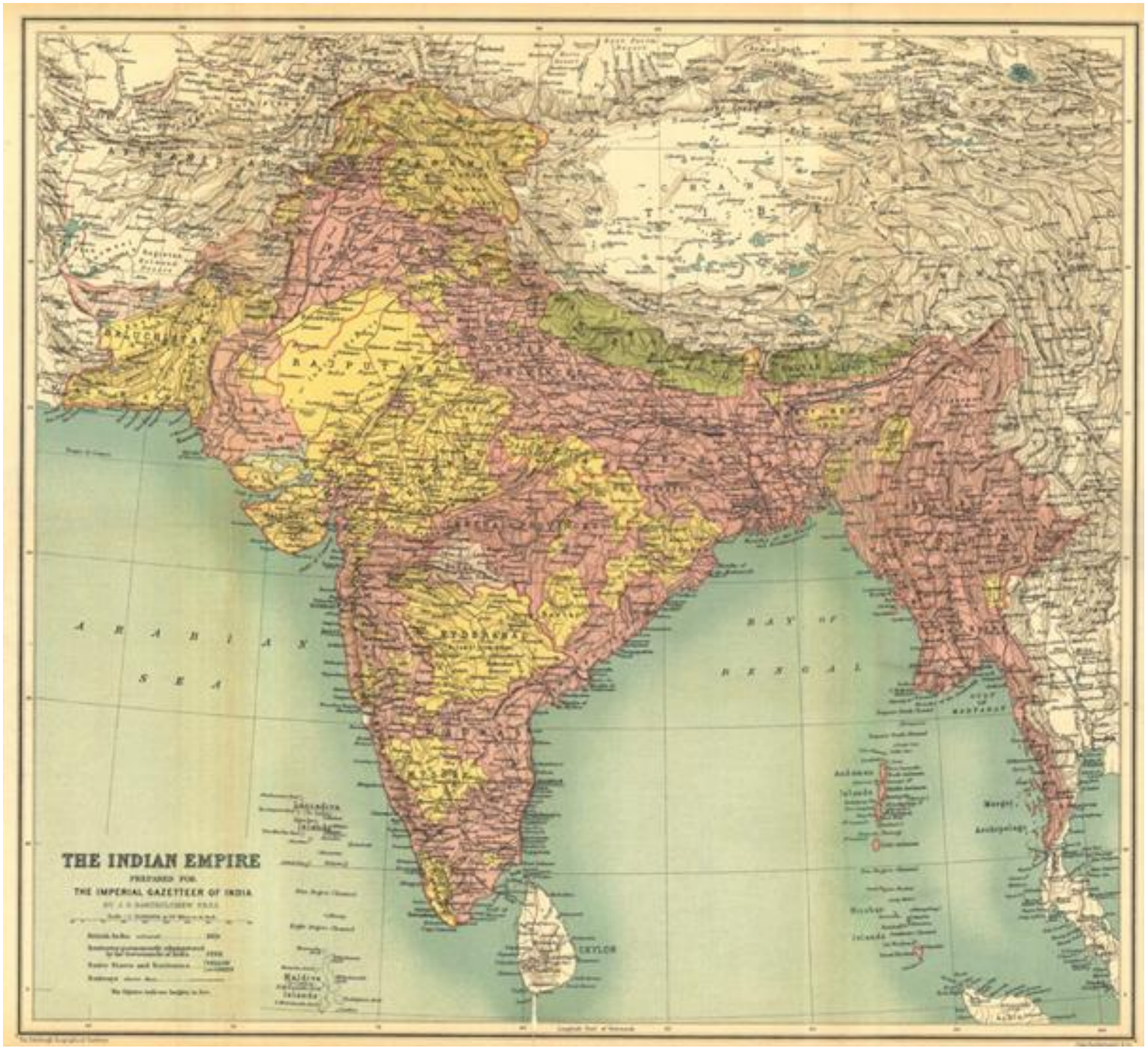

Figura 17: Império Britânico, circa 1939

Legenda: Vermelho - A "Índia Britânica": regiões sob governo direto da Coroa inglesa;

Amarelo e verde - Estados 'nativos e territórios'.

Outros: territórios 'permanentemente' administrados pelo Governo da Índia

Fonte: The Imperial Gazetteer of Índia.

Disponível em: <http://dsal.uchicago.edu/maps/gazetteer/images/gazetteer_frontcover.jpg>. Acesso: 11/10/2014.

\subsection{OS CÓDIGOS DE FOME INDIANOS: INFLUÊNCIAS}

Brennan (1984), lista as seguintes influências para a política de segurança alimentar britânica: (1) A influência de economistas clássicos sobre legisladores e burocratas, principalmente no que diz respeito a não interferência no comércio de cereais; (2) A administração colonial desejava manter os impostos nos níveis então vigentes na tentativa 
de manter latifundiários e comerciantes satisfeitos. O apoio desses grupos era essencial para a manutenção da presença britânica na Índia (o sistema de governo indireto adotado pelos britânicos em boa parte do subcontinente favorecia a governabilidade e possibilitava a arrecadação de fundos para o desenvolvimento da infraestrutura urbana e rural).

Mesmo com a influência ideológica da política do laissez-faire, a partir do final da década de 1870, as políticas públicas lentamente começaram a favorecer mais intervenção estatal em questões sociais. Houve distanciamento das políticas de cunho liberal clássico também em relação ao grau de responsabilidade do Estado na oferta de alimentos (Brennan, 1984; Roy \& Sen, 2010).

Esse distanciamento é claramente evidenciado nas premissas da Comissão de Fome Indiana quando afirma que (1) o Estado não se prestaria a intervir em todos os casos de dificuldade, porém, se moveria quando calamidades públicas que afetassem uma parcela considerável da população de uma dada região ocorressem; (2) a causa das fomes na Índia era principalmente uma questão de desemprego rural. Portanto, a melhor estratégia a ser adotada pelo Estado era prover auxílio por meio de obras públicas e oferecer trabalho aos necessitados, com a consequente infusão de liquidez e incentivos ao comércio de víveres mesmo nas áreas mais afetadas (Índia, 1898; Bhatia, 1991). ${ }^{41}$

Mesmo elaborado sob forte influência ideológica da política de laissez-faire favorecida e imposta pelo império Britânico e desenvolvido em um contexto de apoio generalizado do establishment imperialista em prol do livre comércio e também da crença vitoriana de que qualquer auxílio gratuito desestimularia o trabalho e a busca da autossuficiência, as bases da política encorajavam a aceitação de responsabilidade do estado colonial sobre o acesso ao mínimo necessário para a alimentação (Prerrogativas do neoclassicismo econômico; cada um tem de trabalhar de modo que a sociedade obtenha o máximo de bem-estar e suficiência econômica.). O resultado ultrapassou o viês egoísta e interesseiro da administração colonial e reuniu em um documento o melhor que acadêmicos e practitioners da época tinham a oferecer em termos de experiência e erudição na área de políticas públicas voltadas para situações de calamidade pública que resultassem em insegurança alimentar severa. A pesquisa minuciosa é patente ao se ler o documento, assim como o aprendizado com crises anteriores e o cuidado com as recomendações para a prevenção e mitigação dos efeitos de novas crises alimentares (Dréze, 1988).

Embora permeado do intuito ideológico de reafirmar o livre comércio e a crença vitoriana de que o auxílio gratuito seria desmoralizante, o trabalho da comissão é um marco mundial no combate à fome e raiz de parte do pensamento contemporâneo de segurança alimentar. A principal proposta da estratégia de combate à fome era a organização de

\footnotetext{
${ }^{41}$ Essa estratégia é evocativa de Keynes (1936), quase meio século antes. Veja, também Tily, 2009.
} 
grandes obras públicas: gerar emprego com salários de subsistência e a distâncias razoáveis do domicílio daqueles que se interessavam. A milha extra foi o provimento de auxílio sem expectativa de pagamento em trabalho ou dinheiro para aqueles sem condições de trabalhar. Assim, sob qualquer ângulo, o trabalho da comissão e a política contra a fome resultante, marcaram uma mudança progressista e altruísta no modo como o Estado podia se posicionar ante calamidades que geravam insegurança alimentar. O relatório da Comissão [contra a] de fome indiana e a política geraram um impacto tão marcante que o legado foi vanguardista em seu tempo e guiou os esforços de segurança alimentar no país até pelo menos os anos 1970 (talvez por inércia burocrática) (Bhatia, 1991; Dréze, 1990).42 Deste modo, o acesso à alimentação se tornou a principal intervenção do Estado na vida da população mais pobre da Índia já a partir do século XIX.

\subsection{POLÍTICAS DE SEGURANÇA ALIMENTAR PÓS-COLONIAL: A COMISSÃO DE PLANEJAMENTO}

Conforme visto na seção anterior, o sistema de segurança alimentar indiano atual ainda é parcialmente herança direta do governo colonial britânico. A última grande fome na Índia teve seu ápice no ano de 1943 em Bengal, após um intervalo de 35 anos, no contexto da Segunda Guerra Mundial (1939-1945) e fim do período colonial britânico (1757-1947), Figura 17, que por sua vez também havia se iniciado durante uma grande fome (Mukherjee, 2011).

Entre 1946 e 1947, políticos indianos que seriam os novos líderes da Índia independente, buscavam meios para que o novo Estado se distanciasse de dois fundamentos das políticas públicas de segurança alimentar pós-colonial da maioria dos recém independentes países: a dependência continuada de assistência internacional; e, a busca do Estado por controle interno da distribuição de alimentos por meio do racionamento. Sob a influência da dicotomia ideológica vivida no final da década de 1940, ainda nos estágios iniciais da Guerra Fria, o Congresso Nacional, o partido responsável pela transição, era dominado por quadros de orientação socialista. Estes acreditavam na possibilidade de erradicar a fome por meio do planejamento sistemático da agricultura e na interferência do Estado em todos os níveis de produção e distribuição de alimento (Amrith, 2008).

A primeira tentativa foi a criação de um Comitê Nacional de Planejamento em 1938 pelo cientista social Subhash Chandra Bose. O comitê deveria construir a ponte entre a visão de desenvolvimento dos dois arquitetos da independência: Jawaharlal Nehru e Mohandas Karamchand Gandhi. Este primeiro Comitê teve curta duração e não publicou

\footnotetext{
${ }^{42}$ Veja trechos dos Códigos de Fome no Anexo C. Tradução do autor.
} 
relatórios ou recomendações até 1948-49 quando já estavam ultrapassados e não passavam de curiosidades intelectuais (Chatterjee, 2001).

Uma segunda tentativa não oficial ocorreu em 1944 quando oito industrialistas da atual Mumbai (então Bombaim) patrocinaram um estudo de planejamento geral da economia indiana intitulado, "Um Breve Memorando Esboçando um Plano de Desenvolvimento Econômico para a Índia", que também ficou conhecido como o "Plano de Bombaim. ${ }^{43} \mathrm{O}$ Plano representava a institucionalização e reconhecimento do relacionamento entre empresários e a liderança do movimento de independência. Era o passo inicial para a formação de um capitalismo de estado, que não se concretizou plenamente. O Plano, embora nunca adotado oficialmente, teve algumas de suas ideias incorporadas em planos oficiais subsequentes (Kudaisya, 2014).

Também em 1944, o governo colonial lançou um "Departamento de Desenvolvimento e Planejamento" de duração efêmera. Substituído por um "Conselho Consultivo de Planejamento" pelo governo interino em 1946, a missão do novo grupo de sábios era revisar metas e projetos e fazer recomendações ao novo governo independente, inclusive em questões de segurança alimentar. Com a independência em 1947 e uma sucessão de propostas modestas e sem maiores consequências, um "Comitê de Programa Econômico" foi estabelecido e, sob a recomendação deste comitê, uma comissão permanente de planejamento foi instituída por uma resolução governamental. A Comissão de Planejamento passou a ativa em março de 1950 e sob forte influência dos planos quinquenais soviéticos e chineses, passou a ditar os caminhos das políticas públicas da Índia até meados de 2014 . Foi apenas com a eleição do primeiro ministro Narendra Modi em 2014, que esta perdeu muito de sua autonomia e poder (Kudaisya, 2014; Nayar, 2001; Amrith, 2008; Business Today, 2014).

\subsection{A GÊNESE DO SISTEMA PÚBLICO DE DISTRIBUIÇÃO - PDS}

O Sistema de Distribuição de Alimento até 2014 havia passado por quatro fases e no mesmo ano se iniciava a quinta, no âmbito da lei aprovada ao final do governo do Congresso Nacional da Índia no segundo semestre de 2013.44 A primeira fase se estendeu da origem em 1939 a 1960; período caracterizado (i.) pela expansão paulatina, (ii.) pela ênfase no controle de preços, (iii.) pela dependência na importação de grãos. A segunda fase de 1961-1978: com a crise de meados dos anos 1960, o governo se organiza para atacar a insegurança alimentar crônica de parte considerável da população por meio de uma

\footnotetext{
43 Original: A Brief Memorandum Outlining a Plan of Economic Development for India. Tradução do autor.

${ }^{44}$ As fases são resumidas e servem apenas como auxílio didático, sendo que houve sobreposição de fases e os anos são meramente indicativos de início e fim de período e não linhas temporais rígidas.
} 
abordagem mais abrangente. Há também a consolidação dos órgãos do governo responsáveis pela compra e armazenagem de alimentos. A terceira fase de 1979-1991 (ou 1997) foi caracterizada por maior crescimento do sistema, impulsionado pela produção doméstica e uso máximo da capacidade de estocagem. A quarta fase se estendeu de 1992 (ou 1997) a 2013: o universalismo do sistema foi reposto pela tentativa de direcionamento e identificação objetiva de beneficiários. Por fim, a quinta fase se iniciou em 2013/4 -: a nova lei, Lei de Segurança Alimentar Nacional (National Food Security Act, 2013), também conhecida como, Lei de Direito ao Alimento (Right to Food Act), assinada em 12 de setembro de 2013 e retroativa a 5 de julho de 2013, prevê que os contemplados possam comprar 5 quilogramas de arroz, trigo e milho-miúdo (painço) a preços altamente subsidiados. (Pal, 2011; Departamento de Alimentação e Distribuição Pública, 2013).

\subsubsection{Planejamento da economia}

O planejamento da economia se iniciou ainda no período colonial. O PDS foi criado em 1939, no início da Segunda Guerra Mundial (1939-1945), primeiramente direcionado à província de Bombaim como medida de racionamento de arroz e trigo e posteriormente replicado em outras regiões do país sob orientação do governo colonial britânico (Knight, 1954). O sistema estava direcionado à distribuição equitativa de arroz e trigo aos consumidores urbanos confrontados com inflação no período de guerra por meio de um sistema de lojas particulares e públicas, chamadas "lojas de preço justo" (fair price shops). Já existia uma rede de lojas de preço justo controlada por particulares e pelos governos locais; esta rede foi expandida ano após ano (Ojha, 1987).

Nos 40 anos que precederam a Segunda Guerra Mundial, a produção de alimentos per capita na Índia desabou de 254 quilogramas para 181 quilogramas (Bhatia, 1991:315; Mooij, 1998). Fortuitamente, a importação de arroz a partir da Birmânia (Mianmar) supria a diferença entre a demanda efetiva e a produção doméstica. Porém, com a ocupação da Birmânia pelos japoneses em abril de 1942, a linha de suprimento essencial foi interrompida e precipitou a "Fome de Bengal" discutida neste mesmo capítulo (Sen, 1981, p. 52-85; Mooij, 1998, p. 3)

\subsubsection{A Sexta Conferência de Controle de Preços}

A crise de oferta pautou a Sexta Conferência de Preços de setembro de 1942 organizada pelo governo colonial britânico. A proposta principal para combater a crise estava baseada na estruturação de um sistema centralizado de compra de cereias baseado nos seguintes pontos: 
I. Os conferencistas apoiavam a ideia de eliminar a compra com arbitragem de preços de cereais, inicialmente para trigo, mas a ser estendido a todos os cereais considerados essenciais no subcontinente indiano como arroz, sorgo (Sorghum bicolor), milheto (Pennisetum glaucum), eleusine (Eleusine coracana), cevada, grãode-bico e milho. Para tal, a proposta de proibição de exportação de trigo das províncias e estados superavitários deveria ser rigidamente adotada. Apenas o governo central poderia adquirir trigo para as forças armadas e trabalhadores e para estados e províncias deficitárias até uma quantia predeterminada para cada província ou estado, em coordenação com o estado/ província em questão. O governo central também se encarregaria de organizar o transporte do grão;

II. A compra deveria ser realizada por meio de intermediários escolhidos em consulta com os governos estaduais/ provinciais beneficiados;

III. A Organização Central teria que negociar as compras em coordenação e sob assistência das autoridades responsáveis pelo controle de preços nas províncias/ estados superavitários;

IV. A alocação do cereal assim obtido deveria seguir uma ordem rígida de prioridade dos governos central, provincial e de estado;

V. Os suprimentos forçosamente deveriam ser colocados sob os cuidados de consignatários aprovados pelas autoridades responsáveis, distribuidores homologados pelo estado;

VI. O cálculo das cotas de exportação das áreas produtoras e as cotas correspondentes das áreas consumidoras teria que levar em consideração o princípio de "igualdade de sacrifício": o consumo nas regiões beneficiadas pelo sistema teria que ser uma função da redução percentual de consumo geral ocasionado pela necessidade de interferir no mercado devido à inadequação de oferta. (Knight, 1954, p. 53).

A partir das discussões da Sexta Conferência, os princípios básicos da política de segurança alimentar se desenvolveram sobre os alicerces dos Códigos de Fome. Em dezembro de 1942, um departamento específico foi estabelecido pelo governo central e no âmbito deste, um plano básico para toda a Índia foi concatenado no ano seguinte. Até então uma política de laissez-faire permeava o comércio e preços de cereais na região desde a última grande fome ainda no século 19 (Bhatia, 1991). O primeiro ano de guerra mudou radicalmente a forma como o governo encarava a questão de distribuição e acesso a alimentos, principalmente grãos (Mooij, 1998).

A promulgação da 'Lei de Defesa da Índia' e do 'Regulamento de Defesa da Índia' (Defence of India Rules) de 1939, são a gênese do controle estatal direto do comércio e distribuição de commodities consideradas essenciais, executadas através da 'Ordem de 
Controle de Alimentos' de maio de 1942 (Ojha, 1987). Com o intuito de limitar a especulação com cereais, lojas de preço justo foram iniciadas em outros estados e para combater a fome no estado de Bengal, as lojas foram convertidas em 'lojas de racionamento' (Ojha, 1987).

A conferência de preços de 1942 havia sido a sexta em apenas 4 anos, demonstrando a clara preocupação das autoridades com os preços dos principais cereais, especialmente do trigo. Embora, a segurança alimentar fosse uma das prioridades, o alvo principal da política de distribuição de alimentos era a estabilização de preços (Mooij, 1998). O 'Plano para toda a Índia' formulado pelo novo Departamento de Alimentos em dezembro de 1942, formalizou procedimentos para o provimento de alimentos, por exemplo, contratos em geral, contratos de agentes de compras, distribuição pública, inspeção e armazenamento (Acharya, 1983).

Na mesma política, o primeiro 'Comitê de Política de Grãos' passou a coordenar as recomendações ao Executivo sobre a política de distribuição de alimentos. Como resultado direto das recomendações deste Comitê, ao final da Segunda Guerra Mundial, perto de 800 cidades indianas estavam sob o esquema de racionamento de alimentos (Ojha, 1987). Na esteira da independência, um segundo comitê foi organizado para rever a situação. Provavelmente, influenciado pela política de distanciamento do novo governo de iniciativas do governo colonial, o segundo comitê recomendou o fim do sistema de racionamento, redução das importações de grãos e a liberalização do comércio doméstico de cereais. Essas recomendações, no entanto, se provaram errôneas, pois houve um aumento generalizado de preços de alimentos, isto é, inflação decorrente do aumento de preços de alimentos que levou à uma nova revisão das recomendações de 1947 (Mishra, 1985; Ojha, 1987).

Em reação, logo após a independência, em 1950, a Índia restabeleceu o sistema de racionamento para enfrentar as pressões inflacionárias, fortalecidas pelos altos preços globais nos mercados de grãos pós guerra, que se encontravam em um patamar quatro vezes mais alto do que os preços do período imediatamente anterior à guerra (Bhatia, 1985). Explica Nawani (1994) que a distribuição pública de grãos se estabeleceu como política social de segurança alimentar de forma intencional a partir do primeiro plano quinquenal do departamento de planejamento de 1951. O sistema passou de apenas urbano para incluir a zona rural gradativamente e possuía, em princípio, duas variações geográficas, Áreas de Racionamento Estatutário, nas quais a disponibilidade de arroz e trigo deveria ser apenas por meio das lojas de preço justo ou de racionamento, e as Áreas de Racionamento Não Estatutário, onde as lojas apenas complementavam o mercado. Embora a abundância de disponibilidade de cereais tenha tornado o sistema redundante durante um período de pelo menos 6 anos, ao final do qual o governo havia cessado de adquirir, estocar 
e vender grãos, por volta de 1958, a situação se invertera e o sistema de distribuição público foi restabelecido e ampliado. Na segunda versão do Sistema de Distribuição de Alimentos produtos como o açúcar, carvão e óleo querosene foram incluídos na cesta básica e o número de lojas, na época mais conhecidas como, 'lojas de racionamento' passaram de 18 mil em 1957 para 51 mil em 1961. O sistema havia passado por uma mutação: de sistema de racionamento para um de segurança social, alimentar e econômico, dotado de uma âncora externa (Nawani, 1994).

6.5.3 A Lei Alimento pela Paz de 1966 e a Lei Pública 480 [The Food for Peace Act of 1966, Public Law 480]

O conjunto de agências de auxílio humanitário e agências exportadoras impulsionadas pelo complexo agrícola dos Estados Unidos foi responsável pela maioria das doações recebidas pela Índia após a Segunda Guerra Mundial, especialmente entre 1955 e 1971 (Kamath, 1992). A maior parte foi direcionada ao setor público para, por exemplo, indústrias de fertilizantes, projetos de irrigação de grande escala, projetos de eletrificação rural, produção de laticínios, rodovias, melhorias das ferrovias, financiamento de aviões da empresa de aviação estatal, universidades rurais e de extensão rural e assistência técnica especialmente às universidades estatais (Kamath, 1992). O restante, contudo, foi alimento em espécie no âmbito da Lei Pública 480 dos Estados Unidos da América.

Em julho de 1954, o presidente dos Estados Unidos, Dwight D. Eisenhower (19531961), assinou a Lei 480, também conhecida como, Lei "Alimento pela Paz" - Lei de Assistência de Desenvolvimento de Comércio Agrícola. A lei criava um mercado secundário e permitia que países com poucas ou nenhuma reserva de divisas pagassem em suas moedas nacionais. A Lei 480 tinha como objetivo inicial encontrar mercados para a produção crescente da agricultura dos Estados Unidos e apenas formalizava algo que já havia se iniciado no governo de Harry Truman (1945-1953). Já em 1951, o então presidente Truman havia autorizado o primeiro 'empréstimo' de trigo para a Índia, mesmo em meio à maior proximidade e simpatia da elite indiana com soviéticos e chineses. A Índia precisava de mais cereais para alimentar sua população e os Estados Unidos de mais mercados para escoar sua produção subsidiada de estados politicamente importantes tanto para democratas como para republicanos (Cullather, 2010). O sistema de segurança alimentar indiano é um produto, pelo menos nos 15 anos após a independência, tanto da necessidade indiana quanto da disponibilidade estadunidense.

Em 1956, os Estados Unidos e a Índia negociaram um acordo de três anos e novamente em 1960 outros três. Trigo do centro-oeste americano era despachado de trem e balsa para Nova Orleans e de lá para Bombaim e Calcutá aos cuidados da Corporação de 
Crédito de Commodities (CCC) - empresa estatal do Estado americano responsável pelo financiamento das políticas do Departamento de Agricultura dos Estados Unidos e administrada pela Agência de Serviços Agrícolas e pelo Serviço Agrícola Exterior (USDA, FSA, FAS - siglas em inglês, respectivamente). Era o instrumento para que a Comissão de Planejamento indiana viabilizasse o primeiro plano anual (1951-1956) com ênfase na indústria pesada. Como na maioria dos países de economia de planos, bens de consumo não tinham lugar na lista de prioridades. A Lei 480 permitiu a Índia manter os preços dos alimentos sob controle e suprir a demanda reprimida e crescente por trigo. Enquanto a agricultura nacional ainda não tinha como suprir a demanda, a Lei 480 auxiliou o jovem país independente a manter sua população minimamente alimentada (Cullather, 2010).

\subsection{SISTEMA DE DISTRIBUIÇÃO PÚBLICO RENOVADO - REVAMPED PUBLIC DISTRIBUTION SYSTEM (RPDS)}

Em 1991, nos estados de Orissa e Madhya, principalmente em regiões tribais, um número não especificado de mortes por inanição havia ocorrido em locais onde o PDS e lojas de preço justo estavam operando normalmente e com estoque adequado, pelo menos nos registros oficiais (Singh, 2006). Esta situação levou a Comissão de Planejamento da Índia a elaborar um plano de renovação do PDS.

Assim, após quase quatro décadas de funcionamento sem maiores alterações, em 1992, o governo decidiu fazer algumas alterações a um sistema que claramente já demonstrava sinais de fadiga organizacional e ineficiência generalizada. $O$ governo desejava fortalecer e agilizar o sistema, além de viabiliza-lo em localidades mais distantes das áreas urbanas, por exemplo, em regiões montanhosas de difícil acesso onde parte da população mais pobre se encontrava.

Novos programas foram lançados, alguns especificamente para 1775 blocos mais necessitados e com necessidades especiais. O Programa para Áreas com Alta Probabilidade de Alagamento, Projetos Integrados de Desenvolvimento Tribais, Programa para o Desenvolvimento de Áreas em processo de Desertificação (ou de Deserto), e, Áreas Montanhosas Designadas foram lançados no ano da reforma. O PDS Renovado era regido por um sistema de área (blocos) que deveria melhorar a entrega às lojas de preço justo os produtos incluídos na cesta nas áreas identificadas e alocadas em blocos por parte de governos estaduais. A renovação também incluía mudanças na cesta subsidiada e deveria passar a oferecer produtos como chá, sal, leguminosas e sabão (Governo da Índia, 2005b).

As principais melhorias incrementais que o governo de minoria do Congresso Nacional conseguiu aprovar foram: 
a. Melhoria de acesso: novas lojas de preço justo seriam abertas em comunidades de difícil acesso;

b. Auditorias contra fraudes: fraudes generalizadas seriam duramente combatidas; governos estudais seriam fortemente encorajados a auditar as listas de beneficiários com intuito de remover famílias indevidamente inseridas no sistema e incluir as que haviam sido indevidamente excluídas ou nunca incluídas;

c. Novo sistema de entrega: as lojas deveriam adotar um sistema de entrega de porta em porta com intuito de garantir entregas. O governo subsidiaria a compra de veículos de entrega;

d. Comitês de vigilância: a supervisão das atividades das lojas de distribuição seria mais participativa, com a inclusão de lideranças comunitárias e maior representação feminina no nível das vilas e estado;

e. Logística de distribuição: os governos estaduais deveriam incrementar o sistema logístico com a construção e arrendamento de armazéns intermediários para agilizar as entregas e minimizar desvios e perdas; e,

f. Ampliação da cesta: o PDS incluiria mais artigos na cesta básica, por exemplo, carvão, óleo alimentar vegetal, detergente e sabão (Governo da Índia, 2005).

\subsubsection{Resultados do RPDS}

Cinco anos depois, o RPDS cobria 2.496 blocos em áreas tribais (subdivisões administrativas), áridas, de montanha e remotas (Shankar, 1997). No entanto, já em 1995, um balanço da Organização de Avaliação de Programas, entidade integrante da Comissão de Planejamento do Governo da Índia (1995) levantou 15 pontos a partir de uma pesquisa que utilizou uma técnica de amostragem simples aleatória. No geral, o estudo concluiu que a administração em nível de estado, distrito e bloco era em grande parte adequada e havia conexões e arranjos administrativos funcionais para a implementação eficiente do RPDS. Por outro lado, a adequação na administração não se traduzia no campo. O plano de entrega em domicílio simplesmente não existia nos blocos de 4 dos 6 estados da amostra e nos 2 outros, havia sido implementado apenas parcialmente. De 64 vilas da amostra, em 30, os cartões de provisão não tinham sido fornecidos a todas as famílias identificadas. Os veículos utilitários para entregas em domicílio adquiridos pelos governos estaduais não eram adequados: 20 por cento já precisavam de reparos consideráveis e a distribuição das vans pós aquisição não havia sido feita seguindo o critério de blocos (Governo da Índia, 1995).

Os comitês de vigilância previstos na reforma de 1992 também não tinham sido instituídos de acordo com o plano. Mesmo aqueles que haviam saído do papel, a maioria 
não estava 'vigiando', isto é, realizando a tarefa para a qual haviam sido criados. Talvez como resultado, a distribuição do RPDS, de acordo com o estudo da Organização de Avaliação de Programas, não demonstrava qualquer "uniformidade de proporção" em relação à necessidade real dos estados e sem nenhuma consideração pelos hábitos alimentares das populações dos estados, - questão essencial em um país com divisões religiosas que refletem na alimentação e podem se tornar de vida e morte (Governo da Índia, 1995).

No varejo, embora muitos dos problemas enfrentados pelos proprietários das lojas eram advindos da própria cadeia logística do RPDS - armazenagem imprópria, transporte e custos diversos -, questões internas à administração diária das lojas afligiam o sistema. Uma dessas questões internas recorrentes era a de lojas que abriam em horários irregulares. A qualidade das commodities para a maioria dos respondentes da pesquisa era mediana, exceto pelo querosene, classificado como 'bom'. Dos respondentes qualificados, aparentemente todos, relataram que o funcionamento do programa era insatisfatório. Os respondentes apontaram irregularidades na distribuição, custos de transporte altos, subsídios inadequados, padrões e pesos incorretos, qualidade baixa e "etc.". Para finalizar, os respondentes qualificados (93 por cento) ainda enfatizaram a não disponibilidade das exatas commodities que o RPDS propunha fornecer além do PDS (Governo da Índia, 1995).

\subsection{SISTEMA DE DISTRIBUIÇÃO PÚBLICA DIRECIONADO - TARGETED PUBLIC DISTRIBUTION SYSTEM - TPDS.}

Em mais um esforço organizacional, em 1997, o Governo da Índia lançou o Sistema Público de Distribuição Direcionado, em inglês, "Targeted Public Distribution System, TPDS, com foco nos mais pobres dos pobres: uma mudança considerável, de um sistema universal para um que deveria identificar os beneficiados inequivocamente em um -país onde até o final do século 20, a maioria não tinha nenhum documento de identificação pessoal. O TPDS deveria direcionar a cesta subsidiada baseada em um critério de renda àqueles abaixo da linha da pobreza e àqueles acima (Radhakrishna, \& Subbarao, 1997).

Cada família abaixo da linha da pobreza passou a ter direito a comprar 20 quilogramas de cereais por mês. As linhas de pobreza específicas a cada estado foram estimadas por um grupo de especialistas de 1989 a 1993, conhecido como Comitê Lakdawala, após o presidente do comitê, D. T. Lakdawala, professor da Universidade de Mumbai, morto em 1992 (Panagarya \& Mukim, 2013, Governo da Índia, 2011).

O foco do TPDS era a parte da população que continuava à margem dos esforços do governo como trabalhadores rurais, jornaleiros nos setores informais da economia, puxadores de rickshaws, vendedores ambulantes e moradores de favelas. O PDS era 
criticado por não atender as áreas rurais efetivamente e negligenciar as camadas mais pobres da população. Havia também um consenso crescente quanto à necessidade de direcionar os esforços para abaixo da linha de pobreza. Para essa categoria, as quantidades seriam dobradas, a um custo para as famílias de 50 por cento do custo econômico fixado em abril de 2000. Já para as famílias acima da linha de pobreza, o preço de compra seria 100 por cento do custo econômico a partir da mesma data. Essa mudança anulou o subsídio para as famílias acima da linha de pobreza. O objetivo era concentrar o subsídio inteiramente nos mais pobres (Governo da Índia, 2011). E a questão do foco se tornou o ponto mais fraco do PDS, que já tinha muitos pontos fracos.

Como todo programa que precisa de identificação de cada família ou indivíduo, a inclusão ou exclusão incorretas são esperadas e precisam ser continuamente corrigidas. Variações sazonais de disponibilidade de renda e produção agrícola são comuns, principalmente nas camadas mais pobres. Na Índia, a dificuldade de direcionar corretamente o auxílio é ainda mais complexa devido ao tamanho da população e a inexistência de um registro geral e unificado obrigatório (Tritah, 2003).

\subsubsection{Especificidades do TPDS}

A principal mudança foi a tentativa de dividir a população em duas categorias de renda, acima e abaixo da linha de pobreza, a partir das recomendações do Comitê Lakdawala. A nova focalização permitiria direcionar mais para os mais necessitados. Assim, preços e quantidades passaram a ser utilizados para cada categoria. Em 2001, os mais pobres dos pobres, aqueles com renda menor que 250 rúpias por pessoa por mês, no âmbito do esquema Antyodaya Anna Yojana (AAY), também passaram a ter preço específico (Ray \& Ray, 2011). A partir de 2004, idosos sem renda ou apoio da sociedade, famílias cuja principal geradora de renda é viúva, viúvas, doentes terminais, pessoas com necessidades físicas e/ou mentais especiais, também passaram a ser incluídas no esquema AAY. Os portadores dos cartões de provisão do AAY recebiam 35 quilogramas de arroz a 3 rupias por quilograma em agosto de 2014 (Governo da Índia, 2014; Chandigarh Administration, 2014). O segundo conjunto de mudanças estava na divisão de responsabilidades entre o governo central em Nova Délhi e os governos estaduais. Os governos estaduais passaram a ter mais autonomia em relação a direitos e atribuições, variedade de commodities ofertadas e alguns preços no varejo (Ray \& Ray, 2011).

\subsubsection{A organização e funcionamento do PDS}

O PDS se desenvolveu à volta de novas estruturas e da reorganização de estruturas e organismos existentes. Entre 1960 e 1988, o governo da Índia consolidou o sistema de 
segurança alimentar baseado no planejamento de todos os níveis, da produção à distribuição de alimentos. Centros de pesquisa, como o Instituto Central do Arroz em Cuttack, o Instituto Central de Pesquisa da Batata em Shimla, o Instituto de Pesquisa Agrícola da Índia - o Instituto Pusa, o Banco Nacional para Agricultura e Desenvolvimento Rural em Délhi foram criados para acompanhar a revolução verde indiana de meados de 1960 (Figura 18).

O PDS é responsabilidade conjunta dos governos central e estaduais. O governo central se responsabiliza pelo processo de aquisição, armazenagem, transporte e alocação em granel de arroz, trigo, açúcar e querosene para grande parte dos estados. A parte operacional de alocação nos estados, como a identificação de famílias elegíveis, emissão de cartões de provisão e supervisão das lojas de preço justo são responsabilidade exclusivas dos governos estaduais. Trigo, arroz, açúcar e querosene fazem parte da cesta que pode ser adquirida nessas lojas a preços extremamente subsidiados. .

\section{A Corporação de Alimentos da Índia (FCI)}

O governo da Índia criou o Ministério de Assuntos do Consumidor, Alimentação e Distribuição Pública, dividido em um Departamento de Assuntos do Consumidor e um Departamento de Alimentação e Distribuição Pública. Sob o Departamento de Alimentação e Distribuição, encontra-se a Corporação de Alimentos da Índia, organizada por meio da Lei da Corporação de Alimentos de 1964 com os objetivos de: a) realizar operações de apoio de preços para salvaguarda dos interesses de fazendeiros; b) distribuição de cereais e outros para o PDS; c) manutenção de níveis satisfatórios de estoques reguladores de cereais para o PDS, no contexto maior da Política Nacional de Segurança Alimentar; e, d) regulamentar o preço de mercado de cereais para garantir o fornecimento a preços acessíveis (Corporação de Alimentos da Índia, 2001). A Corporação cresceu até se tornar a maior da Índia e provavelmente o maior sistema logístico do continente com escritórios zonais e regionais em todas as capitais de estado do país (Pal, 2011). No início da década de 2010, a FCl comprava uma média de 17 por cento da produção de trigo e 13 por cento da de arroz a preços determinados pelo governo central indiano conhecidos como Preços de Apoio Mínimo (Singh \& Sen, 2011). A FCI não tem qualquer poder decisório e não se assemelha às autarquias e/ ou agências reguladoras brasileiras. A Corporação apenas cumpre as diretrizes do Ministério da Alimentação e Ministério da Agricultura (Pal, 2011).

\section{Corporação de Armazenagem Central (CWC)}

A Corporação Central de Armazenagem foi criada em 1957 e outras 17 corporações estaduais foram estabelecidas desde então para coordenar todo o sistema logístico 
necessário ao Sistema Público de Distribuição que depende da capacidade de estocar e distribuir os produtos agrícolas adquiridos pela $\mathrm{FCl}$. As corporações foram criadas para a) adquirir e construir armazéns; b) administrar locais de armazenagem para estocar produtos agrícolas, sementes, fertilizantes, adubo, implementos agrícolas e outras commodities autorizadas; c) coordenar e possibilitar o transporte de produtos agrícolas e outros produtos e implementos relacionados de e para os armazéns sob sua responsabilidade; d) ser acionista majoritário de corporações de armazenagem estaduais; e) atuar como agente do Governo Central na compra, venda, armazenagem e distribuição de produtos agrícolas e sementes, fertilizantes, adubo, implementos agrícolas e outras commodities autorizadas; e, f) executar as atividades listadas de acordo com as leis e regulamentos (Governo da Índia, 1962). 
Formulação de Políticas Públicas

Decisão de Objetivos

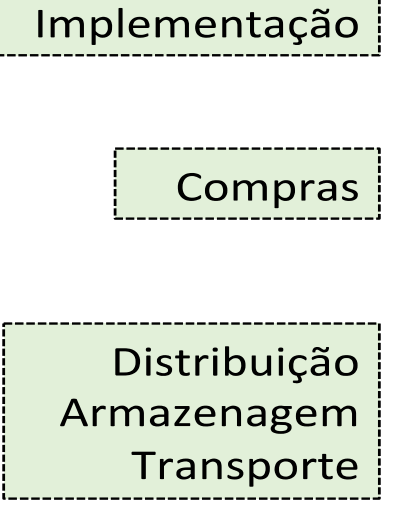

Compras

Distribuição
Armazenagem
Transporte

Figura 18: Estrutura Geral do Sistema Público de Distribuição de Alimentos

Governo da Índia, Comissão de Planejamento

Departamento de Alimentos e Suprimentos Civis / Comissão de Planejamento, Governo da Índia

Ministério da Alimentação e Suprimentos Civis, Departamento de Alimentos

FCI e NAFED - fornecedores:

-- Fazendeiros, comerciantes, Usinas de beneficiamento; importação

\section{Corporação de Armazenagem; Armazéns}

Regionais da $\mathrm{FCl}$

Departamentos estaduais de suprimentos civis e $\mathrm{FCl}$

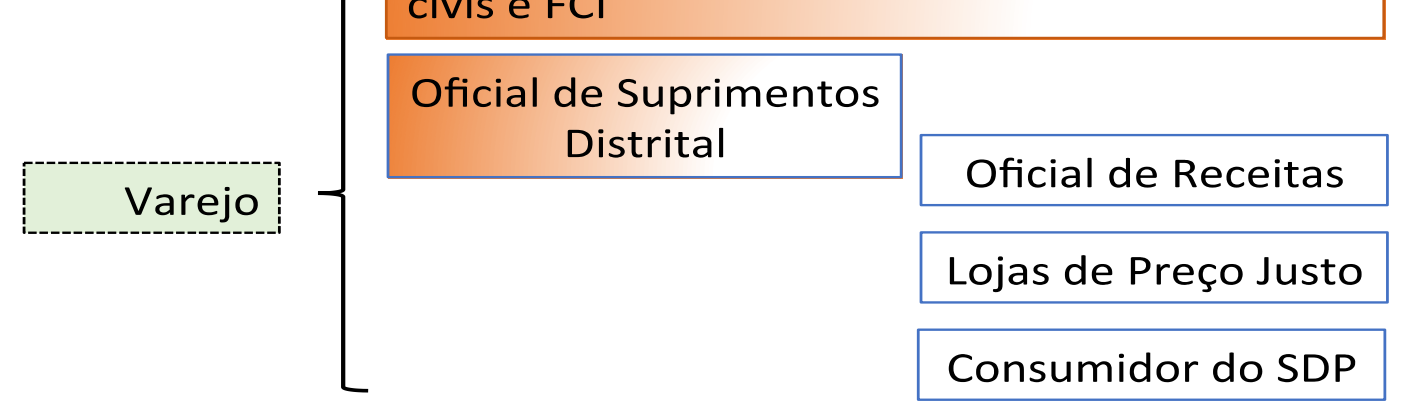

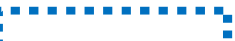 \\ Conselho \\ Consultivo para \\ o Consumidor}

\section{CACP:}

recomendação

de Preços

Federações de

Comércio

Estaduais;

agentes

privados

\section{Atacadistas;}

usinas de

beneficiamento

; exportadores Fonte: Bapna, 1990. Elaboração do autor.

Legenda Siglas

NAFED - National Agricultural Cooperative Marketing Federation of India Ltd

FCl: Food Corporation of India

CACP: Commission for Agricultural Costs and Prices 
Em 2011, o Governo da Índia emendou a lei de 1962 e removeu as provisões que garantiam o apoio financeiro irrestrito do governo central e manteve o apoio e garantias financeiras dos governos estaduais (Governo da Índia, 2011). No ano anterior, uma agência reguladora denominada, "Autoridade Reguladora e de Desenvolvimento de Armazenagem" foi criada com a missão de regulamentar e assegurar a implementação da Lei de Armazenagem. A lei garante aos agricultores o direito de manter armazenado a produção em armazéns certificados e o uso dos recibos de armazenagem como instrumento negociável. Isto é, os agricultores poderiam usar os recibos de armazenagem como garantia de empréstimos em bancos comerciais estatais e privados (Pal, 2011; Governo da Índia, 2007).

Estrutura dos níveis de gerenciamento do PDS

O SDP consiste em 6 níveis de acesso além da esfera do governo central: (1) estadual; (2) distrital; (3) Tehsil/Taluka - Bloco/Sub Divisão; (4) Panchayat; (5) Loja de preço justo; (6) Domicílio (Governo da Índia, 2005a). Conforme esquematizado na Figura 18, a formulação das políticas públicas parte do governo central após a aprovação das leis (acts e bills) no parlamento. A Comissão de Planejamento é o braço do poder executivo que se encarrega da execução política delegada pelo parlamento e chefes do executivo.

\section{Subsídio para Alimentação}

O subsídio para alimentação é a espinha dorsal da $\mathrm{FCl}$ proveniente do Governo da União ou Central, como é conhecido o governo 'federal' na Índia. Em 2011, o valor do subsídio era de cerca de 10 bilhões de dólares americanos (Sud, 2011). No ano fiscal indiano 2011-2012, o orçamento era de 605 bilhões de rúpias indianas, ou cerca de 10 bilhões de dólares estadunidenses, conforme Tabela 3. Já em 2014, o subsídio estava estimado em 12 bilhões de dólares (Governo da Índia, 2014; Josh, 2014). A instância indiana em relação ao subsídio levou, por exemplo, à recusa do país em assinar o Acordo sobre Facilitação do Comércio da Organização Mundial do Comércio em julho de 2014 em Bali. O governo indiano rejeitou assinar o acordo até que suas demandas em relação ao subsídio para a segurança alimentar fossem atendidas (Josh, 2014).

A Índia decidiu negociar, primeiramente, uma cláusula de paz interina em 2013 com membros da OMC que se absteriam de erguer disputas legais contra subsídios agrícolas para estocagem de alimentos em troca de um acordo sobre a facilitação do comércio juridicamente vinculativo. Uma solução permanente poderia ser negociada até 2017 , quando estes subsídios deixariam de ser não acionáveis. A cláusula de paz vem, no entanto, com uma série de condições vinculantes, como, por exemplo, os estoques adquiridos para 
estocagem de programas de segurança alimentar não podem distorcer o mercado aberto e seus preços (Josh, 2014). A Política de Segurança Alimentar indiano faz exatamente isso, além de manipular preços e influenciar diretamente o mercado.

Em segundo, a Índia decidiu se comprometer em relação a outras questões importantes do Acordo sobre Agricultura da OMC que diferencia subsídios agrícolas direcionados ao consumidor e aqueles direcionados ao produtor. Para a esmagadora maioria de países, são os subsídios ao produtor que estão no cerne de suas prioridades nas negociações no Acordo sobre Agricultura (AsA). No caso da Índia, a Lei Nacional de Segurança Alimentar de 2013 não se pronuncia sobre os Preços de Apoio Mínimo, sendo que estes são revistos periodicamente e são considerados subsídios ao produtor no AsA (Bhunia \& Nataraj, 2014; ICTSD, 2014).

Tabela 4 - Alocação do orçamento do Governo da Índia para programas sociais, 2011-2012

\begin{tabular}{l|r}
\hline Setor & $\begin{array}{l}\text { Alocação } \\
\text { Em bilhões } \\
\text { de rúpias } \\
\text { indianas } \\
\text { (INR) }\end{array}$ \\
\hline Serviços de Desenvolvimento Infantil Integrado & 92,94 \\
\hline Programa de Almoço & 103,3 \\
\hline Serviço de bem-estar familiar e de saúde & 456,23 \\
\hline Subsídio para a Alimentação & 605,73 \\
\hline Educação & 633,63 \\
\hline Desenvolvimento Rural & 878,55 \\
\hline
\end{tabular}

Fonte: Kishore et al., 2014

Taxa de câmbio média do dólar estadunidense (USD)/ rúpia indiana (INR) em 2012: INR1 = USD0,018.

Os Preços de Apoio Mínimo são usados pelo Ministério da Agricultura da Índia para proteger o agricultor da variação de preços. Por meio deles o Governo subsidia inclusive e não apenas, sementes, energia elétrica e fertilizantes como forma de manter os custos de produção os mais baixos possíveis para o agricultor. A manutenção desta política inevitavelmente leva a Índia a ultrapassar os limites estabelecidos pelas regras da OMC (Singh \& Sen, 2011; Bhunia \& Nataraj, 2014).

Em terceiro lugar, uma questão mais técnica, no entanto, igualmente crucial, a Índia demanda uma mudança no ano base usado no cálculo de subsídios para à alimentação (Josh, 2014). A Lei Nacional de Segurança Alimentar de 2013 é voltada quase integralmente para o fornecimento de arroz e trigo e outros essenciais aos mais necessitados. O AsA e uma eventual uma cláusula de paz interina abririam o sistema de estocagem e subsídios agrícolas da Índia ao escrutínio internacional. Isto poderia ter efeitos benéficos no longo prazo, mas que em uma visão mais direcionada ao público doméstico, poderia parecer 
cessão de soberania (Bhunia \& Nataraj, 2014). Concomitantemente, o AsA dificultaria futuras inclusões de outros alimentos no PDS, visto como necessário, dada a pobreza nutricional da cesta alimentícia atual (Bhunia \& Nataraj, 2014).

Direito de Proteger: Direito soberano de preservação do Sistema Público de Alimentação

Ao decidir travar as negociações da AsA, o governo da Índia defende seu direito soberano de preservar seu sistema de segurança alimentar baseado em subsídios ao consumidor e ao produtor intactos. Entretanto, subsídios de países em desenvolvimento como a Índia sob o AsA não podem ultrapassar 10 por cento do valor total da produção de cereais. O cálculo feito com base em preços de 1986-1988 inviabiliza a manutenção da Lei de Segurança Alimentar de 2013 que já subsidia mais de 10 por cento da produção. A Índia teria que mudar a política de segurança alimentar de maneira fundamental, algo bastante improvável dada a continuidade do sistema, conforme visto ao longo deste capítulo e previsto na teoria de análise de políticas públicas (Josh, 2014; Hoda \& Gulati, 2008; Bhunia \& Nataraj, 2014)

A posição da Índia impede a aprovação do chamado Pacote de Bali e pode pôr em xeque a própria relevância da OMC, única organização internacional realmente relevante que de fato trabalha com o sistema "um país, um voto". Já no início da década de 2010, países desenvolvidos passaram a investir em negociações bilaterais dada a inabilidade do fórum multilateral em gerar acordos. Permitir que a Índia e alguns outros países façam uso de uma cláusula de paz interina poderia garantir algum progresso na agenda que prevê a eliminação progressiva de todos os subsídios agrícolas que distorcem o comércio no curto prazo. A concessão, no entanto, perpetua, no longo prazo, as distorções causadas pelo atual sistema de segurança alimentar indiano.

\subsubsection{Identificações de famílias abaixo da linha da pobreza}

Conforme mencionado anteriormente, a Comissão de Planejamento do Governo da Índia decidiu adotar a metodologia proposta pelo Comitê Lakdawala na concepção do TPDS. A identificação das famílias elegíveis é a base do TPDS e de outros programas governamentais como os programas do Ministério da Habitação e Redução da Pobreza Urbana: Swarna Jayanti Shahri Rozgar Yojna (SJSRY) para meios de subsistência urbana, Rajiv Awas Yojana (RAY) para redução de habitações urbanas precárias e informais, entre outros (Governo da Índia, 2012). 


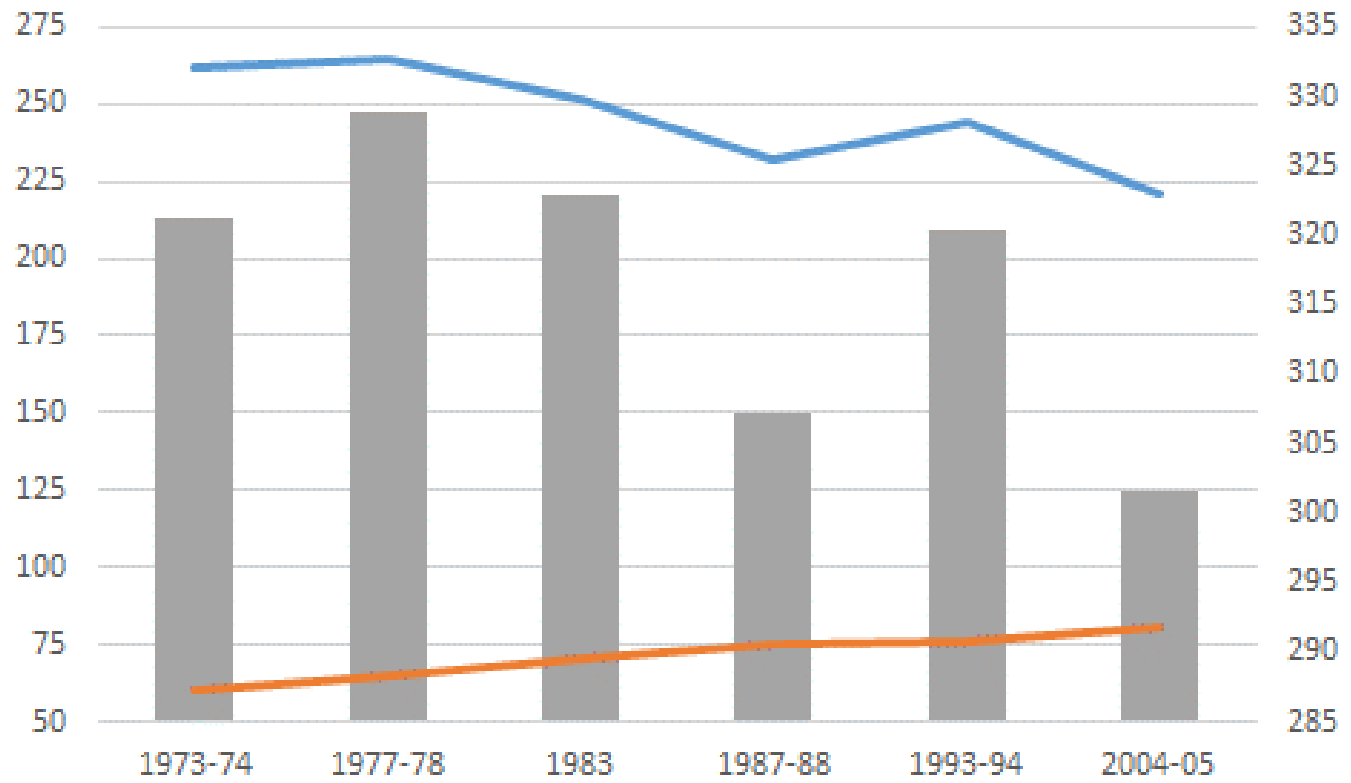

Gráfico 10 - Número de pobres baseado na metodologia do Comitê Lakdawala

Legenda: Linha azul - pobres rurais em milhões. Eixo à esquerda.

Linha vermelha - pobres urbanos em milhões. Eixo à esquerda.

Colunas cinzas - total de pobres em milhões. Eixo à direita.

Fonte: Governo da Índia, 2012. Elaboração e adaptação do autor.

Metodologia de cálculo da linha de pobreza

A Comissão baseou as estimativas no Censo da Índia de 1995 e nas estimativas de pobreza estaduais de 1993-94. A identificação e a implementação do TPDS ficaram a cargo dos governos estaduais que deveriam envolver as autoridades locais - Gram Panchayats, Nagar Palikas e Gram-Sabhas, na identificação de famílias elegíveis. ${ }^{45}$ O Comitê recomendou uma linha de pobreza baseada em um limite mínimo de ingestão de calorias, associado à uma cesta de consumo fixo, com diferenciação por estado. Para tal, a Comissão de Planejamento definiu linhas de pobreza específicas para cada estado tomando como ano base 1973-74. A cesta padronizada de commodities correspondendo à linha de pobreza em nível nacional foi precificada de acordo com os preços prevalentes em cada um dos estados no ano base. Na sequência, a linha de pobreza foi atualizada para expressar corretamente os preços correntes com a aplicação de índices de preços ao consumidor estaduais (Governo da Î́ndia, 2012).

As dificuldades enfrentadas para o cálculo e aplicação da metodologia do Comitê Lakdawala levaram a Comissão de Planejamento a indicar um novo grupo de especialistas

45 Gram Panchayat é uma instituição de governo comunitário em nível de pequenas cidades e vilas dentro da estrutura descentralizada de governo estadual indiano, o Panchayati Raj. Nagar Palika corresponde ao nível municipal em áreas urbanas em cidades menores de 100 mil habitantes (há exceções à regra). Gram-Sabha é o eleitorado de uma vila, isto é, de acordo com a constituição indiana, todos os cidadãos maiores, em vilas entre 1000 e 25 mil habitantes. O sistema vigorou durante parte do período colonial, foi extinto na indepedência e reestabelecido em 1992 (Governo da Índia, 2014b). 
para revisar a metodologia oficial de estimação de pobreza e recomendar mudanças aos procedimentos então vigentes. O comitê Tendulkar, formado em 2005 e encabeçado pelo professor e pesquisador que emprestou seu nome ano comitê, apresentou relatório em 2009, recomendando quatro mudanças relevantes: $a$. abandono da base em calorias; $b$. uniformização da cesta da linha de pobreza, isto é, a não diferenciação entre população urbana e rural; c. adoção de um procedimento de ajuste de preços que se baseasse na mesma base de dados da estimativa de pobreza; $d$. incorporação de um item específico e explícito nos índices de preço para gastos privados em educação e saúde (Governo da Índia, 2012).

A complexidade de uma simples linha separando pobres de não pobres

A principal e mais prejudicial deficiência das diferentes metodologias de estimativa de pobreza utilizada pela Comissão de Planejamento é a subestimação da pobreza (Nanda \& Suresh, 2012). Entre as muitas controvérsias em torno desta estimativa, enumeram-se: 1. Diferenças entre as séries de dados usadas pela Estatística de Contas Nacionais e as séries usadas pela Comissão de Planejamento e os ajustes arbitrários que se fizeram necessários; 2. Divergências quanto ao período de gastos a serem incluídos nas pesquisas, por exemplo, em 1993-94 considerou-se os 30 dias imediatamente anteriores à pesquisa. Mais tarde, a medida foi descartada quando pesquisadores chegaram à conclusão de que muitas despesas importantes não ocorriam em um período tão breve. Passou-se a usar a partir de 1999-2000, um método misto; 3. Em 2002-2007, a Comissão de Planejamento usou 13 parâmetros para o cálculo da linha de pobreza rural e 7 parâmetros para a urbana, com pouca similaridade entre as medidas; e 4. Governos estaduais podem usar quaisquer critérios que julgarem adequados para programas de nível estadual para definirem suas linhas de pobreza estaduais e essas diferenças locais resultam em valores diferentes para a linha de pobreza dependendo do estado, como evidenciado na Tabela 4 (Nanda \& Suresh, 2012). 
Tabela 5 - Linhas de Pobreza estaduais para 2011-12, em dólares (USD), câmbio de agosto de 2014. Metodologia Tendulkar.

\begin{tabular}{|c|c|c|c|}
\hline & Estado & Rural & Urbano \\
\hline 1 & Andhra Pradesh & 14.06 & 16.50 \\
\hline 2 & Arunachal Pradesh & 15.21 & 17.33 \\
\hline 3 & Assam & 13.54 & 16.48 \\
\hline 4 & Bihar & 12.72 & 15.09 \\
\hline 5 & Chhattisgarh & 12.07 & 13.88 \\
\hline 6 & Delhi & 18.72 & 18.54 \\
\hline 7 & Goa & 17.83 & 18.54 \\
\hline 8 & Gujarat & 15.24 & 18.84 \\
\hline 9 & Haryana & 16.60 & 19.12 \\
\hline 10 & Himachal Pradesh & 14.93 & 17.40 \\
\hline 11 & Jammu \& Kashmir & 14.57 & 16.16 \\
\hline 12 & Jharkhand & 12.23 & 15.93 \\
\hline 13 & Karnataka & 14.75 & 17.81 \\
\hline 14 & Kerala & 16.65 & 16.14 \\
\hline 15 & Madhya Pradesh & 12.61 & 14.67 \\
\hline 16 & Maharashtra & 15.81 & 18.41 \\
\hline 17 & Manipur & 18.28 & 19.13 \\
\hline 18 & Meghalaya & 14.52 & 18.87 \\
\hline 19 & Mizoram & 17.43 & 18.89 \\
\hline 20 & Nagaland & 20.77 & 21.29 \\
\hline 21 & Odisha & 11.37 & 14.08 \\
\hline 22 & Puducherry & 21.28 & 21.41 \\
\hline 23 & Punjab & 17.24 & 18.89 \\
\hline 24 & Rajasthan & 14.80 & 16.39 \\
\hline 25 & Sikkim & 15.21 & 20.05 \\
\hline 26 & Tamil Nadu & 14.39 & 15.32 \\
\hline 27 & Tripura & 13.05 & 15.04 \\
\hline 28 & Uttar Pradesh & 12.56 & 15.39 \\
\hline 29 & Uttarakhand & 14.39 & 17.69 \\
\hline 30 & West Bengal & 12.80 & 16.04 \\
\hline & Média Índia & 15.19 & 17.31 \\
\hline
\end{tabular}

Fonte: Governo da Índia, 2013

Em 2014, baseado nas recomendações de cálculo do Painel C. Rangarajan, o Governo da Índia traçou uma nova linha de pobreza: a rural em 32 rúpias indianas por dia 
(Rs. ou INR), Rs. 960 por mês e a urbana, 47 rúpias indianas, Rs. 1410 ao mês. ${ }^{46}$ Pela nova linha, o número de pessoas consideradas pobres passou a 363 milhões, ou cerca de 29.6 por cento da população do país, aumento significativo quando comparado ao número do comitê anterior, Tendulkar, 269,8 milhões, 21,9 por cento (Sharma, 2014; Governo da Índia, 2014). ${ }^{47}$

O cálculo

Embora Alkire \& Seth (2009) se refiram diretamente ao cálculo da linha de 2002, a explicação dos autores serve para exemplificar o cálculo e também para que as críticas técnicas sejam melhor entendidas. O Censo da Linha de Pobreza tem 13 questões para cada domicílio. Cada um dos domicílios recebe um número (inteiro) entre 0 e 4 em cada dimensão, dependendo da resposta à questão. Caso a família respondente caia na pior categoria existente, uma pontuação "0" é atribuída à família na dimensão correspondente. Já as famílias que se encontram na melhor categoria recebem uma pontuação de "4". Famílias em situações intermediárias recebem pontuações de "1", "2", e "3". As pontuações das $i^{n}$ famílias nas 13 dimensões são consolidadas para gerar uma pontuação agregada $G_{i}$. A pontuação mais alta agregada possível para uma família é "52". A pontuação mínima é zero, $\left(0 \leq G_{i} \leq 52\right)$. Um limiar de pobreza $Z_{s}$ é fixado em nível estadual ou em níveis mais baixos para a pontuação agregada. As famílias com uma pontuação agregada abaixo do limiar de pobreza da área são identificadas como Abaixo da Linha de Pobreza (BPL - sigla em inglês). Portanto, a família $i^{n}$ é identificada como "pobre" se $G_{i}<Z_{s}$ e "não pobre" caso contrário. Em nível estadual ou da união (para territórios da união), mais um limite foi estabelecido, o número de pessoas identificadas como BPL ficou limitado a 10 por cento acima dos valores de pobreza de renda da Pesquisa Amostral Nacional estimados em 19992000 (Alkire \& Seth, 2009).

Principais críticas técnicas ao processo de cálculo

As principais críticas técnicas ao processo de cálculo para o nível da linha objetiva de pobreza para toda a população do país:

1. "Cardinalização" de dados ordinais: as variáveis resposta classificadas de 0 a 4 são tratadas como se fossem cardinais. Isto se revela um problema porque a distância entre as categorias de resposta em cada uma das dimensões não são

\footnotetext{
${ }^{46}$ Ao câmbio de 10/08/2014, Rs.32 $=\$ 0.523$, e, Rs. $=\$ 0.77$. De acordo com o Banco Mundial, qualquer pessoa que tenha uma renda inferior a $\$ 1,25$ por dia (medido de acordo com o dólar de Paridade de Poder de Compra) é considerada em situação de extrema pobreza (Banco Mundial, 2014).

47 Para maiores detalhes sobre a metodologia de cálculo da linha de pobreza da Índia de 2014, veja Governo da Índia, 2014, referência completa nas Referências Bibliográficas.
} 
necessariamente idênticas. O tratamento das respostas como se fossem idênticas e cardinais configura um problema técnico e também acaba sendo enganoso do ponto de vista prático;

2. Substituibilidade perfeita através das dimensões: as pontuações nas 13 dimensões são resumidas em um resultado agregado e os pobres são identificados de acordo com um valor limite definido sobre o valor agregado. Essa prática implica que um ganho de um ponto em uma dimensão pode ser compensado por uma perda equivalente em qualquer outra dimensão em qualquer nível. Alkire e Seth (2009) citam o exemplo de uma família que come apenas uma vez por dia, no entanto possui alguns itens a mais de vestuário, ou uma panela de pressão, um ventilador, ou estão bem em qualquer outra dimensão, fato que distorce o nível de vida da família, já que não há substituibilidade perfeita entre as diversas dimensões medidas na vida real.

3. Linhas de pobreza variáveis: a ausência de uma linha de pobreza nacional vinculativa gera distorções. Cada estado e também alguns distritos podem definir suas próprias linhas de pobreza dentro da escala de 52 pontos. Assim, famílias que não são consideradas abaixo da linha em um estado, o são em outros e vice versa.

4. Cotas de pobreza impostas: as estimativas de linhas de pobreza dos estados foram limitadas para que não ultrapassassem em mais de 10 por cento o valor estimado na Pesquisa Nacional por Amostragem de 1999-2000. O limite foi definido pelo governo central por razões fiscais.

5. Representação imprecisa da pobreza monetária: os dados da Pesquisa Nacional por Amostragem de 1999-2000 e 2004-05 revelam que ser identificada como uma família abaixo da linha da pobreza não é uma boa representação ou proxy da pobreza de consumo. A pontuação da medida abaixo da linha de pobreza (BPL) classifica erroneamente quase 49 por cento dos "pobres de consumo" como "não pobres" (Jalan \& Murgai, 2006). Embora a classificação não caracterize necessariamente um problema na própria metodologia, ela parece indicar um problema nos objetivos pelos quais a linha de pobreza é calculada e seus usos para inclusão e exclusão em um programa de segurança alimentar para os mais pobres dos pobres (Alkire \& Seth, 2009, p. 3).

Além das questões metodológicas, as linhas de pobreza também são fortemente criticadas por razões mais gerais, como por exemplo:

a. Qualidade e cobertura dos dados: é documentada a prática de inclusão de famílias que se encontram acima da linha de pobreza na lista de famílias que se encontram abaixo da linha de pobreza por ingerência política (Hirway, 2003; Khera, 2008). Já 
em relação à cobertura dos dados, o Censo da Índia não inclui, por exemplo, os sem teto, pessoas deslocadas internamente, andarilhos e prostitutas (Alkire \& Seth, 2009).

b. Conteúdo dos dados e periodicidade: o questionário de treze itens do censo de 2002 , por exemplo, sofria de dificuldades relevantes de interpretação de algumas das questões constantes. E, como a periodicidade é de cinco em cinco anos, a ausência de revisões intermediárias que acompanhem com menos defasagem o movimento para e da pobreza, as linhas são geradas e, mais importantemente, utilizadas já desatualizadas (Alkire \& Seth, 2009).

\subsubsection{Os problemas gerais do PDS}

Os problemas do PDS, que serão discutidos em mais detalhe no capítulo que segue, são em grande parte estruturais e sistêmicos mais do que conjunturais, e afetam percentuais relevantes na maioria dos estados, conforme discutido ao longo do capítulo (Roy \& Sen, 2010). ${ }^{48}$ Segundo um estudo realizado em 2009, 57 por cento dos produtos do PDS não alcançam os destinatários corretos (Governo da Índia, 2010), e 54 por cento daqueles que são beneficiados, não estão satisfeitos com o programa, especialmente com a qualidade dos produtos (Chandanshiv \& Narwade, 2013). Entre as principais falhas do PDS:

- Erro de inclusão: indivíduos inelegíveis que são incluídos maliciosamente ou não no banco de dados do sistema;

- Cartões de provisão fantasma: cartões falsos com dado/s fictícios. Boa parte do sistema ainda não é computadorizado e uso de cartões falsos ainda é possível;

- Posse indevida de cartões de provisão: famílias migrantes que devido às regras do sistema não podem acessar diretamente a cesta de produtos, frequentemente deixam seus cartões com os donos das lojas de preço justo e em troca recebem um percentual do valor dos mesmos;

- Dificuldades de supervisão das lojas de preço justo: a responsabilidade é estadual e o lobby de donos de loja é influente em vários estados. Ao longo dos anos, diferentes auditorias constataram o desvio de produtos da cesta por parte de proprietários de lojas que demandam mais estoque dos governos por meio de comprovantes de retirada de produtos falsificados;

\footnotetext{
48 Ver também Bhatia (1967) e Mishra (1991).
} 
- Falta de inscrição: um número indeterminado de família abaixo da linha de pobreza oficial do Governo da Índia, USD1,25 (PPC) por dia por pessoa, ou, INR29, não estão inscritas; 49

- Famílias inexistentes em diferentes categorias: a principal categoria, Abaixo da Linha da Pobreza e a segunda, os Mais Pobres dos Pobres ou Esquema Antyodaya Anna Yojana, lançado no ano 2000. Estes cartões falsos geram saídas consideráveis no sistema. Como estes cartões inflam o número de beneficiários, a quantidade disponível em cada uma das lojas de preço justo raramente corresponde às necessidades ou à realidade.

- Dados corretos, cartões na posse de outros: dada as ineficiências na emissão e distribuição de cartões, dados de famílias que deveriam poder comprar a preços subsidiados estão nas mãos de terceiros que recebem por elas;

- Erros de categorização: famílias que se encontram abaixo da linha de pobreza que foram cadastradas como sendo Acima da Linha de Pobreza e vice-versa;

- Inviabilidade econômica das lojas de preço justo: de acordo com um estudo da Comissão de Planejamento do Governo da Índia de 2005 aponta que, apenas 23 por cento das lojas de preço justo são economicamente viáveis. O restante sobrevive por meio do desvio e venda não autorizada de mercadorias destinadas a venda subsidiada no mercado paralelo (Governo da Índia, 2005a); 50

Aos pontos acima, somam-se outros de natureza geral. Por exemplo, o SDP não tem alcance uniforme, muito pelo contrário, é altamente diferenciado em quase todos os parâmetros em cada estado, o que inviabiliza generalizações minimamente válidas. Embora não haja dados atualizados sobre a utilização do subsídio pela população, Janbee (2000), baseado em dados de uma pesquisa nacional realizada em 1986 (NSSO, 1989), afirma que menos de $40 \%$ da população legível, utiliza as lojas de preço justo, além de que a cobertura é acentuadamente mais baixa em estados mais pobres como Bihar, Orissa e Uttar Pradesh. O viés urbano também parece persistir e o padrão de distribuição de cereais não acompanha as disparidades e os níveis de pobreza regionais (Janbee, 2000). Grandes

\footnotetext{
49 Paridade do poder de compra (PPC): o conceito permite que se estime qual seria a taxa de câmbio entre duas moedas para que o câmbio seja comparável com o poder de compra das moedas dos dois países. O cálculo das taxas de câmbio PPC é controversa porque é bastante difícil determinar cestas de produtos comparáveis para realizar as comparações de poder de compra entre países. Para uma explicação concisa e clara, veja Lafrance \& Schembri, 2002.

50 As lojas são cronicamente inviáveis, e mesmo as que parecem ser viáveis, podem o ser por razões ilícitas ou por vieses nas amostras. De acordo com a auditoria da Comissão de Planejamento (2005), considerando a Índia inteira, apenas 38,9 por cento das lojas de preço justo incluídas na amostra do estudo, tiveram renda líquida positiva sobre os custos recorrentes mensais, enquanto 22,7 por cento conseguiram um retorno anualizado de 12 por cento do capital de giro e apenas um terço da última categoria pôde angariar uma renda suficiente para justificar a propriedade e a manutenção de uma loja de preço justo. (Governo da Índia, 2005b, p. 45).
} 
fazendeiros, transportadoras, beneficiadores de cereais, burocratas e políticos parecem ser os maiores beneficiados pelo PDS (Nayak, 2007).

\section{CONCLUSÃO}

A política de segurança alimentar na Índia se encontra intimamente ligada à política agrícola comercial, já que o PDS, um programa de distribuição de alimentos em espécie, tem como maior fornecedor o setor agrícola empresarial nacional. Como a segurança alimentar nacional depende de políticas públicas que de fato atinjam o problema de forma eficaz e eficiente, a política atual é mera medida paliativa, pois alimenta de forma insustentável e sem qualquer atenção aos meios de subsistência do beneficiados. A formulação e implantação de políticas públicas de segurança alimentar sustentáveis na maioria dos países, inclusive desenvolvidos, continua a ser um desafio para formuladores e praticantes (practitioners) de políticas públicas. A agricultura é o principal meio de subsistência da África subsaariana e da Índia, continente e país respectivamente onde se concentram as populações mais inseguras do ponto de vista da alimentação. $O$ desenvolvimento sustentável econômico e ambiental das áreas rurais deveria se encontrar, portanto, no cerne de iniciativas governamentais e da sociedade civil que necessariamente precisam de abordagens holísticas.

Tanto na África quanto no sudeste asiático, governantes, ativistas, religiosos, cientistas e políticos têm debatido ao longo dos anos como enfrentar a fome, sendo que raramente há acordo entre as partes à volta de uma política que todos considerem eficaz e eficiente (Amrith, 2008). Este é o caso da lei de segurança alimentar indiana de 2013. A existência de insegurança alimentar e nutricional em países desenvolvidos, por exemplo, Estados Unidos, é evidência de que o simples crescimento e desenvolvimento econômico, isto é, maior produto interno bruto, não bastam para abolir a fome e garantir a segurança alimentar e nutricional. Essa é uma das principais razões pela qual ao longo dos diferentes estágios de desenvolvimento de um país, existe a necessidade de proteger e garantir a segurança alimentar dos mais vulneráveis (Babu \& Sanyal, 2009).

O PDS construído ao longo de quase oito décadas com estruturas físicas e burocráticas em torno e no interior do mesmo que o tornam parte do próprio tecido da sociedade indiana está enraizado na política socioeconômica pós-independência. Há interesses consolidados em todos os níveis do sistema e qualquer proposta de mudança mais que incremental requer negociações extensivas. A Lei de Direito ao Alimento - Lei de Segurança Alimentar Nacional de 2013, por exemplo, não contempla mudanças estruturais ao sistema. Pelo contrário, fortaleceu o modus operandi ao aumentar e estender o alcance do sistema. Os beneficiários passaram a ter direito a cinco quilogramas por pessoa elegível 
por mês, arroz a 3 rúpias por quilograma, trigo a 2 rúpias por quilograma e painço a 1 rúpia por quilograma. No entanto, embora enraizado e reconhecidamente importante, o PDS é ineficiente e ineficaz do ponto de vista operacional, isto é, mesmo desconsiderando o ônus econômico e financeiro dos governos central e estaduais e carece de reformas estruturais. Talvez um resgate dos preceitos da Comissão contra a Fome do final do século 19 seja um caminho a ser estudado a adaptado à contemporaneidade: trabalho em troca de salários de subsistência e distribuição gratuita de alimento apenas àqueles incapazes de trabalhar. 


\title{
CAPÍTULO 7: O PDS NACIONAL E O PDS EM KARNATAKA - PROPOSTAS PARA MUDANÇAS
}

\author{
7 O PDS NACIONAL E O PDS EM KARNATAKA - PROPOSTAS PARA MUDANÇAS
}

\section{INTRODUÇÃO}

O sétimo, derradeiro e mais longo capítulo deste trabalho de tese de doutorado em Desenvolvimento Sustentável apresenta e analisa em maior detalhe a situação da segurança alimentar na Índia e no estado de Karnataka, as políticas de segurança alimentar e seus resultados, tanto nacionais quanto estaduais. Trata-se, de fato, da tese em seu sentido mais restrito. Primeiramente, em nível nacional, a análise apresenta as dimensões da sustentabilidade no Sistema Público de Distribuição de Alimentos, o PDS. Segue uma discussão sobre a formulação da Lei de Segurança Alimentar Nacional de 2013 e como esta contorna a sustentabilidade mesmo após reformas extensivas. Um dos mais controversos pontos do PDS é apresentado na sequência: a universalização ou não da cobertura do programa. Argumentos a favor e contra são discutidos a partir da literatura. Seguem três tópicos sobre sustentabilidade, primeiro na política de compra (procurement), em seguida, em relação à inclusão de milheto e outros grãos e leguminosas, e por fim, em relação à distribuição, armazenagem e varejo, além da polêmica à volta do estoque de segurança.

A segunda parte do capítulo sete oferece uma das principais contribuições originais desta tese em desenvolvimento sustentável. Quatro propostas de mudanças concretas e factíveis são apresentadas, concisamente. As quatro são passíveis de serem detalhadas e expandidas em futuros artigos do autor.

A terceira parte do capítulo, em primeiro lugar, apresenta o estado indiano de Karnataka e a situação alimentar, a situação de distribuição e armazenagem no atacado e também no varejo, o modo de controle de entrega aos beneficiários e os próprios beneficiários do (T)PDS. Em segundo lugar, apresenta uma proposta para Karnataka, dividida em três pontos principais. Na sequência, uma série de doze propostas secundárias é apresentada em formato de quadro (Quadro 11) ao final do tópico '7.10'. Fechando o capítulo, apresenta-se (o que seria melhor disposto em um box complementar em outro formato) uma discussão sobre como estaria o PDS em sua missão caso o problema da corrupção fosse dirimido.

\subsection{DIMENSÕES DA SUSTENTABILIDADE NO PDS}

Se o desempenho de um sistema de alimentação nacional pode ser julgado em relação à sua efetividade pela produção de quantidades suficientes, então o sistema indiano é efetivo (Mohanty \& Peterson, 2009). No entanto, se além da produção se julgar também a 
distribuição, acesso equitativo para toda a população e confiabilidade desse acesso, então o sistema indiano não cumpre sua função. Desconsiderando a sustentabilidade econômica e ambiental do sistema como um todo, o elo mais fraco da cadeia alimentar indiana no geral, é a logística - transporte, armazenagem e distribuição -, exatamente as fases do TPDS que se encontram diretamente nas mãos de agentes públicos, embora a execução seja terceirizada.

A Lei de Segurança Alimentar Nacional (National Food Security Act, 2013 - NFSA), também conhecida como, Lei de Direito ao Alimento (Right to Food Act), não mudou a essência do TPDS, pelo contrário, pareceu cristalizar e perpetuar o modus operandi vigente desde a tentativa de reforma de 1997. A questão da sustentabilidade - social, econômica e ambiental - continuou ausente. O texto da lei de segurança alimentar de 2013 se esquivou das três dimensões da sustentabilidade: econômica, ambiental e social - institucional. O PDS não dispunha de dispositivos legais, de regulamentação ou organizacional para tornálo mais sustentável e existia a completa ausência de integração horizontal e vertical de uma política ambiental entre políticas agrícola e de segurança alimentar. A análise qualitativa trata da integração da sustentabilidade: (1.) na formulação da política de segurança alimentar da Índia, em especial da Lei de Segurança Alimentar Nacional de 2013, conhecida como NFSA (National Food Security Act 2013); (2.) na política de compra (procurement) do PDS; e na distribuição e armazenagem e varejo do sistema.

O Governo da Índia terminantemente se recusa a seriamente considerar uma mudança na estrutura de subsídios ao setor agrícola mesmo que isso inviabilize acordos na OMC, como discutido anteriormente. Os subsídios aos preços mínimos que financiam a oferta do PDS aumentaram exponencialmente a partir do ano de início do processo de liberalização da economia indiana, 1990 (Gráfico 11). Já na primeira metade da década de 2010, os preços mínimos chegaram a 70 por cento do custo econômico dos grãos adquiridos pela $\mathrm{FCl}$, enquanto os custos, tirando o subsídio para os preços mínimos, contabilizavam quase 30 por cento (Sharma, V. P., 2012). Em 2013-2014, estimava-se que o TPDS custava cerca de 3 por cento do Produto Interno Bruto (PIB) da Índia ou próximo de USD13 bilhões. A proposta desta tese, portanto, tem efeito apenas sobre os 30 por cento despendidos em custos não preços mínimos, já que os 70 por cento restantes estão embutidos na estrutura dos subsídios aos agricultores. 


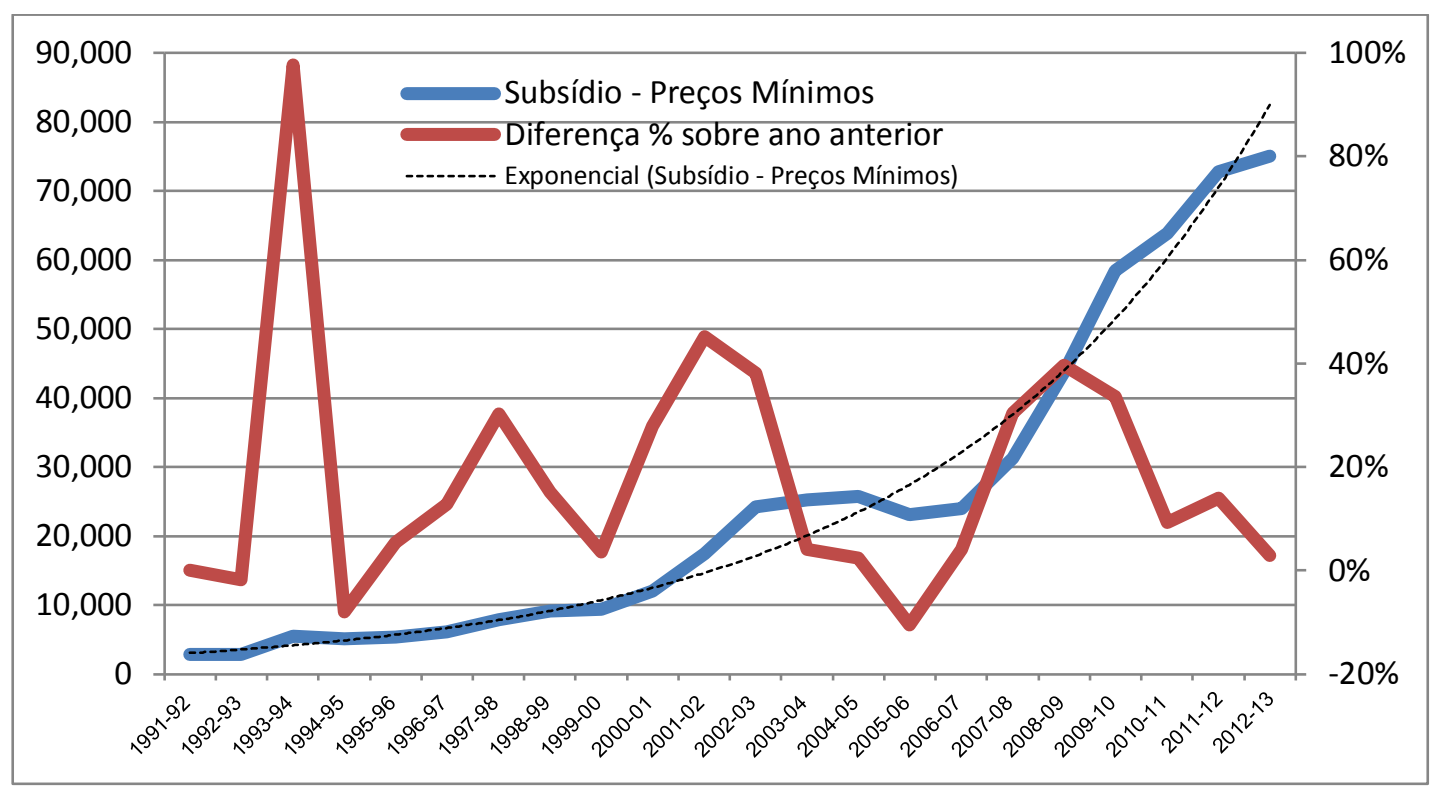

Gráfico 11 - Subsídio aos preços mínimos agrícolas na Índia, 1990 a 2013, em bilhões de rúpias indianas. Fonte: Governo da Índia, 2012. Adaptação e elaboração do autor. 


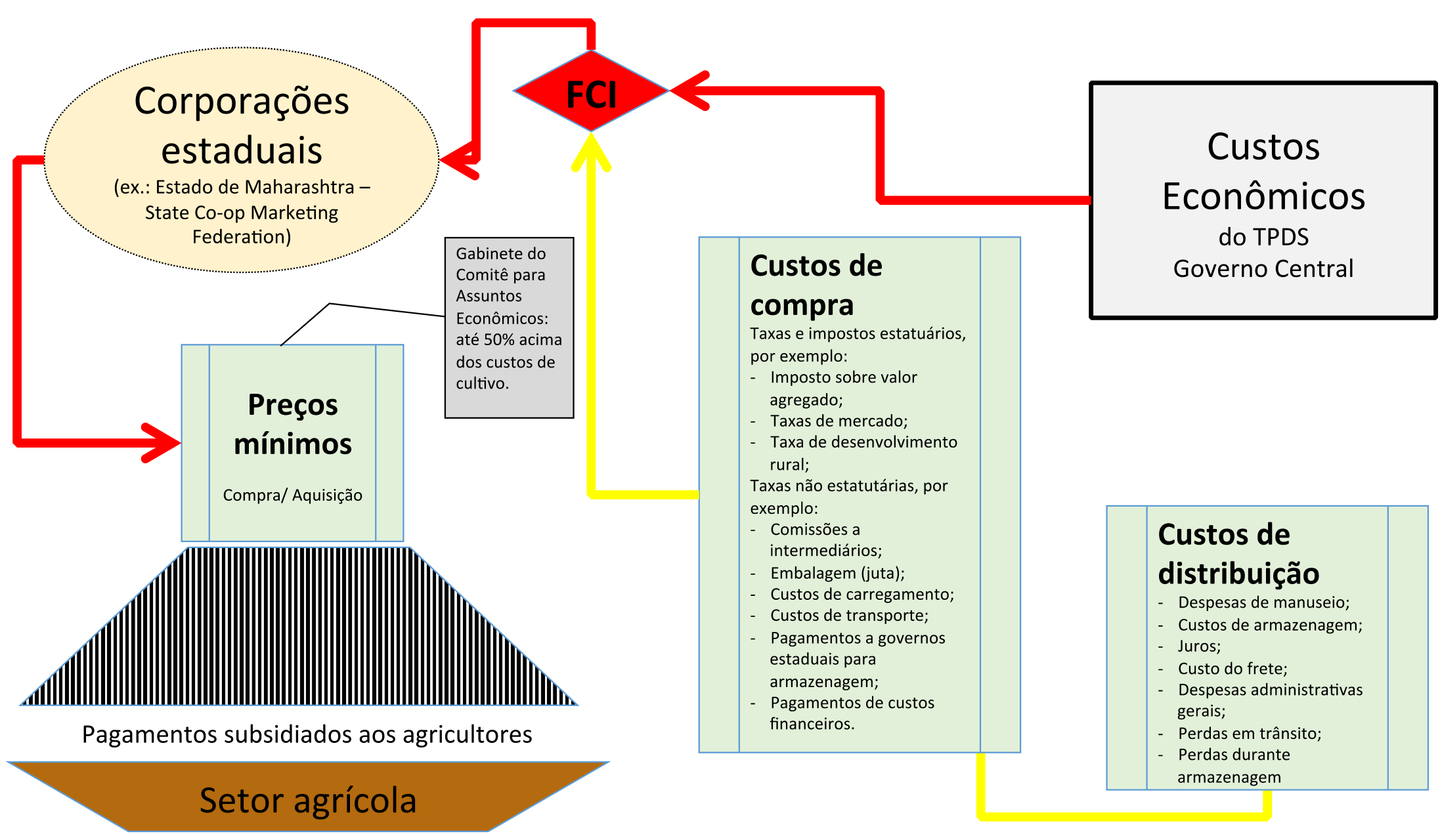

Figura 19: Estrutura e componentes do custo econômico do TPDS - situação atualizada até 2014

Fonte: Sharma, V. P. 2012, p. 5. Elaboração, adaptação e expansão do autor. 


\section{2 (IN)SUSTENTABILIDADE NA FORMULAÇÃO DA POLÍTICA}

O modelo imposto pela NFSA insiste em exigir uma administração extremamente hierarquizada e centrada na distribuição de arroz e trigo, sem distinção de origem, embora haja menção na Lei do uso de outras modalidades e reformas. As reformas explicitamente citadas na Lei incluem, inter alia:

- Entrega nas lojas do TPDS: em reformas anteriores, conforme discutido anteriormente nesta tese, já estava prevista a implementação da entrega. No entanto, onde implementada permaneceu incipiente;

- Digitalização do fluxo de informações e comunicação em todas as fases do sistema com o intuito de assegurar transparência de registros de transações em todos os níveis e impedir desvios: trata-se de uma reforma necessária e também já prevista. Uma vez mais, as resistências de stakeholders permanece;

- Uso do sistema AADHAAR para identificação dos beneficiários: ${ }^{51}$ também anteriormente prevista e também resistida por governos estaduais e diversos segmentos da sociedade civil. A Autoridade da Índia para Identificação Única (UIDAI) criada em 2009, até setembro de 2014 não dispunha de chancela do poder legislativo. Em 2014, a Suprema Corte da Índia declarou que a posse de um documento AADHAAR não poderia ser exigência obrigatória para a disponibilização de serviços públicos, por exemplo, o PDS (Suprema Corte da Índia, 2014);

- Transparência de registros: O Ministério de Assuntos do Consumidor, Alimentação e Distribuição Pública lançou o Portal de Transparência do PDS em outubro de 2012. Quantidades, destinos e preços atualizados são publicizados pelo governo central. Há, também, experiências estaduais de informatização do sistema de distribuição e de portais de transparência, por exemplo, em Chhattisgarh e Délhi (Puri, 2012; Krishnamurthy et al., 2014). Estudos sobre o impacto e relevância desses portais são necessários;

- Preferência a instituições públicas ou órgãos públicos, tais como, Panchayats, grupos de autoajuda e cooperativas para o licenciamento de lojas;

- Preferência para o gerenciamento de lojas de preço justo para mulheres e agrupamentos de mulheres: ambas reformas enfrentam resistência de grupos com interesses na manutenção do status quo. Além de interesses, há questões culturais que dificultam a aceitação, principalmente em áreas rurais (Budhwar et al., 2005).

\footnotetext{
51 Aadhaar, do Híndi para "fundação": um número de identificação de 12 dígitos gerado aleatoriamente, ligado à uma base de dados contendo informações biométricas e pessoais. Seria o primeiro número de Registro Geral do país. (Bhatti, 2011).
} 
Apesar disso, organizações não governamentais, como o Programa Mundial de Alimentos (ou de Programa Alimentar Mundial) da Organização das Nações Unidas (PAM - ONU) na Índia, no âmbito do Programa de Ação para o Desenvolvimento da Organização das Nações - 2013-17 (PAM - ONU, 2014) já trabalham com projetos que procuram maximizar a participação de mulheres em atividades diversas, inclusive de segurança alimentar;

- Diversificação da cesta de alimentos distribuída pelo PDS: novamente, reformas anteriores já previram e há alguns exemplos de alguns estados bem sucedidos (Mujamder, 2009). Seria uma inovação relevante, desviando-se da norma incrementalista de mudanças no PDS;

- Apoio a modelos de distribuição pública locais e bancos de grãos: O PAM - ONU também já trabalha com projetos para o fortalecimento de canais locais de distribuição de grãos, produção local e criação de empregos (PAM - ONU, 2014). Não se encontra documentado se há e quais seriam os esforços para o compartilhamento deste conhecimento com órgãos governamentais;

- Introduzir programas alternativos, tais como, transferência de renda ("cash transfers") e vale alimentação: Já existe uma série de experiências com transferência de renda em dinheiro na Índia, por exemplo, Gangopadhyay et al (2013), apresentam um estudo randomizado controlado em Nova Délhi. Os autores examinaram um experimento que substituiu o cartão de identificação de família abaixo da linha da pobreza por transferências incondicionais em dinheiro para um grupo de famílias. No estudo realizado a partir de 2010 , os autores incluíram um controle para diferenciar entre os efeitos de benefícios de abertura de conta bancária e de transferência de renda. Este estudo concluiu que não havia queda no nível de segurança alimentar com a substituição de distribuição em gênero por dinheiro. Pelo contrário, as famílias tiveram a oportunidade de mudar para outras opções de alimento que não cereais (Gangopadhyay et al., 2013). Há, no entanto, resistência a programas de transferência de renda por ativistas, acadêmicos e organizações não governamentais (Joshi, 2013; Standing, 2012; Akileswaran \& Nair, 2013; Miller, 2012). ${ }^{52}$

$52 \mathrm{O}$ texto da lei que trata das reformas a serem realizadas no PDS n íntegra e no originail:

(1) The Central and State Governments shall endeavour to progressively undertake necessary reforms in the Targeted Public Distribution System in consonance with the role envisaged for them in this Act.

(2) The reforms shall, inter alia, include-

(a) doorstep delivery of foodgrains to the Targeted Public Distribution System outlets;

(b) application of information and communication technology tools including end-to-end computerisation in order to ensure transparent recording of transactions at all levels, and to prevent diversion;

(c) leveraging "aadhaar" for unique identification, with biometric information of entitled beneficiaries for proper targeting of benefits under this Act;

(d) full transparency of records [há experiências localizadas]; 
Como se pode verificar, apenas implicitamente, a NFSA integra as dimensões da sustentabilidade ao propor reformas que encorajam a produção local - dimensão ambiental -, o emprego das mulheres no gerenciamento das lojas e diversificação da cesta de alimentos - dimensões social e econômica. Entretanto, ainda não há nenhuma previsão, por exemplo, da inclusão de uma cláusula que torne compulsório a compra de parte do cereal distribuído de fornecedores da agricultura familiar local, regional ou nacional, como ocorre com o Programa Nacional de Alimentação Escolar (PNAE) no arcabouço maior do Programa Nacional de Fortalecimento da Agricultura Familiar (PRONAF) do governo do Brasil (Saraiva et al., 2013; Lindoso et al., 2009). Os preços mínimos acabam beneficiando apenas os grandes produtores, especialmente dada a concentração extrema de terra agrícola na Índia: 80 por cento dos agricultores possuem apenas 20 por cento da terra, e quase 80 por cento daqueles que dispõem de terra não produzem excedente para vender no mercado e são forçados a trabalhar em terras alheias para sobreviver (Ayar, 2005).

\subsection{SUSTENTABILIDADE E SUBSÍDIOS}

Hoda e Gulati (2013), sustentam que o aumento de subsídios de consumo que resultaria da execução completa da lei de direito ao alimento reduziria a disposição do governo em investir mais na agricultura e resultaria em um quase monopsônio, isto é, o estado como virtualmente o único comprador relevante no mercado, conforme a Figura 19, ilustra, a situação já se aproxima do monopsônio. Além da concentração estatal na economia graneleira, a dominação do governo acaba por atrofiar definitivamente a concorrência privada, além de outorgar a ele mesmo imunidade no caso de reivindicações de indenização em caso de perdas devido a fenômenos naturais, por exemplo, inundações, terremotos, etc., e ocorrências políticas, tais como atentados e guerras (Hoda \& Gulati, 2013).

Há financiamento e crédito bancário agrícola na Índia especialmente para os grandes produtores. Porém, para os médios e pequenos, o sistema bancário comercial ainda é hesitante e inepto ante a necessidade e demanda reprimida. O sistema de cooperativas de crédito ainda engatinha no país, mas parece ser uma aposta promissora para médios e pequenos agricultores, e até para os agricultores familiares (Golait, 2007). Agências

(e) preference to public institutions or public bodies such as Panchayats, self- help groups, co-operatives, in licensing of fair price shops and management of fair price shops by women or their collectives;

(f) diversification of commodities distributed under the Public Distribution System over a period of time;

(g) support to local public distribution models and grains banks;

(h) introducing schemes, such as, cash transfer, food coupons, or other schemes, to the targeted beneficiaries in order to ensure their foodgrain entitlements specified in Chapter II, in such area and manner as may be prescribed by the Central Government. (GOVERNO DA ÍNDIA, 2013c, p. 5). 
governamentais são responsáveis por quase todo o crédito disponível mas enfrentam concorrência acirrada de agiotas rurais fortemente enraizados na cultura local (Kumar et al., 2010). Aliados às variações climáticas, mais mudanças climáticas, oscilações sazonais de preço e uma cultura rural em que a honra se encontra acima da própria vida, a Índia tem a deshonra de ser a campeã de suicídios de agricultores no mundo (Shiva \& Jalees, 2005; Deshpande \& Arora, 2010).

Para os grandes agricultores, uma prática comum de governos estaduais indianos de 2010 a 2013 foi conceder um bônus além de garantir um preço mínimo para agricultores de arroz e trigo, sem nenhuma base lógica ou econômica, apenas como ferramenta para angariar o voto rural (Narang, 2014). O bônus serve para anular o imposto estadual que os governos cobram sobre vendas - um percentual do preço mínimo do grão comprado e repassado pelo governo central. ${ }^{53}$

O governo central acaba por comprar mais e, menos sobra para o mercado aberto, acarretando na de facto nacionalização do mercado de grãos em alguns estados (Saini \& Kozicka, 2014). O principal resultado dessa política paternalista é uma inflação de alimentos mais alta, devido à contração na oferta e da liquidez demasiada do excedente. ${ }^{54}$ Em junho de 2014, o governo central instruiu estados a não autorizarem o pagamento de bônus sobre arroz e trigo. O não pagamento do bônus poderia dissuadir agricultores de arroz e trigo a dedicarem mais área às duas culturas e deter novos entrantes. Consequentemente, a probabilidade de um PDS mais sustentável seria maior, pois haveria mais incentivos à diversificação de cultivares e de culturas. A redução de subsídios sobre subsídios seria benéfica à economia indiana como um todo e o sistema de distribuição pública comprando, armazenando e transportando menos - talvez teria mais incentivos a ser mais sustentável e ser menos ineficiente, menos sujeito à corrupção. Uma redução de $25 \%$ no desperdiço de grãos, garantiria mais segurança alimentar para milhões e milhões de indianos e permitiria mais volume ao mercado privado, assim como uma redução do controle estatal sobre o setor graneleiro, redução da taxa de inflação de alimentos e mais divisas por meio de maior competitividade ao setor agrícola exportador, e mais mercado para pequenos produtores de grãos regionais. No entanto, a implantação da ordem, principalmente em estados governados por partidos oposicionistas e com um lobby ruralista forte, dificilmente será imediata ou completa (Narang, 2014).

\footnotetext{
53 Narang (2014), dá o seguinte exemplo: se um estado declara um bônus de $23 \%$ sobre o preço mínimo e o imposto sobre vendas estadual é de $9,7 \%$, o governo do estado repassa efetivamente apenas $(23-9,7)=13,3 \%$ de preço mínimo aos fazendeiros / agricultores. O restante é repassado pelo governo central.

54 Esse é um problema típico da passagem da economia camponesa (quando a produção das famílias não é monetizada e, portanto, não há uma relação direta entre custo de produção e preço de mercado) para a lógica de mercado, quando o preços são ditados por forças externas aos produtores. Esse processo em geral penaliza os pequenos produtores, pois deixam de produzir para auto-consumo e passam a comprar no mercado, sempre a preços relativamente altos. Veja Bursztyn, 1985; Sabourin, 2009.
} 


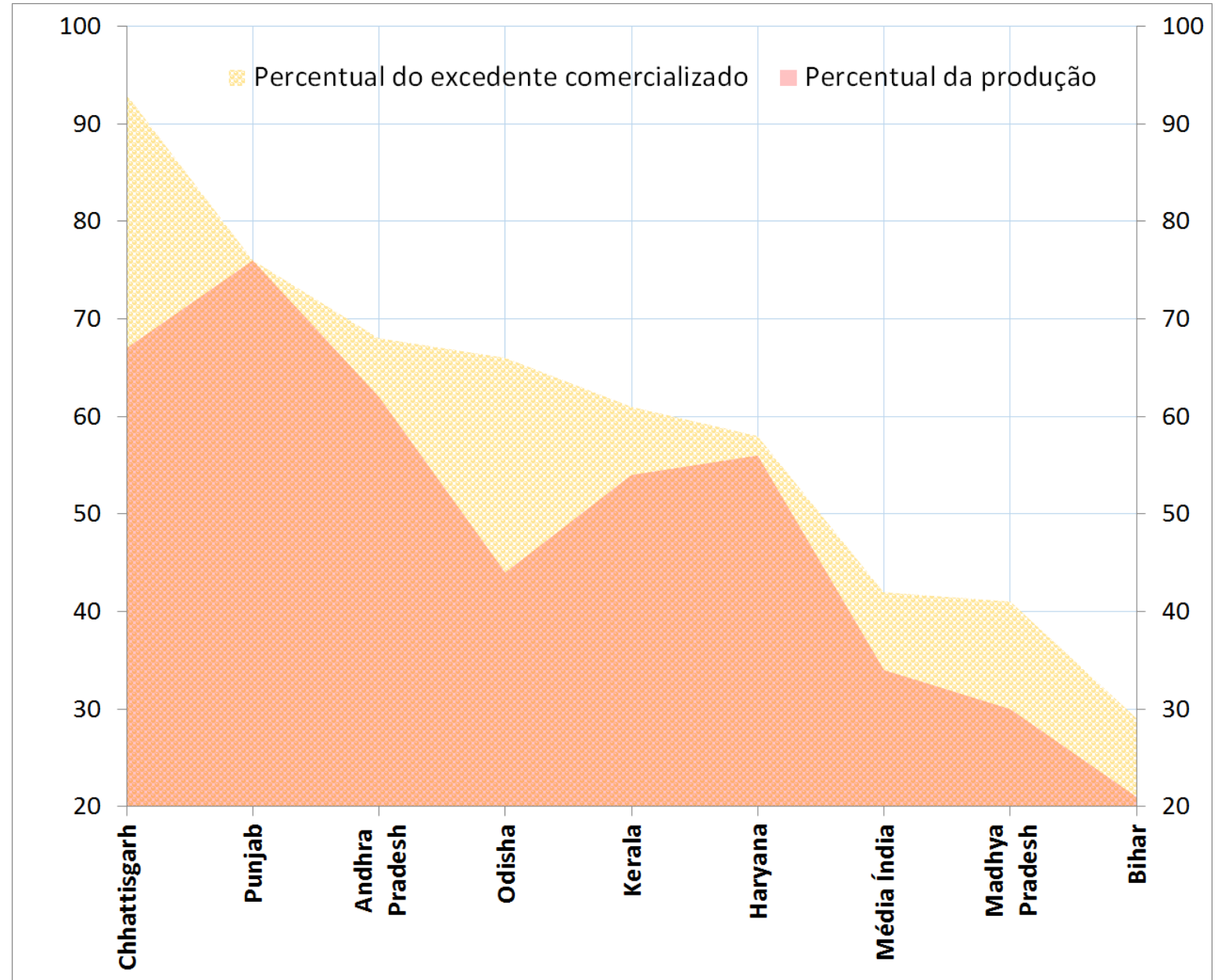

Gráfico 12 - Compra de arroz pela FCI para o PDS por estado como percentual do excedente comercializado e da produção total de arroz, 2012-2013

Fonte: Narang, 2014; Agricultural Statistics at a Glance, 2012; DFPD, 2013.

Elaboração do autor.

\subsection{UNIVERSALIZAÇÃO VERSUS USO DA LINHA DE POBREZA}

No quesito 'sustentabilidade social', parte da comunidade acadêmica e de practitioners defende a volta da universalidade do PDS como forma de coibir a corrupção e o paternalismo politico de inclusão e exclusão que passaram a dominar o sistema a partir de 1997 e atender a todos corretamente. Um preço único eliminaria o incentivo às fraudes de classificação nas listas de famílias abaixo da linha de pobreza oficial (Ayar, 2005). E, a inclusão de outros grãos menores reduziria a pressão sobre a produção de trigo e arroz (Banerjee, 2011). Para os defensores do PDS universal, os critérios de exclusão e inclusão dificilmente serão implementados e mesmo que forem, o serão apenas parcialmente e com muita fraude. Para este grupo, o custo fiscal e as restrições de disponibilidade de alimentos são desprezíveis dados os benefícios da universalização. No caso da questão do direito ao alimento, conforme a própria NFSA expressa, apenas o acesso de todos ao sistema, satisfaria a legislação (Singh \& Sen, 2011). 
Os defensores do PDS universal listam ainda, entre outras razões:

a. Mesmo com o crescimento econômico pós-TPDS, a prevalência de subnutrição, por exemplo, em crianças de até 5 anos de idade, é mais alta do que as médias de países subsaarianos (Naandi Foundation, 2012; Dhanaraj \& Gade, 2012);

b. Diversos estudos indicam que houve uma queda na ingestão de calorias da população (Basu \& Basole, 2012). Não há fatores claramente evidentes que expliquem a causalidade da queda e muito menos uma explicação aceita pela maioria dos estudiosos do assunto. Uma das hipóteses seria níveis mais baixos de atividade física ou melhoras gerais na saúde da população (Deaton \& Drèze, 2009). Um outro estudo, que se opõe a hipótese de Deaton \& Drèze (2009), atribui a diminuição de ingestão de calorias à erosão de renda real e resultante aumento da fome (Patnaik, 2010).

c. De acordo com o Comitê de Alto Nível sobre Política de Grãos de Longo Prazo de 2002, um retorno ao PDS universal seria recomendado dado que o TPDS embotou a eficácia do PDS em seu objetivo inicial de estabilização de preços e também de garantir o subsídio alimentar aos mais pobres (Ministério da Alimentação e Interesses do Consumidor, 2002). O coeficiente de variação de preços reais de cereais aumentou consideravelmente após 1997, provavelmente devido a menor efetividade do manejo público de grãos em reduzir a variabilidade da disponibilidade per capita abaixo da variabilidade na produção per capita (Singh \& Sen, 2011);

d. Quando o PDS era universal em 1993-94, a evasão de arroz era calculada em 19\%, com o TPDS, passou a 40\%; de trigo, de $41 \%$ para $73 \%$ em $2004-05$ (Governo da Índia, 2005a);

e. Muitos dos mais pobres dentre os pobres foram excluídos do TPDS por não conseguirem, pelas mais variadas razões, cartões de identificação "Abaixo da Linha de Pobreza" - BPL. Conforme a Tabela 5, a identificação dos mais pobres não foi tão bem sucedida no TPDS quanto no PDS, isto é comparandose o período anterior em que o sistema era universal (1993-94) e o período posterior (2004-05) em que os mais pobres deveriam ter acesso prioritário;

f. Estados que mantiveram a universalidade ou quase universalidade, casos de Tamil Nadu, Andhra Pradesh, Kerala e Chhattisgarh, são exemplos de bem sucedidas reformas que aumentaram o acesso ao PDS e reduziram os desvios, embora ainda existam deficiências (Mahendran \& Indrakant, 2014; Krishnamurthy et al., 2014); 
g. Os estados que não seguiram a metodologia de identificação da população abaixo da linha de pobreza do Censo de 2002 nem as linhas propostas pela Comissão de Planejamento têm percentual de desvio mais baixos e de acesso mais altos (Singh \& Sen, Abhijit, 2011).

Enfatizando a dificuldade de direcionar políticas públicas sociais na Índia, em setembro de 2014, um ano após a aprovação da Lei de Segurança Alimentar (NFSA), os beneficiados ainda não haviam sido identificados. Previa-se ainda um longo período de espera já que nem os critérios de identificação nem os meios para a realização do censo - o Censo Socioeconômico e de Castas (Socio Economic and Caste Census 2011 - SECC) que se encontrava mais de 2 anos atrasado em relação ao prazo inicialmente estabelecido para sua conclusão, maio de 2012, estavam garantidos. Questões técnicas, operacionais e de treinamento impediam o andamento satisfatório dos trabalhos, além de atrasos por parte dos estados em especificar critérios novos e completar verificações. Outra barreira ao andamento da implementação da nova lei, é a relutância dos estados em excluir aqueles que já fazem parte das listas de beneficiados devido ao custo político relacionado à exclusão de um programa social. Ainda o estado de Tamil Nadu, por exemplo, nunca optou por um sistema de distribuição direcionado e, dado o relativo sucesso do programa estadual, recusa-se a se conformar à norma nacional (Ramakrishnan, 2014; Yadav, 2014). ${ }^{55}$

\footnotetext{
$55 \mathrm{O}$ governo do estado de Tamil Nadu é contra o direcionamento da distribuição de cereais. Enquanto a NFSA prevê a cobertura de até $50 \%$ da população urbana, o estado demanda pelo menos $75 \%$. Mesmo se essas demandas forem atendidas pelo governo central, o estado reluta em identificar famílias com direito ao benefício nos moldes previstos na NFSA. Todos os estados tinham um prazo de um ano para realizar o censo; no entanto, o governo do estado demanda entre 2 a 3 anos para realizar o censo de forma satisfatória (Ramakrishnan, 2014).
} 
Tabela 6 - Percentual de domicílios em cada quintil de gasto mensal per capita na compra de arroz e trigo do PDS

\begin{tabular}{l|l|l}
\hline Quintil - Gasto mensal per capita & $1993-94$ & $2004-05$ \\
\hline $20 \%$ mais baixo & 29.2 & 35.5 \\
\hline Próximos 20\% & 27.8 & 28.1 \\
\hline Próximos 20\% & 27.1 & 23.2 \\
\hline Próximos 20\% & 25 & 18.5 \\
\hline $20 \%$ mais alto & 21.7 & 11.5 \\
\hline Média & 26.2 & 23.4 \\
\hline
\end{tabular}

Fonte: Singh \& Sen, Abhijit, 2011. Elaboração e adaptação do autor.

\subsubsection{Argumentos contra a universalização}

Os principais argumentos contra a volta da universalização do PDS giram em torno de duas premissas: em primeiro lugar, o governo central afirma que as quantidades de arroz e trigo necessárias para abastecer o sistema são proibitivas e resultariam em menor oferta no mercado aberto e preços mais altos; em segundo, também de acordo com o governo, para administrar um subsídio universal, as quantidades ofertadas às famílias abaixo da linha de pobreza teriam que ser reduzidas e os preços subsidiados pelo governo central aumentados (Agnihotri, 2010). ${ }^{56}$

\subsubsection{Estudo de caso do PDS universal no estado de Tamil Nadu: contra o universalismo}

Dhanaraj \& Gade (2012), estudaram o comportamento de famílias acima e abaixo da linha de pobreza em uma cidade de Tamil Nadu, estado com cobertura universal pelo PDS. A pesquisa revelou que a maioria das famílias da amostra classificadas como acima da linha de pobreza pelo censo do estado haviam realizado pelo menos uma compra em uma loja de preço justo no mês anterior. Dos portadores de cartão de compra de arroz, 94 por cento relataram realizar compras mensalmente, enquanto o restante 6 por cento, apontaram pertencer à camada mais alta de renda. Mesmo reconhecendo que a qualidade dos produtos das lojas de preço justo eram inferiores, ao invés de se excluírem do sistema, os de renda mais alta incluídos nos 94 por cento, faziam uso seletivo do arroz: i) relegavam o arroz de qualidade inferior a ocasiões específicas; ii) usavam o arroz para ração animal; iii) revendiam o arroz adquirido a preços subsidiados a preços mais altos (Dhanaraj \& Gade, 2012). Arockiaraj (2013), por sua vez, apresenta mais evidência em escala nacional, por exemplo, do uso de cereais subsidiados do PDS para fins que não alimentação humana, por exemplo, como ração para o gado, venda no mercado paralelo e beneficiamento e venda

\footnotetext{
${ }^{56}$ Para um contra-argumento à questão da disponibilidade, veja Singh \& Sen, 2011.
} 
como farinha de arroz. Aparentemente, são práticas conhecidas, reportadas pela imprensa e parece ser mais comum em períodos de seca.

\subsubsection{Mais argumentos contra a universalidade: Comitê do Juiz Wadhwa}

O Comitê do Juiz Wadhwa foi estabelecido pela Suprema Corte da Índia em 2006, com a assistência do pesquisador N. C. Saxena (2009), conselheiro da corte para segurança alimentar. A Suprema Corte decidiu pela investigação a partir de uma petição do Sindicato Popular para Liberdades Civis (People's Union for Civil Liberties), a mais antiga organização de direitos humanos da Índia. O Comitê preparou uma série de relatórios cobrindo diferentes estados, provavelmente o mais incisivo e completo requisitório do PDS. No ato de constituição do comitê, a Corte observou:

Estamos dando está diretriz incomum em vista do fato quase incontestável de que há corrupção em grande escala envolvida e há escassamente qualquer ação corretiva para pôr fim a este [fato]. A vítima final é o cidadão pobre que é privado de seu direito legítimo ao cereal. O Sistema Público de Distribuição é intencionado a assegurar que o cidadão obtenha o cereal a preços razoáveis tendo em vista os padrões econômicos. (SUPREMA CORTE DA ÍNDIA, 2006) $)^{57}$

Embora preparado durante o período em que o PDS já era TPDS, os relatórios do Comitê do Juiz Wadhwa não apenas documentam a situação deplorável do sistema como um todo mas fortemente condenam a quase universalidade da cobertura do sistema, principalmente a cobertura de famílias acima da linha de pobreza (CJWPDS, 2006). Para o Comitê, as famílias não pobres não deveriam ter acesso ao subsídio já que o mesmo não encontrou justificativas para a generosidade do governo. O Comitê, portanto, também veementemente aconselhou a abolição da categoria 'Acima da Linha da Pobreza' e, simultaneamente, a expansão da banda da categoria abaixo da linha de pobreza (CJWPDS, 2011)..$^{58}$

\footnotetext{
57 Tradução literal e adaptação do original em inglês do autor.

58 Em 2012, o Comitê Wadhwa divulgou 2 objetivos para o PDS de longo prazo: (I) a constituição de uma corporação de suprimentos civis em cada estado; e, (II) Digitalização de todas as operações da PDS. E também, 21 recomendações de natureza variada de curto prazo: (1.) Identificação de beneficiários / erros de inclusão e exclusão; (2) capacidade de armazenagem; (3.) transporte de cereais / grãos do PDS; (4.) viabilidade das lojas de preço justo; (5.) prestação de contas e monitoramento; (6.) alocação de grãos baseado em cada unidade [lojas]; (7.) comitês de vigilância; (8.) mecanismo de reclamações; (9.) alocação de lojas de preço justo; (10.) conscientização de beneficiários; (11.) vigilância e cumprimento [da lei]; (12.) funcionamento das lojas de preço justo; (13.) oferta de farinha de trigo fortificada; (14.) eliminação de cartões de suprimento [de racionamento]; (15.) pesagem eletrônica; (16.) emissão de cartões de suprimento; (17.) implementação de regulamentos emitidos pela Corte anteriormente relacionados, por exemplo, à perda de licença de lojas que não cumprissem regras e regulamentos do PDS; (18.) alocação de cereais do PDS do Governo Central para os estados e unidades da união baseado na população projetada; (19.) amostragem conjunta de qualidade dos produtos recebidos e vendidos pelas lojas; (20.) abolição da categoria Acima da Linha de Pobreza; (21.) medidas especiais para os distritos mais pobres do país. (Suprema Corte, 2012).
} 


\subsection{SUSTENTABILIDADE NA POLÍTICA DE COMPRA (PROCUREMENT)}

Como apresentado no capítulo 6, a $\mathrm{FCl}$ é responsável pela compra de cereais em nome do Governo Central, embora outras agências governamentais também comprem cereais e outros produtos agrícolas e não agrícolas para programas independentes e também para o próprio Governo Central. A alocação final para cada estado é realizada pelo órgão relevante do Governo Central. Os órgãos estaduais fazem a distribuição no varejo de acordo com o número de cartões de provisão registrados em cada loja (Janbee, 2000).

Até meados da década de 1960, conforme discutido anteriormente, a maior parte do grão distribuído no PDS era importado e os preços oferecidos no mercado doméstico não eram remunerativos. A partir da década de 1970, o Bureau de Preços e Custos Agrícolas (Bureau of Agricultural Costs and Prices - BACP) passou a ser a instância de consulta para a $\mathrm{FCl}$ em relação aos preços praticados e aos estoques reguladores (buffer stocks). Regulamentos, procedimentos e arranjos institucionalizados foram criados para reger o mercado e a atuação do governo, com especial atenção para os preços mínimos subsidiados aos agricultores, sem ônus ao consumidor final que também seria beneficiado por subsídios próprios. Também por meio da manipulação de compra e venda subsidiada de mercado, o Governo Central procurou nivelar as diferenças de excedente e déficit entre estados produtores e consumidores (Janbee, 2000). Mais de noventa por cento do arroz é comprado dos estados de Punjab, Andhra Pradesh, Chattisgarh, Haryana, Orissa e Uttar Pradesh, conforme atestado na Tabela 6 (FCl, 2014). A maior parte das compras de trigo é realizada nos estados de Punjab, Haryana, Uttar Pradesh, Madhya Pradesh, Rajasthan, conforme Tabela 7 e Figura 20. 
Tabela 7: Compra de arroz pela FCI ( x 100 mil toneladas)

\begin{tabular}{lllllllllrr} 
& Punjab & $\begin{array}{l}\text { Andhra } \\
\text { Pradesh }\end{array}$ & Chattisgarh & Haryana & Orissa & $\begin{array}{l}\text { Uttar } \\
\text { Pradesh }\end{array}$ & $\begin{array}{l}\text { Outros } \\
\text { estados }\end{array}$ & \multicolumn{1}{c}{$\begin{array}{l}\text { Total } \\
\text { Variação } \\
\text { ano/ano }\end{array}$} \\
\hline $2003-04$ & 86.6 & 42.4 & 24.0 & 13.3 & 14.1 & 25.5 & 23.0 & 229.0 & 246.7 \\
\hline $2004-05$ & 91.1 & 39.1 & 28.4 & 16.6 & 15.9 & 29.7 & 26.0 & $8 \%$ \\
\hline $2005-06$ & 88.7 & 49.7 & 32.7 & 20.5 & 17.9 & 31.5 & 34.9 & 275.8 & $12 \%$ \\
\hline $2006-07$ & 78.3 & 53.3 & 28.7 & 17.8 & 20.0 & 25.6 & 27.5 & 251.1 & $-9 \%$ \\
\hline $2007-08$ & 79.8 & 76.0 & 27.4 & 15.7 & 23.6 & 28.9 & 35.9 & 287.4 & $14 \%$ \\
\hline $2008-09$ & 85.5 & 90.6 & 28.5 & 14.3 & 28.0 & 40.1 & 54.1 & 341.0 & $19 \%$ \\
\hline $2009-10$ & 92.8 & 75.6 & 33.6 & 18.2 & 25.0 & 29.0 & 46.3 & 320.3 & $-6 \%$ \\
\hline $2010-11$ & 86.4 & 96.1 & 37.5 & 16.9 & 24.7 & 25.5 & 55.0 & 342.0 & $7 \%$ \\
\hline $2011-12$ & 77.3 & 75.4 & 41.2 & 20.1 & 28.7 & 33.6 & 74.2 & 350.4 & $2 \%$ \\
\hline $2012-13$ & 85.6 & 64.9 & 48.0 & 26.1 & 36.1 & 22.9 & 56.8 & 340.4 & $-3 \%$ \\
\hline $2013-14 *$ & 81.1 & 79.2 & 42.9 & 24.1 & 28.2 & 11.3 & 46.5 & 313.1 & $-8 \%$ \\
\hline
\end{tabular}

Fonte: $\mathrm{FCl}$, 2014a. Elaboração e adaptação do autor. Legenda: $\left(^{*}\right)$ até 25/08/2014

Tabela 8: Compra de trigo pela FCI ( $x 100$ mil toneladas)

\begin{tabular}{llllllllr} 
& Punjab & Haryana & $\begin{array}{l}\text { Uttar } \\
\text { Pradesh }\end{array}$ & $\begin{array}{l}\text { Madhya } \\
\text { Pradesh }\end{array}$ & Rajasthan & $\begin{array}{l}\text { Outros } \\
\text { estados }\end{array}$ & Total & $\begin{array}{l}\text { Variação \% } \\
\text { ano/ano }\end{array}$ \\
\hline $2003-04$ & 89.38 & 51.22 & 12.13 & 1.88 & 2.59 & 0.81 & 158.0 & $6 \%$ \\
\hline $2004-05$ & 92.4 & 51.15 & 17.41 & 3.49 & 2.79 & 0.71 & 168.0 & $-12 \%$ \\
\hline $2005-06$ & 90.1 & 45.29 & 5.6 & 4.84 & 1.59 & 0.43 & 147.9 & $-38 \%$ \\
\hline $2006-07$ & 69.51 & 22.29 & 0.49 & & 0.02 & & 92.3 & $21 \%$ \\
\hline $2007-08$ & 67.8 & 33.5 & 5.46 & 0.57 & 3.84 & 0.11 & 111.3 & $104 \%$ \\
\hline $2008-09$ & 99.41 & 52.37 & 31.38 & 24.1 & 9.35 & 10.28 & 226.9 & $12 \%$ \\
\hline $2009-10$ & 107.25 & 69.24 & 38.82 & 19.68 & 11.52 & 7.31 & 253.8 & $-11 \%$ \\
\hline $2010-11$ & 102.05 & 63.35 & 16.73 & 35.38 & 4.76 & 2.89 & 225.2 & $26 \%$ \\
\hline $2011-12$ & 109.58 & 69.28 & 34.61 & 49.65 & 13.03 & 7.18 & 283.3 & $34 \%$ \\
\hline $2012-13$ & 128.34 & 86.65 & 50.63 & 84.93 & 19.64 & 8.97 & 379.2 & $-34 \%$ \\
\hline $2013-14$ & 108.97 & 58.73 & 6.82 & 63.55 & 12.7 & 0.15 & 250.9 & $12 \%$ \\
\hline $2014-15$ & 116.41 & 64.95 & 6.28 & 70.94 & 21.59 & 0.06 & 280.2 & \\
\hline
\end{tabular}

Fonte: $\mathrm{FCl}, 2014 \mathrm{~b}$. Elaboração e adaptação do autor.

A decisão sobre as quantidades compradas é balizada nos alvos de compra pela BACP e FCl. Porém, dado o preço mínimo garantido aos produtores por lei, a $\mathrm{FCl}$ é obrigada a comprar tudo o que é oferecido por eles e acarretar com todos os problemas e conflitos advindos deste pré-requisito legal. No caso do trigo, o preço de compra praticado pela $\mathrm{FCl}$ age como preço mínimo, enquanto o preço para o arroz é imposto como contribuição obrigatória (levy). Os preços nos estados produtores são artificialmente comprimidos para facilitar a compra por meio da proibição de movimentação do produto fora das zonas de produção (Rao, 1993). A ideia é aproximar os preços praticados o máximo possível dos preços de suporte (preços mínimos) (Janbee, 2000). Essa prática, no entanto, 
tem gerado inflação de demanda dos preços de alimentos e é uma clara falha de governo, conforme visto no capítulo 5 desta tese.

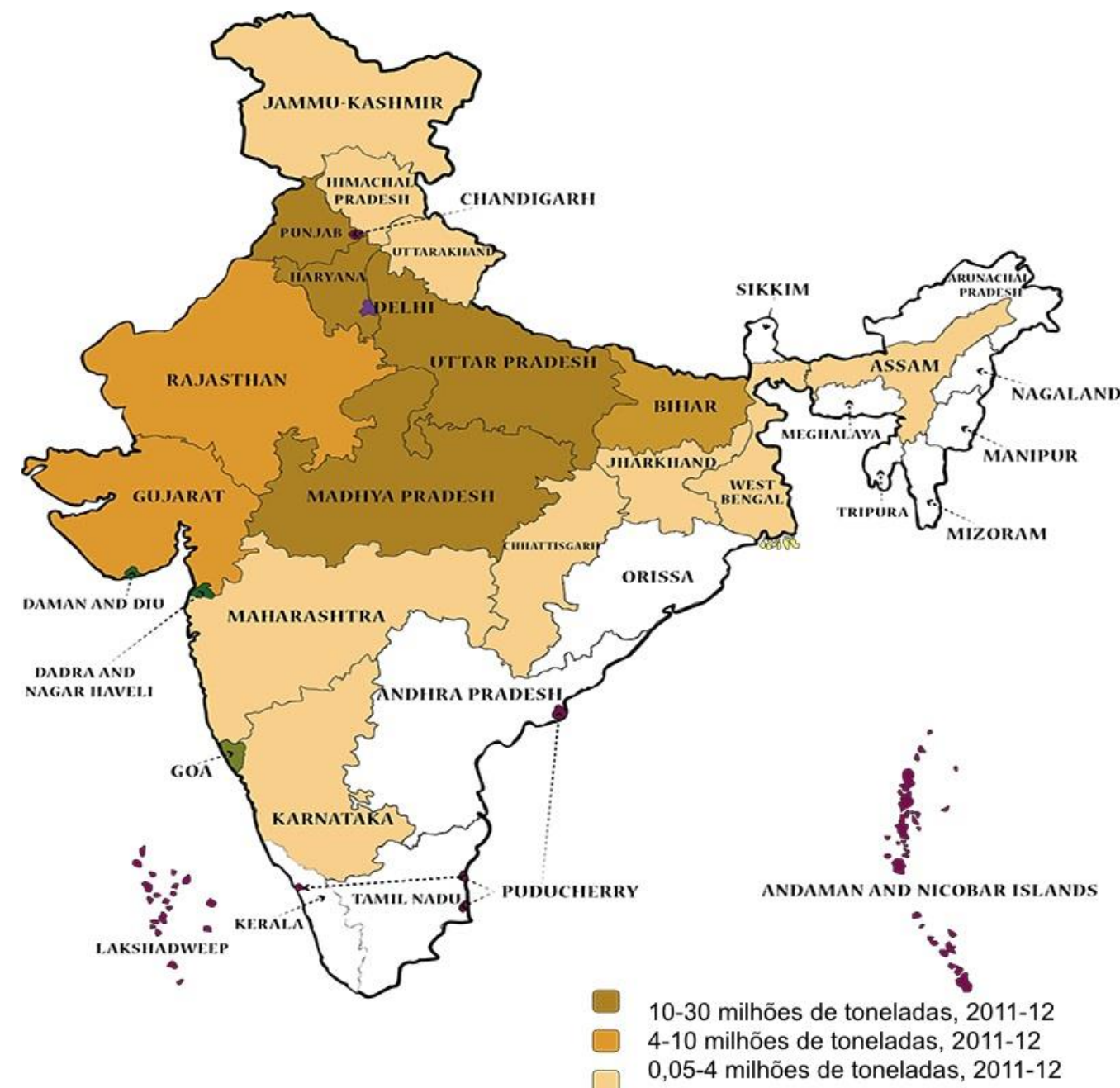

Figura 20: estados produtores de trigo na Índia

Fonte: Farmer's portal, 2013. Disponível em: <http://farmer.gov.in/cropstaticswheat.html>. Acesso: 8/11/2014.

Adaptações e alterações do autor.

Observação: as localidades em destaque em outras cores não são produtoras de trigo; apenas indicam territórios da união e/ ou estados menores.

Na política de compra do PDS, a ausência de integração horizontal e vertical da política ambiental no sistema é patente e é reflexo da mesma situação na política agrícola do país. Da grande variedade de grãos disponível e comumente consumidos pela população da Índia, na maioria das lojas de preço justo, apenas arroz, trigo e açúcar são vendidos. Milheto (Pennisetum glaucum) e outros cereais menores, leguminosas e oleaginosas continuam largamente excluídos do PDS, exatamente aqueles não incluídos na Revolução Verde indiana (Michaelraj \& Shanmugam, 2013). A maioria dos cereais, legumes e oleaginosas excluídos da Revolução Verde Indiana é de sequeiro em contrapartida ao arroz e ao trigo que dependem de irrigação na maioria das grandes áreas produtores. As regiões que receberam investimentos maciços em projetos de irrigação pouco planejados, sofrem de 
efeitos de longo prazo, como esgotamento de aquíferos, produtividade do solo decrescente, destruição de sistemas de semente de regeneração de baixo custo e a proliferação de pragas (Banerjee, 2011; Hazell, 2009). E essa situação foi apenas reforçada pela NFSA de 2013.

\subsection{INCLUSÃO DE MILHETO E OUTROS GRÃOS E LEGUMINOSAS TRADICIONAIS}

A inclusão de milheto, sorgo (conhecido como Jowar na Índia) e outros grãos e leguminosas no PDS tem o potencial de melhorar o nível de sustentabilidade social, econômica e ambiental do sistema como um todo pelo encorajamento à diversificação de culturas e inserção de agricultores atualmente marginalizados. A agricultura de sequeiro na Índia, que corresponde a cerca de 60 por cento da área de plantio líquida e dominante em muitas regiões, seria fortalecida e os meios de subsistência também (Banerjee, 2011). ${ }^{59}$ Outra vantagem é a inclusão da segurança nutricional e não apenas alimentar, já que os cereais menores, as leguminosas e outros são mais ricos em micronutrientes. São exatamente nos micronutrientes que a Índia se encontra em situação alarmante, conforme levantamentos do UNICEF e do Bureau Nacional de Acompanhamento de Nutrição da Índia, Tabela 9, abaixo (UNICEF, 2010; NAAS, 2012).

Tabela 9 - Distribuição (\%) de indivíduos que ingerem menos de 50\% abaixo das recomendações nutricionais de micronutrientes

\begin{tabular}{|c|c|c|c|}
\hline Nutriente & $\begin{array}{l}1-3 \\
\text { anos }\end{array}$ & $\begin{array}{c}\text { Mulheres (>18 anos, } \\
\text { sedentárias) }\end{array}$ & $\begin{array}{l}\text { Homens ( }>18 \text { anos, } \\
\text { sedentários) }\end{array}$ \\
\hline Energia & 42.0 & 5.6 & 10.9 \\
\hline Proteína & 24.6 & 14.2 & 16.7 \\
\hline Cálcio & 79.9 & 46.3 & 40.7 \\
\hline Ferro & 73.5 & 85.1 & 73.0 \\
\hline Vitamina A & 86.6 & 85.7 & 84.9 \\
\hline $\begin{array}{l}\text { Tiamina } \\
\text { (B1) }\end{array}$ & 46.3 & 9.6 & 21.1 \\
\hline Riboflavina & 84.9 & 72.9 & 80.6 \\
\hline Niacina & 37.6 & 4.2 & 11.9 \\
\hline $\begin{array}{l}\text { Ácido } \\
\text { fólico }\end{array}$ & 45.1 & 63.2 & 52.1 \\
\hline Vitamina C & 77.6 & 46.1 & 45.6 \\
\hline
\end{tabular}

Fonte: National Nutrition Monitoring Bureau, 2009.

\footnotetext{
${ }^{59} \mathrm{Na}$ Índia, 60 por cento da área cultivada líquida, 100 por cento das florestas, 66 por cento da pecuária, 85 por cento dos milhetos e leguminosas, 80 por cento da horticultura, 77 por cento das oleaginosas, 66 por cento do algodão e 50 por cento dos cereais são 'cultivados' sem irrigação artificial, segundo a Autoridade Nacional de Áreas de Agricultura de Sequeira da Índia - NRAA, (2013).
} 
Por outro lado, um preço mínimo melhor para culturas de sequeira encorajaria agricultores a dedicar mais terra a essas variedades mais resistentes e nutritivas. No entanto, nas palavras da cientista e filósofa, Vandana Shiva, "a monocultura mental" dos interesses envolvidos, políticos e econômicos, preserva a centralização do sistema e as três monoculturas (Shankar, 2009). O Governo da Índia, Ministério de Assuntos do Consumidor por meio do Departamento de Alimentos e Distribuição Pública divulga preços mínimos para cereais não incluídos no PDS. No entanto, os estados produtores não disponibilizam estrutura física e recursos financeiros para a compra, armazenagem e distribuição dos grãos pelos preços mínimos, que acabam se tornando ficção política (NRAA, 2011).

A descentralização de compras e armazenagem, na tentativa de transferir parte da responsabilidade para mais próximo do consumidor final e assim também a prestação de contas poderia auxiliar na diminuição dos desvios. Preços mínimos mais altos para outros grãos tradicionais e descentralização poderiam injetar nova vida a pelo menos 60 por cento da agricultura indiana. A diversificação encorajaria mudanças paulatinas para uma agricultura mais diversificada e mais local, com menos custos de transporte e armazenagem (Banerjee, 2011).

\subsection{MAIS PONTOS DE INSUSTENTABILIDADE}

Os diversos estudos apresentados ao longo deste capítulo parecem fortalecer a hipótese de que a NFSA nem de forma insustentável tem como atender a questão da segurança alimentar e nutricional. Conforme discutido no capítulo 2 deste trabalho de tese, o acesso à alimentação está intrinsecamente ligado aos meios de subsistência e o acesso àquilo que Ihes garante esse direito é renda satisfatória, continuada e sustentável. Entretanto, de acordo com a Comissão Nacional para Empreendimentos no Setor Não Organizado da Índia (NCEUS - sigla em inglês), 77 por cento da população da Índia é economicamente vulnerável, com gasto per capita de menos de 20 rúpias indianas por dia (NCEUS, 2007). ${ }^{60}$ Deste modo, é evidente que o acesso a alguns quilogramas de cereais subsidiados por mês não é suficiente para mudar a situação de pobreza extrema e garantir verdadeira segurança alimentar e nutricional, embora possa mantê-los vivos (Sinha, 2012). ${ }^{61}$ A variável renda é negligenciada pelas autoridades quando tratam de sexgurança alimentar e nutricional: a lei de segurança alimentar continua divorciada de outras políticas socioeconômicas associadas às condições de vida (Sinha, 2012; NCEUS, 2007).

\footnotetext{
60 Cerca de USD0,30, preços de 2004-2005 (Sinha, 2012).

61 Estudo em 10 pontos do Centro para Apoio e Pesquisa Legislativa (CLRA), uma organização não governamental baseada em Nova Délhi, Sinha (2012), a partir do projeto de lei da NFSA, que sofreu alterações até sua aprovação em 2013, alterações essas que, do ponto de vista do autor, não invalidaram as conclusões do estudo da CLRA.
} 
Além de falhar ao não dar atenção devida à geração de renda, a NFSA ignora a ligação entre a segurança alimentar e a agricultura, ao não considerar que a própria atividade emprega diretamente quase 60 por cento da força de trabalho indiana e gera 55 por cento da renda rural. Em outro nível de análise sobre o mesmo ponto, quando se considera a questão de gênero, mais de 80 por cento das mulheres na zona rural que trabalham fora, estão ocupadas no setor agropecuário. Uma vez mais, o fator renda das mulheres tem efeitos diretos e significativos na segurança alimentar e nutricional das famílias, especialmente dos mais vulneráveis, as crianças, e das mais vulneráveis das vulneráveis, as meninas (Governo da Índia, 2010b). ${ }^{62}$

Contudo, a NFSA apenas reforça os programas de alimentação para mulheres grávidas, os programas de refeição de meio dia para crianças, enquanto meninas adolescentes são consideradas apenas para reformas e programas futuros da NFSA. A NFSA, uma vez mais, falha ao não relacionar programas universais para crianças e adolescentes à segurança alimentar e nutricional de forma direta e no âmbito do sistema educacional governamental. O não-reconhecimento oficial por parte do governo central e dos governos estaduais do papel de meninas e mulheres na força de trabalho no campo impede que, por exemplo, meninas adolescentes mais pobres que cuidam de crianças mais novas, tenham acesso ao ensino médio. Isso ocorre devido à inexistência de creches e/ ou centros de cuidado para pré-escolares, situação que prende o desenvolvimento geral escolar e laboral, de meninas adolescentes, além de ser um dos fatores que contribui para a subnutrição crônica dessa faixa etária (Sinha, 2012). ${ }^{63}$

\subsubsection{Distribuição e armazenagem e varejo}

A distribuição e armazenagem do PDS é extremamente ineficiente e não sustentável. As decisões sobre quantidade alocada a cada estado, escolha de agência de distribuição em nível regional e de varejo e a margem de lucro de cada operação para os operadores

\footnotetext{
62 "Anemia em crianças pequenas, meninas adolescentes e mulheres em todo o ciclo de vida, se reflete também em que de três crianças em quatro são anêmicas (79\%) e a prevalência de anemia em crianças pequenas, abaixo de 3 anos de idade aumentou de 74\% para 79\% entre a Pesquisa Nacional de Saúde da Família (NFHS) de 1998-99 e a NFHS de 2005-06. A menina se torna uma adolescente anêmica e subnutrida, frequentemente destituída de cuidados de saúde adequados e apoio nutricional, oportunidades educacionais, negada do direito de ser criança - casada cedo demais, impregnada cedo, sem recuperação adequada entre gravidezes. Isto perpetua o ciclo vicioso de subnutrição e morbidade que corrói o capital humano por meio de efeitos irreversíveis e Inter geracionais sobre o desenvolvimento físico e cognitivo. O ciclo inter geracional de subnutrição é acentuado por privações múltiplas relacionadas à discriminação de gênero, pobreza e exclusão." (GOVERNO DA ÍNDIA, 2010b, p. 19). Tradução do autor.

63 Desde 1975, o Governo da Índia mantém os Anganwadis, 'abrigos nos pátios', criados pelo programa 'Serviços Integrados para o Desenvolvimento das Crianças' (ICDS), direcionado a crianças abaixo de 6 anos de idade, grávidas e lactantes. Fornecem serviços, por exemplo, de infantário (creche), nutrição suplementar, imunização e check-ups básicos de saúde. O programa também atende mulheres de 15 a 45 anos, principalmente com programas de educação nutricional. O programa sofre com problemas de estrutura física instalações inadequadas, funcionários de menos e áreas de cobertura acima da capacidade de cada centro (Moitra, 2014).
} 
locais e a armazenagem é de responsabilidade compartilhada da $\mathrm{FCl}$ e das corporações estaduais exceto para o estado de Andhra Pradesh que tem uma rede de transporte estatal. O processo de liberação de cargas dos armazéns às lojas é bastante burocrático e de acordo com o Comitê Wadhwa (2011), acarreta em atrasos nos recebimentos mensais de cada loja, e frequentemente, por exemplo, no estado de Maharastra, cuja capital é Mumbai (antiga Bombaim), as sacas de grãos chegavam em média apenas no $25^{\circ}$ dia do mês.

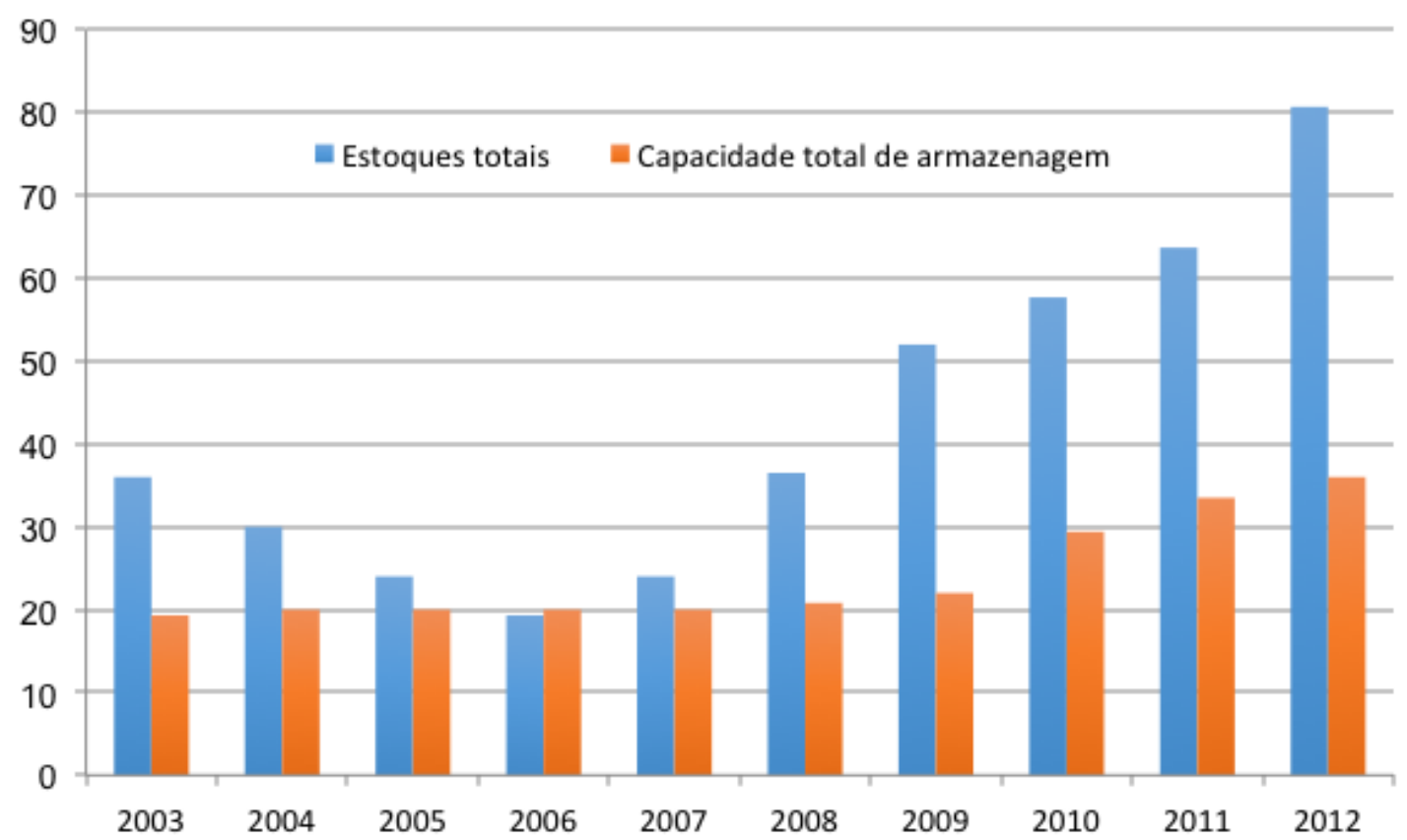

Gráfico 13 - Estoques totais de grãos e capacidade de armazenagem da FCl em nível nacional, 2003-2012 (valores aproximados - em milhões de toneladas).

Fontes: Governo da Índia, 2013d; PDS, 2013.

Outra prática contraproducente é a não retirada completa da alocação destinada a cada estado dos armazéns sob controle da FCl. Devido a situação precária de muitos dos armazéns e 'armagenazem' a céu aberto (Gráfico 12), a perda de grãos é alta e rotineira. A FCl tinha em 2013, 82 milhões de toneladas de grãos, e um déficit de $40 \%$ em capacidade de armazenagem em junho de 2012 (Governo da Índia, 2013b). Após fornecer a quantidade de cereais determinada pela Comissão de Planejamento para o TPDS, a FCl tem a prerrogativa de manter um estoque regulador de segurança (buffer stock). A quantidade adquirida pelo governo cresceu substancialmente entre 2008 e 2012 (de 19,6 milhões de toneladas para 82 milhões) e precisa crescer muito mais para atender a NFSA. Paralelamente, a capacidade de armazenagem tanto estatal quanto privada a serviço da $\mathrm{FCl}$ está praticamente estagnada (Gráfico 12). Esta inabilidade do governo central garantir a conservação do produto adquirido resulta em perdas inaceitáveis em qualquer país e mais ainda na Índia.

De acordo com o a Autoridade Regulatória e de Desenvolvimento de Armazéns da Índia (WDRA - sigla em inglês), 13 por cento do PIB indiano é desperdiçado a cada ano 
devido a perda de grãos ao longo da cadeia de suprimento (Jena, 2013; WDRA, 2013). Por exemplo, as 33 milhões de toneladas de grãos com valor aproximado de 12 bilhões de dólares adquiridos em 2013 para o PDS e outros programas governamentais não tinham local certo para serem armazenadas, de acordo com auditoria interna realizada pelo auditor geral da Índia (WDRA, 2013).

\subsubsection{Estoque de segurança}

A Controladoria e Auditor Geral da Índia (Comptroller and Auditor General of India) (2013), confirmou a falta de distribuição estratégica de capacidade de armazenagem no país. Estados consumidores em geral não dispõem de estrutura física enquanto estados produtores concentraram quase dois terços da capacidade disponível. A falta de coordenação eficiente na alocação de recursos leva à subutilização de capacidade disponível em alguns estados e outros a utilizarem sistemas de armazenagem precários que diminuem a vida útil dos cereais. Complicando ainda mais a equação `quantidade comprada - capacidade de armazenagem ', muito provavelmente por razões políticas, ano após ano, o governo central tem estocado mais do que o necessário. As normas do estoque regulador de segurança obrigatório não são específicas quanto aos elementos individuais do sistema de segurança alimentar que o estoque deve atender. Isto é, não há quantidades ou proporções claras quanto ao que deve atender situações de emergência, o TPDS, reservas estratégicas para outros programas de segurança alimentar, o programa de estabilização de preços de mercado, para citar apenas alguns exemplos de quais deveriam ser os usos do estoque estratégico. Concomitantemente, as normas não são específicas em relação ao estoque máximo que deve ser mantido para cada função. Dada esta situação, há bastante espaço para manipulação e uso político das quantidades alocadas, que há décadas resulta em desperdício e permanência da insegurança alimentar e nutricional na Índia. Mesmo completamente relevando a sustentabilidade ambiental, a situação não se justifica nem dos pontos de vista puramente administrativo, econômico ou de justiça social (Jena, 2013; WDRA, 2013). 


\subsection{BALIZAMENTOS DE UMA PROPOSTA FACTÍVEL}

Uma proposta exequível e não apenas marginal precisa admitir a realidade que domina o sistema público de distribuição de alimentos indiano: a corrupção ubíqua é um entrave à formulação e execução de políticas públicas sustentáveis de segurança alimentar e nutricional e também à administração eficaz e eficiente do TPDS-NFSA. ${ }^{64}$ Uma mudança cultural e institucional é imprescindível mesmo com novos arranjos organizacionais. Tal mudança requer, todavia, muito mais que uma mudança de uma política de governo, mesmo uma que sobrevive sob diferentes nomes a mais de meio século. ${ }^{65}$

Deve-se considerar, também, os interesses legítimos que precisam ser atendidos em qualquer reformulação do TPDS e encontrar caminhos legais e justos para que os mesmos se realizem sem recurso à corrupção. Forças políticas regionais e locais precisam ser contabilizadas em um novo arranjo organizacional e político. Principalmente, o interesse da classe ruralista indiana precisa ser atendido e canalizado por meios que inibam o rentseeking na fonte. A sustentabilidade do TPDS-NFSA passa por um programa focado na coibição do rent-seeking em várias fases do sistema e na aproximação dos controles governamentais e da sociedade civil organizada, e mecanismos para contornar parte da corrupção, especialmente a que ocorre entre a colheita e a entrega às famílias contempladas pelo TPDS. ${ }^{66}$

A maioria das propostas de reforma do TPDS disponíveis na literatura especializada não trata da questão do rent-seeking. Funcionários de diferentes repartições e níveis de governo, pessoas jurídicas diversas e stakeholders privados ainda encontram inúmeras oportunidades para "sangrar" o sistema não importa quão informatizado este seja. Porém, quando corporações e grupos especializados se responsabilizam por parte do processo embora não se resolva a questão da agricultura não sustentável diretamente e a ênfase em cereais não atenda a questão da segurança nutricional - a eficiência e eficácia visando o lucro com perdas mínimas, gera incentivos para a sustentabilidade socioeconômica e ambiental.

Muitas propostas de mudança no TPDS se concentram, por exemplo, na mudança de produto em espécie para dinheiro, cupons ou vales (Jain, 2011; Prabhu, 2009; Mehrotra,

\footnotetext{
${ }^{64}$ Há iniciativas pelo país que lutam tenazmente contra a cultura da corrupção. Veja, por exemplo, Economist, 2014; Chatterjee, S., 2014; CMS, 2011. De acordo com a organizaçãoo não governamental Transparency International, a Índia é um dos países mais corruptos do planeta (Hardoon \& Heinrich, 2011)

.65 Diferente da percepção externa, internacional menos informada, há órgãos governamentais indianos percebidos como honestos e não sujeitos à corrupção, bem quistos e estimados pela classe média indiana, tais como o Banco Central e a Suprema Corte (Economist, 2014).

66 Uma análise de sustentabilidade mais abrangente deveria incluir também uma discussão sobre a questão ecológica, por exemplo, o uso de agrotóxicos, consumo de água (uso consuntivo) na produção e a questão ecológica no armazenamento (presença de roedores, controle de roedores - até mesmo a presença de serpentes respeitadas na tradição hindu) -, e o uso de venenos como fungicidas e inseticidas para conservação do estoque. Esses tópicos poderão ser alvo de pesquisas futuras do autor.
} 
2010). A despeito de todas as vantagens e evidências de muitos estudos de caso nas Américas do Sul e Central, além de Sudeste Asiático, grande parte da sociedade civil organizada indiana é categoricamente contra programas de transferência de renda e segurança alimentar que se utilizem de dinheiro ou vales. ${ }^{67}$ Dada a influência destes formadores de opinião, a possibilidade do governo descartar o TPDS como distribuidor de alimentos e outros produtos como querosene é próxima de nula.

Outras propostas se concentram em questões administrativas, por exemplo, o TPDS $3 S$ do Programa Mundial de Alimentos da Organização das Nações Unidas (3S - Secure Strengthen Save / '3S - Assegurar, fortalecer e economizar'). O TPDS 3S tem o potencial para resolver parte significativa do problema administrativo. Provavelmente, a mais completa de todas a propostas de melhoramentos ao TPDS, o TPDS 3S propõe medidas de digitalização de operações, uso do Aadhaar para identificação de beneficiários, suporte direto do PAM a órgãos do governo, com consultores do PAM trabalhando diretamente com servidores (PAM, 2014a). Em 2014, o TPDS $3 S$ do PAM estava sendo utilizado no estado de Odisha e em testes no estado de Kerala (PAM, 2014b). Propostas como essa não dão atenção à causa de maior vazamento do TPDS-NFSA que é econômica, e requer mudanças no sistema de incentivos à produção e distribuição de lucros e custos.

A proposta deste trabalho de tese se baseia na análise de situações de rent-seeking a partir da teoria da opção pública discutida em algum detalhe no capítulo 5 desta tese. Fugindo da questão de eficiência de mercados da teoria econômica neoclássica e resgatando algo da teoria econômica austríaca sem entrar nos méritos do libertarianismo da última, governos em geral, sofrem do "Problema do conhecimento de Hayek", especialmente no caso da política do Governo da Índia que se utiliza de planejamento geral e centralizado da economia. Resumidamente, o "Problema do conhecimento de Hayek" ocorre quando há dispersão de informação entre unidades econômicas decisórias e há limitações de transmissão de informações entre estas unidades (Kirzner, 1984). A dispersão de informação e a limitação de transmissão de informação tornam qualquer exercício de planejamento central de setores da economia pouco confiáveis, pois o governo não tem como modelar de maneira razoável o movimento das diferentes variáveis econômicas já que desconhece a maioria das variáveis que podem e poderiam influenciar o conjunto de mercados que influenciam mercados múltiplos.

No caso em questão, o Estado indiano, no vácuo criado pelo "Problema do conhecimento de Hayek", criou oportunidades de ganhos acima da média de mercado pela criação de monopólios, reservas de mercado e também por licitações viciadas no âmbito do

67 Conditional Cash Transfers (CCTs). As razões da oposição aos CCTs, como o Bolsa Família do Brasil, por parte da sociedade civil organizada, jornalistas e ativistas indianos são complexas e podem ser alvo de pesquisa futura do autor. 
sistema público de distribuição de alimentos. O Governo da Índia dirimiria oportunidades de corrupção, desvios e perdas no PDS se permitisse a abertura para concorrência real e regulamentada no transporte e armazenagem. Como discutido no capítulo 5 desta tese, governos em geral interferem nos mercados, pois diferente do que acreditam muitos economistas neoclássicos, os mercados não se equilibram nem se regulam por si mesmos. Mesmo os mais ortodoxos, admitem a existência das chamadas "falhas de mercado". Não se trata, portanto, de privatizar a segurança alimentar na Índia, muito menos de confiar os mercado de transporte e armazenagem do TPDS-NFSA à proverbial mão invisível da teoria

econômica neoclássica. É, sim, uma proposta para correção de falhas de governo (Capítulo 5) ocasionadas por políticas públicas frequentemente bem intencionadas mas mal executadas.

Resumindo, três fatores críticos têm impactado negativamente o TPDS: direcionamento fraco da política, alto nível de vazamentos e ineficiência generalizada (Kishore et al., 2014), No TPDS-NFSA, os três fatores críticos supracitados, são, de fato, tipos de perda. Sendo que, há dois conjuntos principais de perdas: (i.) por meio de retiradas indevidas a partir de cartões fraudados e furtos, e (ii.) desvios diretos na distribuição entre fazenda e armazéns pertencentes a $\mathrm{FCl}$ e contratados pela $\mathrm{FCl}$ a armazéns estaduais lojas de preço justo.

\subsubsection{Primeira Proposta}

A recomendação do autor é de transferência de responsabilidade operacional e incentivo à concorrência para a eficiência: a responsabilidade entre a fazenda e o consumidor deve ser de particulares com interesses em ter lucro por tonelada entregue de cereal, complementada por um sistema de regulação estatal e da sociedade civil. O foco é o ganho de eficiência por meio de parcerias público privadas (PPP) para todo o processo pós produção no campo até a entrega do produto nas mãos dos contemplados pelo TPDS, em contraponto à atual configuração do TPDS (Figura 21).

\subsubsection{Segunda Proposta}

O governo central continuaria responsável por toda a operação, mas por meio de licitações, particulares se responsabilizariam e concorreriam para entregar a cada beneficiário aquilo que the cabe. O controle do governo estaria em se certificar de que o produto chegou ao consumidor final sendo os intermediários responsáveis por toda a operação entre fazenda e beneficiado do TPDS, conforme a Figura 30 ilustra. 


\subsubsection{Terceira Proposta}

Empresários indianos, reconhecidos pela eficiência no uso de recursos escassos colocariam fim ao monopólio governamental do TPDS que é extremamente prejudicial à economia agrícola do país. Os empresários deveriam ser recompensados por tonelada de grãos entregue. Isso não eliminaria as oportunidades de corrupção mas certamente dirimiria o quase ilimitado acesso atual, além de tornar o sistema mais eficiente ambientalmente e economicamente.

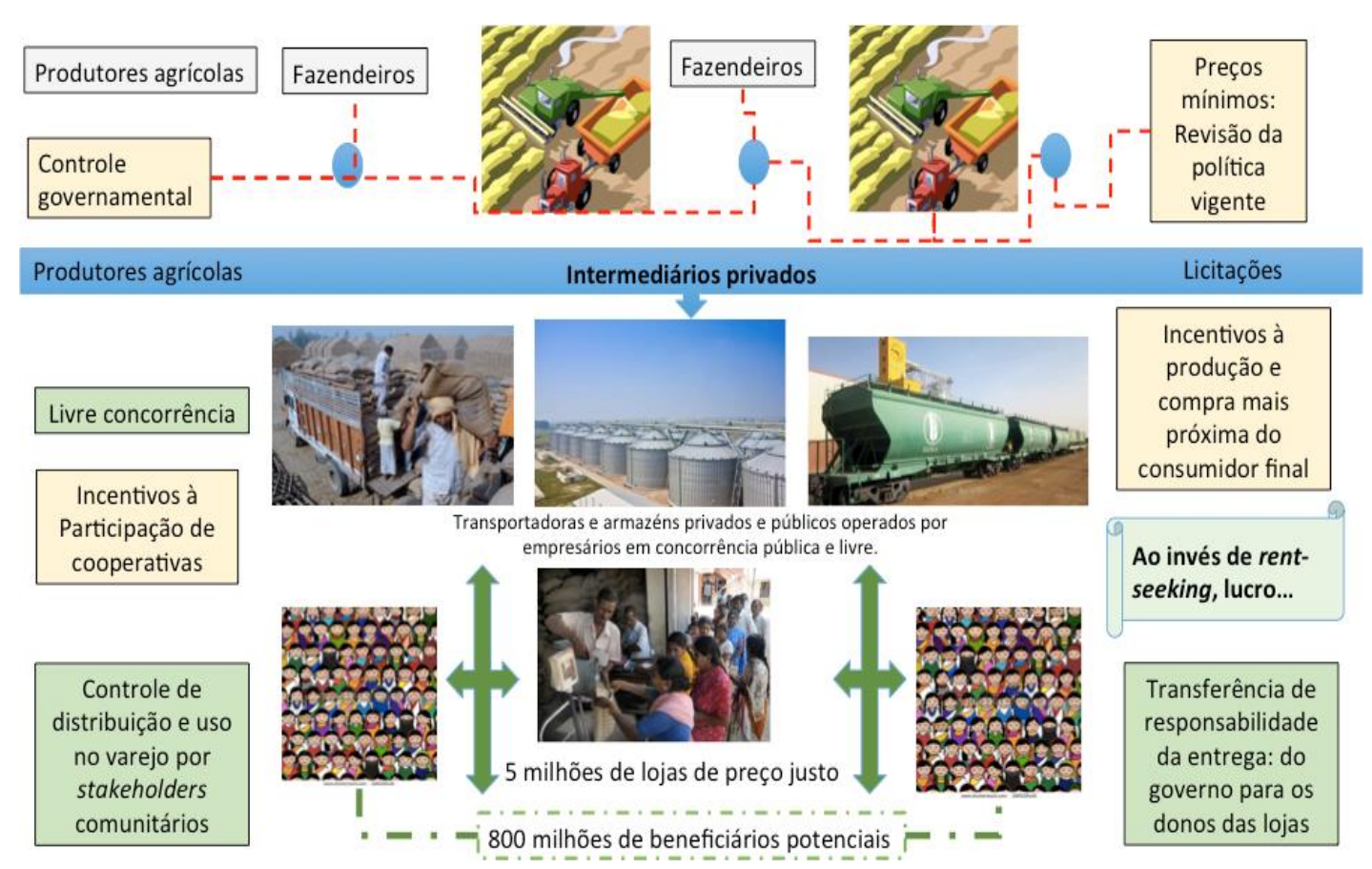

Figura 21: Recomendações de mudança do TPDS-NFSA.

Fonte: o autor

\subsubsection{Quarta Proposta}

O controle final deve ser feito por comissões comunitárias, compostas de beneficiados pelo sistema, representantes de organizações não governamentais nacionais e internacionais e agentes públicos de departamentos de controladoria e auditoria, e não por agentes dos próprios órgãos responsáveis pelo sistema atual. 


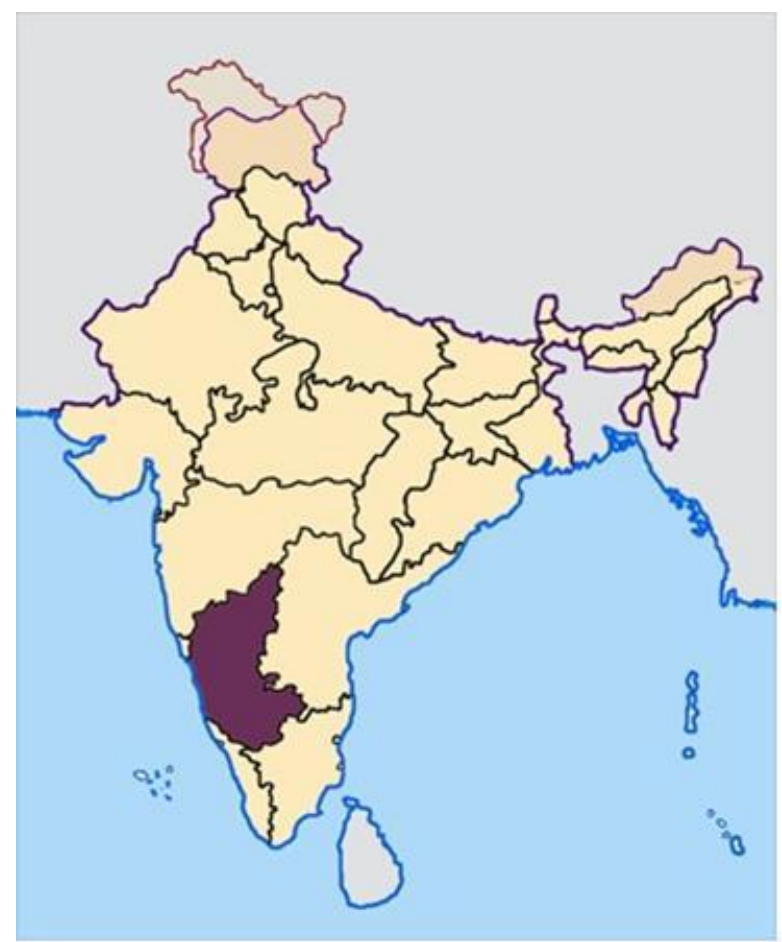

Figura 22: Estado indiano de Karnataka

Fonte: Halo Backwaters. Disponível em: <www.halobackwaters.com/karnataka>. Acesso: 10/10/2014.

O estado criado em 1956, tem pouco mais de 191 mil metros quadrados (um pouco menor que o estado do Paraná) e uma população de 60,6 milhões de habitantes (mais que Espírito Santo, Rio de Janeiro e São Paulo juntos), como pode ser visto na Figura 22. ${ }^{68}$ No índice de fome global (GHI - sigla em inglês) do IFPRI, de 2008, na escala de 10 a 30, sendo 10 , situação de insegurança alimentar séria, enquanto 30 , situação extremamente séria, à Índia é atribuída o valor de 23.30, enquanto para o estado de Karnataka, no estudo comparativo realizado por Menon et al., em 2009, o índice é de 23.73. ${ }^{69}$ De um ranking de 17 estados, Karnataka se encontra em décimo primeiro lugar, classificado no grau de severidade como 'alarmante', no contexto nacional ilustrado na Tabela 10.

\footnotetext{
$68 \mathrm{O}$ estudo de caso abordado neste capítulo se refere especificamente a um dos estados indianos, o estado de Karnataka (Figura 22). De novembro 2012 a setembro 2014, com viagens e ausências no mesmo período, o pesquisador permaneceu cerca de 20 meses em Bangalore capital do estado, onde pôde vivenciar por um período razoavelmente extenso a realidade vivida no estado, tendo visitado algumas vilas e trabalhado como voluntário em uma organização não governamental local.

69 Em 2013, o GHI da Índia foi de 21.3. A escolha do valor de 2008 se fez necessária devido à melhor comparabilidade, já que o estudo de GHI estadual foi realizado apenas em 2008.
} 


\subsubsection{Situação da Segurança Alimentar em Karnataka}

Os mesmos fatores críticos citados anteriormente no caso nacional - direcionamento fraco da política, alto nível de vazamentos e ineficiência generalizada - também ocorrem em Karnataka e refletem na situação ilustrada pela Tabela 10.70

Tabela 10 - Índice de Fome Estadual da Índia e componentes subjacentes - estados selecionados.

\begin{tabular}{|c|c|c|c|c|c|c|}
\hline Estado & $\begin{array}{c}\text { Grau de } \\
\text { severidade }\end{array}$ & $\begin{array}{l}\text { Prevalência } \\
\text { de } \\
\text { subnutrição } \\
\text { calórica } \\
(\%)\end{array}$ & $\begin{array}{l}\text { Proporção } \\
\text { de } \\
\text { subnutrição } \\
\text { entre } \\
\text { crianças <5 } \\
\text { anos (\%) }\end{array}$ & $\begin{array}{l}\text { Taxa de } \\
\text { mortalidade } \\
\text { abaixo de } 5 \\
\text { anos de } \\
\text { idade } \\
\text { (mortes por } \\
100 \text { ) }\end{array}$ & $\begin{array}{c}\text { Valor no } \\
\text { Índice } \\
\text { de } \\
\text { Fome } \\
\text { Estadual } \\
\text { da Índia }\end{array}$ & $\begin{array}{c}\text { Rank no } \\
\text { Índice } \\
\text { de } \\
\text { Fome } \\
\text { Estadual } \\
\text { da Índia }\end{array}$ \\
\hline $\begin{array}{l}\text { Madhya } \\
\text { Pradesh }\end{array}$ & $\begin{array}{l}\text { Extremamente } \\
\text { alarmante } \\
(>30.0)\end{array}$ & 23.4 & 59.8 & 9.4 & 30.87 & 17 \\
\hline Jharkhand & & 19.6 & 57.1 & 9.3 & 28.67 & 16 \\
\hline Bihar & & 17.3 & 56.1 & 8.5 & 27.30 & 15 \\
\hline Chhattisgarh & & 23.3 & 47.6 & 9.0 & 26.63 & 14 \\
\hline Gujarat & & 23.3 & 44.7 & 6.1 & 24.70 & 13 \\
\hline Orissa & & 21.4 & 40.9 & 9.1 & 23.80 & 12 \\
\hline Karnataka & & 28.1 & 37.6 & 5.5 & 23.73 & 11 \\
\hline Maharashtra & $\begin{array}{l}\text { Alarmante } \\
(20.9-29.9)\end{array}$ & 27.0 & 36.7 & 4.7 & 22.80 & 10 \\
\hline $\begin{array}{l}\text { Uttar } \\
\text { Pradesh }\end{array}$ & & 14.5 & 42.3 & 9.6 & 22.13 & 9 \\
\hline West Bengal & & 18.5 & 38.5 & 5.9 & 20.97 & 8 \\
\hline Rajasthan & & 14.0 & 40.4 & 8.5 & 20.97 & 7 \\
\hline Tamil Nadu & & 29.1 & 30.0 & 3.5 & 20.87 & 6 \\
\hline Haryana & & 15.1 & 39.7 & 5.2 & 20.00 & 5 \\
\hline Assam & Sério & 14.6 & 36.4 & 8.5 & 19.83 & 4 \\
\hline $\begin{array}{l}\text { Andhra } \\
\text { Pradesh }\end{array}$ & $(10.0-19.9)$ & 19.6 & 32.7 & 6.3 & 19.53 & 3 \\
\hline Kerala & & 28.6 & 22.7 & 1.6 & 17.63 & 2 \\
\hline Punjab & & 11.1 & 24.6 & 5.2 & 13.63 & 1 \\
\hline Índia & & 20.0 & 42.5 & 7.4 & 23.30 & \\
\hline $\begin{array}{l}\text { Média } \\
\text { nacional }\end{array}$ & & 20.5 & 40.5 & 6.8 & 22.6 & \\
\hline
\end{tabular}

Fontes: Menon et al., 2009. IIPS, 2007; NSSO, 2007; von Grebmer et al., 2008. Elaboração e adaptação do autor.

70 'Vazamento' é a diferença entre a alocação de grãos do Governo Central e a retirada determinada por cada domicílio conforme estimado pelas pesquisas de consumo - NSS. 
No caso do estado de Karnataka, as duas principais causas gerais de perdas são $\left(1^{\circ}\right)$ a distribuição indevida, 38\%, e $\left(2^{\circ}\right)$ desvios na distribuição, 39\% (Gráfico 14). Distribuição indevida ou o excesso de alocação de produtos do PDS ocorre quando há alocação de oferta (suprimentos) realizadas pelo Governo Central e pelo governo estadual em razão de (a.) cartões de compra de provisões em lojas de preço justo inativos ou fantasmas (informações completamente ou parcialmente falsas) e também, pela (b.) inclusão fraudulenta de famílias ou na categoria 'acima da linha de pobreza' (APL - sigla em inglês) ou 'abaixo da linha de pobreza' (BPL - sigla em inglês). Já as perdas na distribuição são aquelas que ocorrem em todas as fases da cadeia de abastecimento, por exemplo: a) no transporte a granel; b) no transporte ainda na fazenda; e, c) aquelas ocorridas nas lojas de preço justo por qualquer razão.

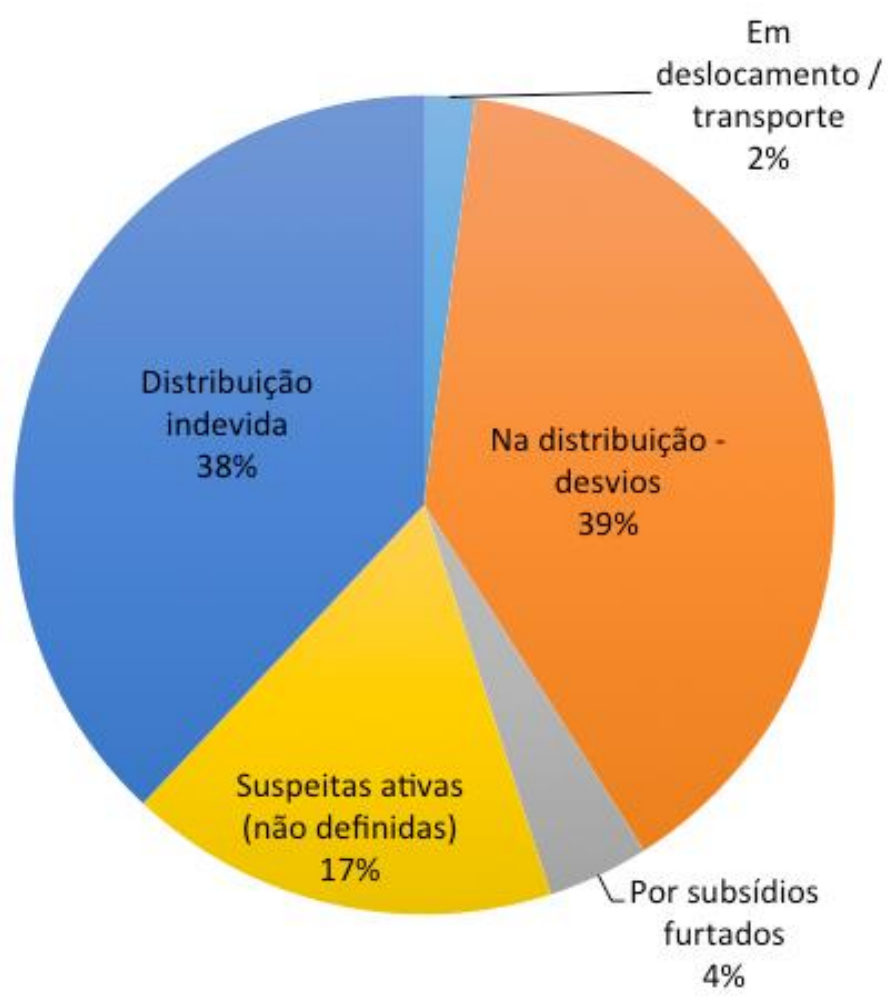

Gráfico 14 - Perdas do TPDS no estado de Karnataka, razões.

Fonte: Grassroots Research and Advocacy Movement (GRAAM). PDS in Karnataka: cost to the exchequer and burden to the taxpayer. Mysore: GRAAM. 2011.

Perdas classificadas na pesquisa GRAAM (2011) como 'suspeitas ativas', referem-se a famílias não elegíveis que mesmo assim conseguem de modo fraudulento retirar mantimentos a preços subsidiados para famílias 'abaixo da linha da pobreza' e deste modo constituem uma 'perda suspeita ativa' para o Tesouro Nacional da Índia. No caso de perdas 'em deslocamento' ou 'transporte', são aquelas que ocorrem no transporte de modo restrito. Essa modalidade parece subestimada, ou talvez já contabilizada nas outras modalidades. A 
categoria 'subsídios furtados' classifica perdas ocorridas quando ocorrem vendas de produtos subsidiados do PDS com preços acima daqueles estipulados pelo governo, estimadas em 4 por cento na pesquisa GRAAM (2011) para o estado de Karnataka.

Distribuição e armazenagem no atacado em Karnataka

Em Karnataka, por lei, três são as entidades envolvidas na distribuição de produtos do TPDS no atacado: a FCI, a Karnataka Food and Civil Supplies Corporation (KFCSC) e a Taluk Agricultural Produce Cooperative Marketing Societies (TAPCMS). No entanto, a Central Warehousing Corporation (CWC) também opera alguns dos armazéns que teoricamente estariam sob a tutela da $\mathrm{FCl}$, enquanto a própria $\mathrm{FCl}$ tem pouca influência direta no estado (CJWSPD, 2009). A situação de armazéns sob custódia das três entidades varia bastante, desde aqueles em completa conformidade com as normas internacionais até aqueles em que, principalmente, o arroz apodrece costumeiramente (NDTV, 2010).

Já em 2008, o Governo Central iniciara a Política de Garantia a Empreendedores Privados da FCl (Private Entrepreneurs Guarantee - PEG - Scheme of FCl) para a construção de armazéns para o PDS e outros programas governamentais. No mesmo ano, o Governo de Karnataka por meio do Departamento de Desenvolvimento de Infraestrutura em 2008, ciente da necessidade de ampliação da capacidade de armazenagem do estado, encomendou um estudo para verificar a viabilidade de parcerias público privadas para a construção e operação sob concessão de armazéns no estado. O estudo apontava que o caminho mais apropriado para o suprimento de capacidade de armazenagem para Karnataka era o envolvimento da iniciativa privada por meio de parcerias público privadas (PPP). Assim sendo, pelo menos 20 armazéns (godowns em inglês indiano) foram construídos com aproximadamente 120 mil toneladas de capacidade total (FISPL, 2012).

Em todo caso, ao final de 2013, Karnataka sofria de um déficit agudo de armazéns adequados. Segundo um estudo de 2013 do Banco Nacional para o Desenvolvimento Rural e Agrícola (NABARD - sigla em inglês), o estado dispunha de pouco mais de 130 mil toneladas de capacidade de armazenagem enquanto a demanda era de quase 195 mil toneladas. O estudo também previa que para o ano fiscal 2016-17, o estado precisaria de mais 2,18 milhões de toneladas de capacidade de armazenagem adicional para commodities do PDS e não PDS (NABARD, 2013).

O déficit crônico de espaço de armazenagem deveria ter sido pelo menos minimizado e não aumentado desde o início das PPP. Causa estranheza o fato de que mesmo com os estudos e previsões em mãos, o Governo de Karnataka não tenha licitado mais armazéns. Caso o gerenciamento e o planejamento da armazenagem do PDS no estado estivesse em mãos de empreendedores particulares, incentivados por preços competitivos, provavelmente 
haveria um excesso de oferta de espaço e não um déficit. $O$ resultado é a constante perda de grãos com consequente perda de sustentabilidade econômica e ambiental.

Distribuição no atacado e varejo em Karnataka

A distribuição no atacado também deveria ser verdadeiramente concorrencial. Em Karnataka, o transporte de produtos já é realizado por terceiros contratados pelo governo por meio de licitações periódicas (CJWSPD, 2009). A falta de coordenação geral de distribuição e a ação do governo como garantidor e responsável por perdas, entretanto permite que perdas e extravios ocorram sem ônus para os operadores terceirizados embora iniciativas para controle de caminhões transportando produtos do PDS se sucedam. Por exemplo, desde 2010, o governo de Karnataka exige que todos os caminhões a serviço do programa tenham cabine e carroceria em amarelo e o número de telefone do programa inscrito nos veículos para eventuais denúncias (Figura 23) e a instalação de sistemas de rastreamento em parte da frota (Governo de Karnataka, 2014; Prabhu, 2010). ${ }^{71}$

O extravio de cargas do PDS, no entanto, continuou, e de acordo com denúncias, devido ao conluio de oficiais dos órgãos de governo responsáveis pela supervisão e auditoria, além de proprietários e gestores de armazéns, transportadoras, usinas de beneficiamento e donos e empregados de lojas de preço justo, sob a proteção de políticos locais (CJWSPD, 2009; Prabhu, 2010).

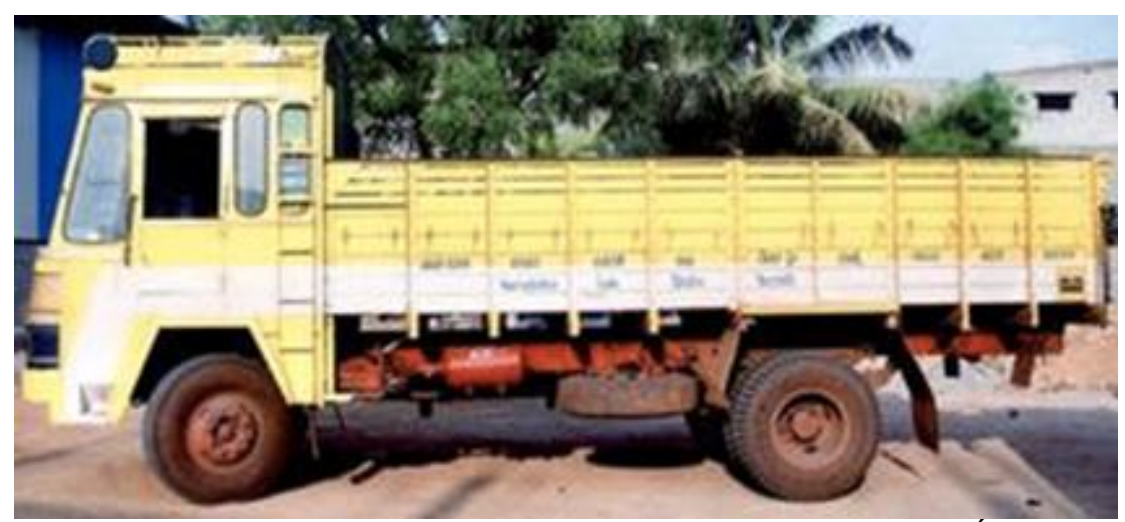

Figura 23: Caminhão de entrega de produtos do PDS em Karnataka, Índia Autor: Desconhecido

Data da fotografia: 2010

Fonte: Prabhu, N., 2010

O transporte de produtos do PDS em Karnataka tem duas fases, dos armazéns e vagões de trem da FCl para armazéns intermediários e depois para as lojas de preço justo.

\footnotetext{
71 O Governo de Karnataka abriu licitação pública para manifestação de interesse em fornecer, instalar e operar um sistema de rastreamento para caminhões carregando grãos e querosene do PDS estadual. Os sistema deveria incluir mapeamento, relatórios de distância, diário de bordo, alertas de paradas fora de rota por SMS e email, redução de peso em locais não autorizados com sensores de peso para grãos e de nível para o querosene (Governo de Karnataka, 2014).
} 
Nas zonas urbanas, os donos de loja arcam com o custo da segunda fase, enquanto na zona rural, o governo do estado se responsabiliza pelos custos. Esta discriminação age também como incentivo à corrupção nas cidades (CJWSPD, 2009). Os preços baixos, o preço do combustível, a conivência de oficiais, a falta de controle externo efetivo, a ausência de participação e controle popular e a concorrência predatória são alguns dos incentivos à corrupção em todos os níveis do sistema. Por outro lado, operadores diversos, sob concessão, responsáveis pela operação como um todo, teriam o incentivo e o interesse em entregar de fato e não desenvolver um sistema público de distribuição de alimentos paralelo.

Controle de entrega aos beneficiários - consumidores e viabilidade das lojas de preço justo

As lojas deveriam ser a ligação entre órgãos e departamentos que controlam o PDS e a população, a vitrine de um programa de segurança alimentar e nutricional bem sucedido e deveriam ser supervisionadas por inspetores de alimentos em relação à qualidade e à quantidade, e também quanto a questões administrativas pelos oficiais de auditoria do Departamento de Alimentos, Suprimentos Civis e Assuntos do Consumidor e da Corporação de Alimentos e Suprimentos Civis do Governo do estado de Karnataka (Governo de Karnataka, 2014). A realidade não poderia ser mais diferente. Há cerca de 22.500 lojas de preço justo no estado (mais de 5 milhões na Índia inteira), das quais menos de 1 por cento são da Karnataka Food and Civil Supplies Corporation (KFCSC), 44 por cento pertencem a cooperativas e 55 por cento a indivíduos (KFCSC, 2014). Como visto no capítulo 7, há farta documentação sobre as irregularidades nas lojas. Neste capítulo, apresenta-se uma tabela consolidada de alguns dos problemas enfrentados pelas lojas de preço justo, alguns dos quais já discutidos nos capítulos 6 e 7 e um conjunto de propostas correspondentes.

O próprio uso de "lojas" em um programa de segurança alimentar e nutricional governamental parece um tanto fora de lugar. A criação de uma rede de lojas paralela ao mercado aberto, com preços equivalentes a aproximadamente 5 por cento do preço médio normal, é um convite escancarado à corrupção e não há controle que seja capaz de coibir a ação de aproveitadores inescrupulosos em todos os níveis, tanto do lado da oferta quanto da demanda. Diversos estudos e auditorias confirmam que pouquíssimas lojas são viáveis e no entanto, há filas de espera em diversos estados para a obtenção de licenças de lojas em alguns estados. Em outros, inclusive Karnataka, o processo é inteiramenre politizado (CJWSPD, 2009). Não há outra razão senão o rent-seeking advindo do desvio - roubo - de cereais, açúcar e querosene de pessoas que vivem com menos de um dólar e vinte e cinco centavos por dia. Conforme parecer da Suprema Corte indiana, os donos das lojas são o epicentro da corrupção do PDS no lado da demanda (Suprema Corte da Índia, 2013). Uma vez mais, isso ocorre pelos incentivos e sinais que levam ao rent-seeking: a quase 
impossibilidade de lucro em lojas que vendem produtos altamente subsidiados e com demanda alta e inelástica.

Esperar que haja lisura por parte de agentes econômicos e políticos em um contexto institucional historicamente marcado pela corrupção é escolher ignorar todas as evidências em contrário. Os interesses estão ainda mais enraizados dada uma característica de lojas de preço justo que o governo de Karnataka procura remover: a hereditariedade da licença para as lojas. Este direito adquirido não tem como ser alterado pela legislação vigente em 2014 que não deve ser retroativa. No entanto, concessões para novas lojas a partir de 2014 não incluem esta cláusula e dão prioridade a agências governamentais e paragovernamentais, sociedades sem fins lucrativos e cooperativas de mulheres (The Hindu, 2014). Essa mudança é construtiva, porém, ainda deixa o sistema vulnerável à ingerência política devido à forte politização de organizações do terceiro setor principalmente na zona rural.

Em junho de 2014, o Governo de Karnataka iniciou um projeto piloto de dois meses para a venda de arroz, trigo e açúcar do TPDS a partir de uma rede varejista local. A experiência foi bem sucedida. Em um dos supermercados selecionados da rede Foodworld no bairro de Malleswaram, na cidade de Bangalore, cerca de 300 beneficiários do TPDS receberam suas cotas no estabelecimento. A maioria dos contemplados aprovou a experiência e entre as razões mais repetidas estavam os dias e horários de funcionamento do supermercado, que abria todos os dias da semana e aos feriados, a ausência de filas, já que a distribuição não se resumia a alguns dias e horários por mês, além do uso de balanças digitais que garantiam a pesagem correta de grãos e açúcar. O profissionalismo e diligência dos funcionários dos mercados também foram elogiados (Gatty, 2014; Deccan Herald, 2014).

Como era esperado houve resistência por parte daqueles que representam os interesses da rede de lojas de preço justo e também alguma resistência dos supermercados ao terem suas marcas associadas a um sistema geralmente mal visto. O espaço necessário para armazenagem do arroz, trigo e açúcar também é um fator limitador, assim como a disponibilização de recursos humanos necessários para a organização de estoque e atendimento. A venda de produtos do PDS não proporciona lucro aos supermercados, mas o governo espera que os varejistas aceitem participar do programa como parte de iniciativas de responsabilidade social corporativa das próprias empresas (Gatty, 2014).

\section{Beneficiários do TPDS em Karnataka}

Em Karnataka, os beneficiários do sistema público de distribuição de alimentos estão divididos em: 
i. AAY: 9\%. Antyodaya Anna Yojana - uma subdivisão do programa indiano contra a fome e parte integral do TPDS, o AAY está direcionado para as 10 milhões famílias mais pobres de entre as pobres, fornece 35 quilogramas de arroz e trigo a 3 rúpias indianas e 2 rúpias indianas por quilograma, respectivamente;

ii. APL: 16\%. Above Poverty Line - Acima da Linha de Pobreza. De acordo com a legislação indiana vigente em 2014, seriam aquelas famílias que têm uma despesa diária de mais USD1,25 (PPC) por pessoa; e,

iii. BPL: $75 \%$. Below Poverty Line - Abaixo da Linha de Pobreza. De acordo com a legislação indiana vigente em 2014, seriam aquelas famílias que têm uma despesa diária por pessoa abaixo de USD1,25 (PPC). ${ }^{72}$ Como pode ser visualizado no Gráfico 35, o número de famílias classificadas como BPL no estado é extremamente alto e exige um sistema de segurança alimentar robusto.

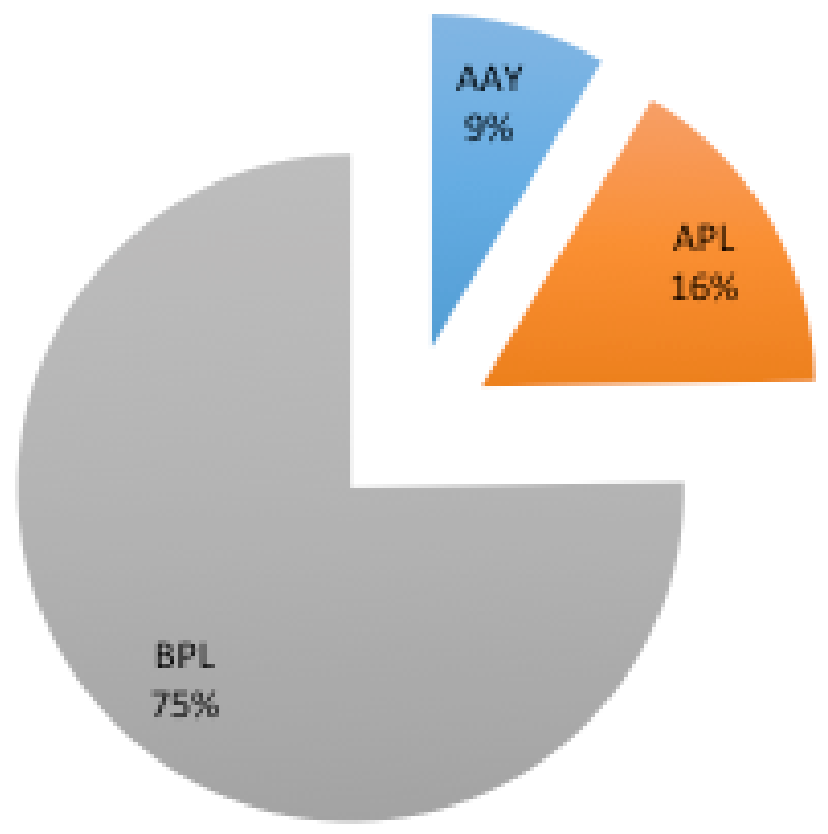

Gráfico 15 - Tipos de cartões do PDS em Karnataka

Fonte: KFCSC, 2014.

Legenda

AAY: Antyodaya Anna Yojana, Programa Indiano contra a Fome, direcionado para as 10 milhões famílias mais pobres das pobres, fornece 35 quilogramas de arroz e trigo a 3 rúpias indianas e 2 rúpias indianas por quilograma, respectivamente.

APL: Above Poverty Line, Acima da Linha de Pobreza. De acordo com a legislação indiana vigente em 2014, seriam aquelas famílias que têm uma despesa diária por pessoa de USD1,25 (PPC).

BPL: Below Poverty Line. Abaixo da Linha de Pobreza. De acordo com a legislação indiana vigente em 2014, seriam aquelas famílias que têm uma despesa diária por pessoa abaixo de USD1,25 (PPC).

\footnotetext{
72 Incluídos nos BPL, há cerca de 3 milhões de famílias que o governo classificou como EBPL, Extra BPL, devido ao limite do Governo Central ao número de famílias que poderiam ser classificadas como BPL como percentual da população total do estado. Em 2011, em contrapartida, Comissão de Planejamento havia calculado a existência de 3 milhões de famílias BPL em Karnataka. O impasse levou o então governo a criar a nova categoria.
} 
A cultura da fraude entre beneficiários genuínos e falsos, se soma aos desafios da TPDS-NFSA no estado de Karnataka. Os beneficiários do programa, clientes das lojas de preço justo se valem dos mais variados esquemas para burlar regulamentos, sistemas e controles, muitas vezes tutelados por políticos locais. O principal meio de fraudar o sistema utilizado por beneficiários é o uso de cartões falsos: cartões emitidos com nomes fictícios, e/ ou com dados incorretos (CJWSPD, 2009).

Com todos os pontos negativos, Karnataka foi um dos primeiros estados a iniciar a digitalização dos processos do PDS a partir de 2007-2009. Milhares de cartões falsificados foram retirados das listas de todos os distritos. Informações biométricas de cada um dos membros das famílias registradas, que constituem uma unidade para os propósitos de alocação de recursos começaram a ser carregados em um sistema disponível na loja de preço justo a qual a família está registrada. O beneficiário fornece o número do seu cartão ao atendente da loja que o insere no terminal e confere as quantidades de cada produto. Após a confirmação das quantidades, o beneficiário deve posicionar a digital cadastrada na máquina que então autoriza a transação. O equipamento reproduz audivelmente mensagens a cada fase da transação - valores e quantidades, recurso muito útil no caso de beneficiários não alfabetizados (CJWSPD, 2009b).

Após um período inicial de emprego construtivo das novas tecnologias, entretanto, o governo do estado abriu uma brecha que permitiu a inserção de milhares de novos cartões falsos uma vez mais entre 2005 e 2012. O governo criou o programa "Cartão de Provisão Provisório", através do qual qualquer adulto que solicitasse um cartão em um dos centros de cadastramento receberia o cartão $B P L$ sem necessidade de comprovação na solicitação e no registro. O processo de avaliação da situação socioeconômica do indivíduo ou da família seria realizado ex post facto. O novo programa não apenas anulou os benefícios alcançados pela digitalização, como gerou uma situação pior que a anterior pois posteriormente o governo permitiu que cartões temporários fossem convertidos em cartões permanentes. $O$ resultado foi um número maior de cartões $B P L$ do que de famílias no estado (Sastry, 2012). De 2006 a 2010, o Departamento de Alimentos e Suprimentos Civis por meio de uma empresa contratada, emitiu nada menos que 5 milhões e 800 mil cartões sem coletar dados biométricos e sem criar um banco de dados dos cartões emitidos (Governo de Karnataka, 2012). Com a obviedade da magnitude da fraude no sistema, o governo estadual tomou a iniciativa de tornar mandatório o recadastramento com dados biométricos de todos os cartões no estado em 2012, que resultou na situação visualizada na Gráfico 16 e na Tabela 11. 


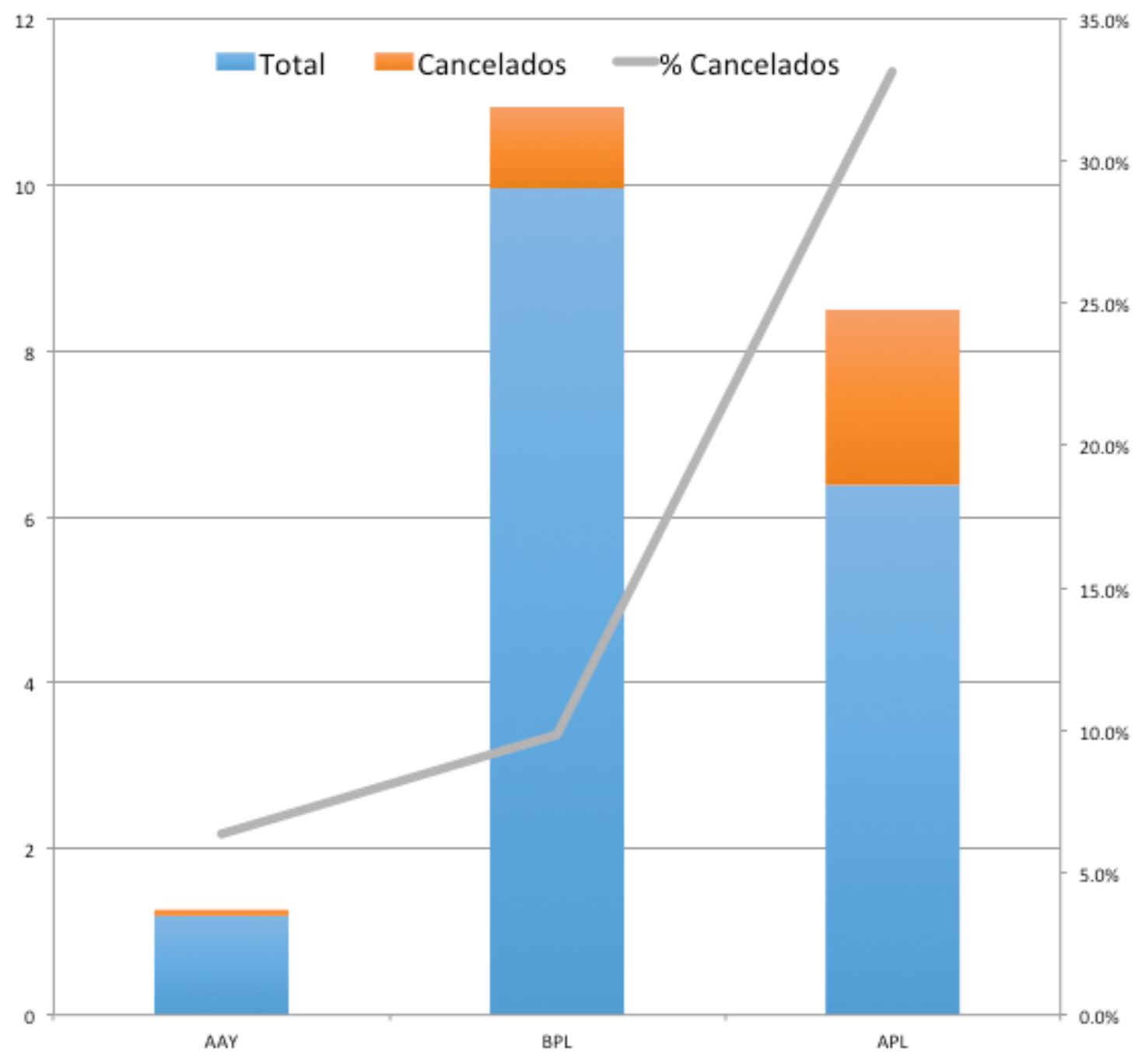

Gráfico 16 - Situação de cartões AAY, BPL e APL do TPDS em Karnataka em outubro de 2012.

Fonte: Governo de Karnataka, 2012; Sastry, 2012. Adaptações e elaboração do autor.

Tabela 11 - Situação de cartões temporários do TPDS em Karnataka em outubro de 2012.

\begin{tabular}{r|r|r|r}
\hline $\begin{array}{r}\text { Cartões Temporários } \\
\text { (estimativa) }\end{array}$ & $\begin{array}{r}\text { Pedidos de conversão de } \\
\text { temporários para } \\
\text { Permanentes }\end{array}$ & Aceitos & Pendentes \\
\hline 5.800 .000 & 3.596 .751 & 554.202 & 3.042 .549 \\
\hline
\end{tabular}

Fonte: Governo de Karnataka, 2012; Sastry, 2012. Adaptações e elaboração do autor.

Um exemplo dos efeitos das perdas e descontrole, é o Programa Anna Bhagya Yojana. Lançado em 2013, o Programa é semelhante ao AAY do governo central. Trata-se de um duplo subsídio do PDS que permite a compra de 30 quilogramas (kg) de arroz a uma rúpia o quilo para 10 milhões de famílias BPL por todo o estado. Famílias constituídas por uma pessoa apenas podem comprar $10 \mathrm{Kg}$, famílias com dois membros, $20 \mathrm{~kg}$ e famílias com mais de 3 membros podem comprar até o máximo de $30 \mathrm{~kg}$ por mês. Além do arroz, o governo estadual se comprometeu a fornecer 150 mililitros de leite por criança até o 100 ano 
escolar, três vezes por semana como medida de apoio ao combate à subnutrição de micronutrientes (Governo de Karnataka, 2013). Além de arroz, o programa também almeja incluir cereais característicos do sul da Índia, cultivados localmente, como o ragi (Eleusine coracana), que seria mais sustentável socioeconomicamente e ambientalmente.

A coligação de partidos oposicionistas logo acusou o governo de atividade eleitoreira já que as eleições legislativas se aproximavam (Business Standard, 2013). O programa, no entanto, se provou, tal como a NFSA no plano nacional, um meio falho de garantir eleitores no plano estadual. Nas eleições para a assembleia legislativa estadual de abril de 2014 , o principal partido de oposição, o Bharatiya Janata Party (BJP), ganhou 17 dos 28 assentos em disputa, enquanto o partido do governador ficou com apenas 9. Embora o resultado não tenha sido melhor do que em 2004 e 2009, não há como generalizar a implicação do baixo impacto eleitoral do uso político de políticas públicas de segurança alimentar e nutricional na Índia a partir deste exemplo (EOECK, 2014). ${ }^{73}$

A tempestividade do Anna Bhagya Yojana é questionável e há evidências de sua utilização eleitoreira e de sua continuidade, principalmente caso haja troca de partido de governo no poder. A maior qualidade do programa é a inclusão de cereais locais. No entanto, esta vantagem é praticamente anulada com o custo de compra a preços de mercado do arroz necessário para suprir a diferença entre aquilo que o governo estadual recebe subsidiado do governo central e a quantidade ofertada pelo Anna Bhagya Yojana (Bennur, 2014). E, mais, o Anna Bhagya Yojana passa pelos mesmos problemas discutidos em relação ao TPDS em geral já que se utiliza dos mesmos canais de armazenagem e distribuição.

\subsection{UMA PROPOSTA PARA KARNATAKA}

A experiência narrada nos pontos anteriores que tratam da situação no estado de Karnataka parece fortalecer uma das principais propostas desta tese presente neste capítulo: o envolvimento da iniciativa privada pode ser benéfico ao sistema público de distribuição em diferentes fases da armazenagem e distribuição desde que haja interesse econômico por parte dos clientes, por exemplo, varejistas, na preservação dos produtos no sucesso da distribuição ao destinatário correto. Em outras palavras, se houver lucro (e, às vezes, prejuízo) advindo e resultante de trocas entre agentes econômicos privados que dependa do funcionamento do sistema, o sistema pode operar pelo interesse dos agentes, mesmo ainda carecendo de regulamentação e supervisão.

73 Em 2004, o BJP conseguiu 18 de 24 assentos disputados pelo partido, enquanto o Congresso Nacional Indiano (CNI), venceu 8 de 28 assentos disputados, enquanto o Janata Dal (JD), 2. Em 2009, BJP: 19; CNI: 6; JD: 3. Em 2014, BJP: 17; CNI: 9; JD: 2. (EOECK, 2014). 


\subsubsection{Primeira Proposta para Karnataka: Fortalecimento de meios de subsistência}

A questão de segurança alimentar e nutricional em Karnataka e na Índia passa não apenas pela redução expressiva da corrupção, mas mais importantemente, pelo fortalecimento de meios de subsistência tradicionais e por programas de geração de renda, como visto no capítulo 2 deste trabalho de tese. Programas como o Mahatma Gandhi National Rural Employment Guarantee Act - Lei Nacional de Garantia de Trabalho Mahatma Gandhi (MGNREGA), fazem a diferença. A lei criou um programa que garante o direito ao trabalho em áreas rurais provendo 100 dias de trabalho remunerado (cerca de USD 2,20 a USD 4 por dia) em um ano para toda família que os membros adultos se dispuseram a trabalhar para o programa. Conhecido como o maior programa de providência social e trabalhos públicos do mundo, o programa desde 2006 gera renda efetiva ao custo de USD18 bilhões de dólares, sendo que 120 milhões de trabalhadores já participaram do programa (Governo da Índia, 2005b; Governo da Índia, 2014a). Programas que geram renda são mais eficazes como medidas de garantia de segurança alimentar e nutricional sustentável do que programas que entregam ou vendem cereais (Pritchard et al., 2008).

\subsubsection{Segunda Proposta para Karnataka: Menos intervenção e manipulação estatal direta}

O mercado de trigo indiano, por exemplo, não precisa da intervenção do governo para produzir o suficiente para a demanda interna e exportar. Levando em consideração a demanda projetada de arroz e trigo e mudanças prováveis na dieta em razão do crescimento de renda, urbanização e outras mudanças demográficas, o mercado indiano de grãos tem a ganhar caso o governo libere o mercado, mesmo preservando o TPDS e os preços mínimos. O estudo de Mohanty e Peterson (2005), sugere que haverá aumento considerável do consumo per capita de trigo devido ao aumento da renda e crescente urbanização. No caso do arroz, a previsão é a estagnação da demanda a partir de 2020 e mais adiante, um decrescimento paulatino. A partir de uma análise matricial de políticas, os autores chegaram a conclusão de que com reduzida intervenção do governo ou mesmo sem intervenção, a produção de trigo pode crescer acima da demanda simplesmente devido às vantagens comparativas do trigo sobre o arroz nas regiões de cultivo (Mohanty \& Peterson, 2005).

\subsubsection{Terceira Proposta para Karnataka: um sistema competitivo regulamentado}

Tal como na proposta para o sistema nacional, em um sistema competitivo regulamentado de transporte, armazenagem e distribuição, o ônus pelas perdas seria de responsabilidade dos agentes privados e não do governo estadual. Os agentes privados teriam que entregar aos reais beneficiários os produtos previstos na lei, com o preço certo, 
na quantidade certa, na qualidade correta e tempo certo sob pena de multas, suspensão de pagamento e por fim, perda de contrato. ${ }^{74}$

\subsubsection{Outras Proposta para Karnataka}

O Quadro 11 resume doze propostas para o estado de Karnataka que podem ser detalhadas, expandidas e criticadas em trabalho futuro.

\footnotetext{
${ }^{74}$ A Lei de 2013 não altera o status quo do sistema e acaba por encorajar o desperdício e a ineficiência.
} 
1 Número mínimo de cartões na zona rural: 300; número mínimo na zona urbana: 500

2 Licenças para a abertura de lojas são em geral apontamentos políticos à revelia da lei.

3 Lojas da KFCSC mal administradas devido conflito de interesses e falta de supervisão.

4 Politização generalizada de cooperativas e associações responsáveis pelas lojas, especialmente na zona rural do estado.

5 Lojas que vendem apenas produtos do PDS em geral não são viáveis.

Custo de transporte na zona rural de (6) responsabilidade do governo do estado.

\begin{tabular}{l|l}
\hline 7 & $\begin{array}{l}\text { Horários e dias de funcionamento } \\
\text { irregulares ou intencionalmente } \\
\text { direcionadas a dificultar o acesso dos } \\
\text { mais pobres. }\end{array}$ \\
\hline 8 & $\begin{array}{l}\text { Donos das lojas não retiram quantidades } \\
\text { alocadas completamente. }\end{array}$ \\
\hline 9 & $\begin{array}{l}\text { Comissão de venda para varejistas } \\
\text { considerada baixa. }\end{array}$
\end{tabular}

10 Em caso de não retirada nos dias em que lojas estão abertas, beneficiário 'perde' direito.

11 Ausência de aparelhos de medição, por exemplo, balanças confiáveis.

12 Impossibilidade de controle real das lojas já que muitos donos têm interesse ativo em fraudar o sistema.
Abolição do número mínimo de cartões do TPDS associados à uma única loja isolada. Beneficiário pode comprar em qualquer loja. *

Lojas conjugadas a lojas estabelecidas na zona urbana e rural e onde não viável, em repartições públicas.

Lojas não podem ser geridas pelo mesmo departamento que as licencia e supervisiona. Lojas devem ser parte de estabelecimentos privados.

A legislação para cooperativas da Índia já estabelece parâmetros que devem ser seguidos por essas entidades. A lei precisa ser cumprida e fiscalizada.

Proposta conforme item 2; Lojas devem ser multi-uso, tais como as "Kirana", comuns em toda a Índia.

O custo de transporte deve recair sobre o cálculo geral da concessão de transporte e armazenagem.

Lojas multi-uso têm 0 interesse de se manterem abertas para a clientela em geral e não apenas em dias de distribuição de produtos do PDS.

Um sistema computadorizado de entrega sob a responsabilidade do concessionário com transferência de saldos e compensação, minimizaria este problema.

A margem de lucro das lojas de preço justo sobre os produtos do TPDS devem ser a média anualizada de margem de lucro de varejistas sobre os mesmos produtos da cesta do programa, com qualidade comparável.

O direito não se extingue com o final do mês de acordo com a legislação em vigor. Um sistema de saldo com previsão de vencimento minimizaria o problema.

Centros de embalamento tipo "cesta básica", kits de segurança alimentar lacrados eliminariam a necessidade de pesagem nas lojas de preço justo. O concessionário poderia ser responsabilizado pelo centro de preparação de cestas básicas.

Subsitituição de lojas de preço justo por centros de distribuição alojados em mercados privados, edifícios de orgãos estatais e entidades civis.

Quadro 11: Seleção de problemas enfrentados pelas lojas de preço justo em Karnataka e propostas correspondentes

Fontes: CJWSPD, 2009; GRAAM, 2011; Governo de Karnataka, 2014.

Elaboração do autor. 


\subsection{SEM CORRUPÇÃO VERSUS COM CORRUPÇÃO}

Por fim, uma dúvida: Sem corrupção, a expansão do TPDS a partir da NFSA melhoraria a situação de segurança alimentar e nutricional em Karnataka e na Índia? A resposta curta e direta à questão acima é "não". Mas por que?

Kaushal \& Muchomba (2013), tentaram responder à pergunta acima estudando o efeito de um aumento exógeno nos subsídios de preço de trigo e arroz resultantes da introdução em 1997 e subsequente expansão em 2002 do TPDS. Os pesquisadores consideraram que quando o TPDS foi introduzido as famílias participantes podiam adquirir 10 quilogramas de arroz ou trigo por família por mês por cerca de um terço do preço de mercado e com a expansão, a quantidade foi majorada em $15 \mathrm{~kg}$, totalizando $35 \mathrm{~kg}$. Kaushal e Muchomba (2013), usaram a probabilidade de posse de um cartão do PDS como uma variável instrumental para prever o subsídio de preço de alimentos das famílias. Além disso, focaram em famílias na zona rural com uma despesa per capita menor que a média em estados onde o TPDS é visto como funcionando bem. ${ }^{75}$ Separaram em dois padrões de consumo razoavelmente distintos: um cuja alimentação é baseada à volta de arroz e trigo, e um segundo grupo de distritos cuja alimentação é baseada em cereais menores (Pennisetum glaucum, Vigna mungo, Eleusine coracana etc.). No primeiro tipo de distrito, o consumo médio de arroz e trigo por família é de $35 \mathrm{~kg}$, a quantidade máxima subsidiada ou mesmo maior, fazendo com que o subsídio de preço do alimento tenha um efeito de renda. Para estes distritos, Kaushal e Muchomba (2013), estimaram o efeito sobre a nutrição e padrões de consumo do aumento de renda gerado pelo subsídio do TPDS. No segundo grupo, o consumo médio mensal de arroz e trigo por família foi calculado em $16 \mathrm{~kg}$, e o preço subsidiado é o preço marginal para a maioria das famílias após a expansão do TPDS. Para este grupo, estimou-se o efeito do subsídio de preço dos alimentos sobre os padrões de consumo e nutrição.

De acordo com os autores, a expansão do TPDS aumentou a quantidade subsidiada per capita mensal nos distritos com alto consumo de trigo e arroz, de 15 para 18 rúpias indianas, sendo que no cálculo, USD 1 seria igual a 15,54 rúpias indianas em Paridade de Poder de Compra, ao câmbio de 2004-2005. Esta quantidade representa 5 por cento da despesa per capita em trigo e arroz no período anterior à expansão do TPDS. Por outro lado, nos distritos onde há a predominância de cereais menores, o TPDS aumentou o desconto de preço percentual sobre o arroz e o trigo de 19 a 21 por cento. A estimativa do efeito de renda do subsídio no consumo de calorias não foi encorajadora: a quantidade do subsídio de preço de arroz e trigo do TPDS teve um efeito negativo e estatisticamente

\footnotetext{
75 Os autores consideram famílias com despesa individual menor que USD 1.04, PPC.
} 
insignificante sobre o consumo total de calorias. No quesito mudanças nos padrões de consumo, as conclusões foram: um aumento de 1 por cento em quantidade de subsídio aumentaria o consumo de calorias a partir de trigo e arroz em 5,5 por cento e também aumentaria o consumo de calorias a partir de dois grupos de alimentos não subsidiados, óleos comestíveis, açúcar e substitutos; simultaneamente, diminuía o consumo de calorias a partir de cereais menores em 42,7\%, exatamente aqueles grãos mais saudáveis e ambientalmente e socioeconomicamente mais sustentáveis. O aumento no desconto de preço de trigo e arroz também tiveram pouco ou nenhum efeito sobre o consumo total de calorias em distritos onde cereais menores são mais importantes para a dieta básica. Concomitantemente, o subsídio tem o efeito de mudar os padrões de consumo em direção ao aumento de consumo de calorias a partir de grãos subsidiados como arroz e trigo, ao invés de cereais menores. Já em relação ao efeito do subsídio sobre o consumo de proteína e gordura, este é estatisticamente insignificante nos dois grupos de distritos. Os autores concluíram que o TPDS tem efeito negligenciável sobre a segurança alimentar e nutricional, embora tenha efeito sobre os padrões de consumo. O subsídio aumenta o consumo de cereais subsidiados e algumas outras fontes de calorias mais caras, e simultaneamente diminui o consumo de grãos menores. A mudança nos padrões de consumo é o principal resultado da política que embora não intencional tem consequências indesejáveis com impactos socioeconômicos profundos, mas sem o esperado impacto nutricional (Kaushal e Muchomba, 2013).

\section{CONCLUSÃO}

No capítulo sete, as evidências documentais levantadas ao longo do trabalho de tese sobre o estado da arte na definição, mensuração, avaliação de políticas públicas e histórico das políticas de segurança alimentar convergiram para fundamentar a constatação da insustentabilidade geral do Sistema Público de Distribuição de Alimentos da Índia (T)PDS. Embora existam melhoras significativas em alguns estados, o sistema indiano de segurança alimentar se revelou deficiente na distribuição, no acesso equitativo e na confiabilidade desse acesso. O Sistema, conclui-se, encontra-se aquém de suas atribuições previstas no ordenamento jurídico indiano.

A insustentabilidade do PDS se desdobra da formulação da política ao financiamento por meio de subsídios, passa pela produção, armazenamento inicial, distribuição no atacado e distribuição no varejo. Não há evidências conclusivas em relação à correção da universalidade do sistema ou não. Entretanto, em outros pontos, como, por exemplo, a sustentabilidade na política de compra e do estoque de segurança, as evidências documentais apontaram claramente para a necessidade de mudanças significativas. Esta primeira parte do capítulo é encerrada com quatro breves propostas para mudanças 
incrementais, e não gera em si mesma conclusões mas engendra direcionamentos possíveis para o PDS em nível nacional.

$\mathrm{Na}$ segunda parte do capítulo, na apresentação e na discussão sobre o caso do estado de Karnataka, os mesmos quesitos deficitários do sistema nacional foram revisitados em nível estadual. As deficiências do PDS estadual refletiram a situação média nacional e, destarte, três propostas principais e doze propostas secundárias, contribuições do autor deste trabalho, foram apresentadas. Das propostas se conclui que o sistema público estadual, embora melhor avaliado, padece dos mesmos problemas nacionais e carece de mudanças que o torne mais sustentável. Como há forte resistência organizacional, institucional e cultural a mudanças significativas, mudanças incrementais como as propostas na décima parte do capítulo, têm o potencial para gerar ganhos reais e duradouros. Por fim, conclui-se que o PDS com ou sem corrupção - se não ocorrem mudanças em toda a cadeia - permanecerá ineficiente. A conclusão final do capítulo reflete a disposição presente ao longo desta última parte do trabalho: o PDS é um sistema que dificilmente será reinicializado ou restruturado; mudanças secundárias, como as contidas nas propostas deste trabalho, no entanto, fariam uma diferença revitalizadora profunda na eficiência e eficácia do sistema como um todo no curto prazo. 


\section{CONCLUSÃO GERAL}

Este trabalho discutiu políticas públicas para a segurança alimentar na Índia. Apresentaram-se conceitos, históricos, impactos e direcionamentos de políticas que afetam ao menos $10 \%$ da população mundial. O objetivo geral foi apresentar a segurança alimentar e nutricional, as políticas de segurança alimentar e nutricional, formas de medição, mostrar em que medida são exitosas e propor caminhos alternativos já que o acesso à alimentação é a principal intervenção direta do Estado indiano no dia a dia de seus cidadãos.

Primeiramente, foram abordados os conceitos pertinentes à discussão proposta. As definições à volta das quais as políticas de segurança alimentar trabalham - segurança alimentar, meios de subsistência, entre outros - foram apresentadas e utilizadas de forma referencial e crítica. Conclui-se que as conceituações e definições são úteis e se encontram na fronteira do conhecimento da área. Por outro lado, em segundo lugar, a qualidade de conceituação e definição não é acompanhada pelas medidas e indicadores utilizados para operacionalizar conceitos e definições. Medir segurança alimentar, nutrição e níveis de fome ainda não é tarefa simples e corriqueira para organizações não governamentais e governos, principalmente com limitações orçamentárias e temporais. Na sequência, teorias e modelos de políticas públicas foram apresentados, com ênfase na praticidade e utilidade para a análise. Na segunda parte do trabalho, conceitos, teorias, definições e modelos de análise discutidos nas partes 1 e 2 foram implicitamente utilizados para apresentar, discutir, analisar e criticar o sistema de segurança alimentar indiano no geral, e especificamente, o caso do estado de Karnataka, espelhado no caso geral. O contexto do trabalho foi então utilizado para apresentação de uma proposta de reforma do sistema e o desenvolvimento de algumas considerações críticas já que se concluiu que não há vontade e capital político para uma mudança completa.

Os resultados e conclusões apresentados neste trabalhao de tese são parciais e provisórios dada a natureza mutável do objeto de pesquisa. Conforme apresentado na introdução geral deste trabalho de tese, esta guiou-se por meio de duas questões de contextualização teórica e metodológica da pesquisa e uma de fim [propósito e escopo] e análise da tese. Primeira questão: a segurança alimentar e nutricional pode ser definida e medida objetivamente? Segunda: políticas públicas em geral e de segurança alimentar e nutricional especificamente podem ser analisadas qualitativamente e quais são os fundamentos? Terceira: no contexto do arcabouço das primeiras duas questões, o sistema público direcionado de distribuição de alimentos da Índia é sustentável sob o prisma socioeconômico e ambiental?

As hipóteses (ou respostas provisórias) foram geradas pela pesquisa: 
- Em relação à primeira questão, segurança alimentar e nutricional pode ser definida e medida objetivamente de forma satisfatória embora não sem dificuldades relevantes;

- Em relação à segunda questão, políticas públicas em geral e de segurança alimentar e nutricional especificamente podem ser analisadas qualitativamente e há pesquisa consolidada sobre o campo;

- Em relação ao terceiro problema:

- O sistema público direcionado de distribuição de alimentos da Índia (TPDS) não é sustentável e gera custos socioeconômicos e ambientais consideráveis;

- A falta de sustentabilidade é patente sob todos os níveis e pilares da sustentabilidade abordados por este trabalho de pesquisa;

- Há forte resistência institucional e organizacional a mudanças significativas;

- Os serviços providos pelo TPDS não garantem o mínimo necessário para a segurança alimentar e nutricional;

- A ênfase na venda subsidiada de cereais sem fortalecimento de meios de subsistência ou geração de renda inviabiliza uma política de segurança alimentar e nutricional sustentável.

Assim sendo, em relação às hipóteses levantadas e geradas ao longo da pesquisa, segue uma análise conclusiva.

\section{- A segurança alimentar e nutricional pode ser definida e medida objetivamente de forma satisfatória, embora não sem dificuldades relevantes.}

A definição da FAO de quatro pilares - disponibilidade, acesso, utilização e estabilidade, utilizada como base para a elaboração de indicadores é bastante abrangente e permite a modelagem de indicadores que são aproximações razoáveis da realidade de segurança alimentar. O redirecionamento ocasionado pelos estudos de Amartya Sen, da oferta para a demanda, resultou no foco renovado no indivíduo e a incorporação definitiva do termo "nutricional" à definição de segurança alimentar. Essa mudança se refletiu na metodologia, por exemplo, da FAO/FIVIMS, que considera o ambiente natural, cultural, social, político, institucional e socioeconômico no contexto da vulnerabilidade em diferentes níveis até a utilização e ingestão de nutrientes. As características básicas dos indicadores seletividade, memória e nível de análise quando considerados em conjunto permitem uma apreciação real das limitações e capacidades de cada indicador. Entre os indicadores analisados, demonstrou-se que indicadores de diversidade da dieta são os mais adequados para balizar políticas públicas de segurança alimentar e nutricional. Quando analisado à luz 
dos três requisitos escolhidos para análise, baseados na literatura disponível, (i.) validade transversal, (ii.) validade intertemporal, e (iii.) relevância nutricional, os indicadores de dieta se sobressaem e são os mais confiáveis. Isso não significa que sejam livres de pontos fracos. Existe a necessidade de se assumir alguns fatores arbitrariamente e também simplificar procedimentos que podem por vezes comprometer resultados.

\section{- Políticas públicas em geral e de segurança alimentar e nutricional} especificamente são passivas de análise qualitativa e há pesquisa consolidada sobre o campo, embora sua aplicação além da descrição seja limitada.

As teorias e modelos apresentados - modelo institucional, de processo, de grupo, elite, racional, incremental, teoria de jogos, opção pública e modelo sistêmico - se prestam ao melhor entendimento dos movimentos e processos que levam à formulação, discussão, aprovação e execução de políticas públicas. Todavia, a análise de políticas públicas que passa da descrição ou narração requer informações que raramente estão disponíveis, principalmente em países em desenvolvimento.

A coleta e processamento de dados antes, durante e após a implantação de uma política, além de censos e pesquisas amostrais regulares, levadas a cabo seguindo as melhores práticas metodológicas, de compliance, prestação de contas (accountability) e interpretação de dados balanceada e imparcial são inseparáveis de modelos e teorias em constante evolução, que buscam explicações, respostas e caminhos, que estão na base das ciências sociais aplicadas.

No caso da Índia, por exemplo, as três características conferidas às políticas públicas pelas instituições que as implementam - legitimidade, universalidade e coercibilidade - são postas em cheque devido às falhas de governo e governança. $O$ logrolling e o comportamento rent-seeking de políticos e empresários corrompem não apenas o processo político mas especialmente a execução das políticas públicas, como foi observado no caso do estado de Karnataka.

A alternância e sobreposição de conflito e coordenação por parte de forças e interesses econômicos e políticos por meio de transferências políticas de interesse econômico (PESTs - sigla em inglês), enxergam o Estado e o governo como meros mecanismos de transferência de renda e riqueza, da coletividade para alguns grupos de interesse. Esse padrão de comportamento é observado em relação à política de segurança alimentar na Índia, onde os arranjos organizacionais e institucionais favorecem políticas produtivas e também predatórias. A política de subsídios agrícolas que sustenta o PDS e a NFSA resulta no inchaço do mercado de arroz e trigo e no atrofiamento de outros grãos não incluídos no sistema. 
- No contexto do arcabouço das primeiras duas questões, o sistema público direcionado de distribuição de alimentos da Índia não é sustentável sob o prisma socioeconômico e ambiental.

Desdobramentos:

O sistema público direcionado de distribuição de alimentos da Índia (TPDS) não é sustentável e gera custos socioeconômicos e ambientais consideráveis.

O primeiro fator de insustentabilidade do TPDS é sua própria base, isto é, a agricultura que gera a oferta de cereais distribuídos pelas lojas de preço justo. O modelo de produção baseado na Revolução Verde indiana é extremamente predatório do ponto de vista socioeconômico e ambiental.

Do ponto de vista socioeconômico, por exemplo, salários são próximos ou abaixo do mínimo para subsistência, há trabalho infantil generalizado e há exclusão de pequenos agricultores que não conseguem vender o excedente da produção a preços competitivos. A política de subsídios beneficia grandes fazendeiros e intermediários e resulta na expulsão dos menores que crescentemente migram para as cidades, que já passaram de suas capacidades de absorção há décadas.

Do ponto de vista ambiental, os danos causados pela agricultura convencional são largamente conhecidos e dão pouco sinal de mudanças, já que não há incentivos para tal. Pelo contrário, o sistema de segurança alimentar encoraja a produção convencional e a consolida a cada expansão do sistema.

A falta de sustentabilidade é patente sob todos os níveis e pilares da sustentabilidade abordados por este trabalho de pesquisa.

A lei do sistema indiano de segurança alimentar, inclusive a reforma de 2013-14, apenas tangencia questões de sustentabilidade. Não há nenhuma menção direta ao tema embora o compromisso de diversificar a cesta de alimentos (cereais) incluídos no sistema público de distribuição e eventual inserção de uma política de compra e distribuição local acene para um possível redirecionamento em um futuro não tão distante. A ausência de integração horizontal e vertical de uma política ambiental do Governo Central nas políticas públicas em geral e nas políticas públicas de segurança alimentar especificamente, é o principal empecilho à uma reorganização em direção à sustentabilidade. A hierarquização e especialização excessivas geram burocracias e processos burocráticos em todos os níveis de governo.

Há forte resistência institucional e organizacional a mudanças significativas.

O uso político da estrutura do sistema público de distribuição de alimentos, principalmente em nível estadual, inviabiliza mudanças ao sistema existente já que agentes 
políticos percebem riscos especialmente eleitorais em qualquer alteração que de alguma forma reduza ou mude benefícios. Mesmo mudanças ou correções universalmente aceitas como necessárias, como foi o caso dos cartões de racionamento falsos em Karnataka, são por vezes invertidas em manobras políticas com fundamentação eleitoreira. Conforme previsto no modelo de incremental, a reformulação de políticas públicas na Índia se dá como uma atividade de continuação e mudanças marginais. Adicionalmente, os custos imobilizados (ou enterrados) no PDS inviabilizam o abandono ou reorganização radical do sistema devido aos altos custos envolvidos.

\section{Os serviços providos pelo TPDS não garantem o mínimo necessário para a segurança alimentar e nutricional, mesmo havendo exceções localizadas e altíssimo custo ao contribuinte indiano.}

De fato, o TPDS não garante segurança alimentar e nutricional. Com tudo isso, as boas novas, esperançosas, são que há melhorias a despeito do TPDS-NFSA.

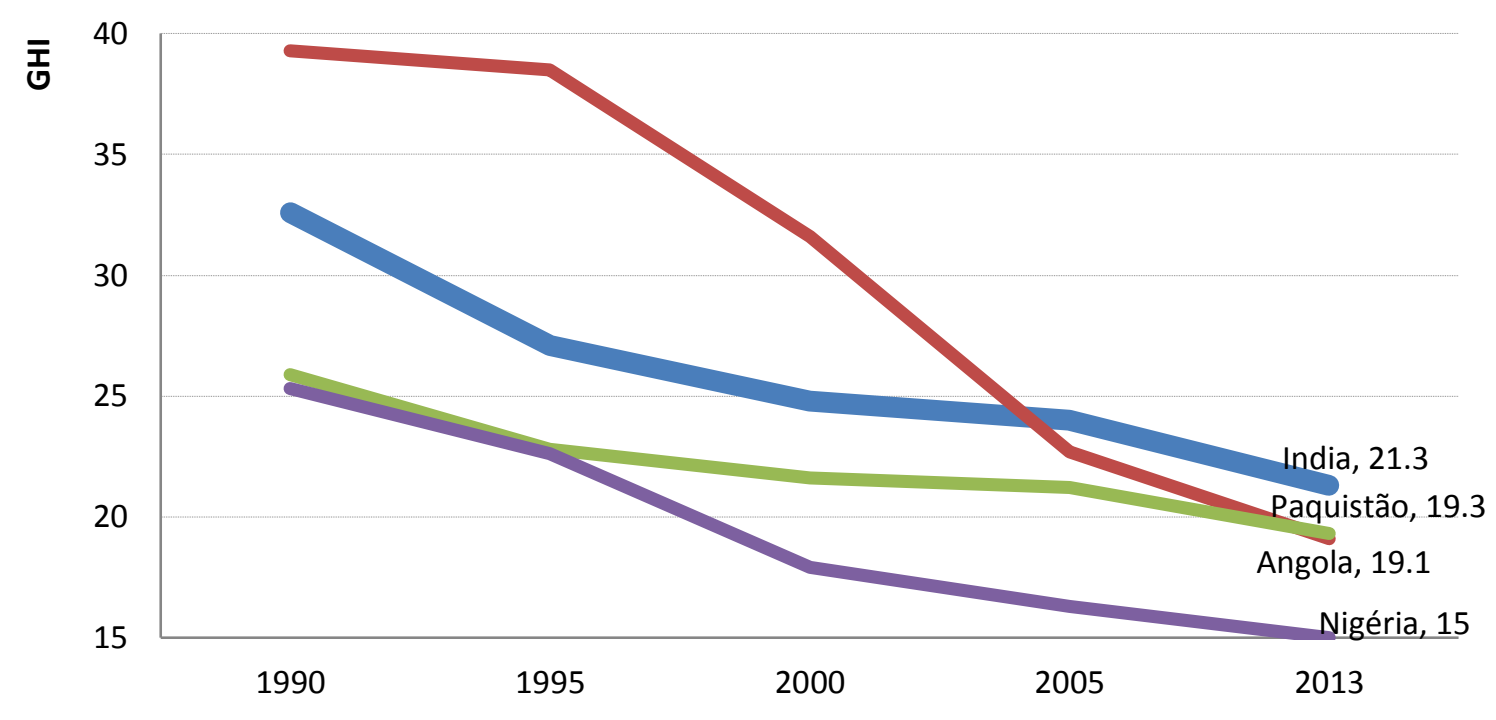

Gráfico 17 - Índice de Fome Global [Global Hunger Index (GHI)] Fonte: IFPRI, 2014. Elaboração do autor.

A Índia tem melhorado no ranking do Índice de Fome Global do Instituto de Pesquisa em Política Alimentar (IFPRI), como se averigua no Gráfico 17, embora ainda esteja em situação pior que vários países muito menos desenvolvidos. A fome aguda está diminuindo paulatinamente e o país passou da classificação "alarmante" para "séria" no índice de 2014. De 45,1 por cento de crianças abaixo de 5 anos de idade abaixo do peso para a idade em 2005-06, chegou-se a 30,7 por cento em 2013 (IPFRI, 2014). A queda expressiva é indicação de que mesmo com a corrupção e ineficiência generalizadas, no conjunto de políticas e programas do governo, o pouco que chega à população mais necessitada está 
fazendo alguma diferença. Mesmo assim, como aponta Sharma (2014), não há muito a comemorar quando uma em cada três crianças indianas abaixo da idade de 5 anos está abaixo do peso em 2014.

Mesmo cientes da situação por meio de auditorias internas e externas, sucessivos governos têm se mostrado incapazes de realizar mudanças reais, a despeito de inúmeras alterações e atualizações na lei, novos regulamentos, comissões e comitês - há um abismo entre a intenção e a implementação do TPDS (NRAA, 2011; WDRA, 2013; Controladoria e Auditor Geral da Índia, 2013). Provavelmente, os principais fatores são políticos. Os preços mínimos, os bônus sobre os preços mínimos e a obrigatoriedade de compra por parte da FCl são munição política, principalmente em nível estadual e distrital (Jena, 2013).

\section{A ênfase na venda subsidiada de cereais sem fortalecimento de meios de} subsistência ou geração de renda inviabiliza uma política de segurança alimentar e nutricional sustentável.

A conclusão ao final deste trabalho de tese não poderia ser expressa em meias palavras: vender arroz e trigo a preços subsidiados sem ações de geração de renda apenas mantém os mais pobres vivos.

As respostas provisórias (ou hipóteses) construtivas geradas pela pesquisa da primeira parte e da segunda parte do trabalho de tese são negadas em relevância pela situação do sistema público direcionado de distribuição de alimentos da Índia (TPDS) que não é sustentável e gera custos socioeconômicos e ambientais consideráveis. Pior ainda é que, além de insustentáveis, os serviços providos pelo TPDS não garantem o mínimo de segurança alimentar e nutricional (embora hajam exceções). A não aceitação por parte dos establishments político, ativista e acadêmico indiano de mudanças estruturais do sistema de segurança alimentar e nutricional (por exemplo, 'vales alimentação' ou, então, dinheiro, como é o caso do Bolsa Família no Brasil) e a ênfase na venda subsidiada de cereais sem fortalecimento de meios de subsistência ou geração de renda inviabiliza uma política de segurança alimentar e nutricional sustentável.

Crises alimentares e insegurança alimentar crônica não são nem serão no curto prazo evitadas pela transformação do sistema alimentar convencional em sistema ambientalmente sustentável. No entanto, os fundamentos ecológicos da agricultura e portanto da segurança alimentar são reais e os efeitos da agricultura convencional sobre eles, inegáveis. Os fundamentos socioeconômicos da segurança alimentar, disponibilidade e acesso, precisam ser alcançados prioritariamente. Não é possível, contudo, indefinidamente postergar a conversão do sistema e continuar a erodir os fundamentos ecológicos do sistema alimentar, já que sem fundamentos não há alimento (Alcamo, 2012). Na Índia, disponibilidade e acesso 
já são uma realidade, porém, o custo ecológico tem sido ignorado e os fundamentos ecológicos da segurança alimentar comprometidos.

É a partir do problema de pesquisa e das hipóteses geradas que advém uma proposta de mudança para um dos entraves à maior sustentabilidade do TPDS - NFSA. Dada a complexidade dos problemas enfrentados, não há solução única para todas as mazelas, a proverbial silver bullet. Conforme visto ao longo da segunda parte, os problemas do PDS ou TPDS não são conjunturais e sim, estruturais, políticos e históricos. Os interesses e direitos adquiridos pelos stakeholders do lado da oferta desde sua gênese são profundamente enraizados e fazem parte do próprio tecido do qual a sociedade indiana é tecida. Como previsto no modelo da opção pública, os benefícios de alguns - no caso, os grandes produtores rurais - são suportados pela coletividade que paga pelo privilégio de um grupo altamente organizado e eficiente na defesa e continuidade de suas regalias. Embora o princípio do bem público, no caso, a segurança alimentar e nutricional dos mais pobres, de fato seja um dos fatores motivadores da política pública por parte da elite política, o uso político do PDS gera externalidades negativas que reforçam o grau de insustentabilidade. $O$ PDS e seus stakeholders do lado da oferta se comportam como um pequeno estado dentro do Estado indiano - soberano, que mina os incentivos à eficiência de todo o complexo agrícola alimentar da Índia.

Alcançar segurança alimentar e nutricional para todos depende, pragmaticamente, do governo e suas políticas, programas e projetos. Devido ao tamanho e complexidade do desafio, apenas o próprio governo, ou pelo menos, iniciativas com ativa e ampla participação dos governos central, estadual e distrital serão capazes de inverter a situação de insegurança alimentar e nutricional da maioria da população do País. Também, pragmaticamente, qualquer proposta de solução da situação de segurança alimentar indiana deve considerar a permanência do sistema público de distribuição no que diz respeito à sua estrutura organizacional. Por mais insustentável - do ponto de vista ambiental e do ponto de vista socioeconômico - que o sistema público de distribuição de alimentos seja, o custo político de desativá-lo e substituí-lo completamente, mais do que os custos financeiros e econômicos, por exemplo, por vales alimentação ou por cash transfers, torna improvável e proibitivo para qualquer governo à frente do Estado indiano realizar tal mudança. 


\section{REFERÊNCIAS}

ABBOTT, P. C.; HURT, C.; TYNER, W. E. What's Driving Food Prices in 2011? Oak Brook, IL: Farm Foundation. 2011.

ABBOTT, P. Development Dimensions of High Food Prices. Working Paper. Paris: OECD. 2009. 95p. Disponível em: <http://www.oecd.org/tad/agriculturalpolicies/42972908.pdf>. Acesso: 13/08/2013.

ABBOTT, P.; HURT, C.; TYNER, W. What's Driving Food Prices? March 2009 Update. Despite reversal of conditions, complexity and drivers of food prices remain unchanged. Farm Foundation, Oak Broak, IL. Atualização de relatório, 2009. Disponível em: < http://www.farmfoundation.org/news/articlefiles/1702-Farm\%20-\%203-10-09\%20\%20Food\%20Prices\%20Update\%20-\%20Book\%20for\%20Posting.pdf >. Acesso: 25/08/2013.

ABBOTT, P.; HURT, C.; TYNER, W. "What's Driving Food Prices?" Farm Foundation, Oak Broak, IL. Atualização de relatório, Julho 2008. Disponível em: < http://www.farmfoundation.org/news/articlefiles/404-FINAL\%20WDFP\%20REPORT\%20728-08.pdf>. Acesso: 25/08/2013.

ACHARYA, K. C. S. Food Security System of India: Evolution of the Buffer Stocking Policy and its Evaluation. Nova Delhi: Naurang Rai - Concept Publishing Company. 1983.

ACTION CONTRE LA FAIM (ACF). Food Security and Livelihood Assessments: A Practical Guide for Field Workers. ACF International: Nova York. 2010.

ADAMS, A. E.; SWISHER, M.E.; MONAGHAN, K. N. Defining Community Food Security. AEC 383. Gainesville: Agricultural Education and Communication Department, Florida Cooperative Extension Service, Institute of Food and Agricultural Sciences, University of Florida. 2010. 4p. Disponível em: <http://edis.ifas.ufl.edu/pdffiles/WC/WC06400.pdf>. Acesso: 13/11/2013.

AGARWAL, B. Food Crises and Gender Inequality. Working Paper no. 107. New York: Departamento de Assuntos Sociais e Econômicos da Organização das Nações Unidas, 2011, 28 p.

AGNIHOTRI, A. Pawar rejects universal PDS. The Asian Age, Nova Délhi, 8 agosto 2010. Índia. Disponível em: <http://archive.asianage.com/india/pawar-rejects-universal-pds-715.> Acesso: 27 setembro 2014.

AKILESWARAN, K; NAIR, A. India's cash transfer model: a rushed and flawed welfare scheme? Why a failure to link payments to inflation and other drawbacks will make new cash benefits inadequate for India's worst off. The Guardian, Londres, 19 agosto 2013, Global Development Professionals Network. Disponível em: <http://www.theguardian.com/globaldevelopment-professionals-network/2013/aug/19/india-cash-transfer-welfare>. Acesso: 22/09/2014.

ALCAMO, J. The Ecological Foundation of Food Security \& Realizing Sustainable Food Systems. In: NAIROBI LAUNCH. 16 outubro 2012. Disponível em: <http://www.unep.org/science/chief-scientist/Portals/76/docs/NairobiLaunch_Presentation.pdf>. Acesso: 20/03/2013.

ALI, D.; SAHA, K. K.; NGUYEN, P; TEDLA, M; MENON, P.; RAWAT, R.; RUEL, M. Household food insecurity is associated with higher child undernutrition in Bangladesh, 
Ethiopia, and Vietnam, but the effect is not mediated by child dietary diversity. Journal of nutrition, Bethesda, MD, v. 143, n. 12, p. 2015-2021. 2013.

ALKIRE, S.; SETH, S. Determining BPL Status: Some Methodological Improvements. The Indian Journal of Human Development, Nova Délhi, v. 2 n. 2, p. 407-424, 2009.

AMRITH, S. Food and Welfare in India, c. 1900-1950. Comparative Studies in Society and History, Cambridge, Reino Unido, v. 50, n. 4, p. 1010-1035, 2008.

ANDREYEVA, T.; LONG, M. W.; BROWNELL, K. D. The Impact of Food Prices on Consumption: A Systematic Review of Research on the Price Elasticity of Demand for Food. American Journal of Public Health, v. 100, n. 2, p. 216-222. 2010.

APPADURAI, A. Gastropolitics in Hindu South Asia. American Ethnologist, Arlington, VA, v. 8, p. 494-511. 1981.

ARIMOND, M; RUEL, M. Dietary Diversity Is Associated with Child Nutritional Status:

Evidence from 11 Demographic and Health Surveys. Journal of Nutrition, Bethesda, MD, v. 134, n. 10, p. 2579-2585. 2006.

AROCKIARAJ, J. Delta farmers feed PDS rice to cattle. Times of India, Mumbai, 3 fevereiro 2013. Disponível em: <http://timesofindia.indiatimes.com/city/madurai/Delta-farmers-feed-

PDS-rice-to-cattle/articleshow/18359507.cms>. Acesso: 28/09/2014.

AYAR, S. Colossal sham: Public distribution system turns out to be an abject failure, multicrore rupee scam." India Today, Nation, 3 outubro 2005.

BABU, S. C; SANYAL, P. (Eds.). Food Security, Poverty and Nutrition Policy Analysis: Statistical Methods and Applications. International Food Policy Research Institute:

Washington, D.C., 2009.

BANCO MUNDIAL. Poverty and Hunger: Issues and Options for Food Security in Developing Countries. Washington, D.C. 1986.

Protecting Progress: The Challenge Facing Low-Income Countries in the Global Recession. In: G-20 LEADERS' MEETING, Pittsburgh, EUA, 24-25 de setembro, 2009.

Food Price Watch Banco Mundial - Fevereiro 2011. Disponível em:

<http://www.worldbank.org/foodcrisis/food_price_watch_report_feb2011.html>. Acesso: 04/08/2013.

Global Monitoring Report 2012: Food Prices, Nutrition, and the Millennium Development Goals. Washington DC: World Bank. 2012.

Annual Report 2013. Washington, D.C.: Banco Mundial. 2013. Disponível em: <http://siteresources.worldbank.org/EXTANNREP2013/Resources/93048871377201212378/9305896-1377544753431/1_AnnualReport2013_EN.pdf>. Acesso: 03/08/2013.

Choosing and Estimating a Poverty Line. Disponível em:

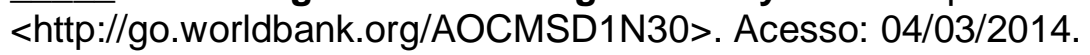

Poverty headcount ratio at $\$ 2$ a day (PPP) (\% of population). Disponível em: <http://data.worldbank.org/indicator/SI.POV.2DAY>. Acesso: 10/08/2014. 
BANERJEE, K. Decentralised Procurement and Universalised PDS. Economic \& Political Weekly, Mumbai, v. 66, n. 52, p. 19-22, 2011.

BAPNA, S. L. Food Security Through PDS - The Indian Experience. In: TYAGI, D.S.; VYAS, V. S. (Eds.). Increasing access to food: the Asian experience. New Delhi; Newbury Park, California: Sage Publications, 1990. cap. 3, p. 57-82.

BARRETT, C. B. Measuring Food Insecurity. Science, Washington, DC, v. 327 n. 5967, p. 825-828.

BARRETT, C.B.; LENTZ, E. Food Insecurity. In: DENMARK, R. et al. (eds.). The International Studies Compendium Project. Oxford: Wiley-Blackwell. 2010.

BARRETO, M. L.; SANTOS, L. M.; ASSIS, A. M.; ARAÚJO, M.P.; FARENZENA, G.G.; SANTOS, P.A.; FIACCONE, R.L. Effect of vitamin A supplementation on diarrhea and acute lower-respiratory-tract infections in young children in Brazil. Lancet, Londres, v. 344, n. 8917, p. 228-231. 1994.

BARTELMUS, P. Quantitative Eco-nomics: How sustainable are our economies? Nova York: Dordrecht Springer Science Business Media B.V. 2008.

Sustainability Economics, An Introduction. Series: Routledge Textbooks in Environmental and Agricultural Economics. Nova York: Routledge. 2013.

BASU, K.; BASOLE, A. The calorie consumption puzzle in India: An empirical investigation. Working Paper n. 285. Cambridge, Massachusetts: Political Economy Research Institute (PERI), 2012. 34p. Disponível em:

$<$ http://www.peri.umass.edu/fileadmin/pdf/working_papers/working_papers_251300/WP285.pdf>. Acesso: 27/09/2014.

BAUMGARTNER, Ruedi; HOGGER, Ruedi. (Eds.). In search of sustainable livelihood systems. Nova Delhi, Índia: Sage Publications Ltd. 2004.

BEARDSWORTH, A.; KEIL, T. Sociology on the Menu: An Invitation to the Study of Food and Society. New York: Routledge. 2002.

BEDER, S. Costing the Earth: Equity, Sustainable Development and Environmental Economics. New Zealand Journal of Environmental Law, Auckland, v. 4, p. 227-243. 2000.

BEEGLE, K.; WEERDT, J. De, FRIEDMAN, J; GIBSON, J. Methods of Household Consumption Measurement through Surveys: Experimental Results from Tanzania. Journal of Development Economics, Amsterdam, v. 98, n.1, p. 3-18. 2012.

BELL, D.N.F.; BLANCHFLOWER, D. G. The crisis, policy reactions and attitudes to globalization and jobs. In: BACCHETTA, M.; JANSEN, M. (Eds.) Making Globalization Socially Sustainable. Genebra: International Labour Organization and World Trade Organization. 2011. Cap. 3, p. 85-113.

BENNUR, S. Anna Bhagya, a success story in Mysore. The Hindu, Chennai, 29 julho 2014. Disponível em: <http://www.thehindu.com/news/national/karnataka/anna-bhagya-a-successstory-in-mysore/article6193955.ece >. Acesso: 25/10/2014.

BERNARDO, G. L.; PROENÇA, R. P. C.; FIATES, G. M. R.; CALVO, M. C. M. Índices de diversidade alimentar para avaliação da dieta. Ceres, Viçosa, v. 6, n. 2, p. 105-120. 2011. 
BERTALANFFY, L. V. General System theory: Foundations, Development, Applications, New York: George Braziller. 1976.

BERTI, P. R. Intrahousehold distribution of food: A review of the literature and discussion of the implications for food fortification programs. Food and Nutrition Bulletin, Tóquio, v. 33, n. 3 (Suplemento), p. 163-169. 2012.

BISHOP-SAMBROOK, Clare. A manual for gender-focused field diagnostic studies: IFAD's gender strengthening programme in Eastern and southern Africa. Roma: International Fund for Agricultural Development - IFAD. 2001.

BHAGAT, R. B. Food Security and Food Policy in India. Government in Management, Nova Délhi, v. 44, n. 2, p. 37-45. 2012.

BHATIA, B. M. Famines in India: A Study in Some Aspects of the Economic History of India with Special Reference to Food Problem, 1860-1990. Bombaim: Konark Publishers. 1991.

BHATT, M. S (Ed.). Poverty and Food Security in India: Problems and Policies. Nova Délhi: Aakar Books. 2004.

BHATTI, B. Aadhaar-Enabled Payments for NREGA Workers. Economic \& Political Weekly, Mumbai, v. 47, n. 49, 2012.

BHUNIA, A.; NATARAJ, G. Indian food security and the WTO deal. East Asia Forum. 2014. Disponível em: <http://www.eastasiaforum.org/2014/01/25/indian-food-security-and-the-wtodeal/>. Acesso: 26/07/2014.

BLACK, R. E.; ALLEN, L. H; BHUTTA, Z. A.; CAULFIELD, L. E.; de ONIS, M.; EZZATI, Majid; MATHERS, C.; RIVERA, J. Maternal and child undernutrition: global and regional exposures and health consequences. The Lancet, Londres, v. 371, n. 9608, p. 243-260. 2008.

BORGHINI, A. "Philosophy of Hunger". Disponível em:

<http://philosophy.about.com/od/Philosophical-Theories-Ideas/a/Philosophy-Of-Hunger.htm>. Acesso em: 02/07/2013.

BORGWARDT, E. FDR's Four Freedoms and Wartime Transformations in America's Discourse of Rights. In: SOOHOO, C.; ALBISA, C. DAVIS, M.F. (eds.). Bringing Human Rights Home: A History of Human Rights in the United States. Philadelphia, Pennsylvania: University of Pennsylvania Press. 2009. cap. 2, p. 40-67.

BOYD, R. Scientific Realism. In: ZALTA, E. N. (ed.). The Stanford Encyclopedia of

Philosophy. Stanford, California: Stanford University. 2002. Disponível em:

<http://plato.stanford.edu/archives/sum2010/entries/scientific-realism/>. Acesso: 23/04/2014.

BRAND, F. S.; JAX, K.. 2007. Focusing the meaning(s) of resilience: resilience as a descriptive concept and a boundary object. Ecology and Society, Wolfville, Canada, v.12, n.1, [online]. Disponível em:<http://www.ecologyandsociety.org/vol12/iss1/art23/>. Acesso: $18 / 09 / 2014$.

BRASSLEY, Paul; SEGERS, Yves, MOLLE, Leen Van (Eds.). War, Agriculture, and Food: Rural Europe from the 1930s to the 1950s. Nova York, EUA: Routledge. 2012.

BRENNAN, L. The development of the India Famine Codes: personalities, policies and politics. In: CURREY, B.; HUGO, G. (Eds.) Famine as a geographical phenomenon. 
GeoJournal library, Volume 1 (edição ilustrada). Dordrecht, Holanda: D. Reidel Publishing Company - Springer. 1984. cap. 5, p. 91-111.

BRINKMAN, H. J.; de PEE, S.; SANOGO, I.; SUBRAN, L.; BLOEM, M. W. High Food Prices and the Global Financial Crisis Have Reduced Access to Nutritious Food and Worsened Nutritional Status and Health. Journal of Nutrition, Bethesda, MD, v. 140, n. 1, p. 15351615. 2010.

BUCHANAN, J. M. Cost and Choice: An Inquiry in Economic Theory. Ann Arbor: University of Michigan Press. 1969.

BUCHANAN, J. M. Rent Seeking and Profit Seeking. In: BUCHANAN, J. M.; TOLLISON, R. D.; TULLOCK, G. (Eds.). Toward a Theory of the Rent-Seeking Society. College Station, Texas: Texas A \& M University Press. 1980. cap. 1, p. 3-15.

BUCHANAN, J. M.; TULLOCK, G. The Calculus of Consent: Logical Foundations of Constitutional Democracy. Indianapolis, IN: Liberty Fund, Inc.1999.

BUDHWAR, P. S.; SAINI, D. S.; BHATNAGAR, J. Women in Management in the New Economic Environment: The Case of India. Asia Pacific Business Review, Londres, v. 11, n.. 2, p. 179-193. 2005.

BURSZTYN, M. O poder dos donos: Planejamento e clientelismo no Nordeste. 3. ed. Rio de Janeiro: Garamond. 2008.

BURSZTYN, M. A.; BURSZTYN, M. Fundamentos de política e gestão ambiental: os caminhos do desenvolvimento sustentável. Rio de Janeiro: Garamond. 2012.

BURTON, M.; HIGLEY, J. Invitation to elite theory: The basic contentions reconsidered. In: DOMHOFF, G. W.; DYE, T. (Eds.). Power Elites and Organizations. Beverly Hills: Sage. 1987. cap. 4, p. 219-238.

BUSINESS STANDARD. Karnataka launches 'Anna Bhagya' scheme for BPL families. To supply free milk to school children for three days a week. Business Standard, Mumbai, 10 julho 2013. Disponível em: <http://www.business-standard.com/article/economypolicy/karnataka-launches-anna-bhagya-scheme-for-bpl-families-113071000911_1.html>. Acesso: 24/10/2014.

BUSINESS TODAY. PM Narendra Modi to announce role for Planning Commission shortly. Business Today, Noida, Índia, 11 julho 2014. Disponível em:

$<$ http://businesstoday.intoday.in/story/pm-narendra-modi-to-announce-role-for-planningcommission/1/208083.html>. Acesso: 14/07/2014.

BUTLER, E. Public Choice - A Primer. Londres: The Institute of Economic Affairs. 2012.

CAFIERO, C.; GENNARI, P. The FAO indicator of the prevalence of undernourishment.

FAO, Roma, Background Paper. 2011. Disponível em:

<http://www.fao.org/fileadmin/templates/ess/ess_test_folder/Workshops_Events/Food_Secur ity_for_All_FEB2011/Background_paper.pdf>. Acesso: 28/02/2014.

CALO, Muriel; SARBOROUGH, Greg; TROY, Lisa. Food Security and Livelihood

Assessments: A practical guide for field workers. Nova York: Action Against Hunger. 2010.

CANNON, T.; TWIGG; J.; ROWELL, J. Social Vulnerability, Sustainable Livelihoods and

Disasters. Londres: Benfield Hazard Research Centre. 2003. 
CANNON, T. Reducing People's Vulnerability to Natural Hazards - Communities and Resilience. UNU-WIDER, Helsinki, Research Paper n. 2008/34. 2008. Disponível em: <http://www.wider.unu.edu/publications/working-papers/research-

papers/2008/en_GB/rp2008-34/_files/79269469163225299/default/rp2008-34.pdf>. Acesso: $15 / 07 / 2013$.

CARNEY, D.; DRINKWATER, M.; RUSINOW, T.; NEEFJES, K.; WANMALI, S.; SINGH, N. Livelihoods approaches compared. Londres, UK: Department for International Development (DFID). 1999.

CARNEY, D. Sustainable livelihoods approaches: Progress and possibilities. Londres: Department for International Development (DFID). 2003.

CARRUBBA, C.; VOLDEN, C. Coalitional Politics and Logrolling in Legislative Institutions. American Journal of Political Science, East Lansing, Michigan, v. 44, n. 2, p. 261-277, 2000.

CARTER, C.; RAUSSER, G.; SMITH, A. The Food Price Boom and Bust. Agricultural and Resource Economics Update, Berkeley, v. 12, n. 2, p. 2-4, 2008.

CASTRO, J. A. Geografia da fome. O dilema brasileiro: pão ou aço. 10. ed. Rio de Janeiro: Antares, Achiamé, 1982.

. Geopolítica da fome. 2. ed. Rio de Janeiro: Casa do Estudante do Brasil, 1953.

CASTRO, J. A. de; CASTRO, A. M. de. Fome, um tema proibido: últimos escritos de Josué de Castro. Rio de Janeiro: Civilização Brasileira, Grupo Editorial Record. 2003.

CELASUN, O.; MIHET, R.; RATNOVSKI, L. Commodity Prices and Inflation Expectations in the United States. Working Paper 12/89. Washington, DC: International Monetary Fund, 2012. 24p. Disponível em: <https://www.imf.org/external/pubs/ft/wp/2012/wp1289.pdf>.

Acesso: 30/08/2013.

CENTRE FOR MEDIA STUDIES - CMS. Índia Corruption Study: 2010. Is the Scenario Changing? [online]. Nova Délhi: CMS. 2011. Disponível em:

<http://unpan1.un.org/intradoc/groups/public/documents/apcity/unpan047870.pdf >. Acesso: 01/08/2014.

CHAMBERS, R.; G. CONWAY. Sustainable rural livelihoods: Practical concepts for the 21st century. Institute of Development Studies Discussion Paper, Brighton, n. 296. 1991.

CHANDANSHIV, M. M; ; S.S. NARWADE. An Evaluation of PDS in Maharashtra - A case study. Excel Journal of Engineering Technology and Management Science, Aurangabad, India, v. 1, n. 4, 2013. [online]. Disponível em: <http://excelpublication.com/wpcontent/uploads/2013/07/6.-Dr.-S.-S.-Narwade..pdf>. Acesso: 09/06/2014.

CHANDIGARH ADMINISTRATION. Antyodya Anna Yojana. Food and Supplies and Consumer Affairs, Chandigarh Administration. 2014. Disponível em: <http://chdfood.gov.in/Antyodya.aspx>. Acesso: 01/08/2014.

CHATTERJEE, P. Development planning and the Indian state. In: CHATTERJEE, P. (ed.). State and Politics in India. Nova Délhi: Oxford University Press. 2001. cap. 7, p. 271-302.

CHAUDHRI, R.; TIMMER, C. P. The impacts of changing affluence on diets and demand patterns for agricultural commodities. Working Paper n. 70. Washington, DC: Banco Mundial. 1983. 89p. 
CHEN, S.; RAVALLION, M. The Developing World Is Poorer Than We Thought, But No Less Successful in the Fight against Poverty. Working Paper 4703. Washington, DC: Banco Mundial, 2008, 89p.

CHINNAKALI, P.; UPADHAY, R. P.; SHOKEEN, D.; SINGH, K.; KAUR, M.; SINGH, A. K.; GOSWAMI, A.; YADAV, K.; PANDAV, C. Prevalence of Household-level Food Insecurity and Its Determinants in an Urban Resettlement Colony in North India. Journal of Health, Population and Nutrition, Dhaka, Bangladesh, v. 32, n. 2, 2014.

CLAY, E. Food Security: Concepts and Measurement. Paper of FAO Expert Consultation on Trade and Food Security: Conceptualising the linkages. Roma, 11-12 Julho de 2002.

Food security: A status review of the literature. ESCOR Research Report. No. R5911. Londres: Overseas Development Institute (ODI).1997.

CMMAD. Our Common Future. [Brundtland Report] Oxford University Press: Oxford, UK, 1987.

COMITÉ DE SEGURANÇA ALIMENTAR MUNDIAL (CFS). Coming to terms with terminology. 39a Sessão, Roma, Itália, 15 a 20 de outubro de 2012. Roma: Organização das Nações Unidas para Alimentação e Agricultura (FAO). 2012.

COMITÊ DE SEGURANÇA ALIMENTAR MUNDIAL (CFS). Reform of the Committee on World Food Security - Final Version. Agenda Item III. Roma: FAO. 2009. Disponível em: $<$ http://www.fao.org/fileadmin/templates/cfs/Docs0910/ReformDoc/CFS_2009_2_Rev_2_E_ K7197.pdf >. Acesso em: 15/06/2013.

COMITÊ DO JUIZ WADHWA PARA O SISTEMA PÚBLICO DE DISTRIBUIÇÃO. (CJWSPD). Report on the State of Maharashtra. Relatório. Nova Délhi: Comitê Central de Vigilância do Sistema de Distribuição Pública. 2011. Disponível em:

<http://maharashtratimes.indiatimes.com/photo.cms?msid=8158776>. Acesso: 28/09/2014.

. Justice Wadhwa Committee on Public Distribution System (PDS) Karnataka.

Relatorio. Nova Délhi: Comitê Central de Vigilância do Sistema de Distribuição Pública. 2009. Disponível em: <http://pdscvc.nic.in/Karnatka-report.doc>. Acesso: 28/09/2014.

. Justice Wadhwa Committee on Public Distribution System (PDS) Andhra Pradesh. Relatório. Nova Délhi: Comitê Central de Vigilância do Sistema de Distribuição Pública. 2009. Disponível em: <http://pdscvc.nic.in/ap\%20report.htm>. Acesso: 23/10/2014.

. Justice Wadhwa Committee on Public Distribution System (PDS) - Report on Computerisation of PDS Operations. Relatório. Nova Délhi: Comitê Central de Vigilância do Sistema de Distribuição Pública. 2009. Disponível em:

<http://pdscvc.nic.in/report\%20on\%20computersisation\%20of\%20PDS.htm>. Acesso:

23/10/2014.

COMPTON, J.; WIGGINS, S.; KEATS, S. Impact of the global food crisis on the poor: what is the evidence? Relatório. Londres: Overseas Development Institute Report. 2010. $110 p$.

COMPTROLLER AND AUDITOR GENERAL OF INDIA. CAG. Report no.-7 of 2013-Union Government. Relatório. Nova Délhi: Food Corporation of Índia. 2013. 61p. Disponível em: <http://www.saiindia.gov.in/english/home/Our_Products/Audit_Report/Government_Wise/uni on_audit/recent_reports/union_performance/2013/Civil/Report_7/Chap_3.pdf >. Acesso:

09/10/2014. 
CONCEIÇÃO, P.; LEVINE, S.; BRIXIOVA, Z. The Food Price Spikes of 2008/09 and 2010/11: Impacts and Policies in African Countries. United Nations Development Programme Working Paper. Regional Bureau for Africa. 2011. 25p.

CONGLETON, R. D.; HILLMAN, A. L.; KONRAD, K. A. Forty Years of Research on Rent Seeking: An Overview. In: CONGLETON, R. D.; HILLMAN, A. L.; KONRAD, K. A. (Eds.): Forty Years of Research on Rent Seeking. Volumes 1 \& 2. Heidelberg: Springer. 2008. Overview, p. 1-42.

CONNELL, C. L.; LOFTON, K. L.; YADRICK, K.; REHNER, T. A. Children's Experiences of Food Insecurity Can Assist in Understanding Its Effect on Their Well-Being. Journal of Nutrition, Bethesda, MD, v. 135, n. 7, p. 1683-1690. 2005.

CONTINI, E.; PENA JÚNIOR, M. A. G.; SANTANA, C. A. M.; MARTHA JÚNIOR, G.

Exportações: motor do agronegócio brasileiro. Revista de Política Agrícola, Brasília, n. 2, p. 88-102, 2012.

COOK, B. Food Security: Implications for the Earlier Years. Background Paper. Toronto: Toronto Public Health. 2006. 126p.

CORDEIRO, L. S.; WILDE, P. E.; SEMU, H.; LEVINSON, F. J. Household Food Security is Inversely Associated with Undernutrition among Adolescents from Kilosa, Tanzania. Journal of Nutrition, Bethesda, MD, v. 142, n. 9, p. 1741-1747. 2012.

COZZOLINI, S. F. Biodisponibilidade de nutrientes. Barueri: Manole. 2005.

CULLATHER, N. The Hungry World: America's Cold War Battle against Poverty in Asia. Cambridge, Massachusetts: Harvard University Press. 2010.

D`ALISA, G. Dimensions of sustainable development: a proposal of systematization of sustainable approaches. Working Paper. Foggia, Itália: Dipartimento di Scienze Economiche, Matematiche e Statistiche, Università degli Studi di Foggia. 2007. 14p.

DALE, C: Dictionary of Aeronautical Terms. 3. ed. Newcastle, Estado de Washington: Aviation Supplies \& Academics, 2012.

DANISH REFUGEE COUNCIL (DRC). A Sexual and Gender-Based Violence Rapid Assessment Doro Refugee Camp, Upper Nile State, South Sudan. Copenhagen: Danish Refugee Council. 2012. 19p.

DAVIS, M. Late Victorian Holocausts: El Nino Famines and the Making of the Third World. Londres: Verso. 2001.

DEATON, A. The Financial Crisis and the Well-Being of Americans. NBER Working Paper 17128. Cambridge, MA: National Bureau of Economic Research. 2011. 54p.

DEATON, A. Price indexes, inequality, and the measurement of world poverty. Presidential Address. American Economic Association, Atlanta, janeiro 2010. Disponível em: $<$ http://www.princeton.edu/ deaton/downloads/presidential\%20address\%2019january\%2020 10\%20all.pdf>. Acesso: 04/03/2014.

DEATON, A.; DRÈZE, J. Nutrition in India: Facts and Interpretations. Economic and Political Weekly, Mumbai, v. 44, n. 7, p. 42-65. 2009. 
DEATON, A.; DUPRIEZ, O. Purchasing Power Parity Exchange Rates for the Global Poor. American Economic Journal: Applied Economics, Pittsburgh, PA, v. 3, n. 2, p. 137-166. 2011.

DEATON, A.; PAXSON, C. On urban versus rural poverty in India. Nova Jersey: Princeton University. 1995. 34p.

DEATON, A.; TAROZZI, A. Prices and Poverty in India. In: GUPTA, K. R. Poverty in India. Nova Délhi: Atlantic Publishers and Dist. 2008. cap. 3, p. 12-59.

DECCAN HERALD. PDS now moves to supermarkets. Deccan Herald, Bangalore, 5 junho 2014. Disponivel em: <http://www.deccanherald.com/content/411874/pds-now-movessupermarkets.html\#>. Acesso: 23/10/2014.

DEITCHLER, M. BALLARD, T; SWINDALE, A.; COATES, J. Validation of a Measure of Household Hunger for Cross-Cultural Use. Food and Nutrition Technical Assistance II (FANTA-2) project technical report. Washington, DC: US Agency for International Development. 2010. 65p.

DERISSEN, S.; QUAASA, M.; BAUMGÄRTNER, S. The relationship between resilience and sustainable development of ecological-economic systems. Working Paper Series in Economics No. 146. Lüneburg, Alemanha: University of Lüneburg. 2009. 14p.

DESHPANDE, R. S.; ARORA, S. Agrarian Crisis and Farmer Suicides. Nova Délhi: SAGE Publications India Pvt. Ltd.

DE SOTO, H. The Other Path: The Invisible Revolution in the Third World. Londres: I. B. Tauris, 1989.

DEV, S. M. Climate Change, Rural Livelihoods and Agriculture (focus on Food Security) in Asia-Pacific Region. Working Paper 2011-014. Mumbai: Indira Gandhi Institute of Development Research. 2011. 68p.

DEVEREUX, S. Sen's Entitlement Approach: Critiques and Counter-critiques. Oxford Development Studies, v. 29, n. 3, p. 245-263, 2001.

DEPARTMENT FOR INTERNATIONAL DEVELOPMENT (DFID). Sustainable Livelihoods Guidance Sheets. Folhas de orientação. Londres: DFID. 1999. 26p.

DEPARTMENT OF FOOD AND PUBLIC DISTRIBUTION. Procurement of Foodgrains. Disponível em: <http://dfpd.nic.in/?q=node/640>. Acesso: 02/10/2014.

DJOLOV, G. G. The economics of competition: the race to monopoly. Nova York: Routledge. 2013.

DOCUMENTATION FRANÇAISE, LA. Le Sahel sur la carte du monde. Disponível em: http://www.ladocumentationfrancaise.fr/dossiers/d000540-le-sahel-un-enjeu-international/lesahel-sur-la-carte-du-monde. Acesso: 23/12/2014.

DOMHOFF, G. W. Who Rules America? 5. ed. Nova York: McGraw-Hill. 2005.

DOWELL-JONES, Mary. Contextualising The International Covenant On Economic, Social And Cultural. Leiden, Holanda: Martinus Nijhoff Publishers - Brill Publishers. 2004. 
DRESCHER, L. S.; THIELE, S.; MENSINK, G. B. M. A New Index to Measure Healthy Food Diversity Better Reflects a Healthy Diet than Traditional Measures. Journal of Nutrition, Bethesda, MD, v. 137, n. 3, p. 647-651. 2007.

DRÈZE, J. Famine Prevention in India. Working Paper No. 45. Helsinki: World Institute for Development Economics Research of the United Nations University. WIDER-UNU. 1988. $143 p$.

Famine Prevention in India. In: DRÈZE, J.; SEN, A. (Eds.). The Political Economy of Hunger. Vol. 2. Nova Délhi: Oxford University Press. 1990. cap. 1, p. 72-81.

DRÈZE, J.; SEN, A. Hunger and Public Action. Oxford: Clarendon Press, 1989.

DUNN, W. N. Public Policy Analysis. International Edition. Nova Jersey: Pearson Education, Limited. 2012.

DYE, T. R. Understanding Public Policy. 14. ed. Londres: Pearson. 2012.

DYE, T. R. Políticas Públicas e Desenvolvimento - Bases Epistemológicas e modelos de análise. In: HEIDEMANN, F. G.; SALM, J. F. (orgs.). Políticas públicas e desenvolvimento: bases epistemológicas e modelos de análise. Brasília: Editora Universidade de Brasília, 2009. cap. 3, p. 99-129.

EASTON, D. A Framework for Political Analysis. Englewood Cliffs, NJ: Prentice-Hall Publishers. 1965.

ECKER, O.; BREISINGER, C.; PAUW, K. Growth is good, but not enough to improve nutrition. Conference Brief n. 7. Nova Délhi: 2011. 24p.

ECONOMIST, THE. Fighting corruption in Índia. A bad boom. Graft in India is damaging the economy. The country needs to get serious about dealing with it. The Economist, Londres, Briefing. 15 março 2014.

ELOY, L.; COUDEL, E.; TONI, F. Pagamentos por Serviços Ambientais no Brasil. Sustentabilidade em Debate, Brasília, v. 4, n. 1, p. 17-20, 2013.

EMPACHER, C., WEHLING, P. Soziale Dimensionen der Nachhaltigkeit. Theoretische Grundlagen und Indikatoren. Diskussionspapiere 13. Frankfurt am Main: Institut für sozialökologische Forschung (ISOE) GmbH. 1999.

ENCICLOPÉDIA MÉDICA MEDLINE PLUS. 2013. U.S. National Library of Medicine. Disponível em: <http://www.nlm.nih.gov/medlineplus/encyclopedia.html>. 10/02/2013.

ENGSTROM, E. J.; VANBERG, G. Assessing the Allocation of Pork: Evidence From Congressional Earmarks. American Politics Research, Thousand Oaks, California, v. 38, n. 6, p. 959-985. 2010.

ENTREPRISES POUR L'ENVIRONNEMENT (EPE). The economic pillar of sustainable development: a business perspective. Informe. Nanterre: Association Française des Entreprises pour l'Environnement. 2004. 22p.

ESCRITÓRIO DO OFICIAL ELEITORAL CHEFE, KARNATAKA - EOECK. Previous Elections Results. Governo de Karnataka. Disponível em: <http://ceokarnataka.kar.nic.in/>. Acesso: 24/10/2014. 
ESWARAN, H.; LAL, R.; REICH, P. F. Land degradation: An overview. In: BRIDGES, E. M.; HANNAM, I. D.; OLDEMAN, L. R.; PENING de VRIES, F. W. T.; SCHERR, S. J.;

SOMPATPANIT, S. (Eds.). Responses to land degradation. Proceedings of the Second International Conference on Land Degradation and Desertification, Khon Kaen, Tailândia. Nova Délhi: Oxford University Press. 2001. [online]. Disponível em:

<http://www.nrcs.usda.gov/wps/portal/nrcs/detail/soils/use/?cid=nrcs142p2_054028>.

Acesso: 4/09/2013.

EVANS, D. Policy and Pork: The Use of Pork Barrel Projects to Build Policy Coalitions in the House of Representatives. American Journal of Political Science, Hoboken, Nova Jersey, v. 38, n. 4, p. 894-917. 1994.

FARMERS' PORTAL. Indian Wheat Growing Zones. Governo da Índia. Disponível em: http://farmer.gov.in/cropstaticswheat.html. Acesso: 8/11/2014.

FEEDBACK INFRASTRUCTURE SERVICES PRIVATE LIMITED - FISPL. Warehouse Management System for Karnataka State Warehousing Corporation - A pilot Project for 17 Warehouses. Relatório. Bangalore: Governo de Karnataka, Corporação de Armazenagem do Estado de Karnataka, Departamento de Desenvolvimento de Infraestrutura. 2012. 60p.

FIELD, J. O. The hunger dilemma. Hunger Notes, [online] World Hunger Education Service (WHES). 2002. Disponível em:

<http://www.worldhunger.org/articles/global/Endingwhunger/field.htm >. Acesso em: 27/02/2014.

FIELDHOUSE, D. For Richer, for Poorer? In: MARSHALL, P. J. (ed.). The Cambridge Illustrated History of the British Empire. Cambridge, Reino Unido: Cambridge University Press, 1996, cap. 5, p. 108-146.

FITZPATRICK, T.; CAHILL, M. Environment and Welfare: Towards a Green Social Policy. Nova York: Palgrave Macmillan. 2002.

FOOD CORPORATION OF INDIA. Statewise procurement of rice since kms 2003-04.

Relatório. Disponível em:

<http://www.fciweb.nic.in//upload/Procurement/Statewise\%20Procurement\%20of\%20Rice\%2 0since\%20KMS\%201999-2000_2.pdf>. Acesso: 23/09/2014.

Statewise procurement of wheat for central pool since rms 2003-04(marketing season wise). Disponível em:

<http://www.fciweb.nic.in//upload/Procurement/Statewise\%20Procurement\%20of\%20wheat \%20since\%20RMS\%201999-2000_1.pdf>. 23/09/2014.

FOSTER, J. Absolute versus Relative Poverty. American Economic Review, Pittsburgh, PA, v. 88, n. 2, p. 335-34. 1998.

FOSU, K.; HEERINK, N. Food Security and Nutrition: Implications of Policy Reforms with a case study from Ghana. In: FRAHAN, B. H. de; D’AGOSTINO, V. Policy Reform: the Social Dimension. Nectar Programme. Thematic field - Agricultural Economics and Policy Reforms. Module 4. Louvain, Bélgica: Université catholic de Louvain, Départment de Biologie Appliquée et des Productions Agricoles, Unité d'économie rurale. 2009. [online]. Disponível em: <https://www.uclouvain.be/en-273312.html>. Acesso: 08/09/2014.

FOX, R. L. Alexander the Great. Londres: Penguin UK. 2006.

FUWA, N. Intrahousehold Analysis Using Household Consumption Data: Would the Potential Benefit of Collecting Individual-Level Consumption Data Justify Its Cost? 
MPRA Paper No. 23689. Chiba, Japão: Institute of Developing Economies - Japan External Trade Organization (IDE-JETRO), 2005, 67p.

FUWA, N.; ITO, S.; KUBO, K.; KUROSAKI, T.; SAWADA, Y. Gender Discrimination, Intrahousehold Resource Allocation, and Importance of Spouses' Fathers: Evidence on Expenditure from Rural Andhra Pradesh. The Developing Economies, Chiba, Japão, v. 44, n. 4, p. 375-397. 2006.

FUKUYAMA, F. What is Governance? Governance, Montreal, v. 26, n. 3, p. 347-368, 2013.

GALLOPÍN, G. A systems approach to sustainability and sustainable development. Serie Medio Ambiente y Desarrollo, n. 64. Santiago de Chile: CEPAL, 2003. 42p.

GARRETT, L. Rising Food Prices: causes and consequences. Paris: The Organisation for Economic Co-operation and Development - OECD. 2008. 9p.

GATTY, H. R. PDS stores in supermarkets: Karnataka works on image makeover. Indian Express. [online]. Nova Délhi, 23 junho 2014. Disponível em: $<$ http://indianexpress.com/article/cities/bangalore/pds-stores-in-supermarkets-karnatakaworks-on-image- makeover/99/\#sthash.NBn4kTEr.dpuf>. Acesso: 22/10/2014.

GILBERT, C. L. How to Understand High Food Prices. Journal of Agricultural Economics, Milwaukee, WI, v. 61, n. 2, p. 398-425, 2010.

GIDEY, T. G. Food Security Policy: does it work? Does it help? 2012. Tese (Doutorado em geografia). Faculty of Geo Information, Science and Earth Observation, Universidade de Twente. Enschede, Holanda.

GOBBÉE, J. Industry speaks: reflections on the irrational. International Food and Agribusiness Management Review, College Station, Texas, v. 11, n. 4, p. 175-178, 2008.

GOLAIT, R. Current Issues in Agriculture Credit in India: An Assessment. Reserve Bank of India Occasional Papers, Mumbai, v. 28, n. 1, 2007, p. 79-99.

GOUEL, C. Food price volatility and domestic stabilization policies in developing countries. Working Paper no. 18934. Cambridge, Massachusetts: National Bureau of Economic Research, 2013. 49p.

GOUGH, I.; MEADOWCROFT, J.; DRYZEK, J.; GERHARDS, J.; LENGFELD, H.; MARANDYA, A.; ORTIZ, R. Climate change and social policy. Journal of European Social Policy, Londres, v. 18, n. 4, p. 325-344. 2008.

GRAGNOLATI, M.; BREDENKAMP, C.; SHEKAR, M.; DAS GUPTA, M.; LEE, Y.-K. India's Undernourished Children: A Call for Reform and Action. Washington, DC: The International Bank for Reconstruction and Development; The World Bank. 2006.

GRANTHAM-MCGREGOR, S.; CHEUNG, Y.B.; CUETO, S.; GLEWWE, P., Richter; L.; STRUPP, B. Developmental Potential in the First 5 Years for Children in Developing Countries. The Lancet, Londres, v. 369, n. 9555, p. 60-70. 2007.

GRASSROOTS RESEARCH AND ADVOCACY MOVEMENT (GRAAM). PDS in Karnataka: cost to the exchequer and burden to the taxpayer. Relatório. Mysore, Índia: GRAAM. 2011. $9 p$. 
GREBMER, K. H. von; FRITSCHEL, H.; NESTOROVA, B.; OLOFINBIYI, T.; PANDYALORCH, R.; YOHANNES, Y. Global Hunger Index report 2008. Bonn; Washington, D.C., Dublin: Welthungerhilfe, IFPRI, Concern. 2008. 44p.

GROSS, R; SCHOENEBERGER, H.; PFEIFER, H.; PREUSS, H. A. Community nutrition: definition and approaches. In: SADLER, M; STRAIN, S.; CABALLERO, B. (eds.). Encyclopedia of human nutrition. Academic Press: Londres. 1998. cap. 59, p. 1973-1998.

GROSS, R.; SCHOENEBERGER, H.; PFEIFER, H.; PREUSS, H. A.: The Four Dimensions of Food and Nutrition Security: Definitions and Concepts. InWEnt Overview Paper on Nutrition and Food Security. Bonn, Alemanha: Internationale Weiterbildung und Entwicklung gGmbh, 2000, 17p.

GROVE, R. H. The Great El Nino of 1789 and its Global Consequences: Reconstructing an Extreme Climate Even in World Environmental History, The Medieval History Journal, Los Angeles, v. 10, n. 1 \& 2, p. 75-88, 2007.

GUHA-KHASNOBIS, B.; ACHARYA, S. S.; DAVIS, B. (Eds.). Food Security: Indicators, Measurement, and the Impact of Trade Openness. Oxford: Oxford University Press. 2007.

GUNTZ, S. Sustainability and profitability of microfinance institutions. Research Paper 4/2011. Nürnberg: Center for Applied International Finance and Development (CAIFD), 2011. $53 p$.

HADDAD, L.; PEÑA, C.; NISHIDA, C.; QUISUMBING, A.; SLACK, A. Food Security and Nutrition Implications of Intrahousehold Bias: A Review of Literature. FCND Discussion Paper No. 19. Washington, DC: International Food Policy Research Institute. 1996. 72p.

HAEN, H. de; KLASEN, S.; QAIM, M. What do we really know? Metrics for food insecurity and undernutrition. Food Policy, Amsterdam, v. 36, n. 6, 2011, p. 760-769.

HALL-MATTHEWS, D. Historical Roots of Famine Relief Paradigms: Ideas on Dependency and Free Trade in India in the 1870s. Disasters, Nova Jersey, v. 20, n. 3, 1996, p. 216-230.

. Inaccurate Conceptions: Disputed Measures of Nutritional Needs and Famine Deaths in Colonial India. Modern Asian Studies, Nova York, v. 42, n. 1, 2008, p. 1189-1212.

HARDOON, D.; HEINRICH, F. Daily Lives and Corruption: Public Opinion in South Asia. Berlin: Transparency International. 2011. 32p.

HARVEY, D. Social justice and the city. Athens, Georgia: The University of Georgia Press. [1973] 2009.

HAZELL, P. B. R. The Asian Green Revolution. Discussion Paper 00911. Washinton, DC: International Food Policy Research Institute. 2009. 40p.

HEADEY, D. Was the Global Food Crisis Really a Crisis? Simulations versus SelfReporting. Discussion paper 01087. Washington DC: International Food Policy Research Institute. 2011.72p.

HEADEY, D.; FAN, S. Reflections on the Global Food Crisis. Research monograph 165. Washington DC: International Food Policy Research Institute. 2011. 142p.

HEIDEMANN, F. G.; SALM, J. F. (Orgs.). Políticas públicas e desenvolvimento: bases epistemológicas e modelos de análise. Brasília: Editora UnB, 2009. 
HERRMANN, M. Food security and agricultural development in times of high commodity prices. Discussion Paper no. 196. Genebra: United Nations Conference on Trade and Development. 2009. 40p.

HESPANHOL, A. N.; HESPANHOL, R. A. M. Os efeitos da elevação dos preços das commodities agrícolas sobre a segurança alimentar. Revista Faz Ciência, Francisco Beltrão, PR, v. 12, n. 15. 2010, p. 73-94.

HILL, P. J. Public Choice: A Review. Faith \& Economics, Santa Barbara, CA, n. 34, v. 1999, p. 1-10.

HINDU, THE. No hereditary ownership of new PDS outlets in Karnataka: Minister. The Hindu, Bangalore, 14 junho 2014. Disponível em:

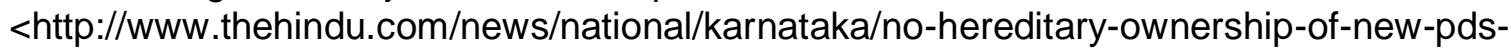
outlets-in-karnataka-minister/article6114641.ece?css=print>. Acesso: 23/09/2014.

HIRAKURI, M. H.; LAZZAROTTO, J. J. Evolução e Perspectivas de Desempenho Econômico Associadas com a Produção de Soja nos Contextos Mundial e Brasileiro. Documentos Embrapa Soja, no. 319. 3. Ed. Londrina: Embrapa Soja. 2011.

HIRWAY, I. Identification of BPL Households for Poverty Alleviation Programmes. Economic and Political Weekly, Mumbai, v. 38, n. 45, p. 4803-38. 2003.

HODA, A.; GULATI, A. WTO Negotiations on Agriculture and Developing Countries. Baltimore, Maryland: Johns Hopkins University Press. 2007.

HODDINOTT, J. Technical guides for operationalizing household food security in development projects. Anotações Técnicas. Washington, DC: International Food Policy Research Institute, Food Consumption and Nutrition Division, IFPRI. 1999. 21p.

HODDINOTT, J.; YOHANNES, Y. Dietary Diversity as a Household Food Security Indicator: Technical Appendix. Washington, D.C.: Food and Nutrition Technical Assistance Project. 2002. 50p.

HOFFMANN, R.; KAGEYAMA, A. Pobreza, insegurança alimentar e pluriatividade no Brasil. In: CONGRESSO DA SOCIEDADE BRASILEIRA DE ECONOMIA, ADMINISTRAÇÃO E SOCIOLOGIA RURAL, 45, 2007, Londrina. Anais... Brasília: SOBER, 2007.

HOLLING, C. S.; GUNDERSON, L. Resilience and adaptive cycles. In: GUNDERSON, L.; HOLLING, C. S. (Eds.): Panarchy - Understanding Transformations in Human and Natural Systems. Washington, D.C.: Island Press. 2002. cap. 2, p. 25-62.

HOOS, I. R. Systems Analysis in Public Policy: a critique. Revised edition. Berkeley and Los Angeles, California: University of California Press. 1983.

HOSPES, O.; HADIPRAYITNO, I. (Eds.). Governing Food Security: Law, Politics and the Right to Food. Wageningen, Holanda: Wageningen Academic Publishers, 2010.

HOTCHKISS, D. R.; MOCK, N. B.; SEIBER, E. E.: The effect of the health care supply environment on children's nutritional status in rural Nepal. Journal of Biosocial Science, Cambridge, v. 34, n. 2, p. 173-192, 2002.

HUNTER, T. Equality for the Earth - The Role of Intergenerational Equity and Customary International Law. The National Legal Eagle, Robina, Queensland, Austrália, v. 17, n. 1, p. 19-21. 2011. 
ICSU-UNESCO-UNU. Ecosystem Change and Human Well-being: Research and Monitoring Priorities Based on the Millennium Ecosystem Assessment. Paris: International Council for Science. 2008.

ÍNDIA. Report of the expert group to review the methodology for measurement of poverty. Expert Group under the Chairmanship of Dr. C. Rangarajan. Relatório. Nova Délhi: Governo da Índia, Comissão de Planejamento. 2014. 92p.

Enhancing Sustainable Livelihoods of the poor through convergence of Mahatma Gandhi NREGA with various schemes. Relatório. Governo da Índia, Ministério do Desenvolvimento Rural. 2014a. 144p.

The National Food Security Act, 2013. No. 20 of 2013. The Gazette of Índia Extraordinary, part II, Section 1. Nova Délhi: Governo da Índia, Ministério da Lei e Justiça. 2013a. Disponível em: <http://egazette.nic.in/WriteReadData/2013/E_29_2013_429.pdf>. Acesso: 22/09/2014.

Report of the Comptroller and Auditor General of India on Storage Management and Movement of Food Grains in Food Corporation of India. Report No. 7 of 2013. Nova Délhi: Union Government, Ministry of Consumer Affairs, Food and Public Distribution, Governo da Índia. 2013b. 115p.

ÍNDIA. National Food Security Act, 2013c. The Gazette of India. Nova Délhi: Departamento de Alimento e Distribuição Pública.

Press Note on Poverty Estimates for 2011-12. Nova Délhi, 22 de julho de 2013. Nova Délhi: Governo da Índia, Comissão de Planejamento. 2013c. Disponível em: <http://planningcommission.nic.in/news/pre_pov2307.pdf>. Acesso: 09/08/2013.

Region-wise capacity of FCl godowns. Relatório. Nova Délhi: Governo da Índia. PDS Portal of India. Ministério de Assuntos do Consumidor, Alimentação e Distribuição Pública, Corporação de Alimentos da Índia. 2013d. Disponível em: <http://www.pdsportal.nic.in/main.aspx\#>. Acesso: 09/10/2014.

. Ministry of Panchayati Raj. Disponível em: <http://www.panchayat.gov.in/home>. Acesso: 09/08/2014.

Report of the Expert Group to Recommend the Detailed Methodology for Identification of Families Living Below Poverty Line in the Urban Areas. Relatório. Nova Délhi: Planning Commission, Perspective Planning Division - Governo da Índia. 2012. 131p.

Expenditure Budget. Volume. 1, 2012-13. Relatório. Ministério das Finanças, Governo da Índia. 10p.

The Warehousing Corporations (Amendment) Bill: Bill No. 57 of 2011. The Gazette of India. Nova Delhi: Governo da Índia. 2011. Disponível em: <http://www.prsindia.org/uploads/media/Warehousing\%20/Warehousing\%20Corporations\%2 0Amendment\%20Bill\%202011.pdf>. Acesso: 26/07/2014.

Press Note on Poverty Estimates. Nova Délhi: Governo da Índia. 2011. Disponível em: <http://planningcommission.nic.in/reports/genrep/Press_pov_27Jan11.pdf>. Acesso: 31/07/2014. 
National Social Assistance Programme (NSAP). Nova Délhi: Ministry of Rural Development. Governo da Índia. 2011. Disponível em: <http://nsap.nic.in/nsap/NSAP\%20About\%20us.pdf>. Acesso: 31/07/2014.

Envisioning a role for Aadhaar in the Public Distribution System. Working Paper. Nova Délhi: UIDAI. 2010a. 16p.

Addressing India's Nutrition Challenges. Report of the Multistakeholder Retreat. Nova Délhi, 7-8 agosto 2010. Nova Délhi: Comissão de Planejamento, Governo da Índia. 2010b. 120p.

The Warehousing (Development and Regulation) Act, 2007. Lei n. 37 de 2007. The Gazette of India. Nova Délhi: Governo da Índia. 2007. Disponível em: $<$ http://www.wdra.nic.in/>. Acesso: 26/07/2014.

INDIA. National Family Health Survey 2005-06 (NFHS-3), National Report. Relatório. Mumbai: International Institute for Populations Sciences - IIPS; Governo da Índia. 2007. $765 p$.

Performance Evaluation of Targeted Public Distribution System (TPDS). Relatório. Nova Delhi: Comissão de Planejamento do Governo da Índia. 2005a. 119p.

The Mahatma Gandhi National Rural Employment Guarantee Act, de 5 de setembro de 2005. The Gazette of India. Nova Délhi: Governo da Índia, Ministério do Desenvolvimento Rural. 2005b.

Report of the High Level Committee on Long Term Grain Policy. Relatório. Nova Délhi: Ministério da Alimentação e Questões do Consumidor. 2002. 2p.

The Food Corporation Act, 1964 Act No 37 of 1964 (As amended up to 29 August, 2001). The Gazette of India. Lei n. 37 de 1964. Nova Delhi: Governo da Índia. 2001.

. Market Intervention Scheme. Nova Délhi: Comissão de Planejamento. Governo da Îndia. 2001. Disponível em: <http://indiabudget.nic.in/es2000-01/chap510.pdf>. Acesso: 02/08/2014.

Evaluation Report on Revamped Public Distribution System. Public Evaluation Organisation of the Planning Commission of India Study No. 161. Nova Delhi: Governo da Índia. 1995. 4p.

Report of the Indian Famine Commission. Relatório. Nova Delhi: Agricole Publishing Academy. [1898] 1979. 403p.

da Índia. 1962.

The Warehousing Corporations Act. The Gazette of India. Nova Delhi: Governo

INTERNATIONAL INSTITUTE FOR SUSTAINABLE DEVELOPMENT. What is Sustainable Development? Environmental, economic and social well-being for today and tomorrow.

Disponível em: <http://www.iisd.org/sd/>. Acesso: 06/09/2014.

INTERNATIONAL CENTRE FOR TRADE AND SUSTAINABLE DEVELOPMENT. WTO Members Weigh Options as India Pushes Food Security Link on Trade Facilitation Deal. Bridges, Genebra, v. 18, n. 27 [online]. Disponível em: <http://www.ictsd.org/bridgesnews/bridges/news/wto-members-weigh-options-as-india-pushes-food-security-link-ontrade>. Acesso: 26/07/2014. 
INTERNATIONAL CONFERENCE ON NUTRITION (ICN). Caring for the Socio-

Economically Deprived and Nutritionally Vulnerable. Major Issues for Nutrition Strategies Theme Paper \# 3. ICN/92/INF/7. Roma: Food and Agriculture Organization of the United Nations/World Health Organization. 1992. 140p.

INTERNATIONAL FEDERATION OF RED CROSS AND RED CRESCENT SOCIETIES. How to conduct a food security assessment: A step-by-step guide for National Societies in Africa. 2. ed. Genebra: International Federation of Red Cross and Red Crescent Societies. 2006.

IPCC. IPCC WGII AR5 Summary for Policymakers. In: FIELD, C.B.; BARROS, V.R.; DOKKEN, D.J.; MACH, K.J.; MASTRANDREA, M.D.; BILIR, T.E.; CHATTERJEE, M.; EBI, K.L.; ESTRADA, Y. O; GENOVA, R. C.; GIRMA, B.; KISSEL, E.S.; LEVY, A.N.; MACCRACKEN, S.; MASTRANDREA, P.R.; WHITE, L.L. (eds.). Climate Change 2014: Impacts,Adaptation, and Vulnerability. Part A: Global and Sectoral Aspects. Contribution of Working Group II to the Fifth Assessment Report of the Intergovernmental Panel on Climate Change. Cambridge, United Kingdom and New York, NY, USA: Cambridge University Press. 2014. 32p.

IRWIN, S. Commodity Index Investment and Food Prices: Does the "Masters Hypothesis" Explain Recent Price Spikes? Agricultural Economics, Nova Jersey, v. 44, n. s1, 2013, p. 29-41.

IRWIN, S. H.; SANDERS, D. R. Index Funds, Financialization, and Commodity Futures Markets. Applied Economic Perspectives and Policy, Oxford, v. 33, n. 1, 2011, p. 1-31.

JACQUET, P. "Price volatility and agricultural development." Agence Française de Développement. Remarks at a conference organized by the French Embassy in London, in partnership with the Financial Times, the London School of Economics and Political Science, Chatham House, the Franco-British Council, and the Institute français, 1 June. Disponível em: <http://www.youtube.com/watch?v=HeSbuXTy94Y>.

JAIN, S. K. The case against cash transfers. Infochange News \& Features. 2011. Disponível em: <http://infochangeindia.org/agriculture/analysis/the-case-against-cashtransfers.html>. Acesso: 13/10/2014.

JALAN, J.; MURGAI, R. An Effective Targeting Shortcut? An Assessment of the 2002 Below-Poverty Line Census Method. Economics Working Paper Series n. 8. Calcutá: Centre For Studies in Social Sciences. 2006. 38p.

JANBEE, S. K. Debates on food security and public distribution system in India. 2000. Dissertação (Mestrado em Ciência Política). Universidade de Hyderabad, Índia.

JENA, M. India's Food Security Rots in Storage. Inter Press Service. 21 junho 2013. Disponível em: <http://www.ipsnews.net/2013/06/indias-food-security-rots-in-storage/>. Acesso: 29/09/2014.

JENSEN, R. T.; MILLER, N. H. A Revealed Preference Approach to Measuring Undernutrition and Poverty Using Calorie Shares. National Bureau of Economic Research - NBER Working Paper 16555. Cambridge, MA, US: National Bureau of Economic Research. 2010.

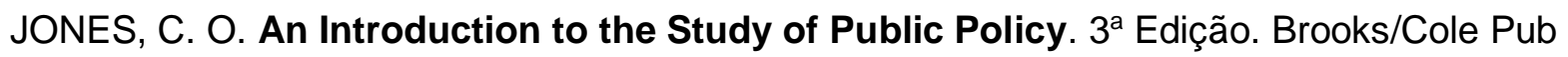
Co.: Pacific Grove. 1984. 
JOSH, J. India decided against signing WTO's Trade Facilitation Agreement. 25 julho 2014. Disponível em: <http://www.jagranjosh.com/current-affairs/india-decided-against-signingwtos-trade-facilitation-agreement-1406283061-1 >. Acesso: 26/07/2014.

JOSHI, S. Cash transfers can help make India less unequal, but are not a magic bullet. Entrevista com Amartya Sen. The Hindu, Chennai, 10 janeiro 2013.

KAC, G.; VELÁSQUEZ-MELENDEZ, G. SCHLÜSSEL, M. M.; SEGALL-CORRÊA, A. M.; SILVA, A. A.; PÉREZ-ESCAMILLA, R. Severe Food Insecurity is Associated with Obesity among Brazilian Adolescent Females. Public Health Nutrition, v. 15, n. 10, p. 1854-1860. 2012.

KAMANOU, G.; MORDUCH, J. Measuring Vulnerability to Poverty. Insurance against Poverty. UNU-WIDER, Helsinki, Discussion Paper No. 2002/58. 2002. 23p.

KAMATH, S. Foreign Aid and India: Financing the Leviathan State. Cato Policy Analysis No. 170. Washington, DC. Cato Institute. 1992. 14p.

KARNATAKA. Expression of Interest (EOI) for Installation of GPS system to the vehicles transporting PDS food grains. No. FSA/Wholesale/E-Tender/05/2013-14. Bangalore: Governo de Karnataka, Escritório do Comissário, Ala do Oficial Chefe de Contas, Departamento de Assuntos do Consumidor e Suprimentos Civis e Alimentos. 2014.

Anna Bhagya Yojana. Bangalore: Governo de Karnataka, Departamento de Alimentos, Suprimentos Civis e Assuntos do Consumidor. 2013. Disponível em: <http://ahara.kar.nic.in/annabhagyyojana.html>. Acesso: 24/10/2014.

Report on district wise addition/deletion in RCs. Bangalore: Governo de Karnataka, Karnataka PDS Data Centre, National Informatics Centre, Food, Civil Supplies \& Consumer Affairs Department. Karnataka. 2012. Disponível em:

<http://ahara.kar.nic.in/fcsstat/Stat_AAY_APL_BPL_Details.aspx>. Acesso: 24/10/2015.

KATTUMURI, R. Food Security and the Targeted Public Distribution System in India. Londres: Asia Research Centre, London School of Economics \& Political Science. Working Paper 38. 2011. 23p.

KAUSHAL, N.; MUCHOMBA, F. How Consumer Price Subsidies Affect Nutrition. Working Paper Series n. 19404. Cambridge, Massachusetts: National Bureau of Economic Research. 2013. 23p.

KEANE, J.; PAGE, S.; KERGNA, A.; KENNAN, J. Climate Change and Developing Country Agriculture: An Overview of Expected Impacts, Adaptation and Mitigation Challenges, and Funding Requirements. Issue Brief n. 2. Genebra, Washington DC: International Centre for Trade and Sustainable Development (ICTSD), International Food \& Agricultural Trade Policy Council (IPC) Platform on Climate Change, Agriculture and Trade. 2009.

KENNEDY, E. Qualitative measures of food insecurity and hunger. In: International Scientific Symposium Measurement and Assessment of Food Deprivation and Undernutrition. 2003, Roma. Anais... Roma: Food and Agriculture Organization of the United Nations. 2003.

KENNEDY, G.; BALLARD, T.; DOP, M. C. Guidelines for Measuring Household and Individual Dietary Diversity. Roma: Food and Agriculture Organization of the United Nations. 2011. 
KEMP, D. D. Exploring Environmental Issues: An Integrated Approach. Londres: Routledge. 2004.

KEYNES, J. M. The General Theory of Employment, Interest and Money. Cambridge, Reino Unido: Macmillan Cambridge University Press. 1936.

Collected Works, Volume XXI (CWXXI). In: MOGGRIDGE, D. E.; JOHNSON, E. S. (Eds.) The Collected Writings of John Maynard Keynes. 30 Volumes. Londres: Macmillan \& Nova York: Cambridge University Press for the Royal Economic Society. cap. [?], p. 19711989.

KARNATAKA FOOD AND CIVIL SUPPLIES CORPORATION - KFCSC. Report on district wise active/inactive FPDs. Disponível em:

<http://ahara.kar.nic.in/fcsstat/Stat_Active_FPS.aspx>. Acesso: 21/10/2014.

KIRZNER, I. M. Economic Planning and the Knowledge Problem. Cato Journal, Washington, DC, v. 4, n. 2, p. 407-418, 1984.

KHERA, R. Access to the Targeted Public Distribution System: A Case Study in Rajasthan. Economic and Political Weekly, v. 43, n. 44, p. 51-56, 2008.

KISHORE, A.; JOSHI, P. K.; HODDINOTT, J. A Novel Approach to Food Security, In: MARBLE, A.; FRITSCHEL, H. (eds.). 2013 Global Food Policy Report. Washington, DC: International Food Policy Research Institute (IFPRI). cap. 3, p. 29-42, 2014.

KLENNERT, Klaus (Ed.). Achieving Food and Nutrition Security: Actions to Meet the Global Challenge. A Training Course Reader. Feldafing, Alemanha: InWEnt - Internationale Weiterbildung gGmbH. 2009.

KNIGHT, H. Food Administration in India, 1939-1947. Stanford: Stanford University Press. 1954.

KOHLER, W. The Task of Gestalt Psychology. Princeton, New Jersey: Princeton University Press. 1969.

KORNHAUSER, W. Politics of Mass Society. New York: Routledge. [1960] 2013.

KREUGER, A.O. The Political Economy of the Rent-Seeking Society. American Economic Review, Pittsburgh, PA , v. 64, p. 291-303, 1974.

KRISHNAMURTHY, P.; PATHANIA, V.; TANDON, S. The Impacts of Reforms to the Public Distribution System in India's Chhattisgarh on Food Security. Economic Research Report n.164. Washington, DC: Economic Research Service, United States Department of Agriculture. 2014. 34p.

KRUGMAN, P.; WELLS, R.; RAY, M. A.; ANDERSON, D. A. Microeconomics. Nova York: Worth Publishers. 2012.

KUDAISYA, M. The Promise of Partnership: Indian Business, the State, and the Bombay Plan of 1944. Business History Review, Cambridge, Reino Unido, v. 88, edição especial 01, p. 97-131, 2014.

KUMAR, A.; SINGH, K. M.; SINHA, S. Institutional Credit to Agriculture Sector in India: Status, Performance and Determinants. Agricultural Economics Research Review, Nova Délhi, v. 23, 2010, p. 253-264. 
KUMAR, D.; DESAI, M. (eds.). The Cambridge Economic History of India, Volume 2:

c.1751-c.1970. Cambridge, Reino Unido: Cambridge University Press. 1983.

LAFFERTY, W. Adapting government practice to the goals of sustainable development.

Relatório de especialista para o seminário da Organização de Cooperação e de

Desenvolvimento Econômico "Improving Governance for Sustainable Development". Paris:

OECD. 34p. Disponível em <http://www.oecd.org/dataoecd/30/54/1939762.pdf>. Acesso:

10/09/2014.

LAFFERTY, W. LAFFERTY, W.; HOVDEN, E. Environmental policy integration: towards an analytical framework. Environmental Politics, Londres, v. 12, n. 3, p. 1-22, 2003.

LAFRANCE, R.; SCHEMBRI, L. Purchasing-Power Parity: Definition, Measurement, and Interpretation. Bank of Canada Review, Ottawa, v. 2002, n. 'outono', p. 27-33, 2002.

LANCASTER, T. D. Electoral Structures and Pork Barrel Politics. International Political Science Review, Montreal, v. 7, n. 1, p. 67-81, 1986.

LANE, P. R. The European Sovereign Debt Crisis. Journal of Economic Perspective, Nashville, v. 26, n. 3, p. 49-68. 2012.

LANZA, A. Lo sviluppo sostenibile. Bologna: II Molino. 1997.

LEAT, P. REVOREDO-GIHA, C.; LAMPRINOPOULOU, C. Scotland's Food and Drink Policy Discussion: Sustainability Issues in the Food Supply Chain. Sustainability, Basel, v. 3, p. 605-631, 2011.

LEVINAS, E. De I'Existence à l'existant. Paris: J. Vrin. [1978] 1993.

LICCO, E. A. Vulnerabilidade social e desastres naturais: uma análise preliminar sobre Petrópolis, Rio de Janeiro. InterfacEHS - Revista de Saúde, Meio Ambiente e

Sustentabilidade, São Paulo, v. 8, n. 1, p. 25-41, 2013.

LINDBLOM, C. E.; WOODHOUSE, E. J. The Policy Making Process. 3. ed. Prentice Hall: Englewood Cliffs, NJ. 1993.

LINDOSO, D.; DEBORTOLI, N.; PARENTE, I.; EIRÓ, F.; ROCHA, J. D.; RODRIGUES FILHO, S.; BURSZTYN, M. Vulnerabilidade socioeconômica da agricultura familiar brasileira às mudanças climáticas: o desafio da avaliação de realidades complexas. Boletim Regional, Urbano e Ambiental do IPEA, Brasília, v. 4, p. 21-31. 2009.

LISTORTI, G.; ESPOSTI, R. Horizontal Price Transmission in Agricultural Markets: Fundamental Concepts and Open Empirical Issues. Bio-based and Applied Economics, Florença, v. 1, n. 1, p. 81-96, 2012.

LUCAS, R.E. Econometric Policy Evaluation: A Critique. In: Lucas, R.E. (ed.). Studies in Business-Cycle Theory. Cambridge (MA): MIT Press. 1976. cap. 4, p. 104-130.

LUTZ, A. E.; SWISHER, M. E.; BRENNAN, M. A. Defining Community Food Security. AEC 383. Gainesville: The Institute of Food and Agricultural Sciences (IFAS). 2010. 4p.

MATSON, P. A.; PARTON, W. J.; POWER, A. G.; SWIFT, M. J. Agricultural Intensification and Ecosystem Properties. Science, Nova York, v. 277, n. 5325, p. 504-509, 1997.

MCCAIN, R. A. Game Theory and Public Policy. Northampton: Edward Elgar Publishing. 2009. 
MACEDO, M. N.; DEFRIES, R. S.; MORTON, D. C.; STICKLER, C. M.; GALFORD, G. L.; SHIMABUKURO, Y. E. Decoupling of deforestation and soy production in the southern Amazon during the late 2000s. Proceedings of the National Academy of Sciences of the United States of America, Washington, DC, v. 109, n. 4, p. 1341-1346. 2012.

MAHENDRAN, A.; INDRAKANT, S. Public Distribution System in Tamil Nadu, India: Rice Supply Scheme of Prospects, Problems and Policy. Journal Academica, Nova York, v. 4, n. 1, p. 38-49. 2014.

MAJUMDER, B. Poverty, food security, and sustainability: public distribution system in Índia. Jaipur: Rawat Publications. 2004.

MALTHUS, Robert Thomas. An Essay on the Principle of Population. 6. ed. Londres: Thoemmes Continuum. [1826]1999.

MARBLE, A.; FRITSCHEL, H. (Eds.). 2013 Global Food Policy Report. Washington, D.C.: International Food Policy Research Institute - IPRI. 2014. 154p.

MASIKA, R.; JOEKES, S. Environmentally Sustainable Development and Poverty: A Gender Analysis. BRIDGE Report 52. Sussex; Estocolmo: Institute of Development Studies University of Sussex. Swedish International Development Cooperation Agency (Sida). 1997. 20p.

MASSET, E. A review of hunger indices and methods to monitor country commitment to fighting hunger. Food Policy, Amsterdam, v. 36, suplemento 1, p. 102-108. 2011.

MASTERS, M. W. Testimony before the Senate Committee on Homeland Security and Governmental Affairs, United States Senate, June 24, 2008. Testemunho. Washington, DC: Senado dos Estados Unidos da América. Comitê para a Segurança Interna e Assuntos Governamentais. 19p. Disponível em: 12/03/2013.

<http://www.hsgac.senate.gov//imo/media/doc/052008Masters.pdf?attempt=2>. Acesso:

MAXCY, K. F.; ROSENAU, M. J.. Rosenau Preventive Medicine and Hygiene. 7. ed. Nova York: Appleton-Century-Crofts.1951.

MAXWELL, S. Measuring Food Insecurity: The frequency and severity of coping strategies. Food Consumption and Nutrition Division Discussion Paper No 8. Washington, DC: International Food Policy Research Institute. 1995. 33p.

MAXWELL, S.; FRANKENBERGER, T. Household Food Security: Concepts, Indicators and Measurements: A Technical Review. Roma; Nova York: International Fund for Agricultural Development e UNICEF. 1992. 6p.

MAXWELL, S.; SMITH, M. Household Food Security: A Conceptual Review. In: MAXWELL, S.; FRANKENBERGER, T. Household Food Security: Concepts, Indicators and Measurements: A Technical Review. Rome and New York: International Fund for Agricultural Development and UNICEF. 1992. cap. 1, p. 1-72.

MAY, P. J. Reconsidering Policy Design: Policies and Publics. Journal of Public Policy, Cambridge, Reino Unido, v. 11, n. 2, p. 187-206, 1991.

MBAKU, J. M. Corruption and Rent Seeking. In: BORNER, S.; PALDAM, M. (Eds.). The Political Dimension of Economic Growth. Londres: Macmillan/Saint Martin's Press. 1998. cap. 10, p. 193-211. 
MEDLINE PLUS ENCICLOPÉDIA MÉDICA. Malnutrion. Disponível em:

<http://www.nlm.nih.gov/medlineplus/ency/article/000404.htm>. Acesso em: 17/06/2013.

MEHROTRA, S. Introducing Conditional Cash Transfers in India: A Proposal for Five CCTs. Nova Délhi: Governo da Índia, Comissão de Planejamento. 2010. 31p.

MEIJERS, J. M. M.; VAN BOKHORST-DE VAN DER SCHUEREN, M. A. E.; SCHOLS, J. M. G. A.; SOETERS, P. B.; HALFENS, R. J. G.; Defining malnutrition: Mission or mission impossible? Nutrition, Amsterdam, v. 26, n. 4, p. 432-440, 2010.

MENON, P.; DEOLALIKAR, A.; BHASKAR, A. India State Hunger Index - Comparisons Across States. Washington, D.C.; Bonn; Riverside: IFPRI, Welt Hunger Hilfe, University of California Riverside. 2009. 36p.

MERNIES, J. Measurement of Food Deprivation. Roma: FAO Statistics Division. 2004. 9p.

MEYER, W. S.; BURN, R.; COTTON, J. S.; RISLEY, H. H. The Imperial Gazetteer of India. Oxford, Reino Unido: Clarendon Press. 1907.

MICHAELRAJ, P. S. J.; SHANMUGAM, A. A study on millets based cultivation and consumption in India. International Journal of Marketing, Financial Services \& Management Research, Nova Délhi, v. 2, n. 4, p. 49-58, 2013.

MILLENNIUM ECOSYSTEM ASSESSMENT. Ecosystems and Human Well-being: Synthesis. Washington, DC: Island Press. 2005.

MILLER, C.; SABIN, L.; WASHINGTON, R. G; CUNNINGHAM, T.; ASHOKANAND, H. S.; GARADY, L. A Qualitative Assessment of the Karnataka Cash Transfer. Phase III Report: Early Impacts of the Karnataka Cash Transfer on Children and Families.

Washington, D.C.; Boston: The USAID, Project SEARCH, Orphans and Vulnerable Children Comprehensive Action Research (OVC-CARE). 2012. 55p.

MISHRA, B. Economics of Public Distribution System in Food-grains. Nova Delhi: Ashish Publishing House. 1985.

MITRA, A. Social capital, livelihood and upward mobility. Habitat International, Amsterdam, v. 32, n. 2, p. 261-269, 2008.

MITRA, S. K. Politics in India: structure, process and policy. Nova York: Routledge. 2011.

MITTAL, A. Food Price Crisis: Rethinking Food Security Policies. G24 Technical Group Meeting. Genebra: Nações Unidas, Intergovernmental Group of Twenty-Four. 2008. 32 p.

MOHANTY, S.; PETERSON, E. W. Food Security and government intervention. In: AZZAM, A. (ed.). Encyclopedia of Life Support Systems (EOLSS). Oxford, UK: EOLSS Publishers. 2009. cap. 1, p. 1-5.

Food security and government interventions a study of indian grain markets. Oxford, Reino Unido: Journal of International Trade \& Economic Development, v. 14, n. 3., p. 337-352. 2005.

MOITRA, S. Are anganwadis simply crèches for the underprivileged? DNA - Daily News and Analysis, Mumbai, 31 maio 2014. Disponível em:

$<\mathrm{http}: / /$ www.dnaindia.com/analysis/standpoint-are-anganwadis-simply-cr-ches-for-theunderprivileged-1992595>. Acesso: 08/10/2014. 
MOOIJ, J. The political economy of the Public Distribution System in India. Journal of Peasant Studies, Londres, v. 25, n. 2, p. 77-101, 1998.

MORRIS, J. The uses of Epidemiology. 3. ed. Edinburgh: Churchill Livingstone. 1975.

MORSE, S.; MCNAMARA, N.; ACHOLO, M. Sustainable Livelihood Approach: A critical analysis of theory and practice. Geographical Paper No. 189. Reading: The University of Reading. 2009. 68p.

MUKHERJEE, J. Hungry Bengal: War, Famine, Riots, and the End of Empire, 1939-1946. 2011. Tese (Doutorado em Antropologia e História) - Universidade de Michigan, Ann Arbor, Estados Unidos.

MUNGER, M. Political science and public choice. In: REKSULAK, M.; RAZZOLINI, L.; SHUGHART II, W. F. (Eds.). The Elgar Companion to Public Choice. Cheltenham, UK: Edward Elgar Publishing Limited. 2013. cap. 3, p. 39-56.

MURPHY, K. The social pillar of sustainable development: a literature review and framework for policy analysis. Sustainability: Science, Practice, \& Policy, Bethesda, v. 8, n. 1, p. 629. 2012.

National Academy of Agricultural Sciences - NAAS. Fighting Child Malnutrition. Policy Paper No. 55. Nova Délhi: National Academy of Agricultural Sciences. 2012. 26p.

NATIONAL BANK FOR AGRICULTURE AND RURAL DEVELOPMENT - NABARD. Warehousing in Karnataka: assessment of gap and potential (2014). Mumbai e Bangalore: NABARD. 2013. 8p.

NAIKEN, L. The Probability Distribution Framework for Estimating the Prevalence of Undernourishment: Exploding the Myth of the Bivariate Distribution. Working Paper Series No ESS/ESSG/009e. Roma: FAO Statistics Division. 2007. 53p. Disponível em: $<$ http://www.fao.org/fileadmin/templates/ess/documents/food_security_statistics/working_pap er_series/WP009e.pdf>. Acesso: 02/03/2014.

NANDA, S.; SURESH, S. Demystifying the Poverty "Line": Political Economy of "Working out" the Poverty Line in India. Working Paper. Bangalore: Public Affairs Centre. 2012. 12p.

NARANG, T. No bonus over MSP directive aims at overhaul of India Grain Sector. Oryza, 22 julho 2014. Disponível em: <http://www.oryza.com/op-ed/no-bonus-over-msp-directive-aimsoverhaul-india-grain-sector>. 02/10/2014.

NATIONAL RAINFED AREA AUTHORITY. CEO's Message - 2013. Disponível em: <http://nraa.gov.in/>. Acesso: 26/09/2014.

Challenges of Food Security and its Management. Position Paper n. 5. Nova Délhi: National Rainfed Area Authority. 2011. 55p.

NATIONAL COMMISSION FOR EMPLOYMENT IN UNORGANISED SECTOR - (NCEUS). Report on Conditions of Work and Promotion of Livelihoods in the Unorganised Sector. Nova Délhi: Governo da Índia, NCEUS. 2007. 394p.

NATIONAL SAMPLE SURVEY ORGANISATION - NSSO. Nutritional intake in India 200405. Report 513 (61/1.0/6). Nova Délhi: Ministério de Estatística e Implementação de Programas, Governo da Índia. Mimeo. 2007. 366p. 
Utilization of public distribution system, 42nd round (July 1986-June 1987). No. 362. Nova Délhi: Ministério de Estatística e Implementação de Programas, Governo da Índia. 1989.

NAWANI, N. P. Indian experience on household food and nutrition security. Roma: FAO. Regional Expert Consultation, FAD-UN, Bangkok. 1994. [online]. Disponível em: <http://www.fao.org/docrep/x0172e/x0172e06.htm>. Acesso: 18/07/2014.

NAYAR, B. R. Globalization and Nationalism: The Changing Balance Of India's Economic Policy, 1950-2000. New Delhi: Sage, 2001.

NAYAR, B. S. The History of Food Security Policy in India with reference to Orissa and Kalahandi: An Integrated and Universal Approach towards PDS. In: NAYAK, B. S. (ed). Nationalizing Crisis: The Political Economy of Public Policy in Contemporary India. Atlantic Publishers \& Distributors: Nova Delhi. 2007. cap. 4, p. 70-100.

NAYLOR, R. L. Managing food production systems for resilience. In: CHAPIN, F.S.; KOFINAS, G. P.; FOLKE, C. (Eds.). Principles of Natural Resource Stewardship: Resilience-Based Management in a Changing World. Springer: Nova York. 2008. cap. 12, 259-280.

NEOGY, S. Gender inequality, mothers' health, and unequal distribution of food: experience from a CARE project in India. Gender \& Development. Londres, v. 18, n. 3, p. 479-489, 2010.

NEW DELHI TELEVISION - NDTV. Now, grain drain in Karnataka. NDTV. Nova Délhi, 4 setembro 2010. Disponível em: <http://www.ndtv.com/article/india/now-grain-drain-inkarnataka-49448>. Acesso: 16/10/2014.

NUBÉ, M. Food energy deficiency, child malnutrition and low body mass index (BMI) in adults: differences and anomalies between Africa and Asia. In: FAO - INTERNATIONAL SCIENTIFIC SYMPOSIUM MEASUREMENT AND ASSESSMENT OF FOOD

DEPRIVATION AND UNDERNUTRITION. 2002, Roma. Anais... Roma: FAO, 2003.

Disponível em: <http://www.fao.org/docrep/005/Y4249E/y4249e0h.htm>. Acesso:

01/03/2014.

OECD. Development Co-operation Report 2001. Paris: OECD Publishing. 2002. 300p.

OECD Framework for Statistics on the Distribution of Household Income, Consumption and Wealth. Paris: OECD Publishing. 2013. 236p. Disponível em: <http://dx.doi.org/10.1787/9789264194830-en>. Acesso: 21/02/2014.

Measuring Sustainable Development: Report on the Joint UNECE/OECD/Eurostat Working Group on Statistics for Sustainable Development. Nova York, Genebra: United Nations. 2009. 114p.

OJHA, G. D. Organisation and Management of Public Distribution System. Nova Délhi: Mittal Publications. 1987.

OLSON, C. Food Insecurity in Poor Rural Families with Children: A Human Capital Perspective. Policy Brief Rural 'Families Speak Project'. Ithaca: Projeto da Divisão de Ciências Nutricionais da Universidade de Cornell. 2006. 3p.

O'NEILL, Onora. Faces of Hunger: An Essay on Poverty, Justice, and Development. Sidney: Allen and Unwin, 1986. 
ONYANGO, A. W. Dietary diversity, child nutrition and health in contemporary African communities. Comp Biochem Physiol A Mol Integr Physiology, Amsterdam, v. 136, n. 1, p. 61-69, 2003.

ORGANIZAÇÃO DAS NAÇÕES UNIDAS. Pacto Internacional sobre os Direitos Econômicos, Sociais e Culturais, adotado em 16 de dezembro de 1966, Resolução da Assembleia Geral 2200 (XXI), 21 UN GAOR Supp. (No. 16) at 49, UN Doc. A/6316 (1966), 993 UNTS 3, em vigor no sistema internacional a partir de 3 Jan. 1976. Disponível em:

http://www.unfpa.org.br/Arquivos/pacto_internacional.pdf. Acesso em: 28/05/2013.

Report of the World Food Conference. Roma; Nova York:

Organização das Nações Unidas. 1974. 9p.

Declaração Universal sobre a Erradicação da Fome e Desnutrição.

Roma: Conferência Mundial de Alimentação. ONU. 1974. 3p.

World Economic and Social Survey 2013: Sustainable Development Challenges. Nova York: United Nations - Department of Economic and Social Affairs. 2013. 216p.

ORGANIZAÇÃO DAS NAÇÕES UNIDAS PARA ALIMENTAÇÃO E AGRICULTURA (FAO). FAO methodology for the measurement of food deprivation: updating the minimum dietary energy requirements. Roma: FAO Statistics Division. 2008. 16p. Disponível em: http://www.fao.org/fileadmin/templates/ess/documents/food_security_statistics/metadata/und ernourishment_methodology.pdf>. Acesso: 28/02/2014.

Politique de sécurité alimentaire: Formulation et mise en oeuvre. Curso, anotações do aluno, lição 1. CTA EU FAO GRET. 2009.

Food Security. FAO Policy Brief no. 2. Roma: FAO. 2006. 4p.

Top-Down and Bottom-Up Approaches. Policy Brief 9. Roma: Climate, Energy and Tenure Division, Natural Resources Management and Environment Department. 2007. $5 p$.

. L'accord sur l'agriculture (OMC): bilan de sa mise en oeuvre. Études de cas sur des pays en développement. Roma, Itália: FAO. 2004.

. Methodology for the Measurement of Food Deprivation. FAO: Roma. 2003.

. Declaração de Roma Sobre a Segurança Alimentar Mundial e Plano de Acção da Cimeira Mundial da Alimentação. Roma: FAO. 1996.

. The State of Food Insecurity in the World 2012. Economic growth is necessary but not sufficient to accelerate reduction of hunger. Roma: FAO. 2012. 65p.

. The State of Food Insecurity in the World 2013. Roma: FAO. 2013. 56p.

Price Volatility in Food and Agricultural Markets: Policy Responses. Roma: FAO, IFAD, IMF,OECD, UNCTAD, WFP, the World Bank, the WTO, IFPRI and the UN HLTF. 2011. 68p.

Food Security Concepts and Frameworks: Concepts Related to Food Security Learner's Notes. Food Security Information for Action. 2008. 
Calories availability. Roma: FAO. 2002. 2p. Disponível em:

$<$ http://www.fao.org/gtos/tems/resources/socioeco/Calories_availability.pdf>. Acesso: $16 / 02 / 2014$.

Food Security indicators. Roma: FAO. Disponível em:

<http://www.fao.org/economic/ess/ess-fs/fs-data/en/\#.U0Jm6k2KDIU>. Acesso: 28/02/2014.

OSEI, A.; PANDEY, P; SPIRO, D.; NIELSON, J.; SHRESTHA, R.; TALUKDER, Z.; QUINN, V.; HASELOW, N. Household Food Insecurity and Nutritional Status of Children Aged 6 to 23 Months in Kailali District of Nepal. Food and Nutrition Bulletin, Boston, v. 31, n. 4, p. 483494, 2010.

OSTROM, V.; OSTROM, E. Public goods and public choices. In: SAVAS, E.S. (Ed.). Alternatives for delivering public services: towards improved performance. Boulder, Westview Press. 1977. cap. 1, p. 7-49.

OTERO, G. ; PECHLANER, G.; GÜRCAN, E. F. The Political Economy of "Food Security" and Trade: Uneven and Combined Dependency. Rural Sociology, Nova York, v. 78, n. 3, p. 263-289. 2013.

OXFAM INTERNATIONAL. Double-edged prices. Oxfam Briefing Paper 121. Oxford, Reino Unido: 2008. 47p. Disponível em: <http://www.oxfam.org/sites/www.oxfam.org/files/bp121double-edged-prices-lessons-from-food-price-crisis-0810>.pdf. Acesso: 26/07/2013.

PAL, B. Organization and Working of Public Distribution System in India: A Critical Analysis. Research on Humanities and Social Sciences, v. 1, n. 1, p. 4-8, 2011.

PAM-ONU. United Nations in Índia. Disponível em: <http://in.one.un.org/page/where-wework>. Acesso: 23/09/2014.

. WFP Innovating with Índia. Nova Délhi: World Food Programme. 2014a. 6p.

Disponível em:

<http://documents.wfp.org/stellent/groups/public/documents/newsroom/wfp261708.pdf>. Acesso: 10/10/2014.

. WFP India Partners With State Government Of Kerala To Improve Targeted Public Distribution System. World Food Programme, News, 26 fevereiro 2014b. Disponível em: $<$ https://www.wfp.org/news/news-release/india-wfp-partners-state-government-keralatargeted-public-distribution-system-ref>. Acesso: 13/10/2014.

PANAGARYA, A.; MUKIM, M. A Comprehensive Analysis of Poverty in India. Working Paper No. 2013-01. Nova York, Columbia University: SIPA - School of International and Public Affairs, ISERP - Institute for Social and Economic Research and Policy Program on Indian Economic Policies. 2013. 74p.

PAPPAS, E. A New Systems Approach to Sustainability: University Responsibility for Teaching Sustainability in Contexts. Journal of Sustainability Education, Tucson, v. 3, 2012. [online]. Disponível em: <http://www.jsedimensions.org/wordpress/wpcontent/uploads/2012/03/PappasJSE2012.pdf>. Acesso: 6/09/2014.

PARASHAR, P. N. History and Problems of Civil Services in India. Volume 3. Nova Délhi: Sarup \& Sons.

PATNAIK, U. On some fatal fallacies. Economic and Political Weekly, Mumbai, v. 55, n. 47, p. 81-87. 2010. 
PELLETIER, D. L. Toward a Common Understanding of Malnutrition Assessing the Contributions of the UNICEF Framework. Background Papers. Washington, DC: World Bank/UNICEF Nutrition Assessment. 2002. 29p.

PELLETIER, D. L.; DENEKE, K.; KIDANE, Y; HAILE, B.; NEGUSSIE, F. The Food-First Bias and Nutrition Policy: Lessons from Ethiopia. Food Policy, Amsterdam, v. 20, n. 4, p. 279298. 2005.

PEREIRA, P. T. A teoria da escolha pública (public choice): uma abordagem neoliberal? Análise Social, Lisboa, v. 32, n. 141, p. 419-442. 1997.

PETZEL, T. E. Testimony before the U.S. Commodity Futures Trade Commission, July 28, 2009. Washington, DC: United States Commodity Futures Commission, 2009. 36p.

PHILLIPS, Ralph W. FAO: its origins, formation and evolution 1945-1981. Organização das Nações Unidas para Alimentação e Agricultura (FAO). Roma: Itália. 1981.

PIESSE, J.; Thirtle, C. Three bubbles and a panic: An explanatory review of recent food commodity price events. Food Policy, Amsterdam, v. 34, p. 119-129. 2009.

PIETERS, H.; VANDEPLAS, A. GUARISO, A.; FRANCKEN, N.; SARRIS, A.; SWINNEN, J.; GERBER, N.; von BRAUN, J.; TORERO, M. Perspectives on relevant concepts related to food and nutrition security. Working paper 1. Haia: Foodsecure, 2012, 30p.

PINDYCK, R. S.; RUBINFELD, D. L. Microeconomia. 6. ed. São Paulo: Pearson Education do Brasil. 2006.

PISANO, U. Resilience and Sustainable Development: Theory of resilience, systems thinking and adaptive governance. Report 26. Viena: European Sustainable Development Network Quarterly, 2012, 46p.

Poirier, B. A Conceptual Guide to Thermodynamics. Chichester, Reino Unido: John Wiley \& Sons, Ltd. 2014.

PRABHU, K. S. Conditional Cash Transfer Schemes for Alleviating Human Poverty:

Relevance for Índia. Discusssion Paper. Nova Délhi: Bureau of Development Policy, United Nations Development Programme (UNDP), 2009, 50p.

PRABHU, N. PDS trucks to go yellow in State. The Hindu, Bangalore, 7 agosto 2010. Disponível em: <http://www.thehindu.com/todays-paper/tp-national/tp-karnataka/pds-trucksto-go-yellow-in-state/article556902.ece>. Acesso: 17/10/2014.

PRITCHARD, B; RAMMOHAN, A.; SEKHER, M.; PARASURAMAN, S.; CHOITHANI, C. To Feed India, to Feed the World: Livelihoods, Entitlements and Capabilities. Londres:

Earthscan - Routledge. 2013.

PURI, R. Reforming the Public Distribution System: Lessons from Chhattisgarh. Economic \& Political Weekly, Mumbai, v. 47, n. 5, p. 21-23. 2012.

PYE, S. T.; SKINNER, I.; MEYER-OHLENDORF, N.; LEIPPRAND, A.; LUCAS, K.; SALMONS, R. Addressing the social dimensions of environmental policy - A study on the linkages between environmental and social sustainability in Europe. Relatório. Bruxelas: European Commission, Directorate-General for Employment, Social Affairs and Equal Opportunities, Unit for Social and Demographic Analysis, 2008, 50p. 
QAYYUM, A; AHMAD, M. Efficiency and Sustainability of Micro Finance Institutions in South Asia. Paper No. 11674. Munique: Personal RePEc Archive, 2006, 38p.

RADDATZ, C. Over the Hedge: Exchange Rate Volatility, Commodity Price Correlations, and the Structure of Trade. Working Paper 5590. Washington, DC: Banco Mundial, 2011, 48p.

RADHAKRISHNA, R.; SUBBARAO, K. India's Public Distribution System: A National and International Perspective. Discussion Paper No. 380. Washington, DC: Banco Mundial, $1997,117 p$.

RAMAKRISHNAN, T. NFSA implementation may hit a roadblock in Tamil Nadu. The Hindu, Chennai, 6 julho 2014. National. Disponível em:

$<$ http://www.thehindu.com/news/national/tamil-nadu/nfsa-implementation-may-hit-aroadblock-in-tamil-nadu/article6181450.ece>. Acesso: 27/09/2014.

RANA, M. S. Reservations in India: myths and realities. Nova Délhi: Concept Publishing Company. 2008.

RAO, C. H. H. (Ed.). Agriculture, food security, poverty, and environment: essays on post-reform India. Oxford University Press. 2005.

RAO, W. M. Wheat Story: Recent Changes in Price Policy. Economic and Political Weekly, Mumbai, v. 28, n. 44, p. 2385-2386. 1993.

RAUSSER, G. C. Political economic markets: PESTs and PERTs in food and agriculture. American Journal of Agricultural Economics, Oxford, Reino Unido, v. 64, p. 821-833. 1982.

Predatory Versus Productive Government: The Case of U.S. Agricultural Policies. The Journal of Economic Perspectives, Nashville, v. 6, n. 3, p. 133-157, 1992.

RAUSSER, G. C.; SWINNEN, J.; ZUSMAN, P. Political Power and Economic Policy: Theory, Analysis, and Empirical Applications. New York: Cambridge University Press. 2011.

RAUSSER, G. C.; GOODHUE, R. E. Public Policy: Its many analytical dimensions. In: GARDNER, B.; RAUSSER, G. (Eds.). Handbook of Agricultural Economics. Volume 2. Amsterdam: Science B.V: 2002. cap. 39, p. 2058-2080.

RAVALLION, M. The Debate on Globalization, Poverty and Inequality: Why Measurement Matters. International Affairs, Londres, v. 79, n. 4, p. 739-753, 2003.

RAVALLION, M. Poverty Lines in Theory and Practice. Living Standards Measurement Study. Working Paper n. 133. Washington, DC: World Bank. 1998. 24p.

RAY, S.; RAY, I. A. Role and Effectiveness of Public Distribution System in Assuring Food Security in India: An Appraisal. Journal of Economics and Sustainable Development, Nova York, v. 2, n. 4, p., 238-251, 2011.

REDCLIFT, M. The Multiple Dimensions of Sustainable Development. Geography, v. 76, n.1, p. 36-42, 1991.

REZITIS, A. N.; SASSI, M. Commodity Food Prices: Review and Empirics. Economics Research International, Cairo, v. 2013, p. 1-15, 2013. 
RIBEIRO, A. C. T.; EGLER, T. T. C.; SÁNCHEZ, F. (Orgs.). Política governamental e ação social no espaço. Rio de Janeiro: Letra Capital Editora Ltda. 2013.

RICCI, P. The content of Brazilian legislative output: national laws or pork barrel politics?

Dados - Revista de Ciências Sociais, Rio de Janeiro, v. 46, n.4, p. 699-734, 2003.

RICE, Amy L; SACCO, Lisa; HYDER, Adnan; BLACK, Robert E. Malnutrition as an underlying cause of childhood deaths associated with infectious diseases in developing countries. Bull World Health Organ [online], Genebra, v.78, n.10, p. 1207-1221, 2000. Disponível em: <http://www.scielosp.org/pdf/bwho/v78n10/78n10a07>.pdf. Acesso em: 08/07/2012.

RICKLEFS, R. The Economy of Nature. 6. ed. New York: W. H. Freeman and Company. 2008.

RIEFF, D. Jagdish Bhagwati and Amartya Sen's disputes are far more consequential than most academic dustups. The National Interest. Washington, DC, 4 setembro 2013. [online]. Disponível em: <http://nationalinterest.org/commentary/battle-the-soul-india8993?page=show $>$. Acesso: 17/11/2014.

RIELY, F.; MOCK. N.; COGILL, B.; BAILEY, L.; KENEFICK, E. Food Security Indicators and Framework for Use in the Monitoring and doEvaluation of Food Aid Programs. Washington, D.C.: Food and Nutrition Technical Assistance Project (FANTA), USAID. 1999.

RIFKIN, J. Entropy: into the greenhouse world. Nova York: Bantam Books. 1989.

The Age of Access: The New Culture of Hypercapitalism, Where All of Life Is a Paid-Fo Experience. New York: Jeremy P. Tarcher/Putnam, 2000.

RISSMILLER, K. Approaching a Model of Policy Change: A Challenge to Political Science. In: EIGHTEENTH INTERNATIONAL CONFERENCE OF THE SYSTEM DYNAMICS SOCIETY, 2000, Bergen, Noroega. Anais... Bergen, Noroega: SDS, 2000.

ROSEN, S.; PETERS, M.; SHAPOURI, S. International Food Security Assessment, 2010 Update: Improved Production Mitigated Impact of Higher Food Commodity Prices. Outlook Report GFA-21-01. Washington, DC: United States Department of Agriculture, Economic Research Service. 2011. 13p.

ROSER, M. Hunger and Undernourishment. Explaining Progress. 2014. Disponível em: <http://www.explainingprogress.com/data/food-agriculture/hunger-and-undernourishment/>. Acesso: 17/04/2014.

ROSS, A.; DOVERS, S. Making the harder yards: environmental policy integration in Australia. The Australian Journal of Public Administration, Sidney, v. 67, n. 3, p. 245260, 2008.

ROUQUAYROL, M.Z.; ALMEIDA FILHO, N. Epidemiologia \& Saúde. 6. ed. Rio de Janeiro: MEDSI, Guanabara Koogan. 2003.

ROY, D.; SEN, M. Final Report on Poverty, Hunger and Public Action: An Empirical Study of on-going Decentralisation Initiatives in West Bengal. Relatório. Cálcuta: Loka Kalyan Parishad / Planning Commission, Government of India. 2010. 98p.

ROY, T. A delayed revolution: environment and agrarian change in India. Oxford Review of Economic Policy, Oxford, Reino Unido, v. 23, n. 2, p. 239-250, 2007. 
RUBINSTEIN, A. Afterword. In: NEUMANN, J. V.; MORGENSTERN, O. Theory of Games and Economic Behavior. Princeton: Princeton University Press. [1944] 2004. Posfácio, p. 633-636.

RUEL, M. T. Operationalizing Dietary Diversity: A Review of Measurement Issues and Research Priorities. Journal of Nutrition, Bethesda, v. 133, n. 11, p. S-3911, S-3926, 2003.

RUSSELL, S. A. HUNGER: An Unnatural History. New York: Basic Books. 2005.

SABOURIN, E. Camponeses do Brasil: entre a troca mercantil e a reciprocidade. Rio de Janeiro: Garamond. 2009.

SAINI, S.; KOZICKA, M. Evolution and Critique of Buffer Stocking Policy of India. Working Paper 283. Nova Délhi: Indian Council for Research on International Economic Relations. 2014. 54p.

SARAIVA, E. B.; SILVA, A. P. F; SOUSA, A. A. S.; CERQUEIRA, G. F.; CHAGAS, C. M. S.; TORAL, N. Panorama da compra de alimentos da agricultura familiar para o Programa

Nacional de Alimentação Escolar. Ciência \& Saúde Coletiva, Rio de Janeiro, v. 18, n. 4, p. 927-936, 2013.

SCHUFTAN, Claudio. The Causes of Hunger and Malnutrition: Macro and Micro

Determinants. In: LATHAM, M. C.; BONDESTAM, L.; CHORLTON, R.; JONSSON, U. (Eds.). Hunger and Society. Vol.1. Ithaca, N.Y: Division of Nutritional Sciences, College of Agriculture and Life Sciences, Cornell University, 1988. cap. 3, p. 33-46.

SCOLARI, D. D. G. Produção agrícola mundial: o potencial do Brasil. In: SCOLARI, D. D. G. (Ed.). Visão Progressista do Agronegócio Brasileiro. Brasília, DF: Fundação Milton Campos, 2006. cap.

SEGALL-CORRÊA, A. M.; MARIN-LEON, L.; HELITO, H.; PÉREZ-ESCAMILLA, R.; SANTOS, L. M. P.; PAES-SOUSA, R. Transferência de renda e segurança alimentar no Brasil: análise dos dados nacionais. Revista de Nutrição, Campinas, v. 21 (Suplemento), p. 39-51, 2008.

SEN, A. Ingredients of Famine Analysis: Availability and Entitlements. The Quarterly Journal of Economics, Harvard, v. 96, n. 3, p. 433-464, 1981.

SEN, A.; DRÈZE, J. Hunger and Public Action. Oxford: Clarendon Press, 1989.

SEN, Amartya. Poverty and Famines: An Essay on Entitlement and Deprivation. Oxford: Oxford University Press, 1982.

Resources, Values and Development. Oxford: Basil Blackwell: 1984.

SHANKAR, K. Revamped Public Distribution System-Who Benefits and How Much.

Economic and Political Weekly, Mumbai, v. 32, n. 13, p. 629-630, 1997.

SHANKAR, M. Agriculture India: looking beyond wheat and rice. Inter Press Service, Roma [online]. 2009. Disponível em: <http://www.ipsnews.net/2009/02/agriculture-india-lookingbeyond-wheat-and-rice/>. Acesso: 26/09/2014.

SHARMA, B. K. Introduction to the Constitution of Índia. Nova Délhi: PHI Learning Pvt. Ltd. 2007. 
SHARMA, K. Hunger games. The Hindu, Chennai, 25 outubro 2014. Disponível em: $<$ http://www.thehindu.com/opinion/columns/Kalpana_Sharma/the-other-half-kalpana-sharmawrites-on-child-hunger-index/article6532919.ece?homepage=true\&artlist=true>. $\quad$ Acesso: 26/10/2014.

SHARMA, R. Food Export Restrictions: Review of the 2007-2010 Experience and Considerations for Disciplining Restrictive Measures. Working Papers No. 32. Roma: FAO Commodity and Trade Policy Research. Trade and Markets Division of the Food and Agriculture Organization of the United Nations (FAO). 2011. 32p.

SHARMA, V. P. Food Subsidy in India: Trends, Causes and Policy Reform Options. Working Paper n. 2012-08-02. Ahmedabad, Índia: Centre for Management in Agriculture, Indian Institute of Management. 2012. 41p.

SHAW, D. John. Global Food and Agricultural Institutions. Nova York: Routledge. 2009.

SHIVA, V.; JALEES, K. Farmers Suicides in India. Nova Délhi: Research Foundation for Science, Technology and Ecology. 2005.

SINGH, H.; SEN, Abhijit. Why Not a Universal Food Security Legislation. Economic \& Political Weekly, v. 46, n. 12, p. 38-47. 2011.

SINHA, D. Why the NFSA Will Not Ensure Nutrition Security. Policy brief series n. 15. Nova Délhi: Centre for Legislative Research and Advocacy (CLRA). 2012. 6p.

SKOUFIAS, E.; TIWARI, S.; ZAMAN, H. Can We Rely on Cash Transfers to Protect Dietary Diversity during Food Crises? Estimates from Indonesia. Policy Research Working Paper, n. 5548. Washington, DC: World Bank, 2011. 38p.

SMITH, L. C. The Great Indian Calorie Debate: Explaining Rising Undernourishment during India's Rapid Economic Growth. Working Paper 430. Brighton: Institute of Development Studies - IDS. 2013. 35p.

SMITH, L. C.; HADDAD, L. J. Overcoming Child Malnutrition in Developing Countries: Past Achievements and Future Choices. Washington, D.C.: International Food Policy Research Institute. 2000.

SMITH, L. C.; HADDAD, L. J. Explaining Child Malnutrition in Developing Countries: A Cross-Country Analysis. Discussion Paper No. 60. Food Consumption and Nutrition Division, International Food Policy Research Institute. Washington, D.C. 1999. 115p.

SMITH, L. C.; SUBANDORO, A. Measuring Food Security Using Household Expenditure Surveys. Food Security in Practice technical guide series. Washington, D.C.: International Food Policy Research Institute. 2007.

SOBEL, R. S.; PELLILLO, A. The Politics of elections and congressional oversight. In: REKSULAK, M.; RAZZOLINI, L.; SHUGHART II, W. F. (Eds.). The Elgar Companion to Public Choice. Cheltenham, UK: Edward Elgar Publishing Limited. 2013. cap. 13, p. 217232.

SOOHOO, C.; ALBISA, C. DAVIS, M.F. (eds.). Bringing Human Rights Home: A History of Human Rights in the United States. University of Pennsylvania Press. 2009 
SPANGENBERG, J. Economic sustainability of the economy: concepts and indicators. International Journal of Sustainable Development, Olney, Reino Unido, v. 8, n. 1-2, p. 4764, 2005.

STERN, N. Stern Review: The Economics of Climate Change, Executive Summary. NovaYork: Cambridge University Press. 2006.

SUPPAN, S. Commodities Market Speculation: The Risk to Food Security and Agriculture. Minneapolis, Minnesota: Institute for Agriculture and Trade Policy. 2008. 16p.

SVEDBERG, P. Undernutrition Overestimated. Economic Development and Cultural Change, Chicago, v. 51, n. 1, p. 5-36, 2002.

SUPREMA CORTE DA ÍNDIA. Writ Pertion (C) No.(s). 196 of 2001. People's Union for Civil Liberties versus Union of India \& ORS. Record of Proceedings. Nova Délhi: Governo da Índia. 2006. Disponível em: <http://pdscvc.nic.in/court\%20judgement.htm>. Acesso: 28/09/2014.

Unique Identification Auth.Of India \&Anr Petitioner(S) Versus Central Bureau Of Investigation Respondent(S). Record Of Proceedings. Nova Délhi: Governo da Índia. 2014. Disponível em: <http://courtnic.nic.in/supremecourt/temp/sr\%20252414p.txt>. Acesso: 05/10/2014.

Writ Pertion (C) No.(s). 196 of 2001. People's Union for Civil Liberties versus Union of India \& ORS. Item No. 205, Corte no. 10. Relatório. Nova Délhi: Governo da Î́ndia. 07/01/2013. Disponível em:

<http://supremecourtofindia.nic.in/outtoday/report_cvc17092012.pdf>. Acesso: 23/10/2014.

SWAMINATHAN, M. S. The crisis of Indian agriculture. The Hindu, Chennai, 15/08/2007, Independent India at 60. Disponível em:

<http://www.hindu.com/af/india60/stories/2007081550320900.htm >. Acesso: 26/06/2014.

SWAMINATHAN, M. S. Science and Sustainable Food Security: Selected Papers of M. S. Swaminathan. Londres: World Scientific Publishing Co. Pte. Ltd. 2010.

SWINDALE, A.; BILINSKY, P. Household Dietary Diversity Score (HDDS) for Measurement of Household Food Access: Indicator Guide. Version 2. Washington, DC: Food and Nutrition Technical Assistance (FANTA), Project of the United States Agency of International Development (USAID). 2006. 15p. Disponível em:

<http://www.fantaproject.org/sites/default/files/resources/HDDS_v2_Sep06_0.pdf >. Acesso: 22/03/2014.

TANSEY, G.; WORSLEY, T. The Food System. Londres: Earthscan Publications Ltd. 1995.

THOMPSON, B.; AMOROSO, L.; MEERMAN, J. Promoting the Expression "Food and Nutrition Security (FNS)": A strategy note from the Nutrition and Consumer Protection Division - AGN. Nota. Roma: FAO. 2009. 2p. Disponível em:

$<$ http://www.fao.org/fileadmin/user_upload/agn/pdf/Food_and_Nutrition_Security-

Strategy_Note.pdf>. Acesso: 28/02/2014.

THOMSON, A; METZ, Manfred. Implications of Economic Policy for Food Security: A Training Manual. Training materials for agricultural planning 40. Food and Agriculture Organization of the United Nations, Deutsche Gesellschaft für Technische Zusammenarbeit (GTZ). Roma, 1999. 298p. 
TIBURCIO, J. A. P. Mensurando um conceito. Sustentabilidade em Debate, Brasília, v. 2, n. 2, p. 189-192, 2011.

TILY, G. Keynes and the financing of public works expenditures. Heterodox Economics Newsletter, Nova York, n. 86, p. 1-17, 2009. [online]. Disponível em:

<http://www.heterodoxnews.com/htnf/htn87/Tily\%20Keynes.pdf>. Acesso: 06/08/2014.

TIMMER, C. P. Causes of High Food Prices. Working Paper n. 128. Manila: Asian Development Bank, 2008. 60p.

TIMMER, C. P. Behavioral dimensions of food security. Proceedings of the National Academy of Science, Washington, DC, v. 109, n. 31, p. 12315-12320, 2010. Disponível em: <http://www.pnas.org/content/109/31/12315.full.pdf>. Acesso: 29/03/2014.

TIMMER, C.P.; FALCON, W.; PEARSON, S. Food Policy Analysis. The Johns Hopkins University Press: Baltimore, Maryland.1983.

TURNER, R. K.; PEARCE, D. W.; BATEMAN, I. Environmental Economics: an Elementary Introduction. Baltimore: Johns Hopkins University Press. 1993.

TYAGI, D.S.; VYAS, V. S. (Eds.). Increasing access to food: the Asian experience. New Delhi; Newbury Park, California: Sage Publications, 1990.

TOLLISON, R. D. The Interest-Group Theory of Government. The Locke Luminary, v. 1, n. 1, p. 4, 1998.

TOMKINS, A.; WATSON, F. Malnutrition and Infection - A review. Discussion paper n. 5. Nova York: UNICEF, Nutrition policy, Administrative Committee on Coordination, Subcommittee on Nutrition (ACC/SCN). 1993. 114p.

TORLESSE, H; KIESS, L.; BLOEM, M. W. Association of Household Rice Expenditure with Child Nutritional Status Indicates a Role for Macroeconomic Food Policy in Combating Malnutrition. Journal of Nutrition, Bethesda, v. 133, n. 5, p. 1320-1325, 2003.

TORRES VITOLAS, C. A. Social capital in poor communities: a case study from rural northern Peru. 2011. Tese (Doutorado em Filosofia - PhD), The London School of Economics and Political Science (LSE), Londres.

TRITAH, A. The Public Distribution System in India: Counting the poor from making the poor count. Toulouse, França: Groupe de Recherche en Economie Mathématique et Quantitative - GREMAQ, Université des Sciences Sociales, 2003. 36p.

TROSTLE, R.; MARTI, D.; ROSEN, S.; WESTCOTT, P. Why have food commodity prices risen again? Relatório WRS-1103. Washington, DC: Economic Research Service, United States Department of Agriculture. 2011. 29p.

TULLOCK, G. The Welfare Costs of Tariffs, Monopolies and Theft. Western Economic Journal, Nova York, v. 5, n. 3, p. 224-232. 1967.

TULLOCK, G.; BRADY, G. L; SELDON, A. Government Failure: A Primer in Public Choice. Washington, D.C.: Cato Institute. 2002.

UNITED NATIONS CHILDREN'S FUND (UNICEF). Vitamin and Mineral Deficiency: A global damage assessment report. New York: United Nations Children's Fund. 2004. 7p. 

1991. 141p.

The State of the World's Children. Nova York: Oxford University Press/ UNICEF.

UNICEF; OMS. Normes de croissance OMS et identification de la malnutrition aiguë sévère chez l'enfant. Déclaration commune de l'Organisation mondiale de la santé et du Fond des Nations Unies pour l'Enfance. Nova York; Genebra: 2009. 12p.

UNITED NATIONS ENVIRONMENT PROGRAMME (UNEP). Avoiding Future Famines: Strengthening the Ecological Foundation of Food Security through Sustainable Food Systems. Nairobi: United Nations Environment Programme (UNEP). 2012. 78p.

Embedding the Environment in Sustainable Development Goals. Discussion Paper 1. Nairobi: UNEP Post-2015, United Nations Environment Programme. 2013. 38p.

VAISHNAV, M. The Demand for Criminal Politicians. South Asia Program Article. Oxford: Oxford India Policy Series, Carnegie Endowment for International Peace. 2013. 3p.

Disponível em: http://carnegieendowment.org/2013/05/01/demand-for-criminalpoliticians/gfol. Acesso: 11/10/2014.

VARGAS, M.; CHANTRY, O. Ploughing through the meanders in Food Speculation. Barcelona: Mundobat, Soberania Alimentaria and GRAIN, 2011. 31p.

VERNON, J. Hunger: A Modern History. Cambridge, Massachusetts; Londres: The Belknap Press of Harvard University Press. 2007.

VIAN, C. E. F. A "comoditização" do processo produtivo e o surgimento dos serviços agrícolas e não-agrícolas no meio rural. Sociedade e Desenvolvimento Rural, Brasília, v. 3, n. 1, p. 1-22, 2009.

WAKIMURA, K. Indian Economy and Disasters during the Late 19th Century: Problems of Interpretation on Colonial Economy. In: INDO-JAPANESE DIALOGUE ON 'THE BRICS AS REGIONAL ECONOMIC POWERS IN THE GLOBAL ECONOMY', 5, 2011, Nova Délhi. Anais... Nova Délhi: Jawaharlal Nehru University, 2011.

WAREHOUSING DEVELOPMENT AND REGULATORY AUTHORITY. Annual report. Nova Délhi: Governo da Î́ndia. 2013. 61p.

WEINGÄRTNER, L. The Concept of Food and Nutrition Security. Background Paper n. 1. International Training Course: Food and Nutrition Security - Assessment Instruments and Intervention Strategies. Bonn: GTZ/WHI/Inwent. 2004. 28p.

WEINGÄRTNER, L. The Concept of Food and Nutrition Security. In: KLENNERT, Klaus (Ed.). Achieving Food and Nutrition Security: Actions to Meet the Global Challenge. A Training Course Reader. Feldafing; Bonn: InWEnt - Internationale Weiterbildung gGmbH. 2009. cap. 1, p. 3-26.

WIKIMEDIA FOUNDATION, INC. Timeline of major famines in India during British rule. Disponível em:

<http://en.wikipedia.org/wiki/Timeline_of_major_famines_in_India_during_British_rule>. Acesso: 06/11/2014.

WILDAVSKY, A. Speaking truth to power. Boston: Little Brown. 1979.

WINKLER, D. R. Modelos: da teoria à prática. In: HEIDEMANN, F. G.; SALM, J. F. (Orgs.). Políticas públicas e desenvolvimento: bases epistemológicas e modelos de análise. Brasília (DF): Ed. UnB, 2009. cap. 3 (Comentário), p. 129-132. 
WORLD METEOROLOGICAL ORGANIZATION. The State of Greenhouse Gases in the Atmosphere Based on Global Observations through 2013. WMO Greenhouse Gas Bulletin. Genebra: World Meteorological Organization - Global Atmosphere Watch Programme. 8p. Disponível em:

$<$ https://www.wmo.int/pages/mediacentre/press_releases/documents/1002_GHG_Bulletin.pd f>. Acesso: 09/09/2014.

WRIGHT, B.D. The Economics of Grain Price Volatility. Applied Economic Perspectives and Policy, Milwaukee, WI, v. 33, n. 1, p. 32-58, 2011.

YADAV, A. Food Security Act beneficiaries yet to be identified. The Hindu. 15 setembro 2014. National. Disponível em: <http://www.thehindu.com/news/national/food-security-actbeneficiaries-yet-to-be-identified/article6410384.ece>. Acesso: 22/09/2014.

YANG, A. A. Bazaar India: Markets, Society, and the Colonial State in Bihar. Berkeley: University of California Press. 1998.

YU, C. H. Test-retest reliability. In: KEMPF-LEONARD, K. (Ed.). Encyclopedia of Social

Measurement. Vol. 3. San Diego, Califórnia: Academic Press. 2005, p. 777-784. 


\section{APÊNDICE}

A. REGISTROS FOTOGRÁFICOS DO PERÍODO NA ÍNDIA. Todos os registros são do arquivo pessoal do autor.

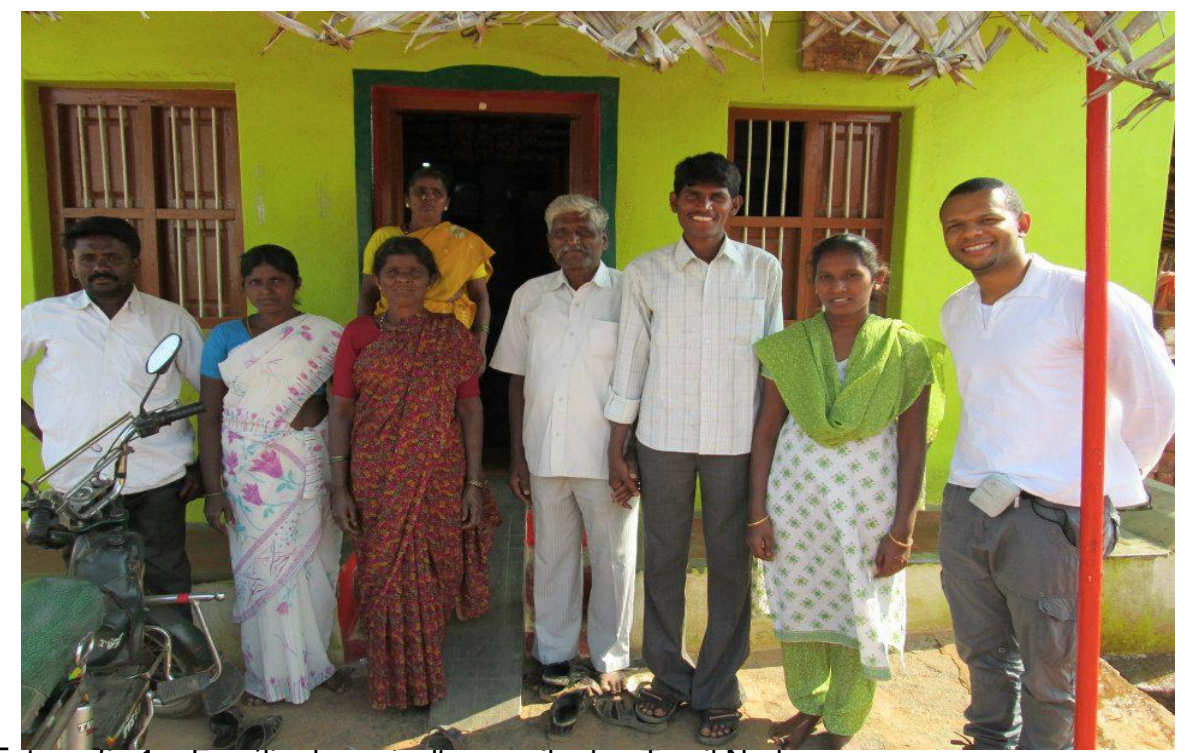

Fotogratia 1 -Familia de agricultores, vila de , Iamil Nadu.

Data: fevereiro de 2013

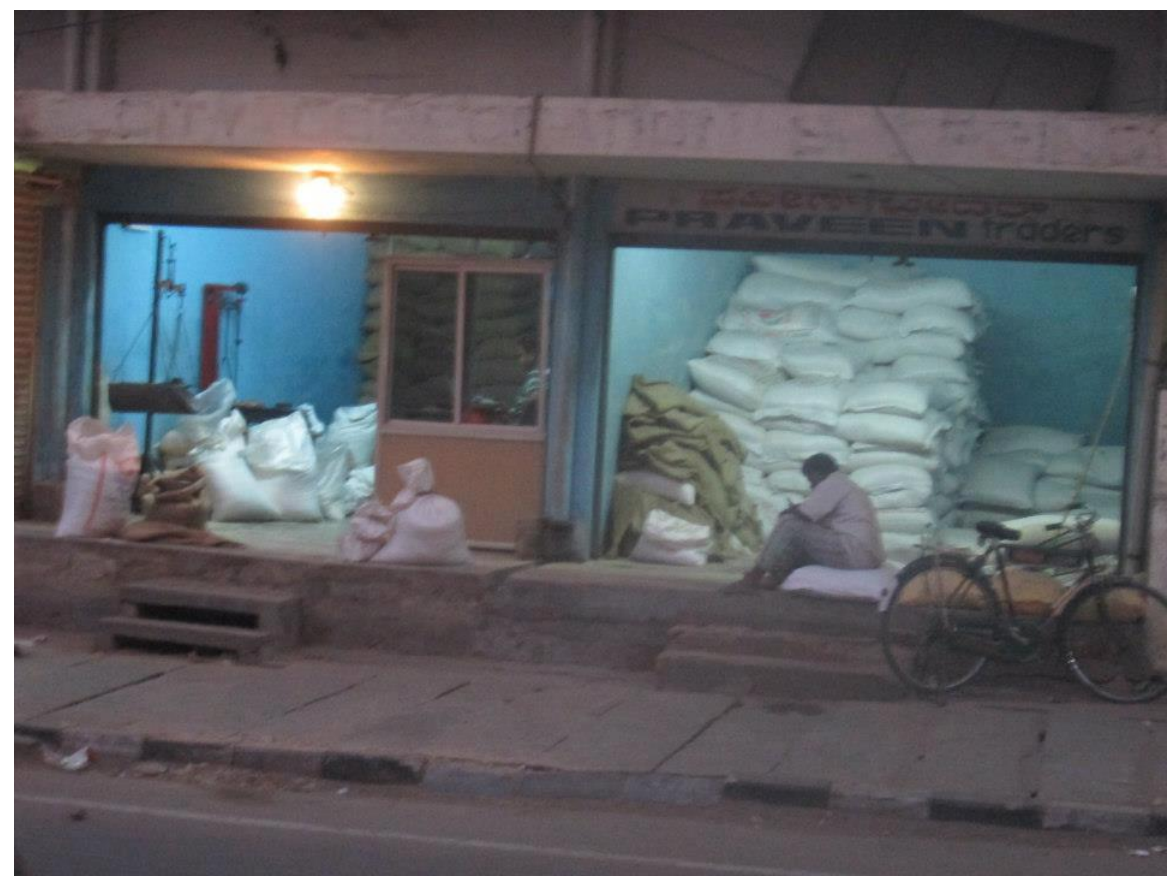

Fotografia 2 - loja de preço justo em Bangalore, estado de Karnataka Data da foto: fevereiro 20013 


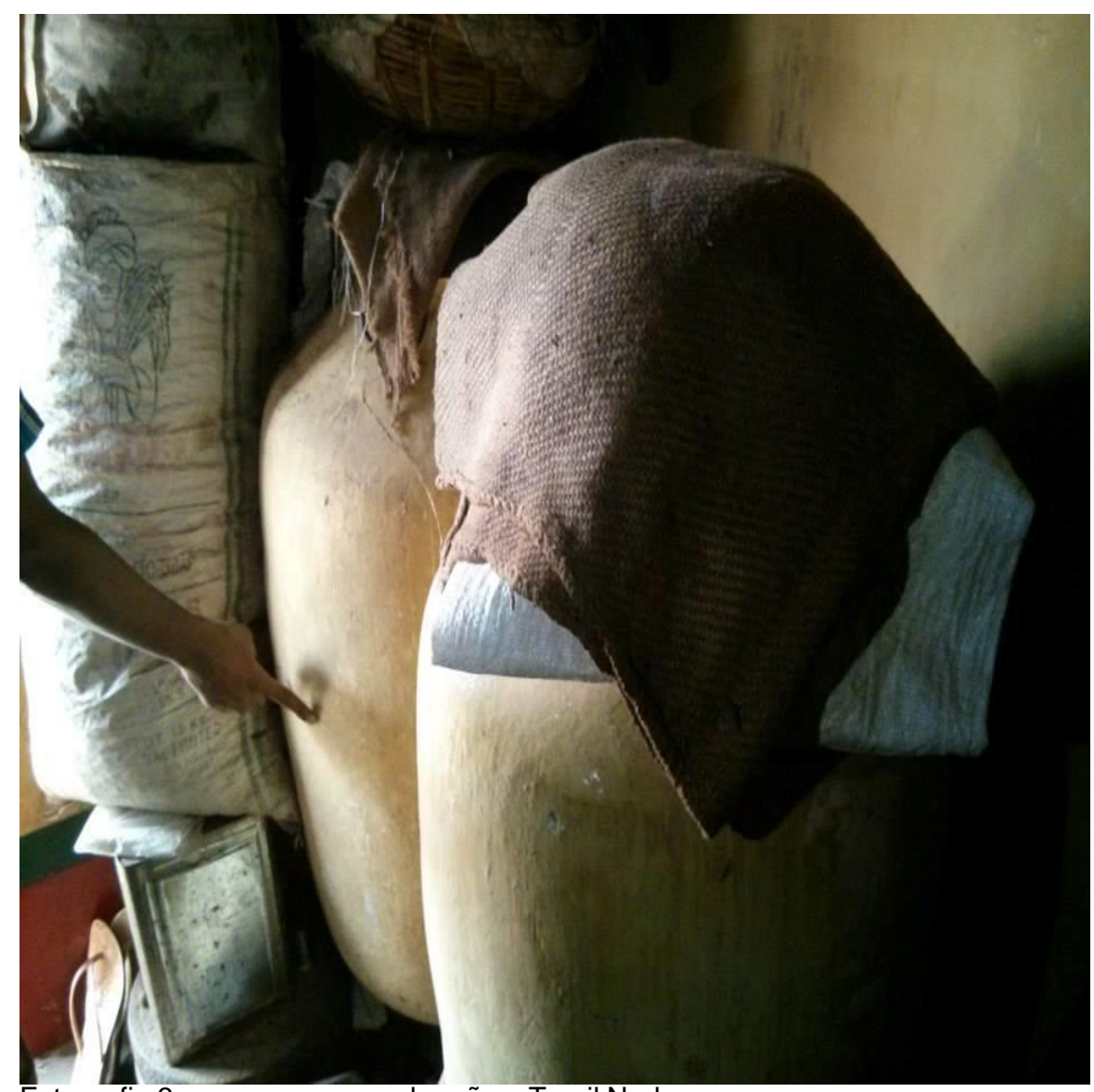

Fotografia 3 - armazenagem de grãos, Tamil Nadu

Data: agosto 2014

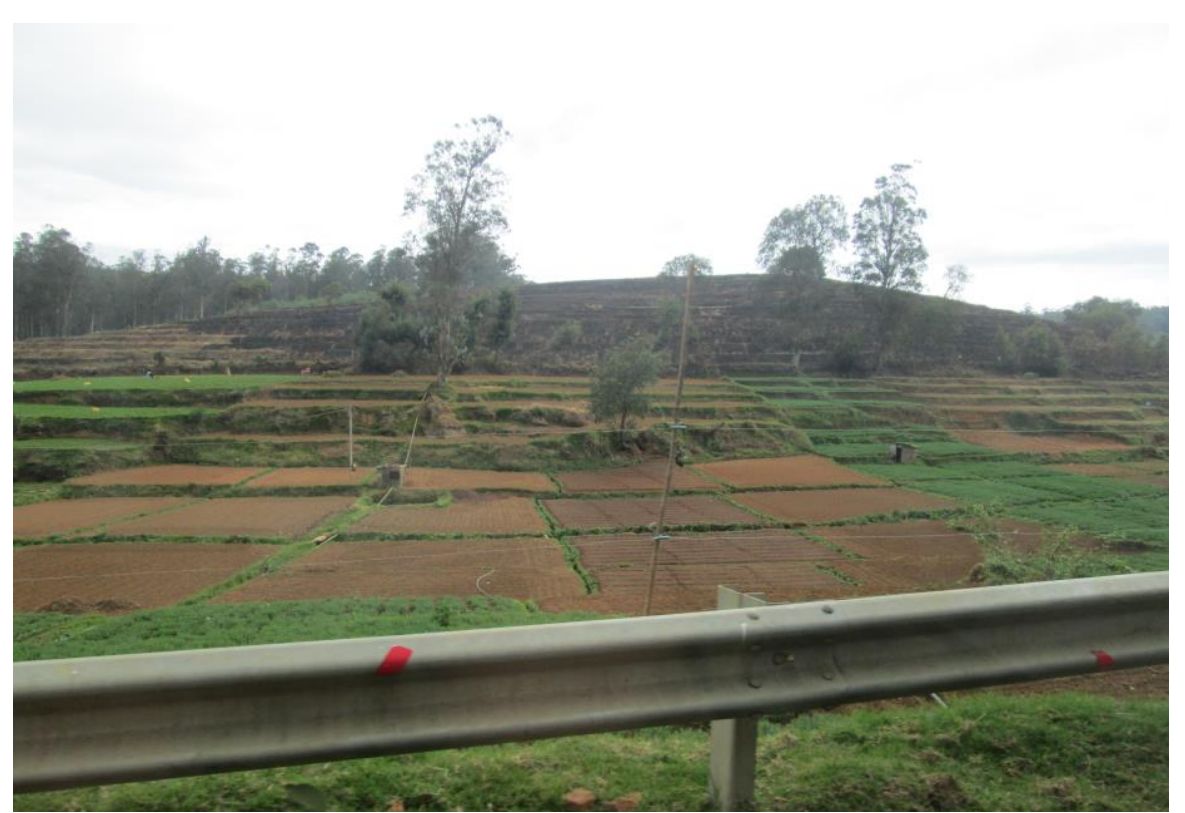

Fotografia 4 - Campo pronto para o plantio, Tamil Nadu.

Data: março 2013 


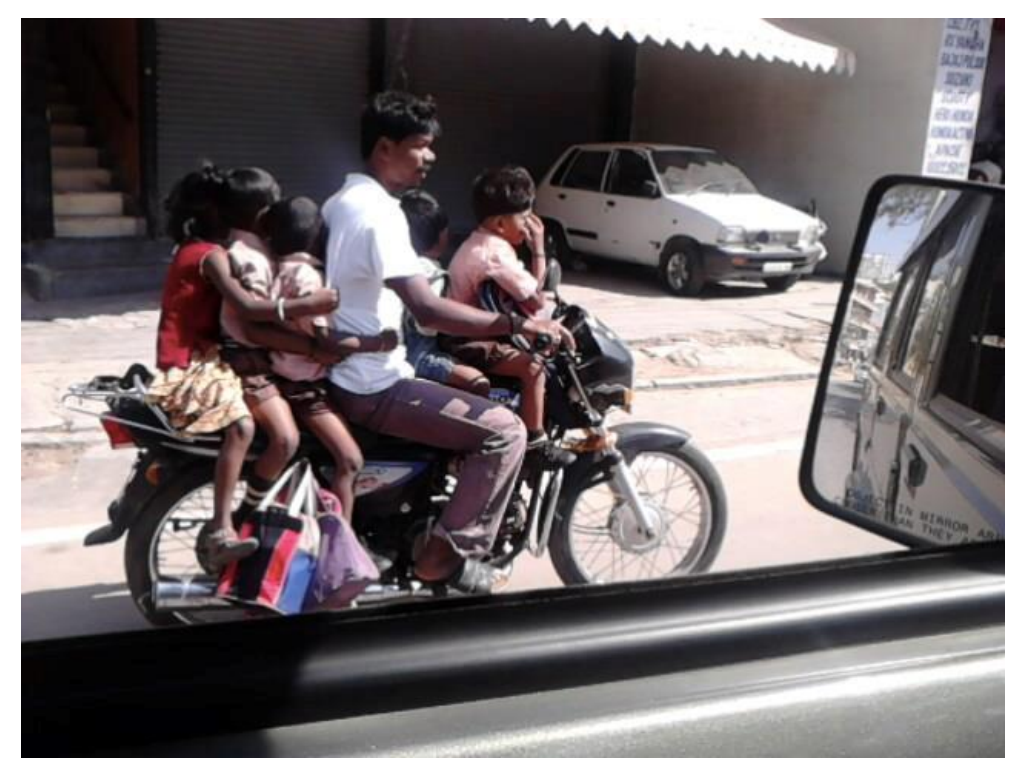

Fotografia 5 - transporte escolar em Bangalore.

Data: dezembro 2012.

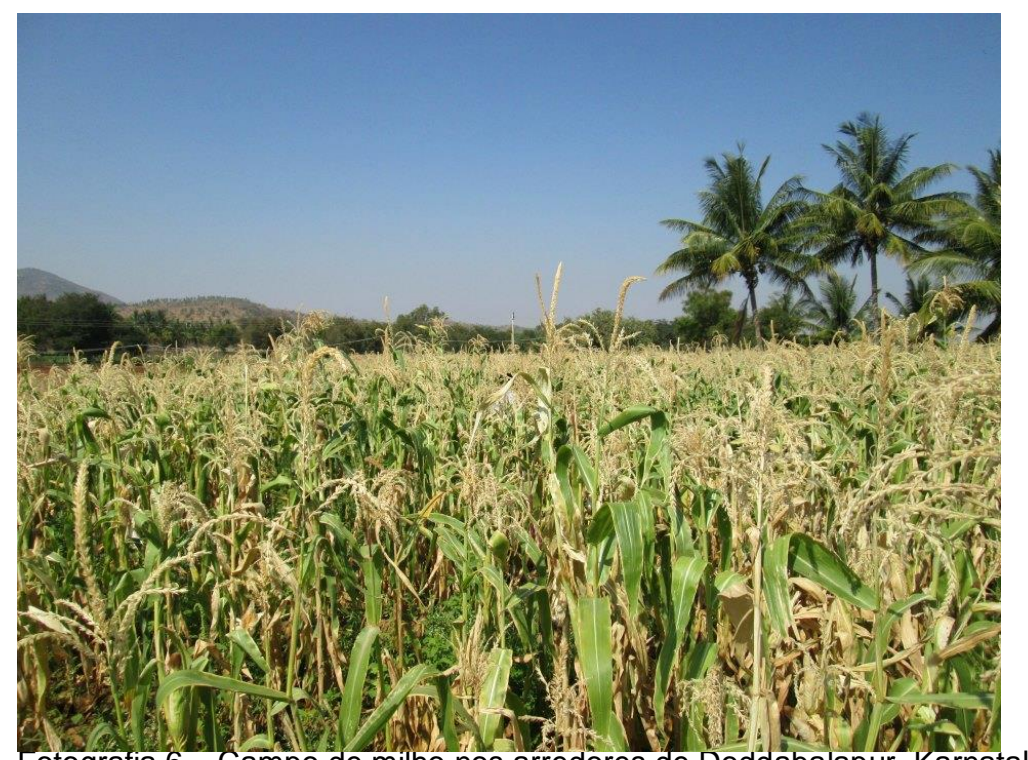

Fotografia 6 - Campo de milho nos arredores de Doddabalapur, Karnataka. Data da foto: agosto 2013 


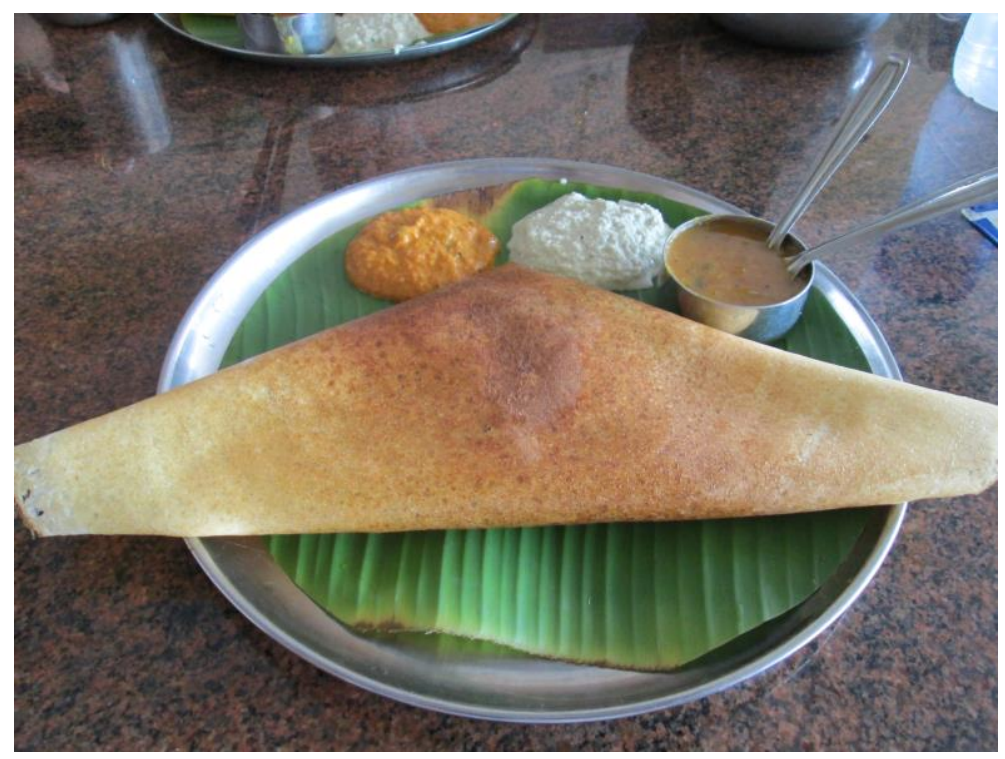

Fotografia 7 - Café da manhã típico do sul da Índia. Data da foto: setembro 2013

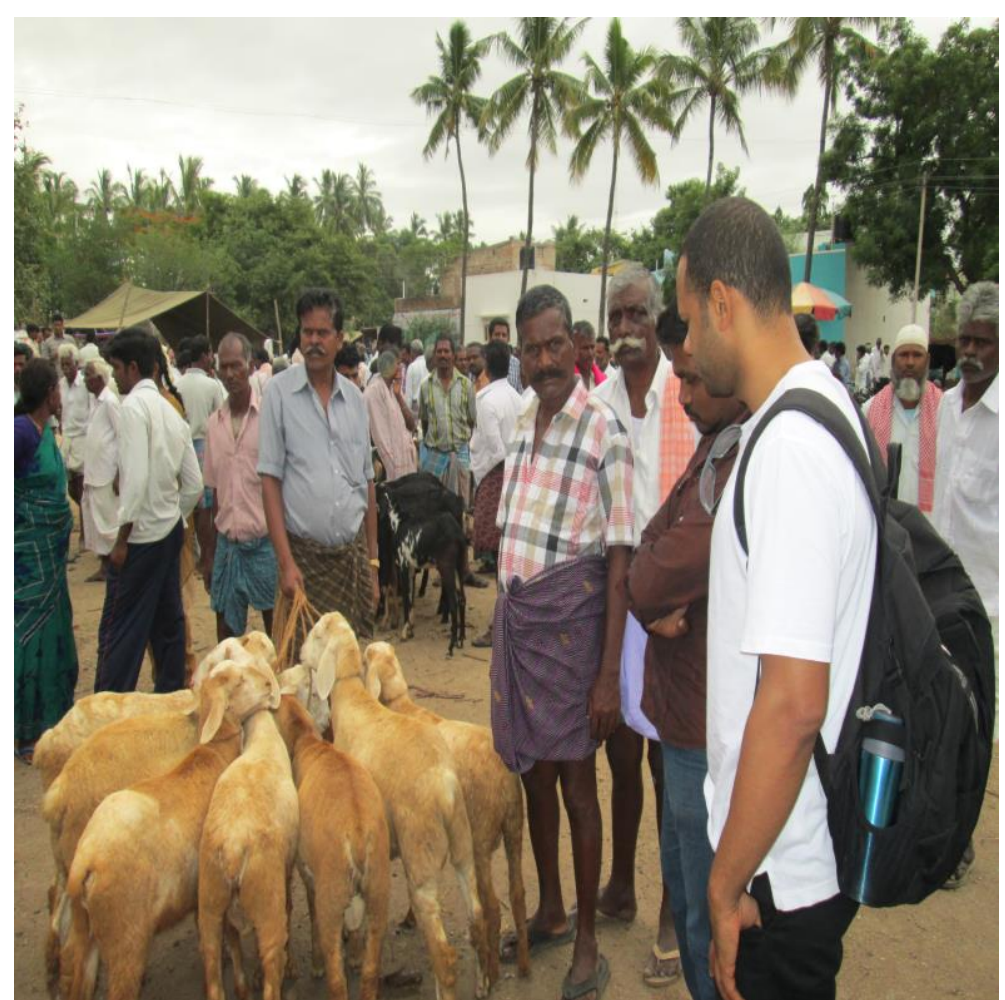

Fotografia 8 - Mercado de ovinos e caprinos em Tamil Nadu. Data da foto: agosto 2013 


\section{ANEXOS}

\section{ANEXO A: EQUAÇÕES DE SEGURANÇA ALIMENTAR E NUTRICIONAL}

\section{Equação de segurança alimentar}

Quantitativamente, uma das fórmulas utilizadas para o cálculo da segurança alimentar parte da definição do conceito para organizar as variáveis nos dois lados da equação, portanto, acesso ao alimento e disponibilidade de alimento, como concisamente explicado por Fosu e Heerink (2009). Os dois lados da equação são igualmente importantes, pois o alimento precisa estar fisicamente disponível e o acesso adequado a este alimento garantido às famílias. Por isso, para a identificação dos determinantes da segurança alimentar, é necessário examinar os determinantes da disponibilidade de alimentos que operam o lado da demanda e os determinantes de acesso ao alimento que operam o lado da oferta da equação. A equação procura incluir os fatores que causam a demanda efetiva para o aumento (ou diminuição) da disponibilidade de alimento ou a oferta de alimento disponível aumentar (ou diminuir).

Para a derivação dos determinantes do acesso ao alimento, assume-se que uma família qualquer consiga utilidade $U$ do consumo de uma commodity agregada de quantidade $q_{f}$, quantidade de uma commodity não alimento agregada $q_{n}$, e quantidade de serviços de infraestrutura or bens públicos e serviços tais como serviços de transporte $q_{s}$ (FOSU \& HEERINK, 2009:3-7). A função de utilidade é dada pela equação 1 bem comportada ${ }^{76}$ :

$$
U=U\left(q_{f}, q_{n}, q_{s}\right)
$$

$$
\text { Onde } \frac{\partial U(\cdot)}{\partial q_{j}}>0 \text { e } \frac{\partial^{2} U(\cdot)}{\partial q_{j}^{2}}<0, \quad j=f, n, s
$$

Denota-se o preço agregado do alimento, o custo para o usuário dos serviços de infraestrutura e preço de não alimentos como $P_{f}, P_{n}$ e $P_{s}$, respectivamente. Supõe-se que renda disponível é denotada por $Y$ e que o domicílio seja 'racional'. Assim, a família maximiza a utilidade na equação (1) sujeita à restriçãoo orçamentária na equação (3):

$$
Y=p_{j} q_{j}
$$

\footnotetext{
${ }^{76}$ Função bem comportada é aquela estritamente convexa e estritamente monotônica.
} 
O problema da família poderia ser resolvido com o procedimento de Lagrange de otimização. ${ }^{77}$ Pode demonstrar que dado que há $N$ famílias ou consumidores, as condições de primeira ordem para a solução deste problema geram um sistema de equações, um dos quais se refere à demanda por alimento:

A direção dos efeitos marginais dos respectivos argumentos são:

$$
\begin{gathered}
q_{f}=q_{f}\left(P_{f}, P_{n} P_{S}, Y, N\right) \\
\partial q_{f} / \partial P_{f}<0, \quad \partial q_{f} / \partial P_{n}<0, \partial q_{f} / \partial P_{S}<0, \quad \partial q_{f} / \partial Y>0, \text { e } \partial q_{f} / \partial N>0 .
\end{gathered}
$$

Os determinantes da demanda por alimento ou acesso ao alimento, portanto, incluem o preço do alimento $\left(P_{f}\right)$, o preço de bens não alimento $\left(P_{n}\right)$, o custo para o usuário de serviços de infraestrutura, por exemplo, os serviços de transporte $\left(P_{S}\right)$, o nível de renda disponível da família e o tamanho da família ou população. Quanto mais alto (baixo) o nível de preço dos alimentos ou mais baixo (mais alto) o custo para o usuário de serviços de infraestrutura (de transporte, por exemplo) mais baixo (mais alto) o preço de bens não alimentos, mais alto (mais baixo) o acesso aos alimentos pelas famílias, levando em consideração que os bens não alimentos são complementares ao alimento. Portanto, quanto mais baixo o preço do alimento, mais baixo o preço de bens não alimento, mais baixo o custo para o usuário de serviços de infraestrutura, e níveis mais altos de renda disponível tendem a melhorar a segurança alimentar por meio do estímulo que esses níveis mais altos ao acesso incrementado ao alimento, mais segurança alimentar, ceteris paribus. Se o oposto ocorrer, há a tendência ao acesso diminuído ao alimento e menor probabilidade de segurança alimentar.

Os determinantes da disponibilidade de alimentos, Fosu \& Heerink (2009), derivam ao assumir que a quantidade total de alimento disponível $Q_{f}$ é dada por

$$
Q_{f}=Q_{d}+Q_{c}+Q_{a}+Q_{v}
$$

Onde $Q_{d}$ denota a produção doméstica de alimento, $Q_{c}$ denota a importação comercial de alimentos, $Q_{a}$ denota a importação de alimentos como assistência humanitária ou doações, empréstimos e concessões, e $Q_{V}$ denota estoques anteriores líquidos (carryover stocks). $Q_{V}$ depende da taxa de juros vigente $R_{d}$. Quando a taxa de juros vigente aumenta (diminui), o custo de oportunidade de armazenagem de alimentos aumenta (diminui), ceteris paribus. Assim sendo, o volume de alimento estocado cai (aumenta), ceteris paribus

$$
Q_{V}=Q_{V}\left(R_{d}\right), \partial Q_{v} / \partial R_{d}<0
$$

Supõe-se que a importação de alimentos como assistência humanitária ou doações, empréstimos e concessões $Q_{a}$ são exógenas. A importação comercial $Q_{c}$ depende do preço

\footnotetext{
77 Procedimento de Lagrange de otimização: o método dos multiplicadores de Lagrange permite encontrar
} extremos (máximos e mínimos) de uma função de uma ou mais variáveis suscetíveis a uma ou mais restrições. 
de alimentos global $W_{f}$, da renda nacional per capita da economia importadora $I$, disponibilidade de divisas estrangeiras ou do nível de reservas estrangeiras $A$, do custo e disponibilidade de financiamento no exterior (off-shore) como proxy da taxa de juros internacional $R_{f}$.

$$
Q_{c}=Q_{c}\left(W_{f}, I, A, R_{f}\right)
$$

Onde $\partial Q_{c} / \partial W_{f}<0, \quad \partial Q_{c} / \partial I>0, \partial Q_{c} / \partial A>0$ e $\partial Q_{c} / \partial R_{f}<0$. A oferta de alimento produzida no país $Q_{d}$, pode ser derivada da seguinte maneira. Suponha que o nível de produção de alimentos seja dada pela seguinte função de produção bem comportada:

$$
Q=Q(H, L, K, Z, M, D, T, G, X)
$$

onde $\mathrm{H}, \mathrm{L}$ e $\mathrm{K}$ denotam fatores convencionais de produção de alimentos, como quantidades físicas de terra agrícola, trabalho e capital, respectivamente. Z, M, D e T denotam vetores de quantidades de tecnologias agrícolas desenvolvidas, como fertilizantes, agroquímicos, sementes selecionadas, gado e tecnologia de irrigação. G denota a quantidade de serviços de infraestrutura. $X$ denota o clima, usando a precipitação de água (chuva) com proxy em áreas de cultivo de alimento doméstico. Aqui $\partial Q / \partial H>0, \partial^{2} Q / \partial H^{2}<0$, e assim por diante. Denota os respectivos preços dos fatores de inputs como $r_{H}, r_{L}, r_{K}, r_{Z}, r_{M}, r_{D}, r_{T}$, e $r_{G}$ e o preço do alimento $P_{f}$.

$$
\max \pi=P_{f} Q-C\left(Q, r_{H}, r_{L}, r_{K}, r_{Z}, r_{M}, r_{D}, r_{T}, r_{G}\right)
$$

Então, o produtor doméstico nacional maximizará o lucro:

Pode-se mostrar que as condições de primeira e segunda ordem para maximização, $\partial \pi / \partial Q=0$ e $\partial^{2} \pi / \partial Q^{2}<0$ resulta na seguinte função de oferta de alimento:

$$
Q=Q\left(P_{f}, r_{H}, r_{L}, r_{K}, r_{Z}, r_{M}, r_{D}, r_{T}, r_{G}, X\right)
$$

para qual $\partial Q / \partial P_{f}>0, \partial Q / \partial r_{i}<0(i=H, L, K, Z, M, D, T e G)$ e $\partial Q / \partial X>0$. A oferta de alimento produzido pelo complexo agropecuário doméstico é portanto determinado pelo próprio preço dos alimentos, os preços dos inputs empregados na produção de alimentos, o custo para o usuário dos serviços de infraestrutura e o clima/tempo.

Um aumento no preço dos alimentos estimula um aumento na oferta doméstica de alimentos, e um decréscimo nos preços unitários tanto de inputs de fatores convencionais e em tecnologias agrícolas avançadas, e nos custos para usuários dos serviços de infraestrutura, ceteris paribus. Substituindo por $Q_{d}, Q_{c}, Q_{a} e Q_{v}$ na equação (5) resulta na seguinte função agregada de disponibilidade de alimento:

$$
Q_{f}=Q_{d}\left(P_{f}, r_{j}, X\right)+Q_{c}\left(W_{f}, I, A R_{f}\right)+Q_{a}+Q_{v}\left(R_{d}\right)
$$

Os argumentos de cada uma das funções $Q_{d}(\cdot), Q_{c}(\cdot)$ e $Q_{v}(\cdot)$ em (11) e o volume de assistência externa para a alimentação são, portanto, os principais constituintes dos determinantes tradicionais de disponibilidade de alimentos. A Tabela 1 resume os fatores e 
as condições sob as quais disponibilidade maior de alimentos pode ser alcançada. Assim, da perspectiva da disponibilidade de alimentos, maior segurança alimentar ocorre quando o preço do produtor do alimento aumenta, os preços dos fatores inputs convencionais baixam, os preços de tecnologias agrícolas baixam, o custo para o usuário de serviços de infraestrutura baixam, as condições do tempo melhoram em áreas produtoras, os preços internacionais dos alimentos baixam, a renda doméstica aumenta, as reservas de divisas externas ou a disponibilidade de divisas externas aumenta, as taxas de juros internacionais caem, o volume de assistência internacional de alimentação aumenta e os juros domésticos baixam. 


\begin{tabular}{|c|c|c|}
\hline Determinante & $\begin{array}{l}\text { Direção do } \\
\text { efeito }\end{array}$ & $\begin{array}{l}\text { Modo de alcançar aumento } \\
\text { na disponibilidade de } \\
\text { alimentos }\end{array}$ \\
\hline Preço do alimento produzido & + & Aumento \\
\hline Aluguel da terra agrícola & - & Redução \\
\hline Salário agrícola & - & Redução \\
\hline Custo do capital agrícola & - & Redução \\
\hline Preços de fertilizantes & - & Redução \\
\hline Preço de agroquímicos & - & Redução \\
\hline $\begin{array}{l}\text { Preços de tecnologias } \\
\text { agrobiológicas }\end{array}$ & - & Redução \\
\hline $\begin{array}{l}\text { Custo para o usuário de } \\
\text { serviços de irrigação }\end{array}$ & - & Redução \\
\hline $\begin{array}{l}\text { Custo para o usuário de } \\
\text { serviços de infraestrutura }\end{array}$ & - & Redução \\
\hline $\begin{array}{l}\text { Tempo/clima em áreas } \\
\text { produtoras }\end{array}$ & + & Aumento \\
\hline $\begin{array}{l}\text { Preços internacionais dos } \\
\text { alimentos }\end{array}$ & - & Redução \\
\hline $\begin{array}{l}\text { Renda nacional da economia } \\
\text { doméstica }\end{array}$ & + & Redução \\
\hline $\begin{array}{l}\text { Reservas internacionais ou } \\
\text { disponibilidade de divisas } \\
\text { estrangeiras conversíveis }\end{array}$ & + & Aumento \\
\hline Taxas internacionais de juros & - & Redução \\
\hline $\begin{array}{l}\text { Volume de assistência } \\
\text { humanitária alimentar }\end{array}$ & + & Aumento \\
\hline Taxas de juros domésticas & - & Redução \\
\hline
\end{tabular}

Tabela 1 - Determinantes tradicionais de disponibilidade de alimentos.

Fonte: Fosu \& Heerink, 2009.

Equação de segurança nutricional

Para derivar os determinantes tradicionais da nutrição, assume-se que existe uma função de preferência familiar conjunta da seguinte forma (Rosenweig \& Schultz, 1983).

$$
U=\left(C_{f i}, C_{n i}, H_{i}, L_{i}, I, a\right)
$$

onde $C_{f i}$ denota o vetor de consumo de alimento do membro 'i' da família, $C_{n i}$, denota o vetor de consumo não alimento, $H_{i}$ denota a situação de saúde do membro 'i' da família. $L_{i}$ denota o tempo de lazer da família 'i', I denota o tamanho da família e 'a' denota os gostos e preferências. Assume-se que há uma função produçãoo de saúde para o membro 'i’ da família:

$$
H_{i}=H\left(N_{i}, B_{i}, \square_{i}, E_{i}, M\right)
$$


Onde $N_{i}$ denota o vetor de ingestão recente de nutrientes do membro 'i' da família. $B_{i}$ denota o uso de serviços de saúde, $X_{i}$ denota episódios de morbidade: doenças e parasitas tendem a reduzir o apetite por comida e absorção de nutrientes consumidos. $E_{i}$ denota o gasto de energia, e $M$ denota um vetor de fatores fixos comuns como preços cheios, salários, distância a clínica mais próxima, estradas, qualidade dos serviços de saúde, práticas dietárias locais e usuais, qualidade de água potável (a prevalência de vetores de doenças no suprimento de água e cercanias).

A família é racional e maximiza a função de utilidade bem comportada na equação (12) sujeita à função de produção de saúde em (13) e à restrição orçamentária de renda total da família. Aplicando o procedimento de otimização de Lagrange, pode-se mostrar que as condições de primeira ordem relevantes resultam em um sistema de funções de demanda de inputs de saúde, três dos quais estão relacionados à ingestão de nutrientes, uso de serços de saúde e morbidade:

$$
\begin{aligned}
N_{i} & =(P, Y, M) \\
B_{i} & =B(P, Y, M) \\
X_{i} & =X(P, Y, M)
\end{aligned}
$$

onde $P$ denota os preços de vetores completos amplamente definidos para incluir custos com dinheiro e custos de tempo. $Y$ denota a renda familiar que é tida como exógena neste exemplo. Lembrando que a situação nutricional depende da ingestão de nutrientes, acesso a serviços de saúde de qualidade, da ocorrência de doenças e parasitas e manutenção de uma situação de saneamento na família.

Assim, $\partial N / \partial Y>0$ e $\partial B / \partial Y>0$. Isto implica que níveis mais altos de renda familiar estimulam níveis mais elevados de ingestão de nutrientes e uso de serviços de saúde e portanto, uma situação nutricional de níveis mais altos, ceteris paribus. Adicionalmente, $\partial N / \partial N P_{f}<0$. Isto implica que preços de alimentos mais elevados tendem a precipitar níveis mais baixos de ingestão de nutrientes, ceteris paribus. Por fim, $\partial N / \partial M, \partial B / \partial M$ e $\partial X / \partial M$ poderia ser positivo ou negativo dependendo do elemento $j$ do vetor $M$ em questão. (FOSU \& HEERINK, 2009:3-7). 


\section{ANEXO B: METODOLOGIA INDICADOR FAO}

Esta seção é resumo do original em inglês para o português, tradução do autor, do seguinte documento:

FAO. FAO methodology for the measurement of food deprivation: updating the minimum dietary energy requirements. Roma: FAO Statistics Division. 2008. 16p. Disponível em: http://www.fao.org/fileadmin/templates/ess/documents/food_security_statistics/metadata/und ernourishment_methodology.pdf>. Acesso: 28/02/2014.

A medida FAO de privação alimento, é baseada em uma comparação do consumo normal de alimentos expresso em termos de níveis de energia (energia dietária) (kcal) com as normas de necessidades mínimas de energia. A parte da população com consumo de alimento abaixo das necessidades mínimas é considerada subalimentada. A FAO apresenta a estimativa de prevalência de privação de alimentação juntamente com os relatórios "Estado da Segurança Alimentar e Nutricional".

A estimativa da proporção da população abaixo do nível de consumo mínimo de energia é definido dentro de uma distribuição de probabilidade:

$$
P(U)=P\left(x<r_{L}\right)=\int_{x<r_{L}} f(x) d x=F_{x}\left(r_{L}\right)
$$

Onde:

$P(U)$ é a proporção de subnutridos no total da população

(x) se refere ao consumo de energia (da dieta)

$r_{L}$ é o ponto de corte refletindo a necessidade mínima de energia

$f(x)$ é a função de densidade de consumo de energia

$F_{x}$ é a função de distribuição cumulativa

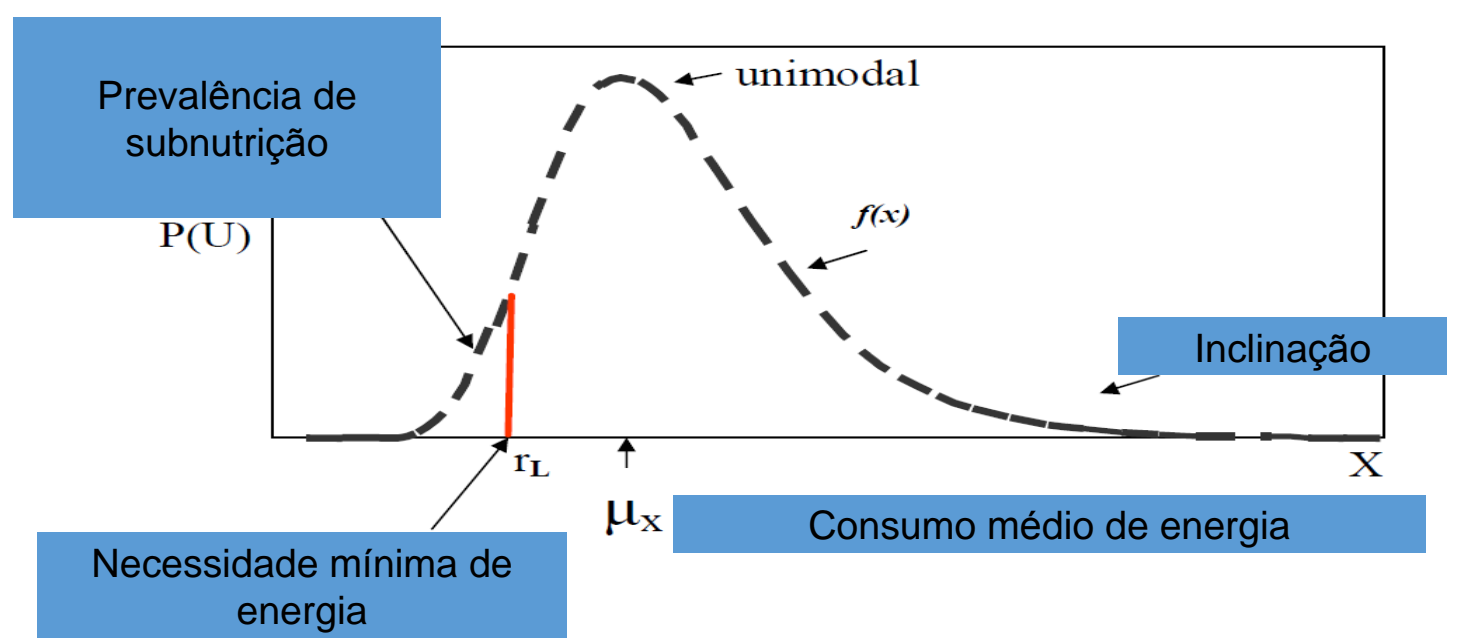

Gráfico 1: Distribuição teórica do consumo de energia da dieta Fonte: FAO, 2008. 
No Gráfico 1, a curva $f(x)$ representa a proporção da população correspondente a diferentes níveis de consumo per capita de energia $(x)$ representado pela linha horizontal. $\mathrm{A}$ área sob a curva até a necessidade mínima de energia que é um ponto de corte na curva, $r_{L}$, representa a proporção subnutrida da população, isto é, a prevalência de subnutrição.

Os procedimentos de estimação partem da função de densidade, $\boldsymbol{f}(\boldsymbol{x})$, que assumese ser uma distribuição log-normal para que os parâmetros $\mu_{x}$ e $\sigma_{x}^{2}$ possam ser estimados sobre a base da média $\bar{x}$, e o coeficiente de variação $C V(x)$. Há duas opções para estimar a média:

1. Dados de planilhas de controle de alimentação - Food Balance Sheet (FBS - sigla em inglês): podem ser usados para a preparação de estimativas anuais para o monitoramento do progresso em segurança alimentar de um país como um todo;

2. Dados de Pesquisa de Orçamento Doméstico - Household Budget Survey (HBS sigla em inglês): são usados para pesquisas de intervalos de 5 a 10 anos devido aos intervalos entre a realização de cada pesquisa.

Por exemplo, para a estimação de consumo de energia a partir de FBSs, a média é representada pela Oferta de Energia da Dieta por pessoa (DES - sigla em inglês), isto é, o consumo humano para o alimento disponível durante o curso do período de tempo utilizado, expresso em termos de energia (kcal/pessoa/dia). A estimativa é derivada dos FBSs compilados com base nos dados de produção (PROD) e comércio (IMPortação e EXPortação) de commodities alimentares. Utilizando estes dados e a informação disponível sobre variações no estoque $(\mathbf{S T C H})$, perdas entre os níveis dos quais a produção é registrada e o domicílio (WASTE - perda) e tipos de uso (SEED - sementes, FEED - ração, FOOD - alimento; inputs para o PROCessamento de produtos derivados e OTHER - outros usos) uma conta de utilização/oferta é preparada para cada commodity em termos de peso. O componente alimento, que é normalmente derivado como um item de equilíbrio, refere-se à quantidade total de commodity disponível para o consumo humano durante o ano. O DES é obtido pela agregação do componente alimento de todas as commodities após a conversão em valores de energia. A Tabela abaixo apresenta uma FBS padrão para um país hipotético em 1999-2001. O DES por pessoa por dia de 2414 calorias (kcal) mostrado na primeira fileira e última coluna da Tabela 1 é o valor utilizado para estimar a média $\bar{x}$ para o país hipotético,

$$
\bar{x}=\mathbf{2 4 1 4}
$$

No caso de estimativas a partir de HBSs, é necessário a conversão de quantidade de diferentes alimentos consumidos no domicílio em valores de energia. Estes dados são normalmente coletados por meio de pesquisas de orçamento que usam amostras grandes 
que permitem estimativas de média não apenas para o nível nacional mas também para níveis subnacionais, tais como regiões específicas e grupos populacionais socioeconômicos. 
Tabela 1 - FBS padrão para um país hipotético, 1999-2001

\begin{tabular}{|c|c|c|c|c|c|c|c|c|c|c|c|}
\hline x1000 toneladas métricas /ano & PROD & + IMP & $+\mathrm{STCH}$ & -EXP & -FEED & -SEED & $-\mathrm{PROC}$ & WASTE & -OTHER & $=\mathrm{FOOD}$ & $\begin{array}{r}\text { CALORIAS POR } \\
\text { PESSOA POR DIA } \\
\end{array}$ \\
\hline & & & & & & & & & & & \\
\hline TOTAL & & & & & & & & & & & 2414 \\
\hline Cereais menos cerveja & 19973.7 & 1116.5 & -355.7 & 6673.9 & 5211.8 & 434.7 & 407.5 & 969.4 & 9.7 & 7027.8 & 1114.5 \\
\hline Raízes ricas em amido & 16956.2 & 133.8 & -1053.9 & 13525.9 & 0.4 & 0.9 & 143.7 & 1350.1 & 3.7 & 1011.4 & 45.2 \\
\hline Açucares & 53406.6 & & -1333.3 & 0.3 & & & 43698.3 & 2753.7 & & 5621.0 & 73.0 \\
\hline Açucar \& adoçantes & 5267.7 & 11.3 & -136.6 & 3360.6 & & & & & 13.0 & 1776.6 & 283.2 \\
\hline leguminosas & 269.5 & 5.7 & & 37.9 & & 21.9 & & 8.2 & & 207.3 & 31.5 \\
\hline Nozes, castanhas & 54.0 & 2.2 & & 15.8 & & & & & & 40.5 & 6.5 \\
\hline oleaginosas & 2337.2 & 873.5 & -198.7 & 38.5 & 1.0 & 14.3 & 1735.2 & 135.9 & & 1087.5 & 100.1 \\
\hline Óleos vegetais & 819.9 & 66.3 & -149.9 & 116.5 & & & & & 272.8 & 348.7 & 137.9 \\
\hline Legumes & 2753.0 & 25.3 & & 372.1 & & & 0.0 & 245.7 & & 2163.9 & 26.8 \\
\hline Frutas (excl. Vinho) & 7270.5 & 55.9 & 0.2 & 1173.2 & & & 14.5 & 566.7 & & 5574.7 & 114.4 \\
\hline Estimulantes & 78.1 & 21.4 & -6.7 & 64.6 & & & & & & 28.5 & 0.9 \\
\hline Condimentos & 67.1 & 7.2 & & 20.9 & & & & 1.9 & & 51.6 & 6.9 \\
\hline Bebidas alcoólicas & 2114.9 & 28.4 & & 78.9 & & & & & 24.0 & 2040.4 & 163.4 \\
\hline Mel & 3.0 & 0.2 & & 1.6 & & & & & & 1.6 & 0.2 \\
\hline Carne & 1902.5 & 3.3 & & 271.6 & & & & 20.7 & & 1614.8 & 150.9 \\
\hline Miúdos & 75.7 & 2.8 & & 0.4 & & & & & & 77.7 & 3.8 \\
\hline Gordura animal & 31.8 & 19.1 & & 0.7 & & & & & 5.6 & 44.6 & 15.6 \\
\hline Leite exceto manteiga & 409.4 & 1095.4 & & 81.1 & & & & 12.3 & 12.0 & 1400.1 & 32.1 \\
\hline Ovos & 812.0 & 1.3 & & 6.8 & & 137.4 & & 40.6 & & 628.4 & 42.6 \\
\hline Peixe, frutos do mar & 3458.0 & 532.1 & 1.7 & 809.3 & 1185.9 & & & & & 1996.5 & 62.2 \\
\hline Produtos aquáticos & 30.1 & 0.5 & & 14.5 & & & & & & 16.1 & 0.2 \\
\hline Diversos & & & & & & & & & & & 2.1 \\
\hline
\end{tabular}

$\left.{ }^{*}\right)$ Quantidades de alimentos convertidas em valores de energia e divididos pela população total e por 365 dias.

Fonte: FAO, 2008 
Para estimar o coeficiente de variação, $C V(x)$, o $C V$ de consumo de energia da dieta por pessoa da família é formulado do seguinte modo:

$$
C V_{x}=\sqrt{C V^{2}(x \mid v)}+C V^{2}(x \mid r)
$$

Onde, $\boldsymbol{C} \boldsymbol{V}_{(x)}$ é o $\boldsymbol{C}$ total diário da família (ou domicílio) de consumo de energia por pessoa, $\boldsymbol{C} \boldsymbol{V}(\boldsymbol{x} \mid \boldsymbol{v})$ é o componente correspondente à renda diária por pessoa da família $(v)$ e $\boldsymbol{C V}(\boldsymbol{x} \mid \boldsymbol{r})$ é o componente correspondente à necessidade de energia $(r) \cdot \boldsymbol{C} \boldsymbol{V}(\boldsymbol{x} \mid \boldsymbol{r})$ é considerado como um componente fixo e é estimado para corresponder a cerca de 0,20. No entanto, $\boldsymbol{C V}(\boldsymbol{x} \mid \boldsymbol{v})$ é estimado baseado em dados de pesquisas domiciliares.

Para estimar $\boldsymbol{C} \boldsymbol{V}(\boldsymbol{x} \mid \boldsymbol{v})$, a seguinte formulação é usada:

$$
C V(x \mid v)=\sigma(x \mid v) / \mu(X) .
$$

O numerador da proporção é derivado de:

$$
\sigma(x \mid v)=\sqrt{\left[\sum_{j=i}^{k} f_{j}(x \mid v)_{j}^{2}-\left(\sum_{j=1}^{k} f_{j}(x \mid v)_{j}\right)^{2 / n}\right] /(n-1)}
$$

e o denominador, que é a média geral de consumo de energia da dieta por pessoa por dia, é derivado de:

$$
\mu(x)=\sum(x) / n
$$

Onde $k$ é o número de classes de renda e $f_{j}$, o número de domicílios incluídos na pesquisa e $(x \mid v)_{j}$ é o consumo médio diário de energia da dieta por pessoa no domicílio da classe $j_{n}$ de renda ou despesa.

Assim, os dados necessários para se estimar $\boldsymbol{C V}(\boldsymbol{x} \mid \boldsymbol{v})$ são as médias dos consumos diários por pessoa por classe de renda ou gasto de cada família de $\boldsymbol{n}$ famílias (ou domicílios) e o número de famílias em cada classe. A tabela abaixo apresenta a média do consumo total diário de consumo de energia por pessoa em cada classe por decil de família por pessoa de uma pesquisa de orçamento familiar nacional conduzida em um país hipotético (amostra de 2370 famílias).

Tabela 2 - Consumo de energia da dieta médio por pessoa por decil de gasto familiar 


\begin{tabular}{|r|r|}
\hline Decil de & $\begin{array}{r}\text { Média de } \\
\text { consumo de } \\
\text { despesa } \\
\text { energia da } \\
\text { familiar } \\
\text { dieta (Kcal } \\
\text { por } \\
\text { pessoa }\end{array}$ \\
\hline 1 & pessoa/dia) \\
\hline 2 & 1554 \\
\hline 3 & 1874 \\
\hline 4 & 2066 \\
\hline 5 & 2263 \\
\hline 6 & 2413 \\
\hline 7 & 2461 \\
\hline 8 & 2530 \\
\hline 9 & 2474 \\
\hline 10 & 3093 \\
\hline 3373 \\
\hline
\end{tabular}

Fonte: $\mathrm{FAO}, 2008$

Utilizando os dados da Tabela 2, $\boldsymbol{C V}(\boldsymbol{x} \mid \boldsymbol{v})$ é estimado deste modo:

$$
\boldsymbol{C V}(\boldsymbol{x} \mid \boldsymbol{v})=\sigma(\boldsymbol{x} \mid \boldsymbol{v}) / \mu(x)=508 / 2410=0.211
$$

Consequentemente, dado que $\boldsymbol{C V}(\boldsymbol{x} \mid \boldsymbol{r})$ corresponde a 0.20 , obtêm-se

$$
\boldsymbol{C V}(\boldsymbol{x})=\sqrt{0.211^{2}+0.20^{2}}=0.29 \text {. }
$$

Além do coeficiente de variação, ainda é necessário calcular:

1. A estimativa de necessidade mínima de energia (o ponto de corte), $r_{L}$. Para tal, é necessário estimar:

a. Peso corporal de referência;

b. Estimativa de necessidade mínima de energia para crianças e adolescentes, menores de 18 anos;

c. Estimativa de necessidade mínima de energia para adultos;

d. Estimativa de necessidade geral mínima de energia diária por pessoa;

2. A estimativa da proporção e número de subnutridos.

Nota do autor: Como cada uma das estimativas acima requer algum grau de arbitrariedade para alguns dos parâmetros, há divergências e controvérsias sobre a acurácia e grau de confiança de cada parâmetro e das estimativas gerais geradas. Como há diferenças significativas, por exemplo, no peso corporal de referência de diferentes grupos étnicos e populações, alguns pesquisadores algumas variações, principalmente na Índia podem ser explicadas por meio deles. Veja, por exemplo, a disputa entre os aclamados economistas indianos Jagdish Bhagwati e Amartya Sen (Rieff, 2013). 


\section{ANEXO C: CÓDIGOS DE FOME}

O conteúdo do Anexo C é uma tradução de trechos do seguinte documento:

ÍNDIA. Report of the Indian Famine Commission. Relatório. Nova Délhi: Agricole Publishing Academy. [1898] 1979. 403p.

O Relatório da Comissão Indiana [contra] a Fome exemplifica as origens das políticas indianas de segurança alimentar.

Nomeação e objetivos da missão

Comissão apontada para formular orientação futura que a experiência da Fome de 1897 tem a ensinar. Nossa Comissão foi apontada com a aprovação do Secretário de Estado de Sua Majestade sob as ordens de Sua Excelência o Governador Geral em Conselho na Resolução do Governo da Índia, Departamento de Receitas e Agricultura, No. 35-245-26 (Fome), datado de 23 de dezembro de 1897. O objeto da Comissão foi examinar e comparar sistemas de alívio à fome sancionados para diversas províncias, e as medidas de fato empregadas durante a recente fome; inquerir sobre o grau de sucesso alcançado por tais medidas; e registrar as lições e recomendações sugeridas pelas experiências alcançadas enquanto os fatos estão recentes nas mentes das testemunhas.

$[\ldots]$

A organização para a assistência de socorro que foi elaborada em cada província seguindo a orientação da Comissão contra a Fome de 1878, e assimilada pelos Códigos [leis] contra a Fome Provinciais, têm sido agora pela primeira vez colocadas em prática em larga escala na maior parte das provícias afetadas; e, no geral, passaram bem no teste. No entanto, enquanto a experiência no ano passado sugeriu que não havia a necessidade de alterações nas linhas gerais que foram prescritas como base para a administração do socorro, achou-se necessário, em quase todas as províncias, afastar-se em alguns aspectos não pouco importantes de provisões detalhadas no Código para atender as diferentes condições de perigo. E a direção que estes afastamentos tomaram variaram de província para província.

A experiência assim ganhada será de valor incalculável quando a Índia estiver face a face novamente com uma situação de fome. Mas para que esteja disponível para orientação futura, é essencial coletar e coleciona-la enquanto os fatos estão recentes e inseri-los nos Códigos de Fome atualizados. É sem dúvida o caso que, enquanto as linhas gerais sobre as quais o socorro é administrado podem ser apropriadamente precritos para toda Índia, variações em detalhes serão necessárias sob condições variáveis a serem encontradas em diversas províncias, e cada província deve reter seu Código individual. Mas é certo que quase toda província terá algo a aprender da experiência de outras, e será recomendável tomar medidas especiais para a coleta dessa experiência; e especialmente, onde o custo do socorro e o número de socorridos tenha sido maior do que em outros lugares em proporção à intensidade da situação de emergência e a população afetada por esta, inquirir sobre quais tenham sido as razões do excesso, e se uma aderência às linhas seguidas em outras províncias não poderia em ocasião futura reduzir o cutos sem diminuir a eficácia das medidas adotadas. 
$[\ldots]$

Fortalecimento de meios de subsistência

Eles [a Comissão contra a Fome de 1878] também foram convidados a aconselhar sobre medidas da mais diversa natureza possível, tais como 'diminuir a severidade das fomes, ou posicionar as pessoas em uma situação melhor para enfrenta-las. O programa que foi elaborado por eles sob o título 'Medidas de proteção e prevenção' foi conformemente desde entãpo ativamente processado; e embora muito ainda permanece e sempre permanecerá a ser feito, as omissões e defeitos são inteiramente reconhecidos, e estão sendo gradualmente tratados à medida que a oportunidade se apresenta, e pesquisa geral desta natureza não se fazem mais necessários ou aconselháveis. Portanto, também, a experiência do ano passado tem demonstrado que as linhas gerais da política elaborada em 1878 permanece sem necessidade de reconsideração. São os detalhes do progrma que carecem de revisão. Mas em tais questões, detalhes são dificilmente menos importantes do que princípios.

$[\ldots]$

Situação

As colheitas tinham sido pobres em Karnal e Rohtak a partir de 1882, e nestes distritos as situações de calamidade mais sérias eram antecipadas. O leste e sudeste do distrito de Karnal estavam protegidos pelo Canal Ocidental de Jumna, mas nos tahsils de Kaithal e Karnal não havia produção do tipo rabi na maioria das vilas. ${ }^{12}$

$[\ldots]$

Medidas e planejamento

As medidas de assistência compreendiam (I) a suspensão do imposto fundiário onde julgavase necessário; (2) a concessão de empréstimos para a abertura de poços, and mais tarde, quando as chuvas de 1884 chegaram, para adiantamentos de sementes e gado; (3) a provisão de obras de estrada e tanque pelos conselhos distritais para os desempregados com taxas normais de salários. Obras regulares de assistência contra a fome não foram abertas, mas em adição ao emprego providenciado pelos conselhos distritais, uma quantidade considerável de obras de terraplanagem estava em progresso nos canais e estradas de ferro. Uma obra grande de drenagem foi iniciada em maio de 1884 em uma parte do distrito de Rohtak, mas poucos trabalhadores compareceram, e [por isso] foi encerrado apoós 2 ou 3 meses. Nos canais, a colheita de culturas de de primavera também geraram trabalho bom e remunerado para muitos. Um programa de obras importantes para os propósitos de assistência foi preparado no caso de falta de chuvas em 1884 e um [um] círculo de assistência de acordo com o código contra a fome foi mapeado em relação à mesma contigência. [...] O relatório de Karnal relatou que as pessoas estavam alegres e devido aos baixos preços e ampla suspensão do imposto fundiário.

$[\ldots]$

\footnotetext{
1 Tahsil ou Taluk: é uma divisão administrativa comum no sudeste asiático.

2 Produção agrícola tipo rabi é aquela característica da estação chuvosa no sudeste asiático. A produção agrícola do tipo kharif, cultivados na estação seca.
} 
Importância da caridade privada - o papel da sociedade civil

Atenção especial foi também direcionada para o incentivo à caridade privada e ao enlistamento de cooperação de residentes locais influentes e espírito público no atendimento de tais situações de calamidade como se espera que ocorra.

Abrigos para os pobres

Página 210, parágrafo 357

Em relação aos abrigos para os pobres [poor-houses], eles são instituições necessárias, e a despesa com elas e os números [de pessoas] admitidas em províncias diferentes dependia tanto das condições locais que nenhuma questão de economia relativa se levanta. Em Madras, o estágio de calamidade que necessita de abrigos para os pobres se diz que ainda não foi atingido; no entanto, cozinhas [comunitárias] são muito numerosas, e é provável que mendigos e andarilhos receberam nelas auxílio que em outras províncias obteriam apenas se fossem admitidos como internos [admitidos] de um abrigo para pobres. [...] É possível que o número de abrigos para pobres poderia ter sido de algum modo reduzido por meio da maior extensão do sistema de assistência em vilas. Mas com uma situação de fome tão intensa como foi essa nestas províncias e com migrantes afluindo [em grandes números] vindos de estados nativos, uma população considerável de [admitidos] abrigos para pobres era inevitável.

\section{Salários de trabalhadores}

P. 211, parágrafo 259

Não é fácil verificar ou justamente comparar a taxa salarial em províncias diferentes, devido à falta de uniformidade nos rendimentos. Em alguns, a quantia mostrada como paga aos trabalhadores inclui pagamentos a estabelecimentos de obras, e devido a contingências e outros itens diversos; em alguns inclui subsídios para dependentes. [...] O salário por unidade de trabalhador é a média de salario retirado por todo trabalhador, sem distinção de idade ou sexo, enquanto o salário por unidade do sexo masculino, assumindo que todo homem recebe a unidade de salario do sexo masculino e toda mulher e criança três quartos e três oitavos respectivamente do mesmo salário. 


\section{REPORT OF THE INDIAN FAMINE COMMISSION I 898 .}

\section{CHAPTER I.}

INTRODUCTORY.

Our Commission was appointed with the approval of Her Majesty's Secretary Appointment of the Commission: of State under the orders of His Excellency the its object.

Governor General in Council contained in the ResoIution of the Government of India, Department of Revenue and Agriculture, No. 35-245-26 (Famine), dated the 23rd December 1897. The object of the Commission was to examine and compare the systems of famine relief sanctioned for the several provinces, and the measures actually employed during the recent famine; to inquire into the degree of success attained by those measures; and to record the lessons and recommendations suggested by the experience gained while the facts were fresh in the minds of the witnesses.

2. The following abservations taken from the Resolution appointing the Scope of the inguiry.

Commission may be usefully quoted, as they give a

directed. full description of the object and scope of the inquiry

"The organisation for the relief of distress which has been elaborated in each province on the lines laid down by the Famine Commission of 1878 , and embodied in the Provincial Famine Codes, has now, for the first time in most of the affected provinces, been practically tested on a large scale; and on the whole it has stood the trial well. But while the experience of the past year has suggested no alterations in the main lines which were pren. scribed as the basis for the administration of relief, it has been found necessary, in almost every province, to depart in some not unimportant respects fidith the detailed provisions of the local Code in order to meet the differing conditions of distress. And the direction which these departures have taken has varied from province to province. 


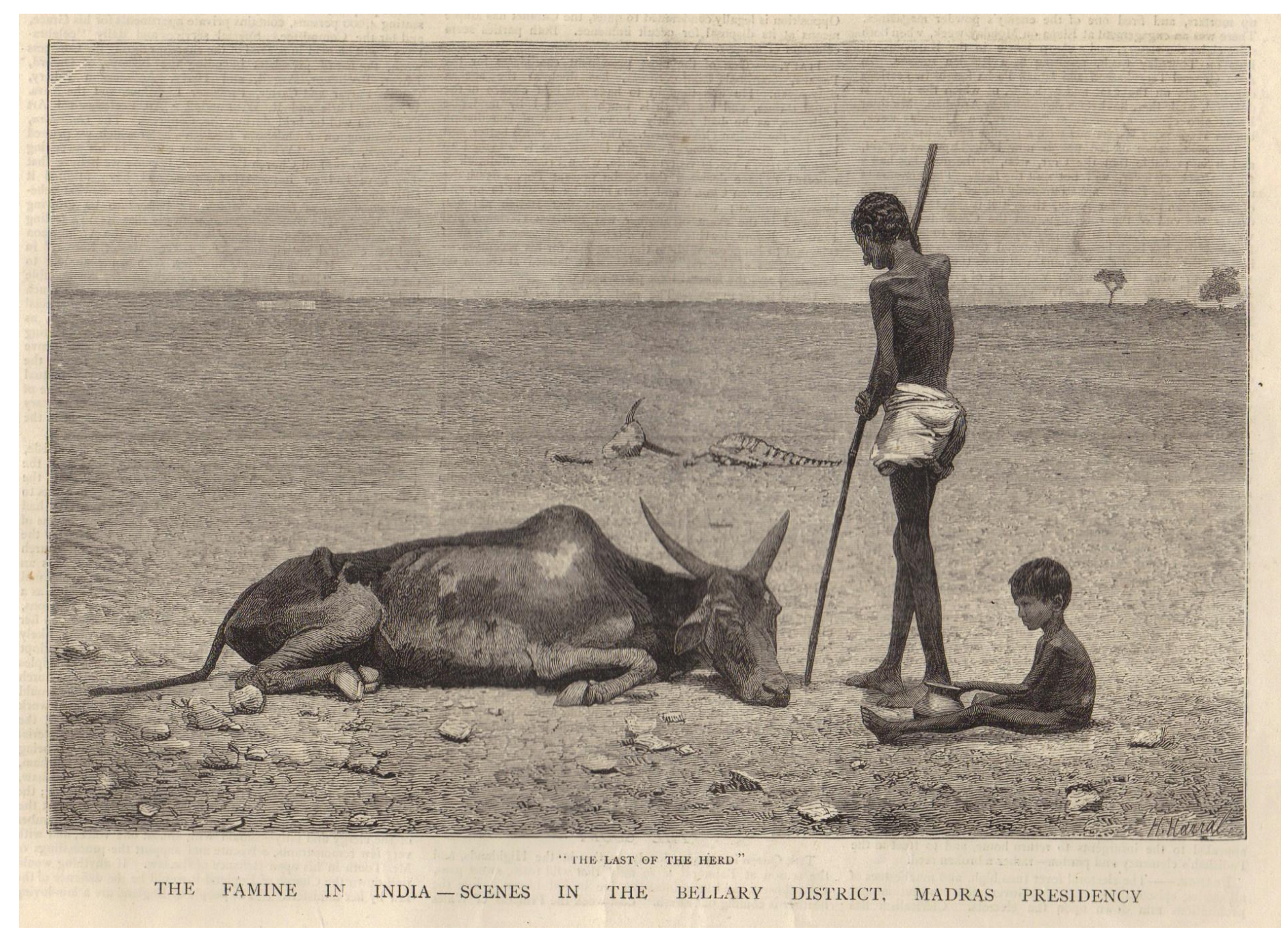

Fotografia 1: The last of the herd. Autor: Willoughby Wallace Hooper. Data:1876. Disponível em: http://www.museumsyndicate.com/item.php?item=65023. Acesso: 10/11/2013 


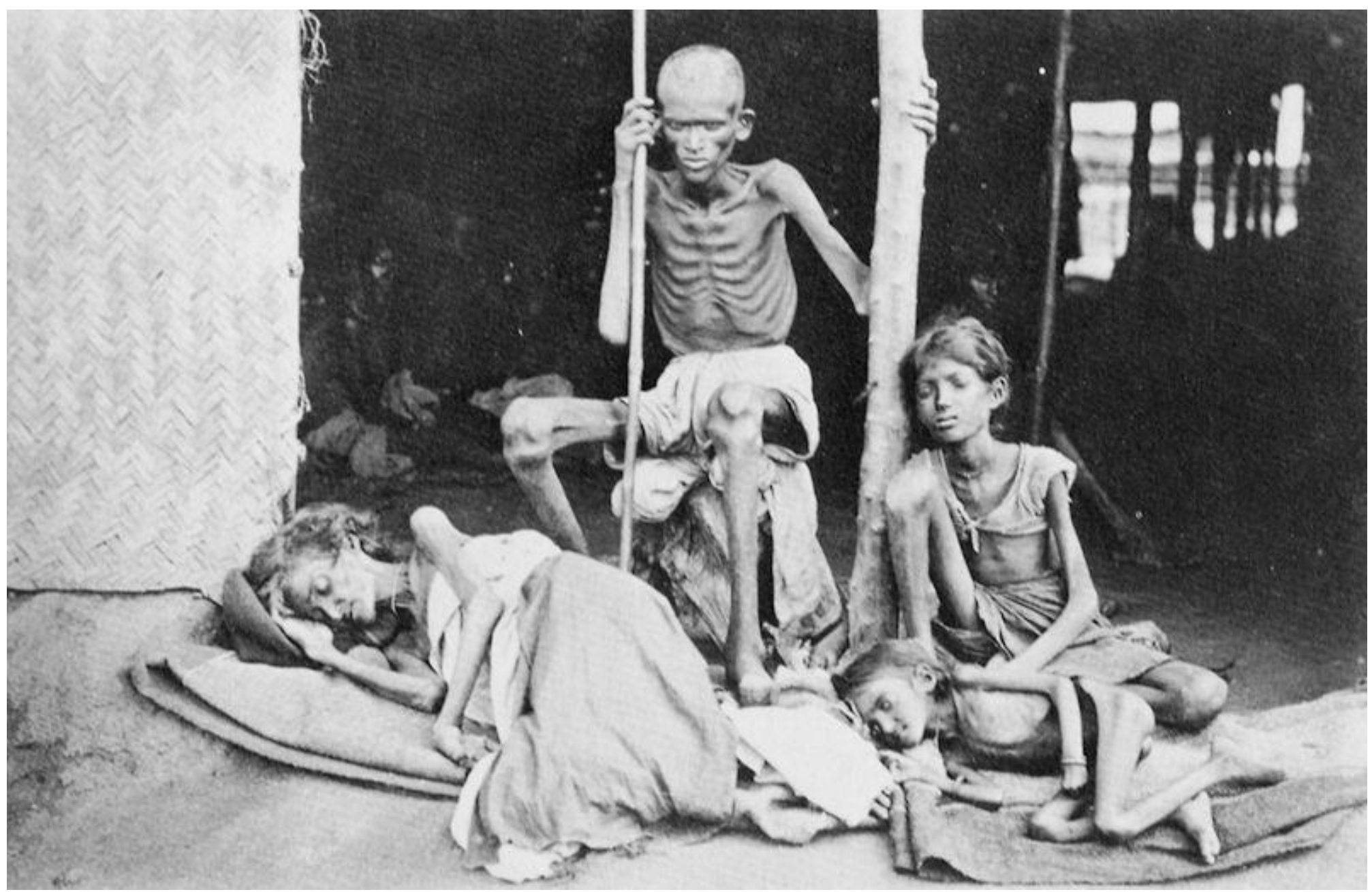

Fotografia 2: Victims of Madras Famine, Índia. Autor:

Willoughby Wallace Hooper. Data: 1876 .

Disponível em: http://www.museumsyndicate.com/item.php?item=65023. Acesso: 10/11/2013 


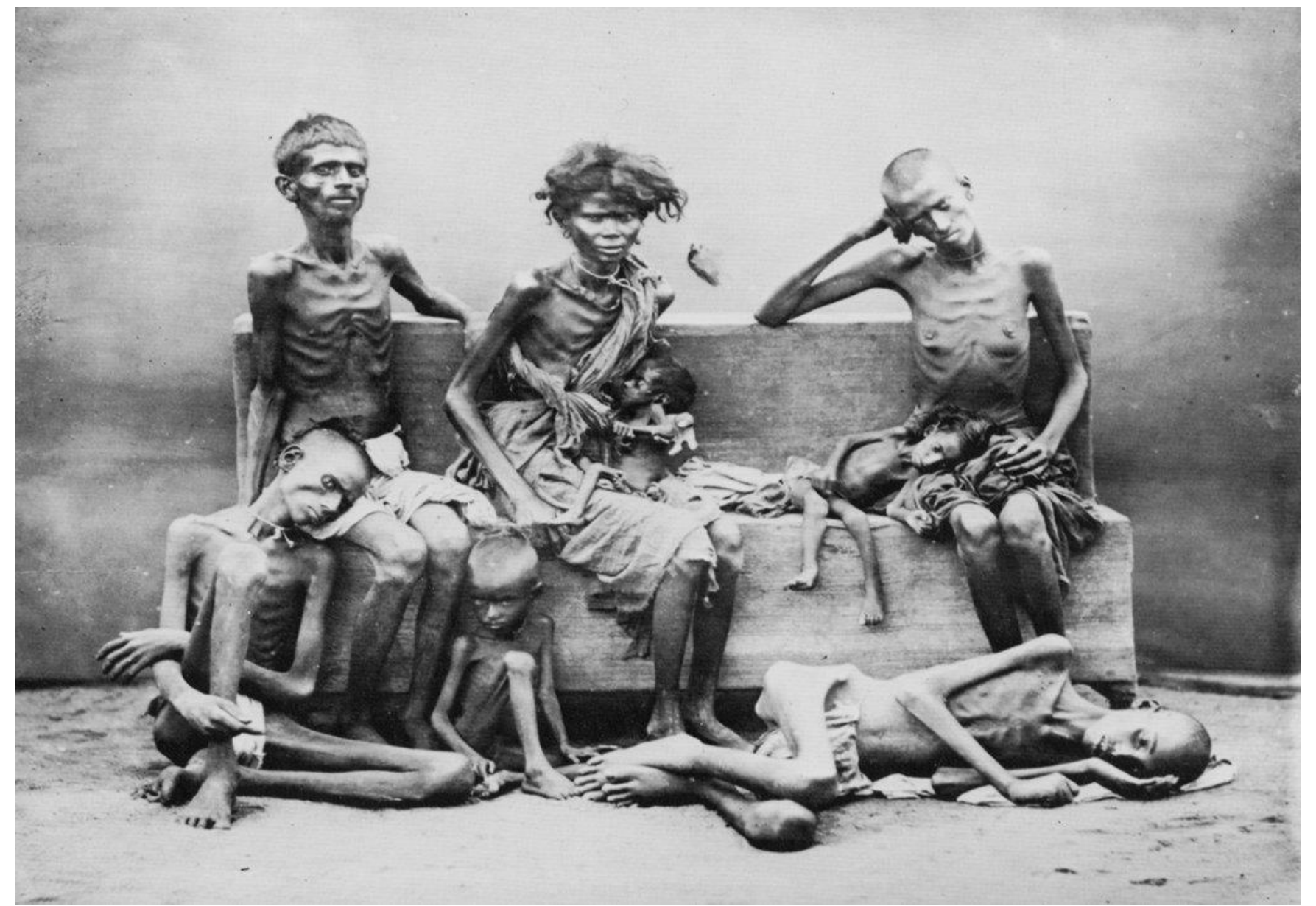

Fotografia 3: Victims of Madras Famine, Índia. Autor: Willoughby Wallace Hooper. Data:1876. Disponível em:http://www.museumsyndicate.com/item.php?item=65024. Acesso: 10/11/2013 


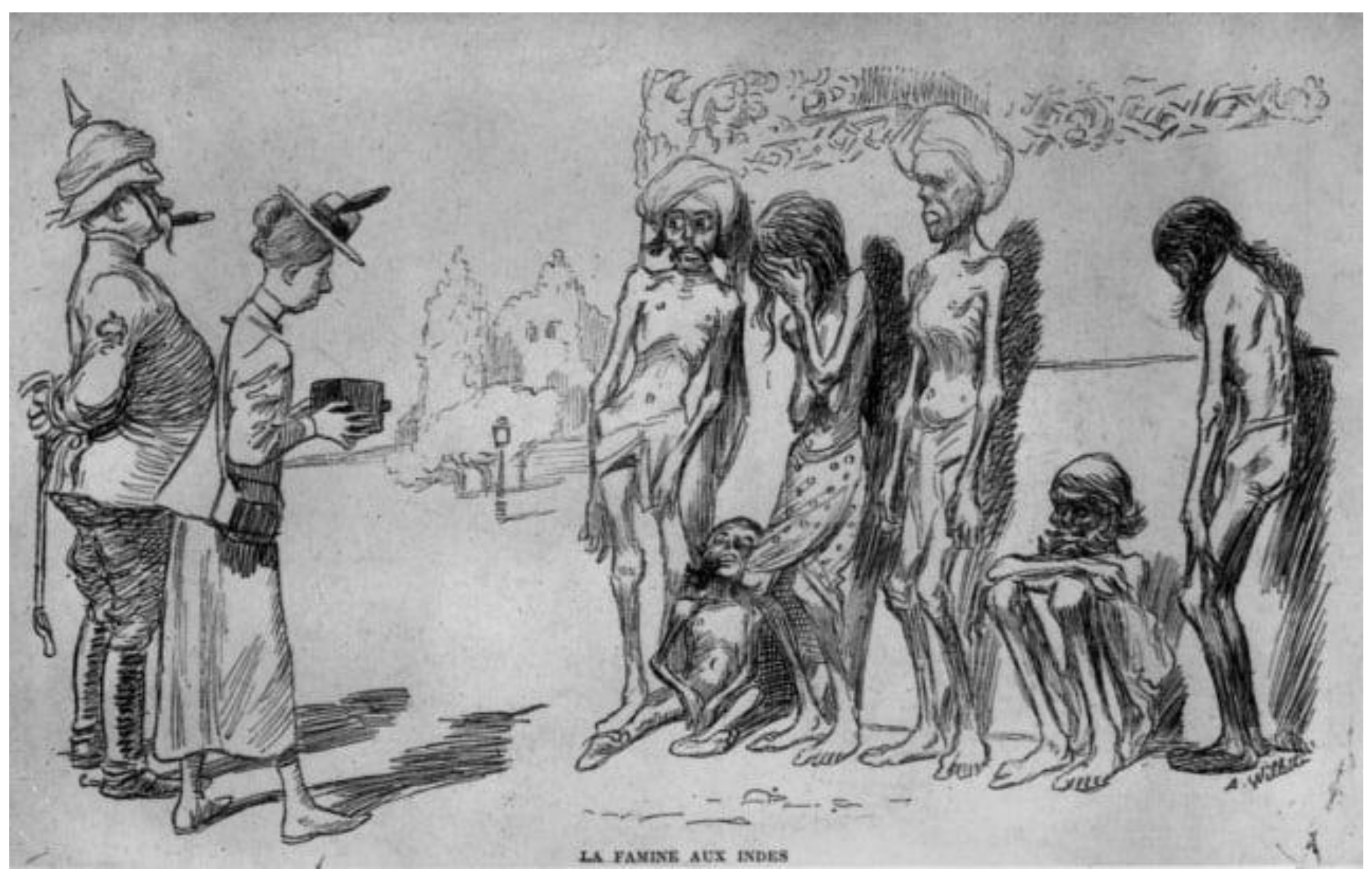

Figura 1 - Western tourists gawk at Indian famine victims, 1899-1900.

Autor: Desconhecido.

Disponível em: <http://asianhistory.about.com/od/asianenvironmentalhistory/ss/India_Famine1899_3.htm>. Acesso: 22/11/2014. 


\section{ORIGNAL TITLEPACE \\ REPORT}

of $\mathrm{xH}$

\section{INDIAN FAMINE COMMISSION}

\section{8.}

SIMLA:

PRINTED AT THE GOVERNMENT CENTRAL PRINTING OFFICE.

ז898. 


\section{ÍNDICE REMISSIVO}

AADHAAR

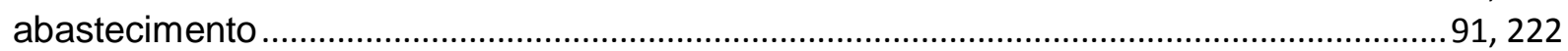

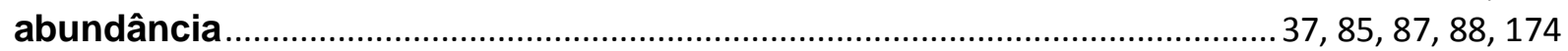

acesso ... 24, 25, 28, 34, 37, 38, 39, 40, 41, 44, 51, 52, 53, 61, 63, 64, 65, 67, 68, 69, 70, 71, 76, 81, 90,

$110,113,116,121,139,141,143,145,155,169,170,173,176,177,183,196,203,204,205,207$,

$212,213,219,233,242,284,285,289$

acomodação $85,87,88$

África saheliana . .35

África subssariana. .8

agricultura orgânica.

água..... $39,41,53,63,67,68,77,81,89,91,154,286,289$

água potável $39,41,53,68,81,289$ aleatoriamente 89,199 alocação ótima .87 Amartya Sen. $28,36,110,262$

Appadurai. .41 arcabouço áreas de risco $25,39,44,46,61,78,135,201,237$

armazenagem . 9, 30, 109, 119, 172, 178, 180, 181, 183, 196, 207, 212, 213, 214, 215, 218, 223, 226, $230,231,233,281,285$

atualidade 59,82

background. .30

baixa renda $64,72,90,108,109$

Bangalore biodiversidade $63,89,91$

Bolsa Família bolsa família

Brasil .... 8, 27, 31, 33, 64, 78, 94, 96, 100, 109, 110, 131, 157, 164, 201, 217, 242, 250, 254, 258, 271, 274

CAPES

cash transfers $200,243,261$

casta castas .81 Códigos de Fome complexidade compromisso $6,8,27,195,226,253,255,258,262,267,271$

comunitária

Conferência de San Francisco $30,164,165,168,170,173,296,299$ $25,28,29,73,77,81,88,89,116,187,243$

consumo $36,41,48,55,57,64,78,82,87,94,98,99,102,117,118,119,120,121,122,123,124$

$125,126,127,128,129,130,132,135,154,156,173,176,186,190,201,221,231,234,284,288$ contaminação 
correlação

crescimento econômico

custo $26,41,59,68,73,98,103,112,122,124,126,130,132,134,135,147,148,154,157,179,196$, $203,205,211,225,230,231,233,241,243,284,285,286,287$

Decrescimento

degradação.

$75,78,80,89,90,91$

degradação ambiental

$78,89,90$

descentralização

212

desenvolvimento $8,24,35,36,48,56,58,59,62,65,67,74,77,78,79,81,82,85,87,88,89,90,94$,

$97,102,110,122,123,126,127,131,135,147,153,155,169,170,185,193,213,254,257,278$

desenvolvimento socioeconômico assimétrico.

desflorestamento

DFID.

$17,28,61,62,63,64,65,66,67,68,69,250,253$

dimensão ambiental

$58,88,89,201$

dimensão econômica

dimensão social

$29,58,80,81,88$

direcionamento

$29,30,172,205,218,221$

Direitos Econômicos

$17,34,35,269$

disjunção cognitiva

.27

distribuição....9, 25, 26, 30, 31, 35, 41, 51, 52, 73, 74, 77, 78, 81, 87, 89, 111, 112, 119, 122, 125, 131 ,

$163,170,172,173,174,177,178,180,181,192,193,194,196,199,200,202,205,208,212,213$,

215, 216, 217, 218, 222, 223, 224, 225, 226, 230, 231, 233, 237, 238, 240, 242, 243, 290, 291

divisão social

.81

ecocêntrica

$58,86,87,88$

ecossistema

educação.

$35,39,51,55,61,63,68,81,122,124,128,187,213$

efeitos colaterais

. .82

elite.

emissões

emissão

82

empiria.

emprego.

27

entrevistas

$71,81,112,170,201,228$

equidade $29,58,81,82$

escambo $29,144,145,146,165,175,243,249$

escassez

escolas

especialização

27

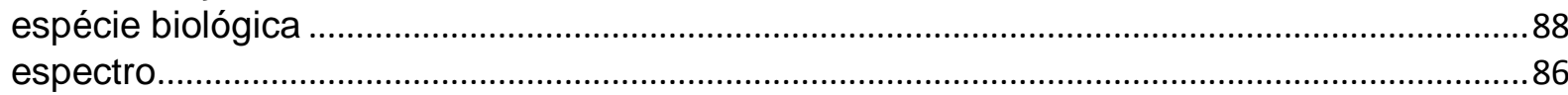

estacionário

.87

Estados Partes

.34

estruturais

estrutural

$28,31,125,191,193,242,243$

eutrofização

$85,112,113,151$

exceções

explicativa

$26,31,67,159,186,241,242$

exploratória

26,128

factíveis

30,73

FAO..18, 28, 33, 34, 38, 39, 44, 54, 56, 57, 69, 93, 98, 99, 113, 117, 118, 119, 121, 126, 127, 132, 134, $135,249,251,262,266,267,268,269,270,271,275,276$ 
fases $26,44,69,171,196,199,216,222,224,230$

fenômenos naturais

82,201

ferro

53,166

fome...... 7, 29, 34, 36, 37, 54, 55, 57, 110, 113, 118, 119, 121, 129, 130, 165, 166, 169, 170, 173, 174, $193,204,220,227,241,250$

força. $37,70,71,72,74,82,138,144,152,213$

formação do solo

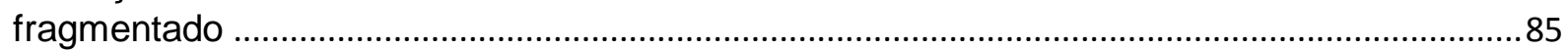

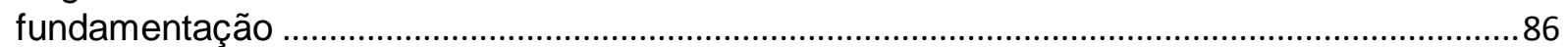

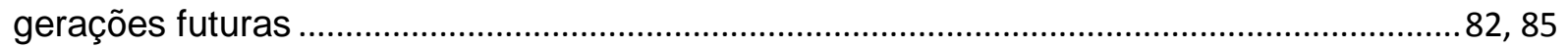

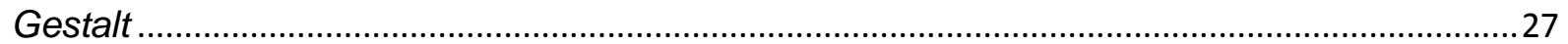

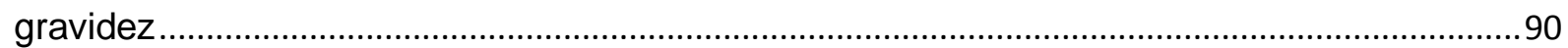

grupo $29,33,40,41,52,53,66,67,68,93,117,122,123,126,143,144,157,159,171,178,186,200$, 203, 234, 243

híbrida.... 26

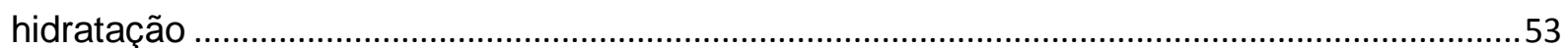

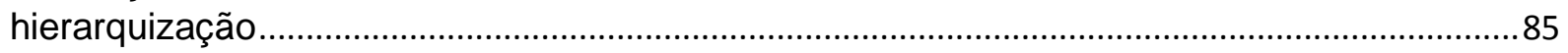

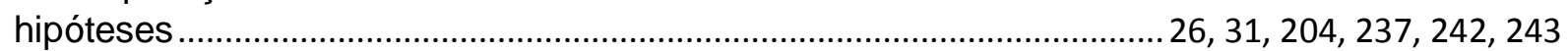

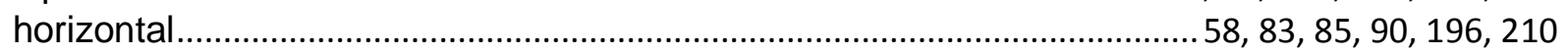

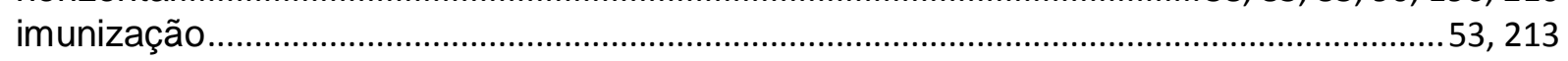

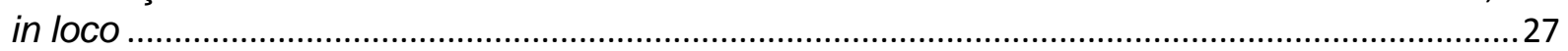

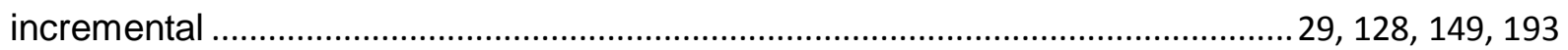

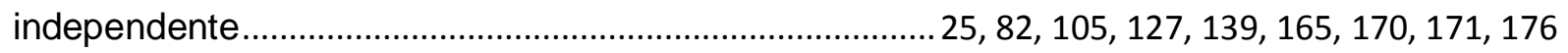

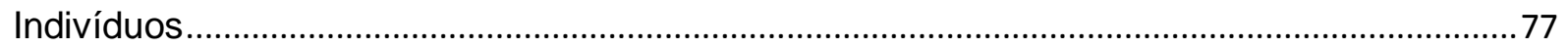

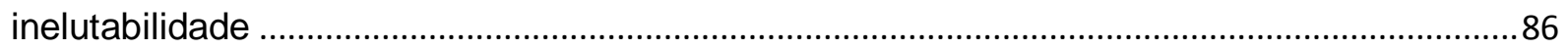

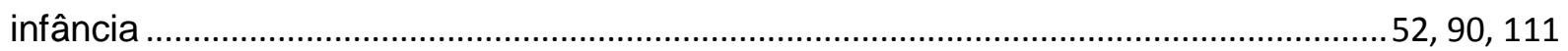

institucional ........................................ 26, 29, 35, 58, 64, 65, 80, 138, 142, 196, 216, 226, 238, 240

integração …….............................................................. 58, 78, 83, 85, 90, 98, 109, 196, 210

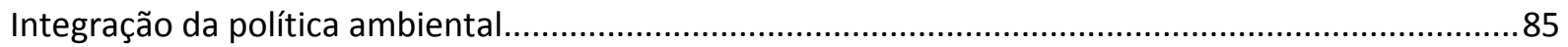

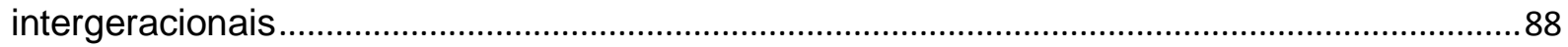

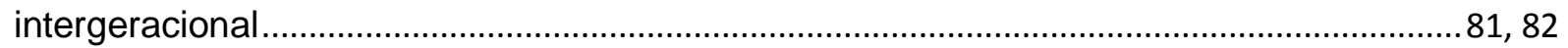

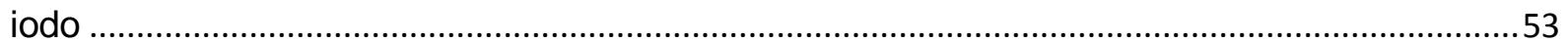

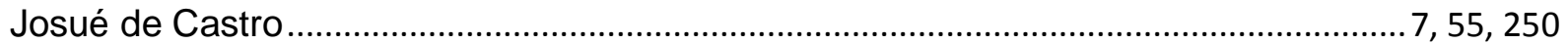

Karnataka..... 17, 18, 25, 27, 30, 218, 220, 222, 223, 224, 225, 226, 227, 228, 229, 230, 231, 233, 249, 251, 254, 255, 256, 258, 262, 266, 267, 268

Kurt Waldheim.

legais

legal

$37,82,137,183,196,216$

leguminosas

$126,176,210,211$

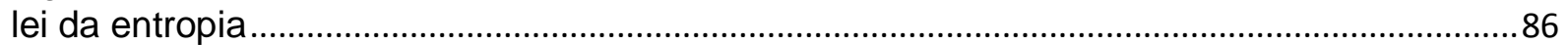

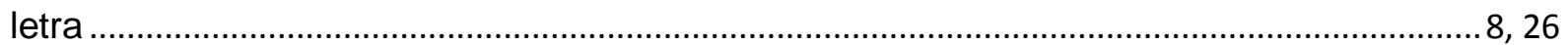

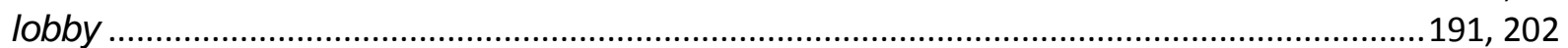

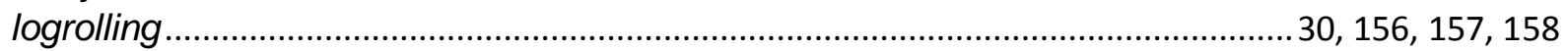

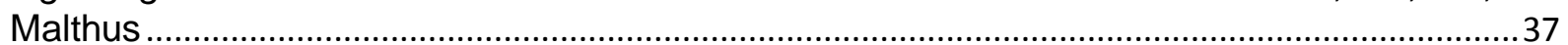

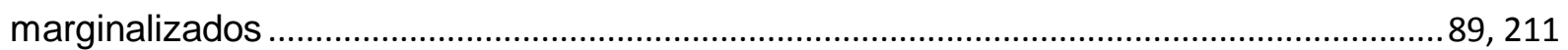

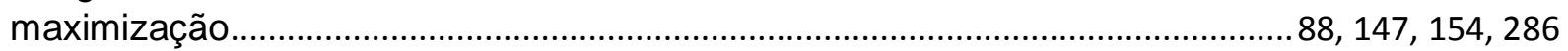

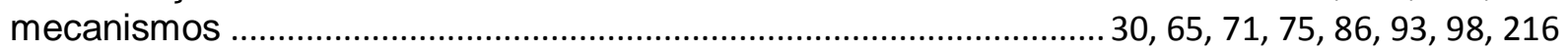

meio ambiente...................................................... 41, 53, 57, 78, 79, 81, 83, 85, 87, 89, 99

mensuração ………………………………............. 24, 25, 27, 29, 110, 111, 114, 117, 123, 129

modelos .................................................. 25, 27, 29, 107, 135, 137, 138, 160, 200, 254, 257, 278

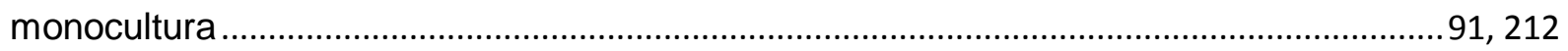

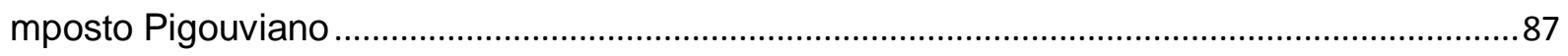


mudanças climáticas

$82,94,100,264$

N. C. Saxena

narrativas

30

necessidade $.27,28,34,42,51,54,55,67,68,69,82,90,97,112,116,122,123,136,150,153,154$, $173,175,178,179,193,223,228,233$

neutras .90

NFSA18, 30, 196, 199, 201, 203, 205, 211, 212, 213, 214, 216, 217, 218, 228, 230, 241, 243, 272, 275 nó górdio

objetivo. $24,25,54,67,104,146,153,164,175,179,204$

objetivos $25,28,34,38,59,62,65,67,68,69,77,81,85,121,129,131,147,155,156,160,180,190$, 207

objeto

$24,25,26,27,151$

oleaginosas. $94,210,211$

ONU.....

opção pública

oportunidades

orientação sexual.

países desenvolvidos.

pesquisa dedutiva

pilares $18,28,35,36,80,135,200,269,270$ $29,153,154,155,156,158,217,243$ $52,71,81,213,216,217,219$

pobres..... 38, 61, 65, 68, 72, 73, 82, 89, 90, 93, 100, 120, 122, 123, 125, 128, 136, 162, 178, 179, 186, $187,189,190,192,204,207,213,227,233,243$

políticas públicas .....8, 24, 25, 26, 27, 29, 40, 58, 70, 73, 77, 81, 90, 97, 112, 116, 130, 137, 138, 141, $142,143,144,145,147,148,149,150,151,152,153,154,155,159,160,162,165,169,170,171$,

$183,185,193,205,216,218,230,237,238,239$

população .....25, 36, 37, 39, 46, 49, 54, 65, 68, 74, 75, 82, 90, 102, 108, 109, 111, 117, 118, 119, 120, $122,150,157,162,164,166,169,170,171,175,176,178,179,187,189,192,196,204,205,207$, $210,212,220,225,227,241,243,285$

populacional $52,76,87,122,123,127$ prática $24,26,27,29,36,41,44,73,93,121,131,151,156,157,190,202,209,214,278$

preço mínimo. $202,209,212$

processo..... 27, 29, 45, 64, 72, 75, 85, 96, 111, 113, 141, 142, 144, 147, 149, 150, 151, 153, 154, 156, $158,163,176,180,189,196,214,216,218,225,228,278$

Produto Interno Bruto.

18,196 proteção $63,65,70,72,73,74,75,82,89,110,113,224$ racional. $29,55,146,147,148,149,150,151,155,284,289$

radical .86

recursos. 35, 36, 37, 39, 40, 51, 52, 53, 59, 61, 62, 63, 64, 65, 66, 67, 69, 72, 73, 74, 82, 85, 87, 89, 94, 110, 112, 122, 136, 144, 155, 156, 158, 212, 215, 219, 226, 228

Redistribuição equitativa

reforma..... . .81

regulamentos $35,162,176,177,196,199,216$

religião $24,27,65,73,89,181,207,228,242$

rent-seeking

resiliência

$30,156,158,159,216,217,225$

Revolução Verde $57,59,70,71,74,75,79,80$

sequeiro .78, 210

Shigelose 210,211

shortcomings . .48

Síndrome de Marlow .28 sistêmico .48 sobrepostas $29,151,152,153$ .26 
sustentabilidade...4, 25, 26, 30, 41, 57, 58, 59, 63, 64, 67, 77, 78, 79, 80, 81, 85, 86, 88, 91, 196, 201, $203,211,215,216,224,231,238,240,243$

sustentável......8, 24, 25, 26, 30, 31, 59, 61, 67, 76, 79, 81, 85, 87, 88, 89, 90, 113, 193, 202, 212, 213, $216,230,231,237,238,240,242$

tabus . .51

Tecnocêntricos

87,88

teoria de jogos

29,150

teorias $25,28,29,125,155,160$

terras marginais .82

tradicional 74,91

transparência. 199

transparência. 159, 199

USAID $19,126,130,135,266,273,276$

Vandana Shiva 212 varejo $30,178,179,208,213,224$

velhice 90

vertical $58,83,85,90,196,210$ vitamina $49,53,54$

vulnerabilidades .90

Wadhwa $17,207,214,251$ 